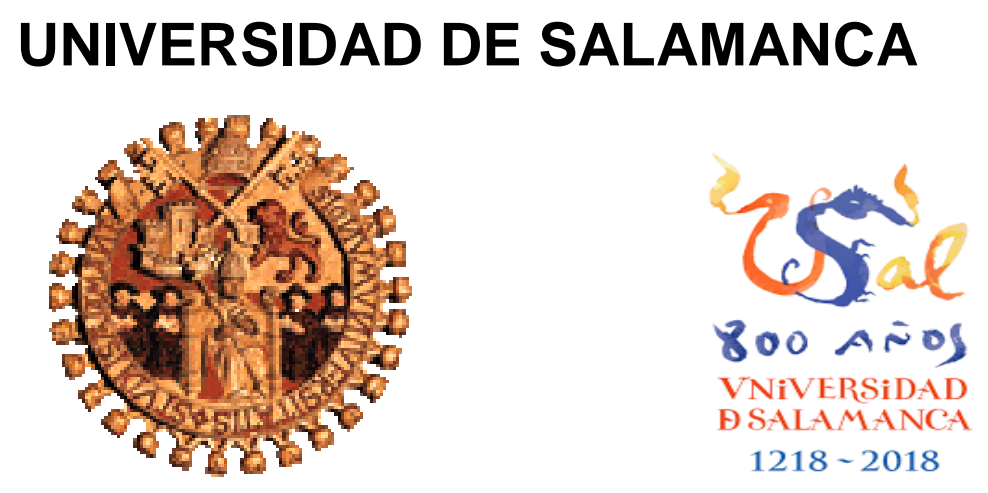

FACULTAD DE MEDICINA

DEPARTAMENTO DE CIRUGÍA

\title{
INFLUENCIA DE LA TERAPIA ANTIDIABÉTICA EN LA RESPUESTA AL TRATAMIENTO DE LA IISFUNCIÓN ERÉCTIL
}

\author{
Dạ. Lorena Suárez Gutiérrez
}

\section{TESIS DOCTORAL}

Junio 2017 

PROF. Dr. D. FRANCISCO SANTIAGO LOZANO SÁNCHEZ,

DIRECTOR DEL DEPARTAMENTO DE CIRUGÍA, DE LA FACULTAD DE MEDICINA DE LA UNIVERSIDAD DE SALAMANCA.

\section{CERTIFICA:}

Que la presente Tesis Doctoral, titulada "Influencia de la terapia antidiabética en la respuesta al tratamiento de la disfunción eréctil”, realizada por $\mathrm{D}^{\mathrm{a}}$. Lorena Suárez Gutiérrez, para optar al Título de Doctor por la Universidad de Salamanca, reúne todas las condiciones necesarias para su presentación y defensa ante el Tribunal Calificador.

Para que conste y a petición del interesado, expido el presente certificado en Salamanca a 20 de Junio de 2017.

Fdo. Prof. D. Francisco Santiago Lozano Sánchez. 

DRA. D ${ }^{\mathrm{a}}$. MARÍA FERNANDA LORENZO GÓMEZ, DOCTORA EN MEDICINA Y CIRUGÍA, ESPECIALISTA EN UROLOGÍA, PROFESORA ASOCIADA DE UROLOGÍA, ACREDITADA PROFESOR CONTRATADO DOCTOR, DEL DEPARTAMENTO DE CIRUGÍA DE LA UNIVERSIDAD DE SALAMANCA, Y LA DRA. D ${ }^{\mathrm{a}}$. BÁRBARA YOLANDA PADILLA FERNÁNDEZ, DOCTOR EN MEDICINA Y CIRUGÍA, ESPECIALISTA EN UROLOGÍA, PROFESORA DEL CURSO DE FORMACIÓN ESPECÍFICA DE SUELO PELVIANO DE LA UNIVERSIDAD DE SALAMANCA, URÓLOGA DEL HOSPITAL UNIVERSITARIO DE CANARIAS (TENERIFE).

CERTIFICAN:

Que D ${ }^{a}$. Lorena Suárez Gutiérrez ha realizado bajo su dirección el trabajo titulado "Influencia de la terapia antidiabética en la respuesta al tratamiento de la disfunción eréctil”, considerando que reúne las condiciones necesarias para ser presentado como Tesis Doctoral en la Universidad de Salamanca.

Para que así conste y obre a los efectos oportunos, se expide el presente certificado, en Salamanca a 20 de Junio de 2017.

Fdo. Profa. Dra. D ${ }^{\mathrm{a}}$. MF. Lorenzo Gómez Fdo. Profa. Dra. Da . BY. Padilla Fernández 

A mis padres Pilar y Joaquín, por inculcarme que sin esfuerzo no se consiguen los logros. 



\section{AGRADECIMIENTOS}

Deseo dejar constancia de mi agradecimiento a todos los profesionales que han hecho posible este trabajo.

A mis directoras, Dra. Lorenzo Gómez y Dra. Padilla Fernández por su dedicación y esfuerzo en mi aprendizaje, tanto profesional como personal.

A todo el Departamento de Cirugía, a su Director Prof. Dr. D. Francisco Santiago Lozano Sánchez, por permitirme desarrollar este trabajo, y en especial a la Dra. Lorenzo Gómez por inculcarme mi interés por la investigación y por su absoluta dedicación y consejo científico en la metodología de este estudio y por hacer realidad uno de mis mayores retos tanto a nivel profesional como personal.

Al Dr. D. Luis Labairu Huerta por su contribución a la parte teórica del proyecto. 



\section{ÍNDICE}

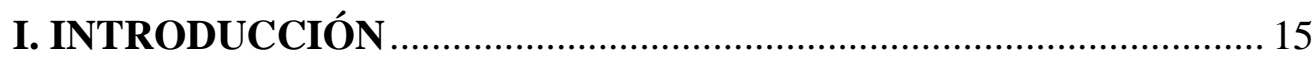

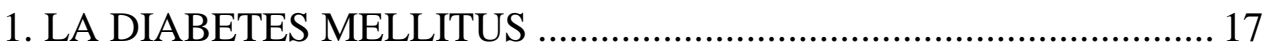

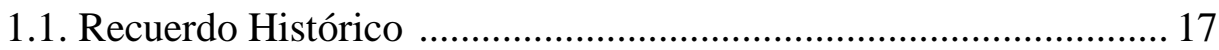

1.2. Definición de la Diabetes Mellitus ................................................... 17

1.3. Epidemiología de los distintos tipos de DM................................. 18

1.4. Etiopatogenia de la DM.............................................................. 24

1.4.1 Etiopatogenia de la DM tipo 1 .......................................... 24

1.4.1.a1. Genes HLA y DM tipo 1 ....................................... 25

1.4.1.a2. Asociaciones genes HLA y DM tipo 1 .................. 26

1.4.1.a3. Genes no HLA .................................................. 27

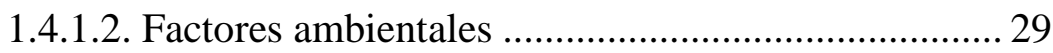

1.4.1.2a. Papel de los virus ............................................... 29

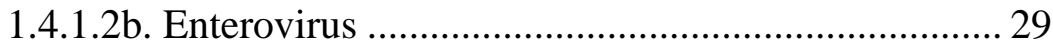

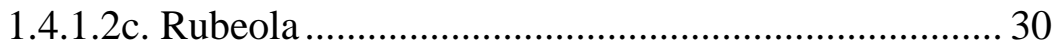

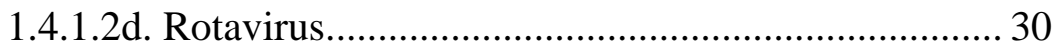

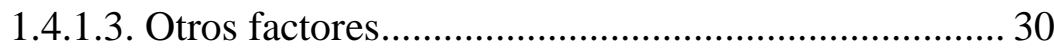

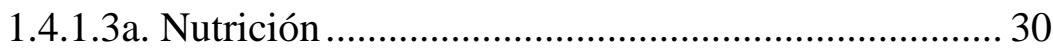

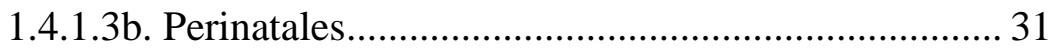

1.4.1.4. Autoinmunidad ....................................................... 32

1.4.1.4a. Inmunopatolofisiología celular .............................. 32

1.4.1.4b. Inmunopatofisiología humoral ............................ 32

1.4.2. Etiopatogenia de la DM tipo 2 ......................................... 34

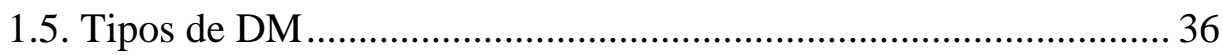

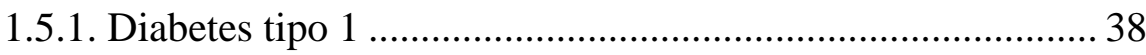

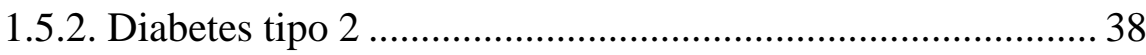

1.5.3. Otros tipos específicos de DM ............................................. 39

1.5.4. Diabetes gestacional........................................................... 42

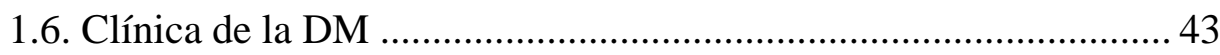

1.6.1. Clínica de la DM 1 ........................................................... 43

1.6.2. Clínica de la DM2 ............................................................. 43

1.7. Diagnóstico de la DM.................................................................. 44

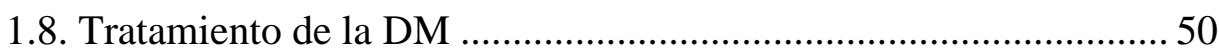

1.8.1. Actuaciones no farmacológicas .......................................... 50 


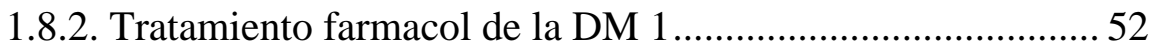

1.8.2.1. Introducción......................................................... 52

1.8.2.2. Pautas de tratamiento intensivo ............................. 53

1.8.2.3. Pautas de tratamiento convencional ........................ 55

1.8.3. Tratamiento farmacológico de la DM 2 ............................. 56

1.8.3.1. Primer paso: Cambio de estilo de vida+ Metformina....................................................... 56

1.8.3.2. Tratamiento inicial: Hemoglobina glicosilada

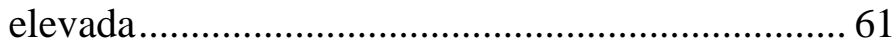

1.8.3.3. Tratamiento farmacológico: Doble terapia............... 61

1.8.3.4. Tratamiento farmacológico: Triple terapia............... 67

1.8.3.5. Tratamiento con insulina ........................................69 69

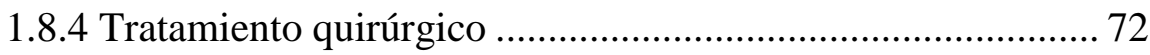

2. DIABETES Y DISFUNCIÓN ERÉCTIL ........................................... 76

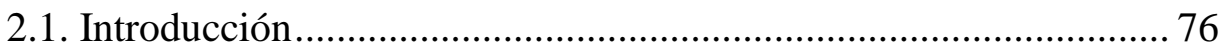

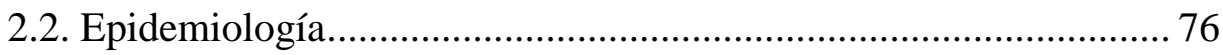

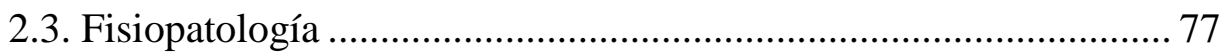

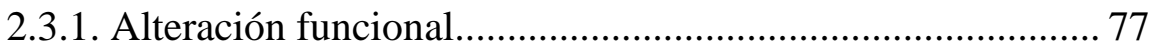

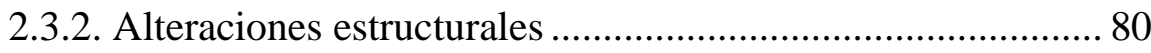

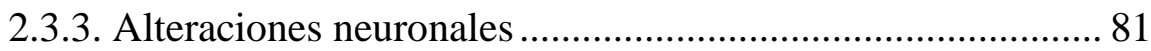

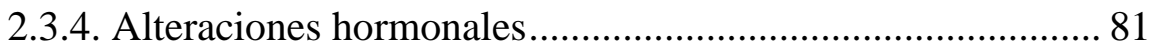

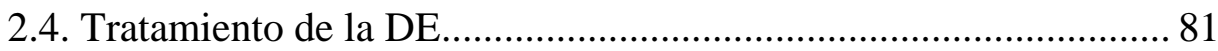

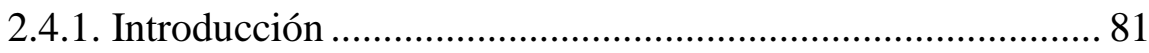

2.4.2. Actuaciones no farmacológicas .......................................... 84

2.4.3. Tratamiento farmacológico oral.......................................... 89

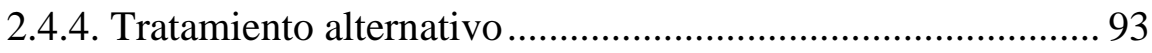

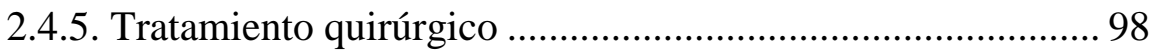

2.4.6. Perspectivas de futuro ..................................................... 101

II. HIPÓTESIS Y OBJETIVOS DEL ESTUDIO ................................. 105

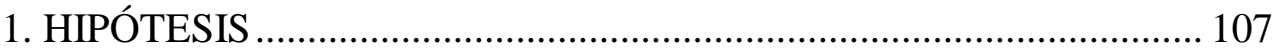

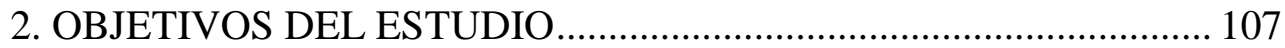

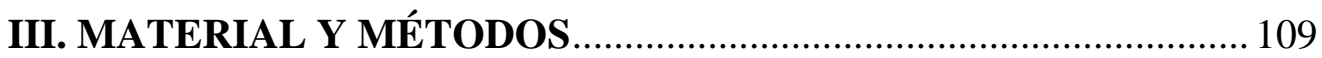

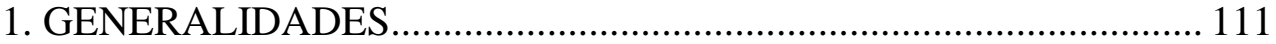




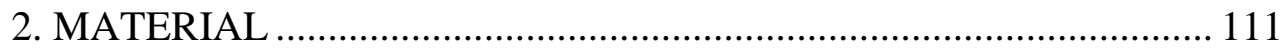

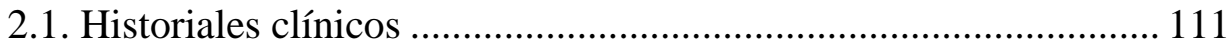

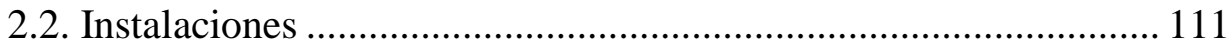

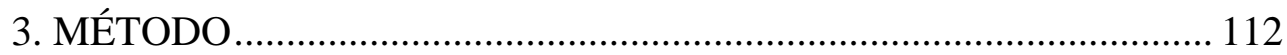

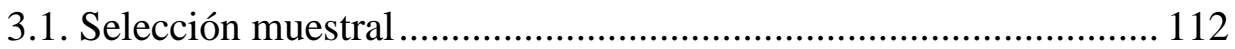

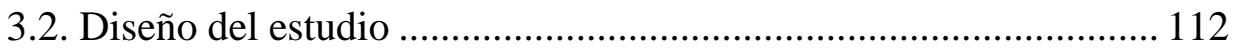

3.3. Grupos de estudio .................................................................... 112

3.4. Variables estudiadas ................................................................ 113

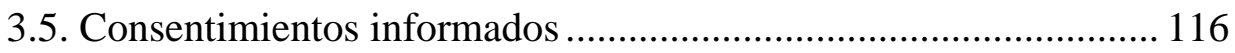

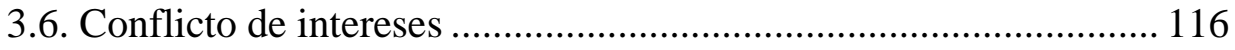

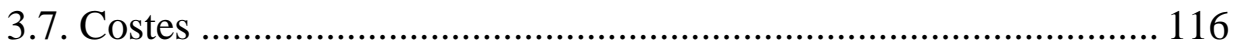

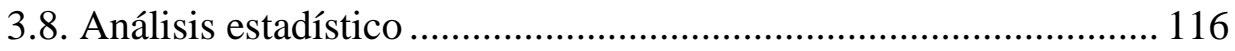

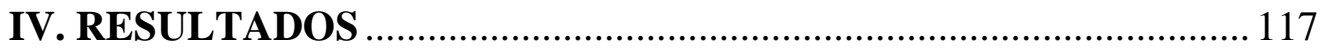

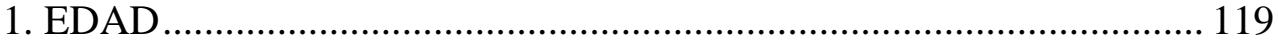

2. TIEMPO DE CONTROL EVOLUTIVO, EN MESES, DESPUÉS DE INSTAURAR EL TRATAMIENTO DE LA DISFUNCIÓN ERÉCTIL ................................................................................... 133

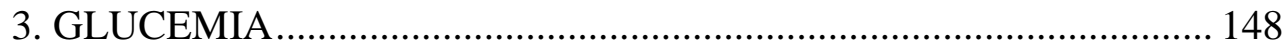

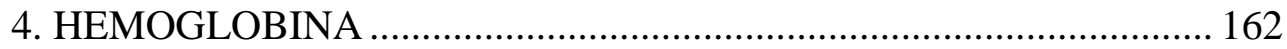

5. HEMOGLOBINA GLICOSILADA NGSP ...................................... 177

6. HEMOGLOBINA GLICOSILADA IFFC .......................................... 191

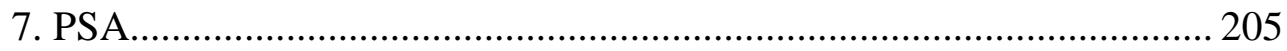

8. DIAGNÓSTICOS SECUNDARIOS ….............................................. 218

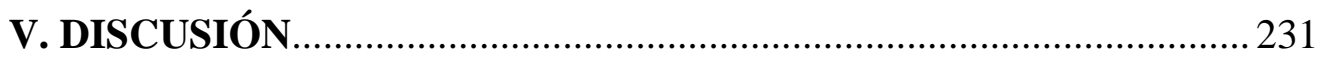

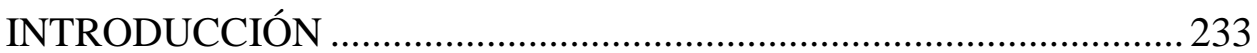

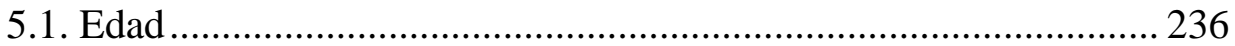

5.2. Tiempo de control evolutivo, en meses después de instaurar el tratamiento de la disfunción eréctil............................................ 237

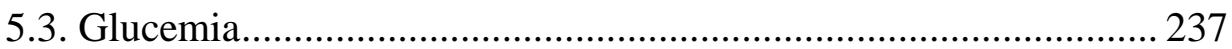

5.4. Hemoglobina glicoslida........................................................ 238

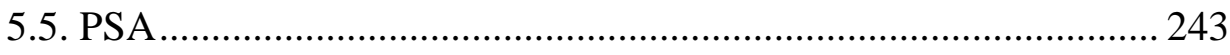


5.6. Diagnósticos secundarios 243

5.6.1. Cardiopatía isquémica 243

5.6.2. Síntomas digestivos e urológicos 244

5.6.3. Psicopatología 245

5.6.4. Antecedentes quirúrgicos 245

5.6.5. Hábitos tóxicos: Tabaco. 248

5.6.6. HTA 250

\section{CONCLUSIONES} 251

VII. ANEXOS 255

ANEXO 1: Índice Internacional de la Función Eréctil o IIEF15 (International Index of Erectile Function) 257

ANEXO 2: Abreviaturas utilizadas en el texto 259

ANEXO 3: Leyenda de figuras 265

ANEXO 4: Leyenda de tablas 273 


\section{INTRODUCCIÓN}





\section{LA DIABETES MELLITUS}

\subsection{RECUERDO HISTÓRICO}

En 1868, el egiptólogo Ebers descubrió un papiro egipcio que databa del 1500 a. C. donde se reflejaba los conocimientos de Medicina de esa época. En un párrafo se hablaba de una enfermedad enigmática que siglos después se bautizó con el nombre griego de "diabetes" y que actualmente se conserva en la Universidad de Leipzig (Bárbara 2007).

Fue en el siglo III a.C. cuando Apolonio de Menfis di o nombre a dicha enfermedad, que es una palabra que en griego significa "pasar a través de" y que explicaría el efecto del agua que inicialmente bebe el diabético y que posteriormente elimina, descrito por Rodríguez Miñón en su último libro (Rodríguez-Miñón 1992).

Finalmente, es en el libro Ayur Vela Suruta que data del 400 a. C. donde se hace referencia por primera vez al sabor dulce de la orina y Cheverd descubrió que el azúcar que presentaba la orina era glucosa. Avanzando en el tiempo, fue en el siglo XX cuando Claude Bernard demostró que la hiperglucemia era el signo más llamativo de la diabetes y nos explicó sobre el papel tan importante que desarrolla el hígado en el metabolismo de la glucosa (Pombo 2007).

\subsection{DEFINICIÓN DE DIABETES MELLITUS}

La diabetes mellitus (DM) comprende un grupo de enfermedades metabólicas caracterizadas por la presencia de hiperglucemia, que aparece como consecuencia de defectos en la secreción y/o acción de la insulina y así la describen en la guía de la asociación norteamericana de diabetes sobre diagnóstico y clasificación de la DM.

La hiperglucemia crónica se asocia con lesiones a largo plazo en diversos órganos, particularmente los ojos, el riñón, los nervios, los vasos sanguíneos y el corazón. Son las llamadas complicaciones de la DM, que pueden afectar a los vasos de pequeño calibre (complicaciones microangiopáticas) y a los vasos grandes (complicaciones macroangiopáticas) (Consultation 1999).

Si nos centramos en el término de DM agruparía a un grupo heterogéneo de síndromes hiperglucémicos con características genotípicas diversas y con otros muchos factores interviniendo en su etiopatogenia; dado 
que puede existir un mecanismo de destrucción autoinmune de las células beta pancreáticas llevando a un déficit absoluto de insulina o por el contrario que existan agentes que conduzcan a una resistencia a la acción de la insulina, conllevando un menor respuesta de esta hormona en los tejidos. Pudiendo asimismo, coexistir fallo tanto en la secreción como en la acción de la insulina (Pombo 2007).

\subsection{EPIDEMIOLOGÍA DE LA DM}

Saber los datos epidemiológicos de la diabetes es algo fundamental dado que nos pone de manifiesto la magnitud del problema que supone esta enfermedad. Así como, para estructurar la planificación de los recursos sanitarios destinados a su atención y posible prevención. En los últimos años se han desarrollado en España algunos estudios epidemiológicos que nos permiten disponer de algunos de los aspectos más relevantes en nuestro país en este sentido (Arno, Santaliestra et al. 2007).

\section{Métodos para estimar la prevalencia de la DM}

Existen diferentes métodos para estimar la prevalencia como serían los registros médicos, la estimación del consumo de fármacos, entrevistas aleatoria a una muestra de la población o realización de pruebas analíticas como una glucemia al azar, o bien una prueba de sobrecarga oral de la glucosa (TTOG), (Goday and Rios 1994), cuya interpretación ha cambiado a lo largo de los años en función de diversos criterios ( WHO (World Health Organization)) (Group 1985). (ADA (American Diabetes Association)), (1997). Todos estos métodos nos informan sobre DM diagnosticada y son la glucemia al azar y la TTOG las que nos informan de la ignorada y en el último caso de situación en riesgo para DM. Y es que hasta 1990 los datos de los que se disponía para estimar la prevalencia eran los extraídos de encuestas de médicos, (Peinado and Matute 1965, Sanchez, Ferre et al. 1980), por los datos de dosis de fármaco diaria definida, o el de la dosis diaria prescrita pero todos estos infraestimaban la prevalencia de DM (Costa, Utges et al. 1992, Calle-Pascual, Vicente et al. 1993) en comparación con los realizados en la población con TTOG que nos dan una estimación más real en la población , dado que los previos no incluían por ejemplo la DM tratada con dieta o la ignorada o que no se registraba. 


\section{Prevalencia de la DM tipo 2 en España}

En España son múltiples los estudios con base poblacional que aportan datos sobre la prevalencia de diabetes total mediante TTOG (conocida e ignorada) e ITG (tabla 1) (Valdes, Rojo-Martinez et al. 2007).

Del análisis de estos datos se desprende que la prevalencia de DM2 entre el 6 y el 10\% establecida en España hasta hace unos años (Goday 2002) estaba basada en estudios antiguos. $\mathrm{Si}$ analizamos los últimos estudios realizados podemos estimar que la prevalencia actual de DM2 en España está entre el 10 y el 15\% (figura 1) (Valdes, Rojo-Martinez et al. 2007, Soriguer, Goday et al. 2012). 


\begin{tabular}{|c|c|c|c|c|c|}
\hline Estudio & $\begin{array}{c}\text { Edad } \\
\text { (años) }\end{array}$ & $\mathbf{N}$ & $\begin{array}{c}\text { DM2 } \\
(\%)\end{array}$ & $\begin{array}{l}\text { ITG } \\
(\%)\end{array}$ & Criterio \\
\hline León, 1992 (16) & $>18$ & 572 & 5,6 & 10,3 & OMS 85 \\
\hline Bayo y col. (17) & $>30$ & 862 & 6,4 & 10,4 & OMS 85 \\
\hline Cerdaña, 1994 (18) & $>6$ & 492 & 5,5 & - & OMS 85 \\
\hline Galicia, 1995 (19) & $40-69$ & 1275 & 7,5 & - & OMS 85 \\
\hline Aragón, 1997 (20) & $10-74$ & 935 & 6,1 & 7,2 & OMS 85 \\
\hline Cataluña, 1999 (21) & $30-89$ & 3839 & 10,3 & 11,9 & OMS 85 \\
\hline Albacete, 2000 (22) & $>18$ & 1263 & 9,8 & - & OMS 98 \\
\hline Guía, 2001 (23) & $>30$ & 691 & 18,7 & 17,1 & OMS 85 \\
\hline SIRS, 2001 (24) & $34-69$ & 2949 & 10,2 & 9,4 & OMS 98 \\
\hline Pizarra, 2002 (25) & $18-65$ & 1226 & 14,7 & 11,5 & OMS 98 \\
\hline Asturias, 2003 (26) & $30-75$ & 1034 & 11,3 & 13,2 & OMS 98 \\
\hline Yecla, 2004 (27) & $>30$ & 286 & 12,6 & 13,2 & OMS 98 \\
\hline Girona, 2004 (28) & $25-74$ & 1748 & 13,0 & - & ADA 97 \\
\hline Telde, 2006 (29) & $30-82$ & 1030 & 13,2 & 11,4 & OMS 98 \\
\hline Valencia, 2006 (30) & $18-88$ & 668 & 14,8 & 11,8 & OMS 98 \\
\hline Sevilla, 2006 (31) & $>18$ & 537 & 10,2 & 7,4 & OMS 98 \\
\hline Estudio $\underline{\text { di@bet.es, }} 2012$ (15) & $>18$ & 5554 & 13,8 & 9,2 & OMS 98 \\
\hline
\end{tabular}

ADA: American Diabetes Association; DM2: diabetes mellitus tipo 2; ITG: intolerancia a la glucosa; OMS: Organización Mundial de la Salud; SIRS: Spanish Insulin Resistance Study.

Tabla 1. Estudios de prevalencia de DM2 en España (Valdes, Rojo-Martinez et al. 2007) 
Figura 1. Prevalencia de DM2 en España (1992 - 2011) (Valdes, Rojo-Martinez et al. 2007).

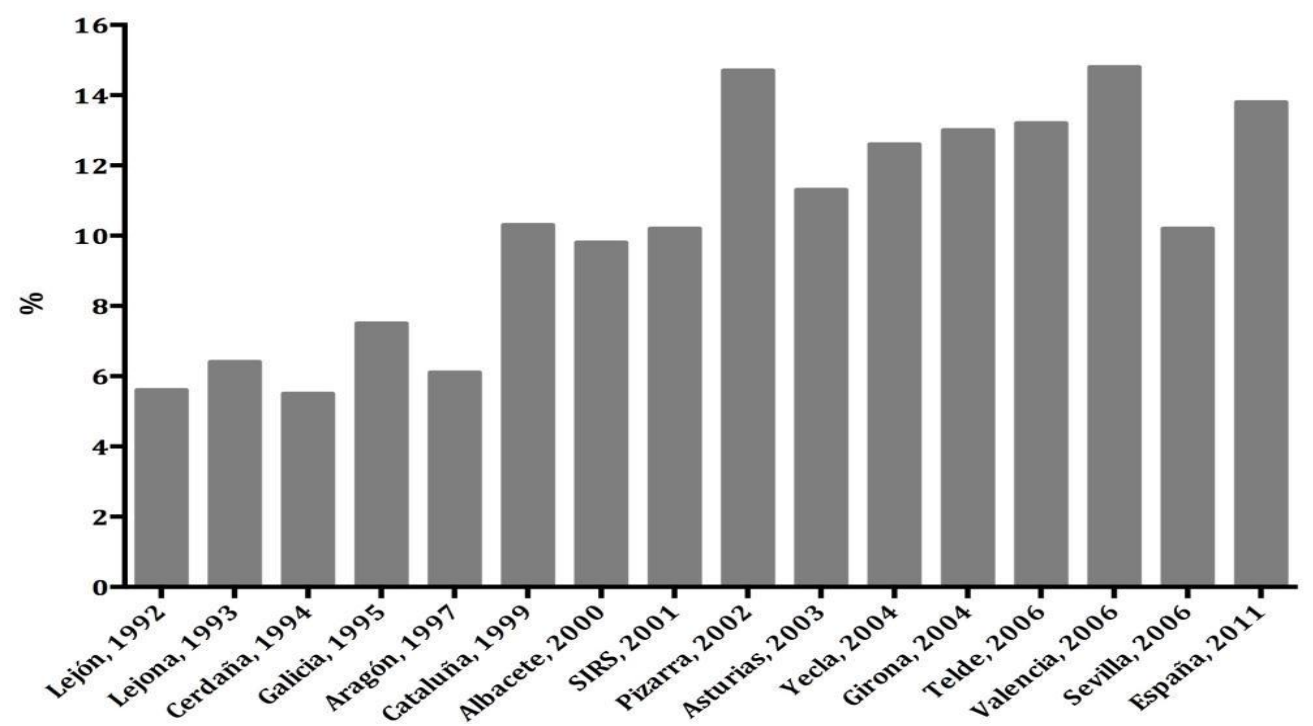

Los resultados del estudio di@bet.es, el primer estudio de ámbito nacional que comprende una muestra representativa de la población adulta española para evaluar la prevalencia de diabetes y otras alteraciones del metabolismo hidrocarbonado, muestra que cerca del 30\% de la población estudiada tiene algún trastorno relacionado con el metabolismo de los hidratos de carbono. La prevalencia total de DM2 ajustada por edad y sexo ha sido del 13,8\% (IC 95\%: 12,8-14,7\%), de los cuales casi la mitad eran casos de diabetes no conocida previamente $(6,0 \%$, IC95\%: 5,4-6,7\%). La prevalencia de GBA ha sido del 3,4\% (IC 95\%: 2,9-4,0\%), la de ITG del 9,2\% (IC 95\%: $8.2-10,2 \%$ ), y la de GBA e ITG del 2,2\% (95\% IC: 1,7-2,7\%) (Soriguer, Goday et al. 2012).

Varios factores han podido influir en el aumento de la DM2 en España, entre ellos destacan:

1. El cambio de los criterios diagnósticos de DM2: en el informe de la OMS de 1998 se decidió reducir el punto de corte de la glucemia en ayunas para diagnosticar diabetes de 140 a $126 \mathrm{mg} / \mathrm{dl}$ (Alberti and Zimmet 1998).Varios estudios han valorado el impacto que ha tenido la aplicación de estos nuevos criterios en la prevalencia de la diabetes en España, y han observado incrementos entre el 1,4 y el 3,5\% (Paños, Sanchís et al. 2000, Soriguer-Escofet, Esteva et al. 2002, Botas, Delgado et al. 2003). 
2. El gradual envejecimiento de la población: al igual que en otros países desarrollados, en los últimos años tanto el aumento en la esperanza de vida como la disminución de la natalidad están motivando un progresivo envejecimiento de la población española con inversión de la pirámide poblacional. Como uno de los factores más determinantes en la prevalencia de la diabetes es la edad, el incremento en el número de individuos en tramos de edad avanzada conduce a un aumento general de la prevalencia de diabetes.

3. El descenso de la mortalidad de los sujetos con diabetes: En relación a la mejora continuada de la calidad asistencial, la mejora del control metabólico y el tratamiento más universal, eficaz agresivo de la DM y de los factores de riesgo cardiovascular (dislipemia, HTA y tabaquismo) puede haber llevado a un descenso de la tasa de mortalidad y una mayor esperanza de vida de las personas con diabetes $\mathrm{y}$, por lo tanto, a un incremento en el número total de individuos afectos.

4. El aumento de la incidencia de diabetes: aunque no existen estudios en España que evalúen los cambios en la incidencia de diabetes en una misma población durante distintos períodos, sí tenemos información de otros países que muestran un incremento de la prevalencia de diabetes en los últimos años. Por ejemplo, en Estados Unidos la incidencia de diabetes diagnosticada en adultos entre 18 y 75 años ajustada por edad se incrementó un $43 \%$, pasando de 4,7 casos cada 1.000 personas-año en 1997 a 7,6 casos por 1.000 personas-año en 2011(Prevention 2013). Por otra parte, llama la atención que en la comparación entre los distintos estudios no se detecta una esperable disminución de la proporción de diabetes ignorada en los trabajos realizados más recientemente y ésta se observa en los grupos de edad más jóvenes.

\section{Prevalencia de la DM tipo 2 en el mundo}

La prevalencia de DM varía significativamente a nivel mundial (Alberti 1993, Zimmet, McCarty et al. 1997) con predominio en algunas zonas del mundo en forma de epidemia y entre las causas que explicarían la variabilidad pueden ser: longevidad, historia familiar, raza, urbanización( dobla el riesgo en la mayoría de los estudios), migración, obesidad, actividad física y nutrición fetal/ neonatal (Bennet, Bogardus et al. 1992). Los grupos conocidos con mayor prevalencia son los indios Pima que constituyen una reserva en el estado de Arizona y la población de Nauru, en Oceanía, donde la enfermedad 
afecta a más del $20 \%$ de la población. La alta tasa de prevalencia de esta enfermedad se explica porque son poblaciones que en un tiempo relativamente corto han pasado de su estilo de vida tradicional al occidental (Trevisan, Vedovato et al. 1998) y esto sucede también en determinados países del sudeste asiático y por ello se piensa que la DM2 será una de las epidemias del siglo XXI.

\section{Incidencia de la DM tipo 2}

Dado que la DM tipo 2 es una enfermedad de curso silencioso, es difícil plantear estudios de incidenica de la enfermedad.

En conjunto, la incidencia anual de DM 2 en estudios europeos publicados varía entre 1,2 y 4.1 casos/ 1000 personas (32-45). En España disponemos de los siguientes estudios de incidencia:

Estudio Lejona (Vazquez, Gaztambide et al. 2000). A los 10 años de la realización del estudio de prevalencia de diabetes en 1985, 594 individuos de la misma población fueron reevaluados con una nueva PTOG. La incidencia de DM2 fue de 8,2 casos por 1.000 personas-año a expensas sobre todo del grupo de varones y marcando la edad como factor importante aumentando el riesgo a partir de los 60 años de edad.

Estudio Asturias (Valdes, Botas et al. 2007). El estudio Asturias incluyó a 700 sujetos que participaron en el estudio de prevalencia de 1998 y 1999, a los que se reevaluó en 2004 y 2005 tras una media de seguimiento de 6,3 años. Para el estudio de la incidencia se seleccionaron sólo a los 630 sujetos que no tenían diabetes en el estudio inicial, para aplicarles nuevamente el cuestionario, la exploración y la PTOG con obtención de sangre venosa basal y tras dos horas (criterios OMS 1998). La incidencia de diabetes fue de 10,8 casos por 1.000 personas-año.

Estudio Pizarra (Soriguer, Rojo-Martinez et al. 2008). En el estudio Pizarra, se reevaluaron en 2003 y 2004 a 824 individuos que participaron en el estudio transversal de 1997 y 1998, tras una media de seis años de seguimiento. La muestra para el estudio de incidencia incluyó a 714 sujetos sin diabetes inicial. En ambas evaluaciones se realizó una PTOG a cada participante (criterios OMS 1998). La incidencia de diabetes fue de 19,1 casos por 1.000 personas-año.

\section{Incidencia de la DM tipo 1}

Hasta 1990 no existían en España datos referentes a la incidencia de diabetes Mellitus tipo 1. Por ello, en la pasada década se realizaron diferentes 
reuniones de consenso para tratar de establecer investigaciones epidemiológicas con metodología estandarizada y validada para disponer de resultados comparables a nivel internacional (al 1996).

El estudio EURODIAB que se prolongó durante 10 años analizó la evolución de la incidencia de DM tipo 1 en una extensa muestra de la población europea (Green, Gale et al. 1992). En una reciente publicación, la investigación ha demostrado que la incidencia de DM tipo 1 en Europa está aumentando pero de forma desigual por edades y países (Group 2000). Se observa que en el segmento de menor edad de 0-4 años la tasa de incidencia ha aumentado un $6.3 \%$ entre 1989 y 1994, mientras que en el grupo de edad de 5-9 años ha aumentado un 3.1\% y en el de 10-14 un 2.4\%. En cuanto a la incidencia en los distintos países el cambio más acusado ha sido en los países del este y centro de Europa coincidiendo con cambios socioeconómico.

\section{4: ETIOPATOGENIA DE LA DM}

\subsubsection{Etiopatogenia de la DM 1}

En la DM tipo 1 se produce un proceso de alteración autoinmune, progresivo y crónico a través de Linfocitos $\mathrm{T}$ autorreactivos que partiendo de un "ataque" no siempre conocido y en personas con una cierta predisposición genética conlleva a una aniquilación selectiva de la célula beta "señalada por autoanticuerpos (ICA, GAD, IA-2, IA-A y otros)

Hay por tanto una colaboración conjunta de los factores ambientales y la genética en la patogenia de la DM tipo 1.

Existen diversas razones para pensar en la manera de como colabora la predisposición genética en la DM tipo 1:

Se habla de un riesgo del $4 \%$ de padecer DM tipo 1 en la población general, lo cual se incrementa en un hermano de un paciente con DM tipo 1 al $7 \%$ y en un $6 \%$ en un hijo y en estudios con gemelos se observa que la concordancia en gemelos dizigóticos es de un $6 \%$ mientras que en los monozigóticos varía de un 30-70\%, según los diferentes estudios. Además, existen incluso modelos animales como son la rata BB (Bioindreding) y el ratón NOD (non obese diabetic) susceptibles de analizar su genética.

Existe una mayor incidencia de la DM tipo 1 en aquellas etnias que tienen una diversa composición genética o en aquellos que aunque comparten la misma genética, habitan en lugares geográficos diferentes con distintas características culturales, alimentarias etc. Llama la atención esta diferencia 
en etnias, dado que existen países donde la incidencia es muy baja como son Perú, China y Venezuela no superior a 0.1/100.000 habitantes por años y otros en los que la incidencia se dispara 60/100.000/ año en Finlandia o Cerdeña con un predominio en ambos casos de prevalencia en niños y adolescentes de 0.25-0.4\%. (Serrano-Ríos 2009).

\subsection{1.a1. Genes HLA y DM tipo 1}

La zona HLA representa un conjunto de genes situados en el complejo mayor de histocompatibilidad y que tienen como cualidad un alto grado de polimorfismo.

La relación entre HLA y DM1A descrita en 1973 por J. Nerup y J. Cadworth, es a través de moléculas de los loci DR y DQ y se ha demostrado en estudios de rastreo genómico que en la región HLA se sitúan los ya mencionados loci que más participan a la predisposición genética de la DM1, en torno a $50 \%$. Dichos loci DR y DQ tienen una franca importancia en la etiopatogenia de enfermedades autoinmunes y en especial en la enfermedad que nos ocupa que sea la DM tipo 1. En este sistema, existe una región que codica las moléculas de clase II, lo cual explica la participación en el proceso de presentación de antígenos previamente captados y procesados por células de las estirpes macrófago-monocito. Se forman complejos péptido- molécula de HLA expuestos a través de las células presentadoras de antígenos y que conducen a un respuesta inmune con la activación de linfocitos TCD4+ que se subdivide a su vez en Th1 denominados cooperadores o Th2 denominados reguladores y dependen de la predisposición individual asociada al complejo HLA clase II a. (Serrano-Ríos 2009).

Existen otros genes relacionados con la etiopatogenia de la DM tipo 1 como son: DOA, DMA y DMB que controlan el procesado de moléculas HLAII por su situación en el complejo endosoma-lisosoma. Los genes TAP1 y TAP2, los cuales participan en el transporte a través del retículo endoplásmico- moléculas HLA II- aparato de Golgi- superficie celular para el procesado de péptidos y su presentación celular. (Serrano-Ríos 2009).

Por último, están descritos otros genes en la que no está descartada su participación en la etiopatogenia de la DM tipo 1, pero donde se sabe que su importancia es mucho menor que el establecidos para las moléculas clase II que serían: La clase III que forma parte también del sistema HLA en sentido centrómero- telómero después de la clase II está formada por numerosos genes : properdina, C2 y C4 del complemento, proteínas del shock térmico, etc., y finalmente y en último lugar en la región HLA estaría la clase I donde 
estarían los genes que codifican la cadena alfa de la b2 microglobulina y sus loci A,B y $\mathrm{C}$ son los antígenos de transplante clásicos.

\subsection{1.a2. Asociaciones genes HLA y DM tipo 1}

Los genes HLA suponen un $45 \%$ de la susceptibilidad genética en la DM tipo 1. Se demostró en estudios con diferentes grupos étnicos y fundamentalmente en la raza caucásica que el $90-95 \%$ de los pacientes diagnosticados de DM tipo 1 eran portadores de los antígenos DR3 o DR 4 o ambos, y en ellos el estado heterocigoto confería mayor susceptibilidad que simplemente el hecho de ser portadores (DR3/X, DR4/X) y había una diferencia significativa en comparación con población no diabética, que so superaba el 55\%.

No nos podemos olvidar de los genes DQ y sobre todo de aquellos alelos que participan en la síntesis de la cadena $\beta$ (DQB1). L. Todd et al (1987) y luego Kahlil, Trucco y Serrano Ríos (1989-92), (Serrano-Rìos, Goday et al. 1999) demostraron que cambios puntuales de un aminoácido en posiciones concretas de la cadena $\beta$, como la sustitución de un residuo de aminoácido aspártico por otro neutro (serina, alanina o valina) suponía un mayor riesgo de DM tipo 1 y que la presencia de Asp. En la posición 57 suponía una protección frente al riesgo de DM tipo 1. Kahlil y Serrano describieron también la importancia de cambios en la cadena alfa como es la presencia de Arginina en la posición 52 en determinados alelos DQ suponía un mayor riesgo y como la presencia de genotipos combinados como DQA1 Arginina 52, DQB1 no aspártico 57 aumenta su significación como marcador de susceptibilidad o protección. Las asociaciones con mayor riesgo de DM tipo 1 en la raza caucásica son: DQA1*0501, DQBI*0201/DQA1*301DQB $1 * 0302$ y por el contrario las que confieren protección frente al desarrollo de DM tipo 1 son determinada por el haplotipo DRB1*1501DQA1*102-DB1*0602. La molécula DQ6 es protectora universal incluso frente haplotipos de alto riesgo. Un detalle a tener en cuenta es que la susceptibilidad genética a través del locus DQ siempre va a estar controlada (aumentada, disminuida o neutralizada) por alelos del locus DR y específicamente por el gen DRB1, que está presente en la cadena $\beta$. Asimismo, la combinación de genotipos DRB1+DQA1-DQB1 supone una diferencia de riesgo respecto a la raza caucásica como los Afroamericanos, los Amerindios o los japoneses.

La relación fenotipo-genotipo HLA supone una marcada heterogeneidad respecto a los haplotipos DR3 vs DR4. Los pacientes con DR4 suelen tener un comienzo más precoz, con mayor agresividad respecto a la autoinmunidad 
con la consiguiente asociación de otras enfermedades autoinmunes. Sin embargo, los pacientes con DR3 suelen tener una evolución más lenta de la enfermedad con un inicio de forma general después de los 30 años. Los mecanismos moleculares de la asociación HLA- DM tipo 1 no están del todo aclarados, si que están descritos una especificidad en la asociación dependiente de la estructura molecular de la región HLA con una zona de hendidura en la que se unen los péptidos en sitios complementarios según la estructura del péptido. Esto explicaría que en ciertas condiciones estos péptidos (autoantígenos) de los islotes se unen a los sitios complementarios en la molécula de clase II del sistema HLA con resultados de protección (DQB1*602) Vs de riesgo (DQB1*302). Incluso ciertos alelos del sistema HLA de clase 1 como el A51 donde existen polimorfismos (microsatélites) tienen mayor susceptibilidad de DM 1 de comienzo juvenil y no de aparición tardía. (Serrano-Ríos 2009).

En resumen, ciertas asociaciones confieren mayor riesgo de DM tipo 1: Según Eisenbarth: (Castano and Eisenbarth 1990, Eisenbarth 2007, Jahromi and Eisenbarth 2007)

"La combinación heterocigota de DQA1x-301-DQB1x302 en haplotipo DR4 y de DQA1x501-DQB1x0201 en haplotipo DR3 resulta en una sinergia que aumenta el riesgo a presentar DM1. El haplotipo DQA1x 301-DQB1x 302 es, en caucasoides, el haplotipo de riesgo para DM1 más prevalente seguido de DQA1x 501-DQB1x201 (52\% de la prevalencia en Caucasoides). El alelo DQB1x602 asociado a DR2 es protector y dominante a los efectos de susceptibilidad de los haplotipos arriba referidos. Debe subrayarse que los genes HLA del locus DR modifican el riesgo conferido por HLADQ, el DR3A30-B18, descrito en la población vascas, confiere un elevado riesgo de DM1 en esa población" (Serrano-Ríos 2009).

\subsection{1.a3. Genes no HLA}

Existen otros genes no HLA que explican una mayor susceptiblidad de la DM tipo 1 que sólo ejercen su efecto en conjunto con alelos HLA adecuados.

Empezando por la existencia de polimorfismo del promotor del gen de la insulina y una sustitución del aminoácido de la tirosín-fosfatasa específica de los linfocitos (PTPN22) se ha asociado a DM tipo 1 en diversas poblaciones. (Pugliese 2004). Se describe que una secuencia repetida en tándem en la región 5 del gen de la insulina ( IDDM2) predisponía a un menor riesgo de diabetes asociado a un elevado número de repeticiones y con una 
mayor expresión de RNA mensajero de insulina en el timo (Bell, Horita et al. 1984). El polimorfismo del gen PTP influye en la señalización del receptor de las células $\mathrm{T}$, y su presencia supone un riesgo asociado con otras enfermedades autoinmunes. Aunque existen genes asociados como son el gen AIRE implicado en el síndrome pliendocrino autoinmune tipo 1 y del gen Scurfy implicado en la poliendocrinopatía ligada X sólo los genes HLA y el de la insulina los únicos en los que se ha demostrado claramente su implicación en la DM tipo 1. Los estudios de investigación se han centrado en buscar genes en común de hermanos con DM tipo 1 y se han generado una larga lista de genes que se les denomina IDDM loci. Posiblemente mucho s de estos loci no se encuentren implicados con la limitación de la falta de medios para detectar la asociación entre distintos loci.

Existen polimorfismo implicados en otras enfermedades como la Enfermedad de Graves que también contribuyen al desarrollo de DM tipo 1 en ciertas poblaciones como es el CTLA4 (Cytotoxic T- Lymphocytes Associated Antigen -4 vs IDDM12) y que se ha demostrado en un metaanálisis de 33 estudios con 5000 pacientes. (Kavvoura and Ioannidis 2005).

Existen estudios de experimentación con ratones NOD que desarrollan una Dm autoinmune muy similar a la DM tipo 1 existe una expresión aumentada del gen IGF1 lo que confiere una mayor susceptibilidad en la DM tipo 1 (Rothe, Jenkins et al. 1997). Así como otro locus que es el IDDM18 que se encuentra cerca del gen que codifica la subinidad p40 de la IL12 (Morahan, Huang et al. 2001).

Sobre el efecto parenteral de la expresión de los genes que se han estudiado en los distintos loci IDDM1; IDDM8; IDDM10 y IDDM15, las pruebas con mayor consistencia sobre la diferencia entre el origen materno o paterno se ha descrito para el locus IDDM2 y hablan de que los alelos protectores del gen de la insulina pierden su capacidad cuando vienen de rama materna en estudios franceses y norteamericanos. Esto se podría explicar mediante el imprinting: un mecanismo que regula el proceso genético silencia una alelo materno o paterno por modificación epigenética a través de la metilación vs la participación del timo implicando genes próximo como el de la IL12 o mecanismos complejos de paramutación (Pugliese 2004). En conclusión, existen diferentes loci distintos de los HLA que contribuyen a un mayor riesgo de presencia de DM tipo 1 pero cuya participación exacta no está descrita y por ello todavía no se pueden incluir por tanto en el consejo genético a diferencia de los loci HLA de los que si se puede hacer valoración de riesgo en recién nacidos. 


\subsubsection{Factores ambientales}

Otra parte importante en la etiopatogenia de la DM tipo 1 son los factores ambientales ya sea desencadenando o controlando el proceso autoinmune descrita en diversos estudios.

Empezaremos hablando de que hay implicar otros factores dado que sólo el 50\% de los gemelos monocigóticos probandos desarrollan la enfermedad, (Redondo, Rewers et al. 1999) y llama la atención como la tasa de concordancia de familiares con DM tipo 1 HLA idénticas sea menor que la gemelos univitelinos (Solesz, Madacsy et al. 1994). Otro hecho que apoyaría la participación de factores ambientales es el aumento de prevalencia en los emigrantes y el hecho de que en los últimos 20 años se haya duplicado la incidencia de DM tipo 1 en distintos lugares, sin guardar relación con la inmuno genética (Group 2000) y sin asociarse el aumento en la tasa de DM tipo 1 sin relacionarse con aumento de genes protectores. (Onkamo, Vaananen et al. 1999).

\subsubsection{2a. Papel de los virus}

Los virus podrían ejercer su acción a través de un efecto directo mediante infección-destrucción de la celula beta o el que explicaría y es más frecuente que es un efecto indirecto desencadenando un proceso autoinmune. Se ha observado en necropsias de pacientes que fallecieron por infección sistémica de enterovirus una insulinitis, con presencia incluso del enterovirus en la célula beta(Sussman, Strauss et al. 1959, Bottazzo, Dean et al. 1985). En contrapartida, también hay referencias que no apoyan la infección por algunos virus Coxsackie, Epstein-Barr, parotiditis y citomegalovirus como en un estudio de 75 pacientes que fallecieron precozmente tras su diagnóstico de DM 1 y que no mostraban lesiones en él por estos virus (Foulis, McGill et al. 1997).

\subsubsection{2b. Enterovirus}

Se ha observado que la infección por enterovirus se encuentra duplicada en los familiares de pacientes con DM Tipo 1 y que desarrollan dicha enfermedad respecto a los que no la desarrollan y también se describe niveles mas altos de Anticuerpos anti- Cosackie B, en gestantes cuyos niños desarrollan una DM tipo 1 posteriormente (Hyoty, Hiltunen et al. 1995). Entre el 40-69\% de los niños recientemente diagnósticos de DM tipo 1 presentan dichos anticuerpos contra Coxsackie B-4 comparando con el 0-4\% de la población sana y es que existe una homología entre estos y los GAD 65 lo 
cual podría desencadenar la respuesta inmune a través de un mecanismo de « mimetismo molecular» (Atkinson, Bowman et al. 1994).

Con la intención de relacionar la infección de Enterovirus con la DM tipo 1 se realizó un estudio prospectivo en Finlandia cuyos resultados describían su mayor frecuencia en los familiares con DM tipo 1 (midiendo Anticuerpo y RNA vírico) (Hyoty, Hiltunen et al. 1995). En contra de esta teoría estaría un estudio Sueco que no encontró diferencias entre los niveles de Ac IgG contra infecciones por Coxsackievirus B sus 5 tipos y los niños recientemente diagnosticados de DM tipo 1 aunque había pasado poco tiempo desde el inicio de la infección y el desarrollo del proceso autoinmune (Tuvemo, Dahlquist et al. 1989) o el hecho de que en Japón no hay aumento de incidencia de Dm tipo 1 a pesar de la elevada frecuencia de viriasis (1993).

\subsubsection{2c. Rubeola}

Se ha relacionado la infección por rubéola congénita como desencadenante de un proceso autoinmune, poniendo de manifiesto una positividad de Anticuerpos (ICA y/o IAA en cerca del 50-80\% de los pacientes con DM tipo 1 y señalando la posible existencia de un proteína de este virus en el que se produjera un mecanismo de reacción cruzada con la célula $\beta$. (Hiltunen, Hyoty et al. 1995).

\subsubsection{2d. Rotavirus}

Se hable de asociación entre infección por rotavirus y Dm tipo 1 en un reciente estudio prospectivo realizado en Australia cuya limitación es que no se estudio la infección por otros virus más prevalentes como son los enterovirus (Honeyman, Coulson et al. 2000).

\subsubsection{Otros factores}

\subsubsection{3a. Nutrición}

Se ha atribuido su papel en la etiopatogenia a través de diversos orígenes como son:

1) La relación entre la ingesta precoz de la leche de vaca y la incidencia de DM tipo 1 (Borch-Johnsen, Mandrup-Poulsen et al. 1984, Gerstein 1994), que en estudios recientes se habla que es una relación débil y sólo tendría importancia en individuos genéticamente susceptibles (Gerstein 1994). Es cierto el hecho de la presencia de títulos elevados de Acs contra ella en niños recientemente diagnosticados (Dahlquist, 
Savilahti et al. 1992), incluso en un estudio randomizado se descarta la influencia de la misma en el desarrollo de DM tipo 1, los primeros nueves meses (Martikainen, Saukkonen et al. 1996).

2) También se habla de que la introducción del gluten en los primeros 3 meses de vida en los niños con genotipo DR3/ DR 4-DQ8 (Ziegler, Schmid et al. 2003) conlleva a la aparición de Acs contra los islotes y que incluso su consumo mediante cereales o arroz después de los siete meses eleva el riesgo de aparición de Ac contra los islotes en pacientes con riesgo aumentado para DM Tipo 1(Norris, Barriga et al. 2003). De hecho en biopsias yeyunales de pacientes con Dm tipo 1 se ha observado un mayor actividad inmunológica de criptas y vellosidades intestinales (Savilahti, Ormala et al. 1999) y se postula que el gluten produce una inflamación intestinal que a su vez produciría una variación inmunológica en un páncreas inmaduro.

3) La ingesta de aceite de hígado de bacalao, rico en Vitamina D durante la gestación previene el riesgo de DM tipo 1 en el niño (Stene, Ulriksen et al. 2000), así como la suplementación adecuada con vitamina D disminuye el riesgo de desarrollo de Dm tipo 1 (1999) e incluso la administración intraperitoneal de $25 \mathrm{OH}$ vitamina D previene su aparición (Mathieu, Waer et al. 1994). Este hecho se explica por una disminución del estrés oxidativo, disminución de las moléculas clase I y la inflamación pancreática por disminución de los nitritos. (Mcfarlane and Scott 2003).

4) Se habla también de una relación positiva con la elevación del peso en el estudio EURODIAB realizado en Finlandia y en otro con niños < 2.5 años (Hypponen, Virtanen et al. 2000) pero con el limitante de defectos en las poblaciones control y al tratarse de estudio retrospectivo (Virtanen and Knip 2003).

\subsubsection{3b. Perinatales}

En un estudio de 892 niños con DM tipo 1 se habla como factores de riesgo: edad materna superior a 25 años, preeclampsia, enfermedades respiratorias e incompatibilidad sanguínea $\mathrm{AB} 0$ y como factores de protección un peso y una longitud baja al nacer (Dahlquist, Patterson et al. 1999). 


\subsubsection{Autoinmunidad}

Es bien conocido que la DM tipo 1 es una enfermedad autoimmune mediada por células $T$ contra las células $\beta$ pancreáticas, pero se desconoce los responsables que llevan al desiquilibrio de tolerancia de autoantígenos insulares (Bach and Chatenoud 2001).

\subsubsection{4a. Inmunopatolofisiologia celular}

La insulinitis demostrada por la infiltración de células mononucleares descrita en 1965 por Gepts fue la primera demostración de la etiopatogenia autoinmune (Gepts 1965).

El estudio sobre pacientes fallecidos con DM tipo 1 recientemente diagnóstico nos ha desvelado ciertas alteraciones inmunológicas. Limitado a los islotes de Langerhans existe una infiltración de linfocitos T CD4 Y CD8 activados con una hiperexpresión de HLA de clase I con un incremento de la presentación antigénica+ macrófagos+ depósitos tanto de Inmunoglobulinas como partes del complemento (Narendran, Estella et al. 2005). El proceso autoinmune iniciado por la activación de las células $\mathrm{T}$ autorreactivas presentes tanto en la circulación, como en el infiltrado pancreático, conducen a la generación de células efectoras frente a autoantígenos y desencadenando un ataque contra las células $\beta$. Existe un disbalance con predominio de los linfocitos Th1 frente a los th2 (Rabinovitch 1998) y esto explica que las citoquinas como la interleuquina 2 , interferón $\gamma$ y el factor de necrosis tumoral $\beta$ se relacionan con una insulinitis destructiva frente a las citoquinas producidas por los th2 que son la IL4 y la IL 10 que protegerían contra la enfermedad y sobre todo un paso clave en la patogenia de la enfermedad es el secuestro de las células $\mathrm{T}$ hacia los islotes (la expresión de quimioquinas y el disbalance de th1 frente a th2 conllevará a distintos tipos de insulinitis y a un posterior ataque o protección contra la célula $\beta$ ) (Mandrup-Poulsen 1996, Rabinovitch and Suarez-Pinzoz 1998).

\subsubsection{4b. Inmunopatofisiología humoral}

En la fase prediabética y contribuyendo a aclarar sobre la etiología en el diagnóstico diferencial de la DM tienen un papel clave la presencia de Anticuerpos antiislote que son un signo de la autoinmunidad humoral.

Por lo tanto, parece que en la fase inicial de la enfermedad, las células T autorreactivas van dirigidos contra unos pocos autoantígenos, la fase progresiva requerirá la diseminación de otros agentes como son GAD 65, GAD 67, ICA 512, IA-2b, GM2-1 gangliósido, CPH, ICA69, Imogen, Hsp65, 
sinaptofisina que potenciarían la respuesta antigénica potenciando la aparición de anticuerpos contra moléculas de la célula $\beta$ en respuesta del contenido citoplasmático.

Los ICA (islet cell antibodies) engloban un conjunto de anticuerpos contra diferentes determinantes antigénicos del islote entre ellos el GAD (descarboxilasa del ácido glutámico) Insulina IA2 (proteín tirosín- fosfatasa) y existen a nivel mundial ensayos específicos de cada anticuerpo, que se han estandarizado para su detección (Falorni and Brozzetti 2005). En niños la sensibilidad diagnóstica de los ICA oscila en tormo al 70-90\% y algo menor en adultos (Vandewalle, Falorni et al. 1995). La especificidad de los ICAS en la DM tipo1 es del 96-98\% respecto al 2-4\% de sanos (Landin-Olsson, Palmer et al. 1992). En torno a un $20-30 \%$ de los familiares con ICA progresan a DM tipo 1, por lo que un título de anticuerpos elevado junto con la positividad de varios de ellos aumenta el riesgo de desarrollo e importa en estudios de prevención (Bonifacio, Bingley et al. 1990). Se ha observado que los ICA son transitorios en estudios prospectivos y que su persistencia parece predecir una pérdida acelerada de la secreción de insulina. Además en función de la edad, el sexo los niveles de péptido $\mathrm{C}$ al diagnóstico influyen en la preservación de la reserva pancreática (Schiffrin, Ciampi et al. 1994).

La presencia de Anticuerpos antiinsulina (AAI) varia en función de la edad siendo de un 50-70\% en niños frente a un 15-20\% en adultos (Vardi, Ziegler et al. 1988) y marcan una insulinitis destructiva acelerada. Su especificidad diagnóstica es del $99 \%$ y su valor predictivo muy elevado en asociación con otros anticuerpos. Se postula una hipótesis que relaciona el titulo de los AAI con la pérdida de funcionalidad $\beta$ y el alelo HLADR4 (Pugliese, Bugawan et al. 1994).

Los autoanticuerpos anti-GAD se encuentran en el 70-75\% de pacientes con Dm tipo 1 y son muy sensibles para el diagnóstico de la diabetes autoinmune latente del adulto y la DM tipo 1 de inicio tardío. Está relacionado con haplotipos de alto riesgo (Sanjeevi, Falorni et al. 1996) y existe un detalle que en el GAD65 se observa un región central homóloga al antígeno vírico Coxsackie B5 aunque no se ha visto reacción de los anticuerpos monoclonales humanos contra esta región (Richter, Mertens et al. 1994).

Los autoanticuerpos anti-IA2 se encuentran entre el $70-80 \%$ en la infancia al debut (Gorus, Goubert et al. 1997) y tienen una asociación con el HLA-DRB $1 * 04$. Se ha visto hasta un $20 \%$ tanto en tipo 1 como en tipo 2, en estudios recientes autoanticuerpos contra la molécula CD38, que es un 
receptor y actúa como mediador fisiológico en la secreción de la insulina y se desconoce el significado de dicha reacción (Antonelli, Tuomi et al. 2002).

\subsubsection{Etiopatogenia de la DM tipo 2}

En la DM tipo 2 la etiopatogenia es multifactorial y poligénica se ha determinado mediante estudios en vivo una disglucosis cuyos participantes son: la Resistencia progresiva de la insulina en diferentes tejidos así como la disfunción progresiva de la célula $\beta$ mediante fenómenos de gluco y lipotoxicidad (Rossetti, Giaccari et al. 1990, Unger 1995) y todo ello llevaba a una progresiva evolución de glucemia basal, intolerancia a la glucosa y diabetes (2006). De Fronzo en 1987 demostró que la colaboración de la RI sobre todo a nivel muscular y hepático junto con la disfunción de la célula $\beta$ eran vitales en el desarrollo de la DM tipo 2 (DeFronzo 1988).

Sabemos que la GBA y la ITG son grados crecientes de RI (Festa, D'Agostino et al. 2004). Ferranini et al (Ferrannini, Gastaldelli et al. 2003) en estudios recientes, basándose en un modelo matemático del metabolismo de la glucosa (Mari, Tura et al. 2002) habla de que el mecanismo patogénico clave en la ITG es la hiposensibilidad de la célula $\beta$ al estímulo secretor de la glucosa y se sugiere una evolución de ITG a DM tipo 2 más abrupta con un factor precipitante desconocido (Ferrannini, Nannipieri et al. 2004).

Estudios recientes realizados (Goldfine, Bouche et al. 2003) en sujetos jóvenes con RI comparando los de sin antecedentes familiares de DM y otro con padres afectos de DM2 con un seguimiento de $26 \pm 6$ se observa que la secreción aguda no era predictora de DM y si lo era la RI y se ponía de manifiesto que esta, era altamente predictora de evolución de DM tipo 2 en los de antecedentes familiares respecto a los que no los tenían que podía ser hasta 20 veces menor sugiriendo que sin antecedentes familiares existe algún otro condicionante que hace que la RI no sea buen predictor y se había visto que los jóvenes normoglucémicos, normotolerantes y sin obesidad pero con al menos dos familiares de primer grado afectos de DM tipo 2 mostraban junto con RI, una menor fosforilación tirosínica en el sustrato 1 del receptor de la insulina y una reducida actividad fosfatidil-inositol-kinasa (Pratipanawatr, Pratipanawatr et al. 2001). El paradigma actual vigentes es que la DM tipo 2 sobreviene cuando la hiposecreción de la célula $\beta$ no podía compensar la RI opuesta establecido por Rabinowitz en 1962 (Rabinowitz and Zierler 1962).

En cuanto a cual es lo que determina la RI Randle et al propuso una explicación llamada "ciclo de glucosa-ácidos grasos" poniendo de manifiesto 
la competencia de ambos sustratos para ser oxidados en tejidos diana de la insulina (Randle, Garland et al. 1963).

Realmente, no se sabe si los AG eran la causa de la RI o aumentaban la ya existente y se piensa como más acertado la segunda afirmación sin olvidarnos que la lipotoxicidad acompañando a la glucotoxicidad aparece en fases iniciar de la DM tipo 2 (Rossetti, Shulman et al. 1987, Belfort, Mandarino et al. 2005). En el origen del RI en la DM tipo 2 van a participar: ISR1 del músculo, el ISR2 en el hígado, el GLUT-4 down controlado en adipocito y músculo, la AMPK y los PPARs $\gamma-\delta$ y poniendo como uno de los actores principales el musculo con su capacidad oxidativa lípídica con una disfunción mitocondrial primaria (Ukropcova, McNeil et al. 2005). Este último argumento se ha visto reforzado por un estudio en jóvenes normotolerantes y delgados con antecedentes familiares en ambas ramas de DM tipo 2 donde se objetiva una disminución de la densidad mitocondrial en torno a un $40 \%$ con descenso del $60 \%$ de la captación de glucosa y aumento en ese porcentaje en el músculo de TG, aumento de la fosforilización del IRS-1 en el aa serina en un 50\% y disminución de la actividad insulínica del Akr (Morino, Petersen et al. 2005). Además Lowel y Schulman nos han esquematizado el papel de la hiperexpresión de la UCP2 en la C $\beta$, proteína de la membrana mitocondrial que cuando se activa libera protones que desacopla el metabolismo oxidativo de la glucosa liberando menos cantidad de insulina en respuesta a la glucosa, ya que esta se hiperexpresa en la $\mathrm{C} \beta$ humana a causa de un polimorfismo del promotor del gen y se eso se ha relacionado con aumento de casos de DM tipo 2 con una presentación más precoz (Lowell and Shulman 2005).

Sabemos que la obesidad es el principal factor ambiental en el desarrollo de DM tipo 2 y es que en la población general, la prevalencia de la DM tipo 2 está muy ligada a la prevalencia de la obesidad. Sin embargo, cuando se mira la asociación con mayor proximidad no se ve la linealidad: Se ha estimado que hasta el $30 \%$ de los sujetos obesos o con sobrepeso desarrollan DM tipo 2 y equivalente a la prevalencia de RI en obesidad o sobrepeso grado II y que se trataría de 35 millones en términos absolutos y la diferencia de 14 millones con el número de pacientes con DM tipo 2 hace sospechar que existe algo más para que un sujeto desarrolle la DM tipo 2 (Ferrannini, Natali et al. 1997). Es posible que otras hormonas como la ghrelina y la obestatina, intervengan también indirectamente (Nogueiras and Tschop 2005), regulando el metabolismo hidrocarbonado a diferencia con el glucagón-like peptide-1 (GLP1) que lo hace directamente en intestino y cerebro. En un estudio de Knauf realizado en ratones donde se objetiva un 
doble circuito regulador cerebro-intestino, que cuando falla lleva a disminución de la secreción de insulina, disminución de la captación muscular de glucosa independiente de la insulina, la disfunción de la $\mathrm{C} \beta$ y en conjunto con el grado de «inflamación de bajo que bajo nivel» asociado a la obesidad (Knauf, Cani et al. 2005). Finalmente en cuanto a el papel que juega la inflamación podría tratarse de un cierto balance pro/ antiinflamatorio pero las evidencias existentes son débiles (Weiss, Taksali et al. 2005).

En resumen aunque hay muchas evidencias que apuntan a la disfunción mitocondrial, probablemente ni la cusa de la RI ni la de la célula $\beta$ sean únicas, sino que se trate de una etiología multifactorial en ambas vertientes y que estén en feliz expresión de Stefasson y esto lleve a la producción de la interfase entre los genes y el ambiente (Grant, Thorleifsson et al. 2006).

\subsection{TIPOS DE DM}

Uno de los mayores retos para los profesionales suele ser establecer el tipo y etiología del paciente en el que se ha determinado la presencia de DM ya que puede haber influencia de fármacos o momentos evolutivos de la enfermedad que causen hiperglucemia y que su suspensión lleve a la normoglucemia (Massó and Gomez 2009).

Un hecho significativo en la historia de la DM fue la publicación de un documento de consenso denominado "Clasification and diagnosis of diabetes mellitus and other categories glucose intolerance" del National Diabetes Data Group y que posteriormente en 1980 se publicó por la OMS. En este se sustituía el concepto de Diabetes Mellitus insulinodependiente (DMID) por Diabetes tipo 1 y diabetes mellitus no insulinodependiente (DMNID) y se completaba la clasificación con la Diabetes gestacional, la intolerancia a la glucosa y otra categoría que englobaba "otros tipos de diabetes". Posteriormente en 1985 la OMS volvió a dejar los conceptos de DMID y DMNID junto con las otras categorías y añadió la DM relacionada con la malnutrición. Finalmente, en junio de 1997 un grupo de expertos en representación de la OMS y la American Diabetes Association establecieron los 4 grupos que en la actualidad tenemos según la ADA en 2003 y que obedece a un punto de vista etiológico: a) DM tipo 1, b) DM tipo 2, c) Otros tipos específicos y d) diabetes gestacional (Massó and Gomez 2009). 


\section{DIABETES MELLITUS TIPO I}

a) Autoinmune.

b) Idiopática.

\section{DIABETES MELLITUS TIPO II.}

1. Predomina la resistencia a la insulina sobre los defectos relativos en la secreción de la hormona.

2. Predominan los defectos en la secreción de insulina frente a la presencia de resistencia a la insulina.

3. OTROS TIPO ESPECÍFICOS DE DIABETES MELLITUS.

a) Defectos genéticos de la función de la célula $\beta$.

1. Cromosoma 12, HNF-1 $\alpha$ (MODY 3)

2. Cromosoma 7, glucocinasa (MODY 2)

3. Cromosoma 20, HNF-1 $\alpha$ (MODY 1)

4. ADN mitocondrial.

5. Otros.

b) Defectos genéticos en la acción de la insulina.

1. Resistencia a la insulina tipo A.

2. Leprachaunismo.

3. Síndrome de Rabson-Mendenhall.

4. Diabetes lipoatrófica.

5. Otros.

c) Enfermedades del páncreas exocrina.

1. Pancreatitis.

2. Pancreatectomía/traumatismo.

3. Neoplasia.

4. Fibrosis quística.

5. Hemocromatosis.

6. Pancreatopatía fibrocalculosa.

7. Otras.

d) Endocrinopatías.

1. Acromegalia.

2. Síndrome de Cushing.

3. Glucagonoma.

4. Feocromocitoma.

5. Hipertiroidismo.

6. Somatostatinoma.

7. Aldotesnoroma.

8. Otras. e) Inducidas por fármacos o sustancias químicas.
a) Vacor
b) Pentamidina.
c) Ácido nicotínico.
d) Glucocorticoides.
e) Hormonas tiroideas.
f) Diazóxido.
g) Agonistas $\beta$ adrenérgicos.
h) Tiazidas.
i) Dilantin.
j) Interferón $\alpha$.
k) Otros.

f) Infecciones.

1. Rubeola congénita.

2. Citomegalovirus.

3. Otras.

g) Formas infrecuentes de Diabetes autoinmunes.

1. Síndrome del hombre rígido. (Stiffmam syndrome)

2. Anticuerpos contra el receptor de la insulina.

3. Otras.

h) Otros síndromes en ocasiones asociados a Diabetes.

1. Síndrome de Down.

2. Síndrome de Klinefelter.

3. Síndrome de Turner.

4. Síndrome de Wolfram.

5. Ataxia de Friedreich.

6. Corea de Huntington.

7. Síndrome de Lawrence-MoonBiedel.

8. Distrofia miotónica.

9. Porfiria.

10. Síndrome de Prader-Willi.

11. Otros.

4. DIABETES MELLITUS GESTACIONAL.

Tabla 2: Clasificación de la diabetes mellitus (ADA, 1997)

(Conget 2002) 


\subsubsection{Diabetes tipo 1}

Supone hasta un $10 \%$ de la DM en el que se produce una destrucción de las células $\beta$ del páncreas conllevando a una deficiencia absoluta de insulina, antes denominada DMID. Se divide a su vez en 2 subtipos: (Massó and Gomez 2009)

a) DM mediada por inmunidad: Es consecuencia de una destrucción autoinmune de las células B del páncreas y por lo tanto en fases precoces de la enfermedad, incluso cuando no existe diagnóstico de DM existen diferentes tipos de anticuerpos circulantes dirigidos contra las células, la insulina, descarboxilasa del ácido glutámico o contra las tirosin fosfatasas, representando el $95 \%$ de los pacientes con DM tipo 1. Se suele diagnosticar en torno a los 25 años de edad sin diferencia entre sexos y con diversa incidencia según la raza y la geografía, siendo más frecuente en raza blanca y en nórdico y se puede asociar a otras enfermedades autoinmunes formando parte de los síndromes pluriglandulares autoinmunes tipo 1 y tipo 2. La rapidez de instauración va a ser diferente en función de la edad: En niños o adolescentes el debut de la DM suele ser con la aparición de síntomas cardinales de poliuria y polidipsia de forma abrupta induciendo a la presentación con un cuadro grave como es la Cetoacidosis Diabética y esto se explica por la rápida destrucción de las células $\beta$. Sin embargo en los adultos la aparición es similar a una DM tipo 2 dado que hay una destrucción más lenta y progresiva de la célula $\beta$ y es lo que se conocería como latent autoinmune diabetes in adults ó DM tipo LADA.

b) DM idiopática: Representa aquellos casos de DM tipo 1 con etiología desconocida y en los que no se halla ni autoinmunidad ni asociación con HLA. Existe una preferencia por grupos étnicos (Ásiáticos y Afroamericanos) con fuerte penetrancia hereditaria y tienen una evolución variable con insulinemia muy fluctuante y con riesgo de episodios de cetoacidosis.

\subsubsection{DM tipo 2}

Se trata de la forma de DM más frecuente ya que constituye del 90-95\% de los pacientes con DM, siendo importante la carga genética y el antecedente de Diabetes gestacional. Patogénicamente se caracteriza por la resistencia a la acción periférica de insulina y un defecto en la insulinosecrección que resiste mediante una hiperinsulinemia compensadora hasta agotamiento de la célula 
$\beta$. Se describe obesidad abdominal en un $85 \%$ de los pacientes llevando al diagnóstico de síndrome metabólico. En estos casos la carga genética es importante pero sin la influencia de factores ambientales como son la vida sedentaria no se pondrán en marcha los mecanismos para el desarrollo del cuadro. Podrían debutar como un cuadro de cetoacidosis con un alta demanda de acción de la insulina, lo cual puede suceder en intervenciones quirúrgicas, infecciones, situaciones de estrés, etc., (Massó and Gomez 2009).

Aunque se trataba de lo que antiguamente se denominaba DMNID en su evolución la secreción de insulina va compensando la RI, pero con el paso de los años el páncreas va claudicando con secreción de insulina insuficiente para compensar la hiperglucemia y requiere insulinizacion en el momento adecuado. Tradicionalmente el diagnóstico se hacía en la edad adulta pero se está adelantando en las generaciones existiendo diagnósticos en adolescentes, siendo raro en niños con marcada obesidad abdominal+ RI. (Massó and Gomez 2009).

\subsubsection{Otros tipos específicos de DM}

En este tercer grupo se incluyen situaciones clínicas de DM, que no tienen relación entre ellas y que se apartan de la frecuencia de los otros 2 principales grupos (Tébar Massó and Ferrer Gomez 2009).

a) Defectos genéticos de las células $\beta$ : Se trata de una DM que tiene su etiología en un mal funcionamiento de la célula $\beta$, lo que induce a un defecto en la secreción, con mínima repercusión en la acción insulínica y se presentan habitualmente en personas jóvenes <25 años y se denominan DM MODY (Maturity Onset Diabetes of the Young) Se debe a un defecto genético que se hereda de forma autosómicamente dominante y en su proceso evolutivo se comporta como una DM tipo 2. Existen varias formas de MODY en función del cromosoma implicado:

- MODY 1: Existe una alteración del gen HNF-4a( HNF es el factor nuclear del hepatocito) en el cromosoma 20, que a su vez es factor de transcripción para la expresión de HNF12

- MODY 2: Existe un alteración del gen de la glucocinasa en el cromosoma $7 \mathrm{p}$ y dado que este codifica la enzima que convierte la glucosa a glucosa 6 fosfato y por lo tanto si no funciona bien, se hace necesario un aumento en las cifras de glucosa para obtener niveles normales en la sercrección de insulina. 
- MODY 3: Se trata de una mutación en el gen HNF-1 $\alpha$ en el cromosoma 12 y es la forma de presentación más frecuente.

- MODY 4: Se trata de una mutación del gen IPF-1 en el cromosoma 13, siendo el IPF-1 un promotor de la insulina. Incluso puede existir agenesia pancreática en formas homocigotas.

Finalmente, existirían formas más infrecuentes como: La mutación en el ADN mitocondrial con casos con DM o sin ella, La falta de conversión de proinsulina a insulina con patrón de herencia autosómico-dominante o la insulina mutada biológicamente inactiva.

b) Defectos en la acción de la insulina de etiología genética: Otras formas infrecuentes de DM y suele tratarse de alteraciones en el receptor ó postreceptor con distintos grados de gravedad en función de la localización del defecto.

$\checkmark$ El conocido como tipo A de resistencia a la insulina con un cuadro clínico en la mujer de Hiperandrogenismo, poliquistosis ovárica, acantosis nigricans y resistencia a la insulina. Existen descritos alteraciones genéticas pero no todos los pacientes se ha descrito la alteración y un ejemplo sería el de la laminina A que codifica una proteína cuyo fin principal es la organización nuclear celular.

$\checkmark$ El leprachaunismo o síndrome de Donohue es una alteración genética en el cromosoma 19 p 13.2 que afecta al receptor de la insulina, con patrón de herencia autosómica-recesiva y que clínicamente cursa con bajo peso y talla al nacer, malformaciones craneofaciales, aumento del tamaño del pene vs clítoris, lipoatrofia y resistencia a la insulina. Se trata de la forma más grave de resistencia a la insulina y los niños afectados mueren precozmente.

$\checkmark$ El síndrome de Rabson- Mendenhall también presenta su alteración genética en el cromosoma 19 con alteración del receptor. Es una forma rara y menos grave que la anterior que se presenta con anomalías en dientes y uñas, rasgos acromegaloides, hiperplasia pineal y alteración de la función tiroidea. 
c) Enfermedades del páncreas exocrino: Sabemos que existen enfermedades como la pancreatitis, en especial, la aguda necróticahemorrágica y la crónica calcificante, algunos traumatismo graves o determinadas infecciones, las pancreatectomías totales o subtotales o el cáncer de páncreas que afectan al páncreas exócrino y que por ende pueden afectar al endocrino y causar DM. Incluso, en el caso del cáncer de páncreas no aparece por la reducción de masa de célula $\beta$, llegando a ser en ocasiones la primera manifestación. No nos podemos olvidar de mencionar la fibrosis quística y a la hemocromatosis donde se puede alterar la secreción de insulina y conllevar a una DM.

d) Endocrinopatías: La aparición de DM en este caso se explica por la acción de hormonas contra-insulares (catecolaminas, hormona del crecimiento, glucagón y cortisol) y por ello en pacientes con feocromocitoma, acromegalia, glucagonoma o síndrome de Cushing va a desarrollar una DM que va a desaparecer con el control o curación de la enfermedad. En otros casos como el somatostatinoma y aldosteronoma se produce una hipokalemia que lleva a una inhibición de la secreción de insulina y que al igual que las situaciones anteriores revierte con la curación.

e) Inducida por fármacos u otras sustancias químicas: El mecanismo por el que se va a desarrollar DM va a ser diferente dado que hay sustancias como el vacor y la pentamidina iv que producen destrucción permante de la célula $\beta$ pancreática. Otras sustancias afectan a la acción de insulina como el ácido nicotínico o los glucocorticoides. En el caso del interferón $\alpha$ desarrollan anticuerpos contra las células de los islotes con déficit insulínico asociado en ocasiones importante.

f) Infecciones: Se ha descrito una probable asociación entre destrucción de células $\beta$ y ciertos virus y se han identificado en pacientes que han fallecido en el transcurso del debut de la enfermedad. Se ha descritos casos de niños con DM tipo 1 con rubeola congénita y también se ha asociado a infección entre otros por virus coxackie $B$, parotiditis $y$ citomegalovirus.

g) Otras formas menos frecuentes de Diabetes de naturaleza inmune:

- Síndrome del hombre rígido: Cursa con una afectación del SNC con espasticidad muscular y paroxismos espasmódicos y 
dolorosos. Se ha encontrado títulos de Anticuerpos Anti-GAD positivos y en un $30 \%$ evolucionan a DM.

- Anticuerpos anti-receptor de insulina: Va a existir un bloqueo en la unión entre receptor e insulina que explicaría la hiperglucemia, pero también se puede producir hipoglucemia como consecuencia de la unión al receptor. Cuando el estado de resistencia a la insulina es muy pronunciado cursa con acantosis nigricans y es lo que antes se denominaba resistencia a la insulina tipo $\mathrm{B}$ e incluso acompaña a enfermedades sistémicas como el lupus eritematoso.

h) Otros síndromes genéticos que se pueden relacionar con DM: Van a existir diversos mecanismos de producción y espectro muy variable y son los siguientes: Down (trisomía 21), Klineferter (Hipogonadismo primario por $47 \mathrm{XXY}$ ), Turner (Hipogonadismo por $45 \mathrm{X0}$ ), Wolfran (Diabetes insípida, atrofia óptica y sordera neurológica+ DM), Ataxia de Fridreich, corea de Huntington, Laurence-Moon- Biedl-Rozabal, Prader Wili , distrofia miotónica, porfiria, etc.

\subsubsection{Diabetes Mellitus gestacional}

Este cuarto grupo se va a definir como la aparición de cualquier grado de intolerancia a la glucosa que es diagnosticada durante la gestación, sin excluir que la paciente ya tuviera una intolerancia a la glucosa previa pero con la condición de que no hubiera sido diagnosticada y su prevalencia oscila entre el $1-14 \%$.

Cuando existe hiperglucemia en el primer trimestre de la gestación eso hace ya pensar en una alteración hidrocarbonada previa y aunque la SOG sea normal no excluye la aparición posterior de DM gestacional.

En la DM gestacional nos interesa una pronta identificación y un tratamiento agresivo ya que es un factor de riesgo de una futura DM tipo 2. Ya que si no tiene un buen control supone un riesgo aumentado de eclampsia con elevada mortalidad perinatal, asi como de macrosomía fetal, hiperbilirrubinemia y malformaciones congénitas. Dado que es el tercer trimestre cuando se produce un mayor empeoramiento del metabolismo de la glucosa, interesan por tanto estrategias de cribado que nos permita un óptimo control de la situación (Tébar Massó and Ferrer Gomez 2009). 


\subsection{CLÍNICA}

Existirían dos formas de presentación atendiendo a los dos grupos principales de DM

\subsubsection{Clínica de la diabetes tipo 1}

Como ya se ha hecho referencia previamente en la DM tipo 1 existiría una destrucción progresiva de las células $\beta$ conllevando aun progresiva pérdida de la reserva de insulina hasta la deficiencia absoluta. En la DM tipo 1 aparecen los síntomas cardinales por la hiperglucemia instaurada de días vs de semanas de evolución consistente en: poliuria, enuresis nocturna en el caso de los niños, polidpsia, polifagia, astenia y pérdida de peso (Lima and Engel 2009).

En tiempos previos se describía la forma de presentación clínica era más repentina y grave, y de forma general era durante la infancia o la edad adulta temprana y debutaban en formas de Cetoacidosis Diabética (CAD). La CAD representa la complicación metabólica aguda más grave siendo característica de la DM tipo 1 y se produce por un déficit absoluto de insulina y un incremento concomitante de las hormonas contrainsulares. Datos de estudios más cercanos en el tiempo sugieren solo hasta el $60 \%$ de los pacientes con DM tipo 1 tienen menos de 16-18 años en el momento de debut (Lima and Engel 2009).

Tras empezar el tratamiento con insulina puede aparecer lo que se conoce como fase de luna de miel. Éste se explica por la evolución a la supresión del efecto glucotóxico y lipotóxico sobre la función de la célula $\beta$ que dura dependiendo del paciente de meses hasta incluso varios años presentando bajas necesidades de insulina y un fácil control metabólico (Barker 2006).

\subsubsection{Clínica de la DM tipo 2}

El $80-90 \%$ de los pacientes con DM tipo 2 son obesos ya que la Resistencia a la insulina factor fundamental en el desarrollo de la DM tipo 2 se asocia también a la Obesidad. Por este motivo la DM tipo 2 ha pasado de considerarse una enfermedad propia del adulto a una entidad que en el momento actual aparece en la infancia y en la adolescencia debido a la gran prevalencia de la obesidad en el momento actual, la cual se prevee que se duplique hacia el año 2025 (Lima and Engel 2009). 
La mayor parte de los casos de DM tipo 2 aparecen dentro del contexto del llamado Síndrome Metabólico, el cual se caracteriza por la presencia de insulinorresistencia e hiperinsulinismo compensador asociado a trastornos del metabolismo hidrocarbonados, HTA, alteraciones lípidicas (descenso de HDL, Hipertrigliceridemia, presencia de LDL tipo B) y obesidad, lo que lleva a un mayor riesgo de morbimortalidad de origen ateroesclerótico (Lima and Engel 2009).

La clínica cardinal de la DM tipo 2 (debilidad, poliuria, etc) se presenta de forma más insidiosa que en la DM tipo 1 a lo largo de semanas y meses pero también podemos encontrar hiperglucemia como un hallazgo casual analítico sin clínica. Este último es el gran problema y el reto ya que la DM tipo 2 se diagnóstica con años de retraso ya que se piensa que en el momento del diagnóstico se encuentra la función de la célula $\beta$ con un funcionamiento del $50 \%$ lo que probablemente suponga unos 10 años de retraso en el diagnóstico aproximadamente. Este hecho, también explica que en el momento del diagnóstico hasta un $20 \%$ de los pacientes presenten complicaciones y que existe un alto porcentaje de pacientes con DM tipo 2 que en el momento actual no han sido diagnosticados. Este hecho, nos pone de manifiesto la importancia de instaurar políticas de diagnóstico precoz en población de alto riesgo (Ceska 2007).

\subsection{DIAGNÓSTICO DE DM}

Independientemente del tipo de DM los datos en los que nos basamos para hacer un diagnóstico de cualquier DM y de las otras categorías del metabolismo hidrocarbonado como la glucemia anormal en ayunas e ITG, están actualmente bien consensuadas y son claros y precisos con el fin de que no haya diferentes criterios diagnósticos. Ya que un Comité de Expertos para el Diagnóstico y Clasificación de la DM, la ADA(American Diabetes 2014), revisa periódicamente los enunciados diagnósticos y la clasificación de dichas alteraciones.

Desde el punto de vista diagnóstico, se consideran 3 situaciones diferentes dentro de las alteraciones del metabolismo hidrocarbonado (Massó and Gomez 2009).

1. Glucosa anormal en ayunas: Se define como una concentración de glucosa en sangre entre $100(5.6 \mathrm{mmol} / \mathrm{l})-126(7 \mathrm{mmol} / \mathrm{l})$ en ayunas de $8 \mathrm{~h}$, donde el paciente va a estar asintomático, aunque ya presenta 
alteraciones metabólicas y puede ya estar formando parte del síndrome metabólico

2. Intolerancia a la glucosa: Para hacer este diagnóstico se exige la realización de un test de tolerancia oral con 75 gr de glucosa y se define cuando el resultado son valores entre 140-200 (11.1 mmol/l)

3. Diabetes Mellitus: El diagnóstico de la DM lo podríamos hacer por varías vías: Basándonos en la HbA1c, la glucemia plasmática en ayunas o midiendo la glucemia a las $2 \mathrm{~h}$ tras una SOG con 75 gr de glucosa.

$\underline{A 1 C}$ : Esta prueba se debe realizar usando un método que sea certificado por el NGSP y estandarizada basándonos en el Control y Complicaciones de la Diabetes Trial (DCCT) como ensayo de referencia. Este método tiene varias ventajas sobre la SOG y la FPG dado que no es preciso el ayuno, tiene mayor estabilidad preanalítica y menos perturbación por el estrés y la enfermedad. En cuanto a las desventajas habría que tener en cuenta el costo y su disponibilidad limitada en ciertas regiones del mundo en desarrollo y que en ocasiones no existe un buena correlación entre la HbA1C y la media de glucosa en los últimos 3 meses, por ello hay que tener en cuenta la edad, la raza y la anemia/ hemoglobinopatías en consideración de utilizar la Hba1c como diagnóstico. Dado que sigue sin estar claro si utilizar el mismo punto de corte de Hba1c para diagnóstico de DM en niños y adolescentes (Cowie, Rust et al. 2010, Nowicka, Santoro et al. 2011, Romualdo, Morales et al. 2012), asimismo la HbA1c puede variar según la raza ya que los Afroamericanos presentan unos niveles de A1 c más elevados que los blancos no-hispanos, incluso en un reciente estudio epidemiológico se observó que los Afroamericanos( con o sin DM) tenían niveles más altos dede fructosamina y albúmina -glicada y menores niveles de 1,5-anhidroglucitol, lo que sugiere que su carga glucémica puede ser superior (Selvin, Steffes et al. 2011). Finalmente como desventaja no nos podemos olvidar de su limitación en caso de Anemia/ Hemoglobinopatía porque en determinadas condiciones tales como el embarazo (segundo y tercer trimestres), la reciente pérdida de sangre o transfusión, terapia con eritropoyetina, o hemólisis se deberían usar la glucemia en ayunas o la SOG. 


\begin{abstract}
Glucemia en ayunas" igual o superior a $126 \mathrm{mg} / \mathrm{dl}(7,0 \mathrm{mmol} / \mathrm{l}) "$, o
Glucemia igual o superior a $200 \mathrm{mg} / \mathrm{dl}(11,1 \mathrm{mmol} / \mathrm{l})$ a las dos horas" durante la realización de un test de tolerancia oral a la glucosa ${ }^{\cdots}$, o

Sintomas de hiperglucemia (poliuria, polidipsia o pérdida inexplicada de peso) junto con una determinación casual ${ }^{\cdots \cdot}$ de glucemia igual o superior a $200 \mathrm{mg} / \mathrm{dl}(11,1 \mathrm{mmol} / \mathrm{l})$

$\mathrm{HbA}_{1 \mathrm{c}}{ }^{\cdots \cdot \cdot}>6,5 \%{ }^{*}$

**A $\mathrm{A}$ C $\geq 6.5 \%$ usando un método que sea certificado por el NGSP y estandarizada basándonos en el Control y Complicaciones de la Diabetes Trial (DCCT) como ensayo de referencia y con sospecha de una hiperglucemia inequívoca.
\end{abstract}

\title{
Figura 2. Criterios para el diagnóstico de Diabetes Mellitus
}

La concordancia entre los diferentes test como la de glucemia plasmática en ayunas con la de $2 \mathrm{~h}$ tras SOG es imperfecta al igual que la que existe entre la Hba1c y la glucemia plasmática en ayunas, De hecho según el National Health and Nutrition Examination Survey (NHANES) con la HbA1c $\geq 6.5$ se identifica un tercio menos casos de diabetes no diagnosticada que un punto de corte de la glucosa en ayunas $\geq 126 \mathrm{mg} / \mathrm{dL}$ (7,0 mmol / L) (Picon, Murri et al. 2012). Numerosos estudios han confirmado que en comparación la $\mathrm{HbA1C}$ y la glucemia plasmática en ayunas respecto a la glucemia a las $2 \mathrm{~h}$ de una SOG, esta última identifica más casos de DM. Por ello a menos que el paciente tenga una hiperglucemia sintomática o una glucemia plasmática al azar de 200 se requiere confirmación de los test. Por otro lado, si un paciente tiene resultados discordantes de dos tests diferentes, el resultado de la prueba que está por encima el punto de corte de diagnóstico se debe repetir y el diagnóstico se hace sobre la base de la prueba confirmada. También hay que tener en cuenta la variabilidad analítica sobre todo en el caso de glucemia plasmática en ayunas y las $2 \mathrm{~h}$ post SOG en las que puede pasar que el primer resultado sea anormal y al repetir sea normal especialmente si las muestras de glucosa son recogidas a temperatura ambiente y no centrifugada con prontitud. Salvo error de laboratorio, estos pacientes probablemente tienen los resultados de pruebas cerca de los márgenes del umbral de diagnóstico y precisan repetirse en 3-6 meses.

Los pacientes a los que hoy etiquetamos como glucemia alterada en ayunas e intolerancia a la glucosa se enmarcarán dentro del concepto de "prediabetes" y se refiere a una situación clínica que puede evolucionar a DM, pero que también con instauración de medidas higiénico-dietéticas e incluso 
fármacos sensibilizantes puede retroceder a una normoglucemia. Sin embargo lo más importante, es identificar si esto va a asociado a un síndrome metabólico ya va a suponer un riesgo cardiovascular en función de las alteraciones que existan (Tébar Massó and Ferrer Gomez 2009).

Sabemos por tanto, que el diagnóstico de DM ha evolucionado y lo que hay que recalcar que este diagnóstico distingue a un grupo de personas que van a presentar un incremento de mortalidad prematura respecto a las personas sin DM con alto riesgo de complicaciones microangiopáticas y macroangiopáticas (Tébar Massó and Ferrer Gomez 2009).

\section{Detección y diagnóstico de la diabetes mellitus gestacional (DMG)}

Sabemos que la Diabetes Mellitus Gestacional conlleva riesgo para la madre y el neonato. The Hyperglycemia and Adverse Pregnancy Outcome (HAPO) study fue un estudio de cohorte multinacional, con 25.000 gestantes demostraron la existencia de resultados de riesgo de efectos adversos maternos, fetales y neonatales que aumentaban continuamente como una función de la glucemia materna a las 24-28 semanas, incluso dentro de los rangos anteriormente considerado normal para el embarazo. Dando lugar a una cuidadosa reconsideración de los criterios diagnósticos de DG.

En embarazadas con factores de riesgo (obesidad central, antecedentes de DM gestacional, glucosuria o antecedentes familiares de DM), debe realizarse cribado, en la primera visita prenatal, para identificar una DM2, no DG, según criterios diagnósticos habituales. (B)

En embarazadas sin diagnóstico previo de DM y sin factores de riesgo, se realizará el cribado de DG entre la semana 24 y la 28 (A), utilizando cualquiera de las dos estrategias siguientes:

- En un paso. Recomendaciones de International Association of the Diabetes and Pregnancy Study Groups (IADPSG): tolerancia oral a la glucosa con 75 g. Será diagnóstico de DG cuando uno de los siguientes valores este alterado.

·Ayunas $\geq 92 \mathrm{mg} / \mathrm{dl}, 1$ hora después: $\geq 180 \mathrm{mg} / \mathrm{dl}, 2$ horas después: $\geq$ $153 \mathrm{mg} / \mathrm{dl}$.

La estrategia de un paso podría aumentar la incidencia de forma significativa de la DG porque es suficiente un valor anormal para el diagnóstico y esto supondría un impacto significativo en los costos, sobrepasando la capacidad de infraestructura médica y la medicalilzación y en estudios realizados se objetivo un modesto beneficio (Crowther, Hiller et al. 
2005, Landon, Spong et al. 2009) y por lo tanto se necesitan más estudios clínicos para valorar la estrategia de un solo paso.

- En dos pasos. Consenso del National Institute of Health (NIH): se recomienda sobrecarga con $50 \mathrm{~g}$ de glucosa, midiendo la glucemia plasmática una hora después ( $1^{\circ}$ paso) y es el test conocido como de O`Sullivan. (Con este punto de corte nos identifica un $80 \%$ de la DM gestacional)

Si el valor es $\geq 140 \mathrm{mg} / \mathrm{dl}$, se realiza test de tolerancia oral a la glucosa (TTOG) con $100 \mathrm{~g}$ ( $2^{\circ}$ paso). Para establecer el diagnóstico de DG es necesario la condición dos puntos glucémicos por encima del rango de la normalidad de los siguientes (midiendo 1,2 y $3 \mathrm{~h}$ tras $\mathrm{SOG}$ ):

Carpenter y Coustan:

Basal $95 \mathrm{mg} / \mathrm{dl}$ (5.3 mmol/l); 1 h $180 \mathrm{mg} / \mathrm{dl}(10 \mathrm{mmol} / \mathrm{l}) ; 2$ h $155 \mathrm{mg} / \mathrm{dl}$ ( $8.6 \mathrm{mmol} / \mathrm{l}), 3 \mathrm{~h} 140 \mathrm{mg} / \mathrm{dl}(7.8 \mathrm{mmol} / \mathrm{l})$

\section{NDDG}

Basal $105 \mathrm{mg} / \mathrm{dl}(5.6 \mathrm{mmol} / \mathrm{l}) ; 1 \mathrm{~h} 190 \mathrm{mg} / \mathrm{dl}$ (10.6 mmol/l); 2 h 165 $\mathrm{mg} / \mathrm{dl}(9.2 \mathrm{mmol} / \mathrm{l}) ; 3 \mathrm{~h} 145 \mathrm{mg} / \mathrm{dl}(8 \mathrm{mmol} / \mathrm{l})$

Esta forma de diagnóstico en dos pasos reduce el riesgo de macrosomía, distocia, bajo peso para la edad gestacional (Horvath, Koch et al. 2010). The American College of Obstetricians and Gynecologists (ACOG) en sus guías en 2013 proponen este criterio diagnóstico.

Las pacientes con DG deben ser revaluadas a las 6-12 semanas del posparto con el TTOG y criterios diagnósticos de no embarazo (Grado de Evidencia E). Las mujeres con antecedentes de DG deben ser controladas durante toda la vida para detectar el potencial desarrollo de diabetes o prediabetes (por lo menos cada 3 años). (Grado de Evidencia B) Las mujeres con antecedentes de DG en las que se diagnosticó prediabetes deben modificar su estilo de vida o prevenir la diabetes con metformina. (Grado de Evidencia A)

Otros conceptos y diagnósticos de interés:

\section{Diabetes Mellitus Neonatal}

La DM neonatal tiene una incidencia muy baja de 1/500.000 recién nacidos vivos donde no se identificado participación de la autoinmunidad ni HLA. 
La clínica cardinal consiste en irritabilidad, poliuria, polidipsia y polifagia que presenta antes del primer mes de vida y puede llevar dependiendo del momento en que se identifique a un cuadro de cetoacidosis diabética. Este cuadro tiene una duración aproximada de 14 días y precisa tratamiento con insulina pudiendo ser autolimitado en un $60 \%$ de los casos o persistir en el resto de los casos (Massó and Gomez 2009).

Como cosa curiosa va a tener una relación con la DM tipo 2, ya que un $40 \%$ de los casos autolimitados van a desarrollar una DM tipo 2 entre los 7 y 20 años y se describe que en un $33.3 \%$ de los casos tienen antecedentes familiares de DM tipo 2 (Massó and Gomez 2009).

\section{Síndrome metabólico}

El diagnóstico de un paciente de Síndrome Metabólico es tener delante a una persona con más alto riesgo cardiovascular y disponiendo de fáciles elementos clínicos (perímetro de cintura, IMC, HTA) o analíticos (TG, HDLc, glucemia plasmática en ayunas) siendo una rutina en la práctica clínica en adultos, pero no tanto en niños, siendo esta franja de edades entre la niñez y la adolescencia en la que los últimos años se esta objetivando un aumento de los casos importante (Massó and Gomez 2009).

\section{Estudios de diagnóstico precoz de la DM tipo 2}

Como ya se había comentado en el caso de la DM tipo 2 suele haber 5 a 10 años de evolución no conocida lo que supone un mayor riesgo cardiovascular y se sabe que tratar otros factores de riesgo asociados pero independientes de la DM mejora el pronóstico de la misma. Por este motivo la OMS impulsa el estudio de DM en sujetos con HTA y también el National Disease in the United Kingdom en caso de pacientes con enfermedad cardiovascular y paradójicamente no supone un menor coste sanitario porque en el caso de no prevenir su progresión, en muchas ocasiones nos vemos obligados a tratar sus complicaciones (Massó and Gomez 2009).

\section{Estándares asistenciales en el diagnóstico de la DM tipo 2}

Según se ha hecho referencia ya la ADA establece 4 niveles de evidencia en sus recomendaciones (A basada en estudios de gran poder aleatorizados y controlados; B basados en estudios de cohorte correctamente realizados; C evidencia con estudios poco controlados y $\mathrm{E}$ basado en consensos de expertos) (Massó and Gomez 2009) 


\section{Pruebas diagnósticas en PreDM o DM:(Massó and Gomez 2009)}

Las pruebas dirigidas al diagnóstico de pre-DM y DM en población adulta asintomática deben restringirse a aquellos con sobrepeso u obesidad (IMC $\geq 25$ ó 23 en Asiáticos Americanos ) y que tengan uno o más factores de riesgo adicionales para DM. En personas sin estos factores las pruebas deberían iniciarse a partir de los 45 años (Grado B)

Si los test son normales se repetirán a los 3 años (C)

Para el diagnóstico de pre-DM y DM se utilizarán tanto la glucemia plasmática en ayunas, la SOG y la Hba1c (B)

En pacientes con glucemia anormal en ayunas la SOG es el que mejor define el riesgo de $\mathrm{DM}(\mathrm{E})$

En las personas en la que se detecte una situación de pre-DM o DM debe identficarse y en su caso tratarse, otros factores de riesgo cardiovascular (B)

Pruebas diagnósticas en niños con pre- DM vs DM tipo 2 (Massó and Gomez 2009)

Se estudiarán niños con sobrepeso (IMC > percentil 85 para la edad y sexo, peso para la altura $>$ percentil 85 o peso $>120 \%$ de su peso ideal para su altura y 2 de los siguientes factores de riesgo:

- Historia de DM tipo 2 en familiares de primer o segundo grado.

- Raza: Indios americanos, afroamericanos, latino-americanos, asiáticoamericanos y nativos de las islas del Pacífico

- Signos de resistencia de insulina o condiciones asociadas a ella: Acantosis nigricans, HTA, dislipemia, síndrome de ovario poliquístico.

- Historia materna de DM ó DM gestacional( E)

- Los estudios podrían iniciarse a los 10 años o al comienzo de la pubertad, si ésta ase adelanta y se repetirá cada 2 años. ( E)

\subsection{TRATAMIENTO DE LA DM}

\subsubsection{Actuaciones no farmacológicas}

La dieta y el ejercicio son parte fundamental del tratamiento de la diabetes. Las recomendaciones dietéticas deberán adaptarse a cada individuo para conseguir los objetivos generales del tratamiento. En este sentido hay 
que considerar que la obesidad es muy frecuente en los diabéticos tipo $2 \mathrm{y}$, por tanto, uno de los principales objetivos será la reducción ponderal. El contenido calórico de la dieta deberá ajustarse en cada individuo en función de su índice de masa corporal y de la actividad física que desempeñe habitualmente. En cuanto a la proporción de nutrientes de la dieta, se recomienda que las proteínas constituyan el 10-20\% del total de las calorías ingeridas, y las grasas menos del 30\%, con menos del $10 \%$ de grasas saturadas. En cuanto a los hidratos de carbono, debe darse más importancia a la cantidad total ingerida que a la procedencia de los mismos, pero deberían evitarse los hidratos de carbono de absorción rápida (Association 2000).

El ejercicio físico, además de constituir un pilar fundamental en el tratamiento de los pacientes diabéticos, contribuye a prevenir el desarrollo de diabetes durante la vida adulta 10-14. En los pacientes con una diabetes tipo 2 el ejercicio moderado y regular (30 min/día) es muy beneficioso, puesto que disminuye la glucemia al aumentar la sensibilidad a la insulina, mejora el perfil lipídico, reduce la presión arterial, contribuye a la reducción ponderal y mejora el estado cardiovascular (disminución de la frecuencia cardíaca en reposo, aumento del volumen sistólico y disminución del trabajo cardíaco). Además, proporciona una mejor sensación de bienestar y calidad de vida. El principal inconveniente del ejercicio en los pacientes diabéticos es la hipoglucemia, que puede ocurrir varias horas después y debe condicionar el ajuste de la pauta terapéutica. Además, en los pacientes con diabetes tipo 1 con mal control metabólico, y en especial tras un ejercicio anaeróbico, puede producirse una descompensación hiperglucémica o incluso cetosis. Al margen de las alteraciones en el metabolismo de la glucosa, el ejercicio físico puede comportar otros riesgos (Helmrich, Ragland et al. 1991, Pan, Li et al. 1997, $\mathrm{Hu}$, Manson et al. 2001, Tuomilehto, Lindstrom et al. 2001). Por tanto, el programa de ejercicio debe planificarse de forma individual en función de la capacidad física del paciente y de los riesgos potenciales (Zinman, Ruderman et al. 2000).

La dieta es más efectiva que la actividad física para lograr una baja de peso, sin embargo, la combinación de actividad física con una dieta cardioprotectora y la reducción de la ingesta calórica contribuye a una mayor pérdida de peso. Un metaanálisis que investigó el efecto de la dieta por sí sola, el ejercicio por sí solo, o la dieta junto al ejercicio para bajar de peso, mostró que la dieta junto al ejercicio y la dieta por sí sola, fueron significativamente más efectivos en lograr una reducción de peso que el ejercicio por sí solo (Miller, Koceja et al. 1997). Aunque la dieta es más 
efectiva, la evidencia sugiere que la actividad física puede ser el principal predictor de un mantenimiento de la pérdida de peso en el tiempo.

\subsubsection{Tratamiento en DM 1}

\subsubsection{Introducción}

El tratamiento intensivo con insulina es la terapia de elección en los pacientes con DM1. Uno de los estudios más impo rtantes realizados que demuestra que este tratamiento es capaz de retrasar las complicaciones microvasculares ha sido el DCCT (The Diabetes Control and Complications Trial) (1993). Posteriormente el estudio EDIC (Epidemiology of Diabetes Interventions and Complications) que continuó al DCCT demostró que además la terapia intensiva era capaz de disminuir la morbilidad y mortalidad cardiovascular (Nathan, Cleary et al. 2005).

El tratamiento insulínico convencional, que consiste en una a tres inyecciones diarias, normalmen te con mezclas de insulina que se administran antes del desa yuno y de la cena y, a veces, de la comida, no refleja una terapia fisiológica como lo hace el tratamiento intensivo. La terapia intensiva imita mejor la secreción fisiológica de la insulina a través de varias inyecciones al día o con bomba de infusión continua. Se administra, por tanto, una insulina basal y una insulina prandial (rápida o ultrarrápida) antes de cada comida. Esto supone una media de 4 inyecciones diarias (una basal y mínimo 3 prandiales). El tratamiento intensivo se puede ver ilustrado en la figura 3.

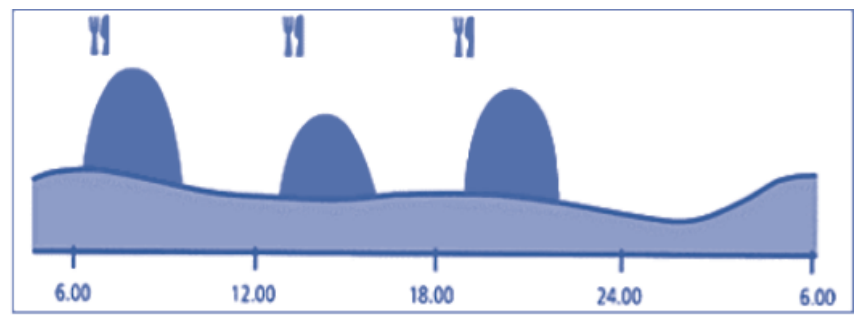

Figura 3. Tratamiento intensivo en DM 1

(Villaizán, Cortés et al. 2009)

A pesar de que se recomienda el tratamiento intensivo en la DM1, hay que tener en cuenta las siguientes consideraciones:

- Precisa una educación diabetológica exhaustiva, conociendo la dieta por raciones, el autoajuste diario de la insulina prandial para adecuarla a las raciones de hidratos de carbono así como a la actividad física prevista de acuerdo a unos objetivo glucémicos. 
- Necesidad de autocontroles de glucemia capilar frecuentes (4 a 7 diarios) para el autoajuste de dosis.

- Mayor riesgo de hipoglucemias y mejor calidad de vida.

- Mayor coste que la terapia convencional a corto plazo (aproximadamente tres veces superior, según refleja el DCCT) (1993) pero más eficaz al prevenir y/o retrasar las complicaciones crónicas (Nathan, Cleary et al. 2005).

La terapia intensiva debe iniciarse al diagnóstico de DM1 pues retrasa el agotamiento de la reserva pancreática, según demuestra el DCCT, lo que ayuda a mejorar el control metabólico y buscar el efecto memo ria glucémica.

\subsubsection{Pautas de tratamiento intensivo}

Las dos modalidades de tratamiento intensivo en la DM1 (multidosis y bomba de insulina) deben ser controladas preferentemente desde atención especializada.

\section{Tratamiento intensivo con multidosis}

Indicación: en todos los pacientes con DM1 que hayan recibido un programa estructurado de educación en diabetes, que realicen de 4 a 7 autocontroles glucémicos diarios, que estén capacitados para mantener un autocuidado activo de la enfermedad, siempre que no existan contraindicaciones de la terapia intensiva por riesgo de hipoglucemias severas repetidas o complicaciones avanzadas de la diabetes (neuropatía autonómica, insuficiencia renal y enfermedad cardiovascular evolucionada).

Las insulinas utilizadas son las siguientes:

Insulinas basales

Insulina glargina: como comentamos previamente una de sus principales ventajas es que no tiene pico en sangre, es plana durante su tiempo de acción, lo que produce un menor número de hipoglucemias sobre todo nocturnas comparada con NPH (Rosenstock, Park et al. 2000). Con respecto a esta última, en la mayor parte de los estudios realizados no ha demostrado mejorar el control glucémico (Hershon, Blevins et al. 2004). En DM1 no influye en el control glucémico el momento del día en el que se administre. Puede ponerse antes del desayuno, la comida, la cena o antes de dormir. Parece que su administración antes del desayuno puede disminuir el número de hipoglucemias nocturnas (Hamann, Matthaei et al. 2003). La mayor parte 
de los pacientes sólo precisan una dosis de glargina pero un $20 \%$ requieren dos dosis porque en ellos es más corta la duración. La insulina glargina no se puede combinar con las actuales insulinas prandiales en la misma jeringa y lugar de inyección.

Insulina detemir: se utiliza también como basal y normalmente en una o dos dosis en los DM1, como NPH, aunque con respecto a ella su duración es mayor. En sucesivos estudios realizados el control glucémico es parecido en ambas, aunque debido a que no presenta pico en sangre y sobre todo a la menor variabilidad en la glucemia, detemir produce menor número de hipoglucemias nocturnas y una menor ganancia de peso (Hermansen, Fontaine et al. 2004).

Insulina NPH: se administra normalmente dos a tres veces al día. Suele presentar un pequeño pico en sangre a las 3-4 horas de su inyección, lo que permite realizar comidas intermedias (media mañana) y no tener que utilizar en esos momentos insulina prandial, como ocurre con las prolongadas. Se puede mezclar en jeringa con las prandiales y disminuir así el número de pinchazos administrados a lo largo del día.

Insulinas prandiales

Las insulinas aspart, glulisina y lispro presentan por su farmacocinética un perfil muy similar al fisiológico de la insulina pancreática. Tienen la ventaja de reducir más rápido que la insulina regular la glucemia postprandial y disminuir la tasa de hipoglucemias (Brunelle, Llewelyn et al. 1998, Hermansen, Fontaine et al. 2004). Permiten además una mayor flexibilidad en el horario de comidas.

Dosificación: la mayor parte de los pacientes con DM1 de reciente diagnóstico comienzan con una dosis entre 0,3-0,5 UI/ kg / día, aunque finalmente la dosis media suele encontrarse entre 0,6-0, 9 UI/ kg / día. En el periodo del desarrollo puberal suelen precisarse dosis mayores debido a la resistencia insulínica que aparece, y también si hay sobrepeso. En todos los casos, se necesitan controles glucémicos diarios para un correcto autoajuste de la dosis.

Del total de unidades calculadas diarias, se utilizará el $50 \%$ como insulina basal y el otro $50 \%$ como prandial. Como comen tamos anteriormente si la basal es detemir o glargina se administrarán por la mañana o por la noche y si es NPH se repartirá en 2 / 3 antes del desayuno y 1 / 3 antes de la cena. Las insulinas prandiales se repartirán antes de las comidas, en proporción a las raciones de carbohidratos ingeridos (aproximadamente, 1 / 3 del total en cada ingesta). Según la actividad física realizada y si la insulina 
basal utilizada es detemir o glargina en mono dosis se suele precisar otra dosis más en las comidas intermedias (media mañana y merienda) cuando se realizan.

\section{Terapia con bomba de infusión continua}

La bomba administra de forma continua análogos rápidos a través de un catéter por vía subcutánea, la insulina basal cada hora (ritmos basales que se programan) y bolos prandiales en las comidas.

Indicación: DM1 en tratamiento intensivo con regímenes basal- bolos al meno s durante seis meses previos con autoajustes frecuentes de la dosis de insulina y una frecuencia media de 4 autocontroles diarios. diabetes.

Haber completado un programa educativo sobre el cuidado de la

HbA1 C>7 \% a pesar de la terapia intensiva con hipoglucemias recurrentes, amplias variaciones de la glucemia preprandial con desviaciones glucémicas severas o fenómeno del alba con glucemias mayor de 200 mg / dl.

El paciente necesita un adiestramiento sobre el manejo de la bomba y cambios de catéteres, además de reforzar el proceso educativo y la motivación. A pesar del mayor coste, es una modalidad creciente de terapia intensiva complementaria al régimen bolo-basal de la que pueden beneficiarse entre 10 al $15 \%$ de los diabé ticos tipo 1 . Según un metaanálisis publicado reciente mente, la $\mathrm{HbA} 1 \mathrm{C}$ disminuye entre $0,21 \%-0,72 \%$ con respecto al tratamiento con multidosis, siendo mayor la mejoría en la infusión continua en pacientes que parten de una HbA1 C más alta (Pickup and Sutton 2008).

\subsubsection{Pautas de tratamiento convencional}

Indicación: pacientes con DM1 en los que el tratamiento intensivo está contraindicado por una diabetes evolucionada con complicaciones severas u otros problemas de salud graves, o no es posible por falta de adherencia o imposibilidad del autocuidado activo (edad avanzada, problemas socioculturales, etc.).

Pautas de Insulinización: dos a tres inyecciones diarias, normalmente con mezclas de insulina antes del desayuno y de la cena y a veces de la comida. Se debe elegir la mezcla más adecuada de las disponibles según el perfil glucémico. Con este tipo de pauta es más difícil el autoajuste de la insulina. 
Dosificación: la dosis de inicio es igual a la utilizada en terapia intensiva (0,3-0,5 UI/ kg), así como la dosis final (0, 6-0, $9 \mathrm{UI} / \mathrm{kg})$. Se reparten 2 / 3 antes del desayuno y $1 / 3$ antes de la cena con ajustes posteriores según los perfiles. En ocasiones se precisa otra dosis antes de la comida.

\subsubsection{Tratamiento de la DM tipo 2}

\subsubsection{Primer paso: cambio de estilo de vida+metformina.}

Respecto del estilo de vida las intervenciones dirigidas a mejorar la actividad física del paciente y la alimentación son partes críticas en el tratamiento del paciente con DM2 Anderson, 2003 \#1800; Klein, 2004 $\# 1801$ \}. La pérdida moderada de peso (5-10\%) contribuye significativamente a la consecución del control glucémico. Por ello se recomienda establecer un objetivo de reducción ponderal o al menos de mantenimiento del peso. Las recomendaciones dietéticas deben ser personalizadas (Association, Bantle et al. 2008).

Al diagnóstico en pacientes motivados con una HbAlc cercana al objetivo (alrededor de 7,5\%) se puede dar una oportunidad a la modificación del estilo de vida durante un periodo de 3-6 meses antes de iniciar el tratamiento farmacológico (generalmente, metformina). Aquellos con hiperglucemia moderada, o en los que se prevea que las modificaciones del estilo de vida no van a ser exitosas, debería iniciarse desde el diagnóstico tratamiento farmacológico (también generalmente metformina), que luego puede ser modificado o incluso suspendido si las medidas de estilo de vida son exitosas. En algunos casos el objetivo de control (HbA1c < 6,5\%) puede conseguirse con algunas modificaciones del estilo de vida (Look, Pi-Sunyer et al. 2007), aunque este planteamiento no siempre es eficaz, ya que depende de las características del paciente y de su grado de adherencia a las recomendaciones.

La Metformina es una biguanida que se utiliza desde hace más de 40 años en Europa. Se absorbe principalmente en el intestino delgado, y no se une a proteínas plasmáticas ni se metaboliza en el hígado. A las 12 horas de la administración por vía oral el $90 \%$ se habrá eliminado por la orina, por filtración glomerular y secreción tubular. Estudios recientes señalan que metformina inhibe la glucólisis aeróbica en el músculo esquelético y favorece la glucólisis anaeróbica, por lo tanto, incrementa el consumo de glucosa en el músculo y, a nivel hepático, inhibe la gluconeogénesis. La actividad clínica principal de la metformina es reducir la resistencia hepática a la insulina, y 
por consiguiente, la gluconeogénesis y la producción de glucosa (Hundal, MKrssak et al. 2000). La metformina no incrementa la secreción de insulina ni produce hipoglucemia. Disminuye levemente la absorción intestinal de glucosa, y puede favorecer la pérdida de peso. En tratamientos a largo plazo, sobre todo en pacientes con hiperglucemia importante, provoca una reducción del 10 al $20 \%$ en los niveles de triglicéridos, ya que disminuye la síntesis hepática de lipoproteínas de muy baja densidad, y se ha comunicado una ligera disminución en los niveles de colesterol total y una pequeña elevación en las cifras de c-HDL (5 al 10\%). También se ha descrito una mayor actividad fibrinolítica y pequeñas reducciones en las concentraciones plasmáticas del factor inhibidor de la activación del plasminógeno tipo I, así como efectos beneficiosos sobre el endotelio vascular y algunos parámetros cardiovasculares.

Es el fármaco de elección para el inicio del tratamiento farmacológico en la DM2 (DeFronzo and Goodman 1995, 1998, Menéndez, Lafita et al. 2010, American Diabetes 2014). La SED aconseja desde el inicio asociar metformina de forma concomitante con las modificaciones del estilo de vida en la mayoría de los pacientes (figura 4) (Menéndez, Lafita et al. 2010). En todo caso, no es recomendable demorar más de tres meses la introducción de metformina si no se ha conseguido el objetivo de control. Para mejorar la tolerancia a este fármaco se aconseja una titulación progresiva de las dosis; (Krentz, Ferner et al. 1994) por ejemplo, con medio comprimido de 850-1.000 mg inicialmente, aumentando a medio comprimido cada 12 horas a los 4-5 días si existe una buena tolerancia, y así progresivamente hasta llegar a una dosis de 850 a $1.000 \mathrm{mg}$ cada 12 horas. Si se observa intolerancia debe reducirse de nuevo a la dosis previa tolerada y reintentar el incremento con un lapso de tiempo mayor.

El principal efecto de metformina es la reducción de la producción hepática de glucosa (Bailey and Turner 1996). Se considera como un fármaco neutro sobre el peso y no aumenta el riesgo de hipoglucemia. Metformina se asocia con efectos secundarios gastrointestinales, y hay que evitar su uso en aquellos pacientes con riesgo de acidosis láctica, como insuficiencia renal avanzada o alcoholismo, aunque se trata de una rara complicación. Según los resultados de algunos ensayos clínicos podría tener algún beneficio cardiovascular, pero los datos clínicos no son robustos (Lamanna, Monami et al. 2011). 


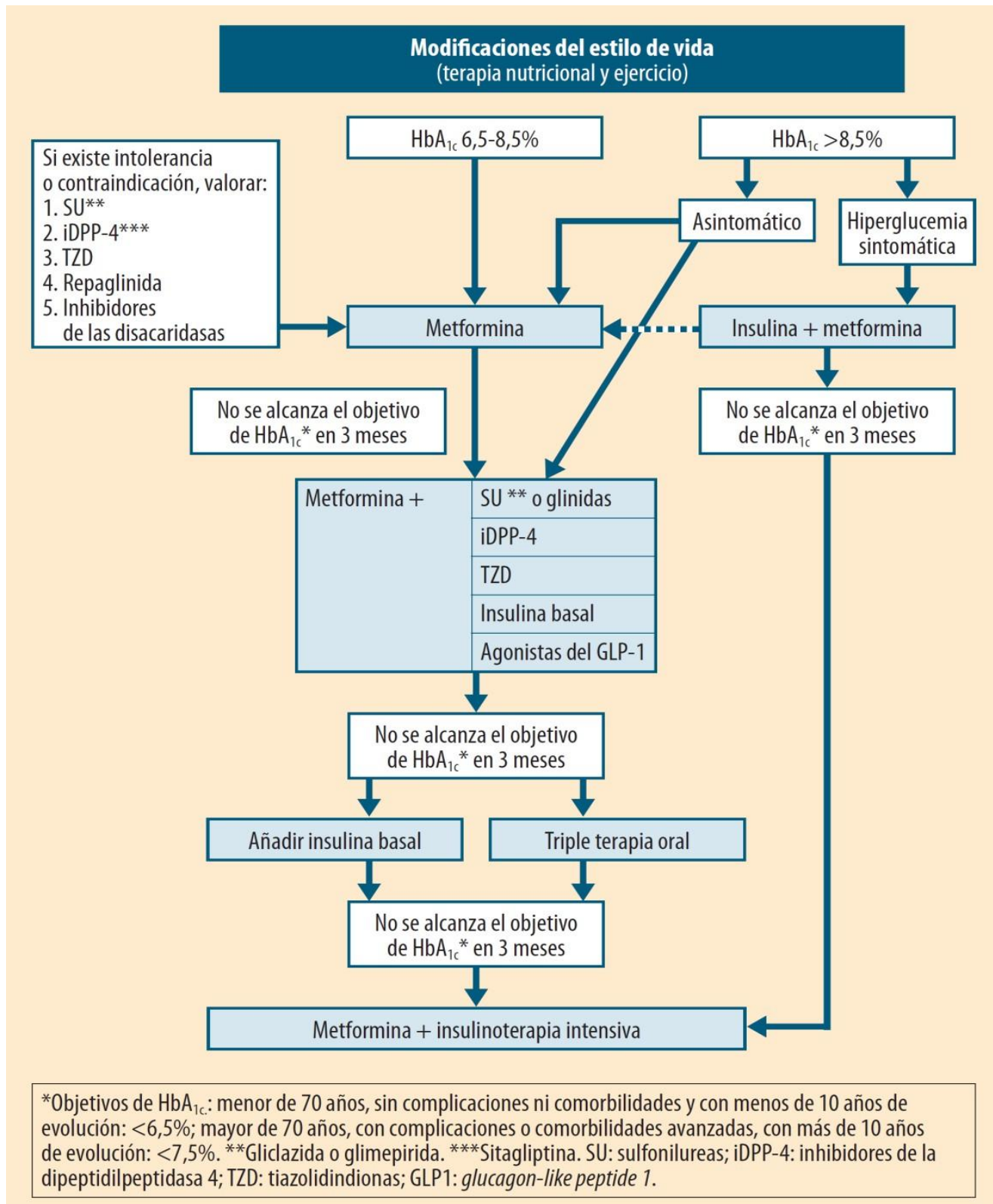

Figura 4. Algoritmo 2010 de la Sociedad Española de Diabetes sobre el tratamiento farmacológico de la hiperglucemia en la diabetes tipo 2 Tomada de: Menéndez et al. (Menéndez, Lafita et al. 2010) 


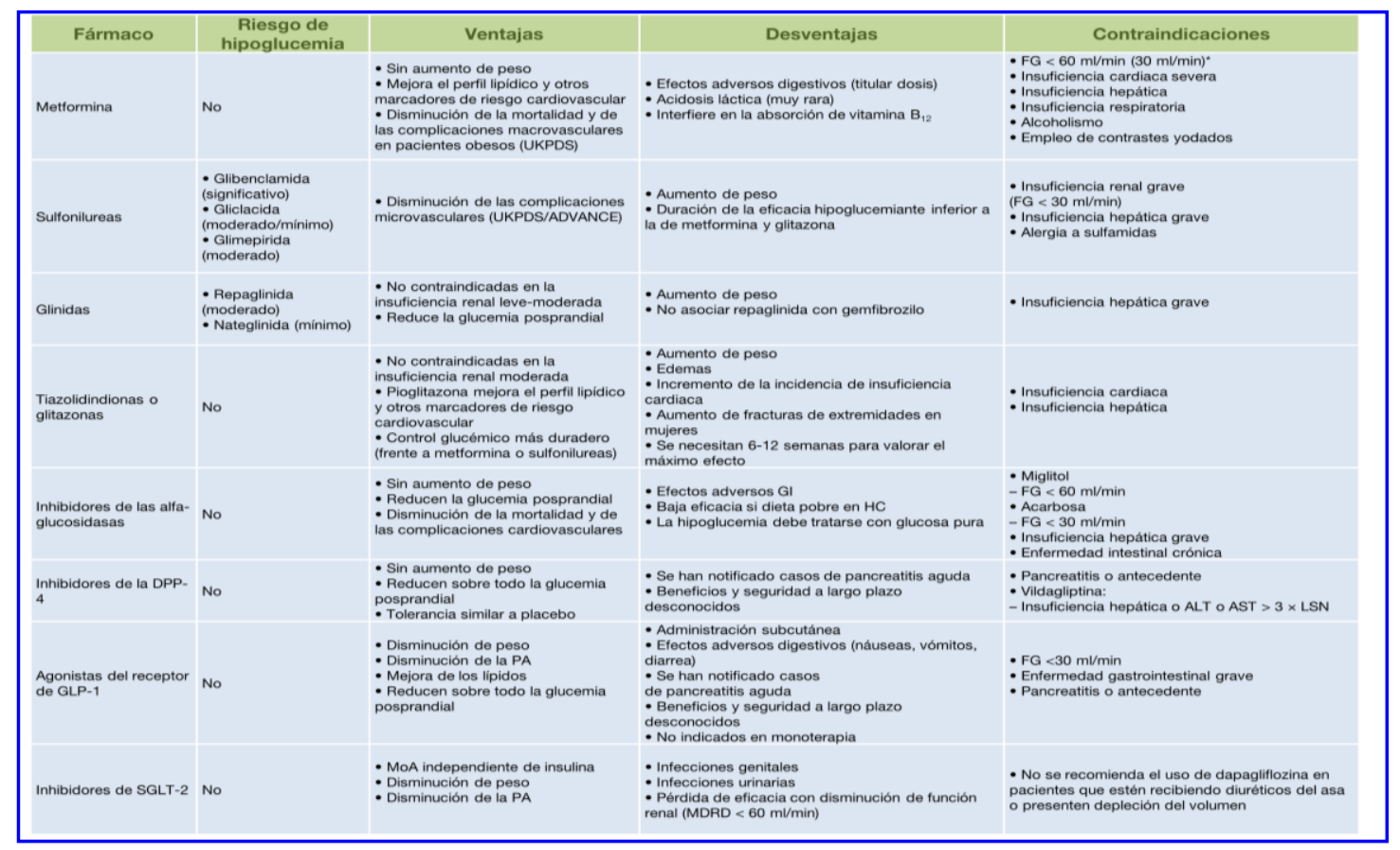

*Ver explicación en el texto. ADVANCE: Action in Diabetes and Vascular disease; ALT: alanino transferasa; AST: aspartato transferasa; FG: filtrado glomerular; GI: gastrointestinales; HC: hidratos de carbono; LSN: límite superior de la normalidad; UKPDS: United Kingdom Prospective Diabetes Study.

Tabla 3. Fármacos antidiabéticos y diabetes Mellitus tipo 2. Modificada de: Menéndez y cols, (Menéndez, Lafita et al. 2010)

La principal contraindicación de la metformina es la insuficiencia renal. En su ficha técnica se recomienda suspender la administración cuando el filtrado glomerular es menor de $60 \mathrm{ml} / \mathrm{min}$, pero según publicaciones recientes podría utilizarse hasta filtrados de $30 \mathrm{ml} / \mathrm{min}$. Se recomienda disminuir la dosis de metformina a la mitad cuando el filtrado baja de 45 $\mathrm{ml} / \mathrm{min}$, y suspender el tratamiento cuando baja de $30 \mathrm{ml} / \mathrm{min}$ (Nye and Herrington 2011). La guía NICE establece esas mismas recomendaciones (Excellence. 2008). Otras contraindicaciones establecidas para metformina son las siguientes: situaciones clínicas que predispongan a la hipoxia (insuficiencia respiratoria e insuficiencia cardíaca descompensadas), alcoholismo, utilización de contrastes intravenosos yodados o anestesia general (suspender 24-48 horas antes). El efecto secundario más temido es la acidosis láctica que, afortunadamente, es poco frecuente, especialmente si no se utiliza metformina cuando está contraindicada. En un metanálisis publicado recientemente, con más de 70.000 pacientes, (Salpeter, Greyber et al. 2010), 
se comparó la incidencia de acidosis láctica asociada a metformina y la concentración de lactato plasmático en pacientes con DM2 en tratamiento con metformina, comparado con los pacientes tratados con otros antidiabéticos orales. Observaron que no había diferencias en la incidencia de acidosis láctica asociada a metformina, con 5/100.000 pacientes/año entre los tratados con metformina comparado con 4/100.000 pacientes/año en tratados con otro antidiabético oral, ni en la concentración de lactato plasmático.

Si no se puede utilizar metformina debe elegirse otro fármaco oral, como una sulfonilurea/glinida, pioglitazona, un iDPP4 o un inhibidor del cotransportador sodio-glucosa tipo 2 (iSGLT-2) (Menéndez, Lafita et al. 2010, Salpeter, Greyber et al. 2010, Garber, Abrahamson et al. 2013, American Diabetes 2014) o agonista del receptor de GLP-1 (arGLP-1) aprobado para monoterapia que es el albiglutide. En la selección del tratamiento deberían tenerse en cuenta las preferencias del paciente, sus características clínicas, susceptibilidades a efectos secundarios y riesgo de aumento de peso y de hipoglucemias (Mullan, Montori et al. 2009, IsmailBeigi, Moghissi et al. 2011).

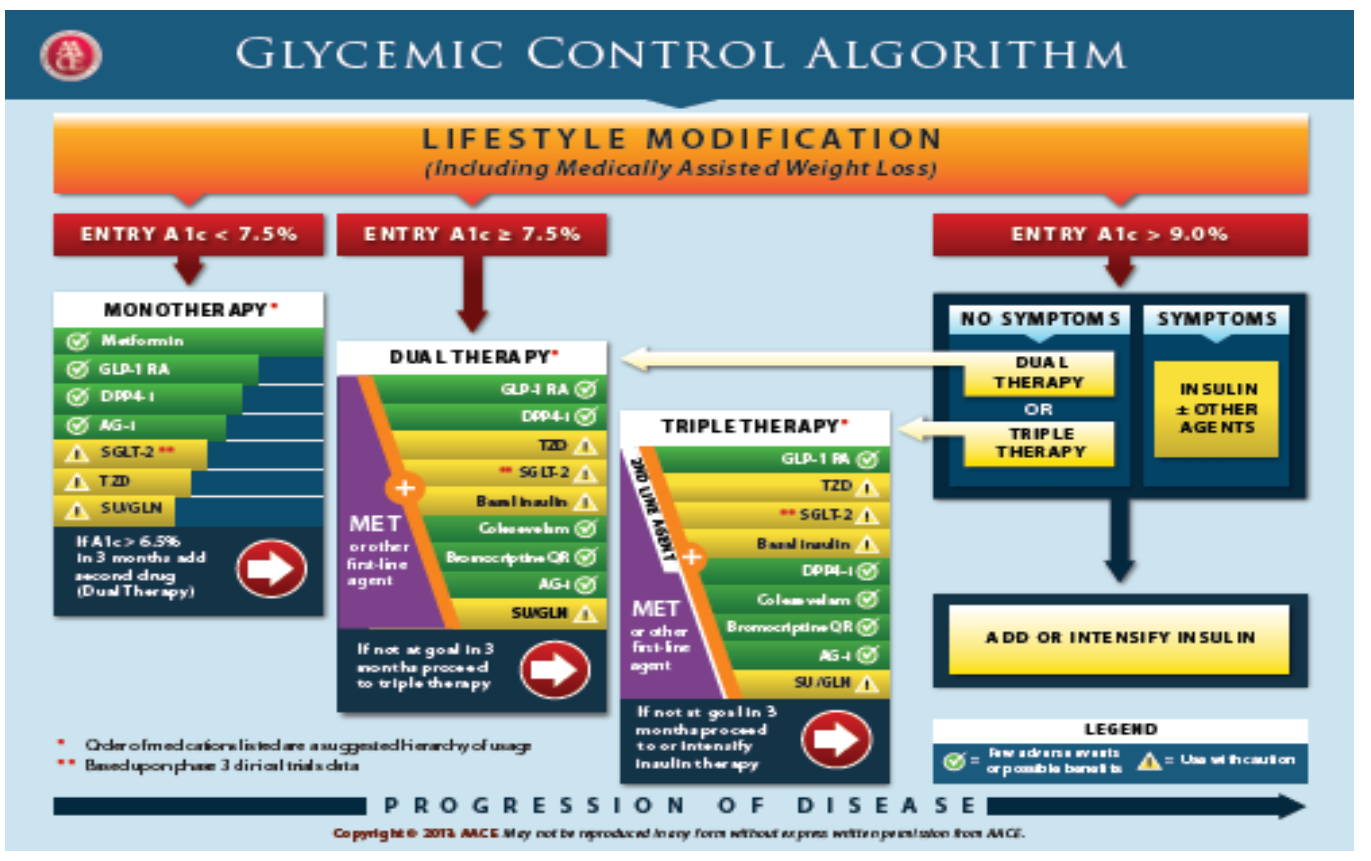

Figura 5. Algoritmo de la Asociación Americana de Clínicos Endocrinólogos sobre el tratamiento farmacológico de la hiperglucemia en la diabetes tipo 2. Tomada de: (Garber, Abrahamson et al. 2013) 


\subsubsection{Tratamiento inicial: hemoglobina glicosilada elevada.}

En pacientes con clínica importante de hiperglucemia (clínica cardinal y/o pérdida de peso) en el momento del comienzo de la misma, suele ser necesario iniciar el tratamiento con insulina, (Ryan, Imes et al. 2004, Bloomgarden 2007, Lingvay, Legendre et al. 2009) sola o asociada con metformina (figura 5). Tras el control inicial y la mejora de la gluco y lipotoxicidad, es probable que desciendan progresivamente las necesidades de insulina, y que en algunos casos pueda mantenerse el control con fármacos orales, bien en monoterapia bien en combinación (Ryan, Imes et al. 2004).

En pacientes asintomáticos es recomendable comenzar con metformina, con una titulación más rápida $\mathrm{y}$, según la respuesta, asociar un segundo fármaco, (Garber, Larsen et al. 2002) controlando la evolución a corto plazo para ajustar el tratamiento definitivo (figura 5).

Algunas Guías de Práctica Clínica, como la de la AACE, recomiendan empezar con doble terapia de inicio cuando la HbA1c al diagnóstico de DM es mayor de $7,5 \%$ y recomiendan triple terapia o insulina cuando la HbA1c es mayor de 9\%. Otras, como el algoritmo de la SED de 2010, recomiendan el tratamiento doble de inicio cuando la HbA1c inicial es mayor del 8,5\% (Garber, Abrahamson et al. 2013).

\subsubsection{Tratamiento farmacológico: doble terapia.}

Cuando el tratamiento con metformina en monoterapia no consigue alcanzar o mantener el objetivo de HbA1c en tres meses el siguiente paso debería ser añadir un segundo fármaco oral, un arGLP1 o insulina basal. (Orozco-Beltran, Gil-Guillen et al. 2007, Garber, Abrahamson et al. 2013, American Diabetes 2014). Cuanta más alta sea la HbA1c más probable será la necesidad de iniciar tratamiento con insulina. En principio se recomienda que los fármacos asociados tengan un mecanismo de acción diferente $\mathrm{y}$ complementaria. Según la respuesta debe incrementarse la dosis hasta la máxima efectiva, algo inferior a la dosis máxima permitida (Menéndez, Lafita et al. 2010). De media la adición de cualquier agente oral se asocia a una reducción de $\mathrm{HbA}_{1 c}$ de un 1\% (Bennett, Maruthur et al. 2011, Gross, Kramer et al. 2011, Karagiannis, Paschos et al. 2012). Si no se consigue una reducción glucémica significativa ("paciente no respondedor"), y se confirma una adecuada adherencia terapéutica, debe suspenderse dicho fármaco y añadir otro con un mecanismo de acción diferente, aunque en la práctica clínica lo habitual es añadir nuevos fármacos a los ya existentes. No es posible hacer 
una recomendación uniforme respecto a la mejor combinación con metformina por la inexistencia de ensayos de efectividad a largo plazo.

Por ello, deben considerarse las ventajas y desventajas de cada fármaco para cada paciente (Tabla 3). Algunos fármacos antihiperglucemiantes inducen aumento de peso, y esto puede asociarse con un empeoramiento de la insulinorresistencia y del riesgo cardiovascular. Una excepción son las tiazolidinedionas (TZD), puesto que la ganancia ponderal que inducen se asocia a un descenso de la resistencia a la insulina (Menéndez, Lafita et al. 2010). Aunque no hay una evidencia clara de que el aumento de peso que se observa con ciertas terapias se traduzca en un incremento sustancial del riesgo cardiovascular, es importante evitarlo mediante la elección del fármaco más apropiado y una adecuada titulación de dosis. Otro aspecto muy importante es el riesgo de hipoglucemias que pueden ocasionar algunos fármacos, y que puede tener efectos devastadores en los casos graves (Cryer 2007). Los efectos gastrointestinales de algunos fármacos pueden ser bien tolerados por algunos pacientes, pero no por otros. Por ejemplo, la retención hídrica puede ser un problema clínico o ser meramente un problema estético, (Loke, Kwok et al. 2011) o el riesgo de fractura ósea puede ser un problema evidente en las mujeres posmenopáusicas (Kahn, Haffner et al. 2006). Con todo lo expuesto, los iDPP4 se han posicionado en los últimos años como una interesante elección terapéutica cuando falla metformina, por tratarse de un fármaco con un mecanismo de acción complementario al de metformina, por su excelente tolerancia (similar a placebo), por su seguridad debido a la ausencia de hipoglucemias (mecanismo de acción glucosa-dependiente) y por su efecto neutro sobre el peso. Los arGLP-1 son también una interesante opción, especialmente en pacientes en los que exista obesidad (solo financiados si el IMC $>30 \mathrm{~kg} / \mathrm{m}^{2}$ ), puesto que, además, son más potentes en la reducción de HbA1c que la mayoría del resto de opciones. Sin embargo, su administración por vía subcutánea, la aparición de intolerancia gastrointestinal en algunos pacientes y la necesidad de visado suponen trabas para una más amplia utilización. La nueva familia de iSGLT-2, de reciente aparición, añade más opciones de elección, teniendo en cuenta que, además, se acompañan de pérdida de peso y de reducciones de presión arterial que pueden ser efectos muy interesantes en gran parte de los pacientes con DM. Sin embargo, también hay que reconocer que los costes son un aspecto crítico en la elección del fármaco antihiperglucémico en muchas situaciones, y tantos los iDPP4 como los ar GLP1 y los i SLGT2 son fármacos de reciente aparición con un coste mayor que el de los tratamientos clásicos. 
Entre las posibles combinaciones en segundo escalón con metformina disponemos de las siguientes:

\section{Sulfonilureas y glinidas}

La asociación metformina-sulfonilureas es la combinación más estudiada y ha demostrado su eficacia y seguridad, (Hermann, Schersten et al. 1994) aunque todavía persiste la duda sobre el incremento de la mortalidad en algún subgrupo, apreciado en el UKPDS29, de aquellos pacientes que iniciaban el tratamiento con sulfonilureas y en los que se asociaba en un segundo escalón metformina. Existen diversos estudios observacionales que se plantearon esta cuestión, (Olsson, Lindberg et al. 2000, Fisman, Tenenbaum et al. 2001, Johnson, Majumdar et al. 2002, Mannucci, Monami et al. 2004, Kahler, Rajan et al. 2007) con algunas discrepancias en sus resultados; resultados que, por otro lado, posiblemente no sean superponibles con los obtenidos con los preparados más recientes. Cuando el objetivo de control de la HbA1c es ambicioso $(<6,5 \%)$, como secretagogos potentes que son inducen un riesgo importante de hipoglucemia, aunque este riesgo es distinto según el principio activo que se utilice (Holstein, Plaschke et al. 2001, Gangji, Cukierman et al. 2007).

Por ello se recomienda plantear una titulación muy cuidadosa de la dosis y utilizar preferentemente gliclazida de liberación prolongada o glimepirida, desaconsejándose la utilización de glibenclamida o clorpropamida (Menéndez, Lafita et al. 2010). Algunos estudios indican que las sulfonilureas inducen el fallo secundario de la célula beta antes que la metformina o que las glitazonas (Johnson, Majumdar et al. 2002). Se asocian también a un incremento de 1-3 kg de peso (Belcher, Lambert et al. 2005). Las glinidas constituyen una buena alternativa a las sulfonilureas en pacientes con ingestas más irregulares por su corto periodo de acción, así como en pacientes alérgicos a sulfamidas o, en el caso de la repaglinida, en pacientes que presenten insuficiencia renal moderada (Moses, Slobodniuk et al. 1999).Otra característica de las glinidas es su acción predominantemente sobre la glucemia posprandial. En cuanto al riesgo de hipoglucemia e incremento de peso pueden considerarse superponibles (Tabla 3)

\section{Inhibidores de la dipeptidil peptidasa-4}

Junto con los arGLP-1 forman un grupo novedoso de secretagogos que actúan tanto sobre la secreción de insulina como sobre la de glucagón, de forma glucosa-dependiente. Las incretinas son hormonas de naturaleza peptídica que forman parte del sistema endógeno de regulación de la glucosa. 
Se liberan principalmente a partir de células de la mucosa de las porciones distales del intestino delgado y del colon, en respuesta a la ingestión y tránsito de los alimentos. Las principales incretinas son el GLP-1 y el polipéptido inhibitorio gástrico o péptido insulinotrópico dependiente de glucosa (GIP). Durante el proceso digestivo, al aumentar los niveles de glucosa, el GLP-1 y el GIP causan un estímulo en la síntesis y liberación de insulina por las células beta del páncreas por un mecanismo glucosa-dependiente. El GLP-1, además, ejerce inhibición sobre la liberación de glucagón, también de forma glucosa- dependiente. Sin embargo, tanto el GLP-1 como el GIP son rápidamente degradados por la enzima DPP-4. En los pacientes con DM2 el GLP-1 está marcadamente disminuido o ausente y hay pérdida del efecto insulinotropo del GIP. Farmacológicamente se han podido desarrollar fármacos que recuperan los niveles plasmáticos y la acción de GLP-1 y que se pueden clasificar en dos grupos: los iDPP4 (fármacos que bloquean la enzima degradadora de GLP-1) y los arGLP-1 (fármacos resistentes a la degradación por la enzima DPP4). Hasta el momento se han comercializado en nuestro país 4 fármacos correspondientes al grupo de los iDPP4: la sitagliptina, la vildagliptina, la saxagliptina y la linagliptina que, administrados por vía oral, incrementan la secreción de insulina e inhiben la secreción de glucagón para aumentar los niveles de GLP-1 y GIP. Presentan ventajas evidentes frente a las sulfonilureas y glinidas: el bajo riesgo de hipoglucemias y su neutralidad en el peso (Bosi, Camisasca et al. 2007, Ahren 2009) (tabla 12). Su potencia no parece ser inferior a la de las sulfonilureas en cuanto a la reducción de la HbA1c (Nauck, Meininger et al. 2007, Ferrannini, Fonseca et al. 2009). Además, pueden utilizarse en situaciones de insuficiencia renal, ya sea titulando la dosis a la mitad o a la cuarta parte de la dosis habitual (saxagliptina, sitagliptina y vildagliptina) o sin necesidad de titulación (linagliptina). Sitagliptina (a dosis de $25 \mathrm{mg} /$ día) y linagliptina pueden usarse incluso en pacientes en hemodiálisis (Ferreira, Corry et al. 2013, Nakamura, Tsuji et al. 2014). También pueden utilizarse en cualquier escalón del algoritmo terapéutico, desde la monoterapia hasta la combinación con insulina. Por todo ello, en los últimos años se han posicionado como la principal alternativa tras el fracaso de metformina en monoterapia, desplazando a las sulfonilureas del segundo escalón terapéutico, especialmente en pacientes con alto riesgo de hipoglucemia. De hecho, es la recomendación preferente en el paciente anciano (Gómez, Díez-Espino et al. 2013). Aún así, se desconoce su seguridad a largo plazo y su influencia en la evolución de la diabetes y sus complicaciones. Aunque la tolerancia es similar al placebo, existen algunas publicaciones que relacionan su uso con un aumento de patología pancreática (Elashoff, Matveyenko et al. 2011). Sin 
embargo, las últimas publicaciones lo desmienten (Li, Shen et al. 2014). De todas formas se sigue recomendando evitarlas si ya hay antecedentes de pancreatitis.

\section{Agonistas del receptor del péptido similar al glucagón 1}

Son preparados de administración parenteral que consiguen un efecto sobre los receptores de GLP-1 más intenso y prolongado que el logrado por los iDPP- 4. En los estudios publicados a corto plazo se ha demostrado que mejoran el control glucémico, sobre todo la glucemia posprandial, y en parte también la glucemia basal (DeFronzo, Ratner et al. 2005). Enlentecen el vaciamiento gástrico, creando sensación de saciedad, con lo que se consigue una reducción de peso sostenida en un apreciable porcentaje de pacientes (Gaal, Gutkin et al. 2008, Monami, Marchionni et al. 2009). Además, consiguen mejorar algunos de los FR vascular (Klonoff, Buse et al. 2008) (tabla 12). Los fármacos pertenecientes a los arGLP-1 actualmente comercializados en España son la exenatida, la exenatida LAR, la liraglutida, la lixisenatida y el Albiglutida. La exenatida fue la primera que se aprobó para uso clínico por la Food and Drug Administration (FDA). Se administra por vía subcutánea en dosis de 5-10 mcg dos veces al día antes de las principales comidas, con un intervalo de tiempo entre ambas de al menos 6 horas; se ha indicado en combinación con metformina y/o sulfonilureas y a metformina con glitazonas, para lograr una reducción adicional de casi un $1 \%$ en la HbA1c y una disminución del peso corporal en cerca de $4 \mathrm{~kg}$ en un año. En nuestro país el tratamiento es financiado si, además de cumplir las indicaciones metabólicas, el IMC del paciente es mayor de $30 \mathrm{~kg} / \mathrm{m}^{2}$. Sus principales efectos secundarios son las náuseas y vómitos, y se han descrito algunos casos de pancreatitis que no parecen estar en relación con el tratamiento. Posteriormente se ha comercializado una forma de presentación que se puede emplear una vez a la semana (exenatida LAR) y que muestra una mayor potencia que la exenatida de administración dos veces al día, tanto en términos de descenso de HbA1c como de reducción de peso. La liraglutida es un análogo acilado de acción prolongada que se administra una vez al día, generalmente a dosis de 1,2 mg/día con independencia de las comidas, con una potencia mayor que exenatida. Al igual que la exenatida las náuseas son el efecto adverso más frecuente, aunque en la mayoría de los casos son leves y transitorias. La última molécula aprobada en España ha sido lixisenatida, de acción corta, pero de administración en una sola dosis al día, con efectos predominantemente sobre la glucemia posprandial. Todos estos nuevos fármacos no se deben emplear en pacientes con neuropatía autonómica digestiva con gastroparesia. Su uso en mayores de 75 años o con insuficiencia 
renal moderada grave está limitada (Zinman, Hoogwerf et al. 2007, Montanya and Sesti 2009) (Tabla 3). Pueden ser un grupo de fármacos muy útiles en pacientes en los que la obesidad suponga un problema esencial, pero queda por definir su papel frente a otros fármacos o frente a otras aproximaciones del tratamiento, como la cirugía. Su utilización en combinación con insulina basal se está mostrando como una interesante y potente asociación.

\section{Tiazolidindionas}

Las glitazonas son activadores del receptor gamma activado por el proliferador de peroxisomas (PPAR $\gamma$ ) que induce la activación de genes encargados de promover la acción de la insulina (Gómez, Díez-Espino et al. 2013). Mejoran la sensibilidad a la insulina en el tejido muscular esquelético y reducen la producción hepática de glucosa (Yki-Jarvinen 2004, Dormandy, Charbonnel et al. 2005). No aumentan el riesgo de hipoglucemia y pueden tener un efecto de control glucémico más duradero que metformina y que las sulfonilureas (Dormandy, Charbonnel et al. 2005). Actualmente el único representante de este grupo terapéutico es pioglitazona. En principio, la indicación se centraría en pacientes con un buen control prandial de la glucemia y elevación de la glucemia basal, que no se corrige totalmente con la metformina. Pioglitazona parece ofrecer un beneficio modesto sobre los eventos cardiovasculares (Dormandy, Charbonnel et al. 2005). Pioglitazona ha sido relacionada recientemente con un posible aumento del riesgo de cáncer de vejiga, (Lewis, Ferrara et al. 2011) que no ha sido confirmado posteriormente. Los efectos secundarios reconocidos de las glitazonas incluyen aumento de peso, retención de líquido y formación de edema y/o insuficiencia cardíaca en pacientes predispuestos, y un incremento del riesgo de fracturas óseas (Dormandy, Charbonnel et al. 2005, Kahn, Haffner et al. 2006).

De hecho, la insuficiencia cardíaca (grado I-IV de la New York Heart Association) es una contraindicación para su utilización (Tabla 3).

\section{Insulina basal}

La asociación de insulina basal a la metformina es una buena opción terapéutica, con seguridad y eficacia probadas (Yki-Jarvinen, Ryysy et al. 1999, Riddle, Rosenstock et al. 2003, Swinnen, Dai et al. 2010). Está indicada preferentemente en aquellos pacientes con un buen control prandial, pero con una $\mathrm{HbA1c}$ por encima del objetivo. Aunque con esta pauta se incrementa el número de hipoglucemias, estas son todavía muy inferiores a las observadas en pacientes con multidosis de insulina. 


\section{Inhibidores de las alfa-glucosidasas}

Su mecanismo de acción se basa en la inhibición de las enzimas alfaglucosidasas intestinales (maltasas, sacarasas, dextrinasas, glucoamilasas) presentes en las vellosidades intestinales, que son las enzimas que actúan en el desdoblamiento de la sacarosa, maltosa y otros oligosacáridos en monosacáridos (glucosa, fructosa, galactosa). El resultado es una demora en la digestión de los hidratos de carbono con reducción de los picos glucémicos posprandiales. Su asociación con metformina es segura, ya que no se van a producir hipoglucemias, pero su eficacia es muy limitada, con descensos de la HbA1c que difícilmente superan el 0,5\% (Chiasson, Naditch et al. 2001). Su limitación principal es la intolerancia digestiva (tabla 12). Por todo ello, no se recomienda como alternativa a un segundo fármaco en este escalón terapéutico. De hecho, no aparecen en el algoritmo de la SED sobre el tratamiento farmacológico de la hiperglucemia en la DM2 (figura 6).

En la elección del fármaco acompañante de la metformina deben tenerse en cuenta muchos factores: edad, sexo, peso, riesgo de hipoglucemia, enfermedades concomitantes (insuficiencia renal, enfermedad cardiovascular), tolerancia, etc (Inzucchi, Bergenstal et al. 2012).

\subsubsection{Tratamiento farmacológico: triple terapia.}

Algunos estudios han demostrado ventajas de añadir un tercer fármaco no- insulínico a la combinación de dos fármacos que ya no consigue mantener los objetivos glucémicos 140-143 (Kendall, Riddle et al. 2005, Roberts, Stewart et al. 2005, Zinman, Gerich et al. 2009, Bell, Dharmalingam et al. 2011).

Sin embargo, la respuesta más robusta se consigue con la adición de insulina. De hecho, puesto que la DM se caracteriza por una pérdida progresiva de células beta, muchos pacientes, especialmente aquellos con enfermedad de mucho tiempo de duración, necesitarán iniciar tratamiento con insulina, que debería hacerse cuando el grado de hiperglucemia dificulte la consecución del objetivo terapéutico (por ejemplo, con HbA1c > 8,5\%) (Rosenstock, Sugimoto et al. 2006). Si se considera iniciar triple terapia con un fármaco no-insulínico debe mantenerse una estrecha vigilancia para cambiar la pauta terapéutica si se demuestra que no se consigue el objetivo. Deben evitarse periodos de tiempo prolongados en hiperglucemia. En la triple terapia la recomendación más importante es utilizar fármacos con mecanismos de acción complementaria. 
Dentro de las distintas y válidas asociaciones de agentes orales, la asociación de metformina, sulfonilurea y glitazona es la más estudiada y la más utilizada en la práctica asistencial 145-149 (Kiayias, Vlachou et al. 2002, Dailey, Noor et al. 2004, Roy, Navar et al. 2004, AJ Scheen, MH Tan et al. 2009, Charpentier, Halimi et al. 2009). Otras opciones son la asociación de metformina, repaglinida y glitazona, (Papa, Fedele et al. 2006) así como la de metformina, glitazona e iDPP-4. En aquellos pacientes con limitaciones para el uso de las glitazonas las alternativas más razonables serían metformina más sulfonilureas más iDPP- 4 (Hermansen, Kipnes et al. 2007) o metformina más repaglinida más iDPP-4 (Tran, Navar et al. 2006). En los últimos años se han publicado combinaciones de triple terapia con los arGLP-1, como se hizo en el estudio LEAD-5 (Russell-Jones, Vaag et al. 2009). Lo interesante de esta combinación es la buena evolución ponderal, el efecto beneficioso sobre FR cardiovascular (HTA, incluso dislipidemia) y el bajo riesgo de hipoglucemia.

Hay que tener en cuenta que el aumento del número de fármacos incrementa a su vez el riesgo de efectos secundarios y de interacciones medicamentosas, aumenta los costes e impacta negativamente en la adherencia del paciente al tratamiento. Debe discutirse con el paciente el fundamento, los beneficios y los efectos secundarios de cada nuevo fármaco. Desafortunadamente, no están bien definidas las características clínicas del paciente más o menos probable que responderá a las combinaciones terapéuticas posibles.

También podemos considerar como triple terapia la combinación de dos antidiabéticos orales con insulina. La mayoría de los pacientes habrán recibido tratamiento con combinaciones de metformina con secretagogos (sulfonilureas o iDPP4). En este caso se procederá a la asociación de una insulina basal. Si el tiempo de evolución es superior a los 10 años, y/o han aparecido complicaciones o patologías intercurrentes, se revisará el objetivo de HbA1c a menos del 7,5\% o el mejor posible, con seguridad para el paciente. Esta pauta puede conseguir un periodo de buen control, pero no excesivamente prolongado, a juzgar por los resultados del estudio 4T, (Holman, Farmer et al. 2009) por lo que la mayoría de los pacientes en un periodo de alrededor de tres años van a requerir una pauta intensificada de insulina (basal plus, basal-bolos, premezclas). En este caso se recomienda mantener el tratamiento con metformina asociado a la insulina y suspender el resto del tratamiento antidiabético oral, especialmente sulfonilureas. Los iDPP4 podremos mantenerlos porque diversos estudios han demostrado que añaden eficacia terapéutica al tratamiento con insulina, aun cuando ya estemos utilizando insulinas rápidas (Mori, Taniguchi et al. 2013). La 
aparición de los arGLP-1 y de los iSGLT-2 han aumentado las posibilidades de combinaciones terapéuticas, por lo que en los próximos años es probable que veamos combinaciones que ahora ni se contemplan (por ejemplo, metfomina + arGLP-1+ iSGLT-2), además de su interesante asociación con diferentes pautas de insulina.

\subsubsection{Tratamiento con insulina}

El deterioro progresivo de la función beta pancreática en la DM-2 hará necesaria en algún momento el inicio de tratamiento con insulina para reestablecer la normoglucemia. En general, la adición de la insulina basal al tratamiento oral previo suele ser el primer paso (Yki-Jarvinen, Dressler et al. 2000, Riddle, Rosenstock et al. 2003, Hermansen, Davies et al. 2006). Progresivamente, el control glucémico se irá deteriorando y necesitará la asociación de insulina prandrial.

\section{Insulina basal}

Actualmente se dispone de análogos de insulina de acción prolongada, como glargina y detemir. Las características farmacocinéticas y farmacodinámicas de ambos, resultan de un perfil de acción más predecible y un riesgo menor de hipoglucemias frente a la insulina neutral protamin Hagedorn (NPH), especialmente menor frecuencia de hipoglucemias graves y nocturnas (Rosenstock, Dailey et al. 2005, Hermansen, Davies et al. 2006). La principal diferencia entre ambos, es la duración de acción y la dosis. La insulina glargina puede administrarse una vez al día, en cualquier momento del día. La administración de insulina glargina antes del desayuno puede ser preferible por la mayor reducción de la frecuencia de hipoglucemias nocturnas y/o de la HbA1c (Fritsche, Schweitzer et al. 2003). La insulina detemir, por su menor duración de acción, debe administrarse de una a dos veces al día en aquellos con DM-2.

\section{Insulina prandial}

Actualmente disponemos de los análogos de insulina de acción rápida lispro, aspart y glulisina.Tienen propiedades farmacocinéticas y farmacodinámicas bastante similares. En general, su inyección, resulta en una concentración máxima mayor y en la mitad de tiempo que la insulina regular humana: reduciendo más eficazmente las excursiones glucémicas posprandiales (diferencia entre la glucemia preprandial y la glucemia posprandial de 1,5-2 horas) y disminuyen el riesgo de hipoglucemia tardía (antes de la siguiente ingesta) (Hirsch 2005). Además, la rapidez de acción permite una administración justo antes de la ingesta o incluso después, frente 
a la insulina regular que debe administrarse 30-45 minutos antes de las comidas para conseguir los mejores resultados.

\section{Modalidades de insulinización}

\section{Insulina basal con ADOS}

La introducción de la insulina basal es la modalidad de insulinización más sencilla tras el fracaso de los agentes orales.Antes de la aparición de los análogos la administración de insulina NPH nocturna (antes de la cena o al acostarse) en combinación con agentes orales, (Inzucchi, Bergenstal et al. 2012) especialmente con metformina, demostró ser la modalidad de insulinización con menor ganancia ponderal manteniendo una eficacia comparable a otras pautas más complejas (Yki-Jarvinen, Ryysy et al. 1999). Este concepto original fue desarrollado más extensamente en la estrategia Treat to Target, basándose en una titulación de la insulina basal para conseguir una glucemia basal optimizada $(\sim 100 \mathrm{mg} / \mathrm{dl})$, manteniendo el tratamiento previo con los agentes orales (Riddle, Rosenstock et al. 2003). Utilizando esta estrategia la insulina glargina y la insulina detemir han demostrado una reducción comparable de la HbA1c frente a la insulina NPH, pero con una menor frecuencia de hipoglucemias graves y nocturnas (Riddle, Rosenstock et al. 2003, Rosenstock, Dailey et al. 2005, Hermansen, Davies et al. 2006).

En el caso de que el paciente no alcance los objetivos terapéuticos (HbA1c $<7 \%$ ), después de un periodo de 3-6 meses, a pesar de que las glucemias basales se encuentren dentro de un rango razonable, será necesario introducir dosis adicionales de insulina de acción rápida para controlar la glucemia posprandial. Esto puede hacerse añadiendo una o más dosis de insulina prandial a la insulina basal o sustituyendo la insulina basal por mezclas prefijadas de insulina (insulina premezclada) dos veces al día, antes del desayuno y antes de la cena (Figura 6). Como otra alternativa estaría la asociación de inhibidores de DPP4, Análogos de GLP1 ó inhibirodes de cotransportadores de SLGT2. 


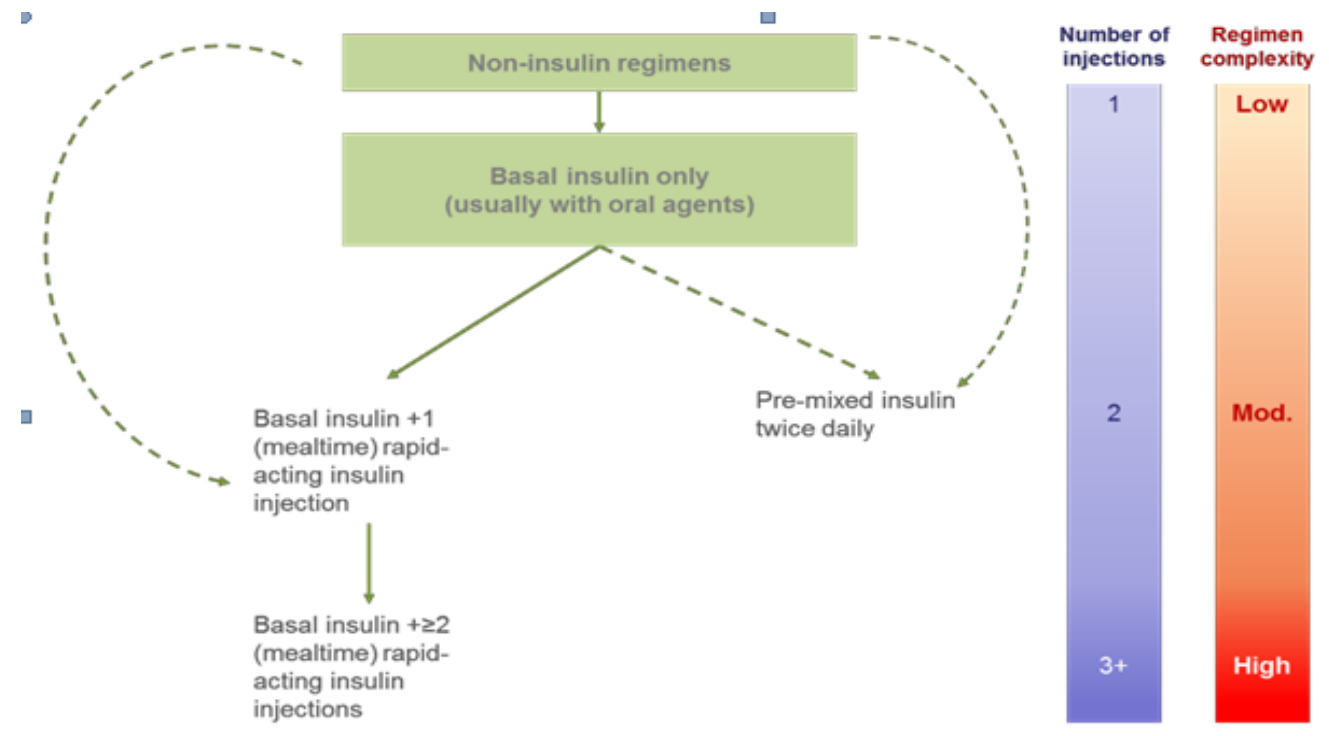

Secuencia basada en el nuevo algoritmo de la American Diabetes AssociationEuropean Association for the Study of Diabetes (ADA-EASD) para el tratamiento de la hiperglucemia en la diabetes tipo 2 (Inzucchi, Bergenstal et al. 2012).

Figura 6. Estrategia de insulinización

\section{Terapia basal-plus}

En esta opción terapéutica, debe administrarse la insulina prandial en la ingesta de mayor contenido de hidratos de carbono (0,05- 0,10 UI/kg o 4 UI en cada ingesta) (Nathan, Buse et al. 2009) incrementando posteriormente el número de inyecciones según las necesidades. Este concepto fue incorporado ya en el algoritmo de tratamiento de la American Diabetes AssociationEuropean Association for the Study of Diabetes (ADA-EASD) de 20088, y ha sido incluido en las nuevas versiones del algoritmo (Inzucchi, Bergenstal et al. 2012, Inzucchi, Bergenstal et al. 2015).

Recientemente, se ha comparado intensificación con la adición progresiva de insulina prandial (aspart) frente la terapia basal-bolus (Rodbard, Visco et al. 2014). La adición escalonada, además de ser mejor aceptada por el paciente, consiguió una reducción comparable de $\mathrm{HbAlc}$ asociada a un menor riesgo de hipoglucemias. 


\section{Terapia bolo-basal}

La estrategia basal-bolus o MDI es la que mejor reproduce la secreción fisiológica de insulina, aunque requiere generalmente $\geq 3$ inyecciones diarias. Frente al tratamiento convencional, el tratamiento con MDI en pacientes con DM-2 reduce la aparición/progresión de las complicaciones microangiopáticas ( Sin embargo, a pesar de las evidencias disponibles, la terapia basal-bolus no ha sido hasta ahora la modalidad habitual en los pacientes con DM-2 avanzada, utilizándose tan solo en pacientes seleccionados y motivados (Ohkubo, Kishikawa et al. 1995).

\section{Insulinas premezclas}

Las insulinas premezcladas fueron introducidas en la clínica con la intención de hacer el tratamiento con insulina más cómodo al paciente, reduciendo el número de inyecciones y evitando posibles errores del propio paciente en la mezcla manual de insulina rápida e insulina NPH. Las nuevas insulinas premezcladas con análogos de insulina de acción rápida (25\% lispro/75\% NPL, 50\% lispro/50\% NPL, aspart 30\%/NPA 70\%, aspart 70\%/NPA 30\%) están sustituyendo las mezclas previas con Insulina regular humana, de las que tan solo queda una variedad (IRH 30\%/NPH 70\%). Las nuevas mezclas con análogos han demostrado un mejor control de la glucemia posprandial frente a las mezclas con insulina humana. En pacientes con DM-2 pueden administrase de una a tres veces al día. Sin embargo, aunque las insulinas premezcladas son ampliamente utilizadas en nuestro medio, es una terapia poco flexible y se asocia con una mayor frecuencia de hipoglucemias frente otras pautas anteriormente descritas (Ampudia-Blasco and Rosenstock 2008, Holman, Farmer et al. 2009, Inzucchi, Bergenstal et al. 2012).

\subsubsection{Tratamiento quirúrgico de la DM tipo 2}

La cirugía bariátrica realizada en pacientes obesos severos ó mórbidos que presentan una diabetes tipo 2, ha demostrado remisiones muy significativas de la enfermedad.

El Swedish Obese Subjects Study (Sjostrom, Lindroos et al. 2004), estudio prospectivo no randomizado de 4.047 obesos, comparó los resultados del grupo control con tratamiento médico y los sometidos a cirugías gástricas con seguimientos hasta 10 años. La remisión de la diabetes tipo 2 en los pacientes quirúrgicos fue del $72 \%$ a los 2 años, sin embargo esa cifra disminuyó al 36\% al cabo de 10 años. En cambio, en el grupo control la remisión fue de 21 y $13 \%$, respectivamente $(\mathrm{p}<0,001)$. Recientemente, se ha 
reportado la significativa reducción de lamortalidad en el seguimiento de los pacientes quirúrgicos, comparados a quienes recibieron tratamiento médico (Sjostrom, Narbro et al. 2007).

Buchwald H. et al (Buchwald, Avidor et al. 2004), publicaron los resultados de un meta-análisis que incluyó 22.094 pacientes sometidos a diversas cirugías bariátricas (banda gástrica, by-pass gástrico, gastroplastía y derivación biliopancreática). La prevalencia de diabetes tipo 2 en el preoperatorio fue de $15,3 \%$, y tuvo una remisión en el 76,8\% y una mejoría en el $86 \%$ de los casos. El by-pass gástrico fue la técnica más usada y mostró una remisión en el $83,7 \%$ de los diabéticos.

En un intento por definir las subpoblaciones de diabéticos obesos severos que más se benefician con cirugía bariátrica, Schauer $\mathrm{P}$. et al (Schauer, Burguera et al. 2003), evaluaron 191 pacientes con diabetes tipo 2 ó con una glicemia de ayuno alterada, sometidos a un bypass gástrico en $\mathrm{Y}$ de Roux (BGYR) con un seguimiento promedio de 20 meses. Se observó mejoría del control metabólico en todos los casos, con una remisión en el 82,7\%. Los mejores resultados se obtuvieron en los pacientes con una diabetes de menor duración, en quienes la diabetes se controlaba sin necesidad de insulina y en los pacientes que lograron las mayores reducciones de peso luego de la cirugía. Si la diabetes tenía más de 10 años, la remisión se alcanzó en el 54\% y si eran insulino-requirentes, en el $62 \%$.

Las series clínicas han demostrado que la mejoría de la glucemia se observa a los días o semanas luego de la cirugía, antes que se produzca una significativa reducción de peso.

Esto ha planteado la hipótesis que existen mecanismos independientes de la baja de peso que mejoran la resistencia y/o la secreción de insulina. En este sentido, se han señalado como importantes la notoria disminución de la ingesta alimentaria y los cambios en la secreción de hormonas intestinales. La modificación anatómica del tracto digestivo de las cirugías que excluyen el paso de alimentos por el duodeno y yeyuno proximal y aceleran el tránsito intestinal hacia el ileon (BGYR), aumentan la secreción postprandial del glucagonlike peptide 1 (GLP-1) que es un secretagogo insulínico que está disminuido en los diabéticos tipo 2 (Kaplan and Ahmad 2008).

Sin embargo, otras técnicas quirúrgicas como la banda gástrica ajustable (Dixon, O'Brien et al. 2008) y la gastrectomía vertical (Vidal, Ibarzabal et al. 2008), (que son procedimientos esencialmente restrictivos) también han demostrado remisiones de la diabetes por sobre el 70\%. En este sentido, hay evidencia de remisión de diabetes en pacientes que son menos obesos. Un 
estudio aleatorizado comparó la banda gástrica ajustable con el mejor tratamiento médico y de cambio de estilo de vida disponible en pacientes con DM2 e IMC entre 30-40 kg/m (Dixon, O'Brien et al. 2008, Penn, White et al. 2013). En general, el $73 \%$ de los pacientes quirúrgicamente tratados alcanzaron la remisión de su diabetes, en comparación con el 13\% de los tratados médicamente. Este último grupo solo perdió el 1,7\% del peso corporal, lo que sugiere que su tratamiento no fue óptimo. El estudio tenía 60 pacientes, y solo 13 tenían un IMC menor de $35 \mathrm{~kg} / \mathrm{m} 2$, haciendo difícil generalizar estos resultados a pacientes diabéticos con obesidad de menor severidad o con una mayor duración de la diabetes.

En un estudio reciente no aleatorizado de 66 pacientes con IMC entre $30-35 \mathrm{~kg} / \mathrm{m} 2$ el $88 \%$ de los mismos tuvo remisión de su DM2 hasta 6 años después de su cirugía (Cohen, Pinheiro et al. 2012) (figura 7).

\section{\%pacientes}

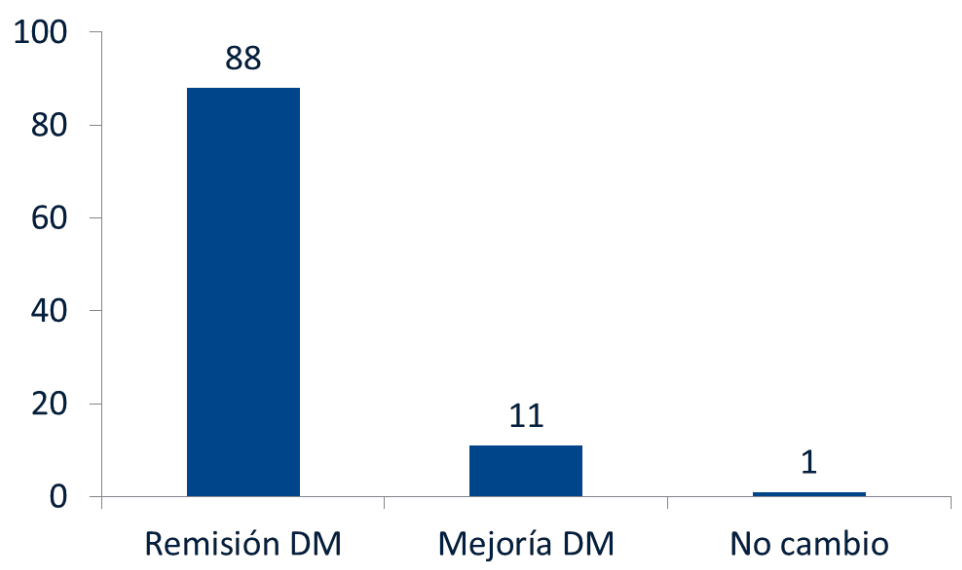

Modificada de: Cohen y cols (Cohen, Pinheiro et al. 2012). $N=66$. Remisión de diabetes: $\mathrm{HbA} 1 \mathrm{c}<6,5 \%$ sin tratamiento antidiabético. Mejoría de diabetes: HbA1c $<7 \%$ con dosis menores de antidiabéticos que en el momento prequirúrgico (y sin insulina).

Figura 7. Cirugía bariátrica y diabetes mellitus tipo 2 en pacientes con IMC entre $30-35 \mathrm{~kg} / \mathrm{m}^{2}$

Se requiere de mayores estudios que aclaren los mecanismos y así definir las mejores estrategias terapéuticas para los pacientes obesos diabéticos con indicación de cirugía bariátrica. Se requieren de ensayos clínicos bien diseñados, con tratamiento de cambios de estilo de vida y tratamiento médico óptimo de la DM y los FR cardiovascular como comparador. 
En 1991, el National Institutes of Health Consensus Development Panel, EEUU, hizo recomendaciones para la indicación de cirugía bariátrica que se han mantenido plenamente vigentes (1991). Entre ellas, se consideró que tenían indicación los pacientes con un IMC $\geq 40 \mathrm{~kg} / \mathrm{m} 2$ y los con un IMC $\geq 35 \mathrm{~kg} / \mathrm{m} 2$ con co-morbilidades importantes que pudieran mejorar con la cirugía, entre las que se señala a la diabetes tipo 2. Entre los requisitos para la cirugía, se planteó que los pacientes debieran haber fracasado a tratamientos médicos previos y estar suficientemente informados para garantizar su colaboración en un adecuado control posterior. Las cirugías deben ser realizadas por equipos médicos capacitados y en el contexto de un programa de manejo multidisciplinario.

La cirugía bariátrica es cara a corto plazo y tiene ciertos riesgos. Las tasas de morbilidad y mortalidad relacionadas directamente con la cirugía han sido reducidas considerablemente en los últimos años, con una tasa de mortalidad a 30 días del 0,28\%, similar a la de la colecistectomía laparoscópica (Buchwald, Estok et al. 2007). Las consecuencias a largo plazo incluyen los déficits de vitaminas y minerales, osteoporosis y la rara pero a menudo documentada hipoglucemia grave por hipersecreción de insulina. Los estudios de cohortes sugieren que el tratamiento quirúrgico puede reducir las tasas de mortalidad a largo plazo (Sjostrom, Narbro et al. 2007). Recientes análisis retrospectivos y estudios de modelación sugieren que estas técnicas pueden ser coste-efectivas cuando se tiene en cuenta la reducción de costes en cuidados de salud subsecuentes (Keating, Dixon et al. 2009, Hoerger, Zhang et al. 2010, Makary, Clark et al. 2010). Sin embargo, estudios recientes aconsejan mantener una cierta precaución sobre los beneficios de la cirugía bariátrica. Los análisis de propensity score de pacientes más mayores con obesidad grave con una alta mortalidad de base en los Centros Médicos de Veteranos, encontraron que el uso de la cirugía bariátrica no se asociaba a un descenso de mortalidad en comparación con el cuidado habitual durante una media de 6,7 años de seguimiento (Maciejewski, Livingston et al. 2011). Otro estudio que siguió durante 12 años a pacientes que habían sido tratados con banda gástrica laparoscópica ajustable (BGLA) encontró que el 60\% estaban satisfechos con el tratamiento. Casi uno de cada tres pacientes tuvo erosión por la banda, y casi la mitad precisó la retirada de sus bandas. La conclusión de los autores fue que "la BGLA parece tener resultados a largo plazo relativamente pobres" (Himpens, Cadiere et al. 2011). 


\section{DIABETES Y DISFUNCIÓN ERÉCTIL}

\subsection{INTRODUCCIÓN}

Existe una clara asociación entre la existencia de DM y el desarrollo de disfunción eréctil (Feldman, Goldstein et al. 1994, Bancroft and Gutierrez 1996, Klein, Klein et al. 1996). La prevalencia de Disfunción eréctil (DE) en los pacientes diabéticos es muy elevada y se triplica el riesgo de sufrir DE grave. Aunque se puede presentar tanto en la DM tipo 1 como la DM tipo 2 la incidencia de la DE va a ser mayor en los pacientes con DM tipo 1 (Fedele, Bortolotti et al. 2000).

\subsection{EPIDEMIOLOGÍA}

Se estima que la prevalencia de DE en pacientes diabéticos va desde el $36 \%$ hasta el 90\% (Fedele, Bortolotti et al. 2000, Giuliano, Leriche et al. 2004, Sasaki, Yamasaki et al. 2005, Malavige and Levy 2009) dependiendo de las poblaciones estudiadas. En relación al rápido incremento de la prevalencia de DM y que gran parte de los hombres con DE diabética representa un alto porcentaje (Wild, Roglic et al. 2004). El inicio de DE ocurre de forma más precoz, adelantándose en 5-10 años sobre los que no presentan diabetes (Romeo, Seftel et al. 2000). Incluso en ocasiones, la DE representa el primer síntoma que nos ayuda a desvelar una DM no diagnosticada pero esto ocurre en pacientes de edad más avanzada (Deutsch and Sherman 1980, Lewis 2001).

Los factores de riesgo que aumentan la probabilidad de sufrir una DE en los pacientes diabéticos son: Mal control metabólico, una mayor duración de la DM, una mayor edad, el hábito fumador y la presencia de enfermedad cardiovascular y otras complicaciones de la DM (Bortolotti, Parazzini et al. 1997, Enzlin, Mathieu et al. 2003, Giugliano, Maiorino et al. 2010).

Un empeoramiento en los niveles de Hbalc, marcador de un mal control metabólico, en los pacientes con DM predice un deterioro de la función eréctil y se asocia a una mayor gravedad de la DE (Romeo, Seftel et al. 2000, Rhoden, Ribeiro et al. 2005). Sin embargo, el efecto beneficioso asociado a buen control metabólico de la DE se observa que parece perderse en los pacientes de más edad (Lu, Jiann et al. 2009). En contrapartida, el consumo de una dieta mediterránea (Giugliano, Maiorino et al. 2010) y la práctica de actividad física en un nivel elevado ejerce un efecto protector sobre la función eréctil en los pacientes con DM tipo 2 (Giugliano, Maiorino et al. 2010). 
Como dato fundamental los pacientes con DM con enfermedad coronaria subclínica presentan una elevada prevalencia de DE, incluso se habla que el riesgo se multiplica por 14 de sufrir enfermedad coronaria previamente no detectada en los pacientes diabéticos que presentan DE y por eso se le considera como un síntoma centinela de la enfermedad cardiovascular (Gazzaruso, Solerte et al. 2008).

\subsection{FISIOPATOLOGÍA DE LA DISFUNCIÓN ERÉCTIL DIABÉTICA}

La diabetes genera una serie de cambios fisiopatológicos que afectan tanto a la función psicológica, la función del sistema nervioso central, la secreción de andrógenos, la actividad neurológica periférica, la contractilidad del músculo liso y la función endotelial (Dunsmuir and Holmes 1996). Cada una de estas alteraciones bien simultáneamente o por separado, pueden ser las responsables de la disfunción eréctil diabética.

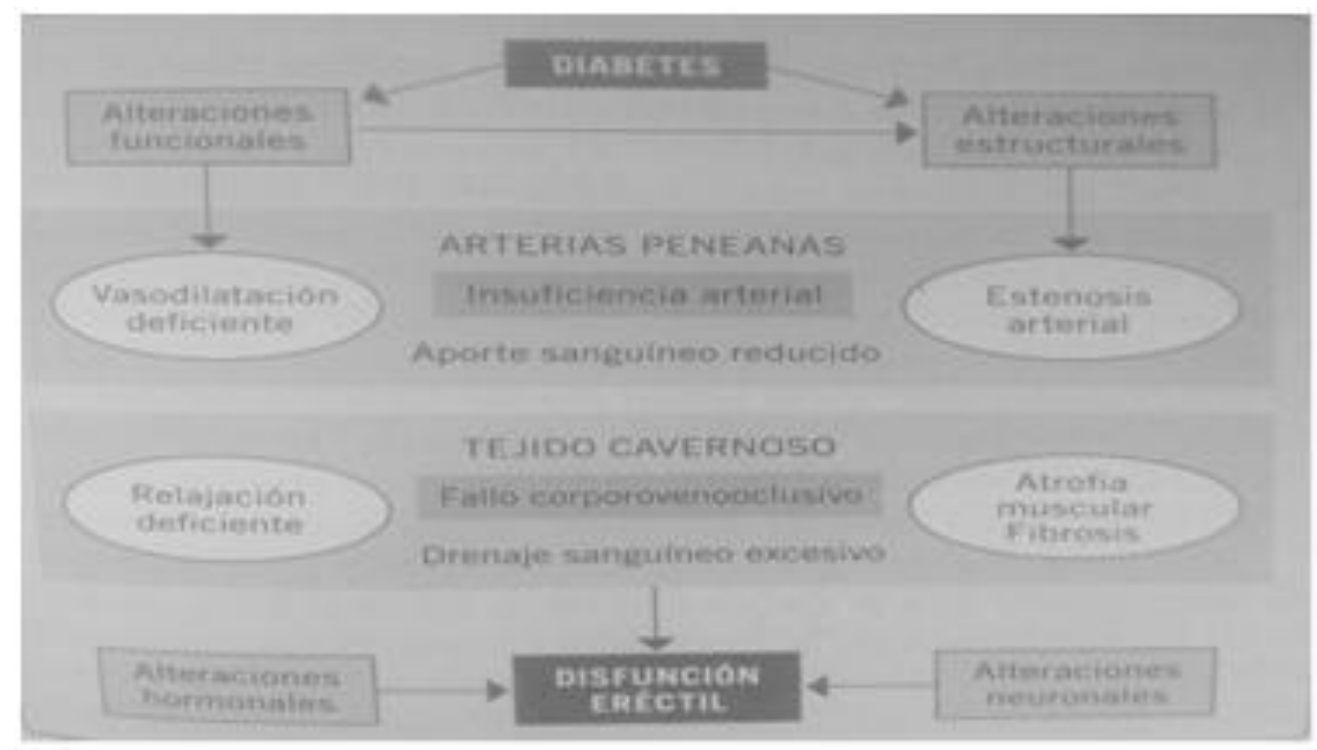

Figura 8. Fisiopatología de la disfunción eréctil diabética

\subsubsection{Alteración funcional}

La vasodilatación de las arterias peneanas y la relajación del músculo liso cavernoso son procesos fundamentales para la función eréctil y estos se ven claramente afectados por la DM. En la DM se produce una alteración tanto de la relajación endotelial como de la neurogénica en el cuerpo cavernoso y este hecho se ha evidenciado en tejido cavernoso de pacientes diabéticos y de modelos animales de diabetes (Saenz de Tejada, Goldstein et 
al. 1989, Azadzoi and Tejada 1992). La alteración de la vasodilatación endotelial y la función neurogénica se va a observar en las arterias de resistencia del pene procedentes de pacientes diabéticos (Angulo, GonzalezCorrochano et al. 2010). Respecto al mecanismo de relajación endotelial en la arteria peneana humana va existir tanto una alteración de la respuesta mediada por el óxido nítrico, tanto como una disminución de la relajación mediada por el factor hiperpolarizante derivada del endotelio ( EDHF) (Angulo, Cuevas et al. 2003). Existiendo claras evidencias de que en el desarrollo de la DE en los pacientes con DM tiene un papel importante el deterioro de la función endotelial asociada a la diabetes (Angelis, Marfella et al. 2001, Pegge, Twomey et al. 2006).

Se sospecha que la alteración en la vía metabólica NO/GMPc puede deberse a una reducción de la síntesis o la biodisponibilidad de NO. En los estudios con modelos animales con DM, se puso de manifiesto un menor contenido de las enzimas responsables de la síntesis de $\mathrm{NO}$ en el tejido cavernoso, tanto en la isoforma neuronal (n-NOS) (Vernet, Cai et al. 1995, Podlasek, Zelner et al. 2001) como de la endotelial (e-NOS) (Akingba and Burnett 2001, Bivalacqua, Usta et al. 2003) con una menor concentración de L- arginina (como concentración intracelular del sustrato NOS) en las ratas diabéticas y con un aumento de la vasodilatación in vivo cuando se administra esta (Angulo, Rodriguez-Manas et al. 1998). En estudios recientes, se ha encontrado un aumento de expresión de la enzima arginasa en el cuerpo cavernoso procedente de pacientes diabéticos y este hecho explicaría la reducción de L- arginina en la DM, ya que el aumento de la arginasa limita la disponibilidad del sustrato en la síntesis de NO (Bivalacqua, Hellstrom et al. 2001).

\section{Incremento del estrés oxidativo}

Se sugiere de forma experimental que la hiperglucemia conduce a una situación de estrés oxidativo tiene un papel importante en la patogenia de la DE en diabetes. En diabetes, se objetiva un aumento en la generación de las especies reactivas de oxígeno( ROS) y por ejemplo el anión superóxido también puede originar otras ROS y reacciona con el NO para formar peroxinitrito causando un disminución en la actividad biológicas del NO (Gryglewski, Palmer et al. 1986). También, el tratamiento con antioxidantes naturales potencia la relajación mediada por NO en el músculo liso peneano de animales diabéticos y mejora la función eréctil en estos animales, (Keegan, Cotter et al. 1999, Gocmen, Secilmis et al. 2000, Keegan, Cotter et al. 2001, Young, Yu et al. 2003) así como con antioxidantes sintéticos que han 
demostrado revertir la $\mathrm{DE}$ en ratas por la vía NO/ GMPc en cuerpo cavernosos y arterias peneanas humanas, reforzando la teoría de la participación del estrés en la DE (Angulo, Peiro et al. 2009).

Se piensa en la existencia de varias fuentes de ROS que conducen al estrés oxidativo en el tejido eréctil del paciente con DM. Una de las fuentes puede ser la glucosilación de proteínas y de hecho la hemoglobina glicosilada, un producto intermedio de la glucosilación, inhibe la relajación dependiente del endotelio en el cuerpo cavernoso dela rata mediante la generación de superóxido (Cartledge, Eardley et al. 2000). Por otro lado, los productos finales de la glicosilación (AGE), acumulados en el tejido erectile (Seftel, Vaziri et al. 1997) y acoplados a sus receptores específicos (RAGE) aumentan el estrés oxidativo intracelular (Wautier, Chappey et al. 2001) e inhiben la actividad de los e-NOS. La teoría de la participación de los AGE en la fisiopatología de la DE se apoya en el hecho de que el tratamiento con Aminoguanidina, un inhibidor de la formación de AGE, mejora la relajación dependiente de endotelio y la función eréctil en las ratas diabéticas.

La NADPH oxidasa es una enzima que genera aniones superóxido en el tejido vascular y por ello se sospecha su participación en la patogénesis de la DE con un aumento de su actividad en la DM y se ha visto una mayor expresión en el cuerpo cavernoso de conejos diabéticos (Shukla, Hotston et al. 2009). Otras fuentes de ROS serían a través de la cadena respiratoria mitocondrial o desacoplamiento de la actividad NOS que pueden llevar al estrés en la DM. De hecho, se ha observado en pacientes con DM tipo 2 aumento de la actividad oxidativa en los monocitos circulantes en pacientes con DE y se reducía con terapia antioxidante (Morano, Mandosi et al. 2007).

\section{Alteración en la contracción del músculo peneano}

Existe una elevación de las respuestas contráctiles a la endotelina 1 (ET-1) un péptido que conlleva a una respuesta constrictora muy potente que también tiene influencia sobre la regulación celular del endotelio y del músculo liso, en tejido cavernosos de ratas y conejos diabéticos (Chang, Hypolite et al. 2003, Wingard, Fulton et al. 2007). Se piensa que el efecto podría estar relacionado con un incremento de la expresión de receptores en tejido cavernoso de los animales diabéticos, en un principio se pensaba en un aumento selectivo del subtipo ETb (Sullivan, Dashwood et al. 1997). Y posteriormente se reveló la participación del subtipo ETa (Chang, Hypolite et al. 2003). Asimismo, se ha observado un aumento de ET-1 en el pene de rata diabéticas lo cual se asocia con un incremento en la apoptosis en tejido cavernoso (Jesmin, Zaedi et al. 2006). 
Por otra parte, también se relaciona la potenciación de las vías de sensibilización del calcio porque participan en el mantenimiento de la respuesta contráctil y entre ellas el aumento en la expresión y activación en la protein cinasa $\mathrm{C}$ y la Rho-Cinasa se les ha puesto como responsables del aumento de la contracción de ET-1 (Chang, Hypolite et al. 2003, Wingard, Fulton et al. 2007). El incremento de la actividad PKC en la diabetes está ampliamente documentado (Inoguchi, Battan et al. 1992, Koya and King 1998) y este puede estar relacionado con el estrés oxidativo en la DM ya que su inducción en células cavernosas de rata (específicamente PKC $\beta I I)$ se previene tratando con Vitamina E (Ganz and Seftel 2000). En la disfunción eréctil parace contribuir en su etiopatogenia la elevación de PKC ya que su inhibición recupera la relajación dependiente del endotelio en el cuerpo cavernoso tanto de animales como de pacientes diabéticos. Por otra parte el aumento de la Rho-cinasa en tejido cavernoso de las ratas diabéticas causa reducción de la actividad de la e-NOS y que administrando un inhidor de de la Rho-cinasa en administración oral crónica previene la elevación de apoptosis y recupera a función eréctil en ratas diabéticas (Bivalacqua, Champion et al. 2004, Li, Park et al. 2011).

\subsubsection{Alteraciones estructurales}

En los pacientes con DM va a existir una disminución en la ratio de la presión sanguínea de la arteria dorsal del pene y de la arteria braquial que explica la alta prevalencia de la insuficiencia arterial peneana en los pacientes con DM y disfunción eréctil (Virag, Bouilly et al. 1985). También va a existir otras alteraciones implicadas en la fisiopatología de la DE como son: reducción del contenido de células musculares lisas, un mayor cúmulo de fibras de colágeno con engrosamiento de la lámina basal y una pérdida de células endoteliales (Mersdorf, Goldsmith et al. 1991). Hay estudios que demuestran un aumento de la apoptosis y una pérdida de integridad del endotelio del tejido cavernoso y esto se va asociar con una menor respuesta a la inyección intracavernosa con una menor liberación de NO (Costa, Soares et al. 2009). Finalmente, en los modelos animales va a existir una pérdidad de músculo liso trabecular y de células endoteliales, mientras que aumenta la matriz extracelular dando lugar a una fibrosis (Simopoulos, Gibbons et al. 2001, Ahn, Sohn et al. 2005, Young, Domes et al. 2008, Kovanecz, Nolazco et al. 2009). 


\subsubsection{Alteraciones neuronales}

Se ha observado que los pacientes diabéticos que presentan DE muestran una reducción de la conducción nerviosa más frecuentemente que los que no tienen DE (Hecht, Neundorfer et al. 2001). En ambos modelos de DE diabética como de DE neuropática se va objetivar un aumento de los marcadores de apoptosis en el nervio cavernoso (McVary, Podlasek et al. 2006). Existe una neurodegeneración selectiva de la inervación nitrérgica, posiblemente causada por la generación de peroxinitrito que se reproduce en modelos animales y en humanos (Cellek, Rodrigo et al. 1999) se observa una reducción de estas respuestas nitrérgicas en el cuerpo cavernosos y las arterias peneanas humanas (Angulo, Gonzalez-Corrochano et al. 2010).

\subsubsection{Alteraciones hormonales}

Se objetiva una alta prevalencia de hipogonadismo en los pacientes diabéticos según evidencias clínicas con niveles bajos de testosterona total y libre (Kapoor, Aldred et al. 2007). La mejoría del control metabólico puede llevar a un restablecimiento del hipogonadismo y se le relaciona con la resistencia insulínica (El-Sakka, Sayed et al. 2009). Este hecho es muy claro en el caso de DM tipo 2 y no lo es tanto para la tipo 1, ya que hay estudios que muestran niveles normales de testosterona por encima de los pacientes con DM tipo 2 (Tomar, Dhindsa et al. 2006, Chandel, Dhindsa et al. 2008). Asímismo, la presencia del Hipogonadismo va a tener un impacto negativo sobre la función eréctil y por ello en los pacientes con DE + DM tipo 2 se observarón niveles bajos de testosterona (Kapoor, Clarke et al. 2007) y la administración de testosterona no sólo mejora la función eréctil, sino también aumenta la respuesta al sildenafilo (Zhang, Filippi et al. 2006).

\subsection{TRATAMIENTO DE LA DE}

\subsubsection{Introducción}

Para establecer los escalones de tratamiento, nos basaremos en el algoritmo propuesto por la Primera Consulta Internacional sobre Disfunción eréctil, celebrada en París en 1999. Se recogen todos los aspectos y en la secuencia adecuada, de un abordaje óptimo para el tratamiento de la DE entendiendo este proceso como multifactorial (Jardin, Wagner et al. 2000).

En la figura 9, se representa el algoritmo de tratamiento de DE según la Segunda Consulta Internacional (2004). 
Entre los escalones del tratamiento del mencionado algoritmo se encuentran:

Primer escalón: Consiste en cambios de estilo de vida, hábitos tóxicos y factores de riesgo modificables.

Segundo escalón: los fármacos de primera línea son los inhibidores de la fosfodiesterasa tipo 5 (iPED5), se incluye el consejo y la educación sexual del paciente y/o su pareja.

Tercer escalón: En el caso de no resolverse la DE o de insatisfacción del paciente con el resultado del tratamiento estarían los fármacos intrauretrales, como la Prostaglandina E1 y también existirían los fármacos vasoactivos intracavernosos $\mathrm{y}$, estos últimos dados que los primeros tienen resultados pobres constituyen la alternativa al tratamiento oral de segunda línea.

Cuarto escalón: Cuando la DE no está todavía resuelta o existe insatisfacción estarían como posibilidades la cirugía vascular o protésica. La cirugía vascular se reserva para pacientes muy jóvenes, afectados por una lesión obstructiva de la arteria peneana o pudenda y que no tengan ningún factor de riesgo cardiovascular y cuyos resultados no están universalmente aceptados. En el caso de la colocación de una prótesis de pene esta decisión sólo debe reservarse sólo debe reservarse para aquellos pacientes que no han respondido a las medidas previas pues el implante supone un proceso irreversible y del cual va a depender tanto conseguir como mantener la erección.

Las estrategias terapeúticas han cambiado tras los malos resultados observados en el seguimiento a largo plazo de las intervenciones quirúrgicas de reconstrucción vascular (Wespes and Schulman 1993, Rao and Donatucci 2001).

Desde 2004 las guías sobre la DE tienen el principio de aproximaciónabordaje en pasos centrados en el paciente. Este "enfoque centrado en el paciente" tiene su inicio cuando tanto el paciente como su pareja reconocen la DE y su propio papel en la evaluación y gestión del problema (Rosen, Hatzichristou et al. 2004).

En el enfoque diagnóstico y en las decisiones terapéuticas se tienen en cuenta los objetivos y preferencias del paciente y su pareja de acuerdo al concepto de gestión dirigido a un objetivo. El paciente a través de un proceso de toma de decisiones guiado por el médico balancea las ventajas y desventajas de cada opción. 
Recientemente, la Segunda Consulta Internacional de Disfunciones sexuales actualizó el algoritmo de manejo de la DE, completando la espiral terapéutica que se había planteado en la Primera Consulta Internacional.

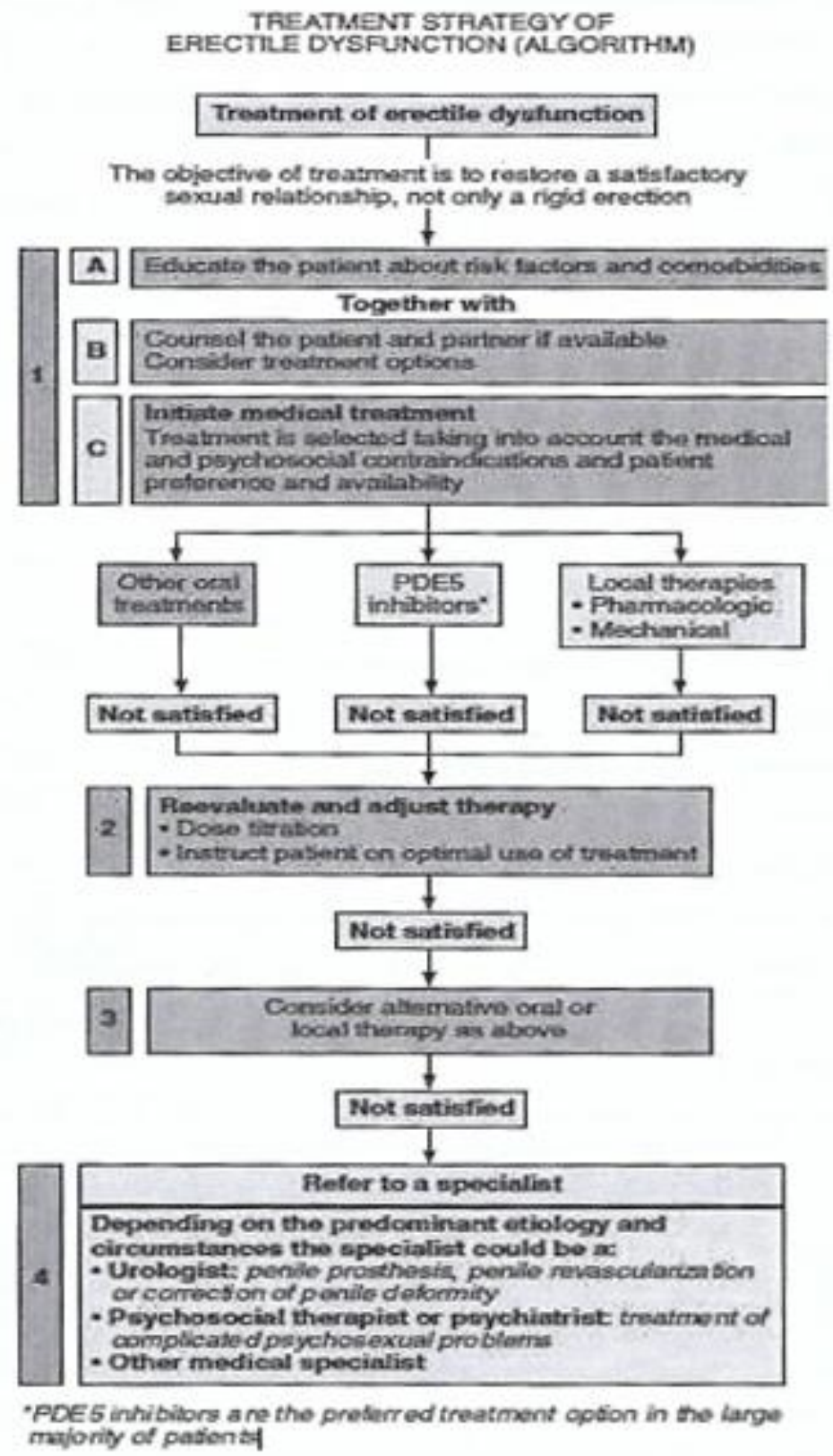

Figura 9. Algoritmo para el tratamiento de la DE (Jardin, Wagner et al. 2000) 


\subsubsection{Actuaciones no farmacológicas}

\subsubsection{Consejo y Educación sexual}

La consulta con el paciente debe incluir una exposición de las expectativas y las necesidades del paciente y de su pareja, por lo que hay que revisar los conocimiento del paciente y su pareja acerca de la DE y los resultados de las pruebas diagnósticas, así como presentar una selección racional de las opciones terapeúticas. La educación del paciente y de su pareja forma parte esencial del tratamiento (Hatzichristou, Rosen et al. 2004).

\subsubsection{Cambios en estilo de vida}

Es muy importante propiciar cambios en el estilo de vida del paciente que dismuya la incidencia de enfermedades cardiovasculares: (2004).

$\checkmark$ Realizar ejercicio de forma regular.

$\checkmark$ Abandonar el tabaco

$\checkmark$ Dieta sana

$\checkmark$ Beber poco alcohol.

Estos posibles beneficios de los cambios en el estilo de vida pueden ser especialmente importantes en pacientes con DE y determinadas enfermedades cardiovasculares ó metabólicas concomitantes como la diabetes o HTA (Moyad, Barada et al. 2004, Moyad, Barada et al. 2004). Hay estudios que demuestran que los cambios intensivos en los hábitos de vida además de mejorar la función eréctil pueden beneficiar a la salud cardiovascular y metabólica en general (Esposito, Giugliano et al. 2004).

Algunos estudios han indicado que los efectos terapéuticos de los inhibidores de la PDE5 pueden potenciarse cuando se tratan de manera intensiva los factores de riesgo concomitantes aunque estos resultados no se han confirmado todavía a largo plazo (Guay 2003).

Factores de Riesgo de Enfermedad Cardiovascular

En la actualidad tenemos datos que ponen de manifiesto de que la DE es síntoma centinela de enfermedad cardiovascular y pudiera serlo de enfermedad metabólica (diabetes, síndrome metabólico) incluso de depresión, así como de un papel interdependiente, y a veces determinante, una de la otra (Goldstein 2000). 


\begin{tabular}{|l|l|}
\hline ECV & DE \\
\hline Edad & Edad \\
\hline Dislipemia & Dislipemia \\
\hline Hipertensión & Hipertensión \\
\hline Diabetes & Diabetes \\
\hline Fumar & Fumar \\
\hline Vida sedentaria & Vida sedentaria \\
\hline Obesidad & Obesidad \\
\hline Depresión & Depresión \\
\hline Varón, Mujer postmenopaúsica & $\begin{array}{l}\text { Enfernedad coronaria, enfermedad } \\
\text { vascular periférica. }\end{array}$ \\
\hline
\end{tabular}

Tabla 4. Principales factores de riesgo de ECV y DE (Martín, Vivas et al. 2011)

En un estudio de 300 pacientes con angor y enfermedad coronaria documentada angiográficamente se cuantificó la alta prevalencia de DE presentándose en un $49 \%$ de los casos, y que esta predecía a la enfermedad cardiovascular en un $67 \%$ de ellos con un período de tiempo de antelación cuantificado en una media de 38.8 meses. Un dato con diferencia estadísticamente significativa era que todos los pacientes con DM tipo 1 desarrollaban la DE antes del episodio cardiovascular (Montorsi, Briganti et al. 2003).

Aunque muy probablemente la actuación sobre las enfermedades causante y /o los factores de riesgo modificables no vaya a revertir por si misma en la DE, va a tener una repercusión sobre la progresión de la enfermedad causante. Incluso, en determinados pacientes, permitirá la recuperación de la función eréctil.

El sedentarismo, la obesidad, el consumo de tabaco, la hipercolesterolemia y el síndrome metabólico son factores de riesgo compartidos entre DE y Enfermedad cardiovascular. Además la DE en sí misma es un factor de riesgo para la enfermedad cardiovascular, y confiere un riesgo equivalente a un hábito tabáquico moderado (OR de 1.46). Los autores de este estudio sugirieron la inclusión de la DE como variable para el cálculo de riesgo cardiovascular (Thompson, Tangen et al. 2005).

En otro estudio, se objetivaba que la presencia de calcio en las arterias coronarias, conocido como indicador de riesgo cardiovascular está asociado a 
la presencia de DE y suponía que la DE es un factor de riesgo coronario (Lee, Ngengwe et al. 2008). Por lo tanto, se deduce que en pacientes con DE y factores de riesgo cardiovascular es obligatoria una evaluación cardiológica.

\begin{tabular}{|l|l|l|}
\hline Riesgo bajo & Riesgo intermedio & Riesgo alto \\
\hline $\begin{array}{l}\text { Asintomático, <3 FR } \\
\text { de EC }\end{array}$ & $\begin{array}{l}3 \text { o más factores de riesgo } \\
\text { EC }\end{array}$ & Arritmias de alto riesgo. \\
\hline $\begin{array}{l}\text { Angina de pecho leve } \\
\text { y estable (evaluada o } \\
\text { en tratamiento) }\end{array}$ & $\begin{array}{l}\text { Angina de pecho moderada y } \\
\text { estable }\end{array}$ & $\begin{array}{l}\text { Angina de pecho } \\
\text { inestable y rebelde al } \\
\text { tratamiento. }\end{array}$ \\
\hline $\begin{array}{l}\text { IM previo no } \\
\text { complicado }\end{array}$ & $\begin{array}{l}\text { IM reciente }(>2 \text { y }<6 \\
\text { semanas) }\end{array}$ & $\begin{array}{l}\text { IM reciente(<2 } \\
\text { semanas) }\end{array}$ \\
\hline $\begin{array}{l}\text { DVI/ICC( Clase I de } \\
\text { la NYHA) }\end{array}$ & $\begin{array}{l}\text { DVI/ICC( Clase II de la } \\
\text { NYHA) }\end{array}$ & $\begin{array}{l}\text { DVI/ICC( Clase III-IV } \\
\text { de la NYHA) }\end{array}$ \\
\hline $\begin{array}{l}\text { Revascularización } \\
\text { coronaria satisfactoria }\end{array}$ & $\begin{array}{l}\text { Secuelas extracardíacas de } \\
\text { enfermedad aterosclerótica( } \\
\text { p.e: ictus o vasculopatía } \\
\text { periférica) }\end{array}$ & $\begin{array}{l}\text { Miocardiopatía } \\
\text { hipertrófica obstructiva } \\
\text { y otras miocardiopatías. }\end{array}$ \\
\hline HTA controlada & & HTA no controlada \\
\hline Valvulopatía leve & & $\begin{array}{l}\text { Valvulopatía moderada } \\
\text { o grave. }\end{array}$ \\
\hline
\end{tabular}

EC: Enfermedad coronaria; ICC: Insuficiencia cardíaca congestiva; DVI: Disfunción ventricular izquierda; IM: Infarto de miocardio; NYHA: New York Heart Association.

Tabla 5. Datos clínicos para estratificar a los pacientes en categorías de riesgo cardiovascular

Se ha visto un aumento de la mortalidad global y enfermedad cardiovascular en varones con DE mayores de 45 años y sin enfermedad cardiovascular previa en Australia por lo que proponer que la DE sea un factor clínico de riesgo y los hombres que la padezcan, incluso en grado leve, deben ser estudiados (Banks, Joshy et al. 2013).

Obesidad

El cambio en los estilos de vida tiene un impacto positivo en la función sexual en al menos un tercio de los varones obesos con DE (Esposito, Giugliano et al. 2004). 
En la obesidad existe una relación entre bajos niveles de testosterona y síndrome metabólico y se asocia significadamente con una mayor contribución orgánica con la DE (Corona, Mannucci et al. 2008).

En una revisión de la evidencia publicada, Hannan et al, demuestra que la DE es un precursor de enfermedad cardiovasculares subyacentes debido a que comparte factores de riesgo (edad, Hipertensión, obesidad) y también en la etiopatogenia (disfunción endotelial) concluyendo que la inactividad física impacta negativamente en la función eréctil. Por lo tanto, las intervenciones tanto según datos clínicos como experimentales sobre la pérdida de peso, la dieta mediterránea y la disminución de la ingesta calórica junto con aumento de la actividad física tienen un beneficio sobre la función eréctil, probablemente por la vía de la reducción de las alteraciones metabólicas y la disminución de la grasa visceral y de la función vascular (Hannan, Maio et al. 2009).

En el trabajo de Espósito se demuestra una relación directa entre ejercicio y dieta y mejoría de la función eréctil en sujetos con DE ó con factores de riesgo cuando son sometidos a un régimen controlado de dieta y ejercicio y en 2 años de seguimiento se objetivaba una mejoría en la puntuación en el IIEF-5 (Esposito, Ciotola et al. 2009).

La dieta mediterránea ha demostrado mejorar la DE en hombres obesos o con síndrome metabólico además de amentar la supervivencia global (Esposito, Giugliano et al. 2010).

\section{Ejercicio}

En un estudio longitudinal del Massachusetts Male Aging Study (MMAS) aparecían las primeras evidencias que relacionan ejercicio y DE refiriendo la relación entre el sedentarismo con una mayor probabilidad de DE. Además, este estudio recomendaba comenzar con la intervención sobre los estilos de vida cuanto antes porque los cambios en edades tardías apenas tenían impacto (Derby, Mohr et al. 2000).

Chang et al, tras analizar los hallazgos de un metanálisis de 7 estudios poblacionales, 1 estudio transversal, 2 estudios de cohortes y 1 ensayo clínico controlado relacionando actividad física y DE se concluye sobre el efecto positivo del ejercicio en la función eréctil: La actividad física moderada se correlaciona con una menor probabilidad de DE (OR de 0.63) y la actividad intensa con una probabilidad todavía menor (OR de 0.42). Aunque con la limitación de que la causalidad no se puede desprender de estudios transversales, la relación entre actividad física y DE parece ser protectora y 
debería ser aclarada con ensayos clínicos y/o estudios de cohorte controlados (Cheng, Ng et al. 2007).

\section{Tabaquismo}

En la actualidad el tabaquismo debe considerarse un factor de riesgo independiente de DE.

En España el estudio EDEM, demostró una asociación entre el consumo de cigarrillos y DE dependiendo del número de cigarrillos consumidos y el tiempo fumando (OR de 2.5 para los fumadores de más de 40 cigarrillos al día) (Martin-Morales, Sanchez-Cruz et al. 2001).

En otro estudio, Chew et al, demostraba que los fumadores activos tienen una mayor probabilidad de padecer DE (OR de 1.57) y este riesgo aumenta con el número de cigarrillos consumidos. La relación entre consumo de cigarrillos y $\mathrm{DE}$ es independiente de la relación entre el consumo de cigarrillos y ECV, por lo que ésta no es un factor contundente (Chew, Bremner et al. 2009).

\section{Alcohol}

El alcohol aunque considerado factor de riesgo para DE, no en todos los estudios parece tener un efecto pernicioso de forma que la evidencia actual no está clara.

Cheng et al, puso de manifiesto mediante un meta-análisis de estudios poblacionales que los resultados fueron que el consumo normal de alcohol se asociaba negativamente con el riesgo de DE (OR de 0.79) mientras que el consumo de más de 8 copas a la semana tenía un efecto protector (OR de 0.85) (Cheng, Ng et al. 2007).

En el Estudio EDEM se demostró una asociación entre abuso de alcohol según el CAGE index y el riesgo de DE con una OR de 1.53 (Martin-Morales, Sanchez-Cruz et al. 2001).

En otro estudio, Chew et al examinan los datos de un estudio poblacional en Australia concluye que sus hallazgos relevan una modesta y negativa asociación entre consumo de alcohol y DE aunque quizá intervenga como factor contundente de ECV y consumo de cigarrillos. Refieren que no está justificado aconsejar a aquellos que consumen alcohol de forma habitual que dejen de hacerlo o reduzcan la ingesta (Chew 2009). 
Basándonos en todo lo anterior, el tema sigue abierto y es controvertido por lo que la recomendación es eliminar hábitos tóxicos como primer escalón en la escalera terapéutica.

\subsubsection{Tratamiento farmacológico oral}

\section{Inhibidores de la fosfodiesterasa 5}

La enzima PDE-5 hidroliza el monofosfato de guanosina cíclico (GMPc) en el tejido cavernoso del pene. La inhibición de la PDE-5 provoca un aumento del flujo arterial que condiciona relajación del músculo liso, aumento de la vasodilatación y erección del pene (Lue 2000). Cuatro inhibidores selectivos de esta enzima han sido aprobados por la Agencia Europea del Medicamento (EMA) y la Food and Drug Administration (FDA) para el tratamiento de la DE. Requieren estimulación sexual para facilitar la erección.

Los tratamientos por vía oral cambiaron completamente el abordaje diagnóstico y terapéutico de la DE (Wespes, Amar et al. 2002).

Aunque los inhibidores PDE5 han mostrado su eficacia en la DE diabética, es necesario aclarar que el grado de eficacia en estos pacientes es menor que en los pacientes no diabéticos objetivando cuando se analizan grupos comparables de pacientes con o sin DM una eficacia más elevada en los no diabéticos. Tanto en Diabetes tipo 1 como en tipo 2 la eficacia de los inhibidores PDE5 se reduce, aunque este efecto parece ser menos profundo en los pacientes con DM tipo 2. El porcentaje de respuesta de eficacia global era del $647.6 \%$ para los diabéticos tipo 2 y era del $51 \%$ para los pacientes diabéticos tipo 1 (66\% de los pacientes que presentaban DE leve-moderada y $30 \%$ de los pacientes con DE grave)

Tipos de inhibidores de la PDE-5

Sildenafilo (Viagra ${ }^{\circledR}$ )

Fue el primer inhibidor PDE-5 y se comercializó en 1998. Es un inhibidor selectivo de la PDE5 con alta afinidad por la misma y por eso necesita una baja concentración (3.5-3.9 mmol/l) para inhibirla al 50\% (ICE $50 \%$ ) (Blazquez, Delgado et al. 2004). Por el contrario la IC50 para inhibir a otras fosfodiesterasas es muchas veces mayor con excepción de la PDE6( 10 veces menor que por la PDE5) explicándose la aparación de efectos visuales 
como la visión azul o mayor percepción del brillo (Corbin, Francis et al. 2002).

Alcanza la concentración máxima en aproximadamente una hora y se metaboliza en el hígado a través de la citocromo P450 por lo que su concentración aumenta con fármacos inhibidores de esta enzima( eritromicina, Ketoconozol y retrovirales) y su eficacia disminuye después de una comida grasa debido a que se prolonga su absorción. La dosis inicial recomendada es de 50mg y debe adaptarse en función de la respuesta y los efectos secundarios. La eficacia llega a mantenerse un máximo de 12 horas (Moncada, Jara et al. 2004). Los acontecimientos adversos son leves y autolimitados con su utilización continua. La tasa de abandonos es similar a la de placebo (Langtry and Markham 1999). La eficacia del sildenafilo se ha ido evaluando en diferentes estudios: En 1998, se evaluó la eficacia del sildenafilo en 21 pacientes diabéticos con DE y mostró un aumento de las erecciones y una mejoría significativa de la función eréctil en el 50-52\% tras tomar una dosis de 25-50 durante 10 días. En otro estudio de mayor duración (12 semanas) con mayor número de pacientes y administrando una dosis variable de $25-100 \mathrm{mg}$, el 56\% de los pacientes comunicaba una mejoría en la función eréctil comparando con el $10 \%$ con placebo. En otro estudio se demostraba una eficacia del $66.6 \%$ en mejoría de las erecciones frente el 28.6\% de los tratados con placebo (Stuckey, Jadzinsky et al. 2003).

Numerosos estudios avalan su eficacia y seguridad; en una revisión de estudios aleatorizados, doble ciego y controlados por placebo fue eficaz indistintamente de los aspectos demográficos, subgrupos etiológicos, gravedad de la DE, además de ser altamente eficaz en diabéticos, hipertensos o en pacientes polimedicados, con una tasa de abandono del $32 \%$ a los 3 años (Carson, Burnett et al. 2002).

Sildenafilo mejora los síntomas del tracto urinario inferior (Sairam, Kulinskaya et al. 2002).

Sus efectos secundarios más frecuentes son: cefalea (13.4\%), rubor facial $(13.1 \%)$, dispepsia (5\%), mareo (2.6\%), rintis $(2.4 \%)$ y anomalías de la visión (4.4\%) y comparando frente a placebo menos del $4 \%$ de los pacientes tuvieron efectos adversos atribuibles al tratamiento (Padma-nathan, Eardley et al. 2002).

\section{Tadalafilo (Cialis®)}

Fue el segundo i PED5 comercializado y tiene un perfil farmacocinético distinto: es eficaz desde 30 minutos después de su administración, con un 
máximo a las 2 horas y la mantiene hasta 36 h después (Porst, Padma-Nathan et al. 2003) y su absorción no se ve afectada por las comidas. Los efectos adversos son leves y autolimitados y la tasa de abandono es similar a placebo siendo la dosis inicial recomendada la de $10 \mathrm{mg}$.

El taldalafilo tiene una IC50 de $0.94 \mathrm{nmol} / 1$ para la PDE5, no tiene apenas afinidad por la PDE6 y tiene una afinidad de sólo 5 veces menor que por la PDE11 que se encuentra en hipófisis y testículos, habiéndose demostrado que no altera los parámetros seminales ni las hormonas reproductivas en hombres tratados durante 6 meses (Hellstrom, Overstreet et al. 2003).

Sus efectos secundarios más frecuentes son cefaleas (14\%), dispepsia $(10 \%)$, mialgia $(5 \%)$, dolor de espalda $(6 \%)$, rubor facial $(4 \%)$, rinitis $(5 \%)$ y su eficacia es independiente de la edad o la etiología de la DE (Brock, McMahon et al. 2002).

Su perfil farmacocinético de mayor vida media permite que sea eficaz a 24 ó 36 horas de su administración, permitiendo plantear el uso pautado en lugar de a demanda (Porst, Padma-Nathan et al. 2003).

En los estudios mejoró las erecciones en subgrupos difíciles de tratar, mejorando la erección en un 64\% de los diabéticos (Saenz-de-Tejada, Anglin et al. 2002).

La dosificación diaria con taldalafilo $5 \mathrm{mg}$ sería útil para pacientes preocupados por el hecho de tomarse o no el tratamiento o por el tiempo transcurrido desde la toma del comprimido y también es una buna opción para prevenir el perjudicial efecto de la programación de las relaciones en aquellos pacientes con una actividad sexual muy frecuente (Fiter and García 2012).

También se ha estudiado la dosificación diaria con 5 o $10 \mathrm{mg}$ de tadalafilo con eficacia similar en ambas dosis y con unos efectos secundarios menos frecuentes que con medicación a demanda y comparable con grupo placebo (Porst, Giuliano et al. 2006).

\section{Vardenafilo (Levitra $\left.{ }^{\circledR}\right)$}

Fue el tercer i PED5 comercializado. Tiene una semivida de alrededor de 4 horas y un tiempo de concentración máxima menor de 1 hora. Tiene una alta afinidad por la PDE5 con una IC50 de $0.7 \mathrm{nmol} / \mathrm{l}$, menor que la del tadalafilo y sildenafilo (Blazquez, Delgado et al. 2004).

Eficaz desde 25-30 minutos después de su administración (más rápido que el sildenafilo), su efecto disminuye con la comida grasa. La dosis inicial 
recomendada es de $10 \mathrm{mg}$. In vitro es 10 veces más potente que el sildenafilo aunque sin mayor eficacia clínica (Bischoff and Schneider 2001). Los efectos adversos son leves y autolimitados y la tasa de abandono es similar a placebo (Keating and Scott 2003). La absorción puede retrarse con una comida grasa (Montorsi, Padma-Nathan et al. 2004).

En los estudios dosis-respuesta, tras 12 semanas de tratamiento los grupos de pacientes tratados con dosis de 5,10 y $20 \mathrm{mg}$ comunicaron mejores erecciones en el $66 \%, 76 \%$ y $80 \%$ respectivamente frente al $30 \%$ de los tratados con placebo (Porst, Rosen et al. 2001). La eficacia fue comprobada tras su comercialización (Potempa, Ulbrich et al. 2004). Los estudios demostraban su eficacia en pacientes diabéticos, mejorado su erección un $72 \%$ frente al $12.6 \%$ del grupo placebo (Goldstein, Young et al. 2003).

Vardenafilo es eficaz en cualquier grado de DE e independientemente de si es psicógena, orgánica o mixta (Donatucci, Eardley et al. 2004). Es seguro en pacientes con comorbilidades como diabetes, hipertensión y dislipemia (Morales, Mirone et al. 2009).

Se objetiva una eficacia similar del vardenfilo con respecto al sildenafilo en pacientes diabéticos tipo 1, aunque algunos estudios le han mostrado eficaz en pacientes que previamente no habían respondido al sildenafilo, alcanzando éxito en la penetración un tercio de los mismos tras el tratamiento con vardenafilo.

\section{Otros inhibidores de PDE5}

Avanfilo (Spedra $\left.{ }^{\circledR}\right)$. De inicio de acción muy rápido y vida media inferior a hora y media con eficacia y seguridad similar a otros i PED5 (Paick, Ahn et al. 2008) que podría ser utilizado preferentemente en pacientes con probabilidad de necesitar nitratos (Limin, Johnsen et al. 2010). Ha sido aprobada su comercialización en Europa en junio de 2013 en dosis de 50, 100 y $200 \mathrm{mg}$.

Un estudio multicéntrico y doble ciego demostró la seguridad y eficacia del avanafilo en hombres con DE leve a grave (Goldstein, McCullough et al. 2012).

Udenafilo (Udzire) Comercializado en 2005 en Corea con el nombre de Zydena que se utiliza en dosis de 100 y $200 \mathrm{mg}$, con eficacia, seguridad y efectos secundarios similares a otros i PED5. Aunque se revelaba porcentajes de eficacia algo superiores pero también el efecto del placebo era superior a lo normal con esta población (Paick, Kim et al. 2009). 
Microdenafilo (Mvix ${ }^{\circledR}$ ) En investigación en Corea con dosis de 50 y $100 \mathrm{mg}$ fue eficaz frente a placebo y su farmacocinética no se altera al asociarlo con alcohol (Kim, Yi et al. 2009).

Lodenafilo (Helleva (B) Investigado en Brasil donde parece ofrecer una buena eficacia y tolerabilidad a dosis de $80 \mathrm{mg}$ (Glina, Fonseca et al. 2010).

Slx-2101. Su metabolito activo es el SLx-2081 (Hatzimouratidis and Hatzichristou 2008) y se investiga como tratamiento de la disfunción eréctil y de la disfunción endotelial y el estrés oxidativo en dosis de 5- 10 mg (Gur, Sikka et al. 2008).

Efectos secundarios de los inhibidores de la PDE5.

\begin{tabular}{|l|l|l|l|}
\hline \multicolumn{1}{|c|}{$\begin{array}{c}\text { Acontecimiento } \\
\text { adverso }\end{array}$} & \multicolumn{1}{|c|}{ Sildenafilo } & \multicolumn{1}{|c|}{ Taldalafilo } & \multicolumn{1}{|c|}{ Vardenafilo } \\
\hline Cefalea & $12.8 \%$ & $14.5 \%$ & $16 \%$ \\
\hline Sofocos & $10.4 \%$ & $4.1 \%$ & $12 \%$ \\
\hline Dispepsia & $4.6 \%$ & $12.3 \%$ & $4 \%$ \\
\hline Congestión nasal & $1.1 \%$ & $4.3 \%$ & $10 \%$ \\
\hline Mareos & $1.2 \%$ & $2.3 \%$ & $2 \%$ \\
\hline Anomalía de la visión & $1.9 \%$ & & $<2 \%$ \\
\hline Dolor de espalda & & $6.5 \%$ & \\
\hline Mialgias & & $5.7 \%$ & \\
\hline
\end{tabular}

Tabla 6. Principales acontecimiento adversos de los i PED5 (Adaptado EMA) (Hatzimouratidis, Amar et al. 2010)

\section{Elección del inhibidor PDE5}

No hay estudios multicéntricos, doble o triple ciego en los que se compare la eficacia o preferencia de los pacientes. La elección del fármaco depende de la frecuencia del coito. Los pacientes deben saber si un medicamento es de acción breve o prolongada, los inconvenientes previsibles y la manera de usarlo (Hatzimouratidis, Amar et al. 2010).

\subsubsection{Tratamiento alternativo}

Cuando fracasa la terapia oral o está contraindicado, se debe ofrecer un tratamiento alternativo: inyecciones intracavernosas o un dispositivo de erección en vacío. Las alternativas terapéuticas existentes son las mismas para 
los pacientes con DE diabéticos que para los pacientes con DE de otras etiologías. Resultados positivos se han obtenido tanto con los aparatos de vació así como las inyecciones intracavernosas.

\subsubsection{Inyecciones intracavernosas}

Virag demostró en 1982 la capacidad de inducir una erección en varones sanos inyectando papaverina directamente en cuerpo cavernoso (Virag 1982) y en 1983 Brindley lo demostró con fenoxibenzamina cuando se inyectó una solución en el pene en directo en el Congreso de la Sociedad Norteaméricana de Urología aunque sus resultados los había publicado en una revista de psiquiatría (Brindley 1983).

Los fármacos usados en la terapia intracavernosa son vasoactivos que producen relajación del músculo liso cavernoso y/o vasos arteriales permitiendo el aflujo masivo de sangre y provocando la erección (Porst and Adaikan 2006).

La respuesta a la inyección intracavernosa de PGE1 no es menor en los pacientes diabéticos que en los no diabéticos y se obtienen porcentajes muy elevados de eficacia con esta terapia.

ALPROSTADILO (PGE1-Caverjetct R, Edex R, Viridal R)

Aunque existan más de 30 tipos de prostaglandinas en los cuerpos cavernosos la PGE1 es la única prostaglandina que produce relajación del cuerpo cavernosos peneano y erección posterior mientras que los demás producen un efecto dual( relajación y contracción) o todo lo contrario (Porst and Adaikan 2006).

El alprostadil es la forma sintética de la PGE1 (Caverject $\mathrm{R}$ en dosis de 10 y 20 ug Y Edex/ Viridal R en dosis de 10,20 y $40 \mathrm{ug}$ ) y es el único tratamiento aprobado para el tratamiento intracavernoso de la DE (Leungwattanakij, Flynn et al. 2001).

Fue el primer tratamiento médico de la DE hace más de 20 años. Se necesita un programa de formación en consulta para que el paciente aprenda el proceso correcto de inyección, en caso de destreza manual limitada se puede enseñar la técnica a la pareja. Existe una pluma especial que evita la visión de la aguja. La erección aparece al cabo de 5-15 minutos y dura en función de la dosis inyectada (Shabsigh, Padma-Nathan et al. 2000). Por tanto, es necesario un cuidadoso asesoramiento en la consulta y un seguimiento estrecho (Vardi, Sprecher et al. 2000). 
Con el alprostadilo intracavernoso se obtienen tasas de eficacia superiores al $70 \%$ en poblaciones generales con DE, así como en subgrupos de pacientes (diabéticos, cardiópatas o enfermedades vasculares) que comunican actividad sexual después del $94 \%$ de las inyecciones y tasas de satisfacción del $87-93.5 \%$ en los pacientes y del 86-90.3\% en sus parejas (Linet and Ogrinc 1996, Porst 1996, Heaton, Lording et al. 2001).

Los efectos adversos son dolor en el pene (50\% de los pacientes después del $11 \%$ de las inyecciones), erecciones prolongadas $(5 \%)$, priapismo (1\%) y fibrosis (2\%) (Lakin, Montague et al. 1990). El dolor suele remitir espontáneamente después de su uso prolongado. Puede aliviarse con aplicación de bicarbonato sódico o anestesia local (Moriel and Rajfer 1993, Kattan 1995). Si hay fibrosis se debe interrumpir las inyecciones varios meses. Los efectos adversos sistémicos son infrecuentes siendo el más habitual la hipotensión leve al utilizar dosis altas.

Está contraindicado en los varones con antecedentes de hipersensibilidad al alprostadilo, riesgo de priapismo o trastornos hemorrágicos. La farmacoterapia intracavernosa se acompaña de tasas elevadas de abandono entre el $41-68 \%$ y su cumplimiento es limitado (Flynn and Williams 1996).

La mayoría de los abandonos suceden en los 3 primeros meses, posteriormente la tasa de abandono es del 10\% anual (Sundaram, Thomas et al. 1997). Los motivos de abandono fueron: deseo de una forma permanente de tratamiento (29\%), ausencia de pareja apropiada (26\%), respuesta escasa (23\%), miedo a las agujas (23\%), miedo a las complicaciones (22\%) y falta de espontaneidad (Gupta, Kirschen et al. 1997).

A los pacientes que no responden a medicación oral se les puede ofrecer inyecciones intracavernosas con una tasa de éxito del 85\% incluso en los pacientes con antecedente de prostatectomía (Raina, Lakin et al. 2004). Sin embargo, casi un tercio de los pacientes que utilizaron estas inyecciones a largo plazo y que también respondieron posteriormente al sidenafilo prefirieron seguir con el programa de inyecciones intracavernosas (Hatzichristou, Apostolidis et al. 2000, Buvat, Lemaire et al. 2002).

La mayoría de los que utilizan inyecciones intracavernosas a largo plazo pueden pasar a recibir sidenafilo a pesar de la fisiopatología subyacente (Montorsi, Althof et al. 2003). Incluso en los pacientes con antecedente de prostatectomía (Raina, Lakin et al. 2004). 
Tratamiento combinado en las inyecciones intracavernosas

La primera combinación la realizó Zorgniotti en 1985 con papaverina y fentolamina (Zorgniotti and Lefleur 1985).

Su indicación son los pacientes con inyecciones dolorosas con PGE1 o cuando la monoterapia con PGE1 se hace ineficaz (Cookson and Nadig 1993, Vozmediano 2012).

\begin{tabular}{|l|l|l|l|}
\hline \multicolumn{1}{|c|}{ Referencia } & Papaverina $(\mathrm{mg} / \mathrm{ml})$ & PGE1 $(\mathrm{ug} / \mathrm{ml})$ & Fentolamina $(\mathrm{mg} / \mathrm{ml})$ \\
\hline Bennet et al & 17.6 & 5.9 & 0.59 \\
\hline Govier et al & 22.5 & 8.3 & 0.83 \\
\hline Israilov et al & 19.4 & 16.4 & 1.6 \\
\hline Marshal et al & 12 & 9 & 1 \\
\hline Shenfield et al & 4.5 & 5 & $0.25 / 0.5$ \\
\hline Mulhall et al & 30 & 10 & 1 \\
\cline { 2 - 4 } & 30 & 25 & 2 \\
\hline \multirow{3}{*}{ Montorsi et al } & 150 & 30 & 5 \\
\cline { 2 - 5 } & 300 & 100 & 10 \\
\cline { 2 - 5 } & 300 & 200 & 20 \\
\hline
\end{tabular}

Tabla 7. Dosis y combinaciones de las combinaciones empleadas en los estudios

(Porst and Adaikan 2006)

Entre estas combinaciones disponemos:

Papaverina/Fentolamina (Bi-mix Ry Androskat R)

Esta combinación en dosis de $30 \mathrm{mg} / 1 \mathrm{mg}$ tiene una efectividad similar al alprostadilo de alrededor del $70 \%$ y una incidencia del priapismo en torno al 6\% (Zorgniotti and Lefleur 1985).

Papaverina+Fentolamina+ Alprostadilo (Trimix R)

Un $5-10 \%$ de los pacientes no responde a las inyecciones intracavernosas combinadas. La combinación del sildenafilo con inyección intracavernosa puede rescatar al $321 \%$ de los pacientes que no responden a inyección triple en monoterapia (McMahon, Samali et al. 1999). Sin embargo, el tratamiento combinado produjo más efectos adversos (33\%). Hay que contemplar esta estrategia antes de pasar a un implante de pene. 
Varios estudios han comunicado que la inyección intracavernosa de tres fármacos combinados es superior a otras preparaciones. En uno de ellos papaverina $(8-16 \mathrm{mg})$ más fentolamina $(0.2-0.4 \mathrm{mg})$ más alprostadilo $(10-20$ ug) fue superior a papaverina (7.5-45 $\mathrm{mg}$ ) más fentolamina (0.25-1.5) (Bechara, Casabe et al. 1997) y se han utilizado con mayores tasas de eficacia si bien su uso no ha sido aprobado.

En otros estudios la combinación triple de papaverina, fentolamina y alprostadilo proporcionó la mayor tasa de eficacia (92\%) con una tasa de efectos adversos similares a la monoterapia con alprastodilo (Bennett, Carpenter et al. 1991, McMahon 1991). Sin embargo la fibrosis es más frecuente cuando se utiliza papaverina (5-10\%) que incluso puede producir hepatoxicidad leve (Levine, Althof et al. 1989).

\subsubsection{Alprastodilo intrauretral (muser)}

Está aprobado su uso en dosis de 125-1000 ug para la DE. La interacción vascular entre la uretra y los cuerpos cavernosos permite la transferencia del medicamento (Guay, Perez et al. 2000).

Se lograron erecciones suficientes para la penetración en el 30-65.9\% de los pacientes (Fulgham, Cochran et al. 1998). Sólo se utilizan las dosis de 500-1000 ug y con tasas bajas de constancia (Mulhall, Jahoda et al. 2001). La aplicación de un anillo de constricción en la base del pene puede mejorar su eficacia (Lewis, Weldon et al. 1998).

Los acontecimientos adversos más frecuentes son dolor local (29-41\%) y mareo (1.9-14\%) siendo la fibrosis y el priapismo muy raros $(<1 \%)$ Hemorragia uretral $(5 \%)$ e infecciones urinarias $(0.2 \%)$ se relacionan con el modo de administración.

Las inyecciones intracavernosas son más eficaces, mejor toleradas y preferidas por los pacientes frente al alprostadilo intrauretral (Shabsigh, Padma-Nathan et al. 2000).

\subsubsection{Dispositivos de constricción por vacío (vacuum)}

Producen una dilatación pasiva de los cuerpos cavernosos junto con el anillo constrictor colocado en la base del pene para retener la sangre en el interior de los mismos, por tanto la erección provocada no es normal al no utilizar vías fisiológicas. El primer mecanismo fue realizado por Jonh King en 1874 y en 1982 la FDA aprobó el uso en disfunción eréctil de un dispositivo llamado Erec Aid R 
La eficacia para conseguir erecciones satisfactorias para la erección es del $90 \%$ con independencia de la causa de la DE y la tasa de satisfacción oscila entre el 27 y el $94 \%$. Los varones con una pareja motivada, interesada y compresiva alcanzan las tasas más elevadas.

El uso a largo plazo de estos dispositivos baja al 50-64\% después de 2 años, la mayoría que dejan de usarlo lo hacen en el plazo de 3 meses (Cookson and Nadig 1993).

Los efectos adversos más frecuentes son dolor, imposibilidad de eyacular, petequias, equimosis, entumecimiento que aparecen en menos del $30 \%$ de los pacientes (Wespes, Wildschutz et al. 2003). Los efectos adversos graves como necrosis de la piel o uretrorragia pueden evitarse si los pacientes retiran el anillo constrictor en un plazo máximo de 30 minutos.

El vacum debe ser considerado como tratamiento de primera línea en hombres que no pueden utilizar el i PED ó tras prostactemía radical y de segunda línea en otras patologías (Brison, Seftel et al. 2013). Puede ser un tratamiento de elección en pacientes de mayor edad, bien informados, con relaciones sexuales infrecuentes y enfermedades concomitantes que requieran un tratamiento no farmacológico e incruento de la DE e incluso como alternativa a las inyecciones intracavernosas (Núñez, Ríos et al. 2000).

También puede utilizarse en combinación con i PED5 en el tratamiento de la DE postPR mejorando la rigidez y la satisfacción (Raina, Agarwal et al. 2005). Parece que cuanto más precozmente se utilice el dispositivo de vacío en esta indicación mejor es el resultado, siendo lo óptimo al mes de la cirugía (Kohler, Pedro et al. 2007).

\subsubsection{Tratamiento quirúrgico}

\subsubsection{Revascularización peneana}

La primera revascularización peneana la realizó Michal en 1972, anastomosando la arteria epigástrica inferior a los cuerpos cavernosos (Michal, Kramar et al. 1973). Posteriormente modificó la técnica haciendo la anastomosis a la arteria dorsal del pene (Michal, Kramer et al. 1980).

El perfeccionamiento de las técnicas de anastomosis mediante espatulación y técnicas de microcirugía mejora los resultados habiéndose publicado altas tasas de éxito (Hauri 1984) y manteniéndose a largo plazo en la mitad de ellos (Jarow and DeFranzo 1996). 
La preservación del ligamento fundiforme previene el acortamiento del pene y una disección, movilización y transferencia de la arteria epigástrica inferior cuidadosas optimiza el resultado (Goldstein, Bastuba et al. 2008).

Las arterializaciones venosas son más propensas al fracaso que las arteriales y la disfunción venooclusiva de los cuerpos cavernosos es una contraindicación de la revascularización y han dejado de recomendarse debido a sus malos resultados a largo plazo en disfunción venooclusiva (Wespes, Wildschutz et al. 2003).

La Asociación Americana de Urología propone que el paciente candidato a revascularización peneana es un hombre sano de menos de 55 años con DE de corta evolución, enfermedad vascular localizada y sin factores de riesgo (Montague, Jarow et al. 2005). Otros son todavía más restrictivos requiriendo un estudio hormonal normal, ausencia de trastornos psiquiátricos, ausencia de Enfermedad de Peyronie, ausencia de eyaculación precoz, ausencia de enfermedad venooclusiva documentada por Eco Dopller y ausencia de factores neurológicos obteniendo una satisfacción a largo plazo del tratamiento quirúrgico del 80\% (Munarriz, Uberoi et al. 2009).

La cirugía venosa consiste en la arterialización de la vena dorsal profunda (Furlow, Fisher et al. 1990) y se realiza en casos muy seleccionados con tasas de éxito a largo plazo del 40 al $50 \%$ en pacientes que tiene erecciones de corta duración incluso utilizando Iped5, con integridad del sistema arterial y fuga venosa documentada por cavernosografía (Lewis and Munarriz 2007).

Otros autores han publicado tasas de éxito de sólo el $11 \%$ en una muestra de 126 pacientes (Schultheiss 1997).

\subsubsection{Prótesis de pene.}

Un significativo porcentaje de pacientes diabéticos con DE acaba necesitando la colocación de una prótesis peneana.

Existen 3 tipos de prótesis de pene:

- Maleables

- De dos componentes

- De tres componentes.

Respecto a quién estaría indicada: deben evitarse en pacientes muy jóvenes o con disfunciones de origen psicógeno. La indicación más segura es 
la DE irreversible o cuando los tratamientos menos invasivos han dejado de responder de forma satisfactoria para el pacientes y su pareja (Allona 1997).

Hay que tener en cuenta otros factores como la habilidad manual, la edad, patología vesical que precise manipulaciones endoscópicas, traumatismos previos o expectativas del paciente informado que no mejora la líbido, el orgasmo o la eyaculación ni que alargará el pene además de que la erección o la flacidez no serán iguales a las que tuviera en el pasado (Delgado and Blázquez 2012).

En pacientes con DE de causa diabética no se recomienda la implantación de prótesis maleables por el incremento del riesgo de erosión. Actualmente, los implantes son una solución atractiva para los pacientes que no responden a terapia oral de la DE (Montorsi, Deho et al. 2004). Resultados

Las prótesis proporcionan una elevada tasa de satisfacción (70-87\%) (Holloway and Farah 1997) siendo preciso un correcto e intenso asesoramiento (Tefilli, Dubocq et al. 1998, Wilson, Cleves et al. 1999). En una serie europea se ha comunicado una satisfacción del 97\% para el paciente (Natali, Olianas et al. 2008).

Los pacientes prefieren las prótesis inflables de tres componentes debido a que se logran erecciones de aspecto más natural, (Montorsi, Rigatti et al. 2000) aunque las prótesis inflables de dos componentes son fiables, más fáciles de implantar y con menos complicaciones mecánicas (Goldstein, Newman et al. 1997). Los modelos hidráulicos proporcionan mayor grado de satisfacción que los semirrígidos (Beutler, Scott et al. 1986).

Los resultados de satisfacción son mejores a los 12 meses que a los 6 meses de la intervención (Mulhall, Ahmed et al. 2003) y se ha demostrado que mejoran los sentimientos de tristeza, ansiedad, frustración, depresión y vergüenza con la actividad sexual (Tefilli, Dubocq et al. 1998).

La insatisfacción puede deberse a cuando el paciente aprecia una pérdida de longitud del pene que es más frecuente en reimplantes posteriores a infección o en implantes en pacientes con Enfermedad de Peyronie (Montorsi, Guazzoni et al. 1996).

\section{Complicaciones}

Las complicaciones más frecuentes son los fallos mecánicos y la infección. La infección se produce por contaminación bacteriana durante la cirugía, (Szostak, DelPizzo et al. 2000) siendo los microorganismo más 
frecuentemente observados los Staphylococcus en el 35-56\% de los casos manifestándose habitualmente hacia el sexto mes, una quinta parte las producen gérmenes gramnegativos que se manifiestan en el primer mes (Jarow 1996).

La incidencia de infecciones en un primer implante es de hasta $8 \%$ (Minervini, Ralph et al. 2006) mientras que en los segundos implantes aumenta hasta el 13\% (Carson 2003). Impregnar la prótesis de antibiótico desciende la posibilidad de infección postoperatoria (Carson 2004) o si se va a utilizar una prótesis con cubierta hidrofílica (Wolter and Hellstrom 2004). Es factible un tratamiento de rescate en la infección con la retirada y reimplantación al mismo tiempo después de una irrigación copiosa de los cuerpos cavernosos con varios medicamentos, con un éxito del 82\% (Mulcahy 2000). La adición de material sintético en la cirugía incrementa el riesgo de infección hasta el 30\% (Henry, Wilson et al. 2005).

No se encuentran diferencias significativas en la aparición de infecciones postquirúrgicas entre pacientes diabéticos y no diabéticos (Wilson, Carson et al. 1998). Aunque en un principio la colocación de una prótesis se consideraba contraindicada en pacientes con mal control glucémico, el seguimiento clínico de pacientes con elevada Hba1c no revela mayor incidencia de infecciones en estos pacientes (Wilson, Carson et al. 1998).

Los fallos mecánicos incluyen el escape de líquido de los cilindros o del reservorio, fallo en las conexiones, rotura de tubos conectores y la dilatación o deformación de los cilindros. Se ha estimado una sobrevida de las prótesis del $60 \%$ a los 15 años (Wilson, Delk et al. 2007) y con modelos más recientes de un $81.3 \%$ a los 10 años (Dhar, Angermeier et al. 2006).

\subsubsection{Perspectivas terapéuticas de futuro.}

La inclusión del estudio de las disfunciones sexuales en el top de las prioridades de investigación en EEUU en la National Urology Research Agenda del 2010 por parte de la American Urological Association Foundation es consistente con la mejora de la calidad de vida y de otras enfermedades demostradas con el estudio y el tratamiento de la DE (Foundation.).

\section{Dobesilato}

La administración conjunta de sildenafilo + dobesilato en estudios resultó en recuperación completa de la función eréctil en ratas diabéticas promoviendo la relajación del tejido eréctil de forma simultánea por varias 
vías (Angulo, Cuevas et al. 2005). La administración del dobesilato en pacientes diabéticos ha mostrado una cierta mejoría en su función eréctil (Videla, Villoria et al. 2008) y sería interesante evaluar este tratamiento en combinación con una inhibidor PDE5 para determinar si aumenta la eficacia de éste en el tratamiento de la DE asociada a la diabetes.

\section{Terapia génica}

En estudios con ratas diabéticas, se ha empleado para sobreexpresar en el tejido cavernoso el gen humano (hSlo) que codifica para el canal de potasio activado por calcio de gran conductancia (BKca, maxi-K). El resultado es la recuperación de la capacidad eréctil en estos animales (Christ, Day et al. 2004).

Se ha realizado un ensayo clínico evaluando el tratamiento con terapia génica del maxi-K en pacientes con $\mathrm{DE}$ de diversas etiologías que resulto en un cierto grado de eficacia y un buen perfil de seguridad (Melman, BarChama et al. 2006). Este abordaje podría ser útil en la DE eréctil diabética y permitiría la administración combinada de terapia oral.

\section{Terapia con células madre}

Se ha sugerido recientemente la aplicación de la terapia celular como alternativa terapéutica en la DE diabética. La inyección intracavernosa de células madre mesenquimales derivadas del tejido adiposos ha mostrado eficacia tanto en recuperar la función endotelial y neurogénica, mejorando la función eréctil en ratas con diabetes tipo 2 (Garcia, Fandel et al. 2010). El hecho de emplear células autólogas fácilmente obtenibles en cantidad suficiente del tejido adiposo sugiere una relativamente sencilla translación de este abordaje terapéutico en la práctica clínica

\section{Otros}

Ingenería tisular inyectando polipéptidos antiogénicos como el factor de crecimiento de endotelio vascular.( VEGF) (Burchardt, Burchardt et al. 1999).

Potenciadores acción NO mediante la modulación de la guanilato ciclasa soluble con estimulantes como la molécula BAY 41-8543 mejorarían la erección humana (Lasker, Pankey et al. 2013).

Ondas de choque extracorpóreas: Un estudio randomiza a 67 hombres que llevaban más de un mes sin tomar un i PED5 a recibir 12 sesiones de este tratamiento o un tratamiento simulado demostrando mejoría en los parámetros medidos por pletismografía peneana y con el cuestionario EHS. Ninguno tuvo 
efectos adversos y 19 de los que recibieron un tratamiento real tuvieron una puntuación de más de 3 en el EHS frente a ninguno que describiera esta mejoría en el grupo en que simuló el tratamiento (Vardi, Appel et al. 2012). 



\section{HIPÓTESIS Y OBJETIVOS DEL ESTUDIO}





\section{HIPÓTESIS.}

Hipótesis nula: La terapia antidiabética no influye en la respuesta al tratamiento de la disfunción eréctil.

Hipótesis alternativa: La terapia antidiabética sí influye en la respuesta al tratamiento de la disfunción eréctil.

\section{OBJETIVOS DEL ESTUDIO}

1. Conocer la relación entre la edad y el tratamiento de la diabetes con la respuesta al tratamiento de la disfunción eréctil.

2. Conocer la relación entre la glucemia basal y el tratamiento de la diabetes con la respuesta al tratamiento de la disfunción eréctil.

3. Conocer la relación entre el control de la diabetes mediante la medición de la hemoglobina glicosilada con los métodos NGSP e IFCC y el tratamiento de la diabetes con la respuesta al tratamiento de la disfunción eréctil.

4. Conocer la relación entre el PSA sérico y el tratamiento de la diabetes con la respuesta al tratamiento de la disfunción eréctil.

5. Conocer la relación entre los principales diagnósticos secundarios y el tratamiento de la diabetes con la respuesta al tratamiento de la disfunción eréctil. 



\section{MATERIAL Y MÉTODOS}





\section{GENERALIDADES}

Se realiza un estudio retrospectivo multicéntrico observacional. Se revisaron historiales clínicos de 1416 varones que consultaron por disfunción eréctil en Clínica Urológica Plaza España (Salamanca), Hospital Clínico Universitario de Salamanca, Hospital General Santísima Trinidad (Salamanca) y en el Servicio de Urología del Hospital Universitario de Donostia.

El estudio fue presentado y aprobado por la Comisión de Investigación del Complejo Asistencial de Salamanca.

A partir de la información contenida en los historiales clínicos, se elaboró un documento Excel que contenía las variables del estudio.

\section{MATERIAL}

\subsection{HISTORIALES CLÍNICOS}

El material de estudio consistió en 1416 historiales clínicos de pacientes varones mayores de 16 años que consultaron por disfunción eréctil en los centros referidos, de entre los cuales se seleccionan 191 pacientes diabéticos.

Se elabora un documento electrónico Excell de recogida de datos que contiene las variables estudiadas. Los datos son analizados con un paquete estadístico NCSS277/GESS2006.

\subsection{INSTALACIONES}

Es un estudio realizado por el Grupo de Investigación tutelado en el Programa de Doctorado de Cirugía y Odontoestomatología con vínculos con APFIEQ-CyL (Asociación para la Promoción de la Formación e Investigación en Especialidades Quirúrgicas en Castilla y León) a su vez relacionada con el Departamento de Cirugía de la Universidad de Salamanca.

La recolección de datos se llevó a cabo sobre la documentación clínica del Grupo de Investigación, que comienza a ser construida en Enero de 2000 y llega hasta la fecha de registro de este proyecto doctoral.

El Grupo de Investigación tiene su sede en el Departamento de Cirugía de la Universidad de Salamanca, Avda. Alfonso X El Sabio s/n. 37007 Salamanca. 


\section{MÉTODO}

\subsection{SELECCIÓN MUESTRAL}

La selección muestral se obtuvo de los pacientes que fueron atendidos por disfunción eréctil, de forma secuencial y sucesiva, retrospectiva, exhaustiva, desde mayo de 2016. La fecha de mayo de 2016 se decide para evaluar el control evolutivo mínimo de 8 meses posterior al tratamiento y finalización de la recogida de datos.

El tamaño de la muestra fue calculado con el software Epidat 3.1 para comparar grupos investigados según la respuesta al tratamiento por disfunción eréctil y en relación al tratamiento de la diabetes mellitus, obteniendo un $n$ mínimo por grupo de 30 (Ahnn and Anderson 1995).

\subsection{DISEÑO DEL ESTUDIO}

Se trata de un estudio multicéntrico retrospectivo observacional de los historiales de 1416 varones con disfunción eréctil (DE), de entre los cuales se distinguen los que padecen diabetes mellitus (DM).

Los profesionales colaboradores rellenan un cuaderno de recogida de datos por paciente. En dicho cuaderno no constan datos personales o que puedan permitir el reconocimiento del sujeto, respetando la legislación vigente sobre la protección de datos de carácter personal. Todas las personas que intervienen en la investigación cumplen las normas y legislación vigente de buena práctica clínica (Lorenzo 2015).

Posteriormente se realiza un análisis estadístico de estos datos, organizados en un documento Excel.

\subsection{GRUPOS DE ESTUDIO}

GA: GRUPO A $(n=191)$ : varones con disfunción eréctil con diabetes mellitus.

GB: GRUPO B ( $\mathrm{n}=796)$ : varones con disfunción eréctil sin diabetes mellitus con diagnósticos secundarios.

GC: GRUPO C $(n=429)$ : varones con disfunción eréctil sin diabetes mellitus sin diagnósticos secundarios. 
GAa $(n=80)$ : pacientes con disfunción eréctil con diabetes mellitus con resultado exitoso a su tratamiento de la DE.

GAb ( $n=64)$ : pacientes con disfunción eréctil con diabetes mellitus con resultado parcial a su tratamiento de la DE.

GAc ( $n=47)$ : pacientes con disfunción eréctil con diabetes mellitus con resultado de fracaso a su tratamiento de la DE.

GBa ( $\mathrm{n}=379)$ : pacientes con disfunción eréctil sin diabetes mellitus con diagnósticos secundarios con resultado exitoso a su tratamiento de la DE.

$\mathrm{GBb}(\mathrm{n}=201)$ : pacientes con disfunción eréctil sin diabetes mellitus con diagnósticos secundarios con resultado parcial a su tratamiento de la DE.

$\mathrm{GBc}(\mathrm{n}=216)$ : pacientes con disfunción eréctil sin diabetes mellitus con diagnósticos secundarios con resultado de fracaso a su tratamiento de la DE.

$\mathrm{GCa}(\mathrm{n}=276)$ : pacientes con disfunción eréctil sin diabetes mellitus sin diagnósticos secundarios con resultado exitoso a su tratamiento de la DE.

GCb $(n=76)$ : pacientes con disfunción eréctil sin diabetes mellitus sin diagnósticos secundarios con resultado parcial a su tratamiento de la DE.

GCc $(n=77)$ : pacientes con disfunción eréctil sin diabetes mellitus sin diagnósticos secundarios con resultado de fracaso a su tratamiento de la DE.

GAm ( $n=65)$ : pacientes con disfunción eréctil con diabetes mellitus tratados con metformina.

GAo ( $n=30)$ : pacientes con disfunción eréctil con diabetes mellitus tratados con otros antidiabéticos orales diferentes a la metfomina (saxagliptina, sitagliptina y vildagliptina).

GAc ( $n=96)$ : pacientes con disfunción eréctil con diabetes mellitus tratados con tratamiento combinado de insulina y antidiabéticos orales.

En GAm, GAo y GAc se distinguieron subgrupos a, b y c según respuesta exitosa, parcial o fracaso al tratamiento de la disfunción eréctil respectivamente.

\subsection{VARIABLES ESTUDIADAS}

Se analizaron las siguientes variables:

-Edad. 
-Tiempo de control evolutivo después de la instauración del tratamiento de la DE.

-Glucemia basal.

-Hemoglobina glicosilada determinada por el método NGSP.

-Hemoglobina glicosilada determinada por el método IFCC.

-PSA: Antígeno prostático específico.

-Diagnósticos secundarios (DS).

-Antecedentes quirúrgicos

-Tabaquismo.

-Resultados del tratamiento de la DE en términos de éxito, resultado parcial o fracaso.

Para analizar los DS, condiciones y tratamiento concomitantes, se codificaron como sigue:

\begin{tabular}{|l|l|}
\hline \multicolumn{1}{|c|}{ CONDICIONES MÉDICAS } & \multicolumn{1}{c|}{ Codificación en números } \\
\hline HTA & 2.4 .1$. \\
\hline Cardiopatía isquémica & 2.4 .2$. \\
\hline Alteraciones del ritmo cardiaco & 2.4 .3$. \\
\hline Diabetes & 2.5. \\
\hline -Tipo 1 & 2.5 .1$. \\
\hline -Tipo 2 & 2.5 .2$. \\
\hline Digestivo: gastritis, ulcus & 2.6. \\
\hline Trastorno metabólico & 2.6. \\
\hline -Dislipemia & 2.6 .1$. \\
\hline -Hipotiroidismo & 2.6 .2$. \\
\hline Próstata & 2.8. \\
\hline -HBP & 2.8 .1$. \\
\hline -cáncer & 2.8 .2$. \\
\hline Trastorno psiquiátrico & 2.9. \\
\hline -ansiedad & 2.9 .1$. \\
\hline -depresión & 2.9 .2$. \\
\hline -otros trastornos psiquiátricos & 2.9 .3$. \\
\hline Otras enfermedades & 2.18. \\
\hline ANTECEDENTES QUIRÚRGICOS & 3. \\
\hline
\end{tabular}




\begin{tabular}{|l|l|}
\hline Abdominal & 3.1. \\
\hline Neurológico & 3.2. \\
\hline Pelviano & 3.3. \\
\hline -adenomectomía prostática & 3.4. \\
\hline -prostatectomía radical & 3.5. \\
\hline Otras Q & 3.13 \\
\hline TRATAMIENTOS & 4. \\
\hline DIABETES & 4.1. \\
\hline -metformina & 4.2. \\
\hline -otros antidiabéticos orales & 4.3. \\
\hline saxagliptina, sitagliptina y vildagliptina) & \\
\hline -insulina & 4.4. \\
\hline Broncodilatador & 4.9. \\
\hline Colesterol-hipolipemiante & 4.11. \\
\hline HTA & 4.12. \\
\hline -ARA 2 & 4.13. \\
\hline -Diurético & 4.14. \\
\hline -IECA & 4.15. \\
\hline Patología prostática benigna & 4.16. \\
\hline Protector gástrico & 4.22. \\
\hline PSIQUIATRIA & 4.25 \\
\hline -benzodiazepina & 4.26. \\
\hline -neuroleptico & 4.27 \\
\hline Respiratorio-broncodilatador & 4.29 \\
\hline TÓXICOS & 5. \\
\hline -ninguno & 5.1. \\
\hline Fumador-no consta & 5.2. \\
\hline -no & 5.3. \\
\hline -Activo cig/día & 5.4. \\
\hline -exfumador & 5.5. \\
\hline Otras drogas & 5.7 \\
\hline & \\
\hline
\end{tabular}

Se elabora un documento electrónico Excell de recogida de datos que contiene las variables estudiadas. Los datos son analizados con un paquete estadístico NCSS277/GESS2007. 


\subsection{CONSENTIMIENTOS INFORMADOS DE LOS PACIENTES (REAL DECRETO 651/93)}

Todas los pacientes atendidos por los especialistas que colaboran en con el Grupo de Investigación a nivel científico, en regimen de asistencia sanitaria pública o privada/concertada, al incluir a un paciente en la base de datos, firman el consentimiento informado para que se pueda usar la información clínica relativa a su proceso con fines estrictamente científicos y de investigación y siempre respetando el carácter confidencial de dicha información, Legislación específica por Directiva 2001/20/CE del Parlamento Europeo y del Consejo y cumplimiento de las normas de Buena Práctica Clínica del Ministerio de Sanidad y Consumo y de la Agencia Española del Medicamento y Productos Sanitarios (Lorenzo Gómez 2015).

\subsection{CONFLICTO DE INTERESES}

Los autores del estudio declaran que no hubo conflicto de intereses. Los investigadores no fueron incentivados en ninguna de las fases del proyecto. No se realizaron tratamientos ni pruebas adicionales, ni se incurrió en gastos adicionales a los ordinarios del proceso presentado por las pacientes de acuerdo a los estándares de las Guías de Buena Práctica Clínica (LorenzoGómez, M. (2015). Sujetos participantes en la investigación. Garantías. Guía de buenas prácticas en investigación. C. d. I. d. C. A. U. d. Salamanca@. Salamanca, Comisión de Investigación del Complejo Asistencial Universitario de Salamanca@. 1: 41-53).

\subsection{COSTES}

Se presupuestaron previamente y correspondieron a los gastos asociados al material de oficina, nuevas tecnologías y otros gastos intangibles que asume el Grupo de Investigación. No se generaron gastos adicionales en el aspecto asistencial, a los derivados de forma ordinaria por las patologías tratadas en los pacientes estudiados.

\subsection{ANÁLISIS ESTADÍSTICO}

Se analizan los resultados con estadística descriptiva, t de Student, Chi2, test exacto de Fisher, análisis de la varianza ANOVA. Se aceptó una significación estadística para $\mathrm{p}<0,05$. 


\section{RESULTADOS}





\section{EDAD.}

\subsection{Edad en la muestra general.}

La edad media fue 58.12 años, SD 11.37, mediana 59, rango 16-74 (figura 10).

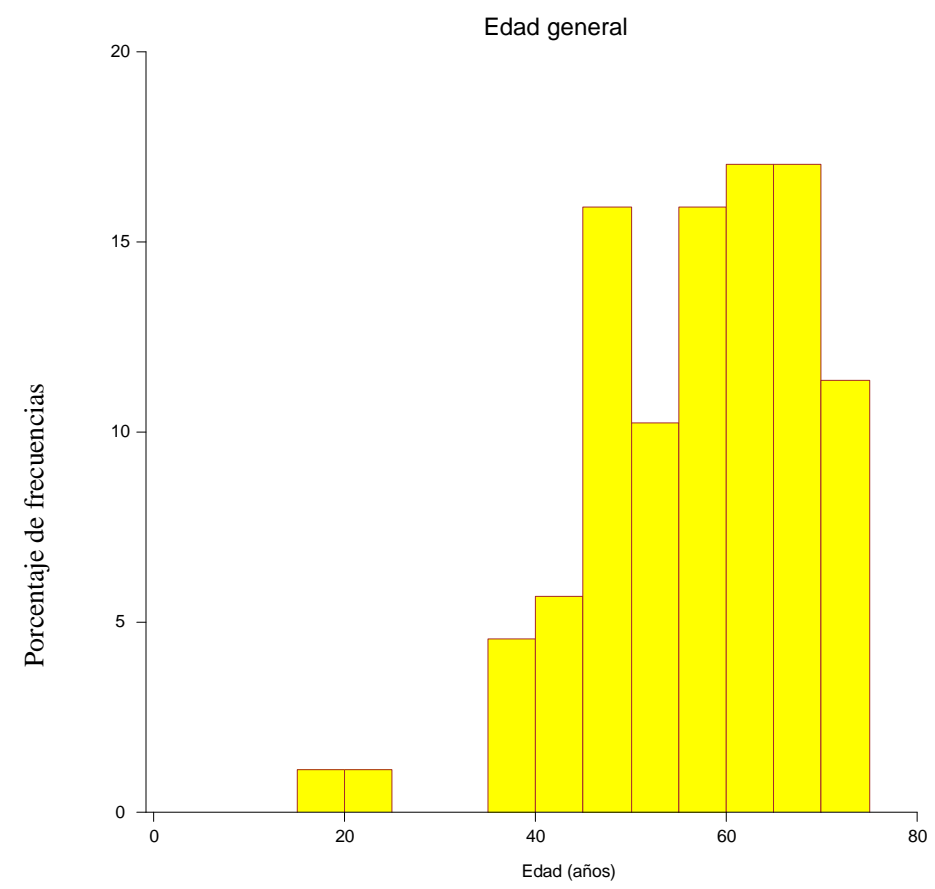

Figura 10. Distribución de la edad en la muestra general.

\subsection{Edad en GA, GB y GC.}

1. La tabla 8 y las figuras 11 y 12 muestran la edad en los grupos. La edad en GB fue inferior $(\mathrm{p}=0.0259)$. La edad fue inferior en el subgrupo GB, la edad en hombre sin Diabetes Mellitus con diagnósticos secundarios es mas joven. Los hombres con Diabetes Mellitus son "mas viejos", tienen mas edad que los hombres sin Diabetes Mellitus con diagnósticos secundarios ( $\mathrm{p}=0.0259)$. 


\begin{tabular}{|l|l|l|l|l|}
\hline Grupo & Edad media & Sd & Mediana & Rango \\
\hline GA & 57.97 & 7.64 & 56 & $46-73$ \\
\hline GB & 57.5 & 12.96 & 59 & $16-74$ \\
\hline GC & 59.33 & 9.33 & 61 & $42-73$ \\
\hline
\end{tabular}

Tabla 8. Edad en GA, GB, GC.

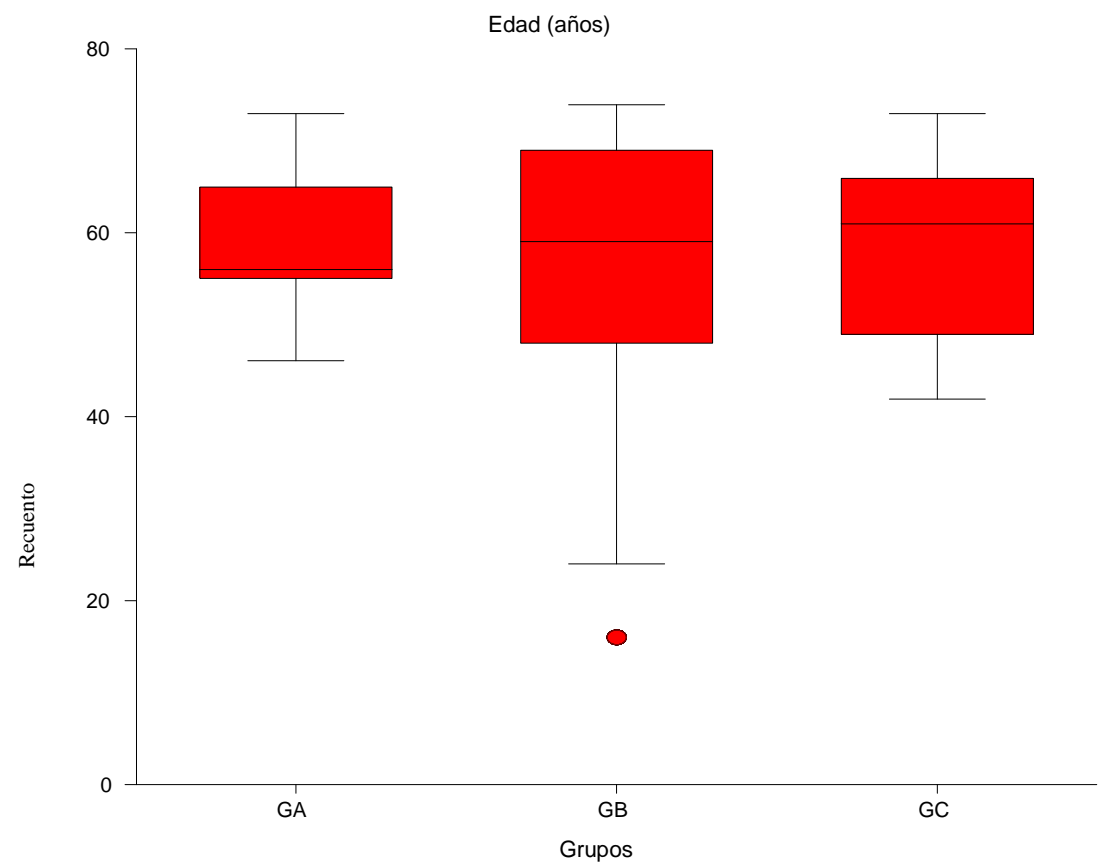

Figura 11. Distribución de la edad en GA, GB y GC. 


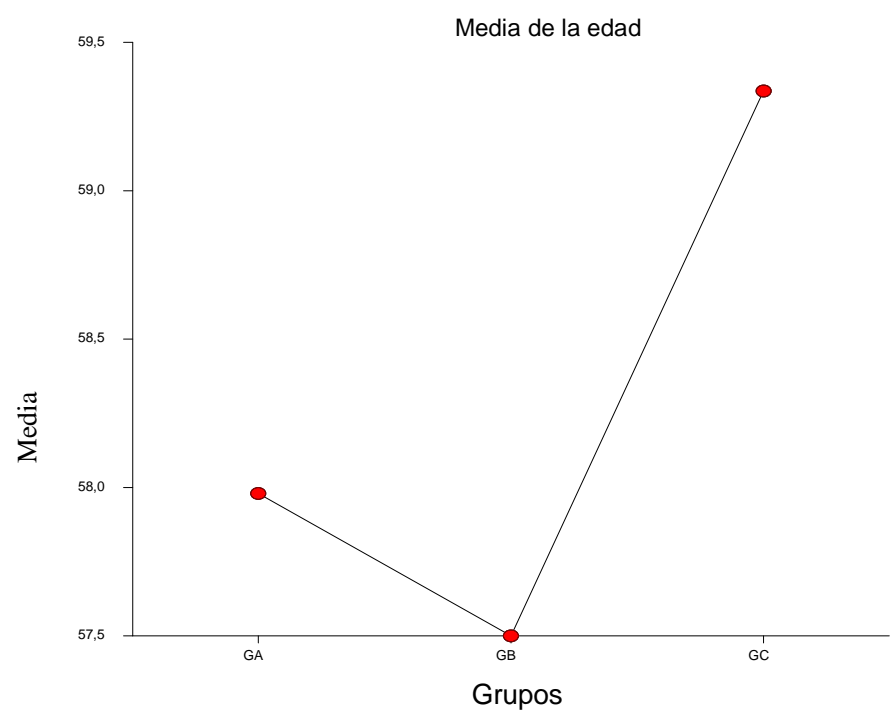

Figura 12. Media de la edad en los grupos.

\subsection{Edad en grupo GA.}

La edad media fue 57.97 años, SD 7.64, mediana 56, rango 46-73 (figura 13).

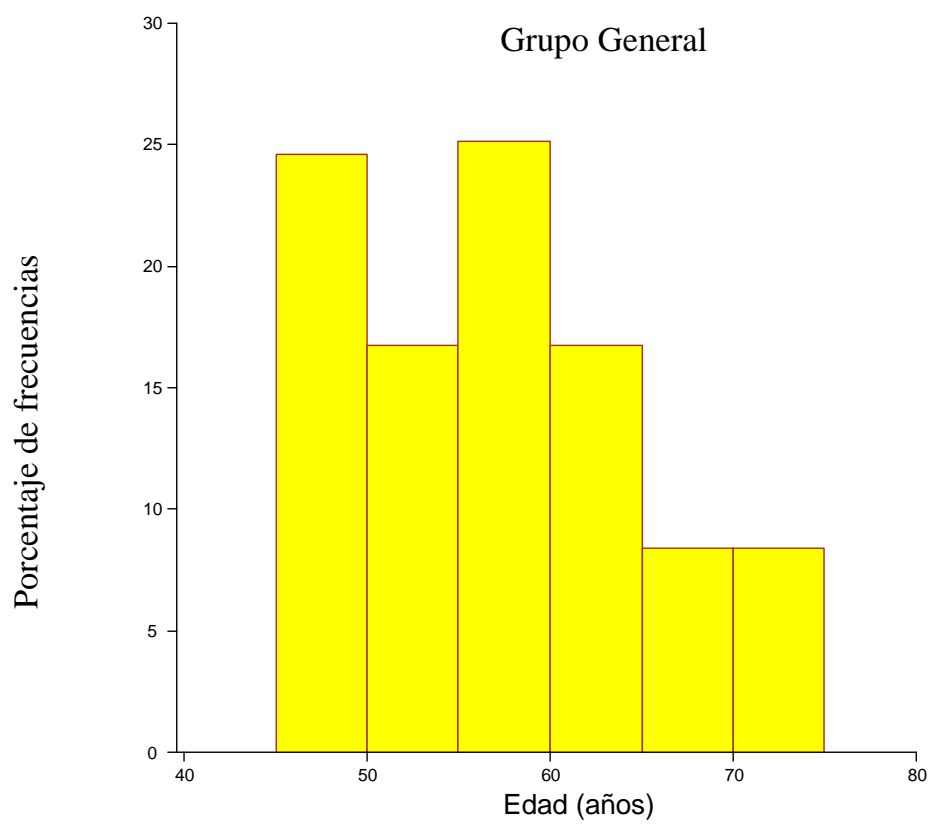

Figura 13. Distribución de la edad en GA. 


\subsection{Edad en grupo GAa, GAb y GAc.}

Comparación entre grupos de pacientes masculinos con disfunción eréctil con diabetes mellitus (GA) y con respuesta al tratamiento exitosa (GAa), parcial (GAb) y fracaso (GAc).

1. La tabla 8 y las figuras 14 y 15 muestran la edad en los grupos. La edad en GAb fue inferior ( $p=0,00032$ ). La edad en el subgrupo GAb fue inferior, aquellos diabéticos con resultado parcial fueron mas jóvenes, los diabéticos de más edad tuvieron más éxito en el tratamiento $(\mathrm{p}=0,00032)$.

\begin{tabular}{|l|l|l|l|l|}
\hline Grupo & Edad media & SD & Mediana & Rango \\
\hline GAa & 60 & 5.90 & 56 & $55-69$ \\
\hline GAb & 55 & 5.08 & 54.5 & $50-61$ \\
\hline GAc & 58.59 & 11.23 & 56 & $50-61$ \\
\hline
\end{tabular}

Tabla 8. Edad en GAa. GAb y GAc.

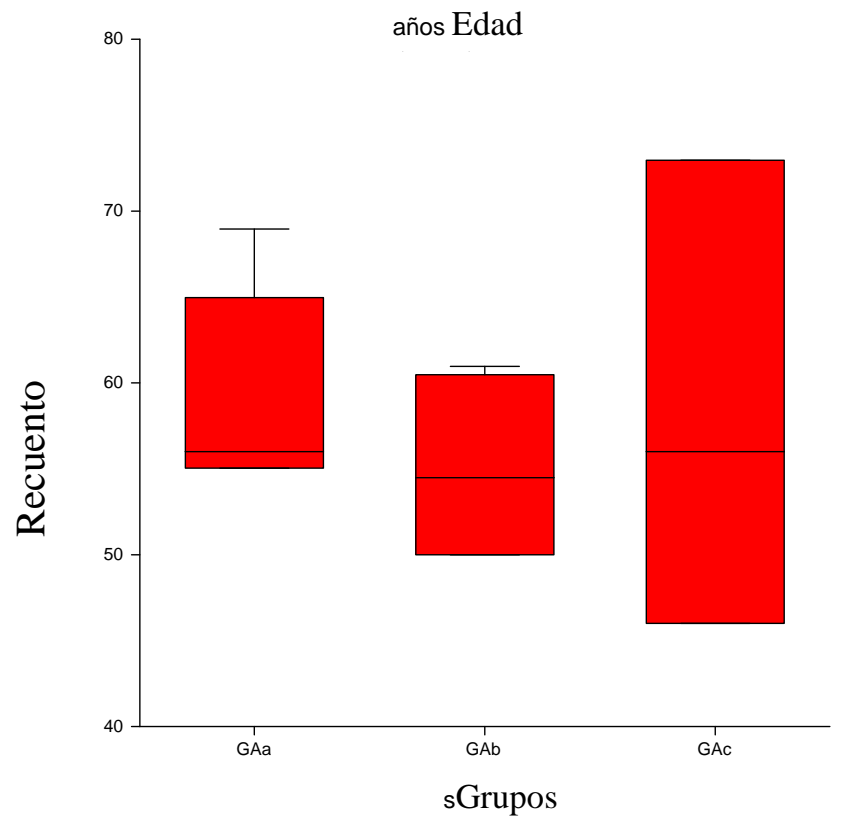

Figura 14. Distribución de la edad. 
RESULTADOS

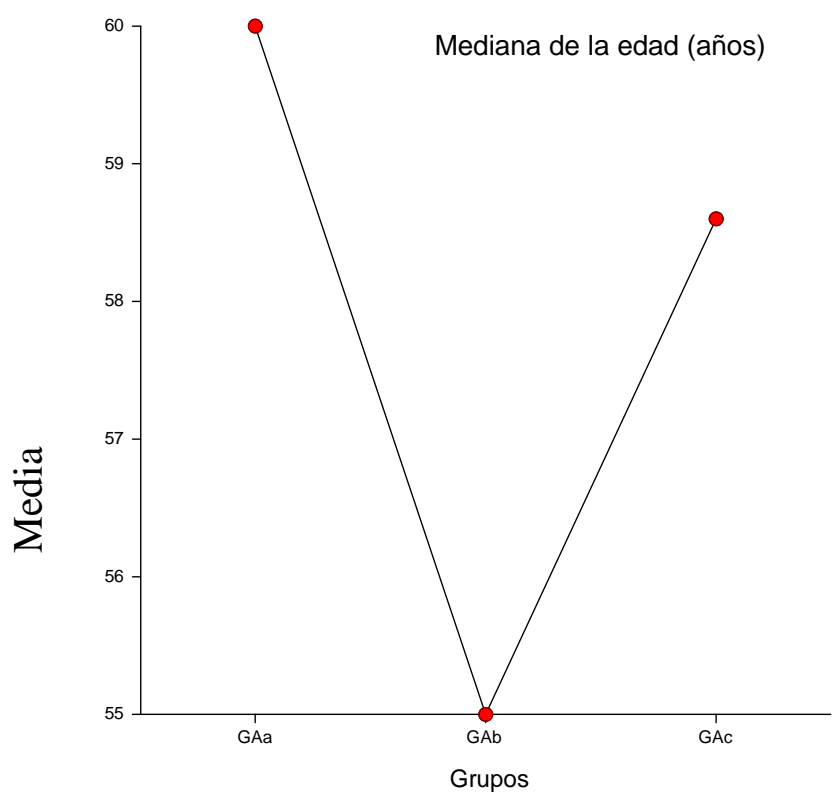

Figura 15. Media de la edad en los grupos.

\subsection{Edad en grupo GB.}

La edad media fue 57.50 años, SD 12.96, mediana 59, rango 58-74 (figura 16).

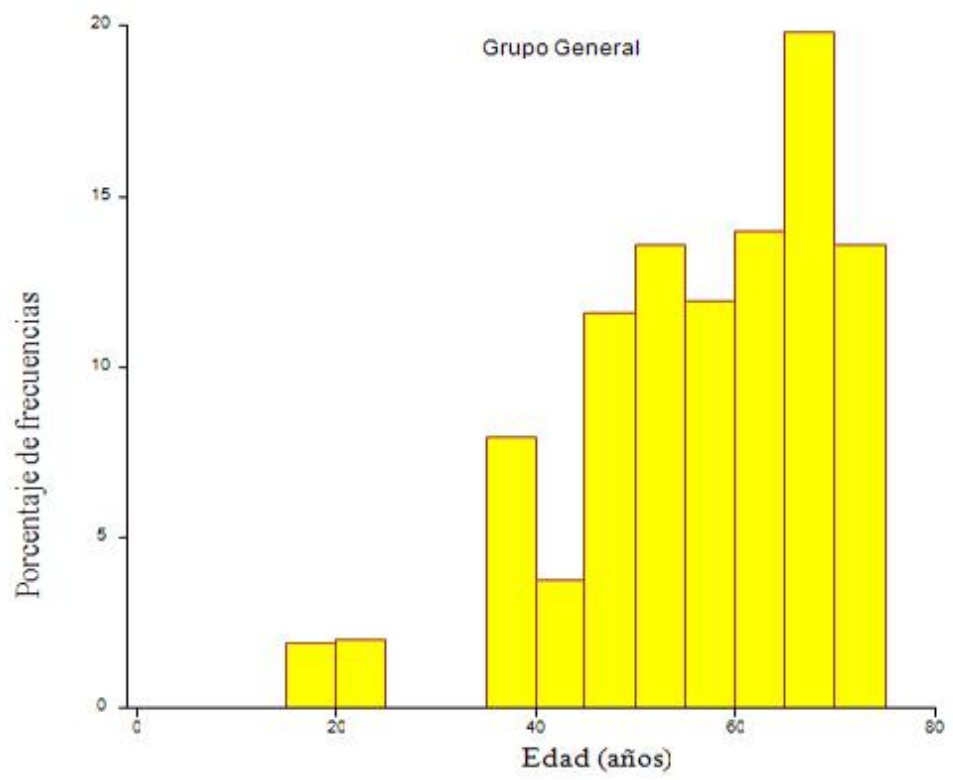

Figura 16. Distribución de la edad en la muestra general GB 
1. La tabla 9 y las figuras 17 y 18 muestran la edad en los grupos. La edad en $\mathrm{GBb}$ fue inferior ( $\mathrm{p}=0.004$ ). La edad en el subgrupo $\mathrm{GBc}$ fue superior, la edad influye en el fracaso al tratamiento de la disfunción eréctil en varones no diabéticos con diagnósticos secundarios $(\mathrm{p}=0.004)$.

\begin{tabular}{|l|l|l|l|l|}
\hline Grupo & Edad media & SD & Mediana & Rango \\
\hline $\mathrm{GBa}$ & 56.94 & 13.97 & 60 & $16-74$ \\
\hline $\mathrm{GBb}$ & 55.99 & 12.76 & 55 & $24-72$ \\
\hline $\mathrm{GBc}$ & 59.88 & 10.89 & 63 & $40-74$ \\
\hline
\end{tabular}

Tabla 9. Edad en Gba, Gbb Y Gbc.

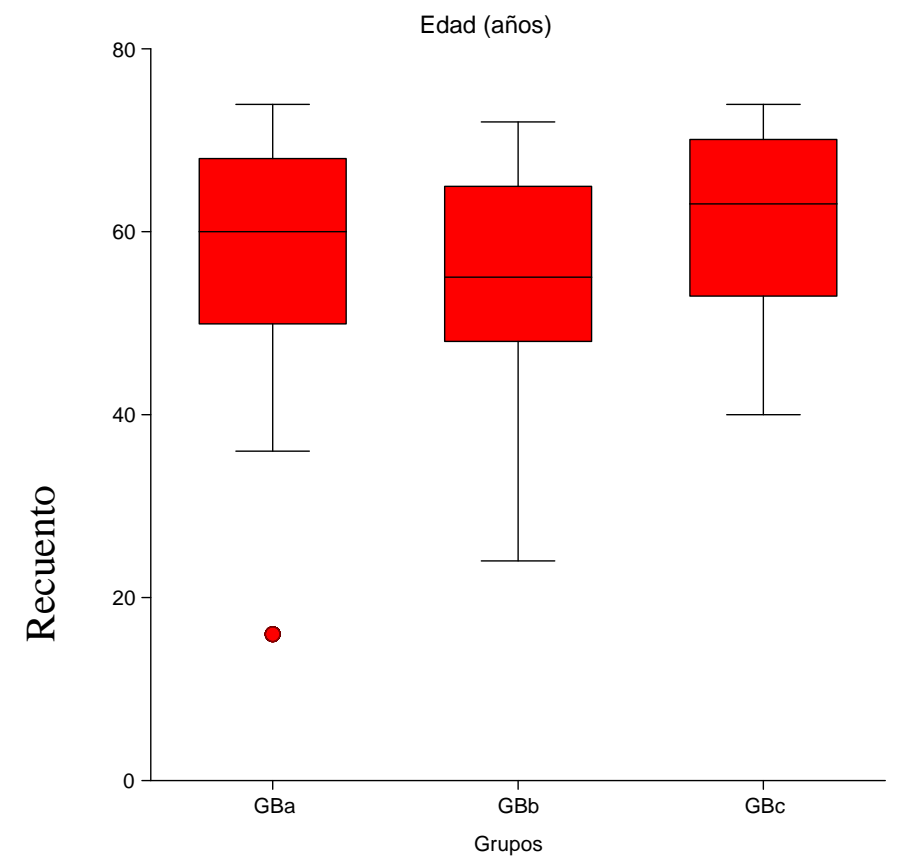

Figura 17. Distribución de la edad. 
RESULTADOS

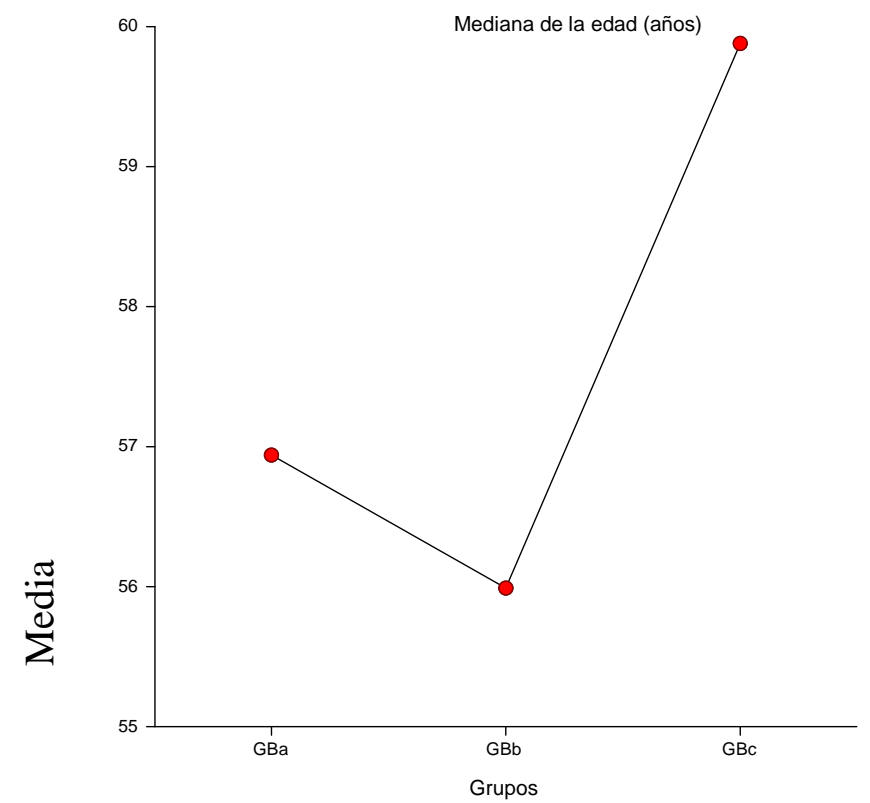

Figura 18. Media de la edad en los grupos.

\subsection{Edad en subgrupos GAa, GBa, GCa.}

La edad media fue 40.74 años, SD 21.72, mediana 47, rango 18-74 (figura 19).

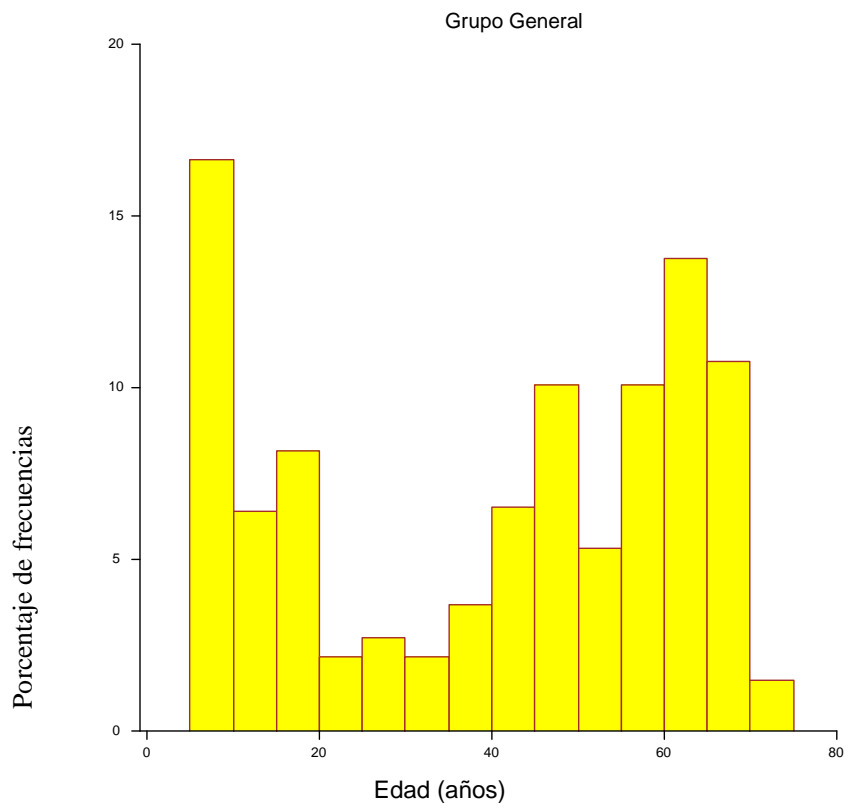

Figura 19. Distribución de la edad en la muestra general. 
1. La tabla 10 y las figuras 20 y 21 muestran la edad en los grupos. La edad en GCa fue inferior ( $\mathrm{p}=0.028$ ). La edad en GCa fue inferior, los varones que consultan con solo disfunción eréctil sin ninguna otra patología y con resultado exitoso fueron mas jóvenes ( $\mathrm{p}=0.028)$.

\begin{tabular}{|l|l|l|l|l|}
\hline Grupo & Edad media & SD & Mediana & Rango \\
\hline GAa & 57.63 & 12.73 & 57 & $16-74$ \\
\hline GBa & 56.22 & 10.53 & 59 & $16-74$ \\
\hline GCa & 56.18 & 8.87 & 59 & $42-66$ \\
\hline
\end{tabular}

Tabla 10. Edad en GAa, GBa y GCa.

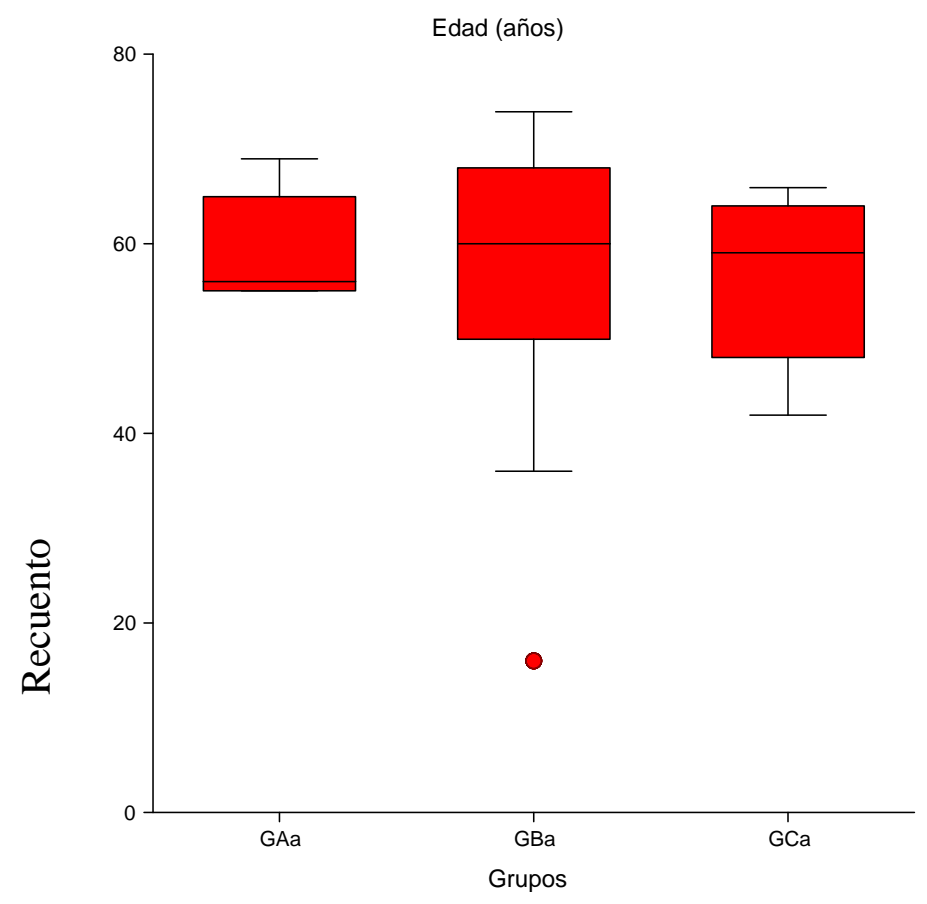

Figura 20. Distribución de la edad. 


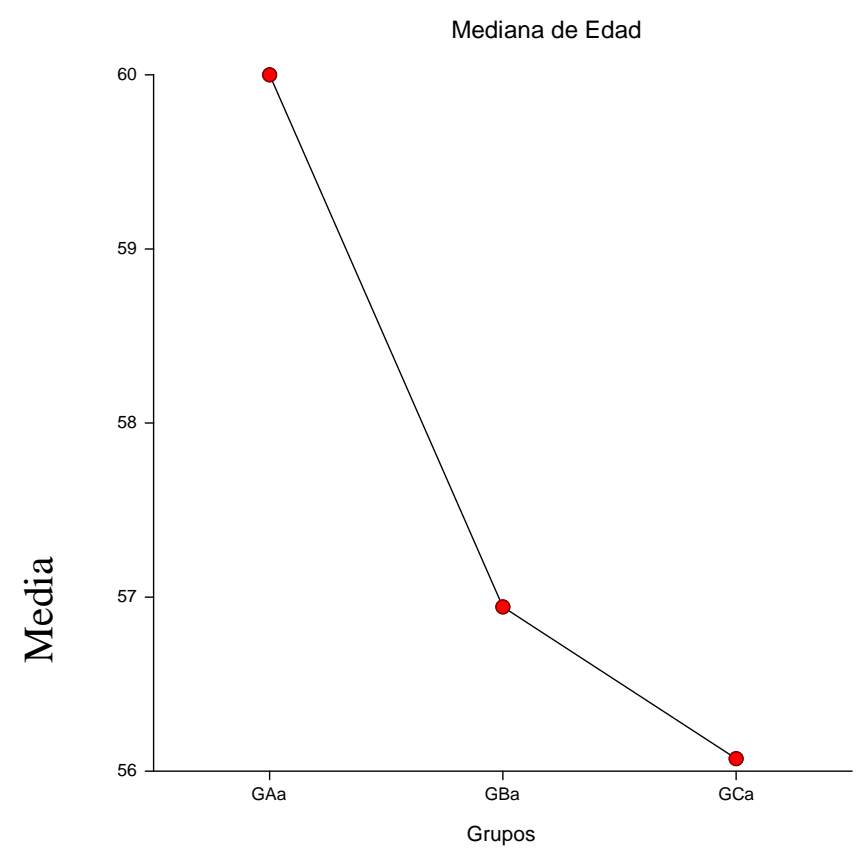

Figura 21. Media de la edad en los grupos.

\subsection{Edad en subgrupo GAm, GAo, GAc}

La tabla 11 y las figuras 22 y 23 muestran la edad en los grupos. La edad en GAo fue inferior $(\mathrm{p}=0.00001)$.

\begin{tabular}{|l|l|l|l|l|}
\hline Grupo & Edad media & SD & Mediana & Rango \\
\hline GAm & 58.95 & 3.69 & 56 & $56-65$ \\
\hline GAo & 50.5 & 4.57 & 50.5 & $46-55$ \\
\hline GAc & 59.66 & 8.94 & 58 & $50-73$ \\
\hline
\end{tabular}

Tabla 11. Edad en GAm, GAo y GAc. 


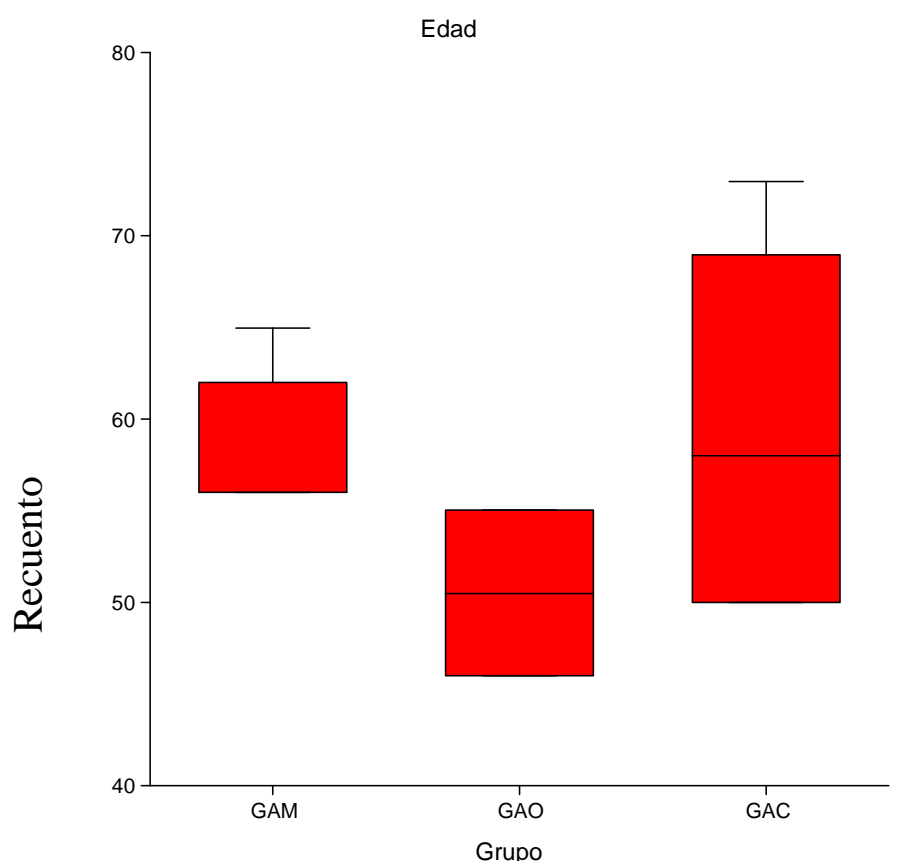

Figura 22. Distribución de la edad.

Mediana de la edad

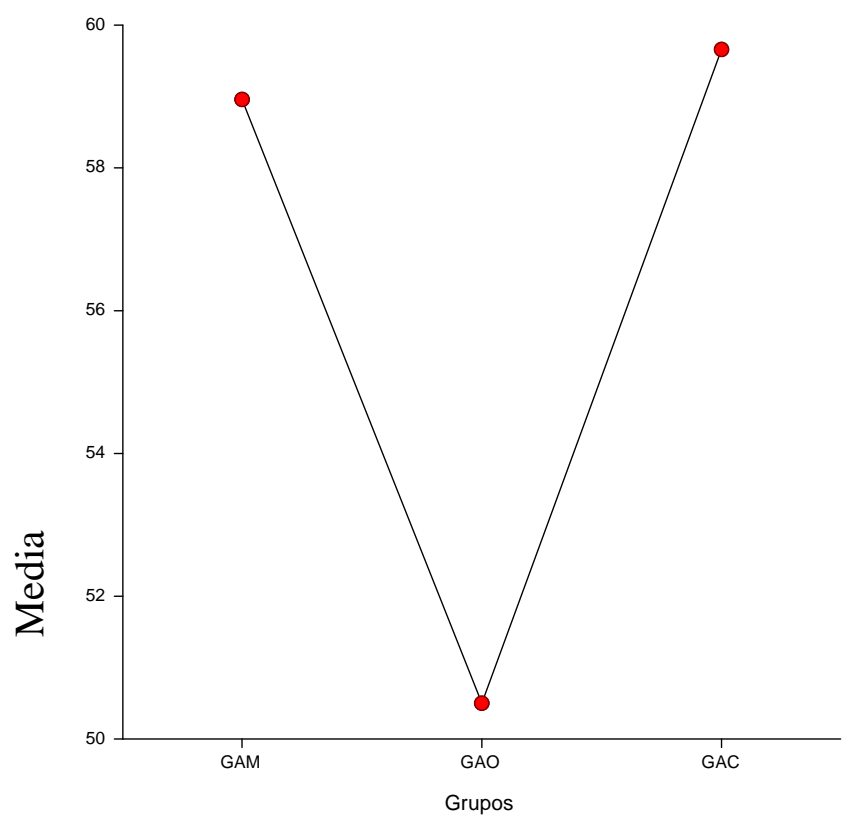

Figura 23. Media de la edad en los grupos. 


\subsection{Edad en subgrupo GAm.}

La edad media fue 58.95 años, SD 3.69, mediana 56, rango 56-65 (figura 24).

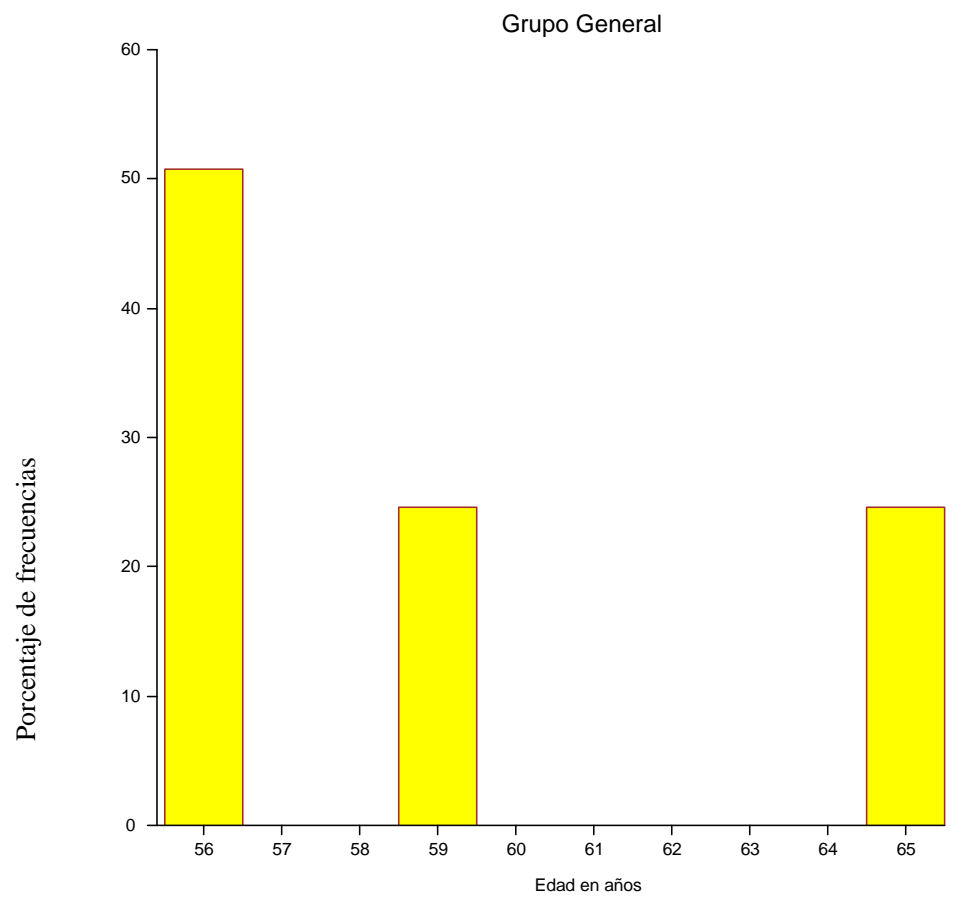

Figura 24. Distribución de la edad en la muestra general.

\subsubsection{Edad en subgrupos GAma, GAmb, GAmc.}

La tabla 12 y la figura 25 muestran la edad en los grupos. La edad en GAmc fue inferior $(\mathrm{p}=0.00018)$.

\begin{tabular}{|l|l|l|l|l|}
\hline Grupo & Edad media & SD & Mediana & Rango \\
\hline GAma & 58.95 & 3.69 & 56 & $56-65$ \\
\hline GAmb & 59 & 0 & 59 & $59-59$ \\
\hline GAmc & 56 & 0 & 56 & $56-56$ \\
\hline
\end{tabular}

Tabla 12. Edad en GAMa, GAMb, GAMc. 


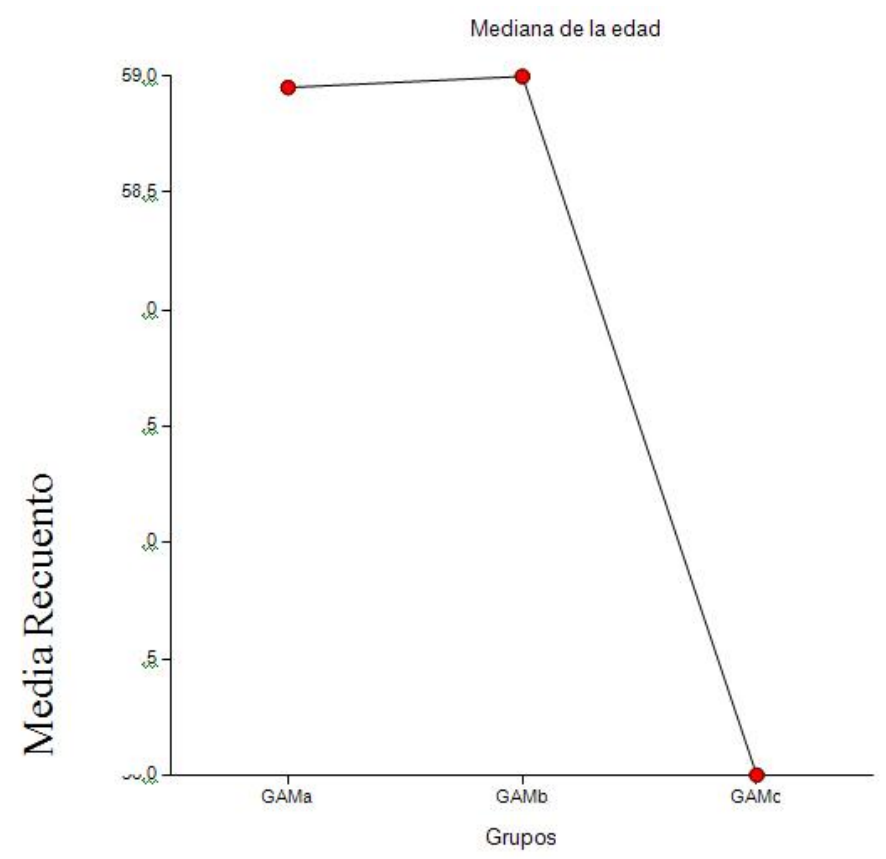

Figura 25. Media de la edad en los subgrupos.

\subsection{Edad en subgrupo GAo.}

La edad media fue 50.15 años, SD 4.52, mediana 46, rango 46-55 (figura 33).

\subsubsection{Edad en subgrupo GAoa, GAob, GAoc.}

La tabla 13 muestra la edad en los grupos. La edad en GAOc fue inferior $(\mathrm{p}=0.00001)$.

\begin{tabular}{|l|l|l|l|l|}
\hline Grupo & Edad media & SD & Mediana & Rango \\
\hline GAOa & 50.5 & 4.57 & 50.5 & $46-55$ \\
\hline GAOc & 46 & 0 & 46 & $46-46$ \\
\hline
\end{tabular}

Tabla 13. Edad en GAOa, GAOb y GAOc.

\subsection{Edad en subgrupo GAc.}

La edad media fue 59.66 años, SD 8.94, mediana 58, rango 50-73 (figura 26). 


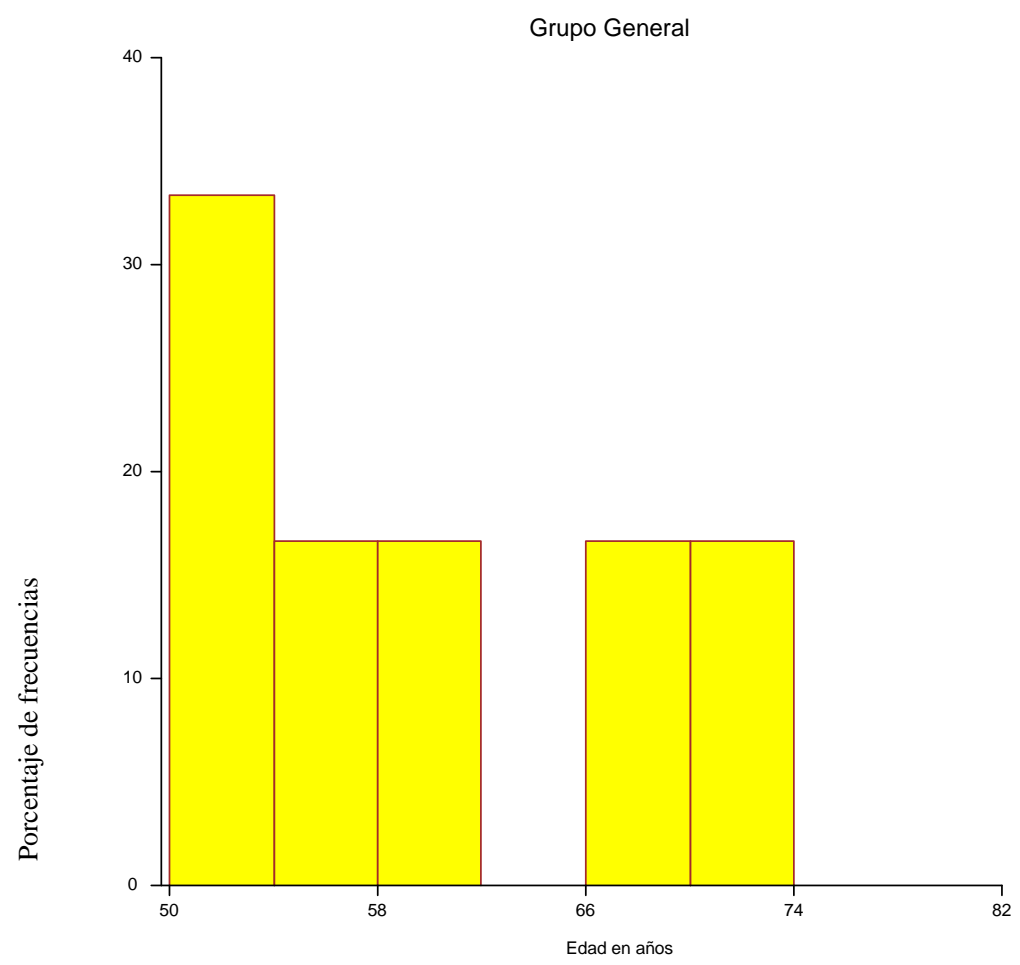

Figura 26. Distribución de la edad en la muestra general.

\subsubsection{Edad en subgrupos GAca, GAcb, GAcc.}

La tabla 14 y las figuras 27 y 28 muestran la edad en los grupos. No hubo diferencias en los subgrupos GACa, GACb y GACc ( $p=0.08943)$.

\begin{tabular}{|l|l|l|l|l|}
\hline Grupo & Edad media & SD & Mediana & Rango \\
\hline GACa & $\mathbf{5 9 . 7 8}$ & $\mathbf{8 . 9 4}$ & $\mathbf{5 8}$ & $\mathbf{5 0 - 7 3}$ \\
\hline GACb & $\mathbf{5 9 . 2 0}$ & $\mathbf{8 . 9 3}$ & $\mathbf{5 5}$ & $\mathbf{5 0 - 7 3}$ \\
\hline GACc & $\mathbf{6 0 . 3 6}$ & $\mathbf{9 . 4 1}$ & $\mathbf{6 1}$ & $\mathbf{5 0 - 7 3}$ \\
\hline
\end{tabular}

Tabla 14. Edad en GACa, GACb y GACc. 


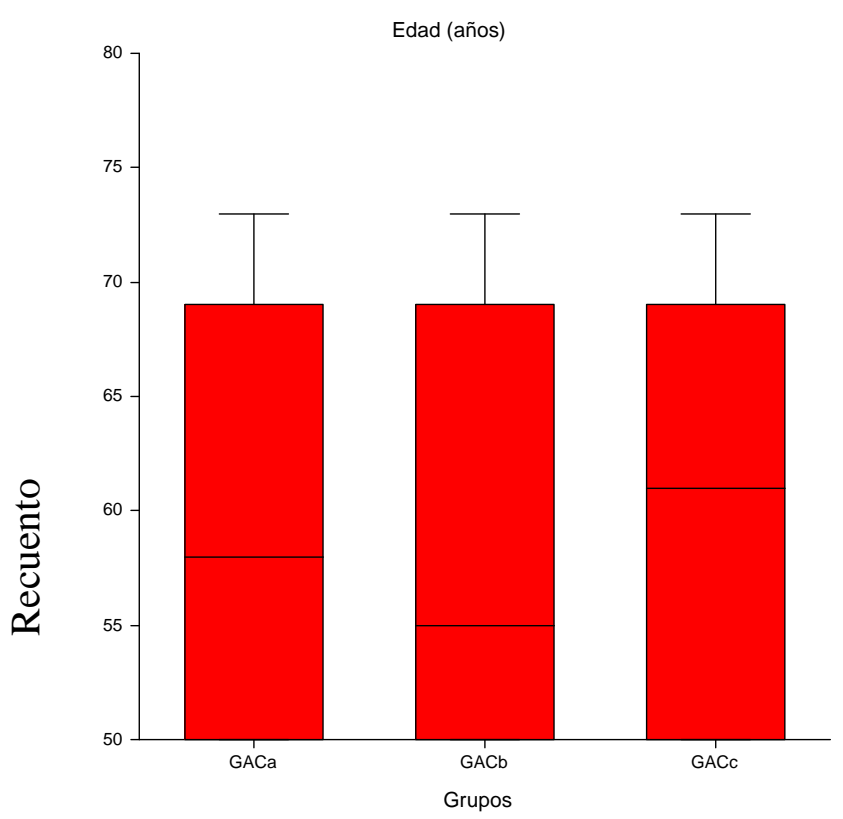

Figura 27. Distribución de la edad.

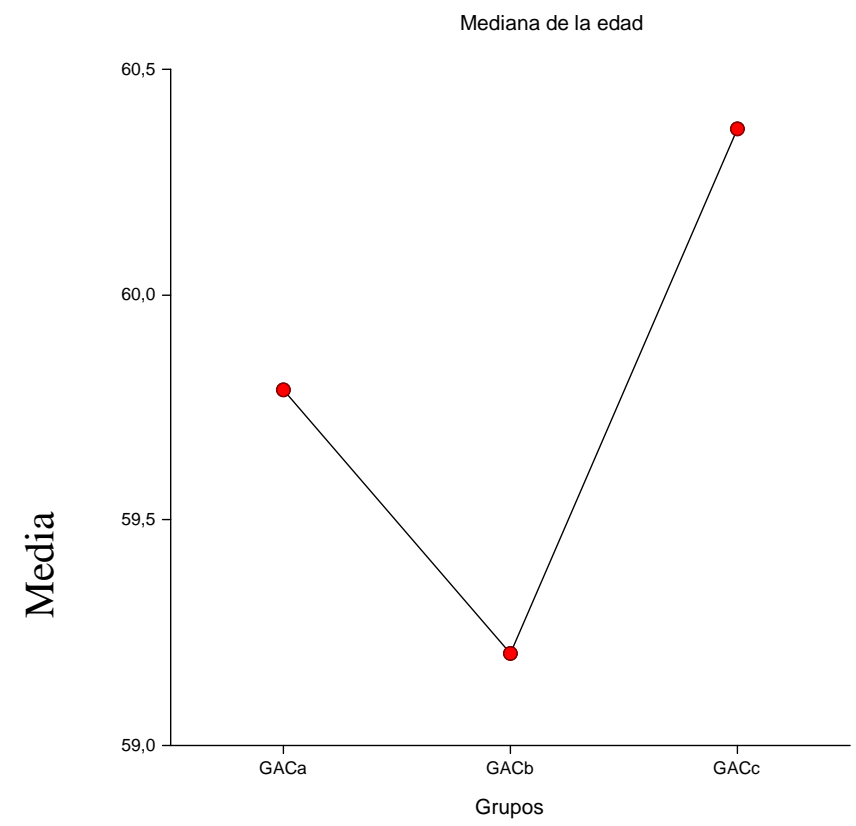

Figura 28. Media de la edad en los subgrupos. 


\section{TIEMPO DE CONTROL EVOLUTIVO, EN MESES, DESPUÉS DE INSTAURAR EL TRATAMIENTO DE LA DISFUNCIÓN ERECTIL.}

2.01. Tiempo de control evolutivo, en meses, después de instaurar el tratamiento de la Disfunción erectil en muestra general

Grupo general (GG) y comparación entre grupos de pacientes masculinos con disfunción eréctil con diabetes mellitus (GA), con diagnósticos secundarios sin diabetes mellitus (GB) y sin diagnósticos secundarios (GC) en el Tiempo de control evolutivo, en meses, después de instaurar el tratamiento de la Disfunción erectil.

El tiempo medio fue 22.79 meses, SD 12.89, mediana 19, rango 8-71 (figura 29).

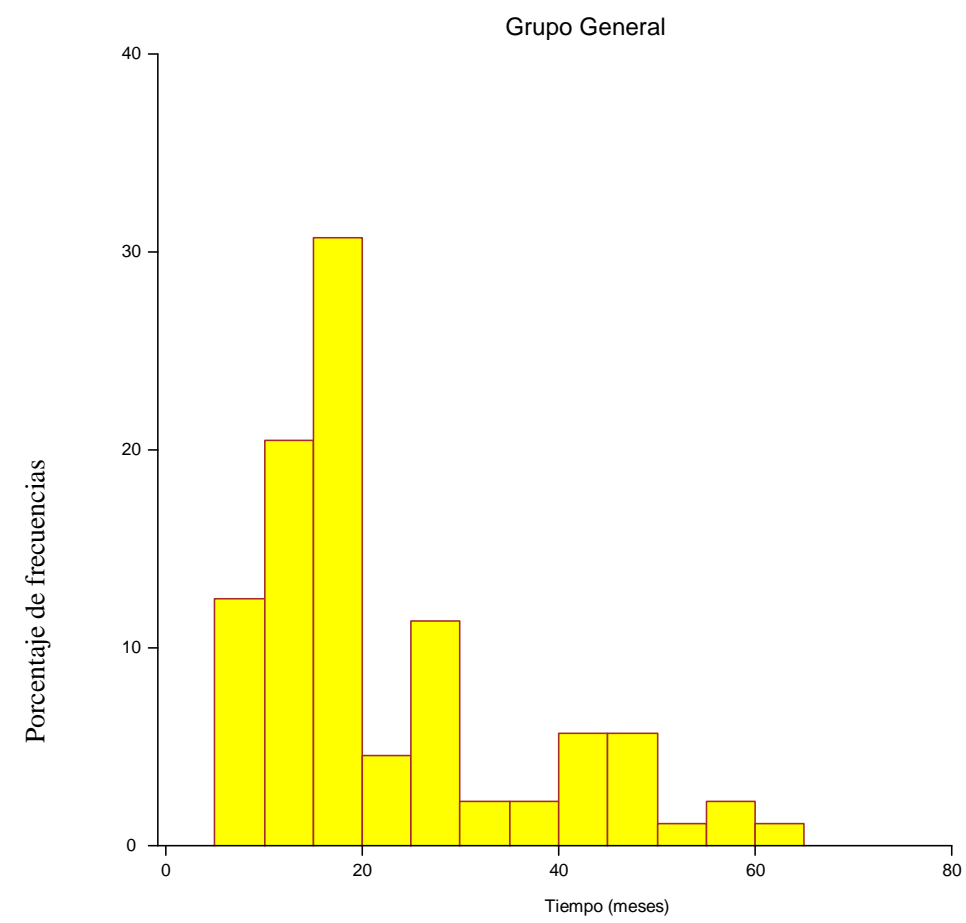

Figura 29. Distribución del tiempo en la muestra general. 
2.02. Tiempo de control evolutivo, en meses, después de instaurar el tratamiento de la Disfunción erectil en Subgrupos GA, GB y GC.

La tabla 15 y las figuras 30 y 31 muestran el tiempo en los grupos. El tiempo de control evolutivo, en meses, después de instaurar el tratamiento de la Disfunción erectil en GC fue inferior ( $\mathrm{p}=0.0001)$.

\begin{tabular}{|l|l|l|l|l|}
\hline Grupo & Tiempo medio & Sd & Mediana & Rango \\
\hline GA & 24.55 & 13.83 & 18 & $11-46$ \\
\hline GB & 26.57 & 13.00 & 20 & $8-61$ \\
\hline GC & 15.64 & 7.97 & 12 & $8-37$ \\
\hline
\end{tabular}

Tabla 15. Tiempo de control evolutivo en GA GB y GC

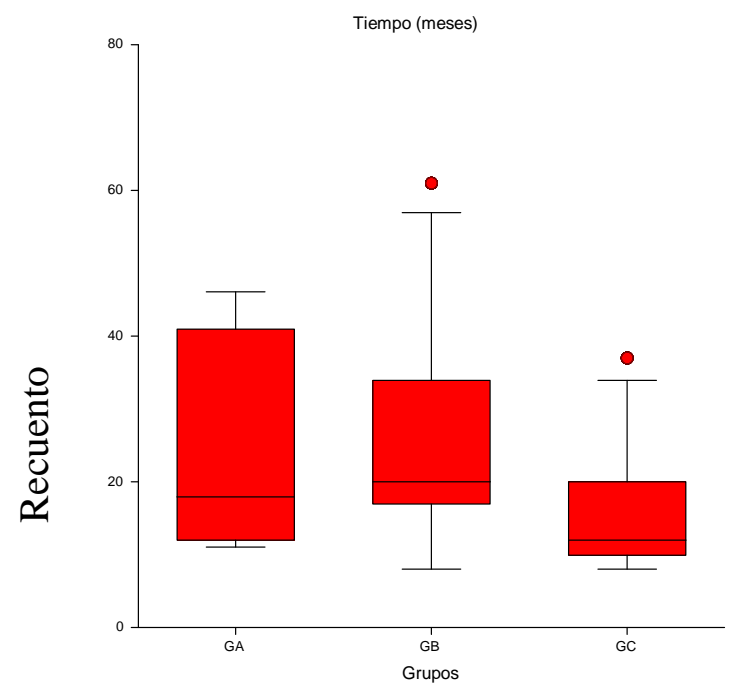

Figura 30. Distribución del tiempo (meses). 


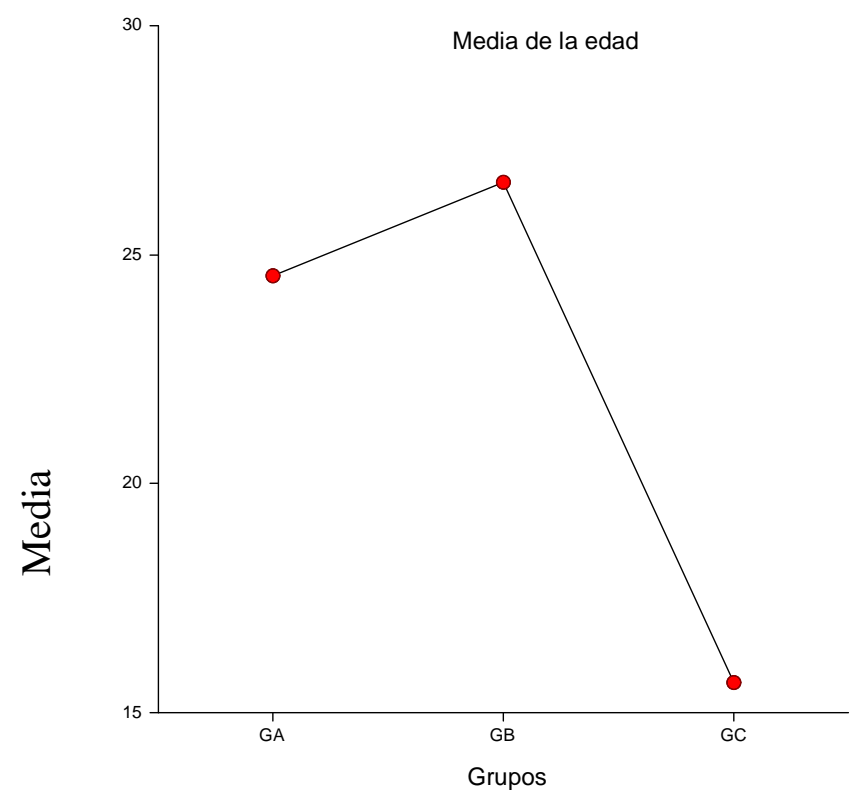

Figura 31. Media del tiempo en los grupos.

2.03. Tiempo de control evolutivo, en meses, después de instaurar el tratamiento de la Disfunción erectil en grupo GA.

El tiempo medio fue 24 meses, SF 13.83, mediana 18, rango 11-46.

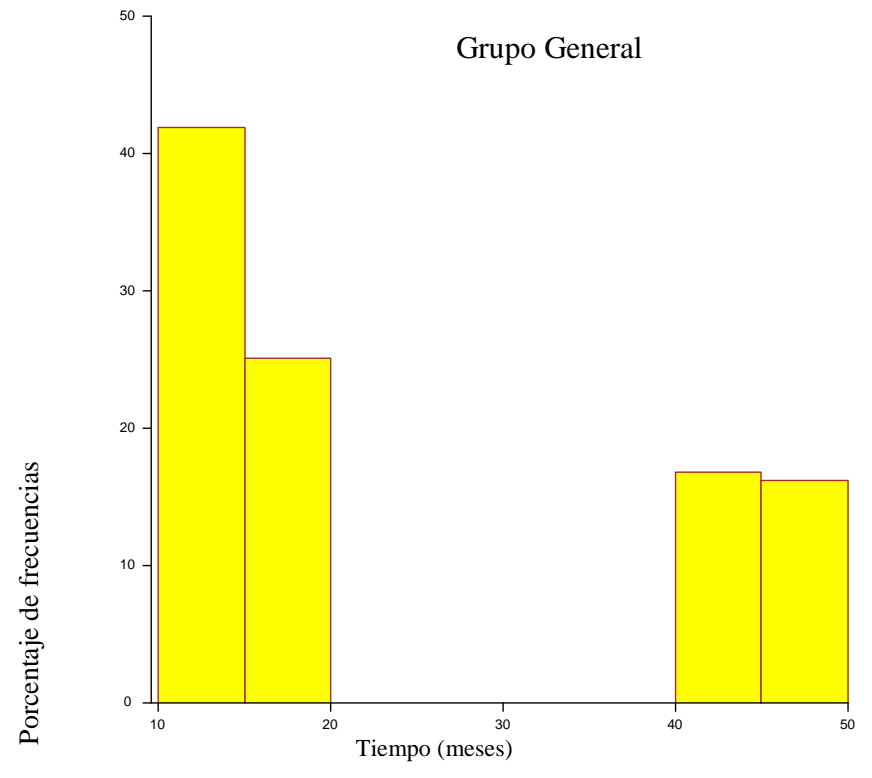

Figura 32. Distribución del tiempo en la muestra general. 
2.04. Tiempo de control evolutivo, en meses, después de instaurar el tratamiento de la Disfunción erectil en subgrupos GAa, GAb y GAc.

Comparación entre grupos de pacientes masculinos con disfunción eréctil con diabetes mellitus (GA) y con tratamiento exitoso (GAa), parcial (GAb) y fracaso (GAc).

El tiempo de control evolutivo tras la instauración del tratamiento de Disfunción eréctil fue inferior en el subgrupo GAa respecto a GAb y GAc, pacientes con Diabetes Mellitus con éxito pero con mínimo de 11 meses de seguimiento $(\mathrm{P}=0.0001)$.

\begin{tabular}{|l|l|l|l|l|}
\hline Grupo & Tiempo medio & SD & Mediana & Rango \\
\hline GAa & 13.2 & 2.49 & 12 & $11-18$ \\
\hline GAb & 37.25 & 10.21 & 41.5 & $20-46$ \\
\hline GAc & 26.59 & 13.58 & 20 & $15-46$ \\
\hline
\end{tabular}

Tabla 16. Tiempo en GAa. GAb y GAc.

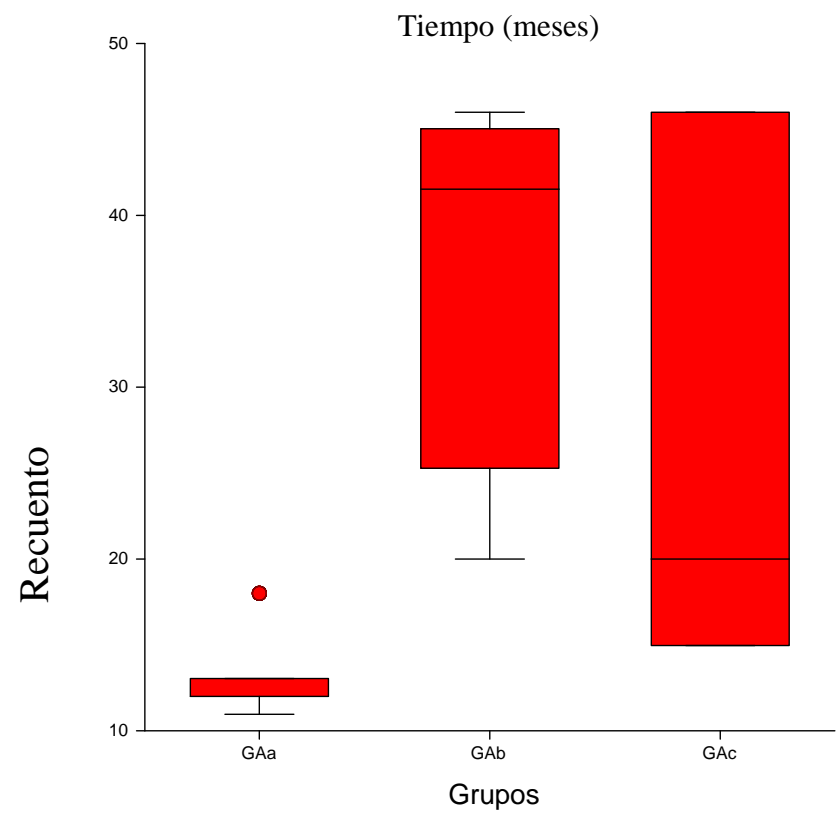

Figura 33. Distribución del tiempo (meses). 


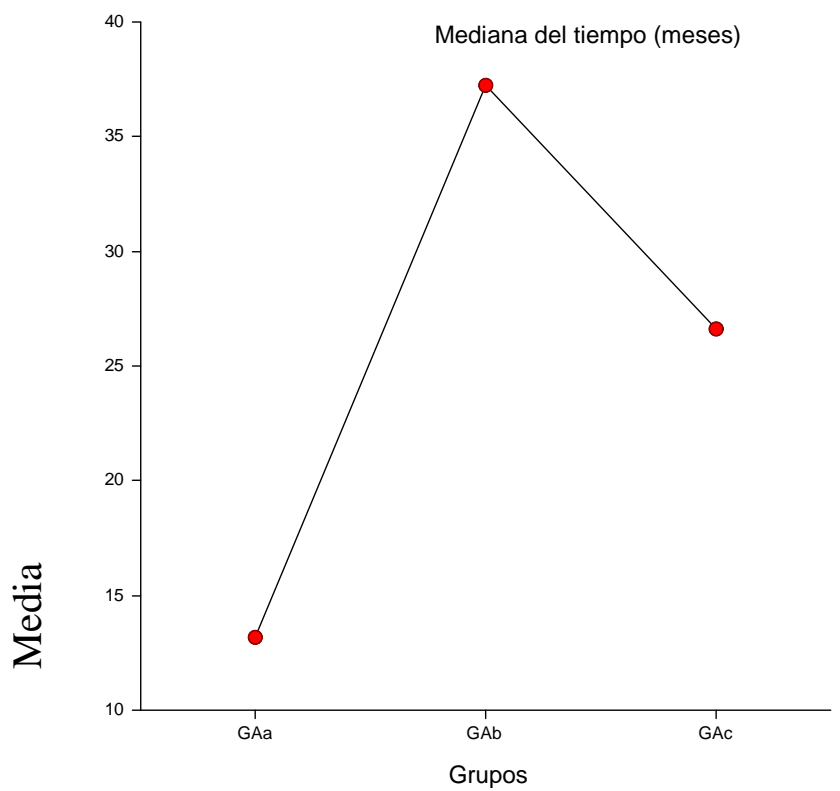

Figura 34. Media del tiempo en los subgrupos.

2.05. Tiempo de control evolutivo, en meses, después de instaurar el tratamiento de la Disfunción erectil en grupo GB.

El tiempo medio fue 26.57 meses, SD 13,00, mediana 20, rango 8-61 (figura 35).

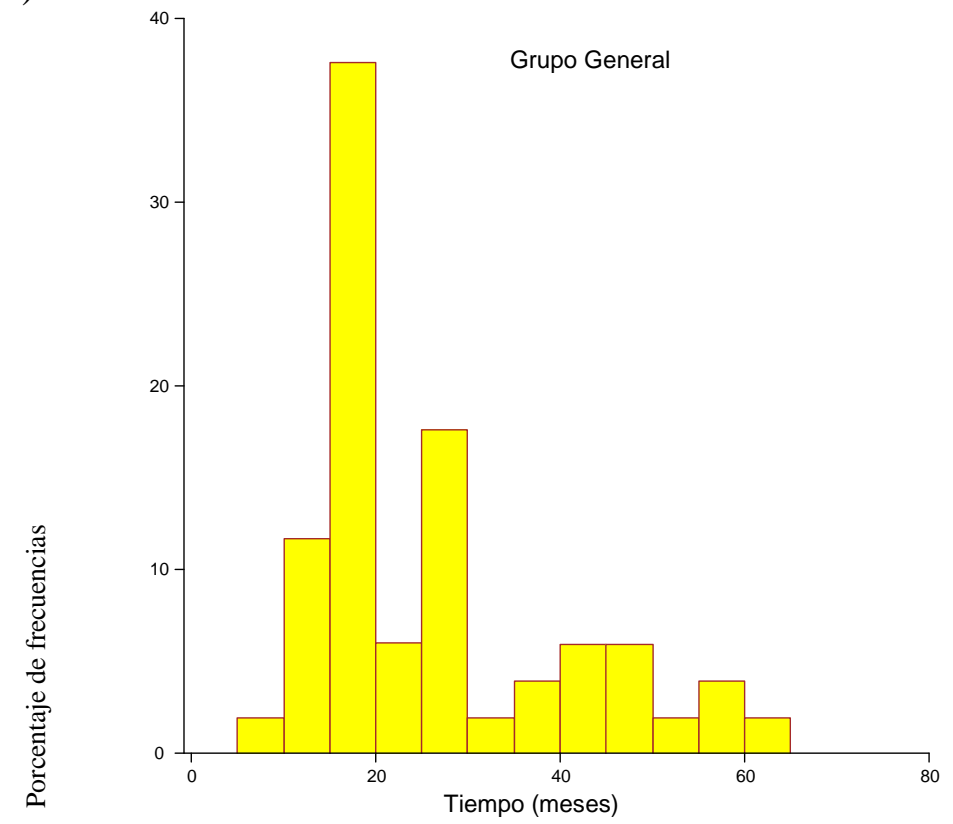

Figura 35. Distribución del tiempo en la muestra general. 
La tabla 17 y las figuras 36 y 37 muestran el tiempo en los grupos. El tiempo de control evolutivo después de instaurar el tratamiento en GBb fue inferior $(\mathrm{p}=0.00002)$.

\begin{tabular}{|l|l|l|l|l|}
\hline Grupo & Tiempo medio & SD & Mediana & Rango \\
\hline$\underline{\text { GBa }}$ & 27.41 & 13.40 & 20 & $14-61$ \\
\hline$\underline{\text { GBb }}$ & 22.99 & 8.46 & 20 & $14-41$ \\
\hline$\underline{\text { GBc }}$ & 28.45 & 15.03 & 23 & $8-56$ \\
\hline
\end{tabular}

Tabla 17. Tiempo en $G B a$. GBb y $G B c$.

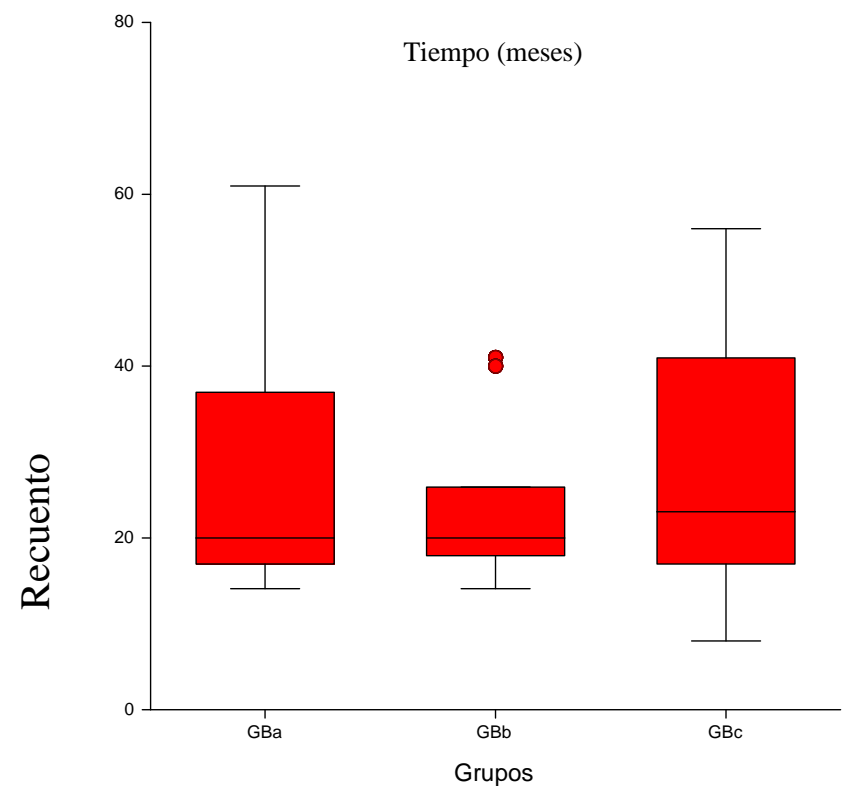

Figura 36. Distribución del tiempo (meses). 


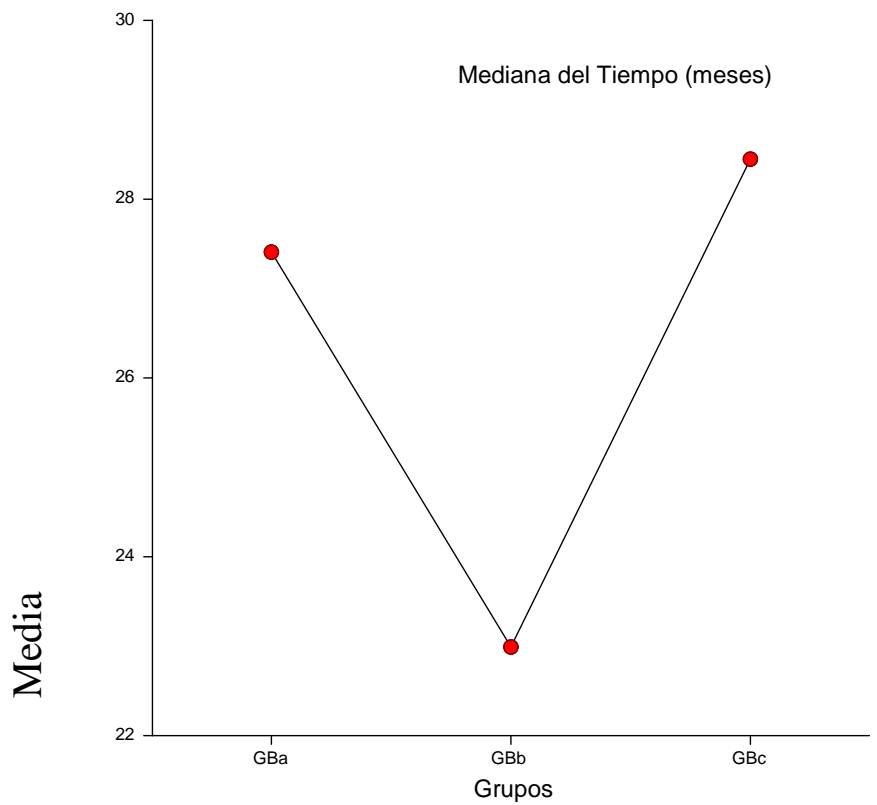

Figura 37. Media del tiempo en los subgrupos.

2.06. Tiempo de control evolutivo, en meses, después de instaurar el tratamiento de la Disfunción erectil en subgrupos GAa, GBa, GCa

El tiempo medio fue 21.73 meses, SD 12.48, mediana 18, rango 8-61 (figura 38).

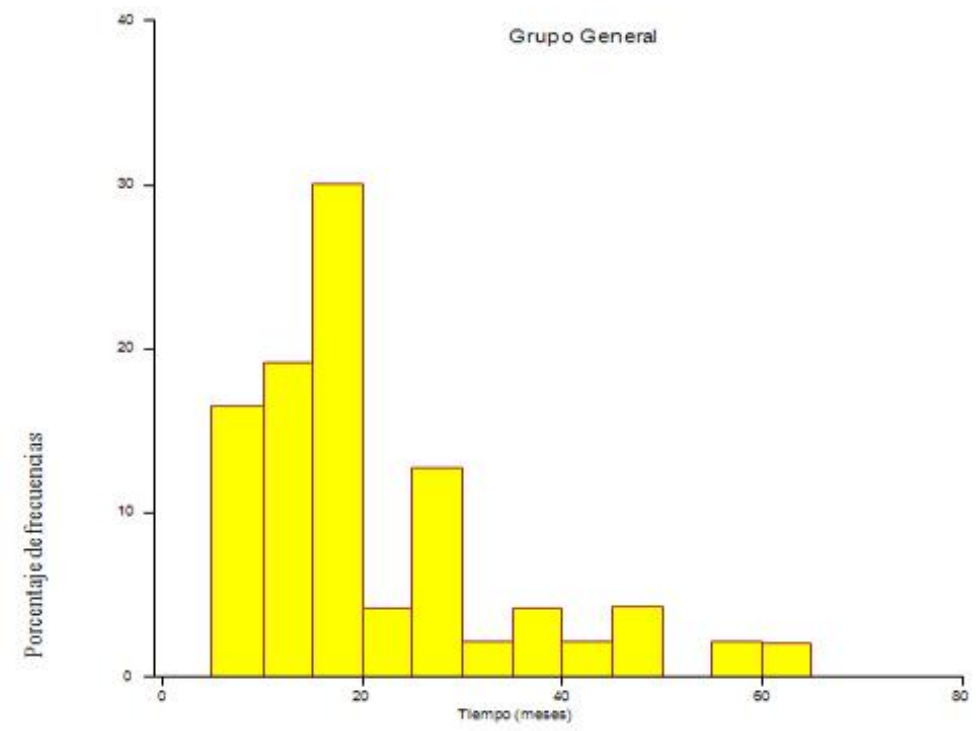

Figura 38. Distribución del tiempo en la muestra general. 
La tabla 18 y las figuras 39 y 40 muestran el tiempo en los grupos. El tiempo de control evolutivo después de instaurar el tratamiento en GAa fue inferior $(\mathrm{p}=0.0001)$.

\begin{tabular}{|l|l|l|l|l|}
\hline Grupo & Tiempo medio & SD & Mediana & Rango \\
\hline GAa & 13.2 & 2.49 & 12 & $11-18$ \\
\hline GBa & 27.41 & 13.40 & 20 & $14-61$ \\
\hline GCa & 16.40 & 8.55 & 14 & $8-37$ \\
\hline
\end{tabular}

Tabla 18. Tiempo de control evolutivo en GAa, GBa y GCa.

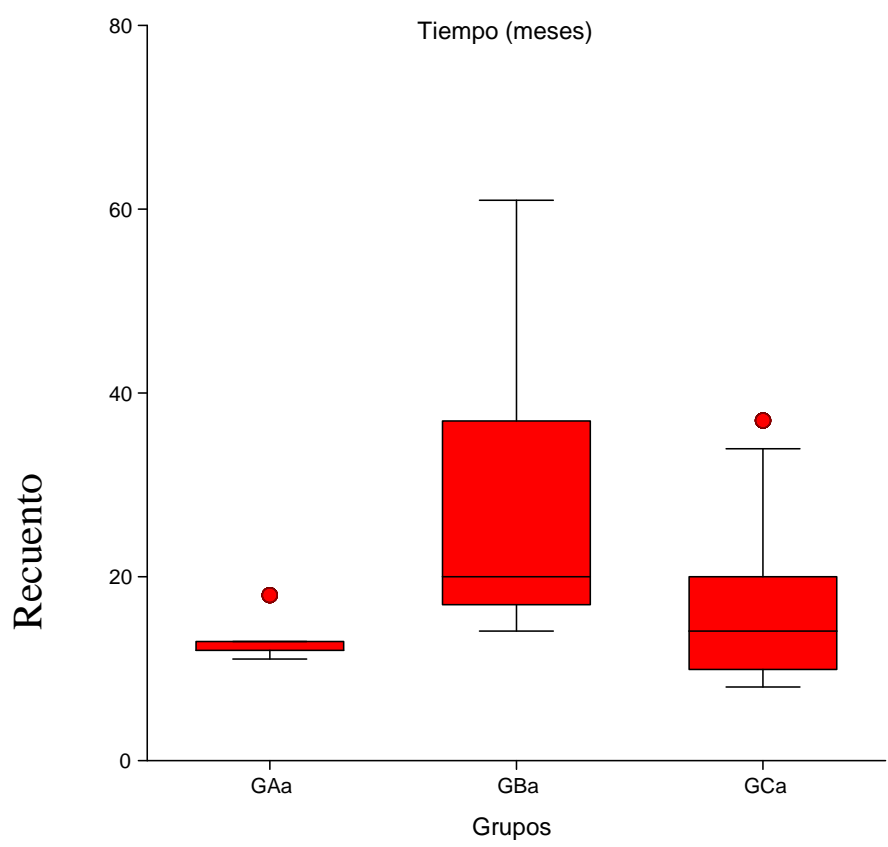

Figura 39. Distribución del tiempo (meses). 


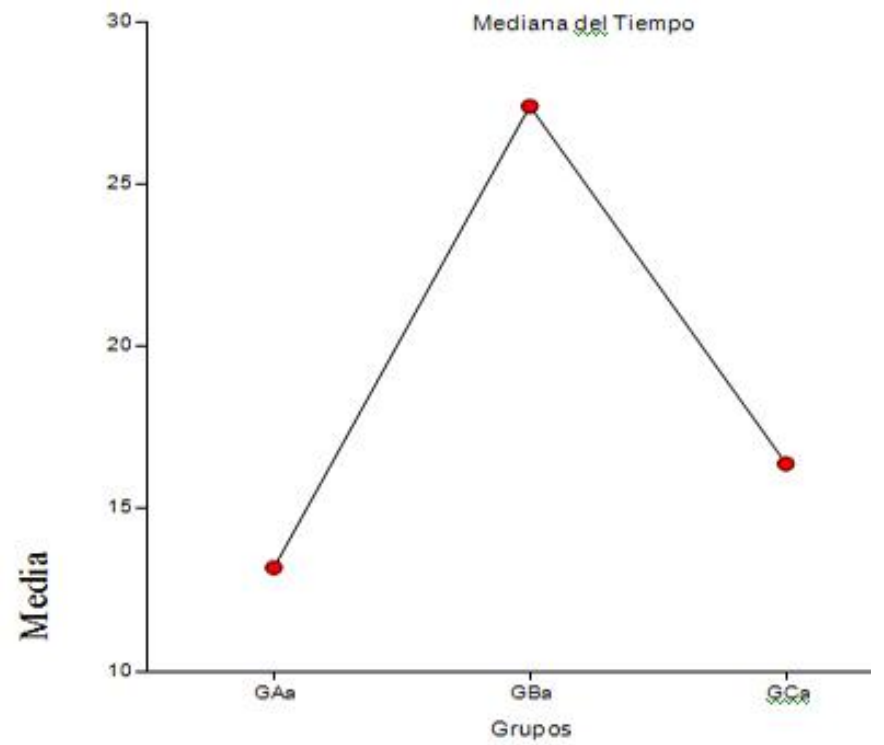

Figura 40. Media del tiempo en los subgrupos.

2.07. Tiempo de control evolutivo, en meses, después de instaurar el tratamiento de la Disfunción erectil en subgrupo GAm, GAo y GAc

El tiempo medio fue 23.70 meses, SD 14.66, mediana 18, rango 8.38-46 (figura 41).

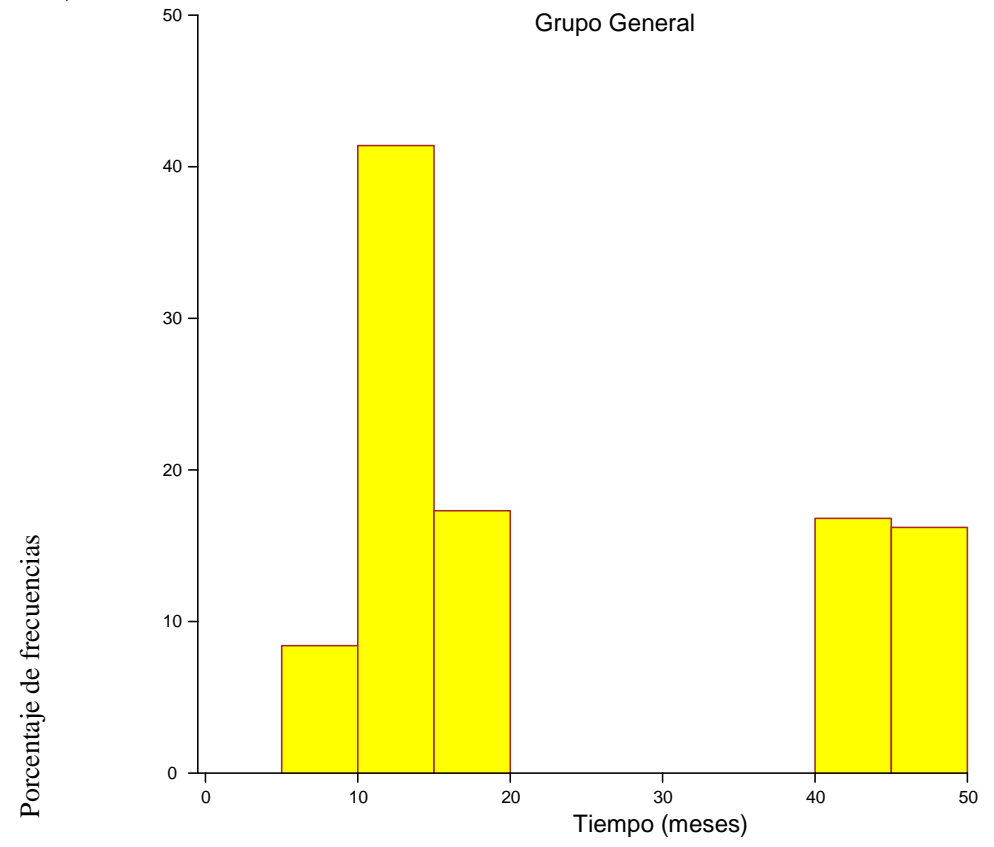

Figura 41. Distribución del tiempo en la muestra general. 
La tabla 19 y las figuras 42 y 43 muestran el tiempo en los grupos. El tiempo después de instaurar el tratamiento de la Disfunción erectil en GAm fue inferior $(\mathrm{p}=0.0001)$.

\begin{tabular}{|l|l|l|l|l|}
\hline Grupo & Tiempo medio & SD & Mediana & Rango \\
\hline GAm & 14.43 & 4.84 & 18 & $8.38-20$ \\
\hline GAo & 29.5 & 16.78 & 29.5 & $13-46$ \\
\hline GAc & 28.16 & 15.33 & 28.5 & $12-46$ \\
\hline
\end{tabular}

Tabla 19. Tiempo en GAm, GAo y GAc.

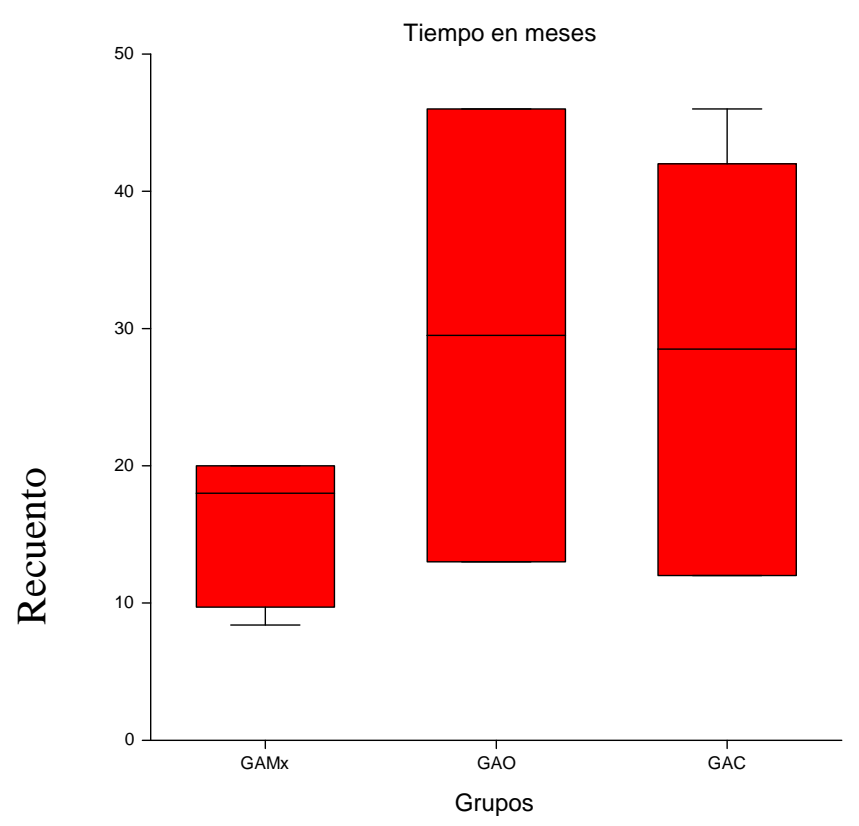

Figura 42. Distribución del tiempo (meses). 


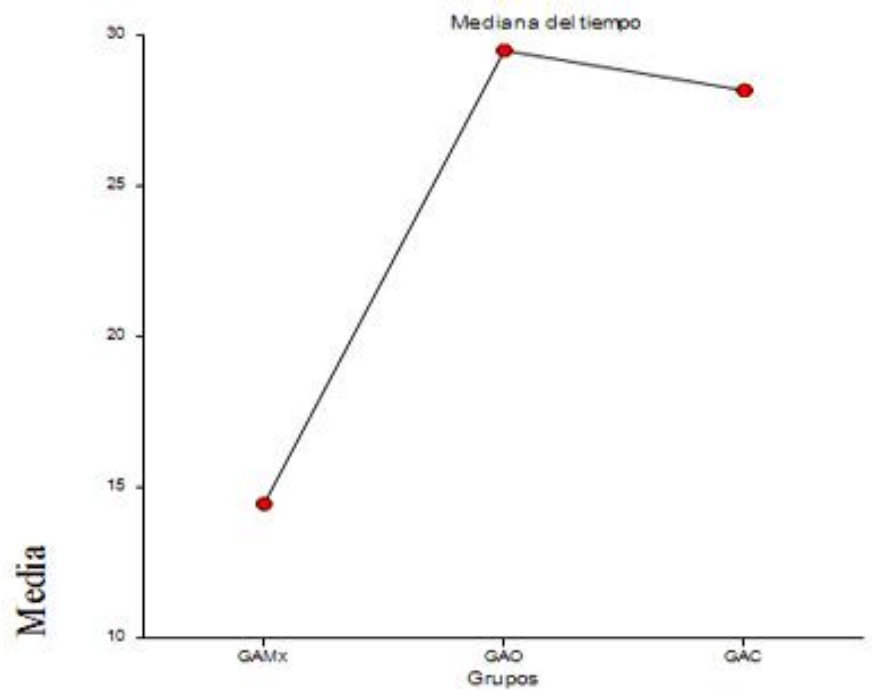

Figura 43. Media del tiempo en los subgrupos.

2.08. Tiempo de control evolutivo, en meses, después de instaurar el tratamiento de la Disfunción erectil en subgrupo GAm.

El tiempo medio fue 14.43 meses, SD 4.84, mediana 18, rango 8.38-20 (figura 44).

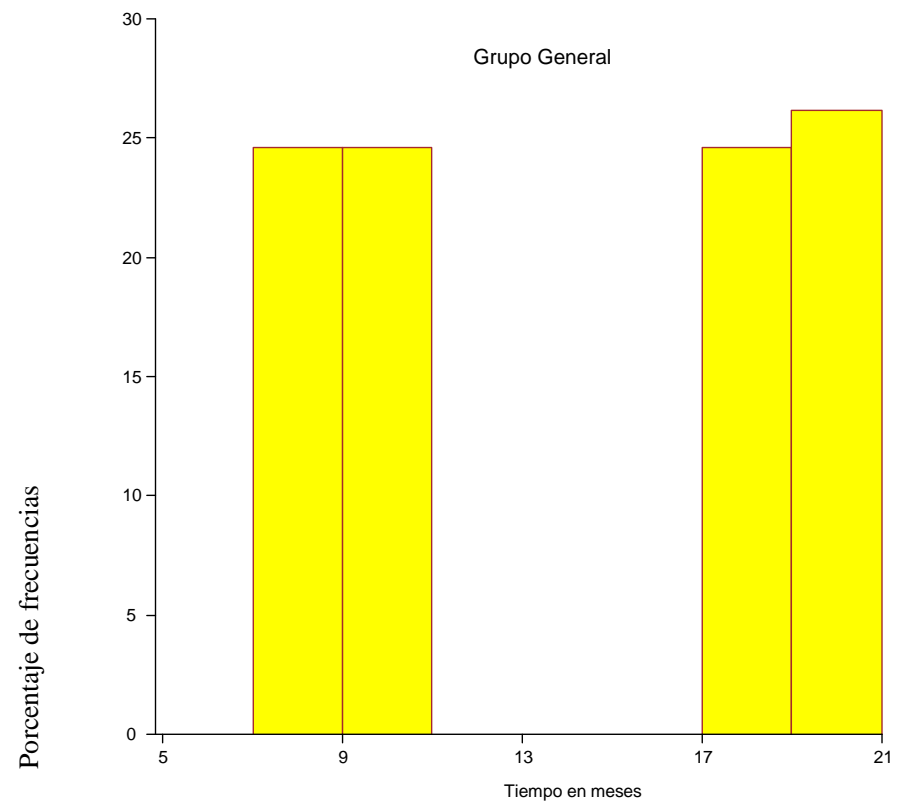

Figura 44. Distribución del tiempo en la muestra general. 
2.08.1. Tiempo de control evolutivo, en meses, después de instaurar el tratamiento de la Disfunción erectil en subgrupos GAma, GAmb, GAmc.

La tabla 20 y la figura 45 muestran el tiempo en los grupos. El tiempo en GAMb fue inferior $(\mathrm{p}=0.0001)$.

\begin{tabular}{|l|l|l|l|l|}
\hline Grupo & Tiempo medio & SD & Mediana & Rango \\
\hline GAma & 14.43 & 4.84 & 18 & $8.38-20$ \\
\hline GAmb & 8.38 & 0 & 8.38 & $8.38-8.38$ \\
\hline GAmc & 20 & 0 & 20 & $20-20$ \\
\hline
\end{tabular}

Tabla 20. Tiempo de control evolutivo en GAma, GAmb, GAmc.

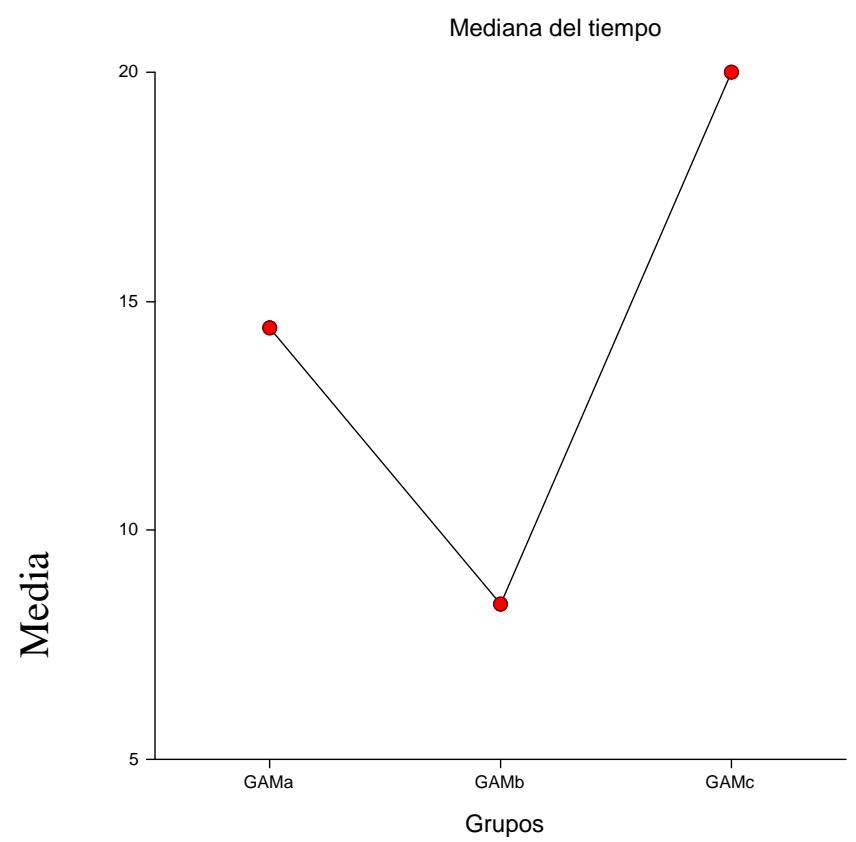

Figura 45. Media del tiempo en los subgrupos.

2.09. Tiempo de control evolutivo, en meses, después de instaurar el tratamiento de la Disfunción erectil en subgrupo GAo.

El tiempo medio fue 22.79 meses, SD 12.89, mediana 19, rango 8-71 (figura 46). 


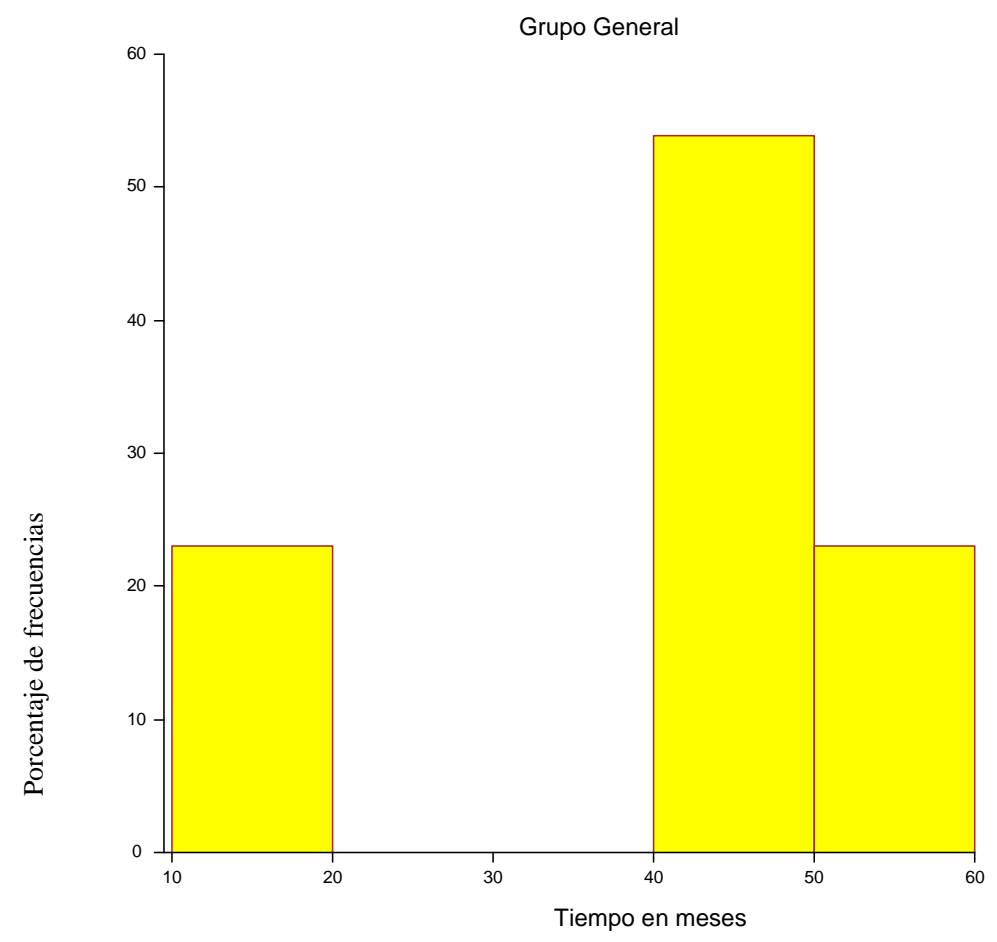

Figura 46. Distribución del tiempo en la muestra general.

2.09.1. Tiempo de control evolutivo, en meses, después de instaurar el tratamiento de la Disfunción erectil en subgrupo GAoa, GAob, GAoc.

La tabla 21 muestra el tiempo en los grupos. El tiempo en GAOa fue inferior $(\mathrm{p}=0.0001)$. No existe grupo GAOb.

\begin{tabular}{|l|l|l|l|l|}
\hline Grupo & Tiempo medio & SD & Mediana & Rango \\
\hline GAoa & 13 & 0 & 13 & $13-13$ \\
\hline GAoc & 46 & 0 & 46 & $46-46$ \\
\hline
\end{tabular}

Tabla 21. Tiempo en GAoa, GAob y GAoc.

2.10. Tiempo de control evolutivo, en meses, después de instaurar el tratamiento de la Disfunción erectil en subgrupo GAc.

El tiempo medio fue 28.14 meses, SD 15.33, mediana 28.5, rango 12-46 (figura 47). 


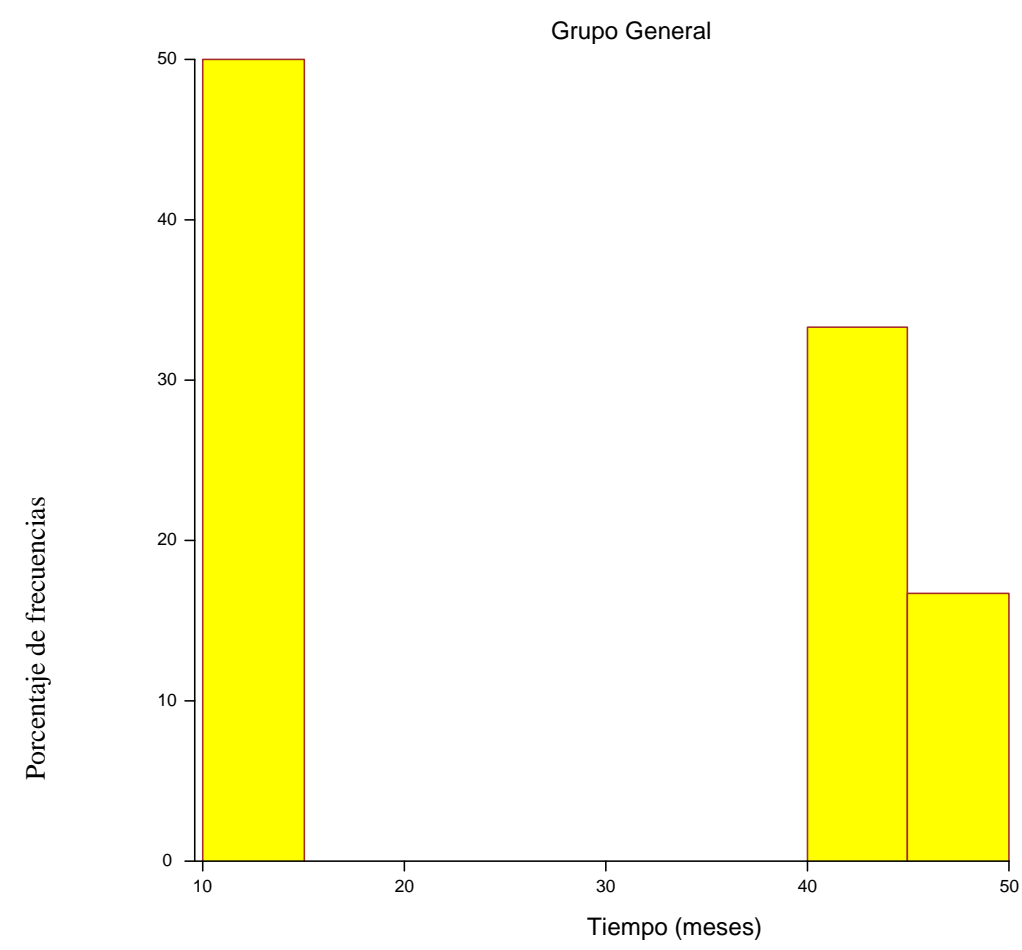

Figura 47. Distribución del tiempo en la muestra general.

2.10.1. Tiempo de control evolutivo, en meses, después de instaurar el tratamiento de la Disfunción erectil en subgrupos GAca, GAcb, GAcc.

La tabla 22 y las figuras 48 y 49 muestran el tiempo en los grupos. No hubo diferencias en los subgrupos GAca, GAcb y GAcc ( $\mathrm{p}=0.8294)$.

\begin{tabular}{|l|l|l|l|l|}
\hline Grupo & Tiempo medio & SD & Mediana & Rango \\
\hline GAca & 27.31 & 15.48 & 15 & $12-46$ \\
\hline GAcb & 29.33 & 15.41 & 42 & $12-46$ \\
\hline GAcc & 27.47 & 15.55 & 15 & $12-46$ \\
\hline
\end{tabular}

Tabla 22. Tiempo en GAca, GAcb y GAcc. 
RESULTADOS

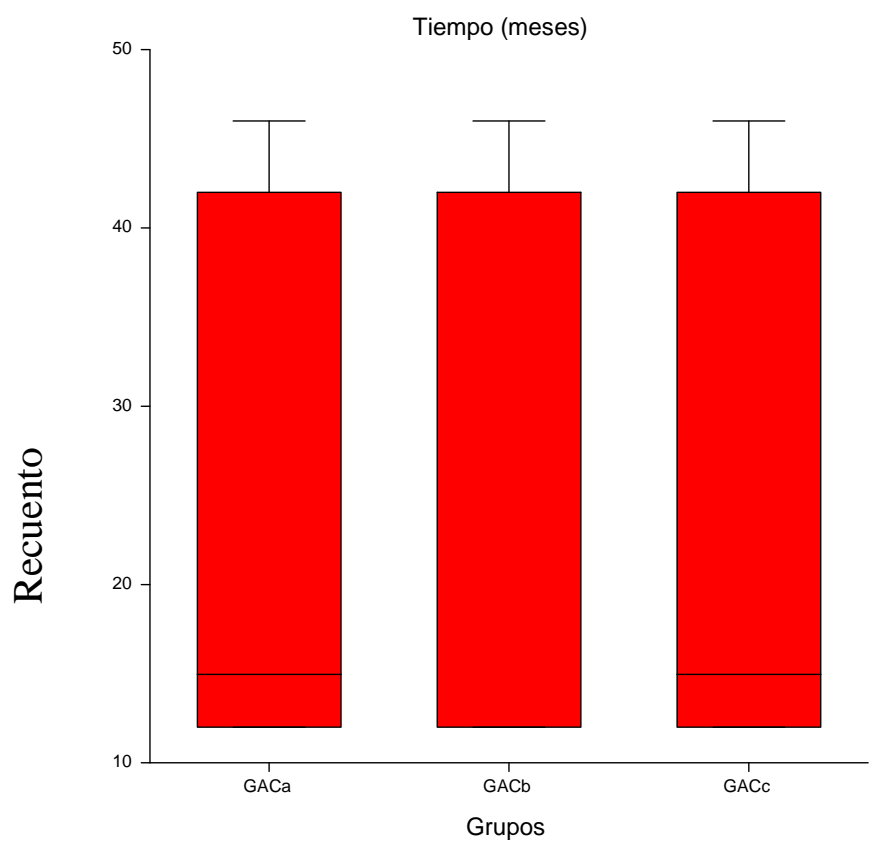

Figura 48. Distribución del tiempo (meses).

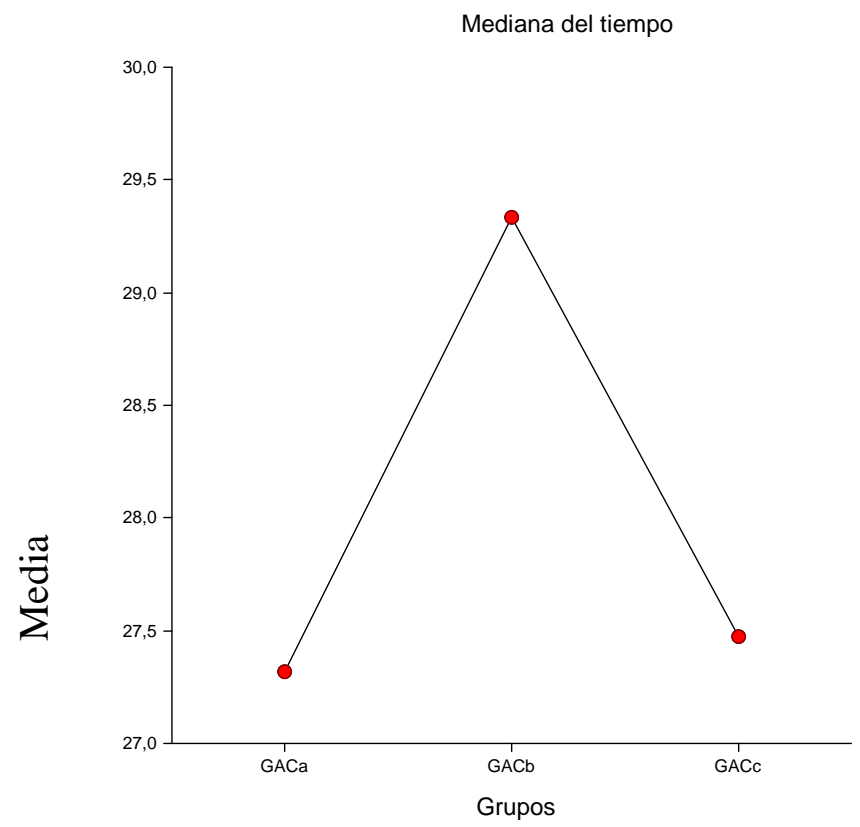

Figura 49. Media del tiempo en los grupos. 


\section{GLUCEMIA}

\subsection{Glucemia en muestra general.}

La media de la glucosa fue 89.75, SD 17.12, mediana 87, rango 64-143 (figura 50).

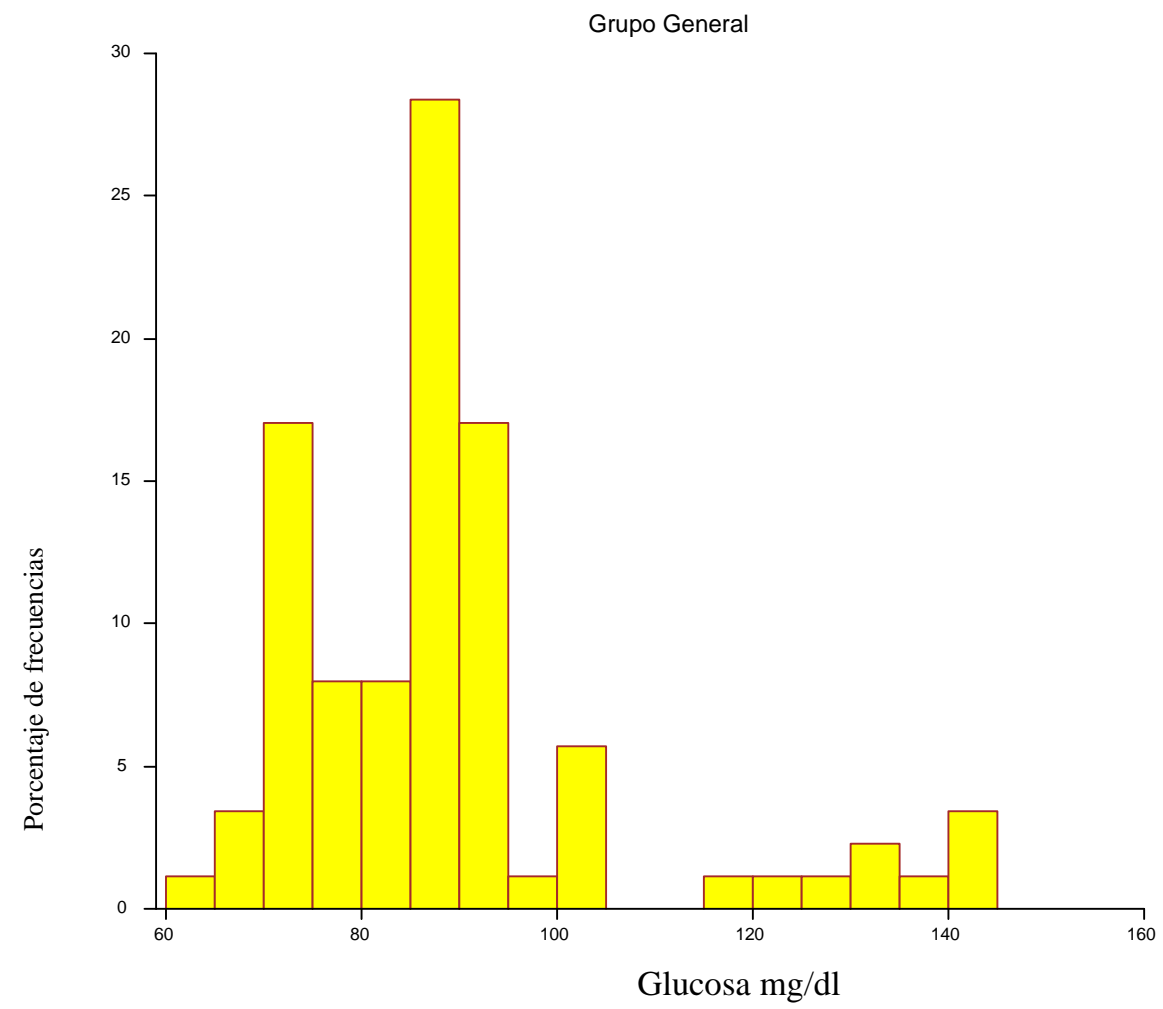

Figura 50. Distribución de la glucosa en la muestra general.

\subsection{Glucemia en Subgrupos GA, GB y GC.}

La tabla 23 y las figuras 51 y 52 muestran la glucosa en los grupos. La glucemia en GB fue inferior, en hombres con disfunción eréctil sin diabetes mellitus con diagnósticos secundarios ( $\mathrm{p}=0.0001)$.

\begin{tabular}{|l|l|l|l|l|}
\hline Grupo & Glucosa media & Sd & Mediana & Rango \\
\hline Ga & 103.64 & 27.64 & 105 & $73-141$ \\
\hline $\mathrm{Gb}$ & 86.42 & 11.59 & 87 & $64-131$ \\
\hline $\mathrm{Gc}$ & 89.53 & 16.16 & 89 & $70-143$ \\
\hline
\end{tabular}

Tabla 23. Glucosa media en GA, GB, GC 
RESULTADOS

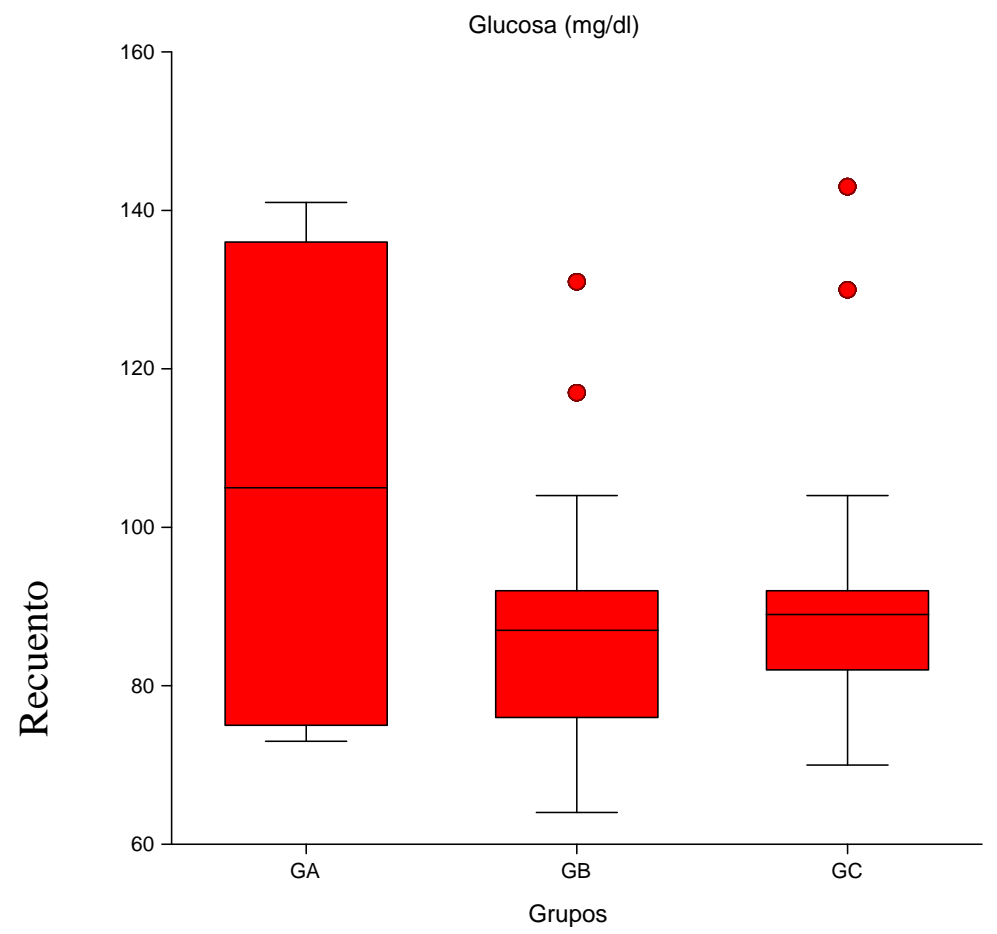

Figura 51. Distribución de la glucemia.

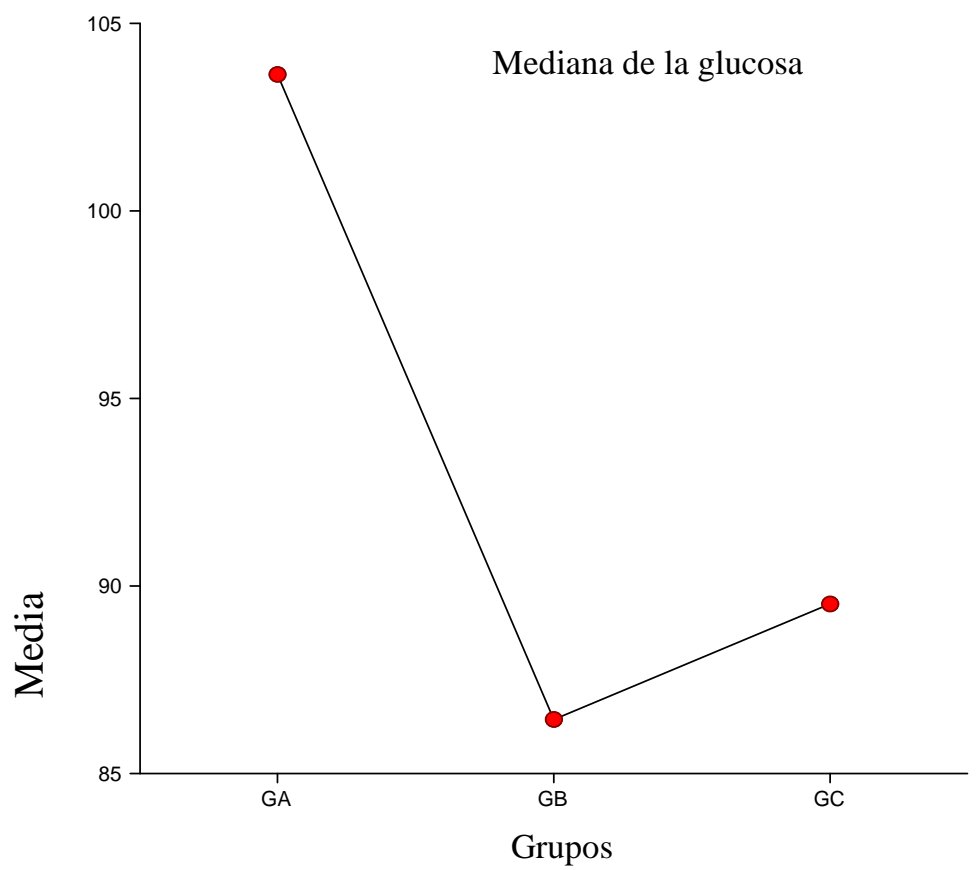

Figura 52. Media de la glucemia en los subgrupos 


\subsection{Glucemia en grupo GA.}

En la glucosa la media fue 103, SD 27.64, mediana 105, rango 73-141 (figura 53).

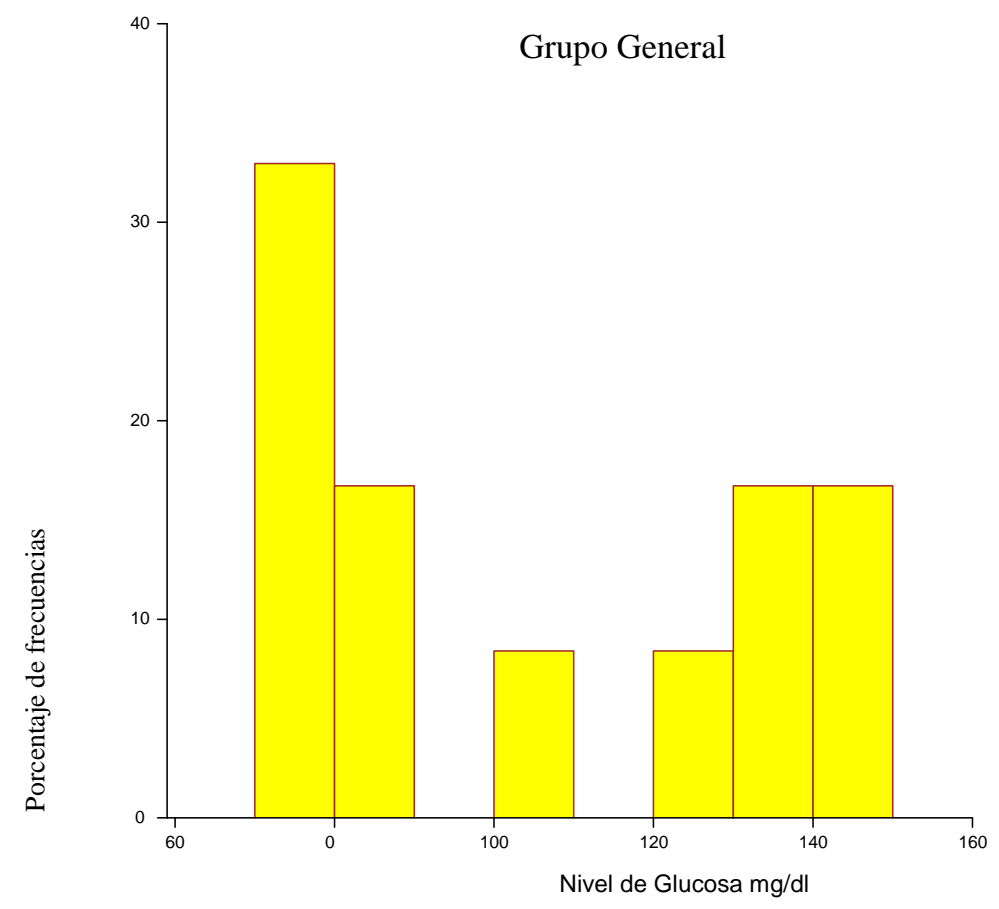

Figura 53. Distribución de la glucosa en la muestra general.

\subsection{Glucemia en subgrupos GAa, GAb y GAc.}

Comparación entre grupos de pacientes masculinos con disfunción eréctil con diabetes mellitus (GA) y con tratamiento exitoso (GAa), parcial (GAb) y fracaso (GAc).

La tabla 24 y las figuras 54 y 55 muestran la glucosa. No hubo diferencia de la glucosa en los subgrupos GAa, GAb, GAc ( $\mathrm{p}=0.0566)$.

\begin{tabular}{|l|l|l|l|l|}
\hline Grupo & $\begin{array}{l}\text { Media de la glucosa } \\
(\mathbf{m g} / \mathbf{d l})\end{array}$ & SD & Mediana & Rango \\
\hline GAa & 101.2 & 23.88 & 105 & $73-131$ \\
\hline GAb & 110.25 & 31.33 & 113.5 & $73-141$ \\
\hline GAc & 98.80 & 27.16 & 83 & $76-136$ \\
\hline
\end{tabular}

Tabla 24. Glucosa en GAa. GAb y GAc. 
RESULTADOS

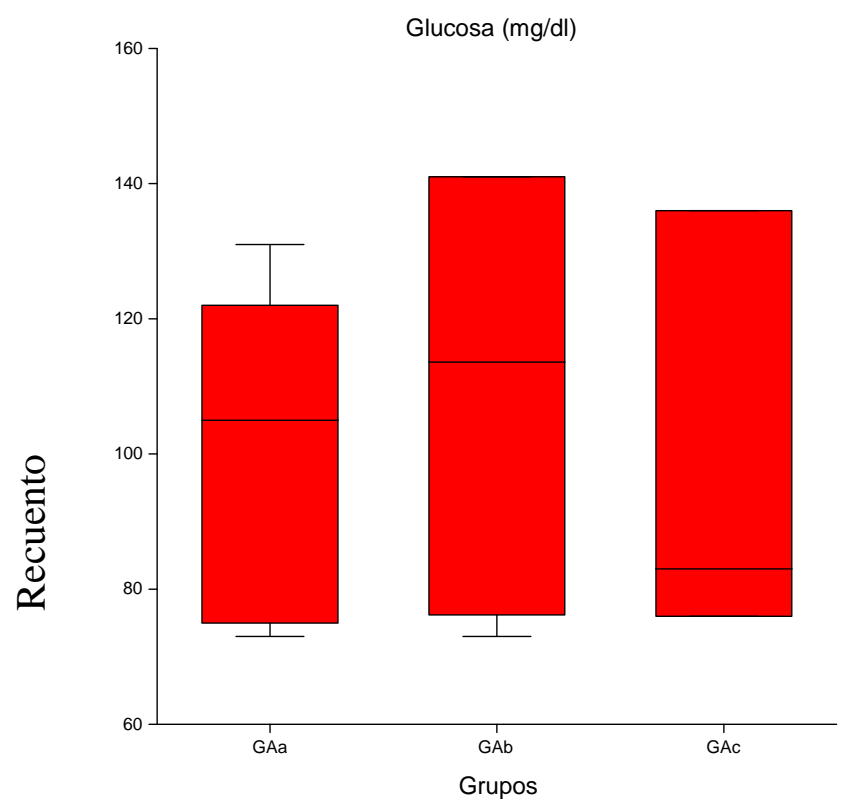

Figura 54. Distribución de la Glucosa.

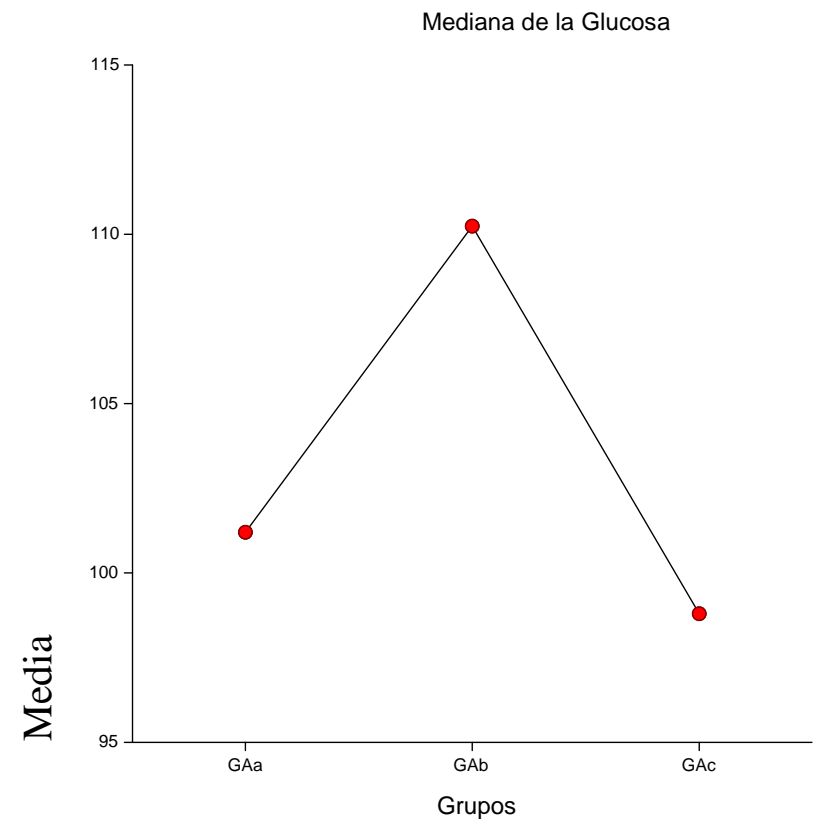

Figura 55. Media de la Glucosa en los subgrupos 


\subsection{Glucemia en grupo GB.}

La media de la Glucosa fue 86.42, SD 11.59, mediana 87, rango 64-131 (figura 56).

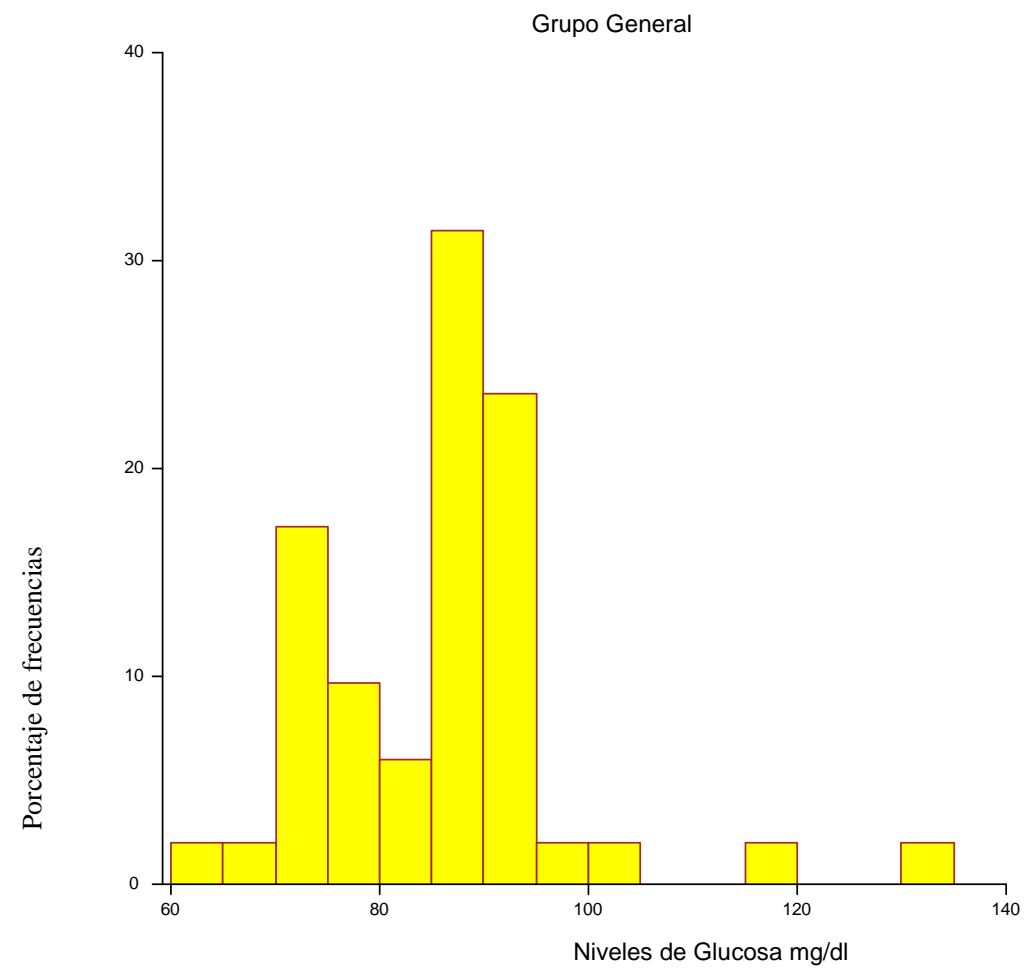

Figura 56. Distribución de la glucosa en la muestra general.

La tabla 25 y las figuras 57 y 58 muestran la glucosa en los grupos. No hubo diferencia de la glucosa en los subgrupos Gba, Gbb, Gbc ( $\mathrm{p}=0.2831)$.

\begin{tabular}{|l|l|l|l|l|}
\hline Grupo & Glucosa media & SD & Mediana & Rango \\
\hline$\underline{\text { Gba }}$ & 85.81 & 7.84 & 90 & $64-97$ \\
\hline$\underline{\text { Gbb }}$ & 87,40 & 14.96 & 87 & $70-131$ \\
\hline$\underline{\text { Gbc }}$ & 86.58 & 13.36 & 88 & $73-117$ \\
\hline
\end{tabular}

Tabla 25. Glucosa media en Gba, Gbb, Gbc. 
RESULTADOS

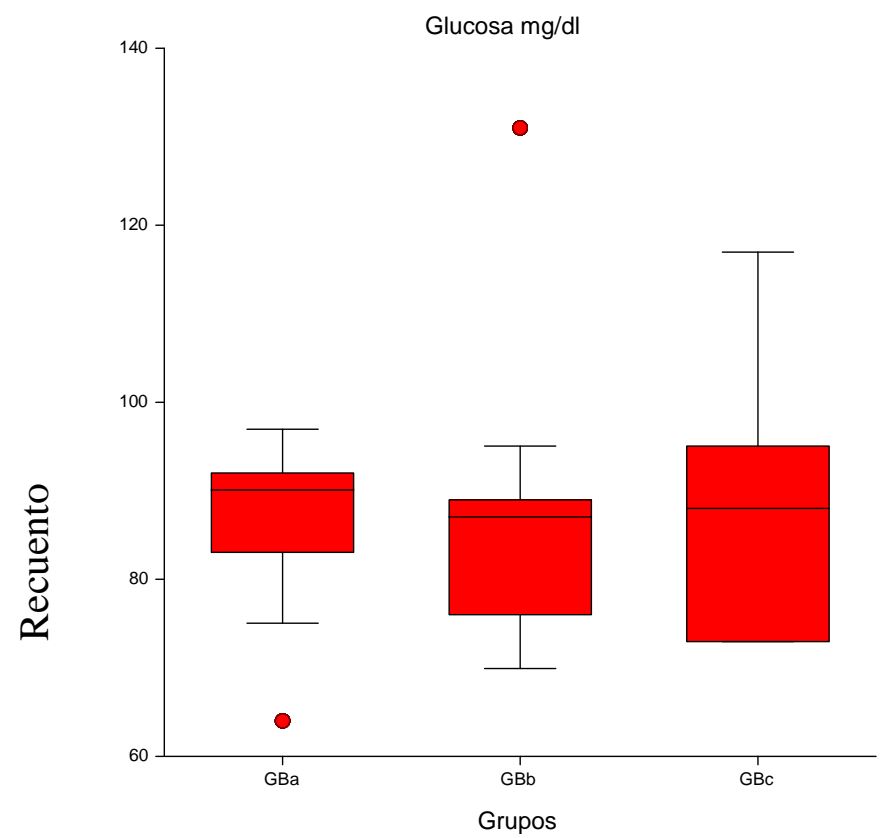

Figura 57. Distribución de la glucosa.

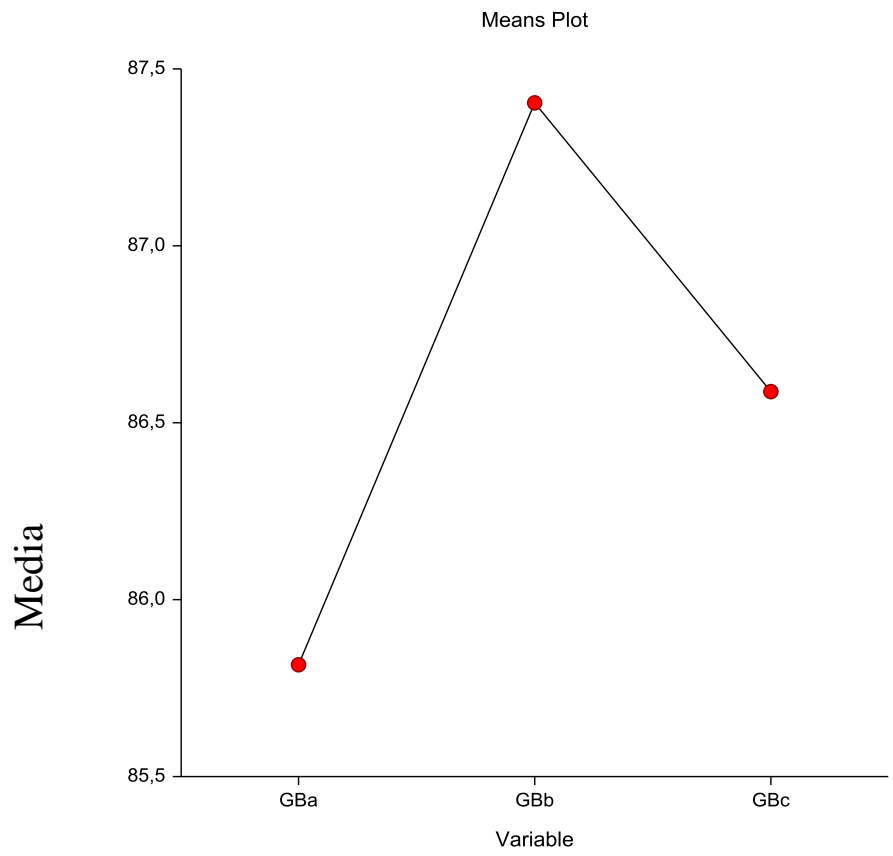

Figura 58. Media de la glucosa en los subgrupos 


\subsection{Glucemia en subgrupos GAa, GBa, GCa.}

La media de la Glucosa fue 89.28, SD 15.51, mediana 90, rango 64-143 (figura 59).

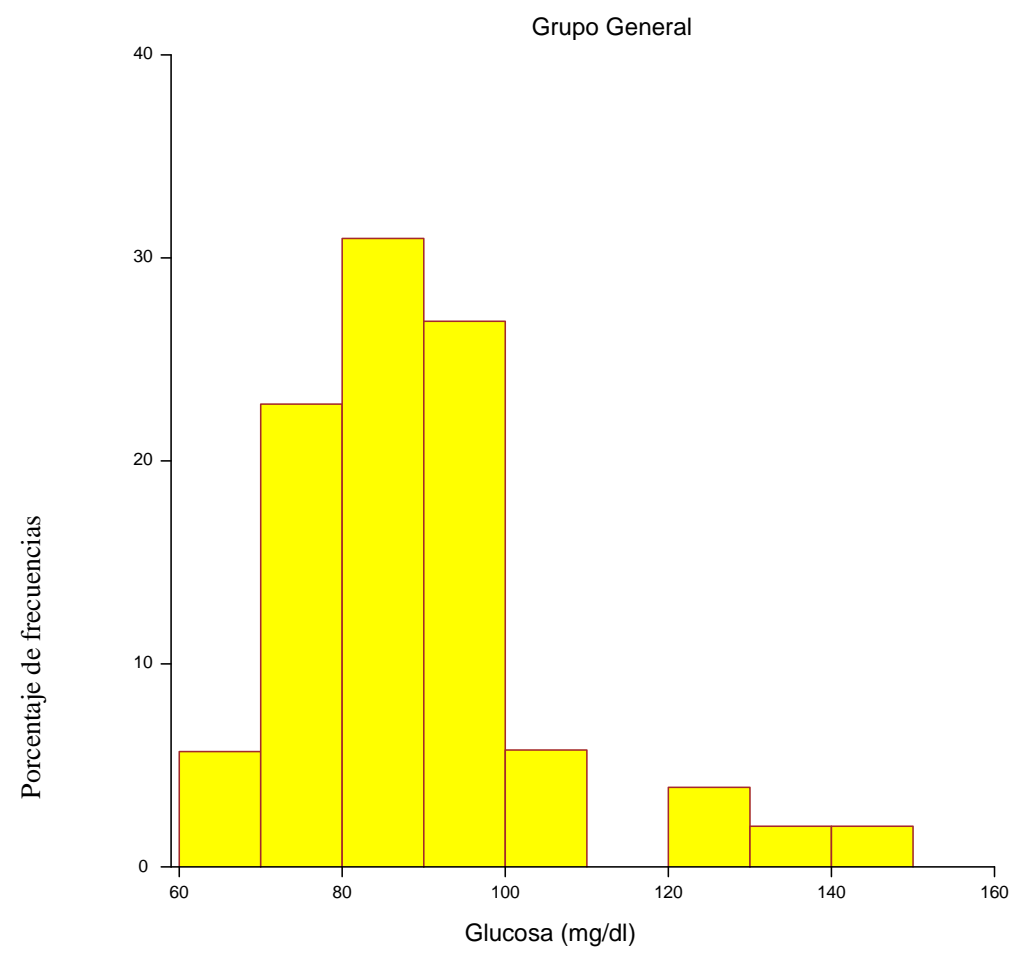

Figura 59. Distribución de la glucosa en la muestra general.

La tabla 26 y las figuras 60 y 61 muestran la glucosa en los grupos. La glucosa GBa fue inferior $(\mathrm{p}=0.0001)$.

\begin{tabular}{|l|l|l|l|l|}
\hline Grupo & Glucosa media & SD & Mediana & Rango \\
\hline GAa & 101.2 & 23.88 & 105 & $73-131$ \\
\hline GBa & 85.81 & 7.84 & 90 & $64-97$ \\
\hline GCa & 90.32 & 17.72 & 90 & $70-143$ \\
\hline
\end{tabular}

Tabla 26. La glucosa media en GÁ, GBa y GCa . 
RESULTADOS

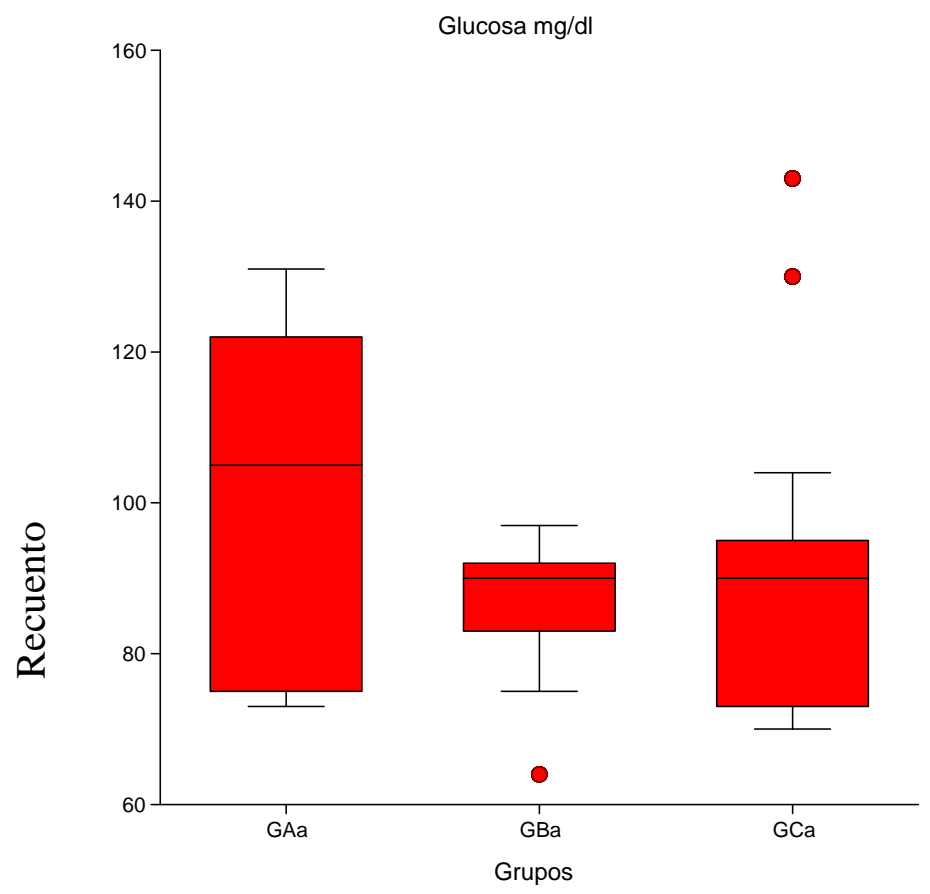

Figura 60. Distribución de la glucosa

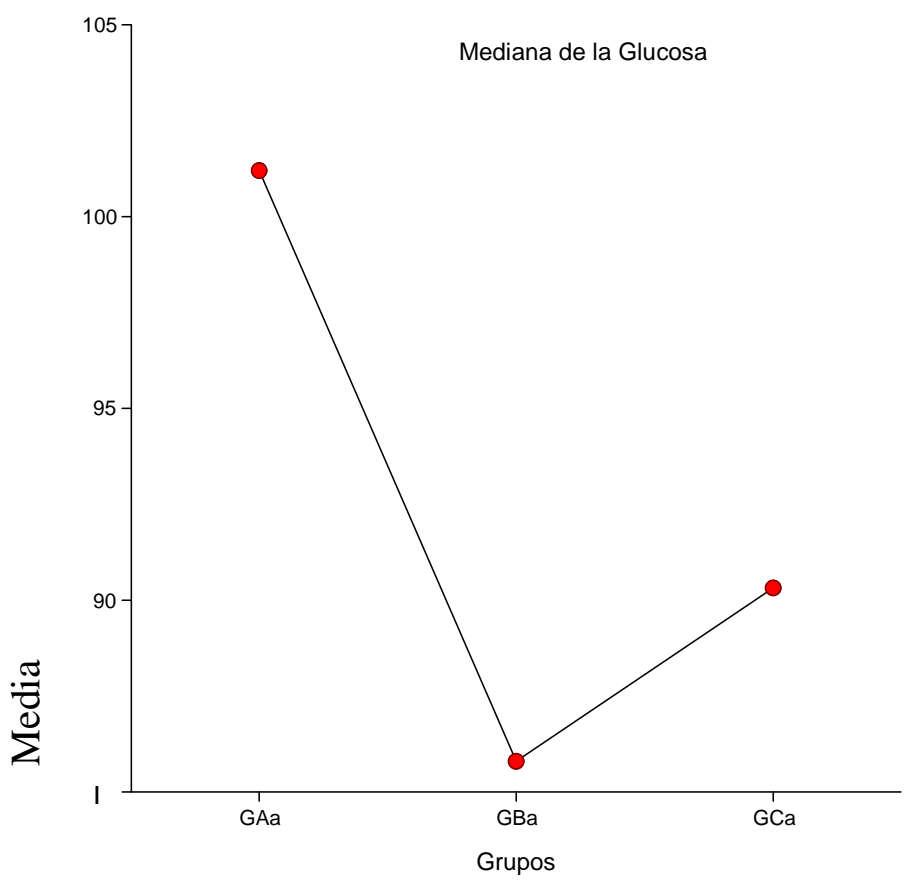

Figura 61. Media de la la glucosa en los subgrupos 


\subsection{Glucemia en subgrupos GAm.GAo.GAc}

La media de la Glucosa fue 103, SD 27.67, mediana 105, rango 73-141 (figura 62).

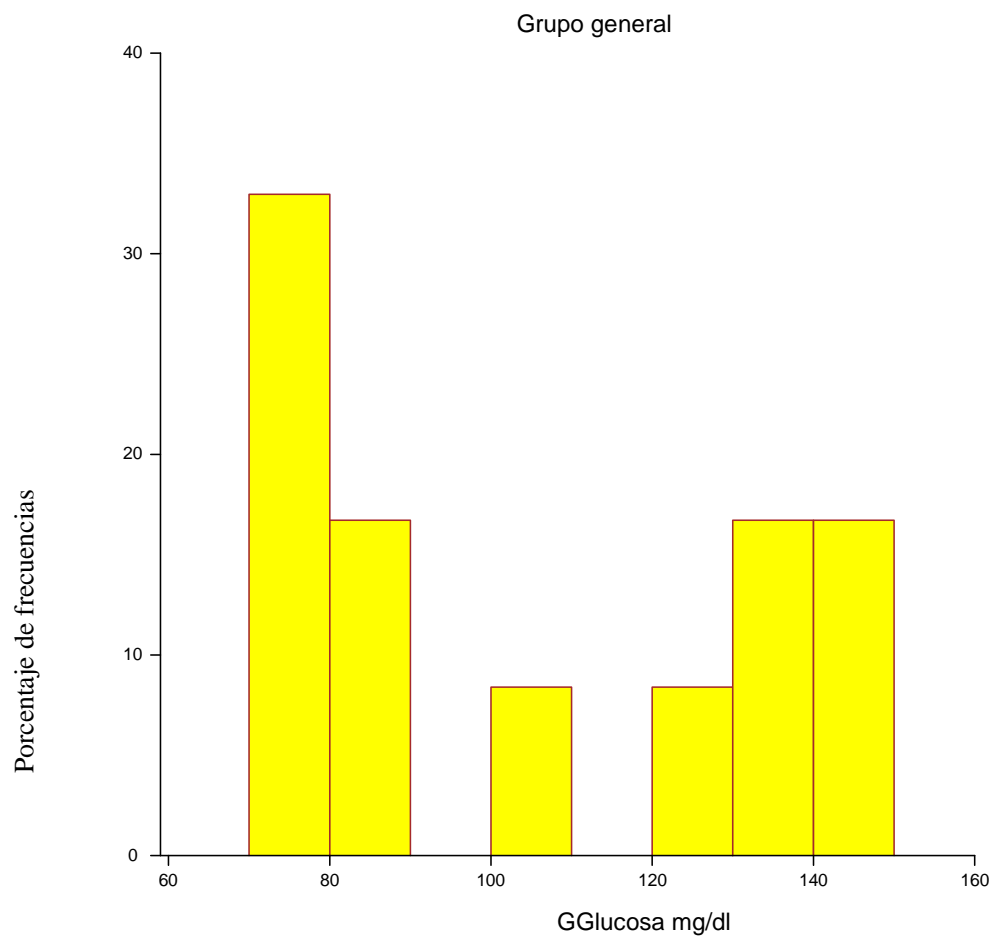

Figura 62. Distribución de la glucosa en la muestra general.

La tabla 27 y las figuras 63 y 64 muestran la glucosa en los grupos. La glucosa en GAm fue inferior respecto a GAo y GAc ( $\mathrm{p}=0.00029)$.

\begin{tabular}{|l|l|l|l|l|}
\hline Grupo & Glucosa media & SD & Mediana & Rango \\
\hline GAm & 93.16 & 26.16 & 86 & $73-136$ \\
\hline GAo & 103.5 & 27.97 & 103.5 & $76-131$ \\
\hline GAc & 110.83 & 2.54 & 113.5 & $73-141$ \\
\hline
\end{tabular}

Tabla 27. Glucosa media en GAm, GAo y GAc. 
RESULTADOS

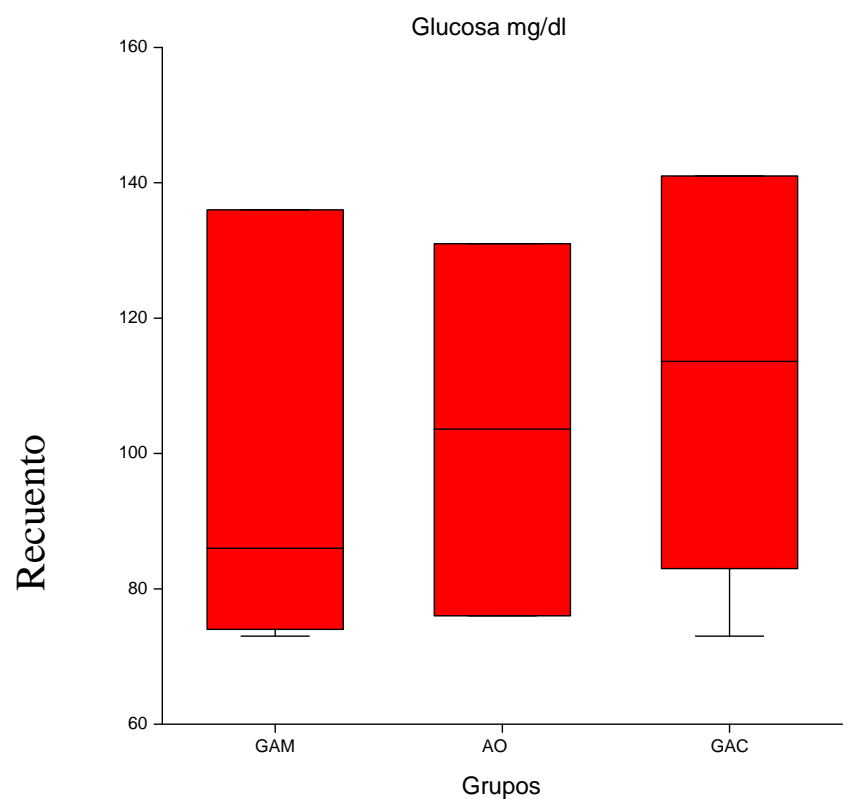

Figura 63. Distribución de la glucosa

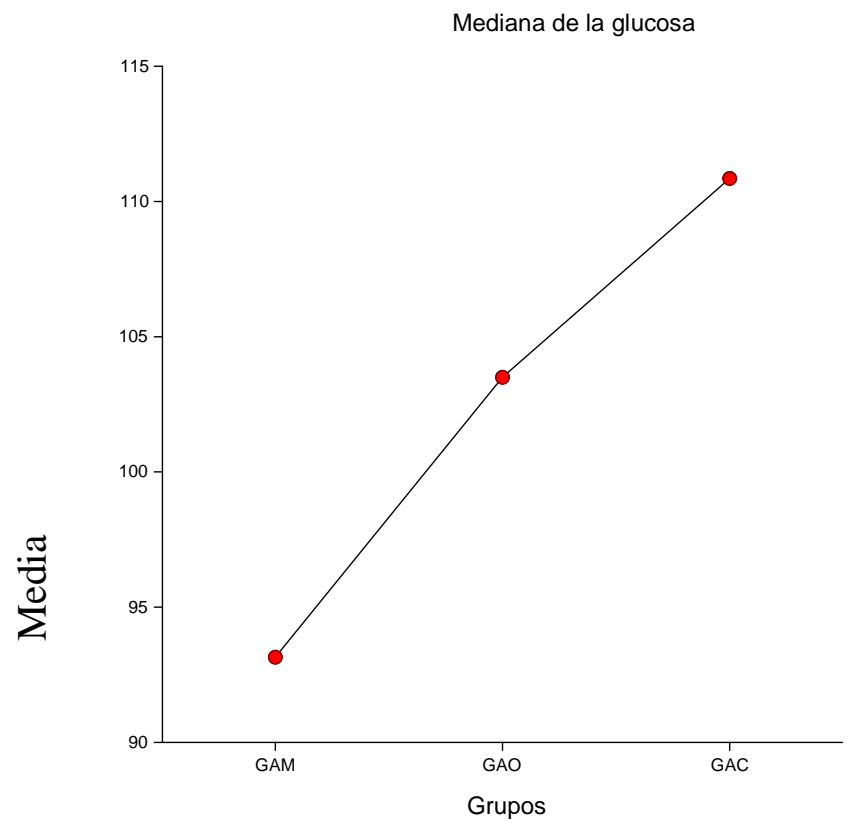

Figura 64. Media de la glucosa en los grupos 


\subsection{Glucemia en subgrupo GAm.}

La media de la Glucosa fue 93.16, SD 26.16, mediana 86, rango 73-136 (figura 65).

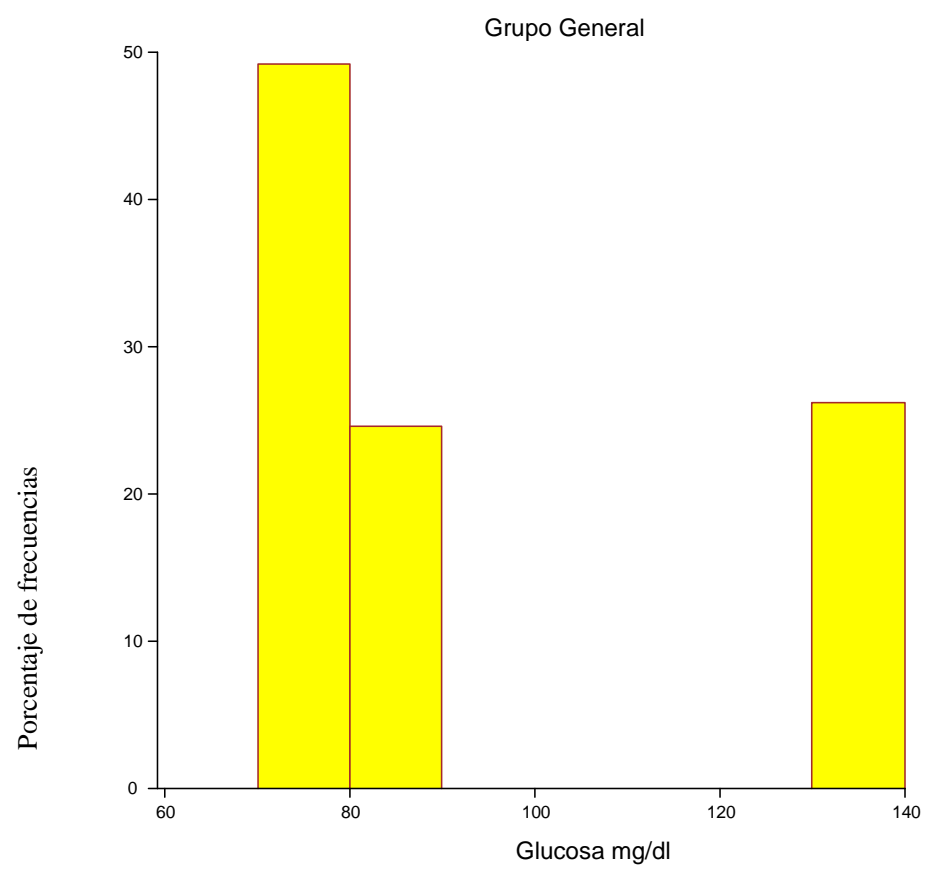

Figura 65. Distribución de la glucosa en la muestra general.

\subsubsection{Glucemia en subgrupos GAma, GAmb, GAmc.}

La tabla 27 y la figura 66 muestran la glucosa en los grupos. La glucosa en GAMa fue inferior $(\mathrm{p}=0.0001)$.

\begin{tabular}{|l|l|l|l|l|}
\hline Grupo & Glucosa media & SD & Mediana & Rango \\
\hline GAma & 74 & 1.01 & 74 & $73-75$ \\
\hline GAmb & 86 & 0 & 86 & $86-86$ \\
\hline GAmc & 136 & 0 & 136 & $136-136$ \\
\hline
\end{tabular}

Tabla 27. La glucosa media en GAma, GAmb, GAmc. 


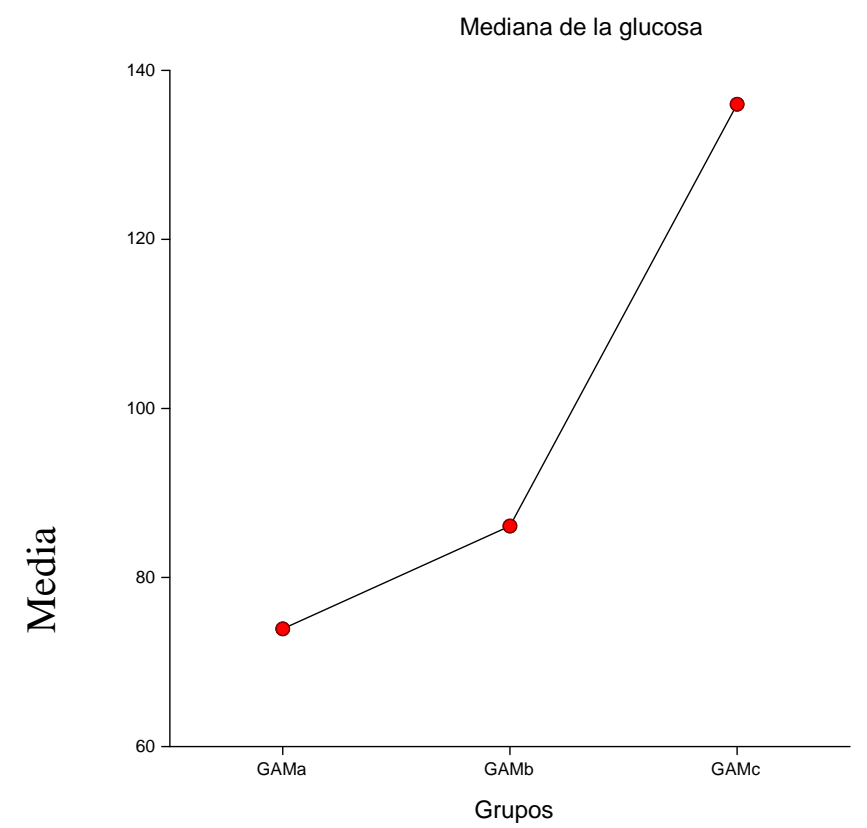

Figura 66. Media de la glucosa en los grupos

\subsection{Glucemia en subgrupo GAo.}

La media de la Glucosa fue 103.5, SD 27.97, mediana 103.5, rango 76131.

\subsubsection{Glucemia en subgrupo GAoa, GAob, GAoc}

La tabla 28 muestra la glucosa en los grupos. La glucosa en GAOc fue inferior $(\mathrm{p}=0.0001)$. No se encontraron pacientes en el subgrupo GAob.

\begin{tabular}{|l|l|l|l|l|}
\hline Grupo & Glucosa media & SD & Mediana & Rango \\
\hline GAoa & 131 & 0 & 131 & $131-131$ \\
\hline GAoc & 76 & 0 & 76 & $76-76$ \\
\hline
\end{tabular}

Tabla 28. Glucosa media en GAoa, GAob y GAoc. 


\subsection{Glucemia en subgrupo GAc.}

La media de la Glucosa fue 110.83, SD 26.54, mediana 113.5, rango 73141 (figura 67).

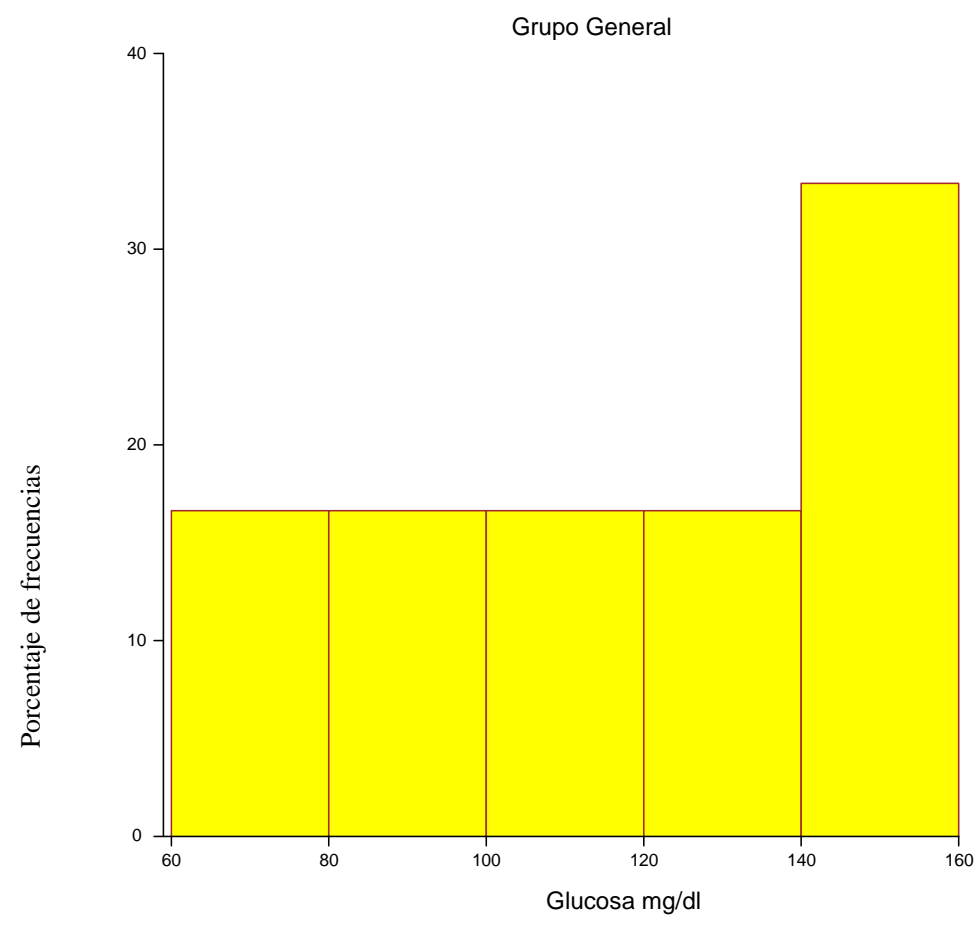

Figura 67. Distribución de la Glucosa en la muestra general.

\subsubsection{Glucemia en subgrupos GAca, GAcb, GAcc}

La tabla 29 y las figuras 68 y 69 muestran la hemoglobina en los grupos. No hubo diferencias en los subgrupos GAca, GAcb y GAcc $(\mathrm{p}=0.96284)$.

\begin{tabular}{|l|l|l|l|l|}
\hline Grupo & Glucosa media & SD & Mediana & Rango \\
\hline GAca & 11.97 & 26.13 & 113.5 & $73-141$ \\
\hline GAcb & 11.41 & 27.31 & 122 & $73-141$ \\
\hline GAcc & 109.36 & 27.17 & 105 & $73-141$ \\
\hline
\end{tabular}

Tabla 29. Glucosa media en GAca, GAcb y GAcc. 
RESULTADOS

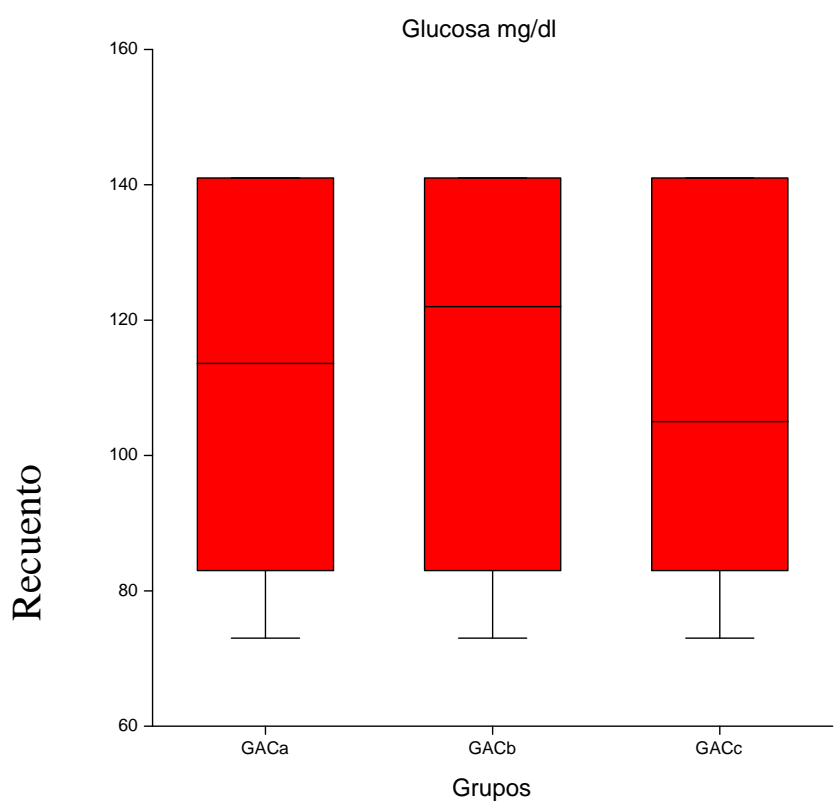

Figura 68. Distribución de glucosa

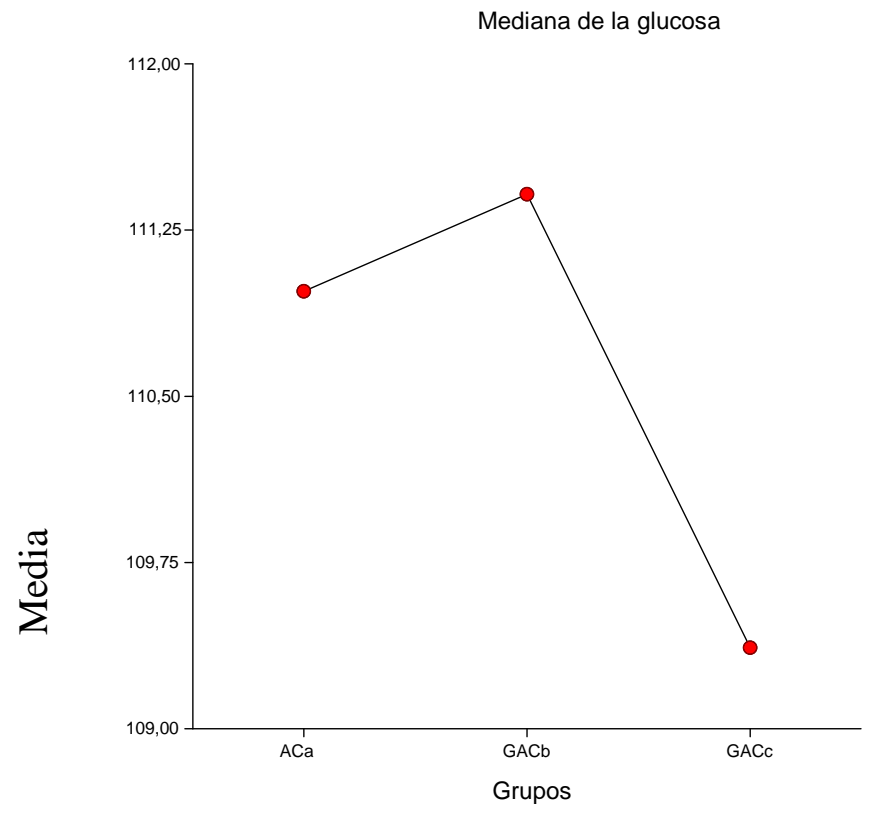

Figura 69. Media de la glucosa en los grupos 


\section{HEMOGLOBINA}

\subsection{Hemoglobina en muestra general.}

La hemoglobina media fue 15.66, SD 1.40, mediana 16, rango 9.5-17.8 (figura 70).

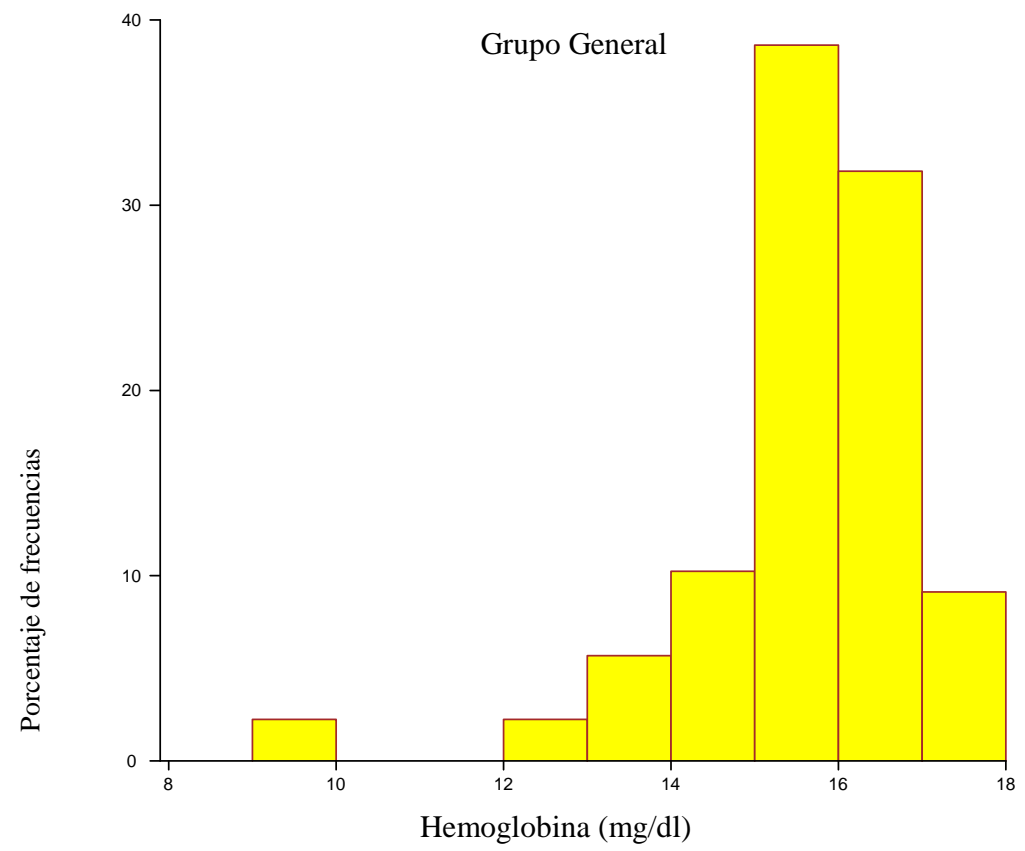

Figura 70. Distribución de la hemoglobina en la muestra general.

\subsection{Hemoglobina en Subgrupos GA, GB y GC.}

Grupo general (GG) y comparación entre grupos de pacientes masculinos con disfunción eréctil con diabetes mellitus (GA), con diagnósticos secundarios sin diabetes mellitus (GB) y sin diagnósticos secundarios (GC) en la hemoglobina.

La tabla 30 y las figuras 71 y 72 muestran la hemoglobina en los grupos. La hemoglobina fue inferior en el subgrupo GA, hombres con Diabetes Mellitus respecto a los hombres sin diabetes mellitus con diagnósticos secundarios y sin diagnósticos secundarios $(\mathrm{p}=0.0001)$. 


\begin{tabular}{|l|l|l|l|l|}
\hline Grupo & Hemoglobina media & Sd & Mediana & Rango \\
\hline GA & 14.73 & 2.40 & 16 & $9.5-16.3$ \\
\hline GB & 15.73 & 1.01 & 15.8 & $13.5-17.7$ \\
\hline GC & 15.88 & 1.19 & 16 & $12.9-17.8$ \\
\hline
\end{tabular}

Tabla 30. La hemoglobina media en GA,GB,GC.

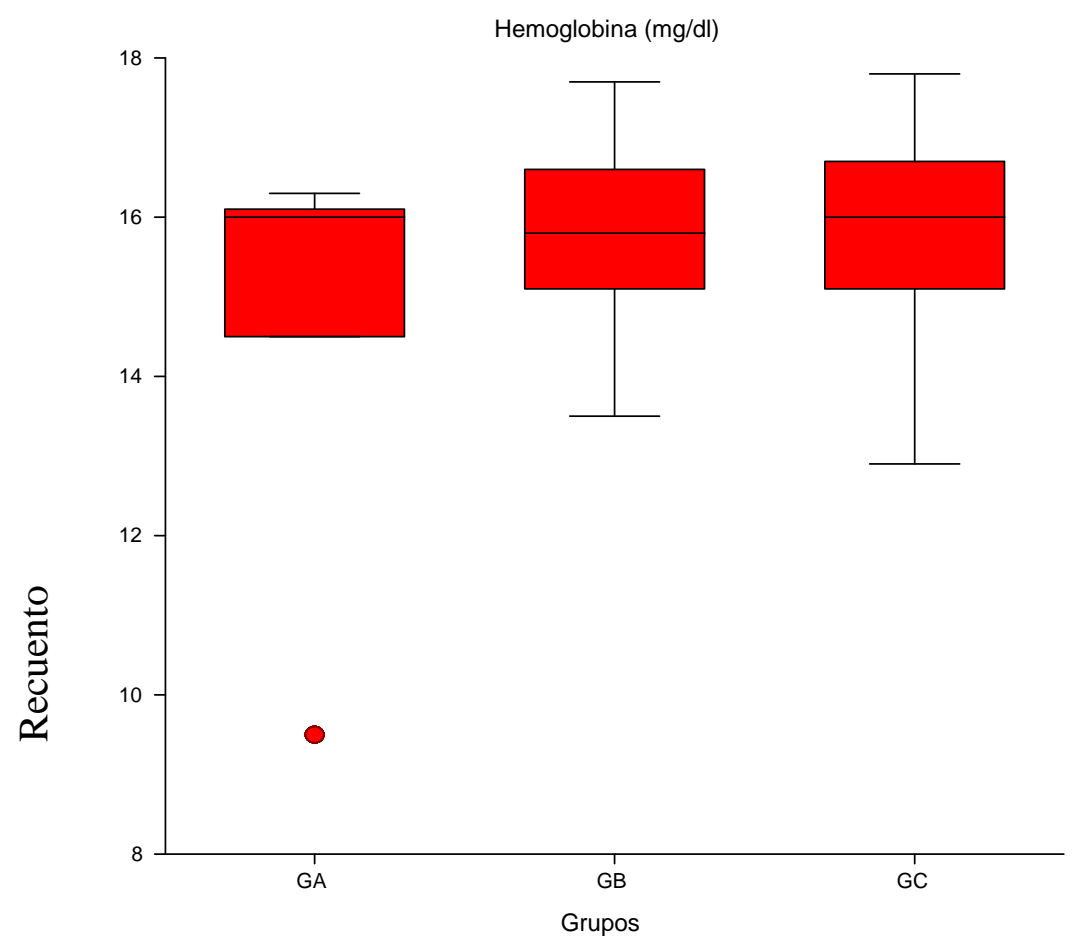

Figura 71. Distribución de la hemoglobina 


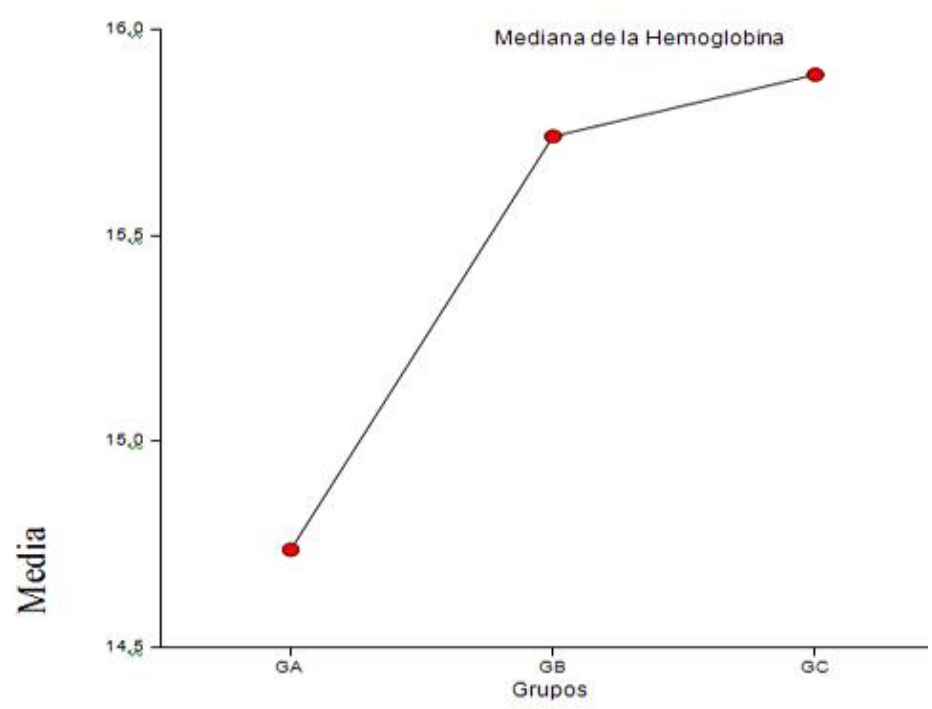

Figura 72. Media de la hemoglobina en los subgrupos

\subsection{Hemoglobina en grupo GA.}

La hemoglobina media fue 15.73, SD 2.40, mediana 16, rango 9.5-16.3 (figura 73).

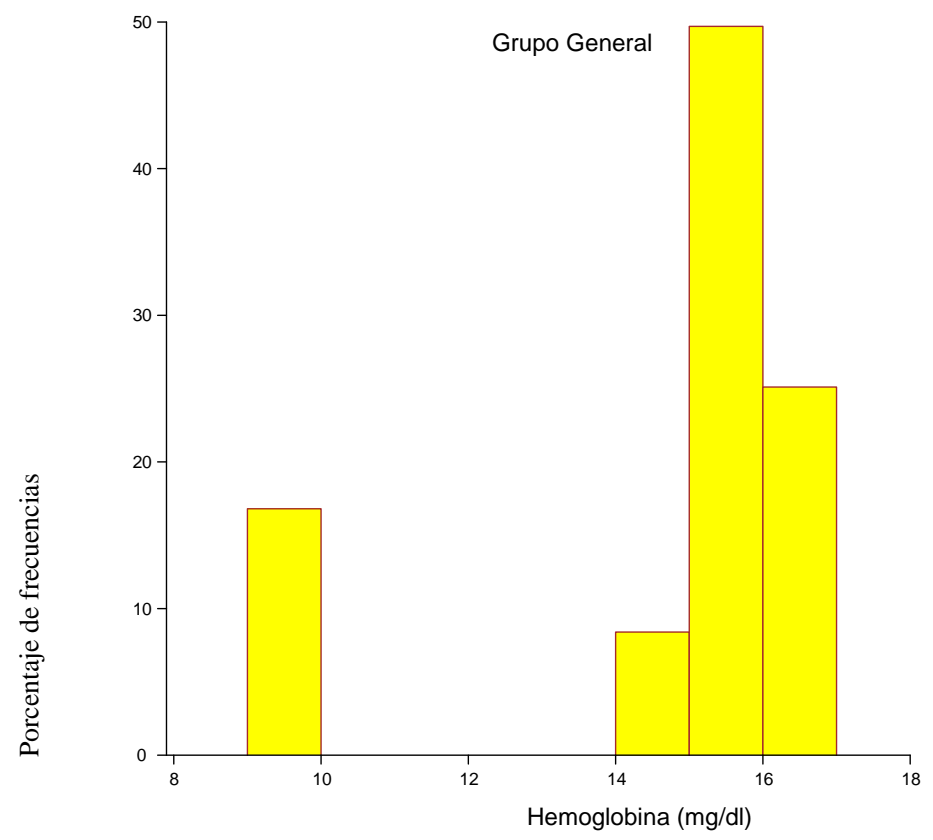

Figura 73. Distribución de la hemoglobina en la muestra general. 


\subsection{Hemoglobina en subgrupos GAa, GAb y GAc}

Comparación entre grupos de pacientes masculinos con disfunción eréctil con diabetes mellitus (GA) y con tratamiento exitoso (GAa), parcial (GAb) y fracaso (GAc).

La tabla 31 y las figuras 74 y 75 muestran la hemoglobina en los grupos. La hemoglobina en GAb fue inferior ( $p=0.0001)$.

\begin{tabular}{|l|l|l|l|l|}
\hline Grupo & Hemoglobina media & SD & Mediana & Rango \\
\hline GAa & 15.46 & 0.58 & 15.7 & $14.5-16$ \\
\hline GAb & 12.9 & 3.42 & 12.9 & $9.5-16.3$ \\
\hline GAc & 16.002 & 0.08 & 16 & $15.9-16.1$ \\
\hline
\end{tabular}

Tabla 31. La hemoglobina media en Gaa. Gab y Gac.

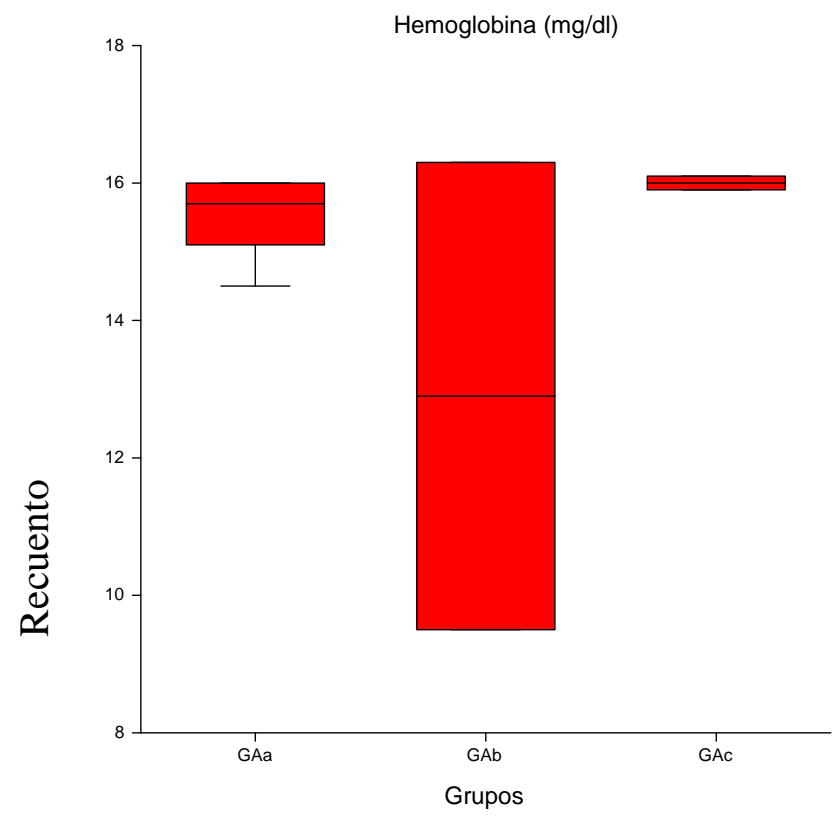

Figura 74. Distribución de la hemoglobina 


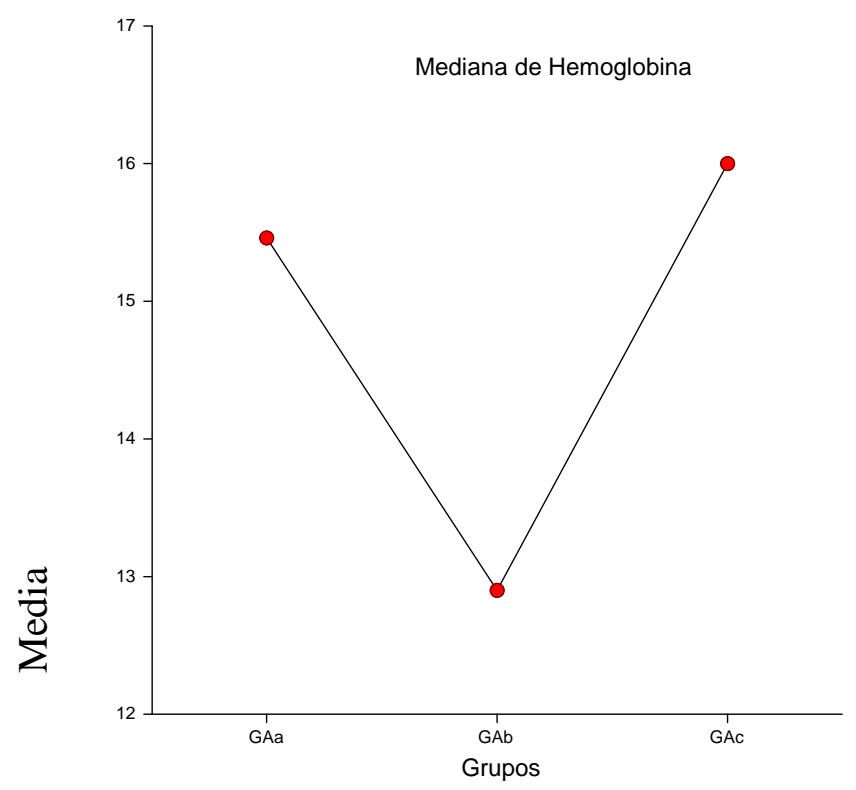

Figura 75. Media de la hemoglobina en los grupos

\subsection{Hemoglobina en grupo GB.}

La hemoglobina media fue 15.73 , SD 0.95 , mediana 15.9 , rango 14-17.7 (figura 76).

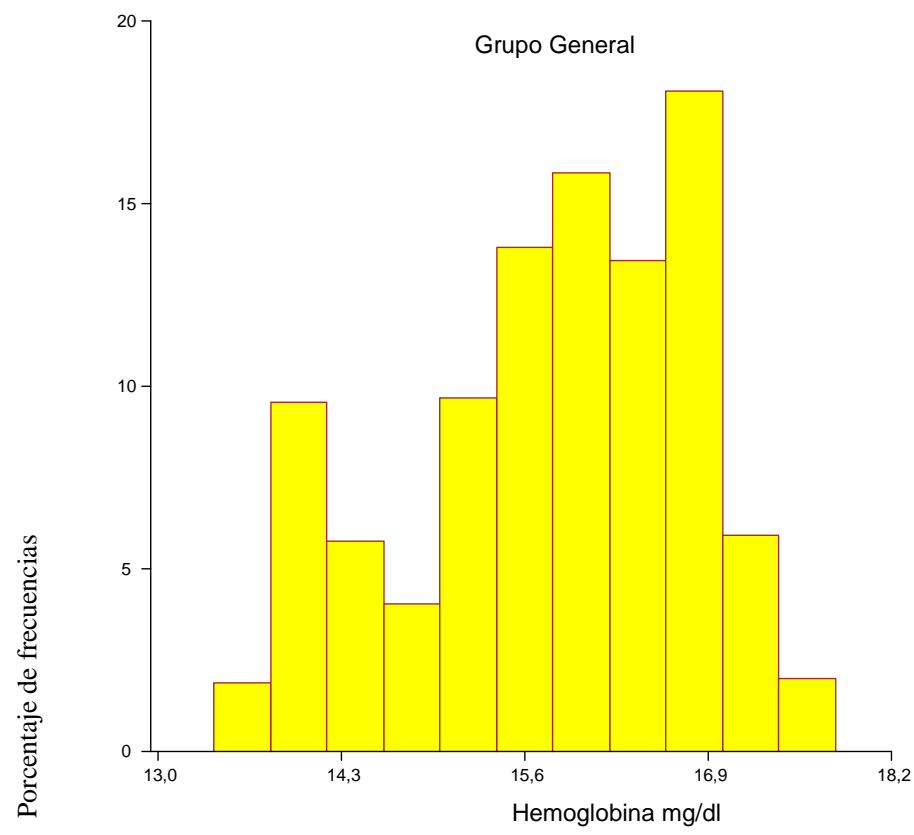

Figura 76. Distribución de la hemoglobina en la muestra general. 
La tabla 32 y las figuras 77 y 78 muestran la hemoglobina en los grupos. No hubo diferencia de la hemoglobina en los subgrupos GBa, GBb, $\mathrm{GBc}(\mathrm{p}=0.3301)$.

\begin{tabular}{|l|l|l|l|l|}
\hline Grupo & Hemoglobina media & SD & Mediana & Rango \\
\hline$\underline{\text { GBa }}$ & 15.99 & 0.95 & 15.9 & $14-17.7$ \\
\hline$\underline{G B b}$ & 15.99 & 0.94 & 15.9 & $14-17.7$ \\
\hline$\underline{\text { GBc }}$ & 15.88 & 1.01 & 15.8 & $13.5-17.7$ \\
\hline
\end{tabular}

Tabla 32. La hemoglobina media en $G B a, G B b$ y $G B c$.

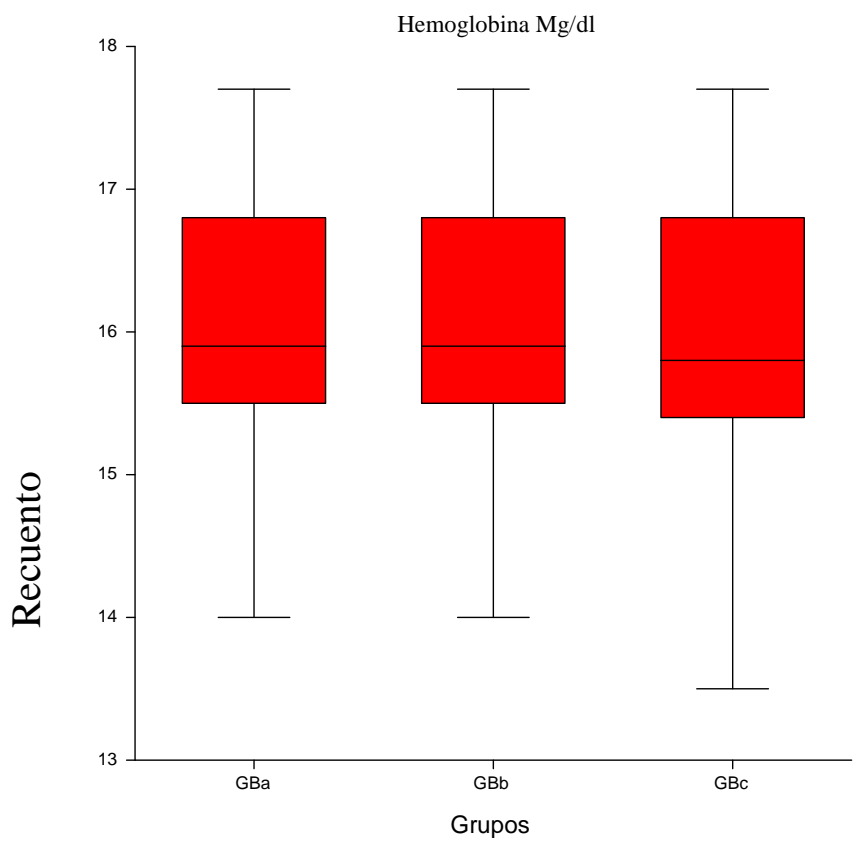

Figura 77. Distribución de hemoglobina 


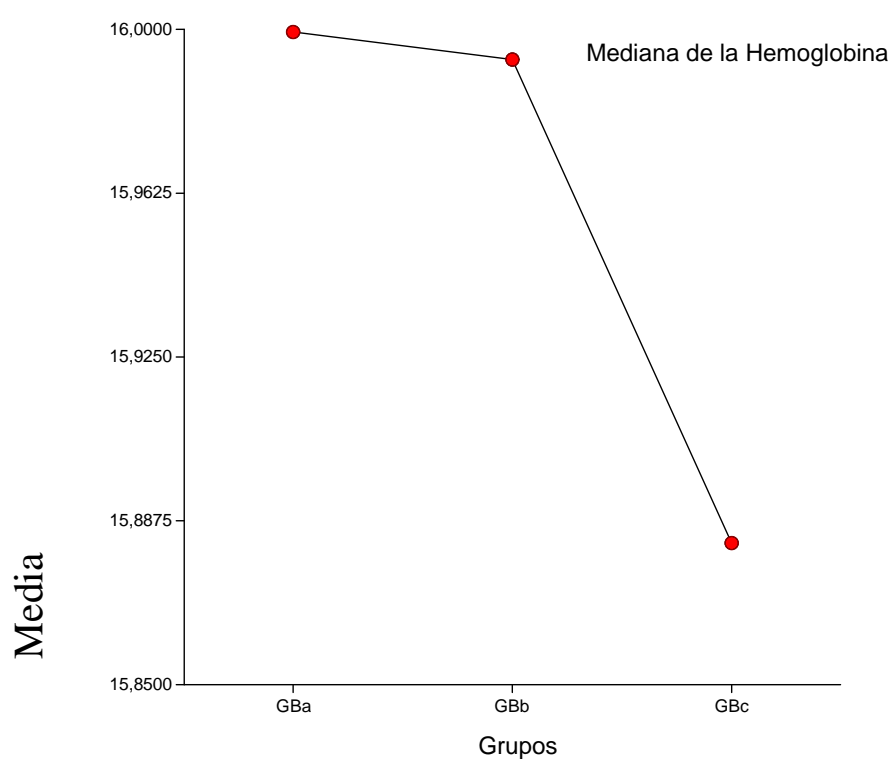

Figura 78. Media de la hemoglobina en los grupos

\subsection{Hemoglobina en subgrupos GAa, GBa, GCa.}

La hemoglobina media fue 21.46, SD 18.84, mediana 15.7, rango 12.919.5 (figura 79).

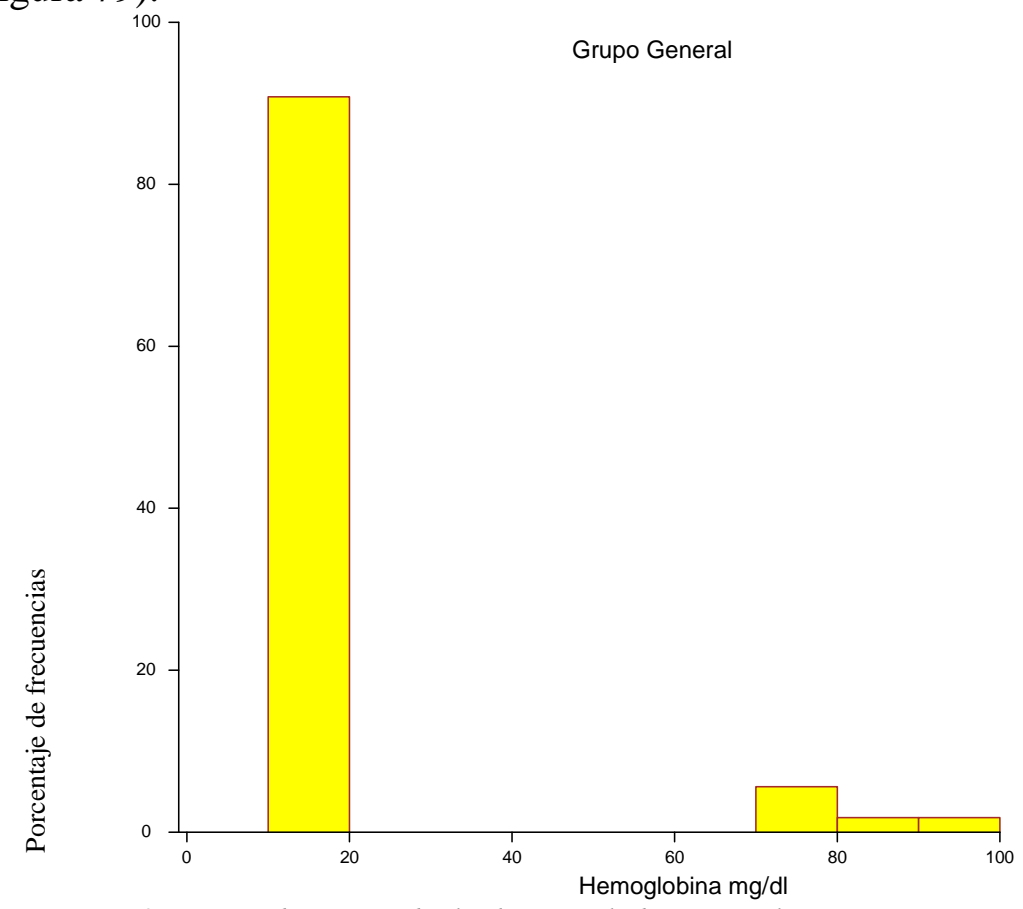

Figura 79. Distribución de la hemoglobina en la muestra general. 
Hemoglobina en subgrupos GAa, GBa, GCa.

La tabla 33 y las figuras 80 y 81 muestran la hemoglobina en los grupos. La hemoglobina glicosilada IFCC en GA fue inferior $(\mathrm{p}=0.0001)$.

\begin{tabular}{|l|l|l|l|l|}
\hline Grupo & Hemoglobina media & SD & Mediana & Rango \\
\hline GAa & 15.46 & 0.58 & 15.7 & $14.5-16$ \\
\hline GBa & 15.99 & 0.95 & 15.9 & $14-17.7$ \\
\hline GCa & 14.86 & 1.23 & 14.9 & $12.9-17.8$ \\
\hline
\end{tabular}

Tabla 33. La hemoglobina media en $G \underline{A a, G B a \text { y } G C a}$

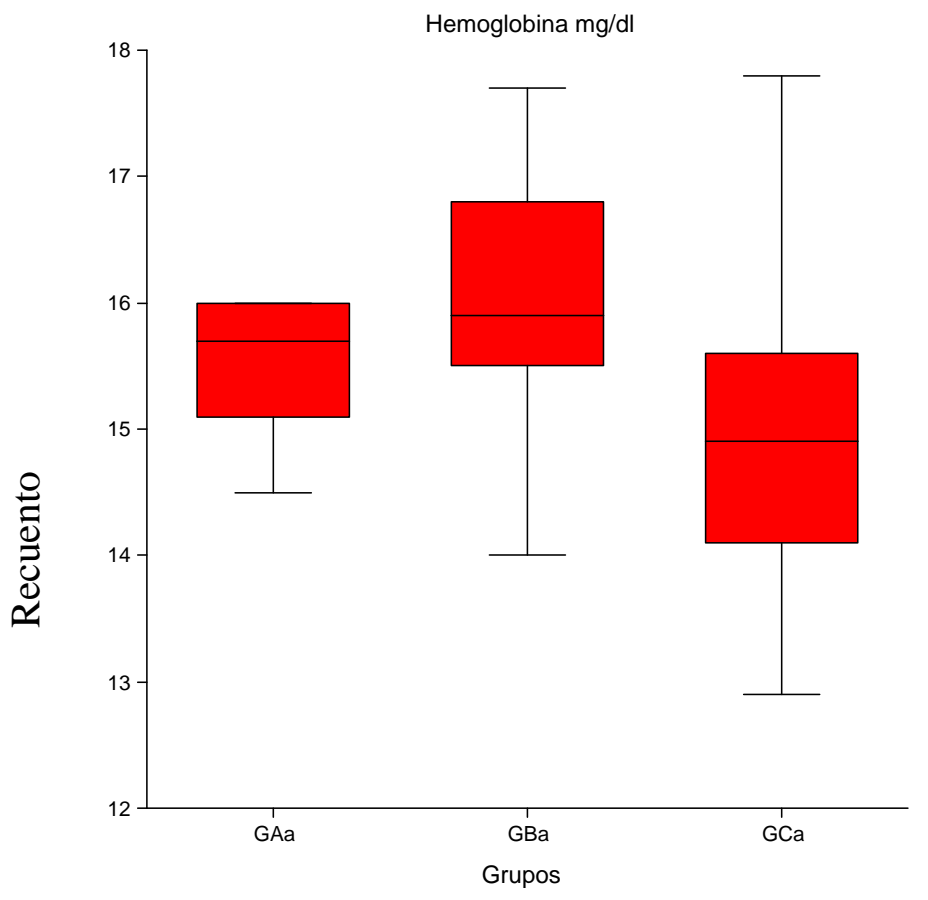

Figura 80. Distribución de la hemoglobina 


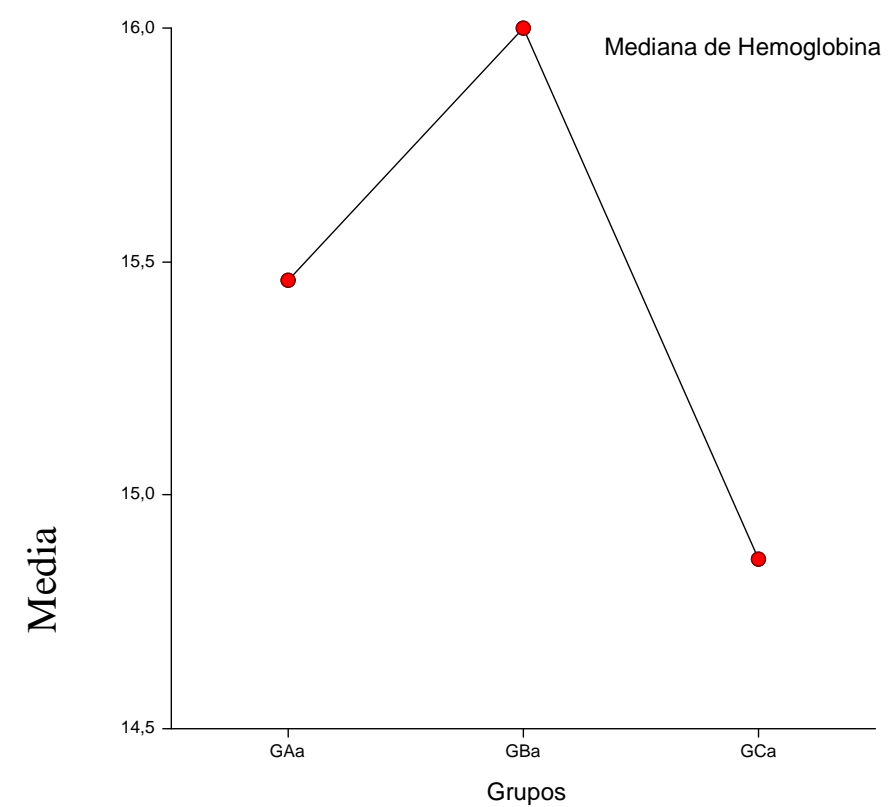

Figura 81. Media de la hemoglobina en los grupos

\subsection{Hemoglobina en subgrupo GAm, GAO, GAC.}

La hemoglobina media fue 14.74, SD 2.40, mediana 16, rango 9.5-16.3 (figura 82).

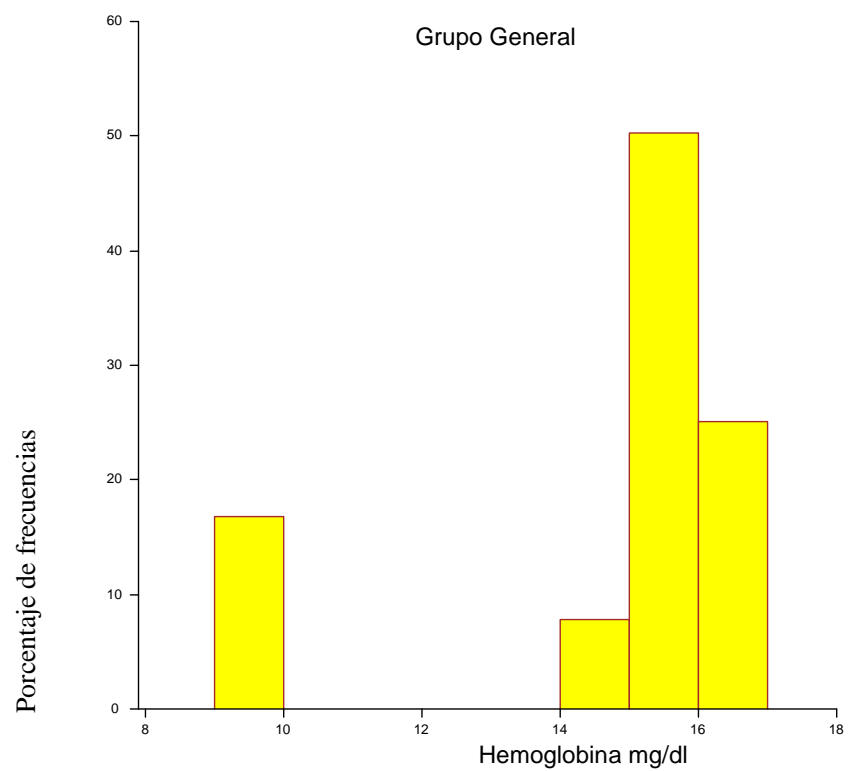

Figura 82. Distribución de la hemoglobina en la muestra general. 
Hemoglobina en subgrupo GAm, GAo, GAc.

La tabla 34 y las figuras 83 y 84 muestran la hemoglobina en los grupos. La hemoglobina en GAc fue inferior ( $p=0.0001)$.

\begin{tabular}{|l|l|l|l|l|}
\hline Grupo & Hemoglobina media & SD & Mediana & Rango \\
\hline GAm & 15.85 & 0.45 & 16 & $15.1-16.3$ \\
\hline GAo & 15.2 & 0.711 & 15.2 & $14.5-15.9$ \\
\hline GAc & 13.85 & 3.09 & 15.85 & $9.5-16.3$ \\
\hline
\end{tabular}

Tabla 34. La hemoglobina media en GAm, GAo, Gac

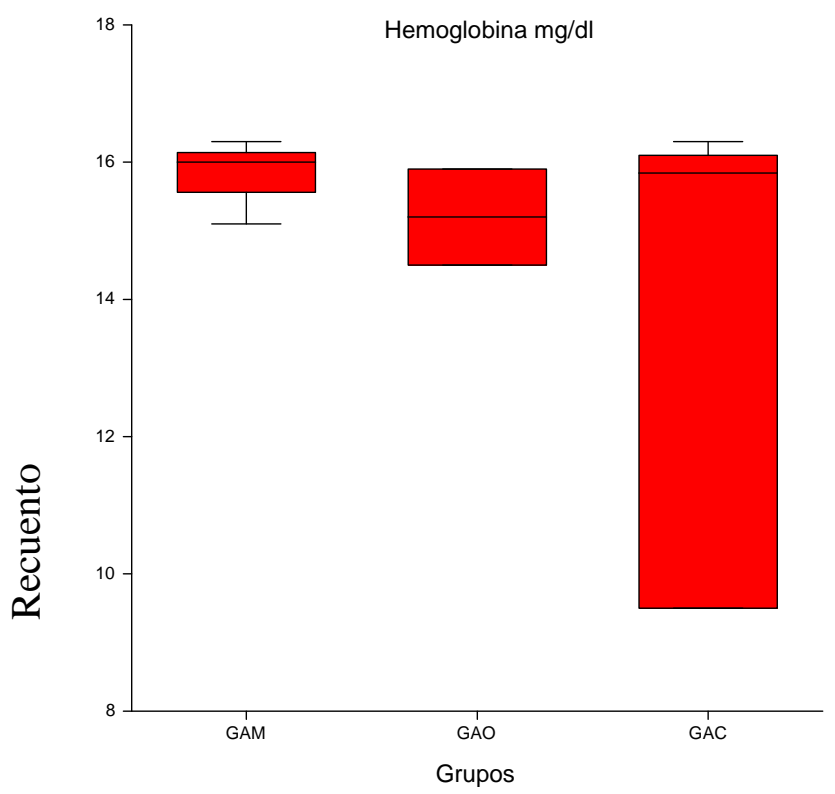

Figura 83. Distribución de la hemoglobina 


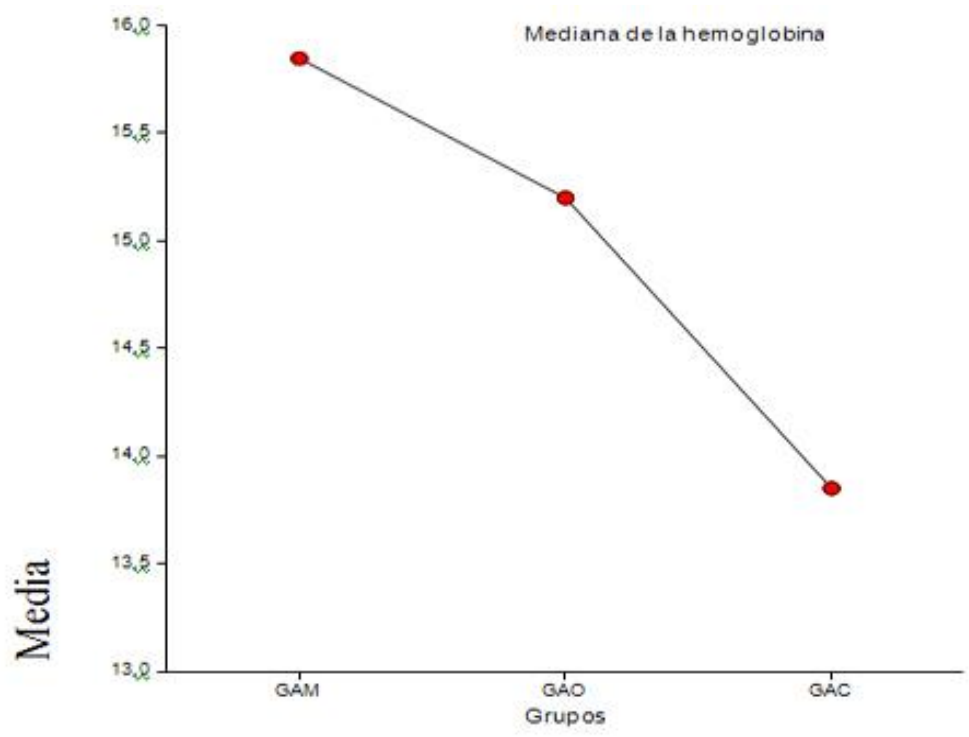

Figura 84. Media de la hemoglobina en los grupos

\subsection{Hemoglobina en subgrupo GAm}

La hemoglobina media fue 15.85 , SD 0.45 , mediana 16 , rango 15.1-16.3 (figura 85).

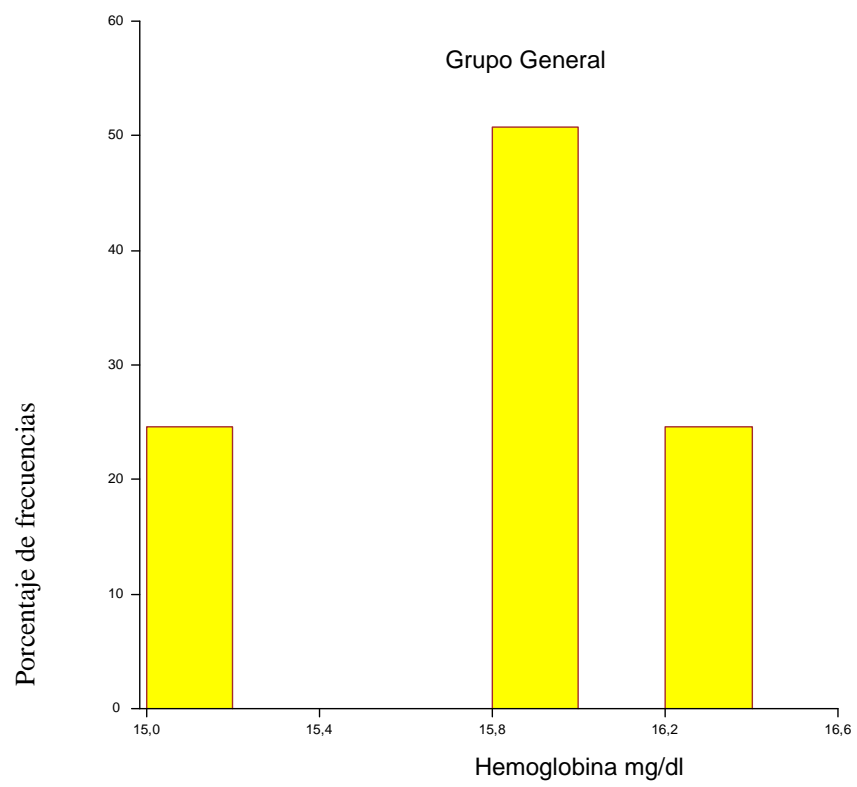

Figura 85. Distribución de la hemoglobina en la muestra general. 


\subsubsection{Hemoglobina en subgrupos GAma, GAmb, GAmc.}

La tabla 35 y la figura 86 muestran la hemoglobina en los grupos. La hemoglobina en GAMa fue inferior $(\mathrm{p}=0.0001)$.

\begin{tabular}{|l|l|l|l|l|}
\hline Grupo & Hemoglobina media & SD & Mediana & Rango \\
\hline GAma & 15.55 & 0.45 & 15.55 & $15.1-16$ \\
\hline GAmb & 16.3 & 0 & 16.3 & $16.3-16.3$ \\
\hline GAmc & 16 & 0 & 16 & $16-16$ \\
\hline
\end{tabular}

Tabla 35. La hemoglobina media en GAma, GAmb y GAmc.

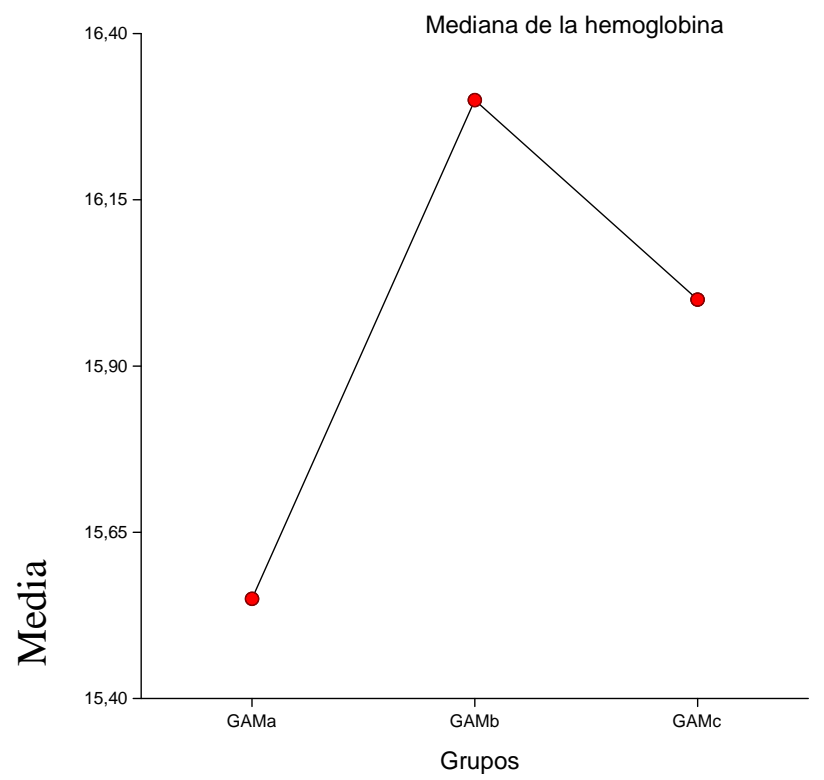

Figura 86. Media de la hemoglobina en los grupos 


\subsection{Hemoglobina en subgrupo GAo} 15.9.

La hemoglobina media fue 15.2, SD 0.71, mediana 15.2, rango 14.5-

\subsubsection{Hemoglobina en subgrupo GAoa, GAob, GAoc.}

La tabla 36 muestra la hemoglobina en los grupos. La hemoglobina en GAOa fue inferior ( $\mathrm{p}=0.0001$ ). No hubo pacientes en el subgrupo GAob.

\begin{tabular}{|l|l|l|l|l|}
\hline Grupo & Hemoglobina media & SD & Mediana & Rango \\
\hline GAoa & 14.5 & 0 & 14.5 & $14.5-14.5$ \\
\hline GAoc & 15.9 & 0 & 15.9 & 0 \\
\hline
\end{tabular}

Tabla 36. La hemoglobina en GAoa, GAob y GAoc.

\subsection{Hemoglobina en subgrupo GAc.}

La hemoglobina media fue 13.85, SD 3.09, mediana 15.85, rango 9.516.3 (figura 87).

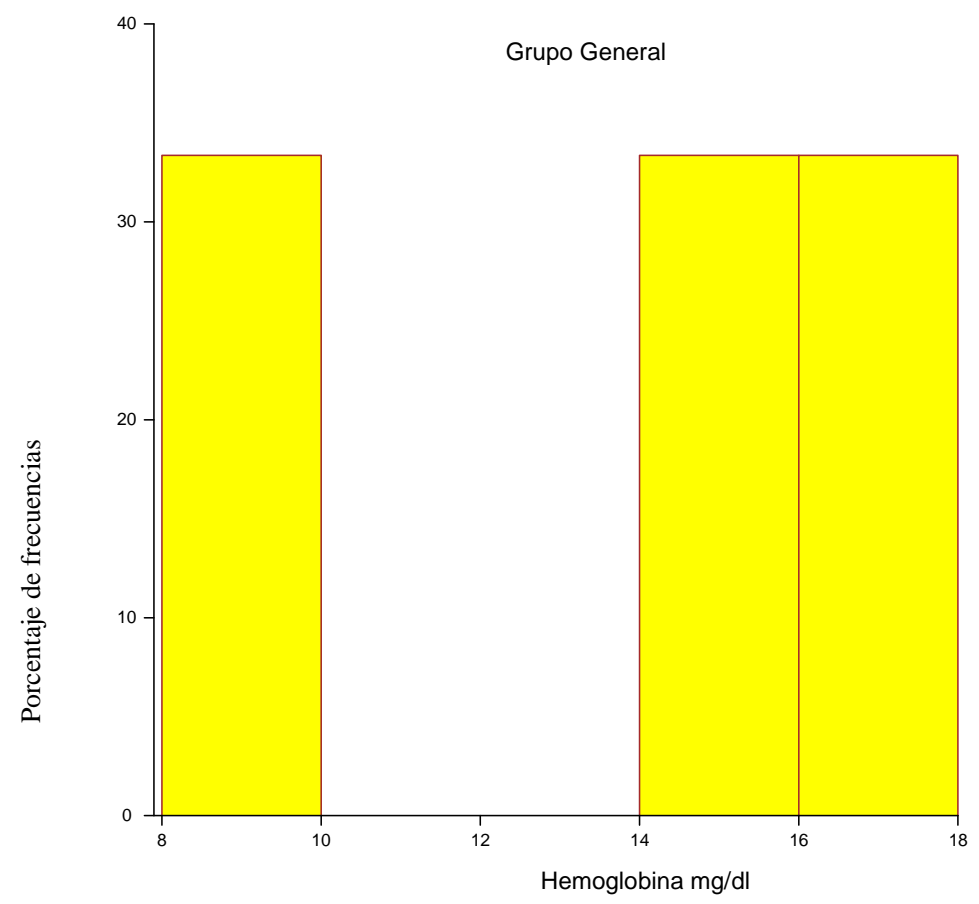

Figura 87. Distribución de la hemoglobina en la muestra general. 


\subsubsection{Hemoglobina en subgrupos GAca, GAcb, GAcc.}

La tabla 37 y las figuras 88 y 89 muestran la hemoglobina en los grupos. No hubo diferencias en los subgrupos GACa, GACb y GACc $(\mathrm{p}=0.9171)$.

\begin{tabular}{|l|l|l|l|l|}
\hline Grupo & Hemoglobina media & SD & Mediana & Rango \\
\hline GAca & 13.95 & 3.07 & 15.85 & $9.5-16.3$ \\
\hline GAcb & 13.68 & 3.18 & 15.7 & $9.5-16.3$ \\
\hline GAcc & 13.96 & 3.12 & 16 & $9.4-16.3$ \\
\hline
\end{tabular}

Tabla 37. La hemoglobina media en GAca, GAcb y GAcc.

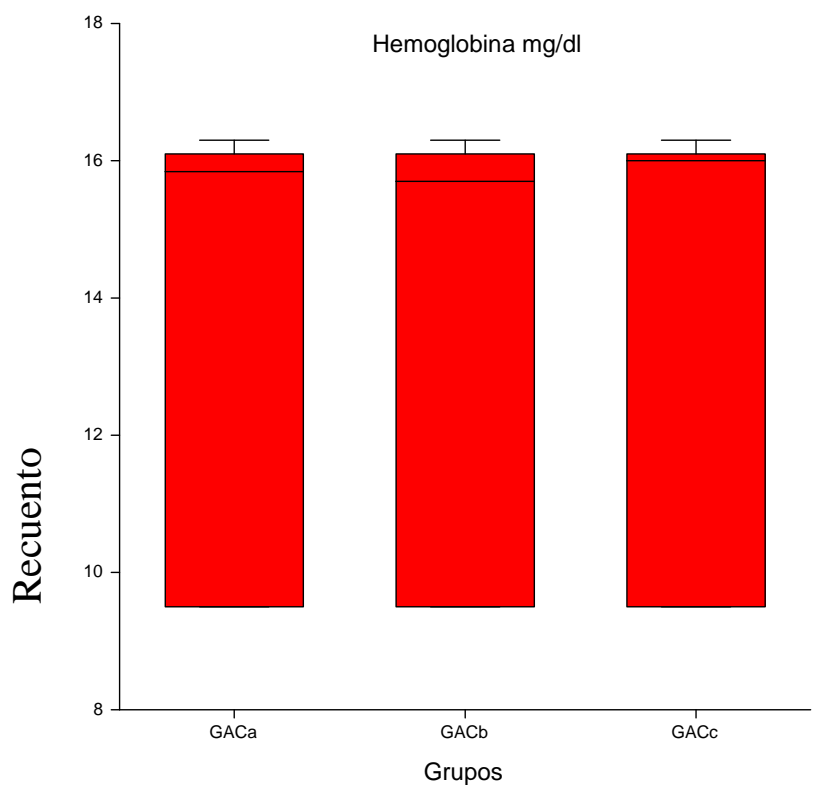

Figura 88. Distribución de la hemoglobina 
LORENA SUÁREZ GUTIÉRREZ

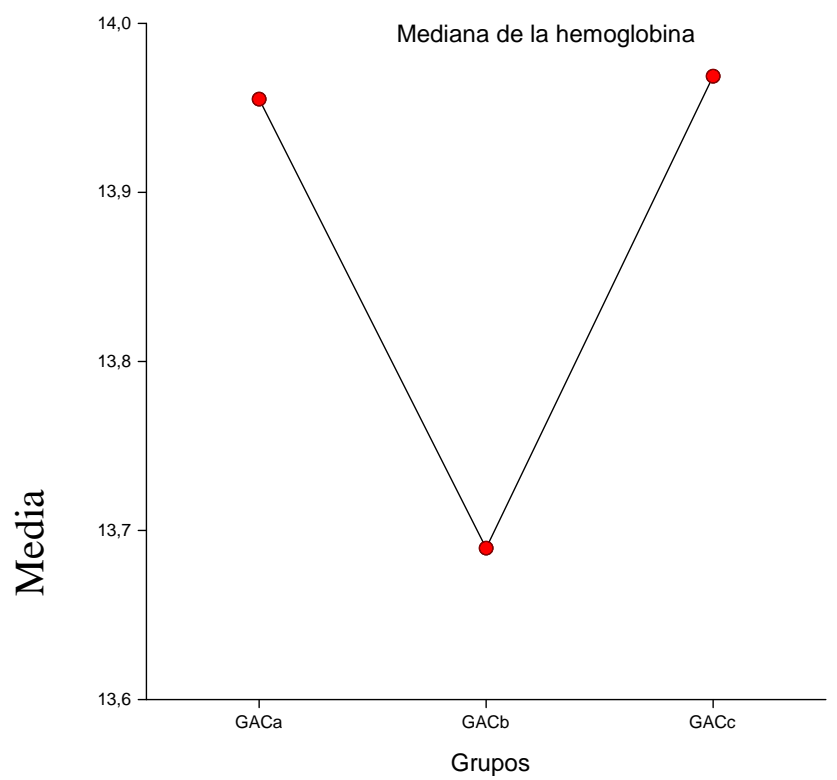

Figura 89. Media de la hemoglobina en los grupos. 


\section{HEMOGLOBINA GLICOSILADA NGSP.}

\subsection{Hemoglobina glicosilada NGSP en muestra general.}

La hemoglobina glicosilada ngsp media fue 6.03, SD 0.79, mediana 5.8, rango 5.1-8.8 (figura 90).

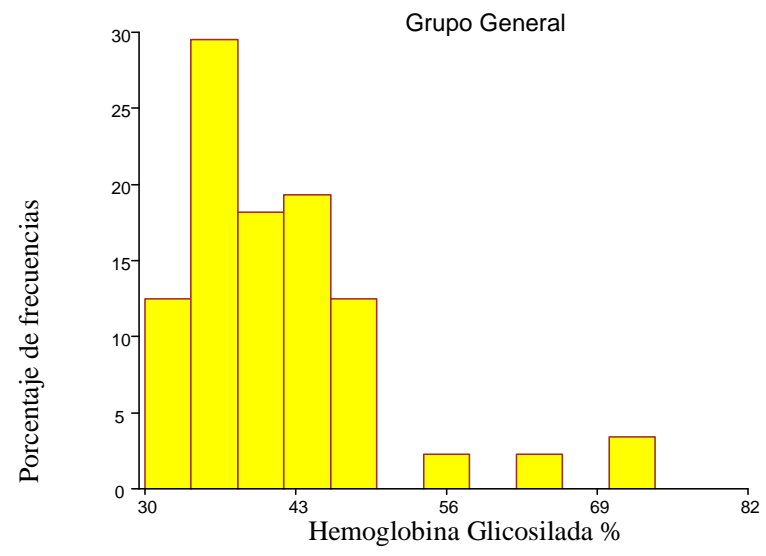

Figura 90. Distribución de la hemoglobina glicosilada NGSP en la muestra general.

\subsection{Hemoglobina glicosilada NGSP en Subgrupos GA, GB y GC.}

Grupo general (GG) y comparación entre grupos de pacientes masculinos con disfunción eréctil con diabetes mellitus (GA), con diagnósticos secundarios sin diabetes mellitus (GB) y sin diagnósticos secundarios (GC) en Hemoglobina glicosilada a1 NGSP.

La tabla 38 y las figuras 91 y 92 muestran la hemoglobina glicosilada ngsp en los grupos. La hemoglobina glicosilada como NGSP fue inferior en el subgrupo GC, los hombres con disfunción eréctil sin Diabetes Mellitus y sin diagnósticos secundarios ( $\mathrm{p}=0.0001)$.

\begin{tabular}{|l|l|l|l|l|}
\hline Grupo & $\begin{array}{l}\text { Hemoglobina glicosilada } \\
\text { NGSP media }\end{array}$ & Sd & Mediana & Rango \\
\hline GA & 6.62 & 0.95 & 6.4 & $5.5-8.8$ \\
\hline GB & 6.05 & 0.67 & 6 & $5.1-8.7$ \\
\hline GC & 5.7 & 0.73 & 5.5 & $5.1-8.7$ \\
\hline
\end{tabular}

Tabla 38. La hemoglobina glicosilada NGSP media en GA,GB y GC. 


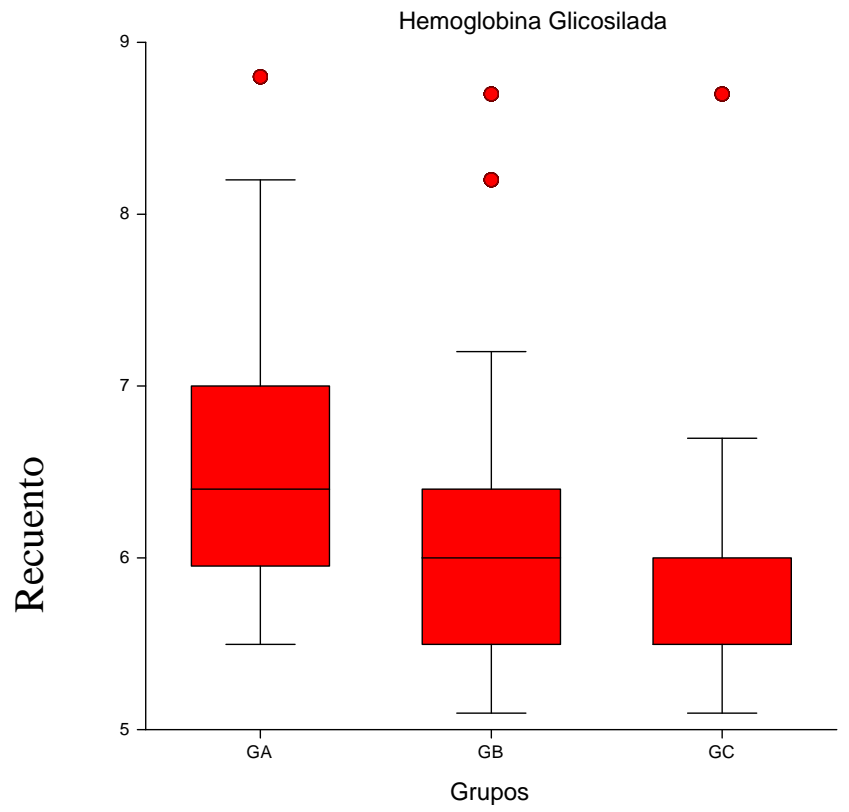

Figura 91. Distribución de la hemoglobina glicosilada NGSP.

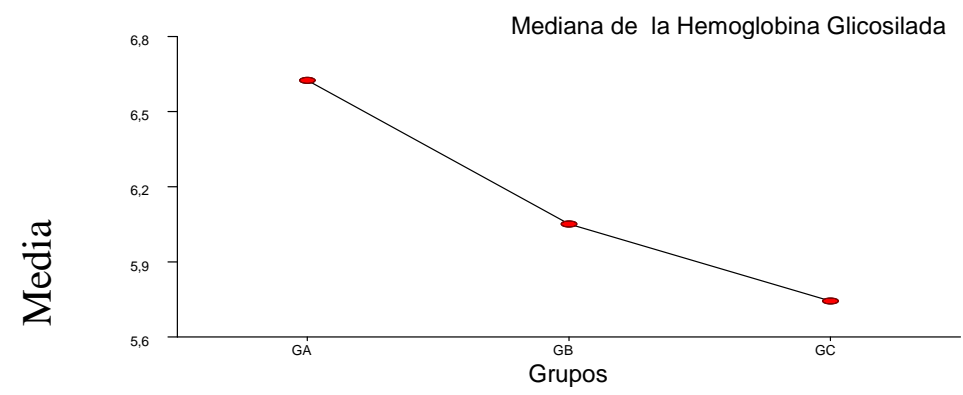

Figura 92. Media de la hemoglobina glicosilada NGSP en los grupos.

\subsection{Hemoglobina glicosilada NGSP en grupo GA.}

En la hemoglobina glicosilada NGSP la media fue 6.62, SD 0.95, mediana 6.4, rango 5.5-8.8 (figura 93). 


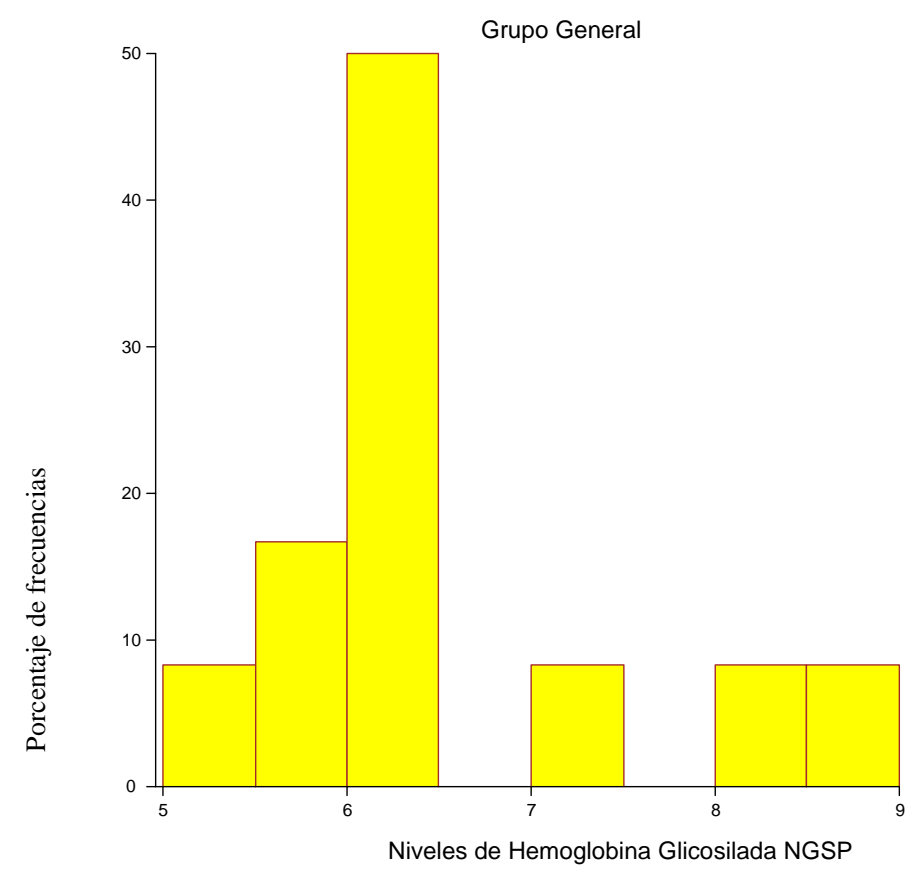

Figura 93. Distribución de la hemoglobina glicosilada NGSP en la muestra general.

\subsection{Hemoglobina glicosilada NGSP en subgrupos GAa, GAb y GAc}

La tabla 39 y las figuras 94 y 95 muestran la hemoglobina glicosilada ngsp en los grupos. No hubo diferencia de la hemoglobina glicosilada ngsp en los subgrupos GAa, Gab, Gac ( $\mathrm{p}=0.0511)$.

\begin{tabular}{|l|l|l|l|l|}
\hline Grupo & $\begin{array}{l}\text { Media de la hemoglobina } \\
\text { glicosilada ngsp }\end{array}$ & SD & Mediana & Rango \\
\hline GAa & 6.76 & 1.16 & 6.4 & $5.6-8.8$ \\
\hline GAb & 6.4 & 0 & 6.4 & $6.4-6.4$ \\
\hline GAc & 6.72 & 1.13 & 6.4 & $5.5-8.2$ \\
\hline
\end{tabular}

Tabla 39. Hemoglobina glicosilada media NGSP en GAa, GAb y GAc. 


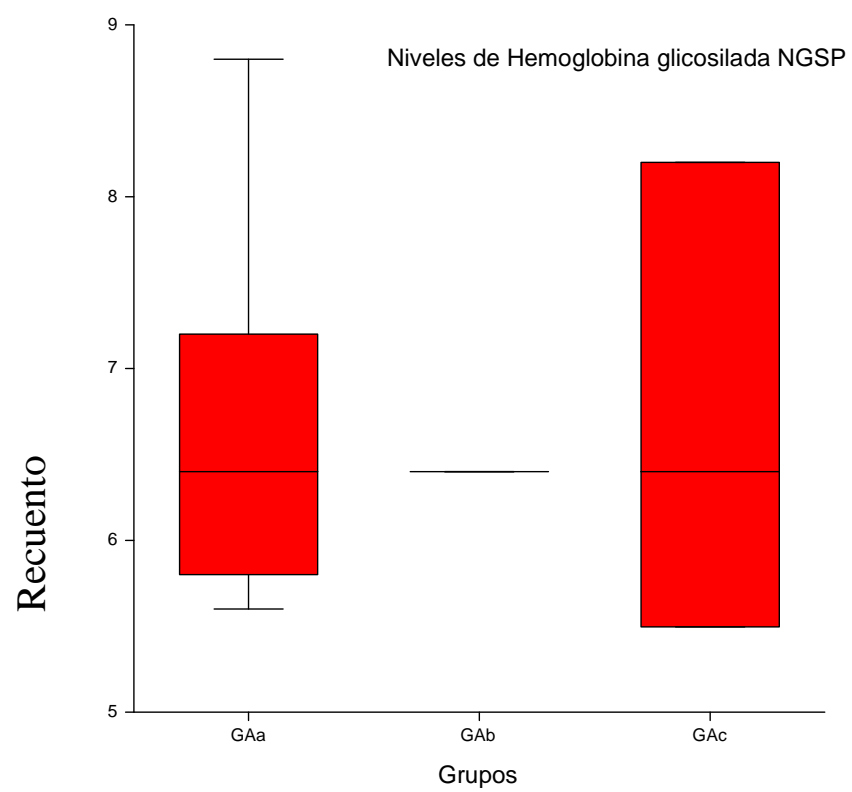

Figura 94. Distribución de la hemoglobina glicosilada NGSP.

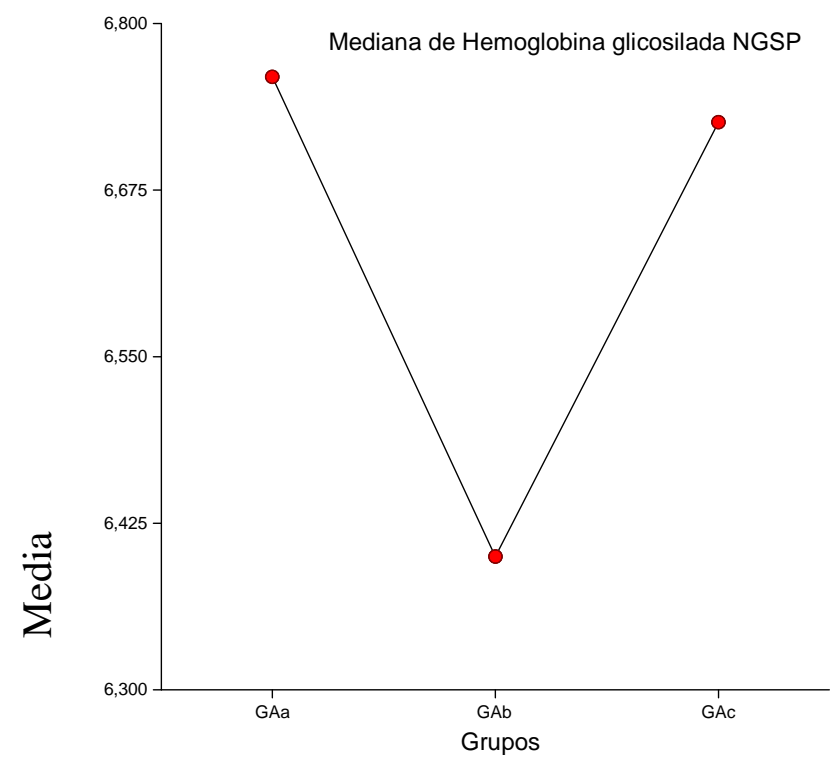

Figura 95. Media de la hemoglobina glicosilada NGSP en los subgrupos.

\subsection{Hemoglobina glicosilada NGSP en grupo GB.}

La hemoglobina glicosilada NGSP media fue 6.05, SD 0.67, mediana 6, rango 5.1-8.7 (figura 96). 


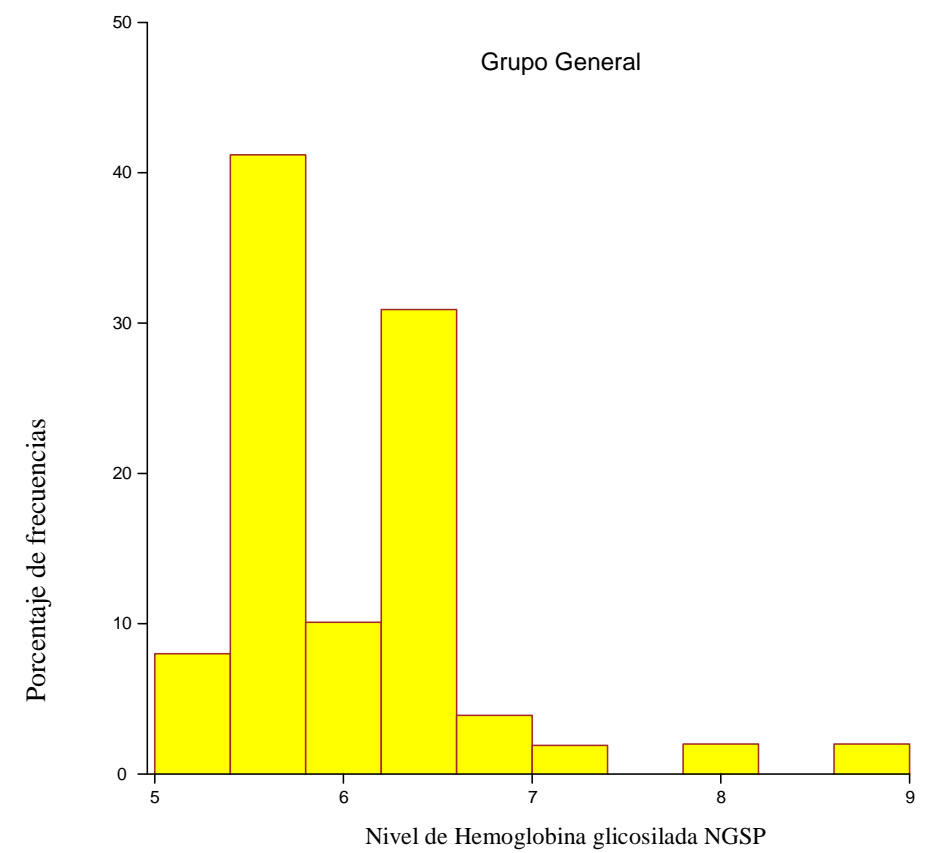

Figura 96. Distribución de la hemoglobina glicosilada NGSP en la muestra general.

La tabla 40 y las figuras 97 y 98 muestran la hemoglobina glicosilada NGSP en los grupos. No hubo diferencia de la hemoglobina glicosilada NGSP en los subgrupos Gba, Gbb, Gbc ( $\mathrm{p}=0.7552)$.

\begin{tabular}{|l|l|l|l|l|}
\hline Grupo & $\begin{array}{l}\text { Hemoglobina glicosilada } \\
\text { NGSP media }\end{array}$ & SD & Mediana & Rango \\
\hline $\mathrm{GBa}$ & 6.05 & 0.85 & 5.8 & $5.1-8.7$ \\
\hline $\mathrm{GBb}$ & 6.02 & 0.38 & 6 & $5.5-6.7$ \\
\hline $\mathrm{GBc}$ & 6.07 & 0.51 & 6 & $5.2-7.2$ \\
\hline
\end{tabular}

Tabla 40. La hemoglobina glicosilada media NGSP en GBa, GBb y GBc. 


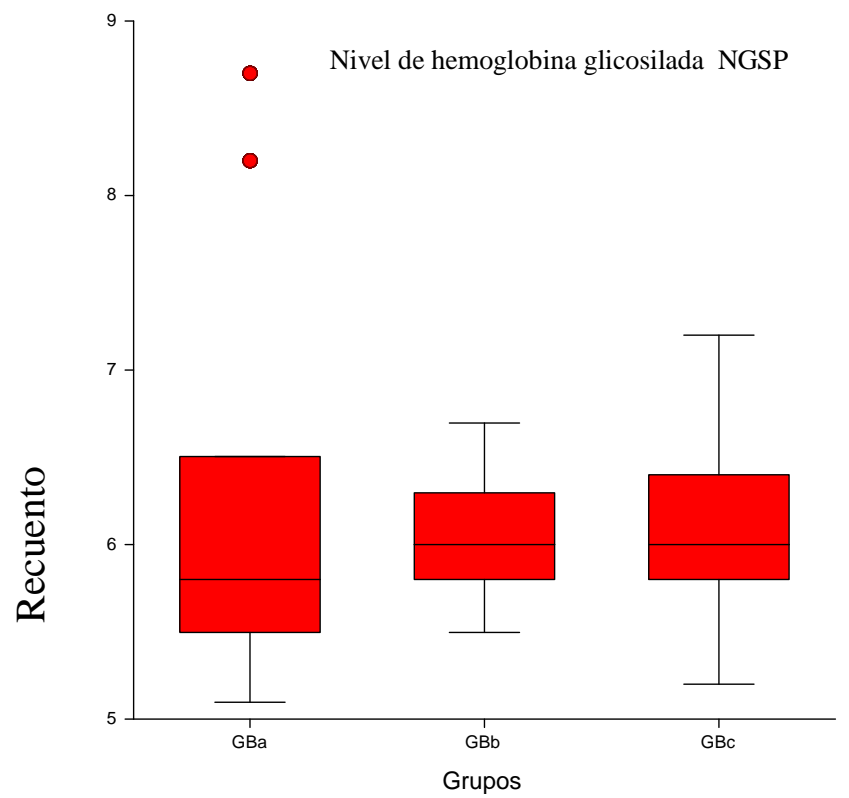

Figura 97. Distribución de hemoglobina glicosilada NGSP.

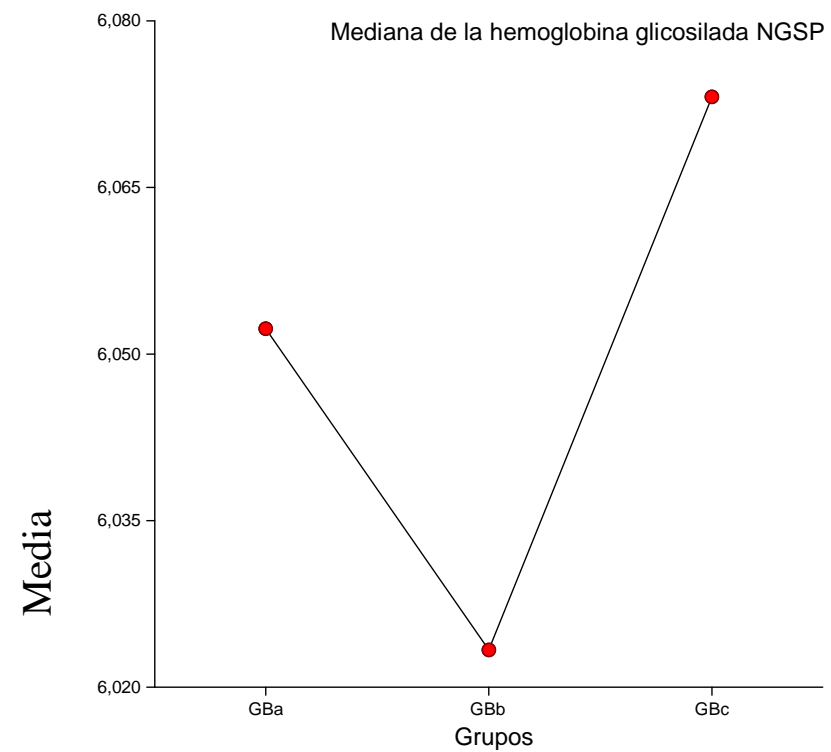

Figura 98. Media de la hemoglobina glicosilada NGSP en los grupos.

\subsection{Hemoglobina glicosilada NGSP GAa, GBa, GCa.}

La hemoglobina glicosilada NGSP media fue 12.86, SD 21.56, mediana 5.8, rango 5.1-9.5 (figura 99). 


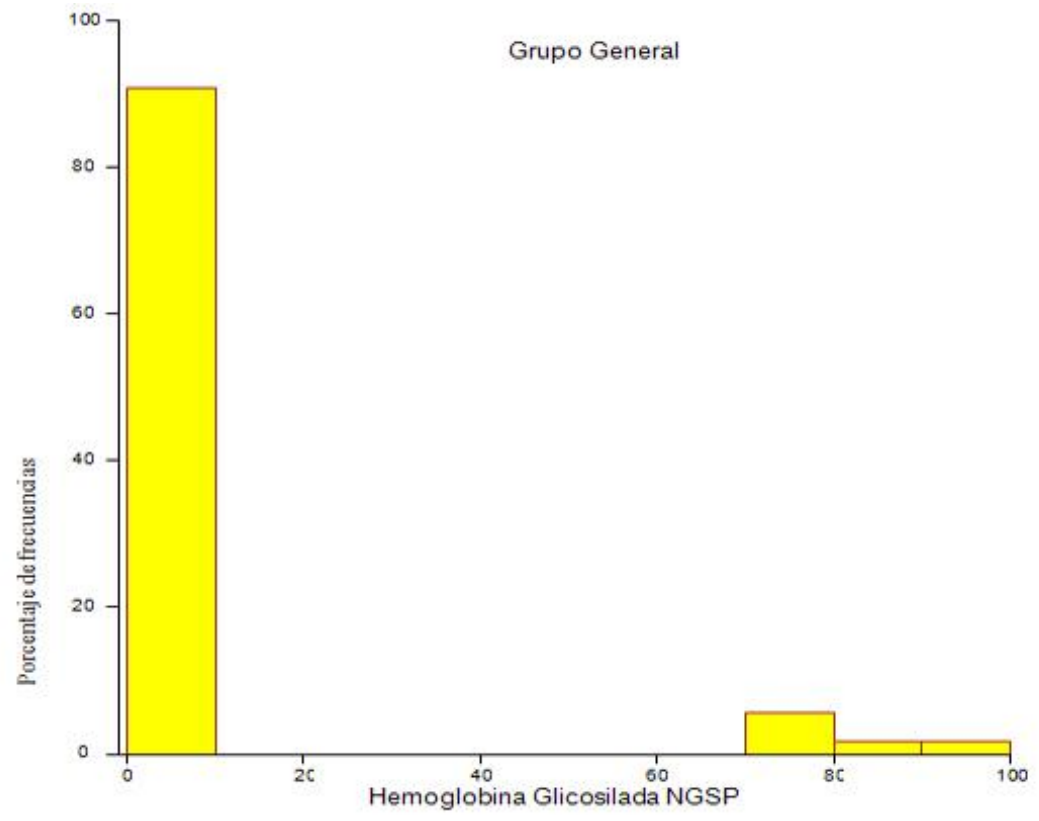

Figura 99. Distribución de la hemoglobina glicosilada NGSP en la muestra general.

La tabla 41 y las figuras 100 y 101 muestran la hemoglobina glicosilada NGSP en los grupos. La hemoglobina glicosilada NGSP en GCa fue inferior $(\mathrm{p}=0.0001)$.

\begin{tabular}{|l|l|l|l|l|}
\hline Grupo & $\begin{array}{l}\text { Hemoglobina glicosilada } \\
\text { NGSP media }\end{array}$ & SD & Mediana & Rango \\
\hline $\mathrm{GAa}$ & 6.76 & 1.16 & 6.4 & $5.6-8.8$ \\
\hline $\mathrm{GBa}$ & 6.05 & 0.85 & 5.8 & $5.1-8.7$ \\
\hline $\mathrm{GCa}$ & 5.80 & 0.81 & 5.5 & $5.1-8.7$ \\
\hline
\end{tabular}

Tabla 41. La hemoglobina glicosilada media NGSP en GAa, GBa y GCa 
LORENA SUÁREZ GUTIÉRREZ

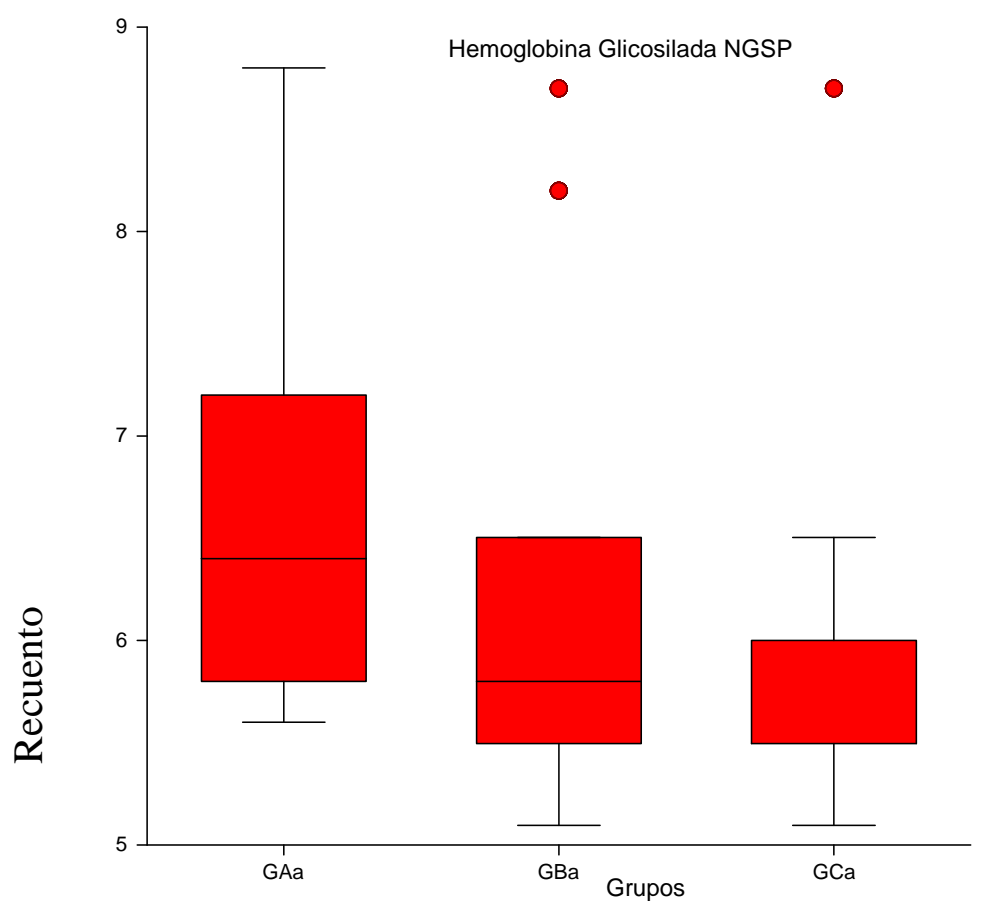

Figura 100. Distribución de hemoglobina glicosilada NGSP.

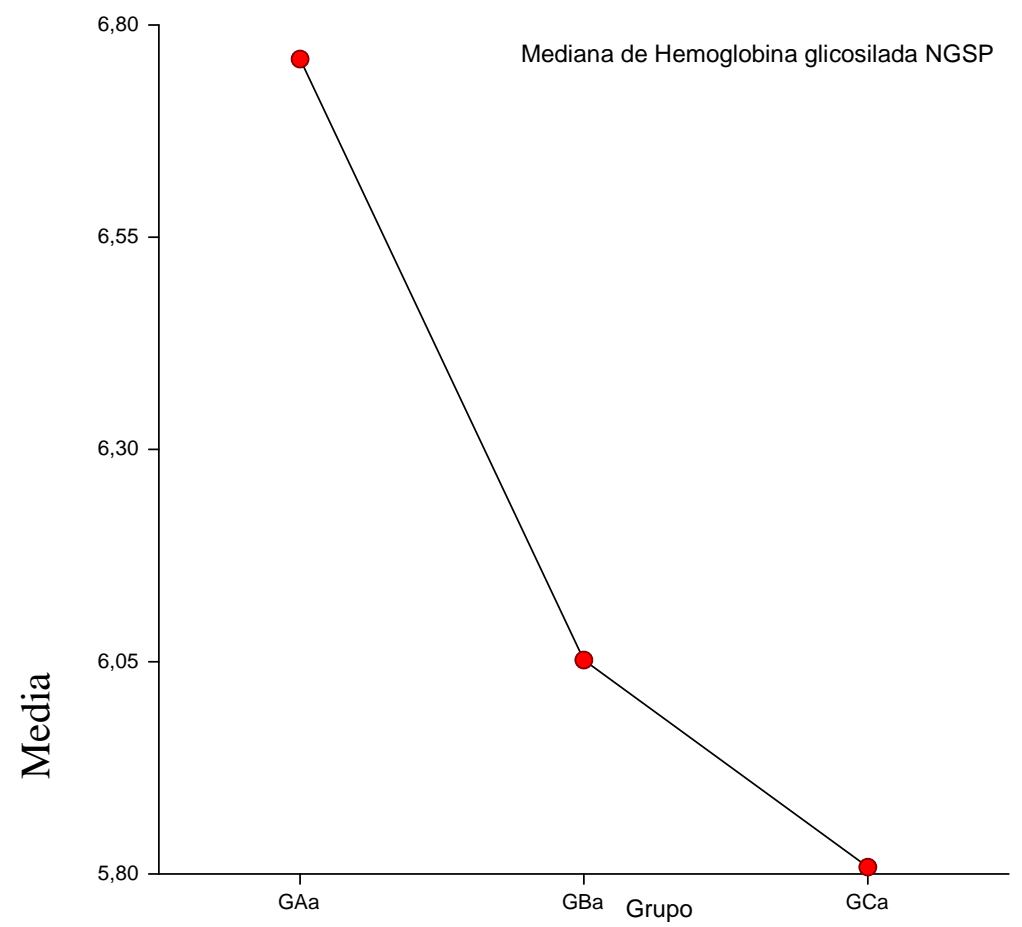

Figura 101. Media de la hemoglobina glicosilada NGSP en los grupos. 


\subsection{Hemoglobina glicosilada NGSP en subgrupo GAm, GAo, GAc.}

La hemoglobina glicosilada NGSP media fue 6.61, SD 0.93, mediana 6.4, rango 5.5-8.8 (figura 102).

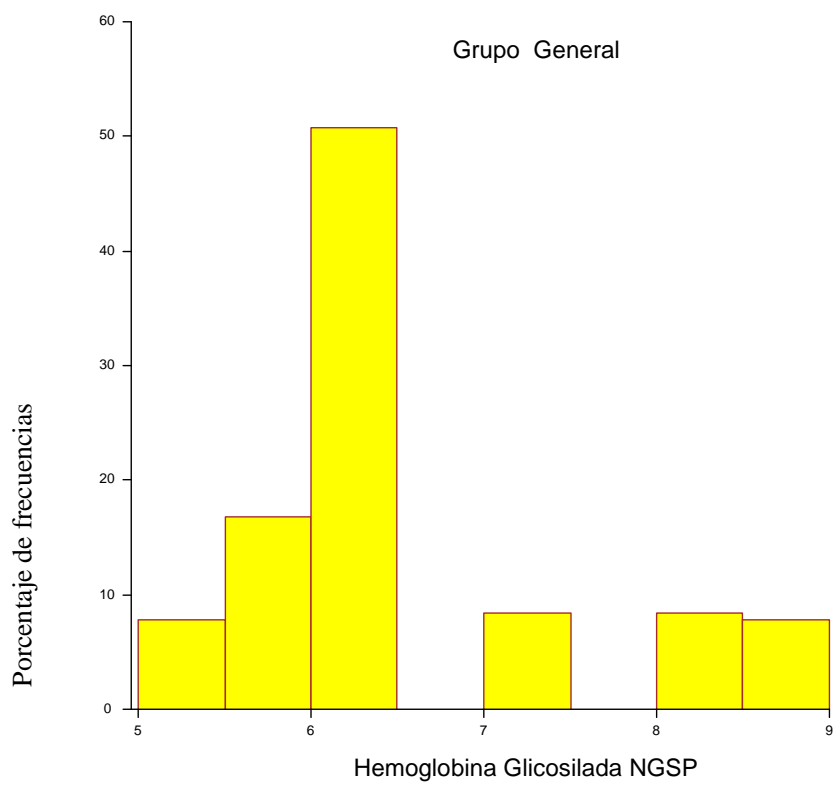

Figura 102. Distribución de la hemoglobina glicosilada NGSP en la muestra general.

La tabla 42 y las figuras 103 y 104 muestran la hemoglobina glicosilada NGSP en los grupos. La hemoglobina glicosilada NGSP en GAm fue inferior $(\mathrm{p}=0.0001)$.

\begin{tabular}{|l|l|l|l|l|}
\hline Grupo & $\begin{array}{l}\text { Hemoglobina glicosilada } \\
\text { NGSP media }\end{array}$ & SD & Mediana & Rango \\
\hline GAm & 6.20 & 0.34 & 6.4 & $5.6-6.4$ \\
\hline GAo & 7.15 & 1.67 & 7.15 & $5.5-8.8$ \\
\hline GAc & 6.7 & 0.77 & 6.4 & $5.8-8.2$ \\
\hline
\end{tabular}

Tabla 42. La hemoglobina glicosilada media NGSP en GAm, GAo y GAc. 


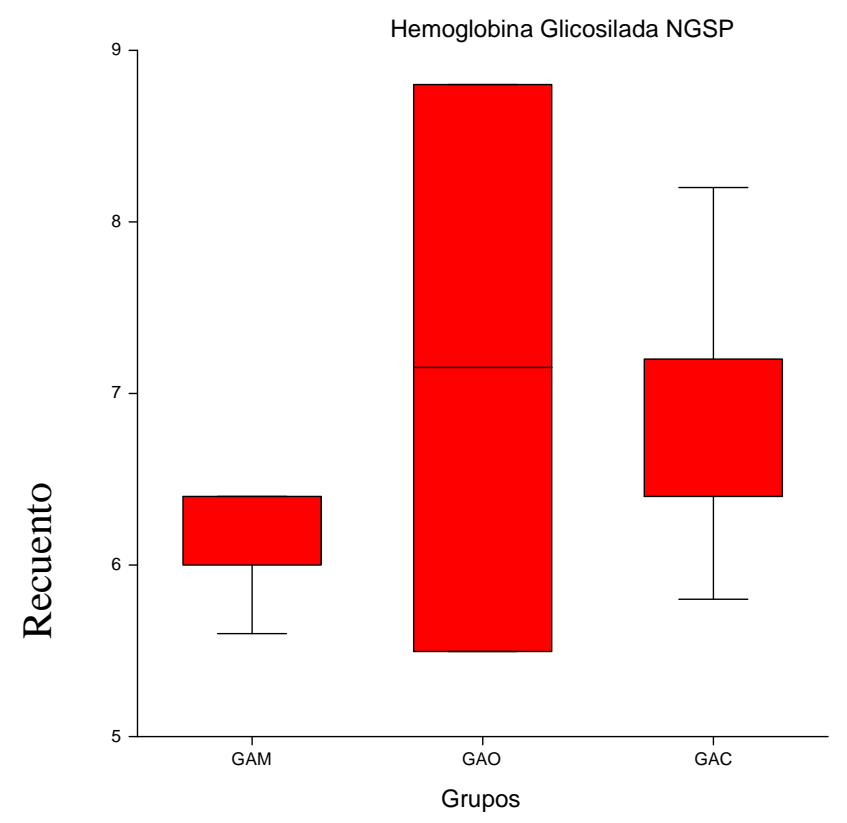

Figura 103. Distribución de la hemoglobina glicosilada NGSP.

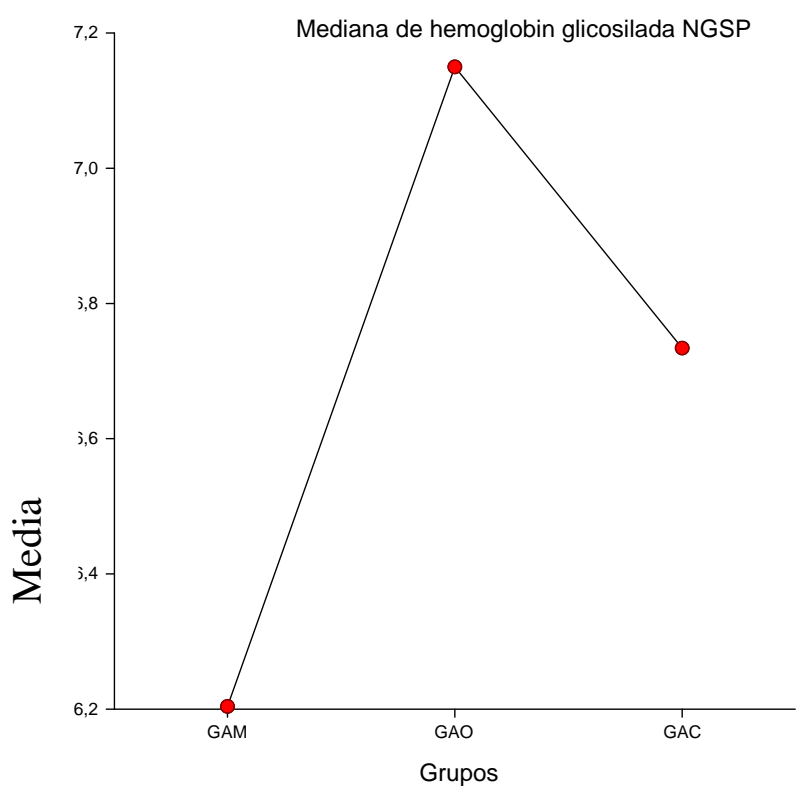

Figura 104. Media de la hemoglobina glicosilada NGSP en los grupos. 


\subsection{Hemoglobina glicosilada NGSP en subgrupo GAm.}

La hemoglobina glicosilada NGSP media fue 6.20, SD 0.34, mediana 6.4, rango 5.6-6.4 (figura 105).

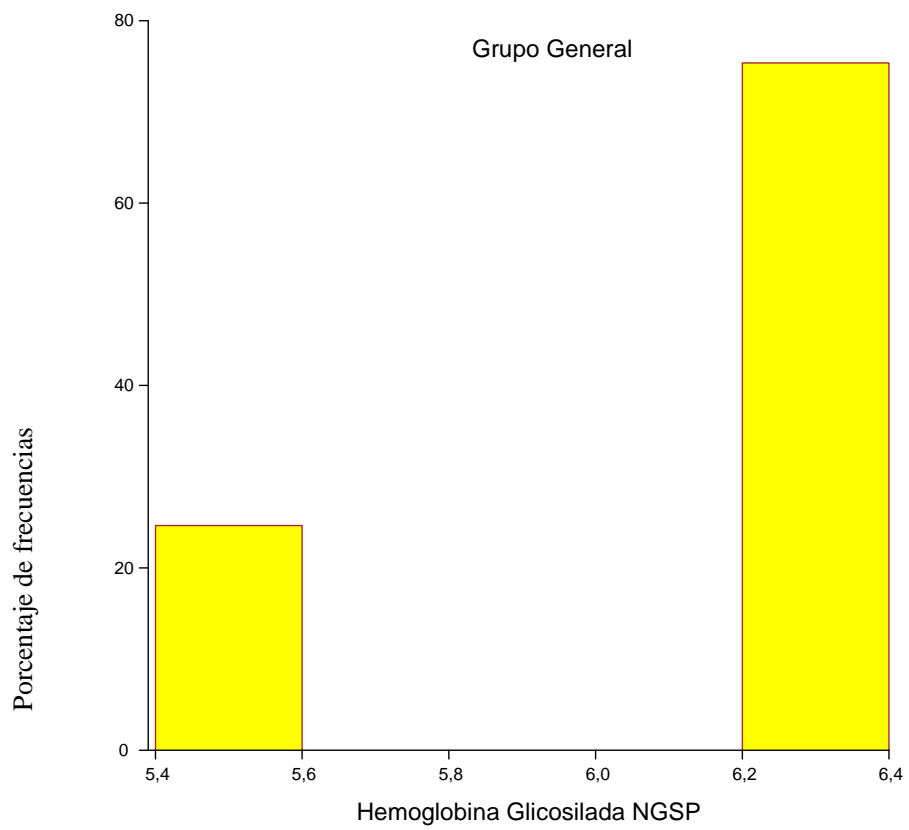

Figura 105. Distribución de la hemoglobina glicosilada NGSP en la muestra general.

5.08.1. Hemoglobina glicosilada NGSP en subgrupos GAma, GAmb, GAmc.

La tabla 43 y la figura 106 muestra la hemoglobina glicosilada NGSP en los grupos. La hemoglobina glicosilada NGSP en GAma fue inferior $(\mathrm{p}=0.0001)$.

\begin{tabular}{|l|l|l|l|l|}
\hline Grupo & $\begin{array}{l}\text { Hemoglobina glicosilada } \\
\text { NGSP media }\end{array}$ & SD & Mediana & Rango \\
\hline GAMa & 6.4 & 0.62 & 5.5 & $5.6-6.6$ \\
\hline GAMb & 6.4 & 0.16 & 6.4 & $6.3-6.5$ \\
\hline GAMc & 6.4 & 0.14 & 6.4 & $6.3-6.49$ \\
\hline
\end{tabular}

Tabla 43. La hemoglobina glicosilada media NGSP en GAma, GAmb y

$\underline{\text { GAmc. }}$. 


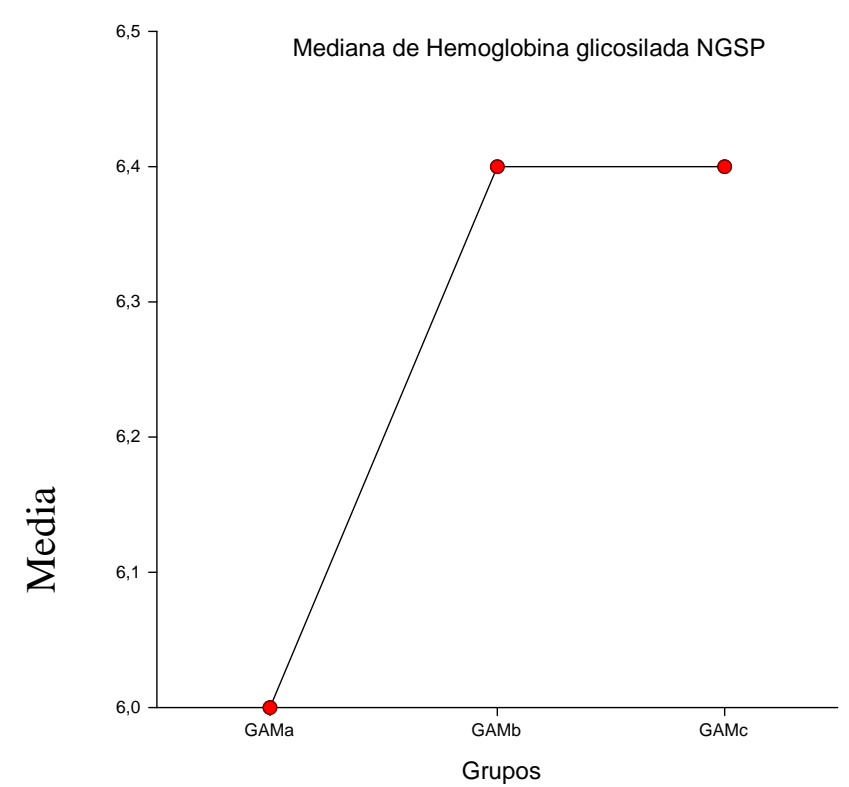

Figura 106. Media de la hemoglobina glicosilada NGSP en los subgrupos.

\subsection{Hemoglobina glicosilada NGSP en subgrupo GAo.}

La hemoglobina glicosilada NGSP media fue 7.15, SD 1.67, mediana 7.15, rango 5.5-8.8.

\subsubsection{Hemoglobina glicosilada NGSP en subgrupos GAoa, GAob,} GAoc.

La tabla 44 muestra la hemoglobina glicosilada NGSP en los grupos. No hubo pacientes en GAob. La hemoglobina glicosilada NGSP en GAOc fue inferior $(\mathrm{p}=0.0001)$.

\begin{tabular}{|l|l|l|l|l|}
\hline Grupo & $\begin{array}{l}\text { Hemoglobina glicosilada } \\
\text { NGSP media }\end{array}$ & SD & Mediana & Rango \\
\hline GAoa & 8.8 & 0.07 & 8.8 & $8.6-8.9$ \\
\hline GAoc & 5.5 & 0.06 & 5.5 & $5.3-5.8$ \\
\hline
\end{tabular}

Tabla 44. La hemoglobina glicosilada media NGSP en GAoa, GAob y GAoc. 


\subsection{Hemoglobina glicosilada NGSP en subgrupo GAc.}

La hemoglobina glicosilada NGSP media fue 6.73, SD 0.77 , mediana 6.4, rango 5.8-8.2 (figura 107).

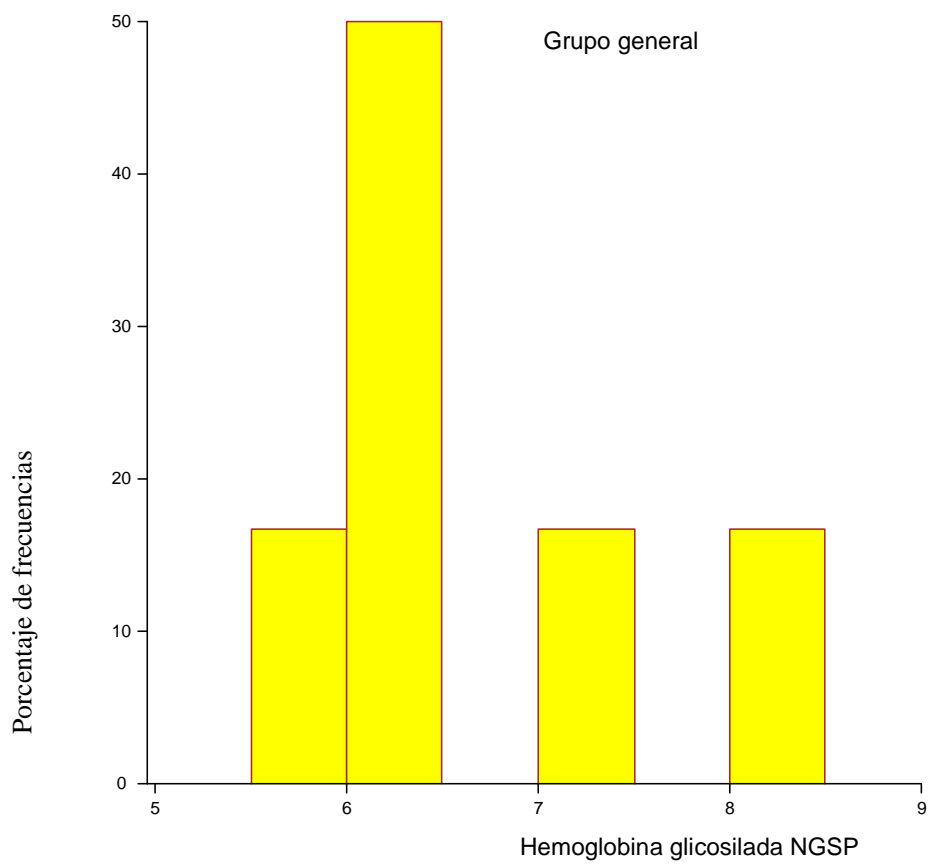

Figura 107. Distribución de la hemoglobina glicosilada NGSP en la muestra general.

5.10.1. Hemoglobina glicosilada NGSP en subgrupos GAca, GAcb, GAcc.

La tabla 45 y las figuras 108 y 109 muestran la hemoglobina glicosilada NGSP en los grupos. No hubo diferencias en los subgrupos GAca, GAcb y GAcc $(\mathrm{p}=0.8889)$.

\begin{tabular}{|l|l|l|l|l|}
\hline Grupo & $\begin{array}{l}\text { Hemoglobina glicosilada } \\
\text { NGSP media }\end{array}$ & SD & Mediana & Rango \\
\hline GAca & 6.72 & 0.78 & 6.4 & $5.70-8.31$ \\
\hline GAcb & 6.70 & 0.75 & 6.4 & $5.71-8.20$ \\
\hline GAcc & 6.81 & 0.84 & 6.4 & $5.61-8.42$ \\
\hline
\end{tabular}

Tabla 45. La hemoglobina glicosilada NGSP en GAca, GAcb y GAcc. 


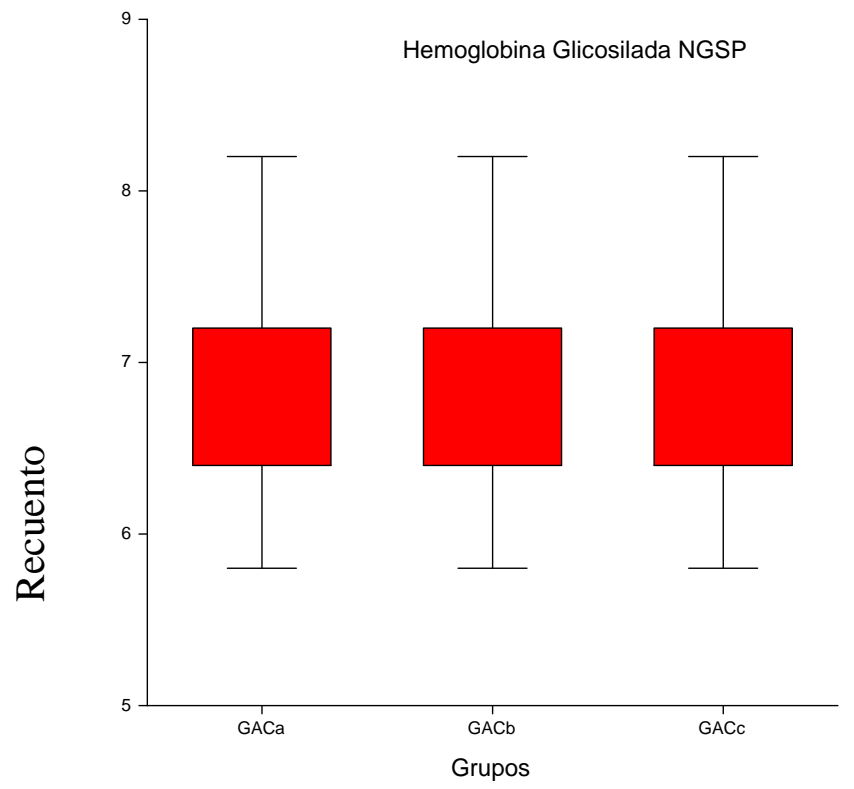

Figura 108. Distribución de la hemoglobina glicosilada NGSP.

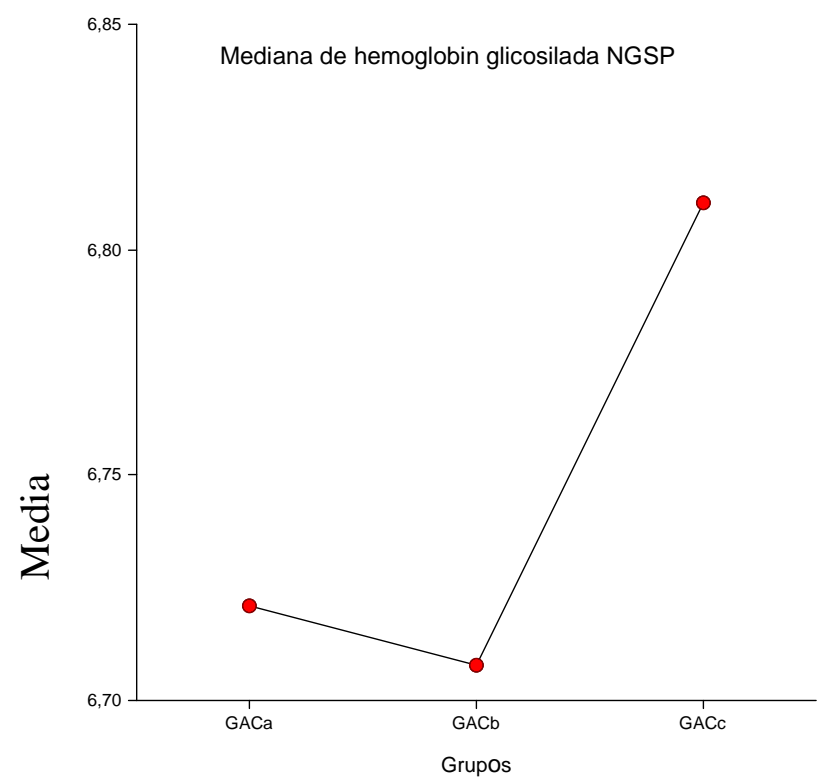

Figura 109. Media de la hemoglobina glicosilada NGSP en los grupos. 


\section{HEMOGLOBINA GLICOSILADA IFCC.}

\subsection{Hemoglobina Glicosilada IFCC en la muestra general.}

La hemoglobina glicosilada ifcc media fue 42.48, SD 8.60, mediana 40, rango 32-73 (figura 110).

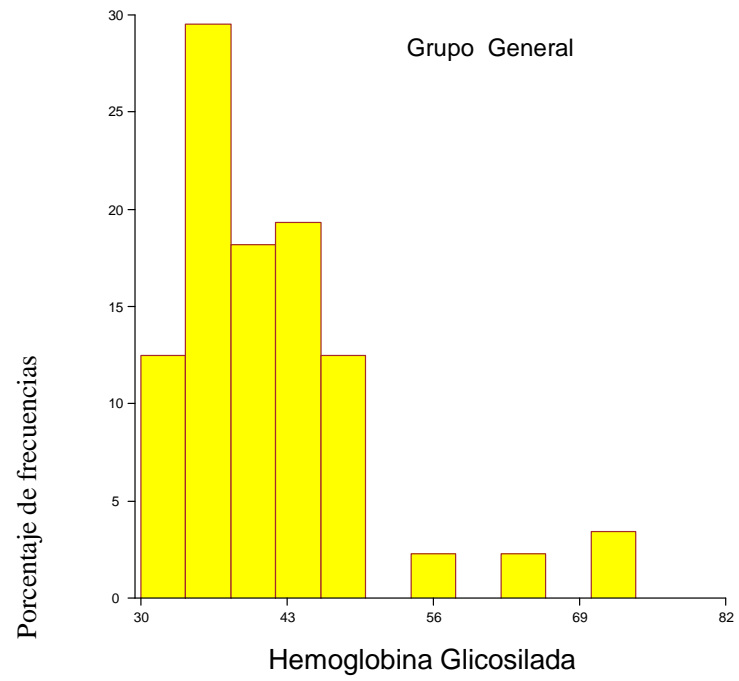

Figura 110. Distribución de la hemoglobina glicosilada IFCC en la muestra general.

\subsection{Hemoglobina Glicosilada IFCC en subgrupos GA, GB, GC.}

Grupo general (GG) y comparación entre grupos de pacientes masculinos con disfunción eréctil con diabetes mellitus (GA), con diagnósticos secundarios sin diabetes mellitus (GB) y sin diagnósticos secundarios (GC) en la Hemoglobina Glicosilada NGSP.

La tabla 46 y las figuras 111 y 112 muestran la hemoglobina glicosilada ifcc en los grupos. La hemoglobina glicosilada medida como IFCC fue inferior en el subgrupo GC, hombres con disfunción eréctil sin Diabetes Mellitus y sin diagnósticos secundarios $(\mathrm{p}=0.0001)$.

\begin{tabular}{|l|l|l|l|l|}
\hline Grupo & $\begin{array}{l}\text { Hemoglobina glicosilada } \\
\text { IFCC media }\end{array}$ & Sd & Mediana & Rango \\
\hline GA & 48.75 & 10.43 & 46 & $37-73$ \\
\hline GB & 42.65 & 7.37 & 42 & $32-72$ \\
\hline GC & 39.34 & 8.01 & 37 & 32.72 \\
\hline
\end{tabular}

Tabla 46. La hemoglobina glicosilada media IFFC en GA, GB y GC. 


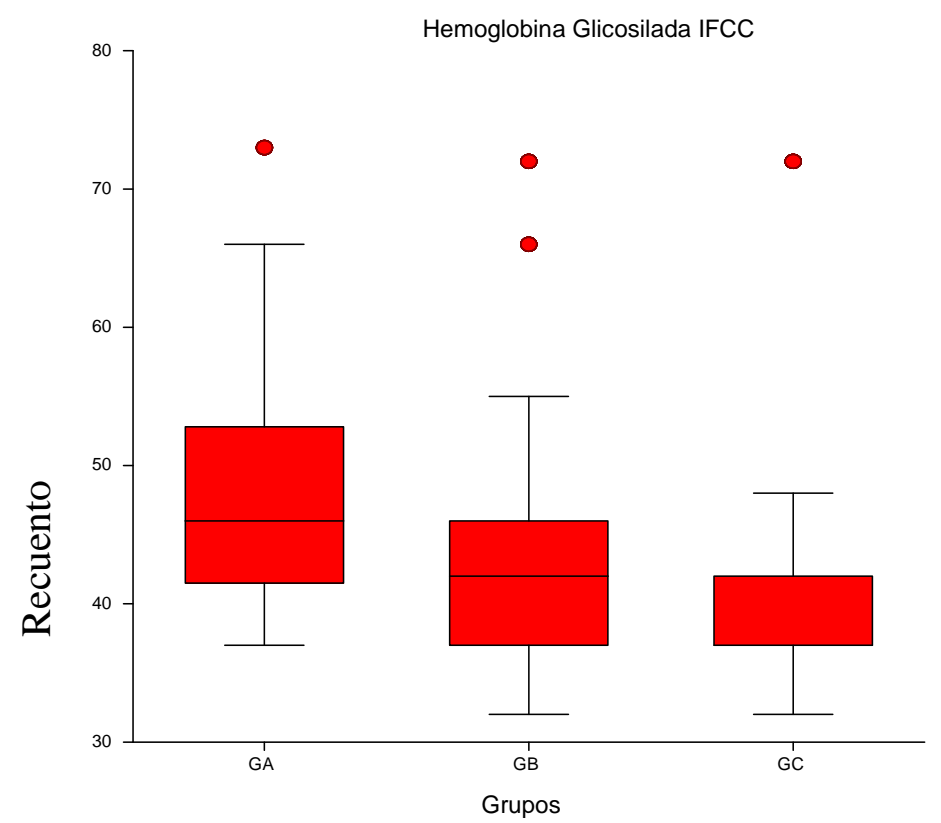

Figura 111. Distribución de la hemoglobina glicosilada IFCC.

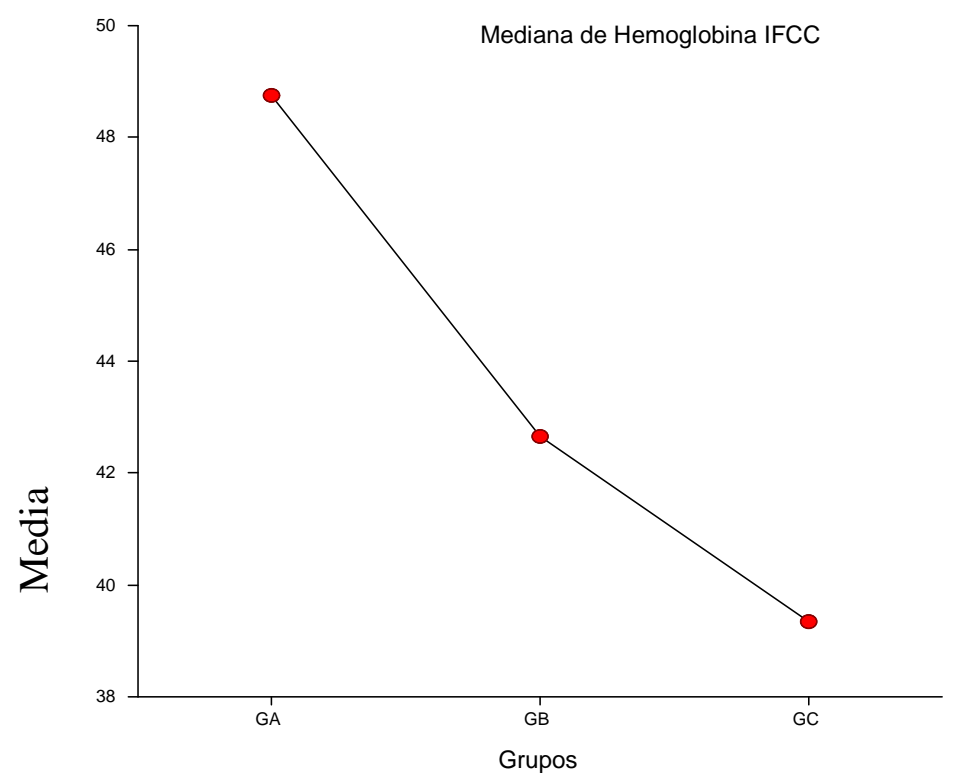

Figura 112. Media de la hemoglobina glicosilada IFCC en los grupos 
6.03. Hemoglobina glicosilada IFCC en muestra general en subgrupos GA

La hemoglobina glicosilada IFCC media fue 54.59, SD 11.16, mediana 55, rango 37-73 (figura 113).

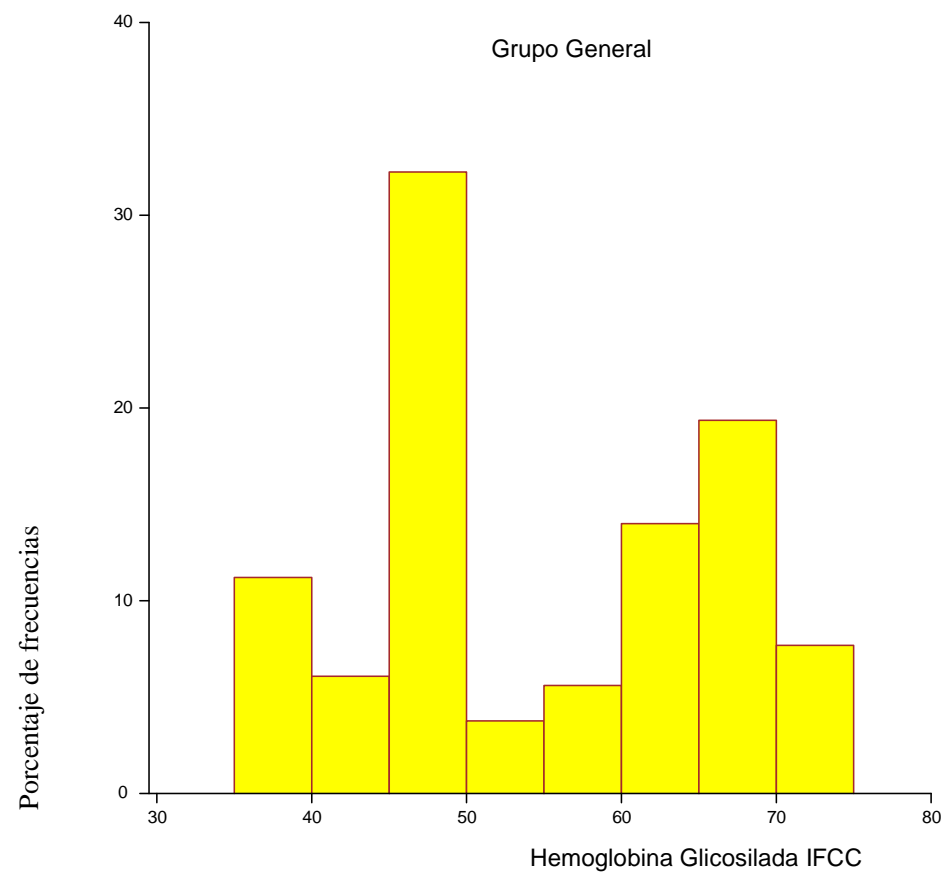

Figura 113. Distribución de la hemoglobina glicosilada IFCC en la muestra general.

\subsection{Hemoglobina glicosilada IFCC en muestra general en grupo GAa, GAb y GAc}

La tabla 47 y las figuras 114 y 115 muestran la hemoglobina glicosilada IFCC en los grupos. La hemoglobina glicosilada IFCC en GAb fue inferior $(\mathrm{p}=0.0373)$.

\begin{tabular}{|l|l|l|l|l|}
\hline Grupo & $\begin{array}{l}\text { Hemoglobina glicosilada } \\
\text { IFCC media }\end{array}$ & SD & Mediana & Rango \\
\hline GAa & 50.4 & 12.83 & 46 & $38-73$ \\
\hline Gab & 46 & 0.04 & 46 & $45-47$ \\
\hline Gac & 49.93 & 12.23 & 46 & $37-66$ \\
\hline
\end{tabular}

Tabla 47. La hemoglobina glicosilada media IFCC en GAa, GAb y GAc. 


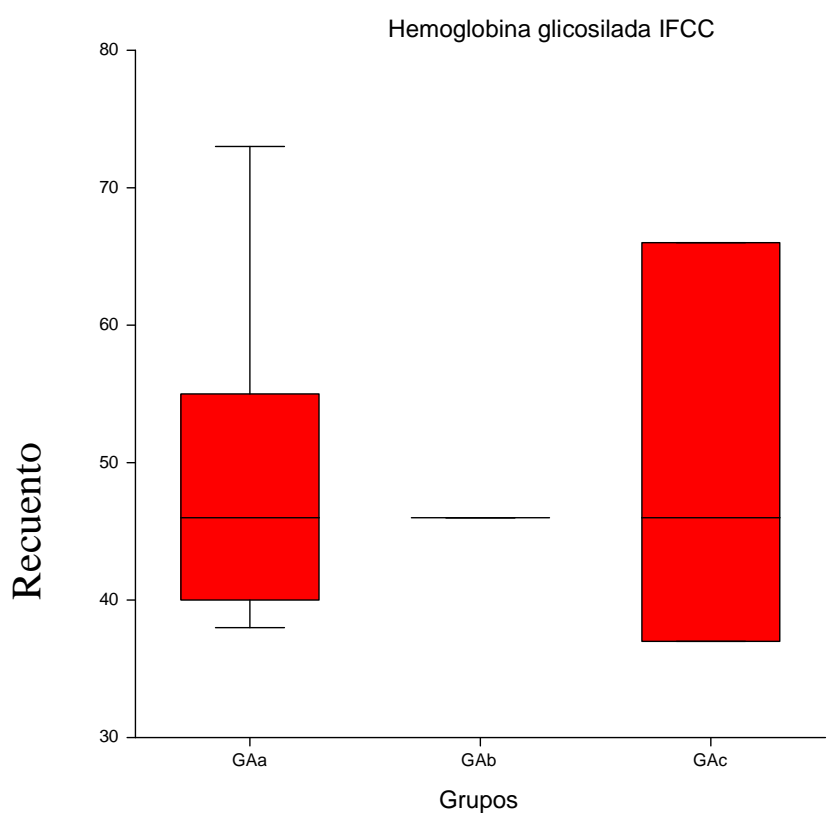

Figura 114. Distribución de la hemoglobina glicosilada IFCC.

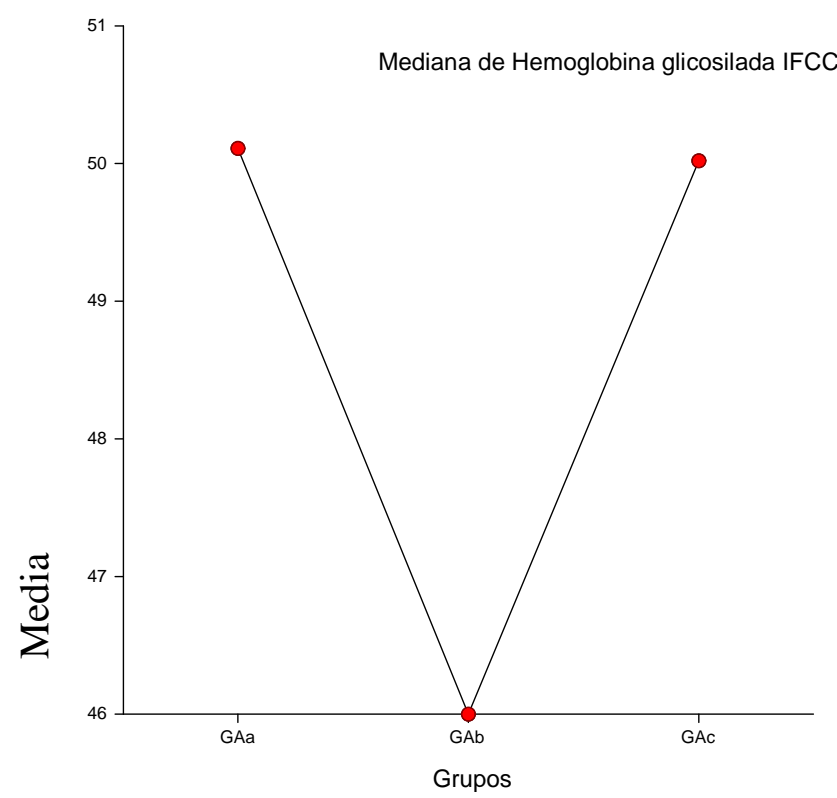

Figura 115. Media de la hemoglobina glicosilada IFCC en los grupos 
GB.

\subsection{Hemoglobina glicosilada IFCC en muestra general en grupo}

La hemoglobina glicosilada IFCC media fue 42.65, SD 9.42, mediana 40, rango 32-72 (figura 116).

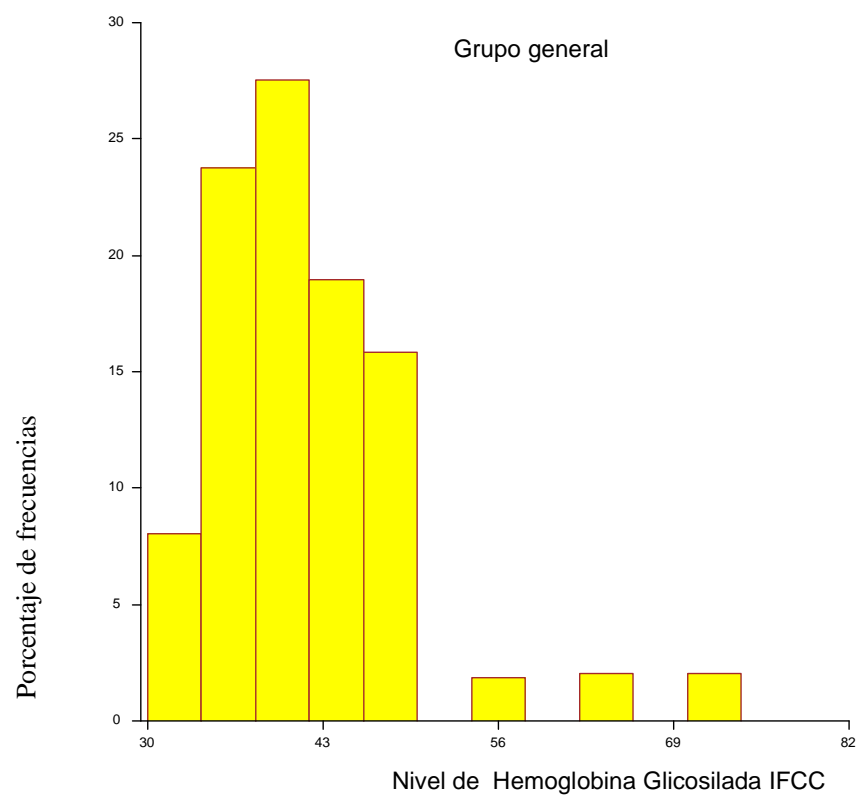

Figura 116. Distribución de la hemoglobina glicosilada IFCC en la muestra general.

La tabla 48 y las figuras 117 y 118 muestran la hemoglobina glicosilada IFCC en los grupos. No hubo diferencia de la hemoglobina glicosilada IFCC en los subgrupos GBa, GBb y $\mathrm{GBc}(\mathrm{p}=0.8812)$.

\begin{tabular}{|l|l|l|l|l|}
\hline Grupo & $\begin{array}{l}\text { Hemoglobina glicosilada } \\
\text { IFCC media }\end{array}$ & SD & Mediana & Rango \\
\hline $\mathrm{GBa}$ & 48.75 & 10.43 & 46 & $37-73$ \\
\hline $\mathrm{GBb}$ & 42.65 & 7.37 & 42 & $32-72$ \\
\hline $\mathrm{GBc}$ & 39.34 & 8.01 & 37 & 32.72 \\
\hline
\end{tabular}

Tabla 48. La hemoglobina glicosilada media IFCC en GBa, GBb y GBc 


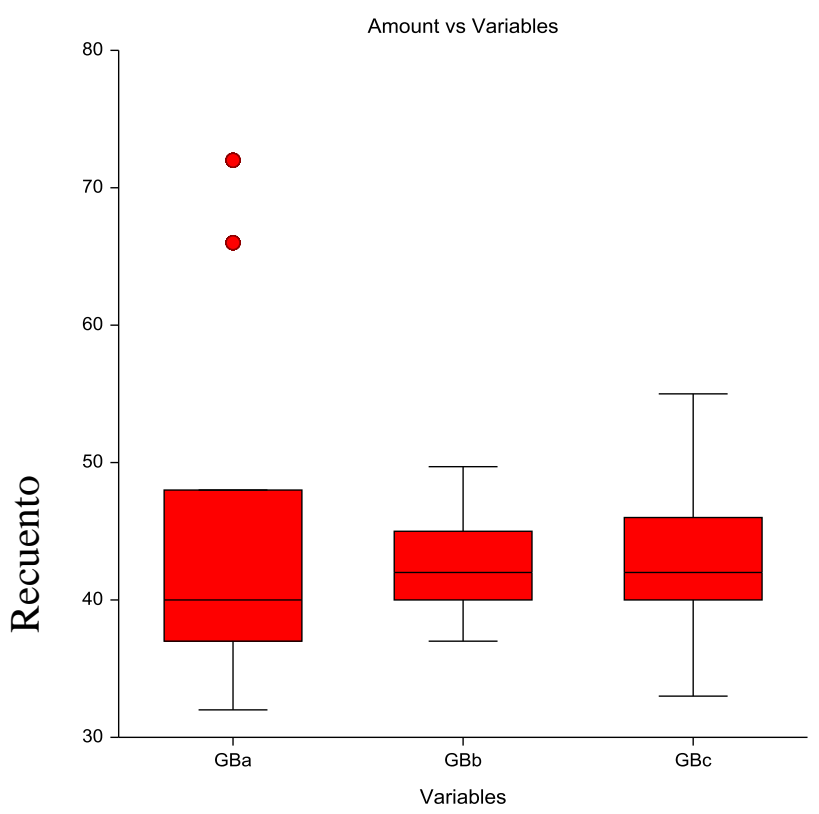

Figura 117. Distribución de la hemoglobina glicosilada IFCC.

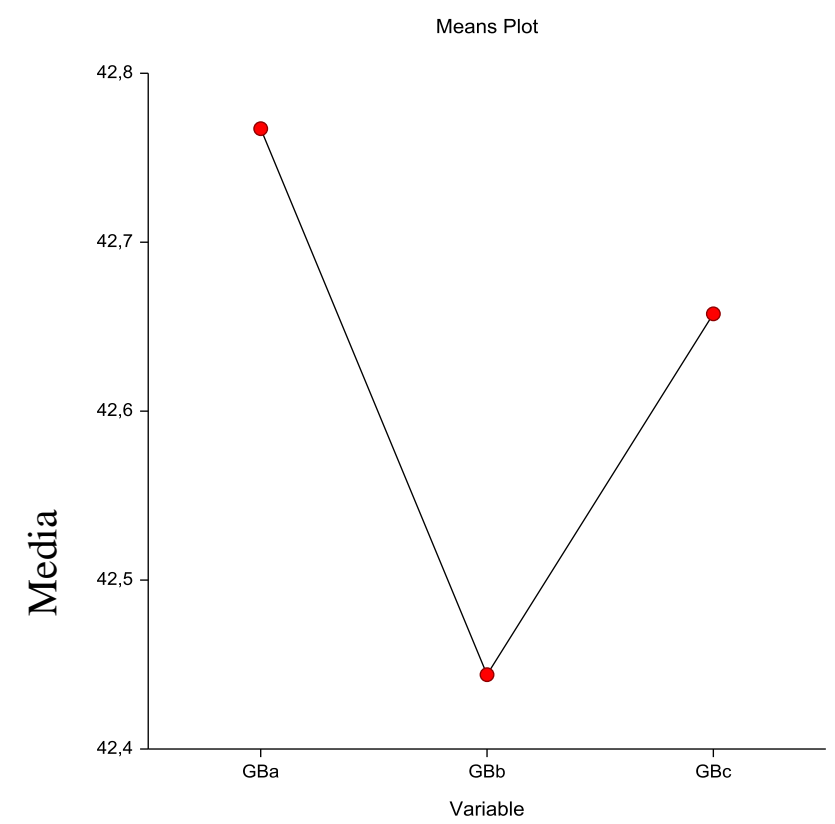

Figura 118. Media de la hemoglobina glicosilada IFCC en los grupos. 


\subsection{Hemoglobina glicosilada IFCC en subgrupos GAa, GBa, GCa.}

La hemoglobina glicosilada IFCC media fue 46.03, SD 14.70, mediana 40, rango 32-95 (figura 119).

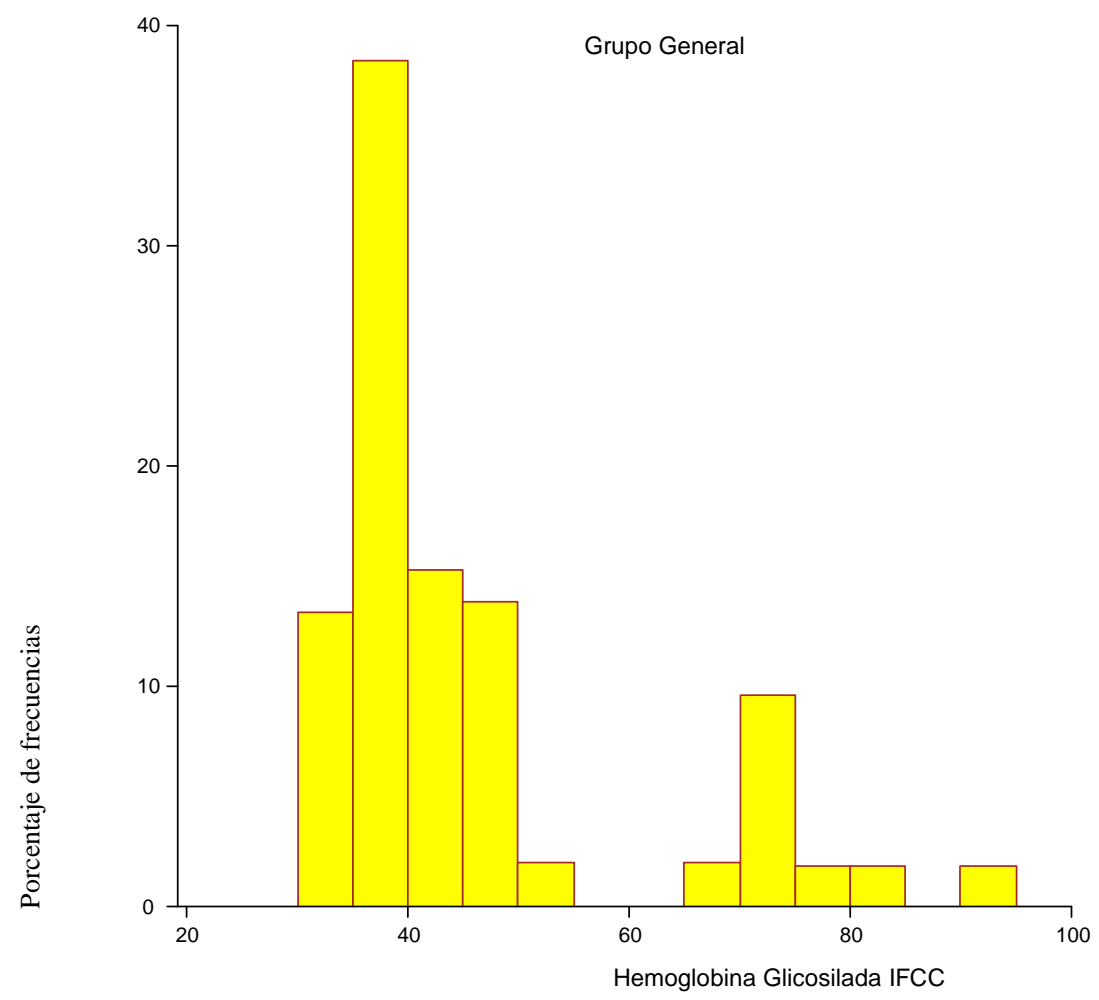

Figura 119. Distribución de la hemoglobina glicosilada IFCC en la muestra general.

La tabla 49 y las figuras 120 y 121 muestran la hemoglobina glicosilada IFCC en los grupos. La hemoglobina glicosilada IFCC en GCa fue inferior respecto a GAa y a $\mathrm{GBa}(\mathrm{p}=0.0001)$.

\begin{tabular}{|l|l|l|l|l|}
\hline Grupo & $\begin{array}{l}\text { Hemoglobina glicosilada } \\
\text { IFCC media }\end{array}$ & SD & Mediana & Rango \\
\hline $\mathrm{GAa}$ & 50.4 & 12.83 & 46 & $38-73$ \\
\hline $\mathrm{GBa}$ & 42.76 & 9.42 & 40 & $32-72$ \\
\hline $\mathrm{GCa}$ & 40.02 & 9.01 & $32-72$ & 37 \\
\hline
\end{tabular}

Tabla 49. La hemoglobina glicosilada media IFCC en GAa, GBa y GCa. 
LORENA SUÁREZ GUTIÉRREZ

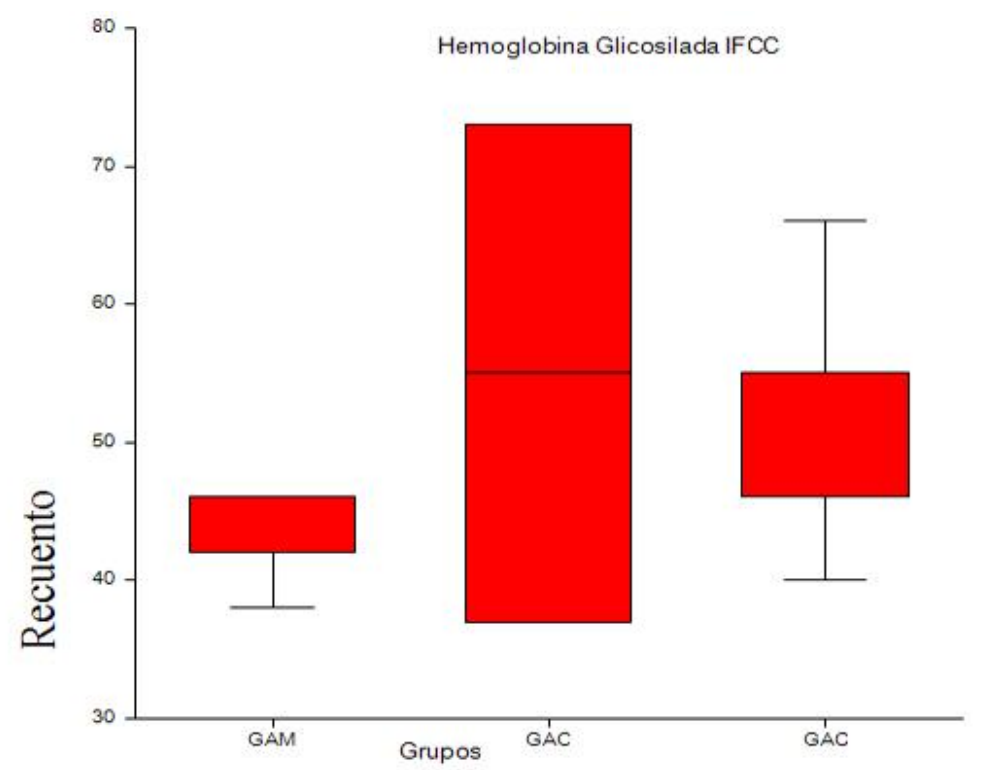

Figura 120. Distribución de la hemoglobina glicosilada IFCC.

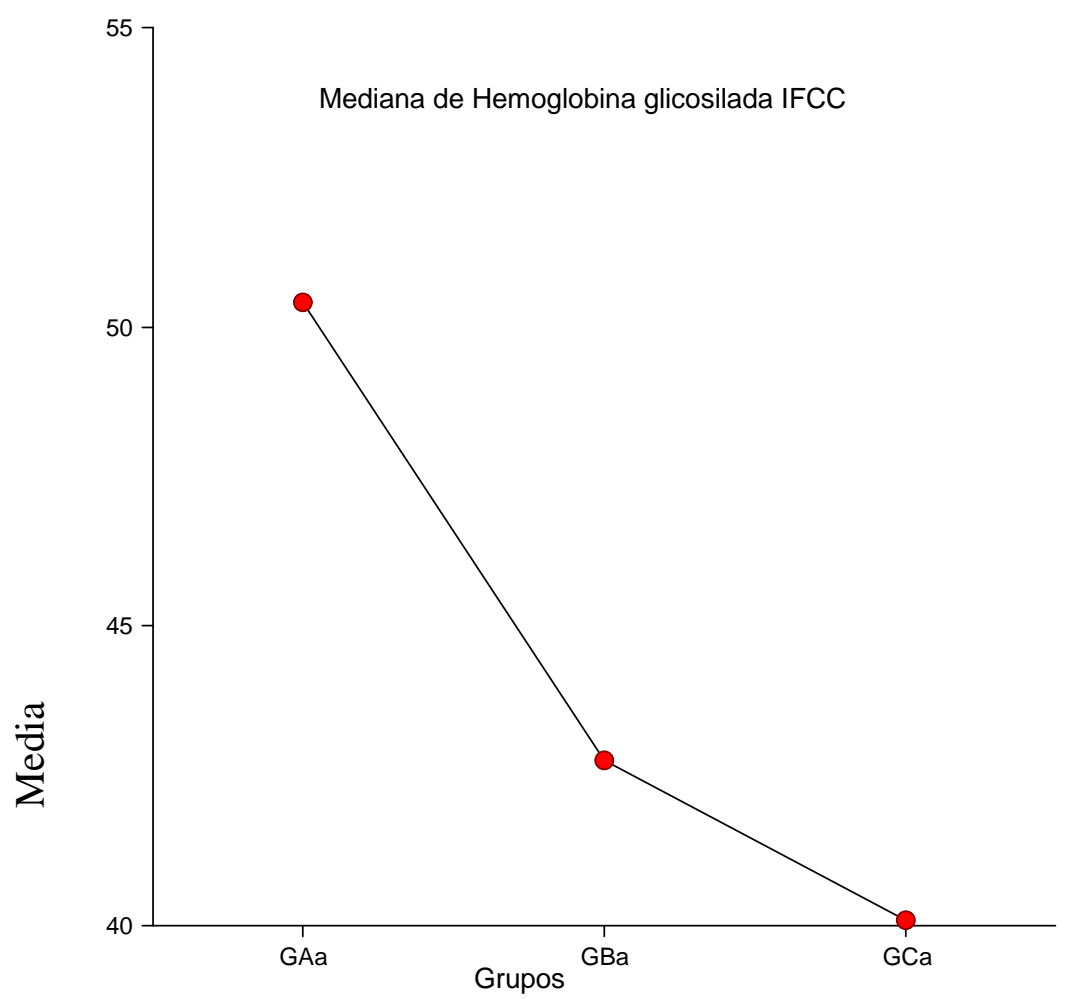

Figura 121. Media de la hemoglobina glicosilada IFCC en los grupo 


\subsection{Hemoglobina glicosilada IFCC en subgrupo GAm, GAo y GAc}

La hemoglobina glicosilada IFCC media fue 48.67, SD 10.28, mediana 46, rango 37-73 (figura 122).

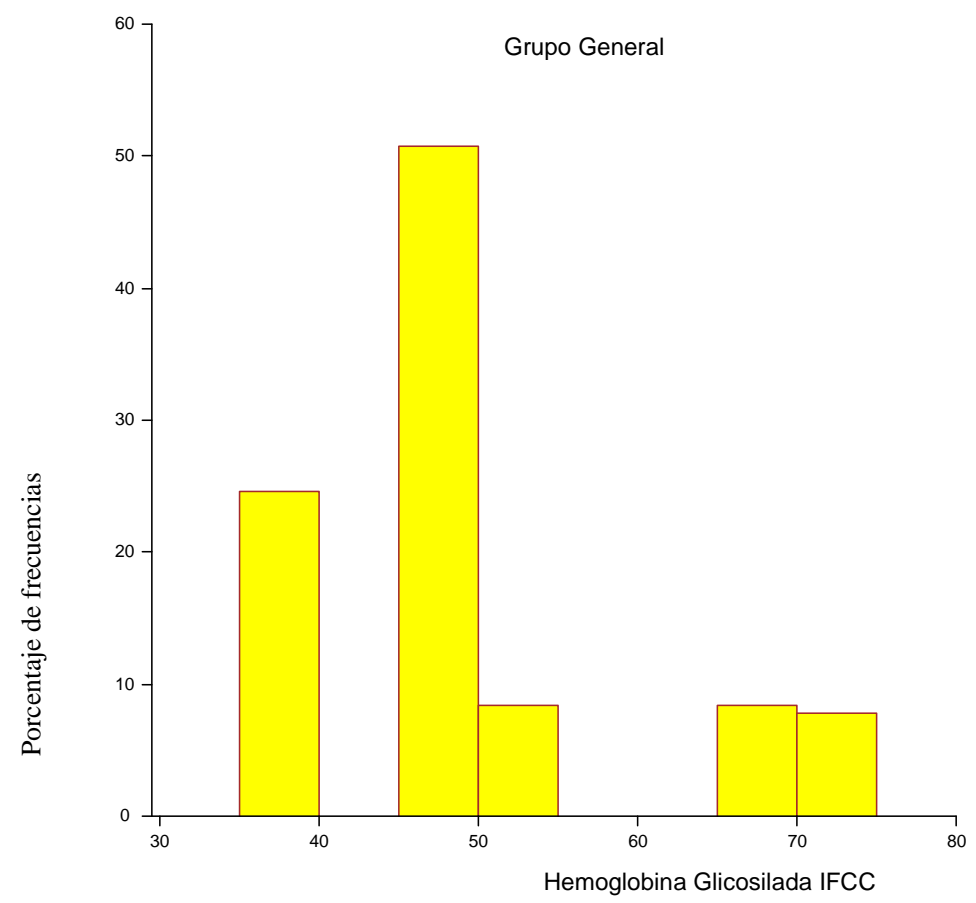

Figura 122. Distribución de la hemoglobina glicosilada IFCC en la muestra general.

La tabla 50 y las figuras 123 y 124 muestran la hemoglobina glicosilada IFCC en los grupos. La hemoglobina glicosilada IFCC en GAm fue inferior respecto a GAo y a GAc ( $\mathrm{p}=0.0001)$.

\begin{tabular}{|l|l|l|l|l|}
\hline Grupo & $\begin{array}{l}\text { Hemoglobina glicosilada } \\
\text { IFCC media }\end{array}$ & SD & Mediana & Rango \\
\hline GAm & 44.03 & 3.47 & 46 & $38-46$ \\
\hline GAo & 55 & 18.30 & 55 & $37-73$ \\
\hline GAc & 49.83 & 8.49 & 46 & $40-66$ \\
\hline
\end{tabular}

Tabla 50. La hemoglobina glicosilada media IFCC en GAm, GAo y GAc. 
LORENA SUÁREZ GUTIÉRREZ

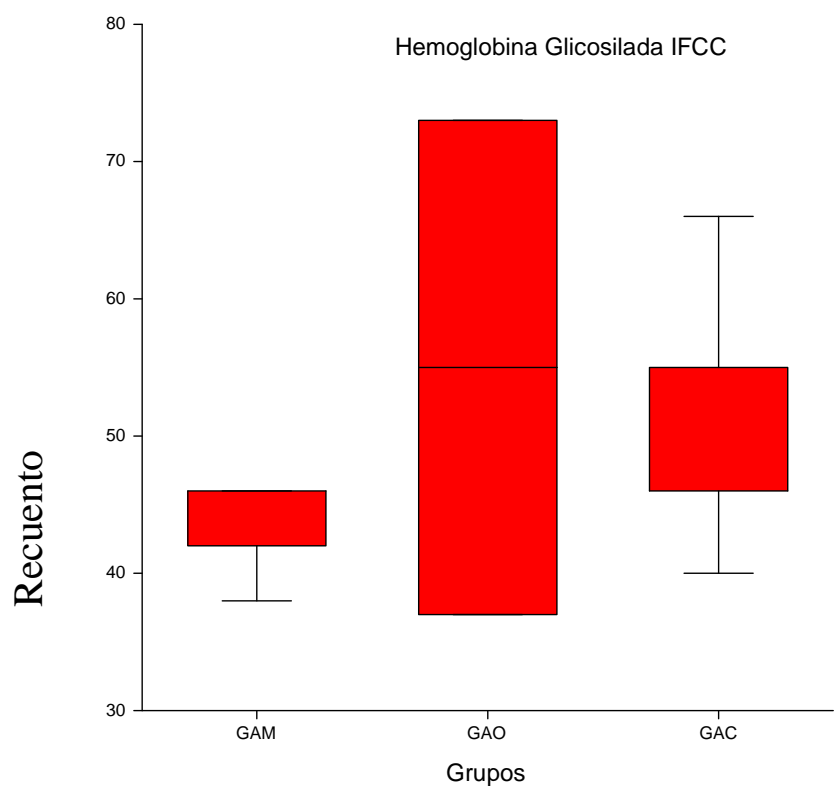

Figura 123. Distribución de la hemoglobina glicosilada IFCC.

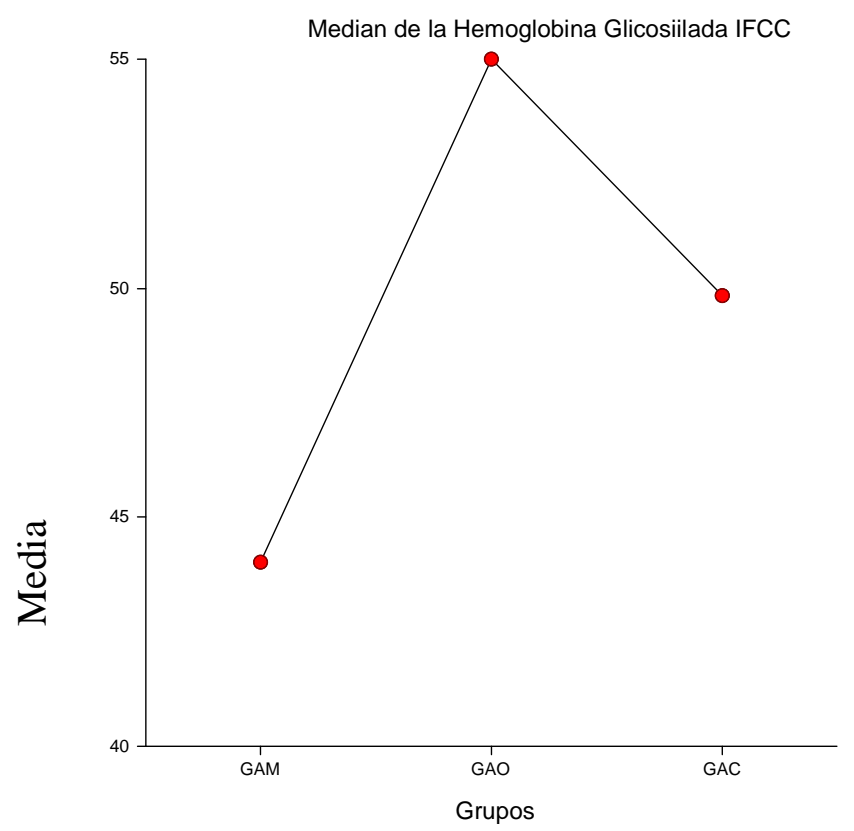

Figura 124. Media de la hemoglobina glicosilada IFCC en los grupos 


\subsection{Hemoglobina glicosilada IFCC en subgrupo GAm}

La hemoglobina glicosilada IFCC media fue 44.03, SD 3.47, mediana 46 , rango 38-46.

\section{GAmc.}

6.08.1. Hemoglobina glicosilada IFCC en subgrupo GAma, GAmb y

La tabla 51 y la figura 125 muestran la hemoglobina glicosilada IFCC en los grupos. La hemoglobina glicosilada IFCC en GAMa fue inferior $(\mathrm{p}=0.0001)$.

\begin{tabular}{|l|l|l|l|l|}
\hline Grupo & $\begin{array}{l}\text { Hemoglobina glicosilada } \\
\text { IFCC media }\end{array}$ & SD & Mediana & Rango \\
\hline GAMa & 42 & 4.06 & 42 & $38-47$ \\
\hline GAMb & 46 & 0.08 & 44 & $44.09-46.08$ \\
\hline GAMc & 46 & 0.09 & 46 & $44.02-46.09$ \\
\hline
\end{tabular}

Tabla 51. La hemoglobina glicosilada media IFCC en GAma, GAmb y GAmc.

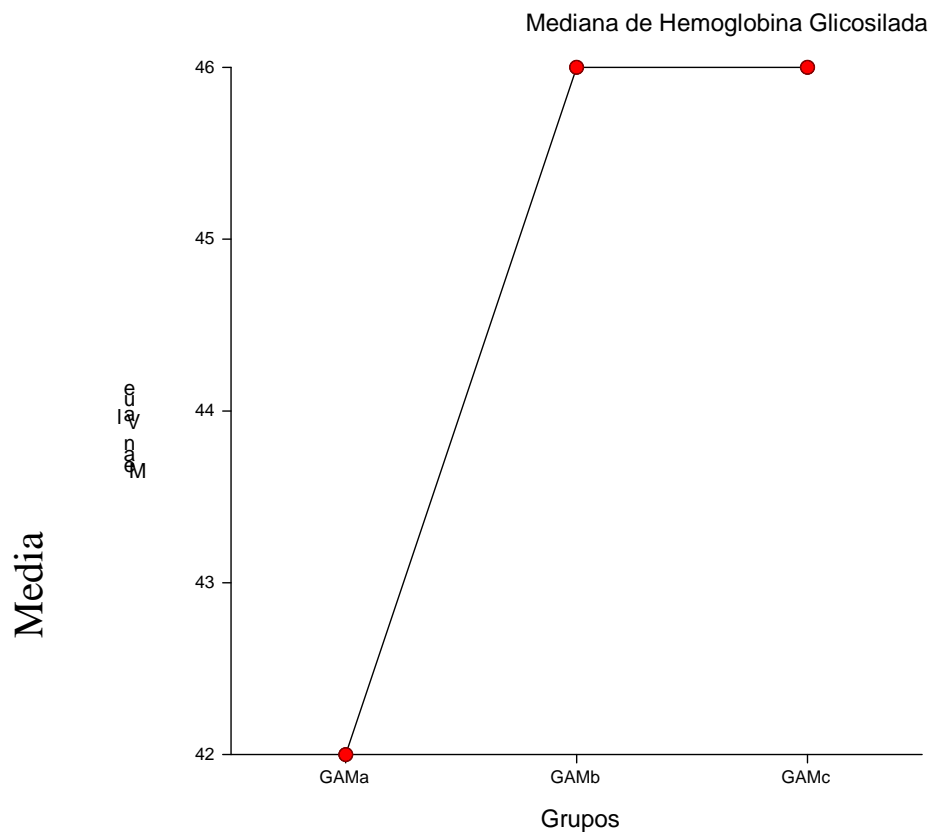

Figura 125. Media de la hemoglobina glicosilada IFCC en los grupos. 


\subsection{Hemoglobina glicosilada IFCC en subgrupo GAo}

La hemoglobina glicosilada IFCC media fue 55, SD 18.30, mediana 55, rango $37-73$.

\subsubsection{Hemoglobina glicosilada IFCC en subgrupo GAoa, GAob y GAoc.}

La tabla 52 muestra la hemoglobina glicosilada IFCC en los grupos. No hubo pacientes en el grupo GAOb.La hemoglobina glicosilada IFCC en GAOc fue inferior $(\mathrm{p}=0.0001)$.

\begin{tabular}{|l|l|l|l|l|}
\hline Grupo & $\begin{array}{l}\text { Hemoglobina glicosilada } \\
\text { IFCC media }\end{array}$ & SD & Mediana & Rango \\
\hline GAoa & 73 & 18.90 & 72.05 & $65-73$ \\
\hline GAoc & 43 & 17.60 & 45 & $37-60$ \\
\hline
\end{tabular}

Tabla 52. La hemoglobina glicosilada media IFCC en GAoa, GAob y GAoc.

\subsection{Hemoglobina glicosilada IFCC en subgrupo GAc}

La hemoglobina glicosilada IFCC media fue 46, SD 49.83, mediana 8.49, rango 40-66 (figura 126).

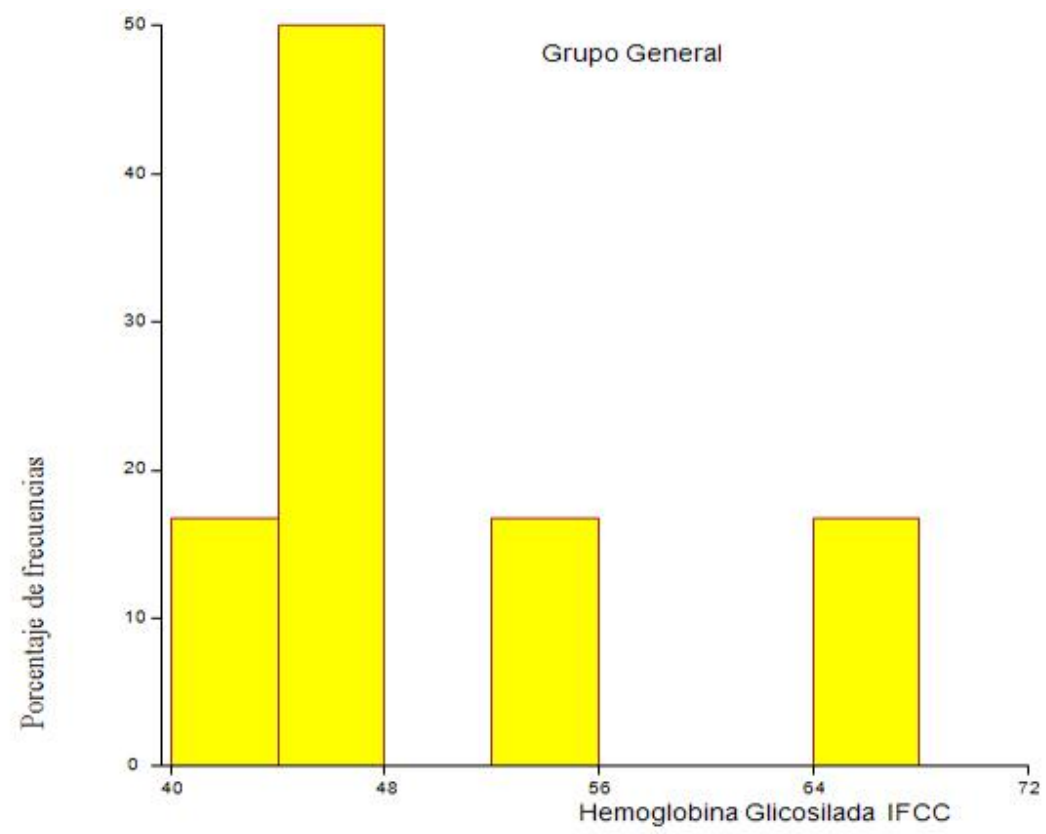

Figura 126. Distribución de la hemoglobina glicosilada IFCC en la muestra general. 


\subsubsection{Hemoglobina glicosilada IFCC en subgrupo GAca, GAcb y GAcc}

La tabla 53 y las figuras 127 y 128 muestran la hemoglobina glicosilada IFCC en los grupos. No hubo diferencias en los subgrupos GACa, GACb y GACc $(\mathrm{p}=0.8867)$.

\begin{tabular}{|l|l|l|l|l|}
\hline Grupo & $\begin{array}{l}\text { Hemoglobina glicosilada } \\
\text { IFCC media }\end{array}$ & SD & Mediana & Rango \\
\hline GAca & 49.71 & 8.53 & 46 & $40-66$ \\
\hline GAcb & 49.53 & 8.29 & 46 & $40-66$ \\
\hline GAcc & 50.68 & 9.23 & 46 & $40-66$ \\
\hline
\end{tabular}

Tabla 53. La hemoglobina glicosilada media IFCC en GAca, GAcb y GAcc.

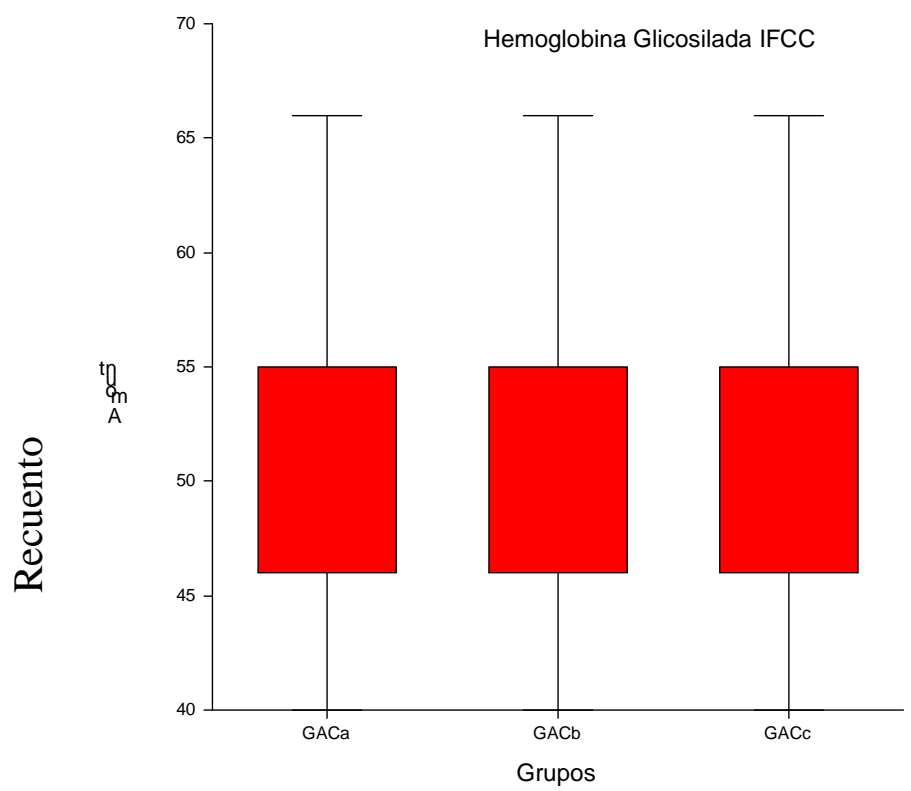

Figura 127. Distribución de la hemoglobina glicosilada IFCC. 
LORENA SUÁREZ GUTIÉRREZ

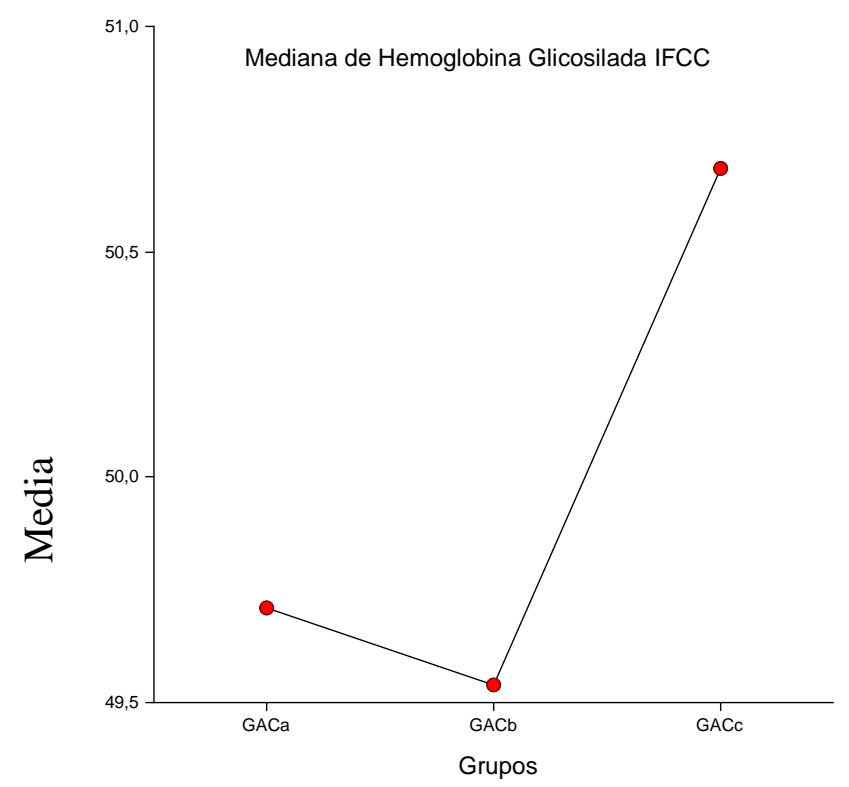

Figura 128. Media de la hemoglobina glicosilada IFCC en los subgrupos 


\section{PSA.}

\subsection{PSA en la muestra general.}

En la PSA la media fue 1.30, SD 1.65, mediana 0.86, rango 0.05-9.37 (figura 129).

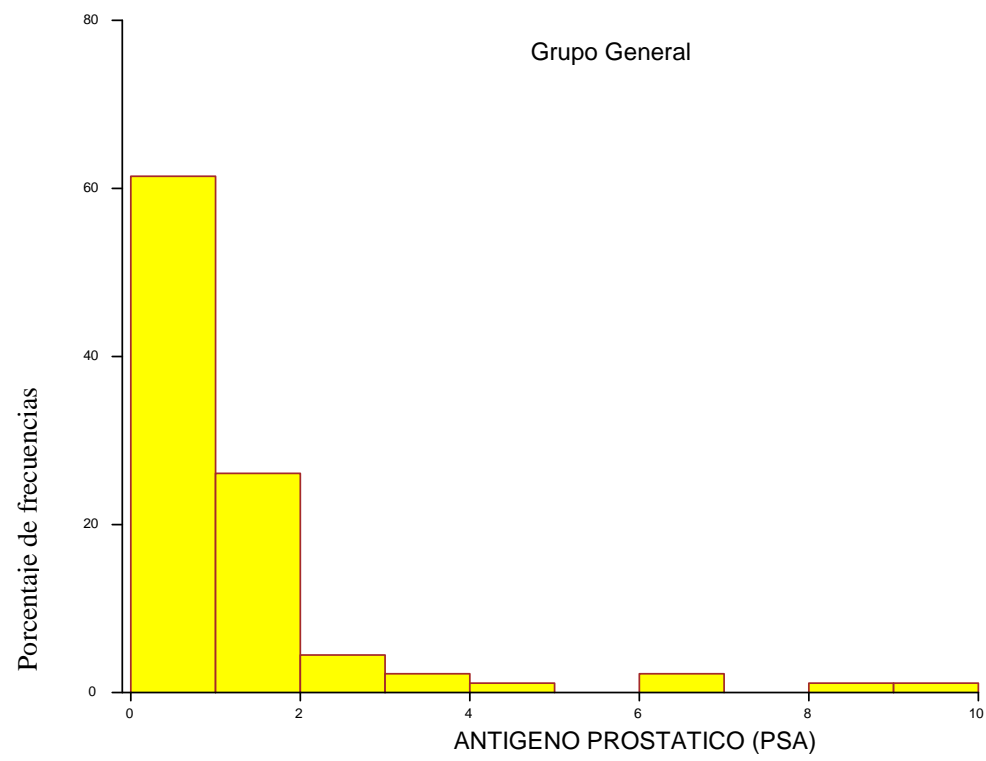

Figura 129. Distribución del PSA en la muestra general.

\subsection{PSA en subgrupos GA, GB, GC.}

Grupo general (GG) y comparacion entre grupos de pacientes masculinos con disfunción eréctil con diabetes mellitus (GA), con diagnosticos secundarios sin diabetes mellitus (GB) y sin diagnosticos secundarios (GC) en PSA.

La tabla 54 y las figuras 130 y 131 muestran el psa en los grupos. No hubo diferencia del psa en los subgrupos GA,GB,GC (p=0.2192).

\begin{tabular}{|l|l|l|l|l|}
\hline Grupo & Media del PSA & Sd & Mediana & Rango \\
\hline GA & 1.49 & 2.16 & 0.8 & $0.011-8.38$ \\
\hline GB & 1.26 & 1.38 & 0.87 & $0.019-6.85$ \\
\hline GC & 1.29 & 1.75 & 0.94 & $0.005-9.37$ \\
\hline
\end{tabular}

Tabla 54. Media del PSA en GA,GB y GC 
LORENA SUÁREZ GUTIÉRREZ

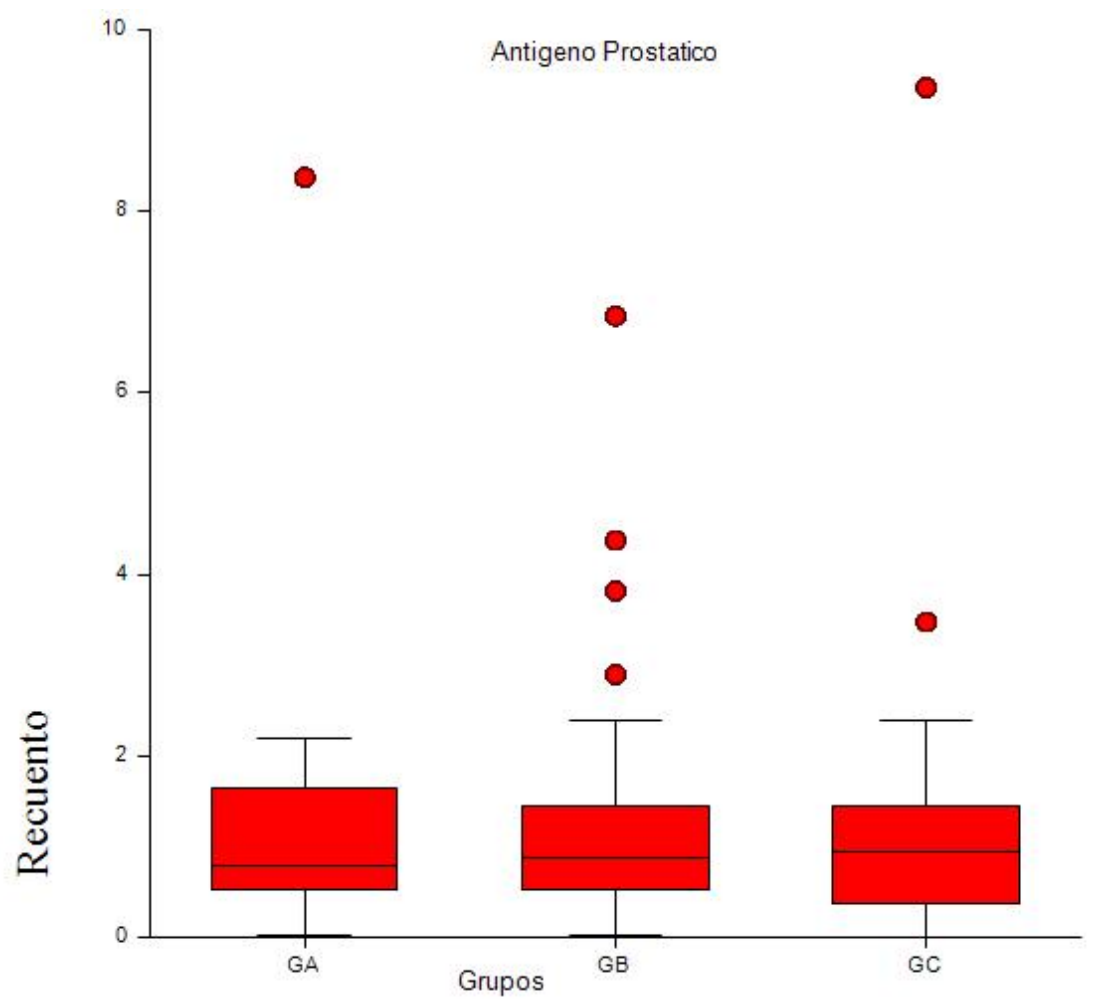

Figura 130. Distribución del PSA.

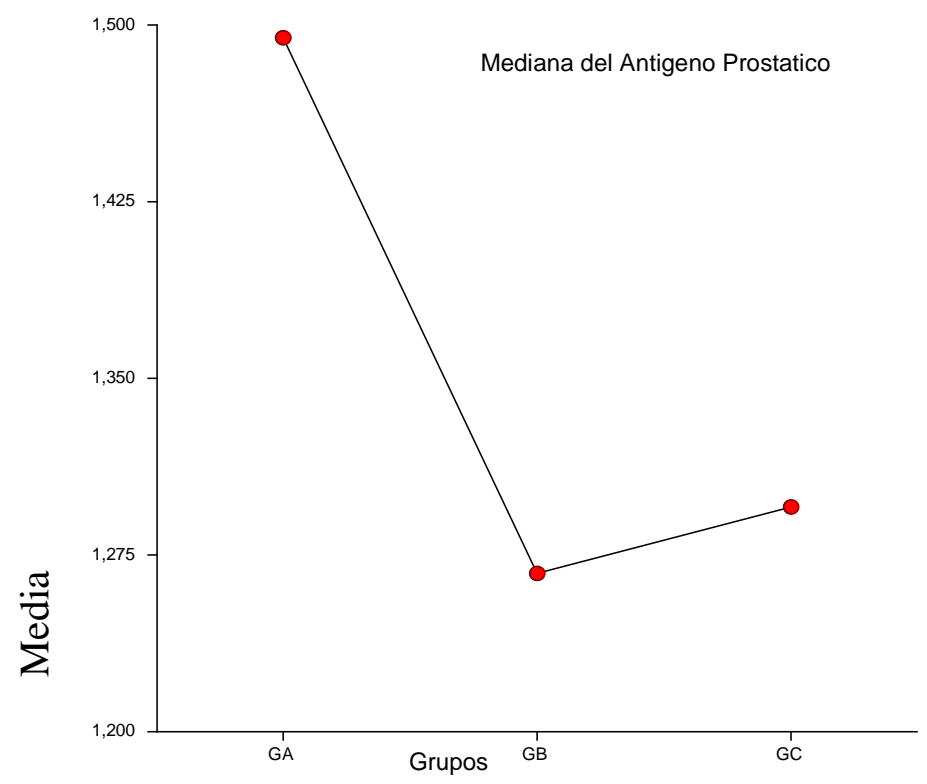

Figura 131. Media del PSA en los grupos 


\subsection{PSA en GA}

La media del PSA fue 1.50, SD 2.17, mediana 0.8, rango 0.011-8.38 (figura 132).

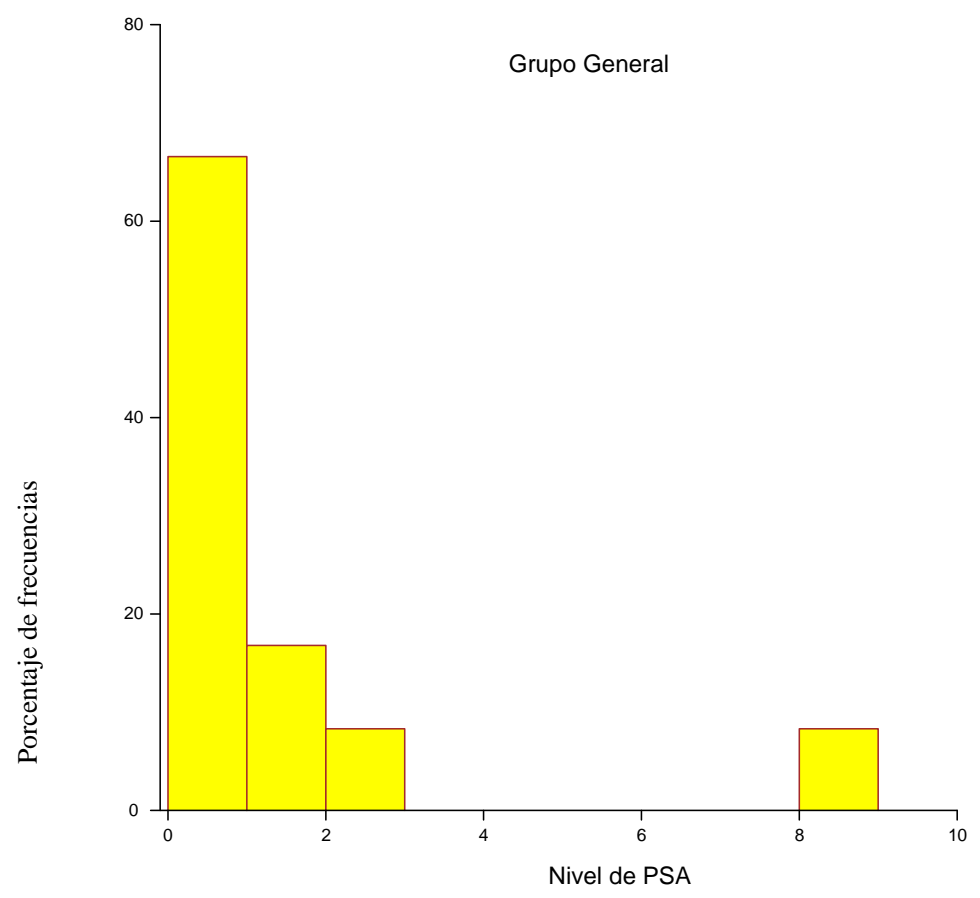

Figura 132. Distribución del PSA en la muestra general.

\subsection{PSA en GAa, GAb, GAc.}

Comparación entre grupos de pacientes masculinos con disfunción eréctil con diabetes mellitus (GA) y con tratamiento exitoso (GAa), parcial $(\mathrm{GAb})$ y fracaso (GAc).

La tabla 55 y las figuras 133 y 134 muestran el PSA. En el grupo GAc fue inferior $(\mathrm{p}=0.0001)$.

\begin{tabular}{|l|l|l|l|l|}
\hline Grupo & PSA media & SD & Mediana & Rango \\
\hline GAa & 0.80 & 0.57 & 0.66 & $0.011-1.78$ \\
\hline GAb & 3.04 & 3.15 & 1.50 & $0.8-8.38$ \\
\hline GAc & 0.59 & 0.47 & 0.49 & $0.05-1.2$ \\
\hline
\end{tabular}

Tabla 55. El PSA medio en GAa, GAb y GAc. 


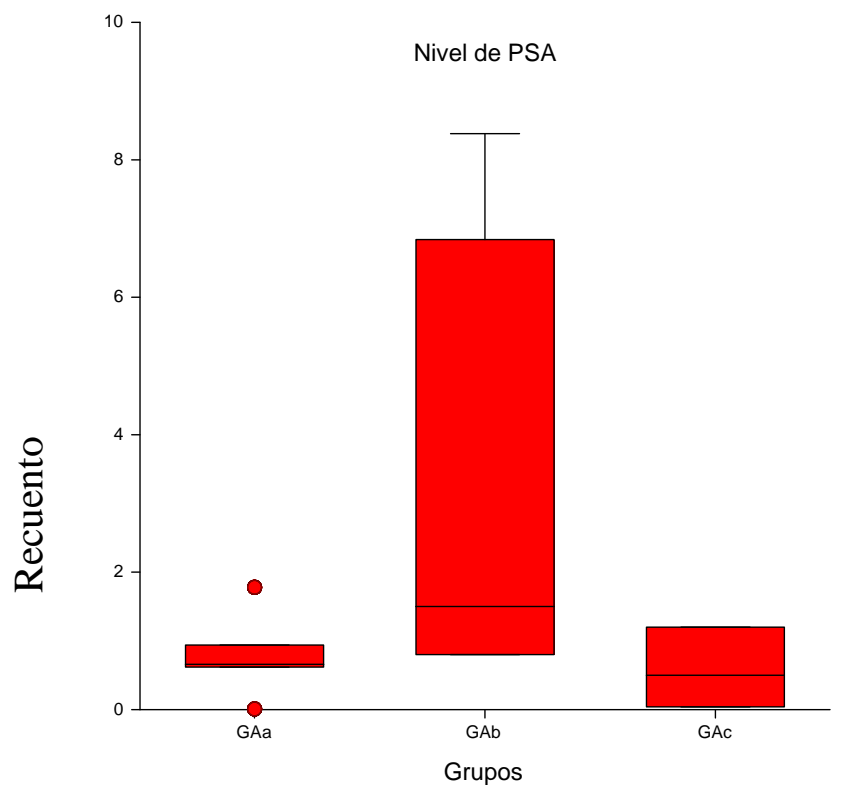

Figura 133. Distribución del PSA

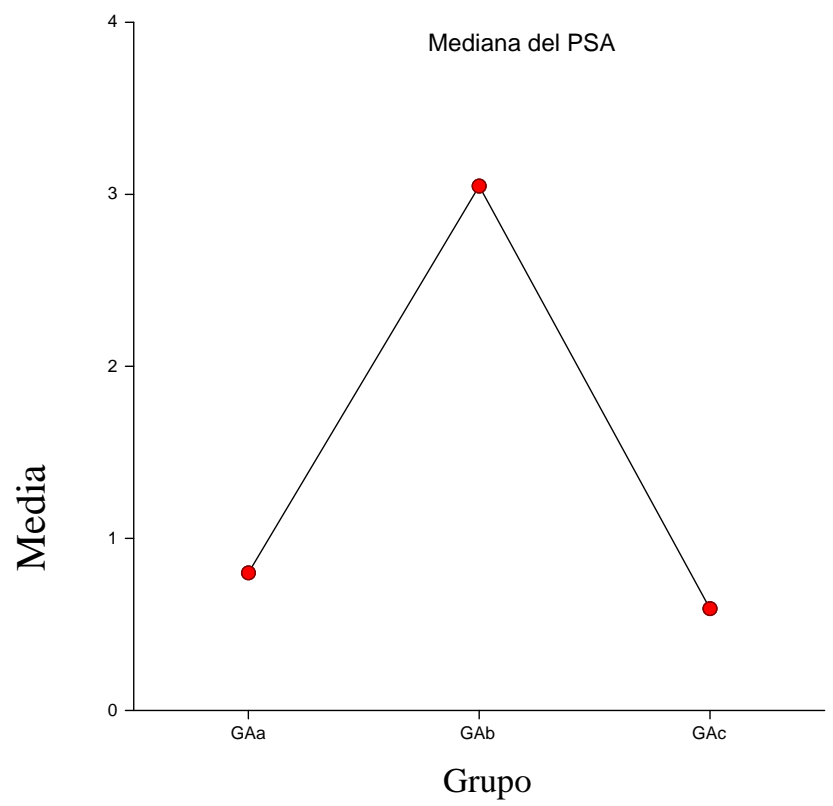

Figura 134. Media del PSA en los grupos 


\subsection{PSA en GB}

En la PSA la media fue 1.26, SD 1.38, mediana 0.872, rango 0.019-6.85 (figura 135).

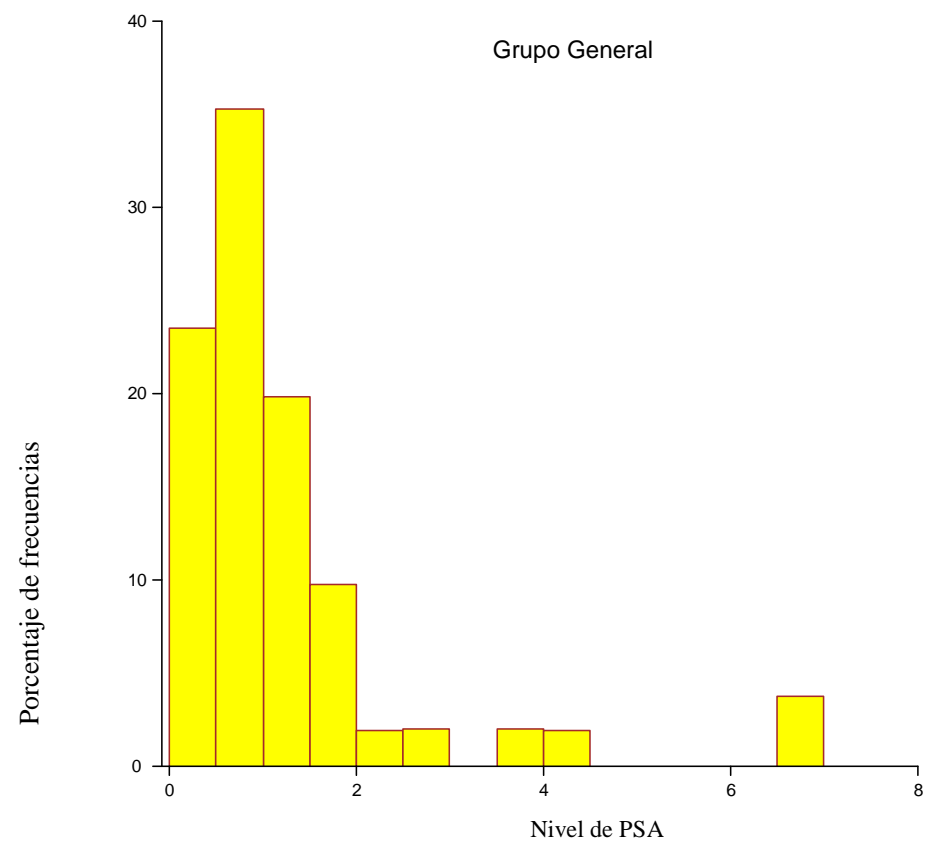

Figura 135. Distribución de la PSA en la muestra general.

La tabla 56 y las figuras 136 y 137 muestran el PSA en los grupos. El PSA en el subgrupo GBb fue inferior respecto a $\mathrm{GBa}$ y $\mathrm{GBc}(\mathrm{p}=0.000001)$.

\begin{tabular}{|l|l|l|l|l|}
\hline Grupo & Media del PSA & SD & Mediana & Rango \\
\hline GBa & 1.26 & 1.01 & 0.99 & $0.25-4.38$ \\
\hline GBb & 0.91 & 0.62 & 0.83 & $0.056-2.38$ \\
\hline GBc & 1.59 & 2.17 & 0.733 & $0.019-6.85$ \\
\hline
\end{tabular}

Tabla 56. PSA en $G B a, G B b$ y $G B c$. 
LORENA SUÁREZ GUTIÉRREZ

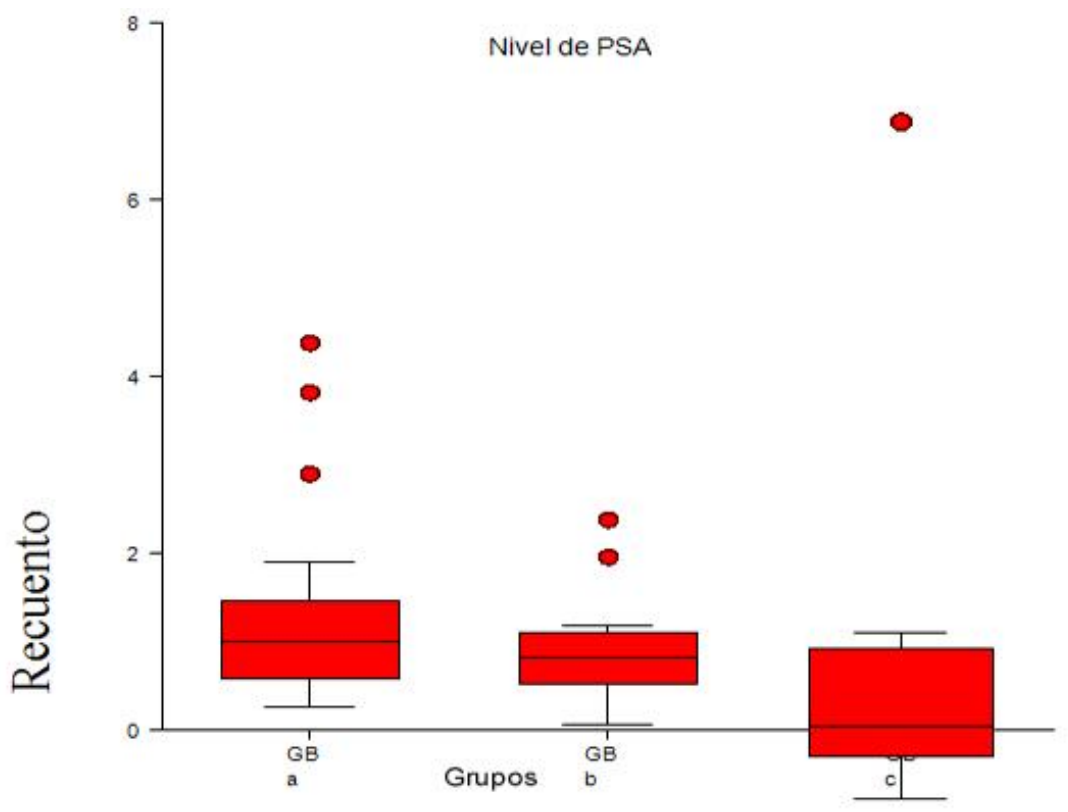

Figura 136. Distribución del PSA.

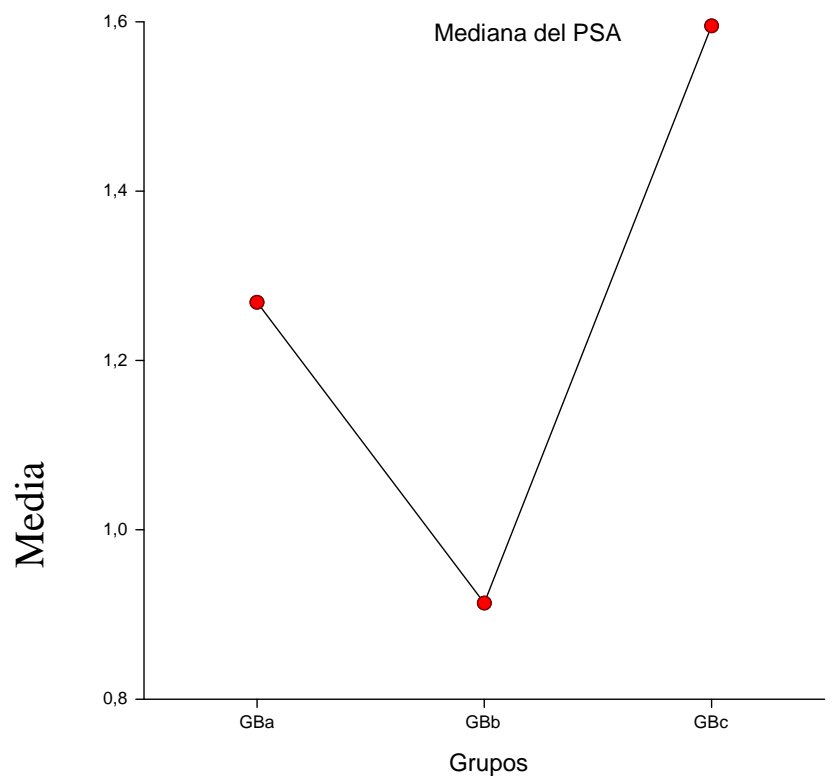

Figura 137. Media del PSA en los grupos 


\subsection{PSA en subgrupos GAa, GBa, GCa.}

En la PSA la media fue 11.84, SD 22.64, mediana 1.48, rango 0.011-95 (figura 138).

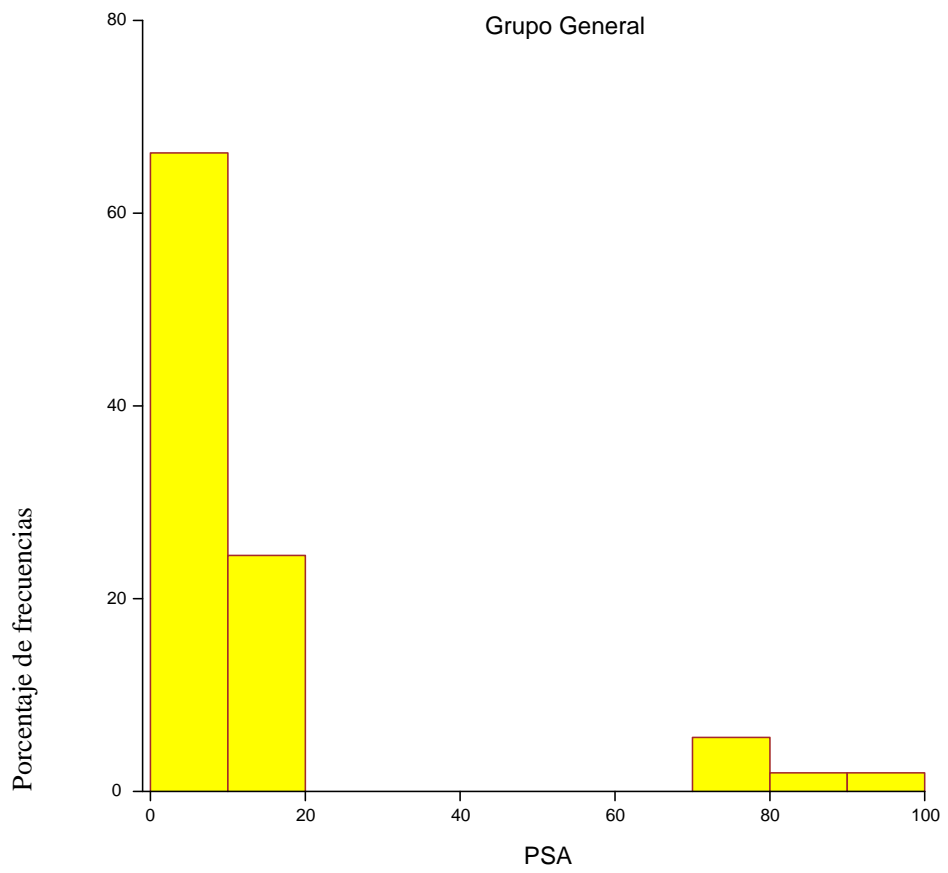

Figura 138. PSA en grupos de éxito GAa, GBa y GCa.

La tabla 57 y las figuras 139 y 140 muestran el PSA en los grupos. El PSA en GAa fue inferior respecto a GBa y GCa ( $p=0.00002)$.

\begin{tabular}{|l|l|l|l|l|}
\hline Grupo & $\begin{array}{l}\text { Media del } \\
\text { PSA }\end{array}$ & SD & Mediana & Rango \\
\hline $\mathrm{GAa}$ & 0.80 & 0.57 & 0.666 & $0.011-1.78$ \\
\hline $\mathrm{GBa}$ & 1.26 & 1.01 & 0.998 & $0.25-4.38$ \\
\hline $\mathrm{GCa}$ & 1.51 & 1.18 & 1.46 & $0.3-3.48$ \\
\hline
\end{tabular}

Tabla 57. PSA medio en GAa, GBa y GCa. 
LORENA SUÁREZ GUTIÉRREZ

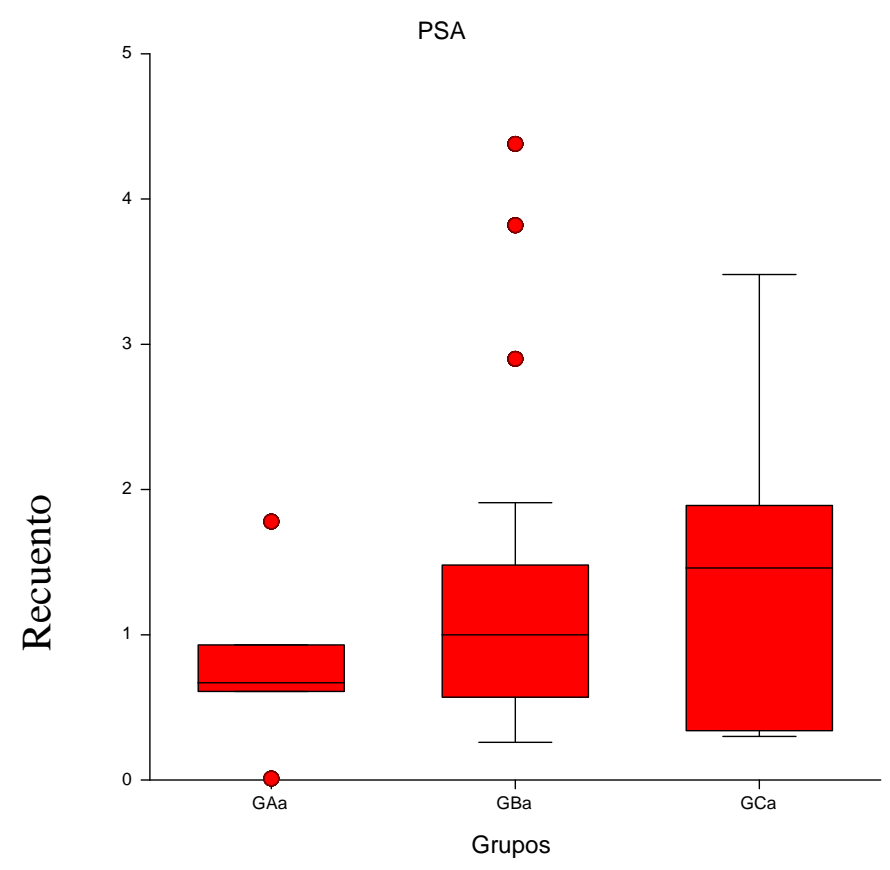

Figura 139. Distribución del PSA.

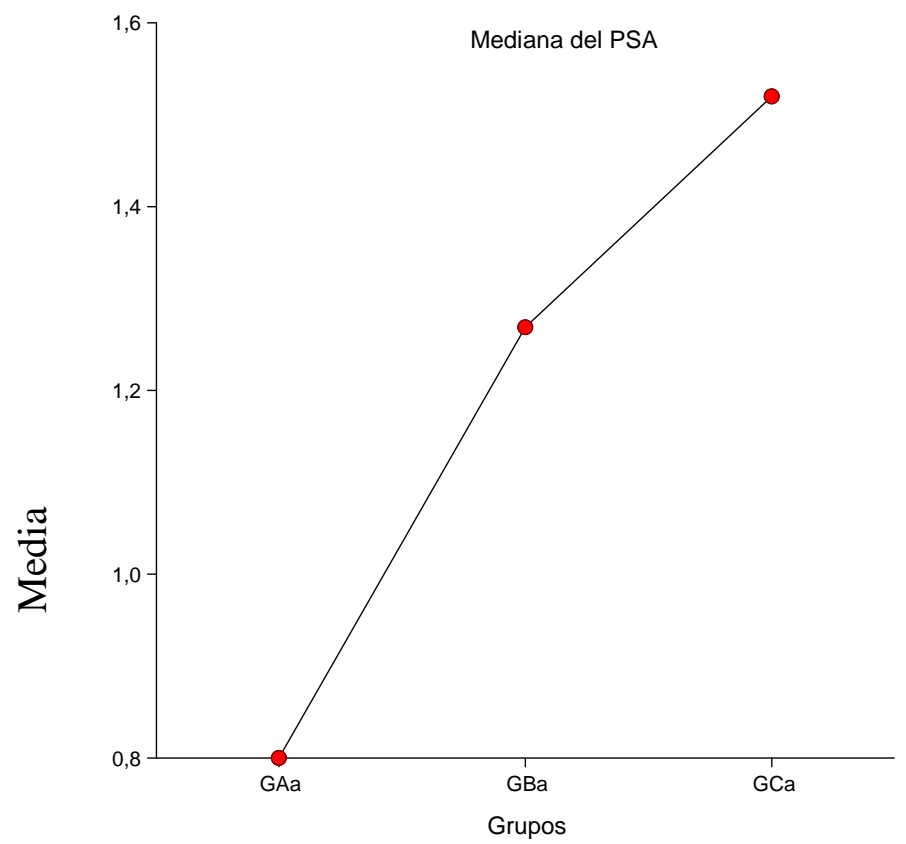

Figura 140. Media del PSA en los grupos 


\subsection{PSA en GAm, GAo y GAc.}

La tabla 58 y las figuras 141 y 142 muestran el PSA en los grupos. No hubo diferencia del PSA en los subgrupos GAm, GAo, GAc $(\mathrm{p}=0.2193)$.

\begin{tabular}{|l|l|l|l|l|}
\hline Grupo & Media del PSA & SD & Mediana & Rango \\
\hline GAm & 4.91 & 6.56 & 1.2 & $0.61-16.3$ \\
\hline GAo & 0.49 & 0.44 & 0.49 & $0.05-0.93$ \\
\hline GAc & 0.82 & 0.67 & 0.73 & $0.011-2.21$ \\
\hline
\end{tabular}

Tabla 58. PSA medio en GAm, GAo y GAc.

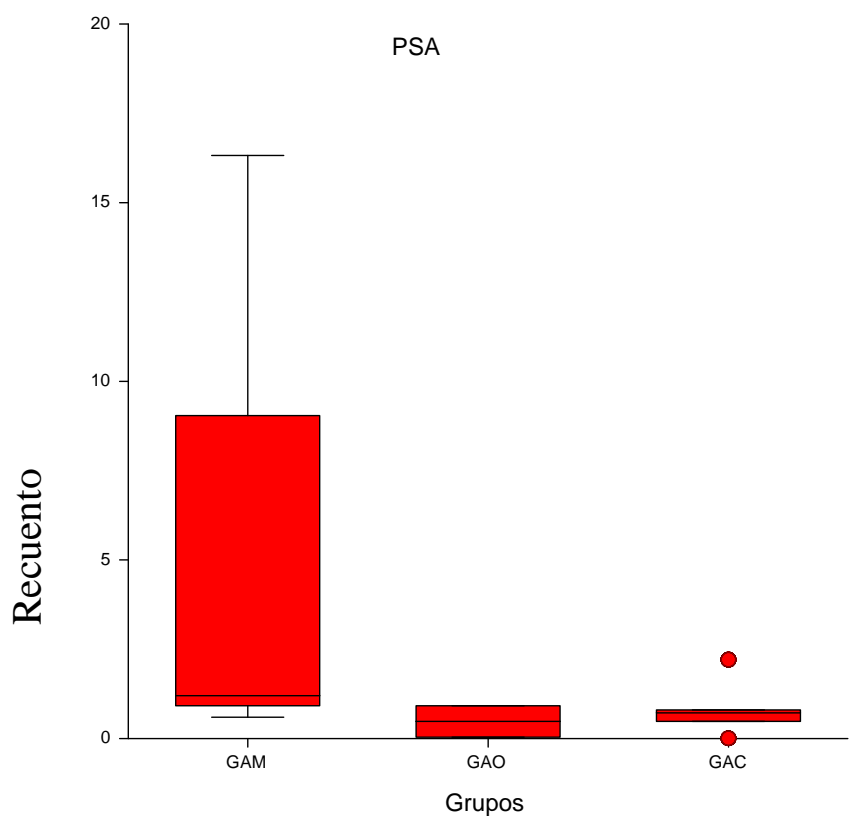

Figura 141. Distribución del PSA. 


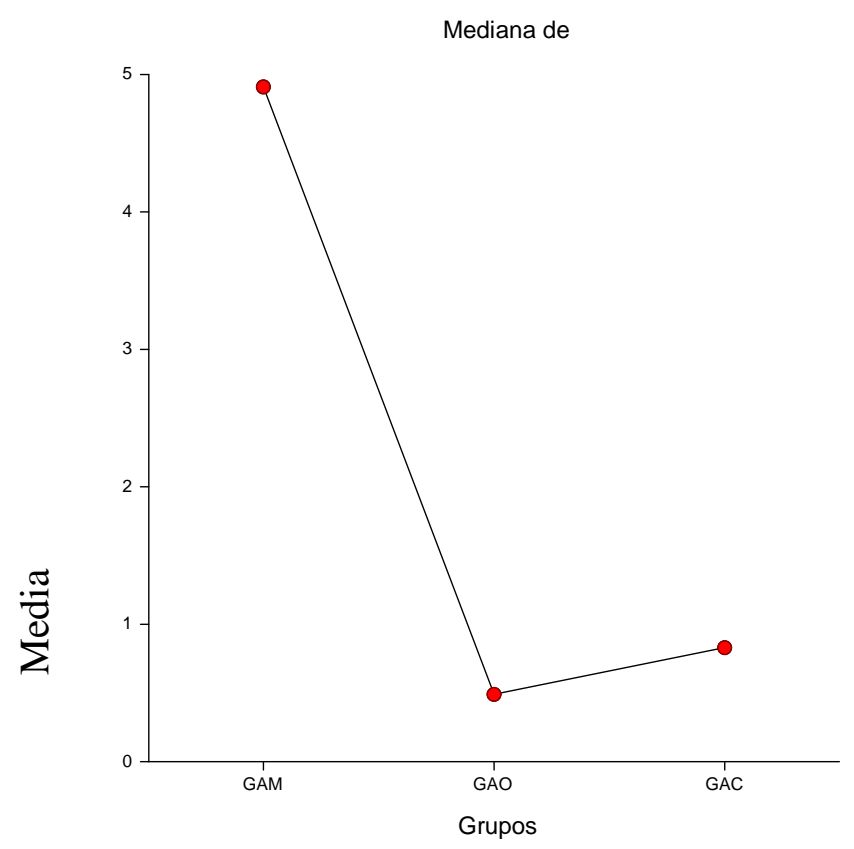

Figura 142. Media del PSA en subgrupos.

\subsection{PSA en subgrupo GAm}

En la PSA la media fue 4.91, SD 6.56, mediana 1.2, rango 0.61-16.3.

\subsubsection{PSA en subgrupo GAma, GAmb y GAmc}

La tabla 59 y la figura 143 muestran el PSA en los grupos. El PSA en el grupo GAma fue inferior respecto a GAmb y GAmc ( $\mathrm{p}=0.00001)$.

\begin{tabular}{|l|l|l|l|l|}
\hline Grupo & Media del PSA & SD & Mediana & Rango \\
\hline GAma & 1.19 & 0.59 & 1.19 & $0.61-1.78$ \\
\hline GAmb & 16.3 & 0 & 16.3 & $16.3-16.3$ \\
\hline GAmc & 1.2 & 0 & 1.2 & $1.2-1.2$ \\
\hline
\end{tabular}

Tabla 59. PSA medio en GAma, GAmb, GAmc. 


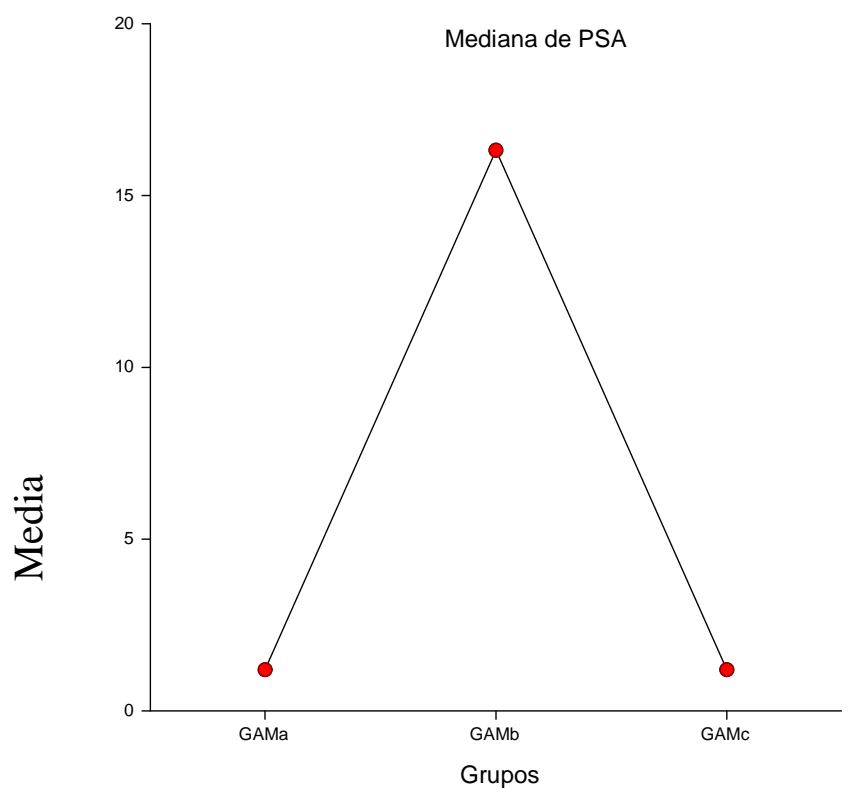

Figura 143. Media del PSA en los grupos

\subsection{PSA en subgrupo GAo}

En la PSA la media fue 0.49 , SD 0.44 , mediana 0.49 , rango $0.05-0$.

\subsubsection{PSA en subgrupo GAoa, GAob y GAoc}

La tabla 60 muestra el PSA en los grupos. El PSA en el grupo GAOc es inferior respecto a GAOa $(\mathrm{p}=0.00001)$. No hubo pacientes en GAOb.

\begin{tabular}{|l|l|l|l|l|}
\hline Grupo & $\begin{array}{l}\text { Media del } \\
\text { PSA }\end{array}$ & SD & Mediana & Rango \\
\hline GAoa & 0.93 & 0.45 & 0.93 & $0.93-0.93$ \\
\hline GAoc & 0.05 & 0.41 & 0.05 & $0.03-0.07$ \\
\hline
\end{tabular}

Tabla 60. PSA medio en GAoa, GAob y GAoc. 


\subsection{PSA en subgrupo GAc}

En la PSA la media fue 0.82, SD 0.67, mediana 0.733, rango 0.011-2.21 (figura 144).

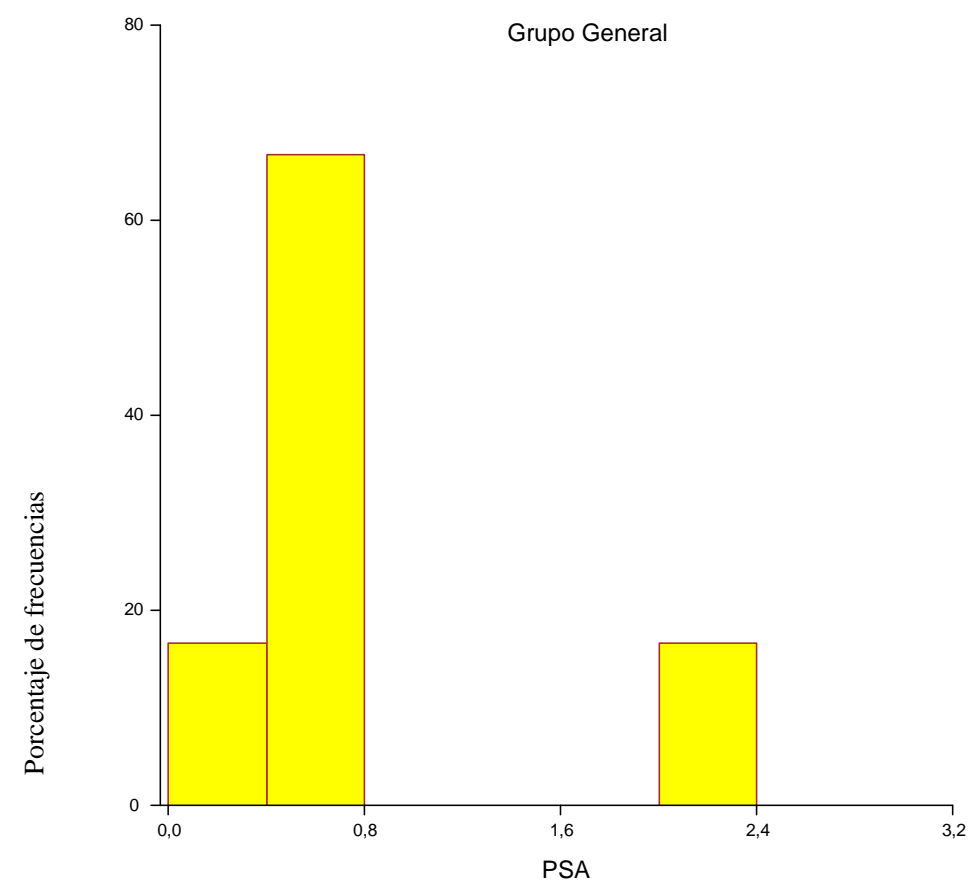

Figura 144. Distribución del PSA en la muestra general en GAc.

\subsubsection{PSA en subgrupo GAca, GAcb, GAcc}

La tabla 61 y las figuras 145 y 146 muestran el PSA en los grupos. No hubo diferencias en los subgrupos GAca, GAcb y GAcc ( $\mathrm{p}=0.9217$ ).

\begin{tabular}{|l|l|l|l|l|}
\hline Grupo & Media del PSA & SD & Mediana & Rango \\
\hline GAca & 0.80 & 0.67 & 0.66 & $0.011-2.21$ \\
\hline GAcb & 0.86 & 0.69 & 0.8 & $0.011-2.21$ \\
\hline GAcc & 0.81 & 0.67 & 0.66 & $0.011-2.21$ \\
\hline
\end{tabular}

Tabla 61. PSA medio en GAca, GAcb y GAcc. 
RESULTADOS

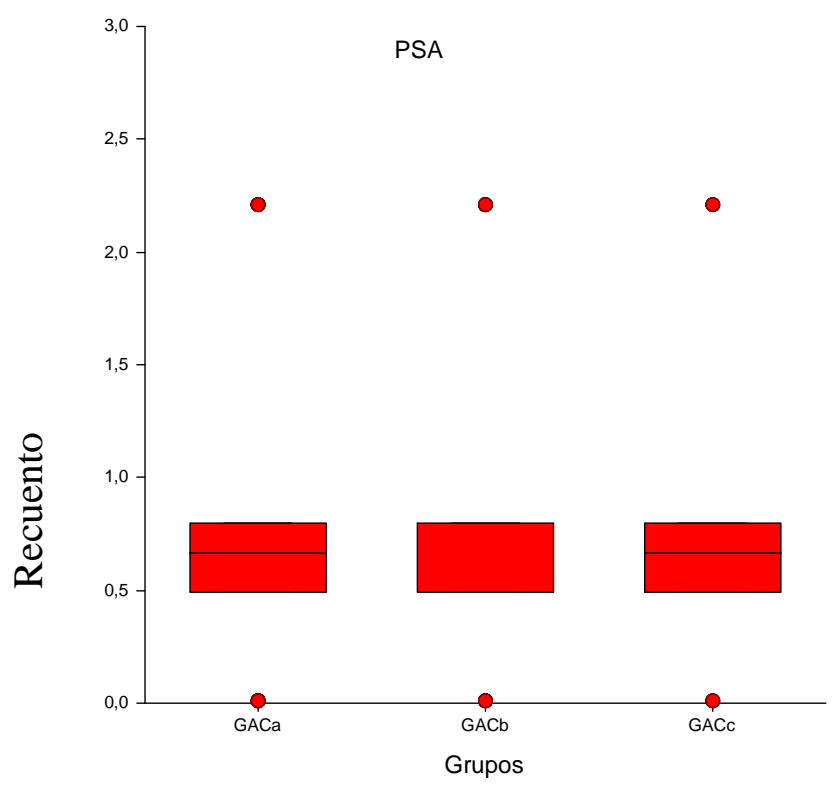

Figura 145. Distribución del PSA.

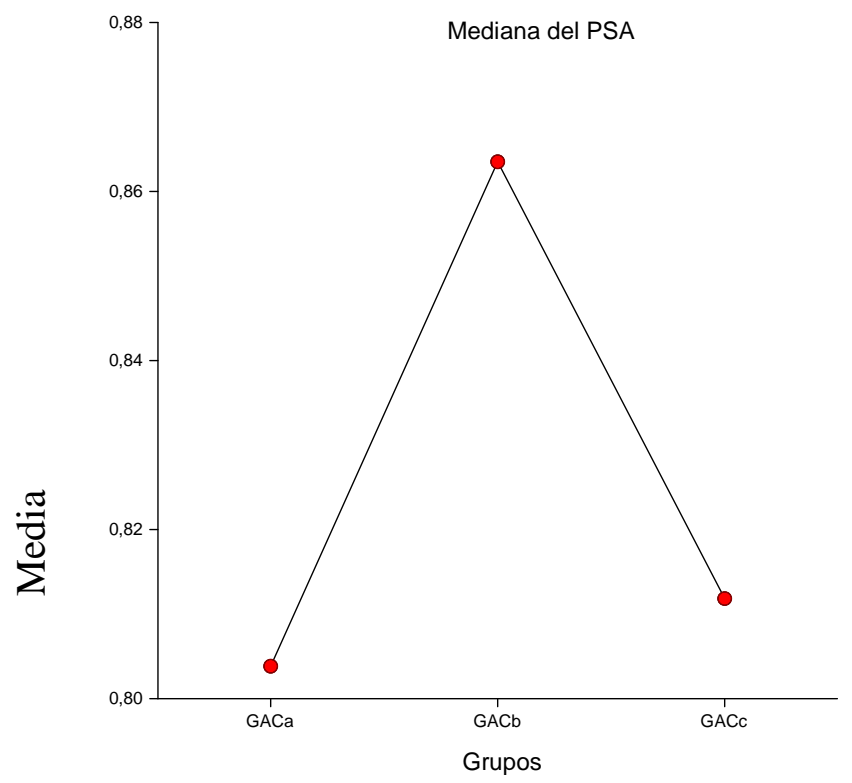

Figura 146. Media del PSA en los grupos 


\section{DIAGNÓSTICOS SECUNDARIOS}

\subsection{Diagnósticos secundarios en la muestra general.}

Diagnósticos secundarios en grupo A, grupo B, grupo C

La tabla 62 muestra la distribución de diagnósticos secundarios y condiciones en el grupo de pacientes con disfunción eréctil con diabetes mellitus, en el grupo de pacientes con disfunción eréctil con diagnósticos secundarios sin diabetes mellitus y en el grupo sin diagnósticos secundarios.

\begin{tabular}{|c|c|c|c|c|c|}
\hline \multirow{2}{*}{$\begin{array}{l}\text { Diagnósticos } \\
\text { secundarios en } \\
\text { disfunción eréctil. }\end{array}$} & Codificación & Grupos & & & \\
\hline & & $\begin{array}{l}\text { GA } \\
\text { (con } \\
\text { diabetes } \\
\mathbf{n = 1 9 1 )}\end{array}$ & $\begin{array}{l}\text { GB } \\
\text { (con } \\
\text { diagnósticos } \\
\text { secundarios } \\
\text { sin diabetes, } \\
\mathrm{n}=796 \text { ) }\end{array}$ & $\begin{array}{l}\text { GC } \\
\text { (sin } \\
\text { diagnósticos } \\
\text { secundarios } \\
n=429 \text { ) }\end{array}$ & General \\
\hline CARDIOLÓGICO & 2.4 & & & & \\
\hline Cardiopatía isquémica & 2.4 .2 & 31 & 78 & 99 & 208 \\
\hline $\begin{array}{l}\text { Digestivo: gastritis, } \\
\text { ulcus. }\end{array}$ & 2.6. & 78 & 296 & 330 & 704 \\
\hline Próstata & 2.8 & & & & \\
\hline Próstata & 2.8 . & 32 & 140 & 330 & 502 \\
\hline Psiquiátrico & 2.9. & 0 & 62 & 330 & 392 \\
\hline $\begin{array}{l}\text { Antecedentes } \\
\text { quirúrgicos }\end{array}$ & 3. & & & & \\
\hline Abdominal & 3.1 . & 32 & 280 & 330 & 642 \\
\hline neurológico & 3.2 . & & & & \\
\hline Pelviano & 3.3. & 0 & 93 & 99 & 192 \\
\hline $\begin{array}{l}\text { Adenomectomia } \\
\text { prostática }\end{array}$ & 3.4 . & 16 & 62 & 330 & 408 \\
\hline Hemorroidectomia & 3.8. & 0 & 31 & 99 & 130 \\
\hline Otras quirúrgicas & 3.12. & 32 & 405 & 330 & 767 \\
\hline PSIQUIATRÍA & 4.26. & & & & \\
\hline -benzodiazepina & 4.27. & 15 & 0 & 330 & 345 \\
\hline TÓXICOS & 5.1. & & & & \\
\hline Activo cig/día & 5.5 . & 47 & 78 & 99 & 224 \\
\hline
\end{tabular}

Tabla 62. Distribución de diagnósticos secundarios y condiciones en el grupo de pacientes con disfunción eréctil. 


\subsection{Comparación de la distribución de los DS entre GA, GB y GC}

La tabla 63 muestra la comparación entre diagnósticos secundarios y condiciones en los grupos A y B de pacientes con disfunción eréctil. La cardiopatía isquémica es mas frecuente en el subgrupo GB que en el subgrupo GA, hay más cardiopatía isquémica en hombres con disfunción eréctil y diagnósticos secundarios que en hombres con disfunción eréctil y Diabetes Mellitus. La disfunción vascular o patología vascular es la primera causa de Disfunción eréctil $(\mathrm{p}=0.0143)$. Es mas frecuente los trastornos psiquiátricos en el subgrupo GB que en el subgrupo GA, en hombres sin Diabetes Mellitus con diagnósticos secundarios así como en tratamiento neuroléptico $(\mathrm{p}=0.0001)$.

Son mas frecuentes los antecedentes quirúrgicos abdominales en el subgrupo GB que en el subgrupo GA $(\mathrm{p}=0.0001)$, también en quirúrgicos pelviano $(\mathrm{p}=0.0001)$, hemorroidectomia $(\mathrm{p}=0.0019)$, y otras cirugías $(\mathrm{p}=0.0001)$.

Existen mas fumadores activos en el subgrupo GA, hombres con Diabetes mellitus que en el subgrupo GB, hombres con disfunción eréctil sin Diabetes Mellitus con diagnósticos secundarios ( $\mathrm{p}=0.0001$ ). Este hallazgo hay que considerarlo con especial precaución, puesto que el tabaquismo es un reconocido factor de riesgo de disfunción eréctil.

\begin{tabular}{|l|l|l|l|l|l|l|}
\hline $\begin{array}{l}\text { Diagnósticos } \\
\text { secundarios en } \\
\text { disfunción eréctil. }\end{array}$ & Codificación & Grupos & & & p \\
\hline & \multicolumn{3}{|c|}{$\begin{array}{l}\text { GA } \\
\text { (con diabetes } \\
\text { n=191) }\end{array}$} & $\begin{array}{l}\text { GB } \\
\text { (con } \\
\text { diagnósticos } \\
\text { secundarios sin } \\
\text { diabetes, n=796) }\end{array}$ & \\
\hline $\begin{array}{l}\text { CARDIOLÓGICO } \\
\text { isquémica }\end{array}$ & 2.4. & $\mathrm{~N}$ & $\%$ & $\mathrm{~N}$ & $\%$ & \\
\hline $\begin{array}{l}\text { Digestivo: gastritis, } \\
\text { ulcus. }\end{array}$ & 2.4 .2$. & 31 & 16.23 & 78 & 40.84 & 0.0143 \\
\hline Próstata & 2.6. & 78 & 40.83 & 296 & 37.18 & 0.3617 \\
\hline Psiquiátrico & 2.8. & 32 & 16.75 & 140 & 17.58 & 0.8324 \\
\hline $\begin{array}{l}\text { Antecedentes } \\
\text { quirúrgicos }\end{array}$ & 2.9. & 0 & 0 & 62 & 7.78 & 0.0001 \\
\hline Abdominal & 3. & & & & & \\
\hline
\end{tabular}




\begin{tabular}{|l|l|l|l|l|l|l|}
\hline Pelviano & 3.3. & 0 & 0 & 93 & 11.68 & 0.0001 \\
\hline $\begin{array}{l}\text { Adenomectomia } \\
\text { prostática }\end{array}$ & 3.4. & 16 & 8.37 & 62 & 7.78 & 0.7662 \\
\hline Hemorroidectomia & 3.8. & 0 & 0 & 31 & 3.89 & 0.0019 \\
\hline Otras quirúrgicas & 3.12. & 32 & 16.75 & 405 & 50.8 & 0.0001 \\
\hline PSIQUIATRÍA & 4.26. & & & & & \\
\hline -benzodiazepina & 4.27. & 15 & 7.8 & 0 & 0 & 0.0001 \\
\hline TÓXICOS & 5.1. & & & & & \\
\hline Activo cig/día & 5.5. & 47 & 24.60 & 78 & 9.79 & 0.0001 \\
\hline
\end{tabular}

Tabla 63. Comparación entre diagnósticos secundarios y condiciones entre $G A$ y $G B$.

La tabla 64 muestra la comparación entre diagnósticos secundarios y condiciones en los grupos A y $\mathrm{C}$ de pacientes con disfunción eréctil.

Hubo mas queja de dispepsia en el subgrupo GC, hombres con disfunción eréctil sin diagnósticos secundarios que en el subgrupo GA, con Diabetes Mellitus ( $\mathrm{p}=0.0001)$.

Hubo mas quejas de síntomas tipo prostatismo leve o prostadinia en el subgrupo GC, hombres con disfunción eréctil sin Diabetes Mellitus ni diagnósticos secundarios que en GA, hombres con disfunción eréctil y Diabetes Mellitus ( $\mathrm{p}=0.0001)$.

Hubo más antecedentes de quirúrgicas abdominal y de adenomectomia en pacientes del subgrupo GC, hombres con disfunción eréctil sin diagnósticos secundarios. Esto ocurre porque en el subgrupo GA, hombres con disfunción eréctil y Diabetes Mellitus, los varones consultaron primariamente mas por disfunción eréctil mientras que muchos varones en el subgrupo GC son los que refieren disfunción eréctil en el seguimiento, en consulta de urología general, muchos de los cuales tienen el antecedente de adenomectomia. Por otra parte la adenomectomia fue considerada como quirúrgica abdominal $(\mathrm{p}=0.0001)$. La herroidectomia fue mayor en el subgrupo GC que en el GA y hubo mas consumo de benzodiacepinas en el subgrupo GC que en el GA ( $p=0.0001)$. 


\begin{tabular}{|c|c|c|c|c|c|c|}
\hline Diagnósticos & Codificación & Grupos & & & & $\mathbf{p}$ \\
\hline & & $\begin{array}{l}\text { GA } \\
\text { (con } \\
\text { diabetes } \\
\mathbf{n = 1 9 1 )}\end{array}$ & & $\begin{array}{l}\text { GC } \\
\text { (sin } \\
\text { diagnósticos } \\
\text { secundarios } \\
\mathbf{n = 4 2 9} \text { ) }\end{array}$ & & \\
\hline & & $\mathrm{N}$ & $\%$ & $\mathrm{~N}$ & $\%$ & \\
\hline $\begin{array}{l}\text { Digestivo: gastritis, } \\
\text { ulcus. }\end{array}$ & 2.6. & 78 & 40.83 & 330 & 76.92 & 0.0001 \\
\hline Próstata & 2.8 . & 32 & 16.75 & 330 & 76.92 & 0.0001 \\
\hline Psiquiátrico & 2.9 . & 0 & 0 & 330 & 76.92 & 0.0001 \\
\hline $\begin{array}{l}\text { Antecedentes } \\
\text { quirúrgicos }\end{array}$ & 3. & & & & & \\
\hline Abdominal & 3.1 . & 32 & 15.75 & 330 & 76.92 & 0.0001 \\
\hline Pelviano & 3.3 . & 0 & 0 & 99 & 23.07 & 0.0001 \\
\hline $\begin{array}{l}\text { Adenomectomia } \\
\text { prostática }\end{array}$ & 3.4 . & 16 & 8.37 & 330 & 76.92 & 0.0001 \\
\hline Hemorroidectomia & 3.8 . & 0 & 0 & 99 & 23.07 & 0.0001 \\
\hline Otras quirúrgicas & 3.12 . & 32 & 16.75 & 330 & 76.92 & 0.0001 \\
\hline TRATAMIENTOS & 4. & & & & & \\
\hline PSIQUIATRÍA & 4.26. & & & & & \\
\hline -benzodiazepina & 4.27 & 15 & 7.8 & 330 & 76.92 & 0.0001 \\
\hline TÓXICOS & 5.1 . & & & & & \\
\hline Activo cig/día & 5.5 . & 47 & 24.60 & 99 & 23.07 & 0.6828 \\
\hline
\end{tabular}

Tabla 64. Comparación entre diagnósticos secundarios y condiciones entre $G A$ y $G C$.

\subsection{Diagnósticos secundarios en GA}

\subsection{Diagnósticos secundarios en GAa, GAb, Gac.}

Comparación entre grupos de pacientes masculinos con disfunción eréctil con diabetes mellitus (GA) y con tratamiento exitoso (GAa), parcial (GAb) y fracaso (GAc).

Diagnósticos secundarios en Grupo GAa y Grupo GAb

La tabla 65 muestra la distribución de diagnósticos secundarios y condiciones en el grupo de pacientes con disfunción eréctil con diabetes 
mellitus con tratamiento exitoso y en el grupo de pacientes con disfunción eréctil con diabetes mellitus con tratamiento parcial y fracaso.

\begin{tabular}{|c|c|c|c|c|c|}
\hline \multirow{2}{*}{$\begin{array}{l}\text { Diagnósticos } \\
\text { secundarios en } \\
\text { disfunción eréctil. }\end{array}$} & \multirow[t]{2}{*}{ Codificación } & \multicolumn{4}{|l|}{ Grupos } \\
\hline & & $\begin{array}{l}\text { GAa } \\
\text { (con } \\
\text { diabetes, } \\
\text { éxito } \\
\text { n=80) }\end{array}$ & $\begin{array}{l}\text { GAb } \\
\text { (con } \\
\text { diabetes, } \\
\text { parcial, } \\
\text { n=64) }\end{array}$ & $\begin{array}{l}\text { GAc } \\
\text { (con } \\
\text { diabetes, } \\
\text { fracaso } \\
n=47 \text { ) }\end{array}$ & General \\
\hline Cardio-circulatorio & 2.4 & & & & \\
\hline $\begin{array}{l}\text { Cardiopatía } \\
\text { isquémica }\end{array}$ & 2.4 .2 & 0 & 0 & 31 & 31 \\
\hline $\begin{array}{l}\text { Digestivo: gastritis, } \\
\text { ulcus, metabólico }\end{array}$ & 2.6. & 15 & 32 & 31 & 78 \\
\hline Próstata & 2.8 . & 16 & 16 & 0 & 32 \\
\hline Psiquiátrico & 2.9 . & 0 & 0 & 0 & 0 \\
\hline $\begin{array}{l}\text { Antecedentes } \\
\text { quirúrgicos }\end{array}$ & 3. & & & & \\
\hline Abdominal & 3.1 . & 16 & 16 & 16 & 48 \\
\hline Pelviano & 3.3 . & 0 & 0 & 0 & 0 \\
\hline $\begin{array}{l}\text { Adenomectomia } \\
\text { prostática }\end{array}$ & 3.4 . & 0 & 0 & 16 & 16 \\
\hline Hemorroidectomia & 3.8. & 0 & 0 & 0 & 0 \\
\hline Otras quirúrgicas & 3.13 . & 32 & 0 & 0 & 32 \\
\hline Tratamientos & 4. & & & & \\
\hline Neuroléptico & 4.27 . & 0 & 0 & 15 & 15 \\
\hline Tóxicos & 5. & & & & \\
\hline Activo cig/día & 5.4 . & 16 & 16 & 16 & 48 \\
\hline
\end{tabular}

Tabla 65. Distribución de diagnósticos secundarios y condiciones en el grupo de pacientes con disfunción eréctil y diabetes mellitus según el resultado de tratamiento (éxito, parcial y fracaso).

La tabla 66 muestra la comparación entre diagnósticos secundarios y condiciones en los grupos GAa y GAb de pacientes con disfunción eréctil y diabetes mellitus. 


\begin{tabular}{|c|c|c|c|c|c|c|}
\hline \multirow{2}{*}{$\begin{array}{l}\text { Diagnósticos } \\
\text { secundarios en } \\
\text { disfunción eréctil. }\end{array}$} & \multirow[t]{2}{*}{ Codificación } & \multicolumn{3}{|c|}{ Grupos } & & \multirow[t]{2}{*}{$\mathbf{P}$} \\
\hline & & $\begin{array}{l}\text { GAa } \\
\text { (con } \\
\text { diabetes, } \\
\text { éxito } \\
\text { n=80) }\end{array}$ & & $\begin{array}{l}\text { GAb } \\
\text { (con } \\
\text { diabetes, } \\
\text { parcial } \\
\text { n=64) }\end{array}$ & & \\
\hline & & $\mathrm{N}$ & $\%$ & $\mathrm{~N}$ & $\%$ & \\
\hline Cardio-circulatorio & 2.4. & & & & & \\
\hline $\begin{array}{l}\text { Cardiopatía } \\
\text { isquémica }\end{array}$ & 2.4 .2 . & 0 & 0 & 0 & 0 & 1.0000 \\
\hline $\begin{array}{l}\text { Digestivo: gastritis, } \\
\text { ulcus, metabólico }\end{array}$ & 2.6 . & 15 & 18.75 & 32 & 50 & 0.0001 \\
\hline Próstata & 2.8 . & 16 & 20 & 16 & 25 & 0.5468 \\
\hline Psiquiátrico & 2.9. & 0 & 0 & 0 & 0 & 1.0000 \\
\hline $\begin{array}{l}\text { Antecedentes } \\
\text { quirurgicos }\end{array}$ & 3. & & & & & \\
\hline Abdominal & 3.1. & 16 & 20 & 16 & 25 & 0.5468 \\
\hline Pelviano & 3.3 . & 0 & 0 & 0 & 0 & 1.0000 \\
\hline $\begin{array}{l}\text { Adenomectomia } \\
\text { prostática }\end{array}$ & 3.4 & 0 & 0 & 0 & 0 & 1.0000 \\
\hline Hemorroidectomia & 3.8. & 0 & 0 & 0 & 0 & 1.0000 \\
\hline Otras quirúrgicas & 3.13 . & 32 & 0 & 0 & 0 & 0.0001 \\
\hline Tratamientos & 4. & & & & & \\
\hline Benzodiazepinas & 4.26. & 0 & 0 & 0 & 0 & 1.0000 \\
\hline Tóxicos & 5. & & & & & \\
\hline Activo cig/día & 5.4. & 16 & 20 & 16 & 25 & 0.5468 \\
\hline
\end{tabular}

Tabla 66. Comparación entre diagnósticos secundarios y condiciones entre GAa y GAb.

La tabla 67 muestra la comparación entre diagnósticos secundarios y condiciones en los grupos GAa y Gac de pacientes con disfunción eréctil y diabetes mellitus. 


\begin{tabular}{|l|l|l|l|l|l|l|}
\hline $\begin{array}{l}\text { Diagnósticos } \\
\text { secundarios en } \\
\text { disfunción eréctil. }\end{array}$ & Codificación & \multicolumn{2}{|l|}{ Grupos } & & P \\
\hline & & $\begin{array}{l}\text { GAa } \\
\text { (con } \\
\text { diabetes, } \\
\text { exito } \\
\text { n=80) }\end{array}$ & \multicolumn{2}{|l|}{$\begin{array}{l}\text { GAc } \\
\text { (con } \\
\text { diabetes, } \\
\text { fracaso } \\
\text { n=47) }\end{array}$} & & \\
\hline & & N & $\%$ & N & $\%$ & \\
\hline Cardio-circulatorio & 2.4. & & & & & \\
\hline $\begin{array}{l}\text { Cardiopatía } \\
\text { isquémica }\end{array}$ & 2.4 .2$. & 0 & 0 & 31 & 65.9 & 0.0001 \\
\hline $\begin{array}{l}\text { Digestivo: gastritis, } \\
\text { ulcus, metabólico }\end{array}$ & 2.6. & 15 & 18.75 & 31 & 65.9 & 0.0001 \\
\hline Próstata & 2.8. & 16 & 20 & 0 & 0 & 0.0005 \\
\hline Psiquiátrico & 2.9. & 0 & 0 & 0 & 0 & 1.0000 \\
\hline $\begin{array}{l}\text { Antecedentes } \\
\text { quirúrgicos }\end{array}$ & 3. & & & & & \\
\hline Abdominal & 3.1. & 16 & 20 & 16 & 34 & 0.0926 \\
\hline Pelviano & 3.3. & 0 & 0 & 0 & 0 & 1.0000 \\
\hline $\begin{array}{l}\text { Adenomectomia } \\
\text { prostática }\end{array}$ & 3.4. & 0 & 0 & 16 & 34 & 0.0001 \\
\hline Hemorroidectomia & 3.8. & 0 & 0 & 0 & 0 & 1.0000 \\
\hline Otras quirúrgicas & 3.13. & 32 & 40 & 0 & 0 & 0.0001 \\
\hline Tratamientos & 4. & & & & & \\
\hline Benzodiazepinas & 4.26. & 0 & 0 & 15 & 31.9 & 0.0001 \\
\hline Tóxicos & 5. & 16 & 20 & 16 & 34 & 0.0926 \\
\hline Activo cig/día & 5.4. & & & & & \\
\hline
\end{tabular}

Tabla 67. Comparación entre diagnósticos secundarios y condiciones entre GAa y GAc.

La tabla 68 muestra la comparación entre diagnósticos secundarios y condiciones en los grupos GAb y Gac de pacientes con disfunción eréctil y diabetes mellitus. 


\begin{tabular}{|c|c|c|c|c|c|c|}
\hline \multirow{3}{*}{$\begin{array}{l}\text { Diagnósticos } \\
\text { secundarios en } \\
\text { disfunción eréctil. }\end{array}$} & \multirow[t]{2}{*}{ Codificación } & & \multicolumn{2}{|c|}{ Grupos } & & \multirow[t]{2}{*}{$\mathbf{p}$} \\
\hline & & $\begin{array}{l}\text { GAb } \\
\text { (con } \\
\text { diabetes, } \\
\text { parcial } \\
\mathbf{n}=64 \text { ) }\end{array}$ & & $\begin{array}{l}\text { GAc } \\
\text { (con } \\
\text { diabetes, } \\
\text { fracaso } \\
n=47)\end{array}$ & & \\
\hline & & $\mathrm{n}$ & $\%$ & $\mathrm{~N}$ & $\%$ & \\
\hline Cardio-circulatorio & 2.4 & & & & & \\
\hline $\begin{array}{l}\text { Cardiopatía } \\
\text { isquémica }\end{array}$ & 2.4.2. & 0 & 0 & 31 & 65.9 & 0.0001 \\
\hline $\begin{array}{l}\text { Digestivo: gastritis, } \\
\text { ulcus, metabólico }\end{array}$ & 2.6. & 32 & 50 & 31 & 65.9 & 0.0031 \\
\hline Próstata & 2.8 . & 16 & 25 & 0 & 0 & 0.0005 \\
\hline Psiquiátrico & 2.9 . & 0 & 0 & 0 & 0 & 1.0000 \\
\hline $\begin{array}{l}\text { Antecedentes } \\
\text { quirúrgicos }\end{array}$ & 3. & & & & & \\
\hline Abdominal & 3.1 . & 16 & 25 & 16 & 34 & 0.0926 \\
\hline Pelviano & 3.3 . & 0 & 0 & 0 & 0 & 1.0000 \\
\hline $\begin{array}{l}\text { Adenomectomia } \\
\text { prostática }\end{array}$ & 3.4 . & 0 & 0 & 16 & 34 & 0.0001 \\
\hline Hemorroidectomia & 3.8. & 0 & 0 & 0 & 0 & 1.0000 \\
\hline Otras quirúrgicas & 3.13 . & 0 & 0 & 0 & 0 & 1.0000 \\
\hline Tratamientos & 4. & & & & & \\
\hline Neuroleptico & 4.27. & 0 & 0 & 15 & 31.9 & 0.0001 \\
\hline Tóxicos & 5. & & & & & \\
\hline Activo cig/día & 5.4. & 16 & 25 & 16 & 34 & 1.0000 \\
\hline
\end{tabular}

Tabla 68. Comparación distribución entre diagnósticos secundarios y condiciones entre GAb y GAc.

\subsection{Diagnósticos secundarios en GAa, GBa y GCa}

\section{Diagnósticos secundarios en Grupo GAa, Grupo GBa y Grupo GCa}

La tabla 69 muestra la distribución de diagnósticos secundarios y condiciones en el grupo de pacientes con disfunción eréctil con diabetes mellitus con tratamiento exitoso, en el grupo de pacientes con disfunción eréctil sin diabetes mellitus con diagnósticos secundarios y con tratamiento exitoso y en grupo de pacientes con disfunción eréctil sin diagnósticos secundarios con tratamiento exitoso. 


\begin{tabular}{|c|c|c|c|c|c|}
\hline \multirow{2}{*}{$\begin{array}{l}\text { Diagnósticos } \\
\text { secundarios en } \\
\text { disfunción eréctil. }\end{array}$} & \multirow[t]{2}{*}{ Codificación } & \multicolumn{4}{|l|}{ Grupos } \\
\hline & & $\begin{array}{l}\text { GAa } \\
\text { (con } \\
\text { diabetes, } \\
\text { exito } \\
\mathbf{n = 8 0} \text { ) }\end{array}$ & $\begin{array}{l}\text { GBa } \\
\text { (con } \\
\text { diagnósticos } \\
\text { secundarios } \\
\text { sin diabetes, } \\
\text { exito, } n=379 \text { ) }\end{array}$ & $\begin{array}{l}\text { GCa } \\
\text { (sin } \\
\text { diagnósticos } \\
\text { secundarios, } \\
\text { éxito } \mathrm{n}=276 \text { ) }\end{array}$ & General \\
\hline Cardio-circulatorio & 2.4 & & & & \\
\hline $\begin{array}{l}\text { Cardiopatía } \\
\text { isquémica }\end{array}$ & 2.4 .2 . & 0 & 46 & 76 & 122 \\
\hline $\begin{array}{l}\text { Digestivo: gastritis, } \\
\text { ulcus, metabólico }\end{array}$ & 2.6 & 15 & 93 & 200 & 308 \\
\hline Próstata & 2.8. & 16 & 60 & 200 & 276 \\
\hline Psiquiátrico & 2.9. & 0 & 47 & 200 & 247 \\
\hline $\begin{array}{l}\text { Antecedentes } \\
\text { quirúrgicos }\end{array}$ & 3. & & & & \\
\hline Abdominal & 3.1. & 16 & 143 & 200 & 359 \\
\hline Pelviano & 3.3. & 0 & 80 & 76 & 156 \\
\hline $\begin{array}{l}\text { Adenomectomia } \\
\text { prostática }\end{array}$ & 3.4 . & 0 & 16 & 200 & 216 \\
\hline Hemorroidectomia & 3.8. & 0 & 16 & 76 & 92 \\
\hline Otras quirúrgicas & 3.13. & 32 & 172 & 200 & 404 \\
\hline Tratamientos & 4. & & & & \\
\hline Neuroléptico & 4.27. & 0 & 32 & 200 & 232 \\
\hline Tóxicos & 5. & & & & \\
\hline Activo cig/día & 5.4 . & 16 & 32 & 76 & 124 \\
\hline
\end{tabular}

Tabla 69. Distribución de diagnósticos secundarios y condiciones en el grupo de pacientes con disfunción eréctil y diabetes mellitus, el grupo con diagnósticos secundarios y el grupo sin diagnósticos secundarios según el resultado de tratamiento éxito.

La tabla 70 muestra la comparación entre diagnósticos secundarios y condiciones en los grupos GAa y GBa de pacientes con disfunción eréctil. 


\begin{tabular}{|c|c|c|c|c|}
\hline \multirow{2}{*}{$\begin{array}{l}\text { Diagnósticos } \\
\text { secundarios en } \\
\text { disfuncion eréctil. }\end{array}$} & \multirow[t]{2}{*}{ Codificación } & \multicolumn{2}{|l|}{ Grupos } & \multirow[t]{2}{*}{$\mathbf{P}$} \\
\hline & & $\begin{array}{l}\text { GAa } \\
\text { (con } \\
\text { diabetes, } \\
\text { exito } \\
\mathbf{n = 8 0} \text { ) }\end{array}$ & $\begin{array}{l}\text { GBa } \\
\text { (con } \\
\text { diagnósticos } \\
\text { secundarios } \\
\text { sin diabetes, } \\
\text { exito, n=379) }\end{array}$ & \\
\hline & & $\mathrm{n}$ & $\mathrm{n}$ & \\
\hline Cardio-circulatorio & 2.4 & & & \\
\hline Cardiopatía isquémica & 2.4 .2 . & 0 & 46 & 0.0001 \\
\hline $\begin{array}{l}\text { Digestivo: gastritis, } \\
\text { ulcus, metabólico }\end{array}$ & 2.6. & 15 & 93 & 0.3113 \\
\hline Próstata & 2.8 . & 16 & 60 & 0.4074 \\
\hline Psiquiátrico & 2.9. & 0 & 47 & 0.0001 \\
\hline $\begin{array}{l}\text { Antecedentes } \\
\text { quirúrgicos }\end{array}$ & 3. & & & \\
\hline Abdominal & 3.1. & 16 & 143 & 0.0028 \\
\hline Pelviano & 3.3. & 0 & 80 & 0.0001 \\
\hline $\begin{array}{l}\text { Adenomectomia } \\
\text { prostática }\end{array}$ & 3.4 . & 0 & 16 & 0.0871 \\
\hline Hemorroidectomia & 3.8. & 0 & 16 & 0.0871 \\
\hline Otras quirúrgicas & 3.13 . & 32 & 172 & 0.3894 \\
\hline Tratamientos & 4. & & & \\
\hline Neuroléptico & 4.27. & 0 & 32 & 0.0028 \\
\hline Tóxicos & 5. & & & \\
\hline Activo cig/día & 5.4. & 16 & 32 & 0.0043 \\
\hline
\end{tabular}

Tabla 70. Comparación entre diagnósticos secundarios y condiciones entre GAa y GBa.

La tabla 71 muestra la comparación entre diagnósticos secundarios y condiciones en los grupos GAa y GCa de pacientes con disfunción eréctil. 


\begin{tabular}{|l|l|l|l|l|l|l|}
\hline $\begin{array}{l}\text { Diagnósticos } \\
\text { secundarios en } \\
\text { disfunción eréctil. }\end{array}$ & Codificación & \multicolumn{2}{|l|}{ Grupos } & p \\
\hline & & $\begin{array}{l}\text { GAa } \\
\text { (con } \\
\text { diabetes, } \\
\text { éxito } \\
\text { n=80) }\end{array}$ & \multicolumn{2}{|l|}{$\begin{array}{l}\text { GCa } \\
\text { (sin } \\
\text { diagnósticos } \\
\text { secundarios, } \\
\text { éxito n=276) }\end{array}$} & n & \\
\hline & & N & $\%$ & n & $\%$ & \\
\hline $\begin{array}{l}\text { Digestivo: gastritis, } \\
\text { ulcus, metabólico }\end{array}$ & 2.6. & 15 & & 200 & & 0.0001 \\
\hline Próstata & 2.8. & 16 & 20 & 200 & 72.46 & 0.0001 \\
\hline Psiquiátrico & 2.9. & 0 & & 200 & & 0.0001 \\
\hline $\begin{array}{l}\text { Antecedentes } \\
\text { quirúrgicos }\end{array}$ & 3. & & & & & \\
\hline Abdominal & 3.1. & 16 & & 200 & & 0.0001 \\
\hline Pelviano & 3.3. & 0 & & 76 & & 0.0001 \\
\hline $\begin{array}{l}\text { Adenomectomia } \\
\text { prostática }\end{array}$ & 3.4. & 0 & & 200 & & 0.0001 \\
\hline Hemorroidectomia & 3.8. & 0 & & 76 & & 0.0001 \\
\hline Otras quirúrgicas & 3.13. & 32 & & 200 & & 0.0001 \\
\hline Tratamientos & 4. & & & & & \\
\hline Benzodiazepinas & 4.26. & 0 & & 200 & & 0.0001 \\
\hline Tóxicos & 5. & & & & & 0.1940 \\
\hline Activo cig/día & 5.4. & 16 & & 76 & & \\
\hline
\end{tabular}

Tabla 71. Comparación entre diagnósticos secundarios y condiciones entre GAa y GAc.

Comparación de DS entre GB y GC.

Fue mas frecuente los síntomas prostáticos/prostatodinia en el subgrupo GC, hombres con disfunción eréctil sin diagnósticos secundarios y la automedicación de ansiolíticos que en el subgrupo GB ( $\mathrm{p}=0.0001)$

Fue mas frecuente el antecedente de quirúrgica prostática y hemorroidectomia en el subgrupo GC, varones con disfunción eréctil sin diagnósticos secundarios con respecto a el subgrupo GB, varones con disfunción eréctil y diagnósticos secundarios $(\mathrm{p}=0.0001)$. 
La tabla 72 muestra la comparación entre diagnósticos secundarios y condiciones en los grupos GBa y GCa de pacientes con disfunción eréctil y diabetes mellitus.

\begin{tabular}{|c|c|c|c|c|c|c|}
\hline \multirow{2}{*}{$\begin{array}{l}\text { Diagnósticos } \\
\text { secundarios en } \\
\text { disfunción eréctil. }\end{array}$} & \multirow[t]{2}{*}{ Codificación } & \multicolumn{3}{|c|}{ Grupos } & & \multirow[t]{2}{*}{$\mathbf{p}$} \\
\hline & & $\begin{array}{l}\text { GBa } \\
\text { (con } \\
\text { diagnósticos } \\
\text { secundarios } \\
\text { sin diabetes, } \\
\text { exito, } n=379 \text { ) }\end{array}$ & & $\begin{array}{l}\text { GCa } \\
\text { (sin } \\
\text { diagnósticos } \\
\text { secundarios, } \\
\text { éxito } n=276 \text { ) }\end{array}$ & & \\
\hline & & $\mathrm{n}$ & $\%$ & $\mathrm{n}$ & $\%$ & \\
\hline $\begin{array}{l}\text { Digestivo: gastritis, } \\
\text { ulcus, metabólico }\end{array}$ & 2.6. & 93 & 24.53 & 200 & 72.46 & 0.0001 \\
\hline Próstata & 2.8 . & 60 & 15.83 & 200 & 72.46 & 0.0001 \\
\hline Psiquiátrico & 2.9 . & 47 & 12.40 & 200 & 72.46 & 0.0001 \\
\hline $\begin{array}{l}\text { Antecedentes } \\
\text { quirúrgicos }\end{array}$ & 3. & & & & & \\
\hline Abdominal & 3.1. & 143 & 37.73 & 200 & 72.46 & 0.0001 \\
\hline Pelviano & 3.3 . & 80 & 21 & 76 & 27.53 & 0.0633 \\
\hline $\begin{array}{l}\text { Adenomectomia } \\
\text { prostática }\end{array}$ & 3.4. & 16 & 4.22 & 200 & 72.46 & 0.0001 \\
\hline Hemorroidectomia & 3.8. & 16 & 4.22 & 76 & 27.53 & 0.0001 \\
\hline Otras quirúrgicas & 3.13. & 172 & 45.38 & 200 & 72.46 & 0.0001 \\
\hline Tratamientos & 4. & & & & & \\
\hline Bnezodiazepinas & 4.27. & 32 & 8.44 & 200 & 72.46 & 0.0001 \\
\hline Tóxicos & 5. & & & & & \\
\hline Activo cig/día & 5.4. & 32 & 8.44 & 76 & 27.53 & 0.0001 \\
\hline
\end{tabular}

Tabla 72. Comparación distribución entre diagnósticos secundarios y condiciones entre GBa y GCa.

\section{DIAGNÓSTICOS SECUNDARIOS: HTA}

Dada la importancia fisiopatológica de la HTA en la DE, se analiza de forma independiente este diagnóstico secundario en relación al tratamiento indicado. La tabla 73 muestra la distribución de los tratamientos indicados para la HTA. 


\begin{tabular}{|c|c|c|c|c|}
\hline Grupo & $\begin{array}{l}\text { Tratamiento para la HTA no } \\
\text { especificado (código 4.12.) }\end{array}$ & TTO 4.13. & TTO 4.14. & TTO 4.15. \\
\hline $\begin{array}{l}\text { Muestra } \\
\text { general }\end{array}$ & 160 & 448 & 96 & 320 \\
\hline GA & 96 & 126 & 32 & 128 \\
\hline GAm & 0 & 32 & 0 & 0 \\
\hline GAo & 0 & 30 & 0 & 0 \\
\hline GAc & 48 & 0 & 32 & 64 \\
\hline $\begin{array}{l}\text { GAMa } \\
(\mathrm{n}=32)\end{array}$ & & 16 & & \\
\hline $\begin{array}{l}\text { GAMc } \\
(\mathrm{n}=16)\end{array}$ & & 16 & & \\
\hline $\begin{array}{l}\text { GAOa } \\
(\mathrm{n}=15)\end{array}$ & & 15 & & \\
\hline $\begin{array}{l}\text { GAOc } \\
(\mathrm{n}=15)\end{array}$ & & 15 & & \\
\hline $\begin{array}{l}\text { GACa } \\
(\mathrm{n}=32)\end{array}$ & & & 16 & 0 \\
\hline $\begin{array}{l}\mathrm{GACb} \\
(\mathrm{n}=16)\end{array}$ & 32 & & & 48 \\
\hline $\begin{array}{l}\text { GACc } \\
(\mathrm{n}=48)\end{array}$ & 16 & & & 16 \\
\hline
\end{tabular}

Tabla 73. Distribución de los tratamientos indicados para la HTA.

Hubo más 4.13. en GAMc (100\%) que en GAMa ( $\mathrm{p}=0.0003)$.

No hubo diferencia en 4.13. entre GAOa y GAOc $(\mathrm{p}=1.0000)$.

No hubo diferencia en 4.15. entre GACb y GACc ( $p=1.0000)$. 
V. DISCUSIÓN 



\section{INTRODUCCIÓN}

La disfunción sexual eréctil (DSE) es una condición médica que se define como la incapacidad para lograr y/o mantener una erección suficiente para una actividad sexual satisfactoria. El término DSE define con mayor precisión la naturaleza de dicha disfunción sexual que el de impotencia (1993). Evidentemente no cabe lugar a dudas de que la DSE, por su impacto social, es una causa importante de la disminución de la calidad de vida en los hombres con diabetes mellitus.

$\mathrm{Su}$ frecuencia es significativamente más elevada en la población diabética, cuando se compara con la población general. La DSE se asocia al incremento de la edad, (McCulloch, Campbell et al. 1980) (Bortolotti, Fedele et al. 2001) (Roth, Kalter-Leibovici et al. 2003) mal control metabólico , al mayor tiempo de evolución de la DM (Roth, Kalter-Leibovici et al. 2003), (Klein, Klein et al. 1996). al hábito de fumar, (Bortolotti, Fedele et al. 2001)). al consumo de bebidas alcohólicas (Lundberg, Ertekin et al. 2001) a la depresión, (Fedele, Bortolotti et al. 2000) al uso de algunos fármacos (Kleinman, Feldman et al. 2000) y a las complicaciones microvasculares de la DM, (Romeo, Seftel et al. 2000) entre otros factores.

Se plantea que la prevalencia de la DSE de moderada a completa es de un 20-85 \%.10 El estudio de Massachussets sobre envejecimiento masculino (Feldman, Goldstein et al. 1994) comunica una frecuencia de DSE de $50 \%$ en la población de 40-70 años de edad. Sin embargo, la aparición de DSE en los hombres diabéticos es más temprana y su prevalencia también es mayor, por lo que puede alcanzar hasta un $75 \%$. Se ha descrito que la DSE puede estar presente en más del $50 \%$ de los diabéticos dentro de los 10 años siguientes al diagnóstico de la DM, e incluso puede estar presente en el momento del debut clínico. Su frecuencia en los pacientes entre 23 y 29 años es de un $9 \%$, y aumenta hasta el $90 \%$ cuando se alcanza los 70 años. (Khan, Morgan et al. 2001) Actualmente se estima que existen en el mundo entre 100-150 millones de hombres afectados de DSE, y se espera para el año 2025 un incremento de 322 millones (Bloomgarden 1998) (Laumann, Paik et al. 1999) . Estos planteamientos evidencian que la DSE es un problema de salud, lo que obliga a desarrollar programas dirigidos a su prevención y tratamiento. 


\section{Clasificación de la DSE en el diabético}

La DSE puede ser clasificada en 3 formas. (Burnett 1997)

1. Orgánica. Causada por lesiones neurológicas y/o vasculares (arteriales y/o venosas), lesión de los cuerpos cavernosos o trastornos hormonales, secundarios a endocrinopatías.

2. Psicógena. Causada por inhibición central de los mecanismos de la erección, en ausencia de un daño orgánico.

3. Mixta (Orgánica-psicogénica). Cuando están presentes los factores antes señalados.

\section{Otras alteraciones}

Es importante recordar que el empleo de algunos medicamentos utilizados para tratar enfermedades asociadas a la DM (anexo) pueden contribuir al desarrollo de una DSE en estas personas (American association of clinical endocrinologist. (Guay, Spark et al. 2003) (Costabile 2003).

La DSE es una complicación frecuente en los hombres diabéticos. En la mayoría de los casos es de causa multifactorial. Tiene un impacto negativo en la salud sexual masculina, y por lo tanto, en su calidad de vida. Estos planteamientos obligan a desarrollar programas dirigidos a su prevención y tratamiento.

\begin{tabular}{|l|l|}
\hline TIPO DE MEDICAMENTO & EFECTO SEXUAL SECUNDARIO \\
\hline Antihipertensivos & \\
\hline Diuréticos & Disminución de la libido, DSE \\
\hline Espironolactonas & Disminución de la libido, DSE \\
\hline Tiazidas & \\
\hline Agentes de acción central & Disminución de la libido, DSE \\
\hline Metildopa & DSE \\
\hline Clonidina & Disminución de la libido, DSE y depresión \\
\hline Reserpina & \\
\hline Bloqueadores alfa adrenérgicos & Eyaculación retrógrada \\
\hline Prazosin & Eyaculación retrógrada \\
\hline Terazosin & \\
\hline \hline
\end{tabular}




\begin{tabular}{|c|c|}
\hline Beta bloqueadores & \\
\hline Propanolol & DSE, disminución de la libido \\
\hline Metoprolol & DSE, disminución de la libido \\
\hline \multicolumn{2}{|c|}{ Alfa y Beta bloqueadores } \\
\hline Labetalol & Inhibición de la eyaculación \\
\hline \multicolumn{2}{|c|}{ Bloqueador de los ganglios simpáticos } \\
\hline Guametidina & DSE, eyaculación retrógrada \\
\hline \multicolumn{2}{|c|}{$\begin{array}{l}\text { Inhibidor de la enzima convertidora de } \\
\text { angiotensina }\end{array}$} \\
\hline Lisinopril & DSE en $1 \%$ de los casos \\
\hline \multicolumn{2}{|c|}{ Medicamentos psiquiátricos } \\
\hline \multicolumn{2}{|l|}{ Antidepresivos } \\
\hline \multicolumn{2}{|l|}{ Tricíclicos } \\
\hline Amitriptilina & Inhibición de la eyaculación, DSE \\
\hline Amoxapina & Disminución de la libido, DSE \\
\hline Desipramina & Inhibición de la eyaculación \\
\hline Dexopin & Inhibición de la eyaculación, DSE \\
\hline Imipramina & Inhibición de la eyaculación \\
\hline Maprotilina & Inhibición de la eyaculación \\
\hline Nortriptilina & Inhibición de la eyaculación \\
\hline Protriptilina & Inhibición de la eyaculación, DSE \\
\hline \multicolumn{2}{|l|}{ Agente atípico } \\
\hline Trazodone & Priapismo \\
\hline \multicolumn{2}{|c|}{ Inhibidores de la monoaminoxidasa } \\
\hline Isocarboxázido & Inhibición de la eyaculación \\
\hline Fenelzine & Inhibidor de la eyaculación, DSE \\
\hline \multicolumn{2}{|l|}{ Antipsicóticos } \\
\hline Tiuridazina & $\begin{array}{l}\text { Inhibición de la eyaculación, disminución } \\
\text { de la libido, priapismo }\end{array}$ \\
\hline Clorpromacina & Inhibición de la eyaculación \\
\hline Mesoridazina & $\begin{array}{l}\text { Inhibición de la eyaculación, disminución } \\
\text { de la libido }\end{array}$ \\
\hline
\end{tabular}




\begin{tabular}{|l|l|}
\hline Flufenazina & $\begin{array}{l}\text { Inhibición de la eyaculación, disminución } \\
\text { de la libido }\end{array}$ \\
\hline Inhibidores de la recaptación serotonina & \\
\hline Fluoxetina & Anorgásmica \\
\hline Trifluoperazina & Inhibición de la eyaculación \\
\hline Grupo lioxantene & Inhibición de la eyaculación \\
\hline Clerprotixene & Inhibición de la eyaculación \\
\hline Butifenona & Inhibición de la eyaculación \\
\hline Haloperidol & Inhibición de la eyaculación \\
\hline Antimaníaco & Posible DSE \\
\hline Carbonato de litio & \\
\hline Antiulceroso & Disminución de la libido, DSE, \\
\hline Cimetidina & ginecomastia \\
\hline
\end{tabular}

Tabla 74. Efectos adversos de medicamentos de uso común en la función sexual masculina.

\subsection{EDAD.}

Se analizaron 1416 pacientes con una edad media de 58.12 años. El grupo de pacientes más representado están en el grupo entre 60-65 y 65-70 años. A pesar de que la incidencias de DE aumenta con la edad (Johannes, Araujo et al. 2000) en la práctica clínica los pacientes más mayores son tradicionalmente más reacios a iniciar tratamientos farmacológicos para la DE.

Aunque tradicionalmente la aparición de DE ocurre a edad más temprana en los pacientes diabéticos adelantándose en 5-10 años sobre los que no presentan DM (Romeo, Seftel et al. 2000) en nuestro estudio no había tales diferencias. En algunos casos, especialmente en los pacientes de más edad, la disfunción eréctil representa el primer hallazgo clínico que revela una diabetes no diagnosticada (Deutsch and Sherman 1980, Lewis 2001).

En nuestra muestra los pacientes diabéticos fueros tenían mayor edad respecto al subgrupo de pacientes sin DM con diagnósticos secundarios pero los de mayor edad fueron el tercer subgrupo sin DM ni diagnósticos secundarios. Se objetivó que fueron los pacientes diabéticos de mayor edad los que tuvieron mayor éxito en el tratamiento con una diferencia significativa. 
Sin embargo, una mayor edad influía en el fracaso al tratamiento de la disfunción eréctil en varones no diabéticos con diagnósticos secundarios de forma significativa.

En la comparativa entre los diferentes grupos que presentaban éxito en el tratamiento la edad fue inferior en los varones que consultaban solo con disfunción eréctil sin ninguna otra patología sin establecerse una diferencia significativa.

Se observa una relación en los subgrupos de tratamiento con Metformina y otros Antidiabéticos orales en los que a menor edad hay una mayor fracaso a la respuesta del tratamiento con una diferencia en ambos casos estadísticamente significativa.

\subsection{TIEMPO DE CONTROL EVOLUTIVO.}

El tiempo de control evolutivo, después de instaurar el tratamiento de la DE en la muestra general fue de 22.79 meses existiendo una franca diferencia respecto a los otros dos grupos, en el grupo sin Diabetes y sin otros diagnósticos secundarios.

Dentro del grupo de pacientes diabéticos el tiempo de control evolutivo fue inferior como es lógico en el subgrupo de éxito al tratamiento respecto al de respuesta parcial y fracaso con mínimo de 11 meses de seguimiento siendo una diferencia estadísticamente significativa y dentro de los grupos con respuesta exitosa el subgrupo de más tiempo de seguimiento fue el de pacientes sin DM con diagnósticos secundarios, con un rango superior de 61 meses con una diferencia significativa respecto a los otros 2 grupos.

De forma relevante $\mathrm{y}$ consistente, se encuentran diferencias estadísticamente significativa del tiempo de control evolutivo que es inferior en los pacientes tratados con metformina respecto a los otros dos grupos de tratamiento probablemente esto obedezca a un menor tiempo de evolución de la DM y de ello es importante comentar lo importantes de inciar el tratamiento de la DE lo más precoz posible, para evitar el deterioro de los mecanismos implicados en la erección. Mecanismos como la disfunción endotelial que es la base de la fisiopatología de la enfermedad cardiovascular (Bonetti, Lerman et al. 2003)

\subsection{GLUCEMIA}

Es importante la determinación de glucosa en la evaluación inicial del varón con disfunción eréctil, así como intentar un adecuado control de los 
niveles de glucemia para evitar el empeoramiento, ya que hay estudios que refieren hasta un $12 \%$ de diabéticos no conocidos entre los pacientes que consultan por esta patología. La disfunción eréctil del diabético es multifactorial, de mayor severidad y responde peor al tratamiento oral (Lewis 2001)

En nuestro estudio sin establecerse diferencias estadísticamente significativas la glucemia en los pacientes diabéticos fue mayor dentro del subgrupo de respuesta parcial al tratamiento con un valor medio de 110 $\mathrm{mg} / \mathrm{dlo}$ y siendo la menor la del subgrupo que presentaba fracaso al tratamiento con un valor medio de $98 \mathrm{mg} / \mathrm{dl}$.

Por otra parte en el subgrupo de pacientes tratados con Metformina los que presentan una respuesta exitosa al tratamiento tienen menor nivel de glucemia con una diferencia estadísticamente significativa respecto a los de respuesta parcial y fracaso. Sin embargo, en el subgrupo de Antidiabéticos orales los que tienen respuesta exitosa son los que tienen un nivel medio de glucemia de $131 \mathrm{mg} / \mathrm{dl}$ respecto a los que fracasan con el tratamiento que tiene un nivel medio de glucemia de $76 \mathrm{mg} / \mathrm{dl}$ con una diferencia significativa lo que se podría explicar con la existencia de hipoglucemias no existentes con el grupo a tratamiento sólo con metformina.

\subsection{HBA1C}

La hemoglobina glicosilada (hemoglobina A1c, Hb1c, HbA1c, o A1c) (Larsen, Horder et al. 1990) es un examen que mide la cantidad de hemoglobina que se glucosila en la sangre, y brinda un buen estimado de qué tan bien está siendo tratada la diabetes mellitus (DM) durante los últimos 3 meses (Fig. 1) (Rohlfing, Little et al. 2000) En general, cuanto más alto sea el nivel de HbA1c, mayor será el riesgo para el paciente de desarrollar complicaciones oculares, renales, vasculares y de los nervios periféricos (2007). 


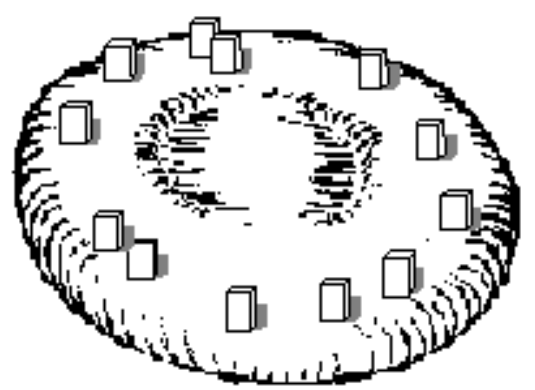

A

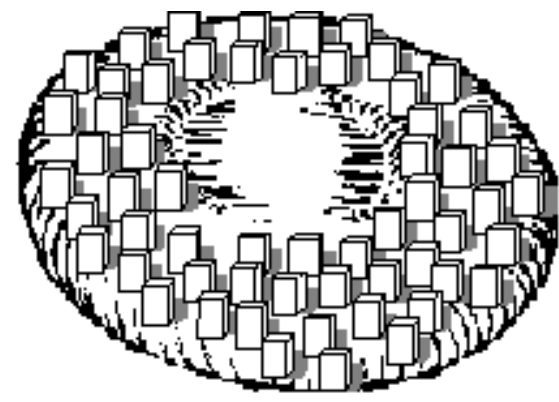

B

\section{A. Hbalc ideal}

B. Hbalc elevada

Fuente: Tomado de Departament of Health Diabetes Centre, Royal Adelaide

Figura 147.

Las hemoglobinas glucosiladas pueden ser A1a, A1b y A1c. Estas hemoglobinas son producto de una pequeña modificación possintética de la hemoglobina A. La hemoglobina A1c representa del 3 al $6 \%$ de la hemoglobina total de los individuos sanos, y puede doblarse (e incluso triplicarse) en pacientes con DM según sus niveles de glucemia. (Peterson, Pavlovich et al. 1998) (Kilpatrick 2000) (Michigan Diabetes Research \& Training Center. Hemoglobin A1c Fact Sheet [citado 26 Dic 2007].

Disponible en: http://www.med.umich.edu/mdrtc/cores/ChemCore/ hemoa1c .htm ) (Larsen, Horder et al. 1990) (Rohlfing, Little et al. 2000) .

\subsubsection{Medición de la $\mathrm{HbA1c}$}

Existen diferentes métodos para cuantificarla, algunos miden el total de las hemoglobinas glucosiladas, pero otros, exclusivamente la concentración de la hemoglobina A1c.1 (Bruce, Benjamin et al. 2007) (Petersen, Finley et al. 2007);(Berg and Sacks 2008) (Little and Sacks 2009) En general, esta última es la que se utiliza con mayor frecuencia en los últimos años.

Existen diversas técnicas para la medición de la HbA1c, unas se basan en las diferencias de carga (cromatografía líquida de alta representación [HPLC]) y otras en la estructura (afinidad por el boronato o técnica de inmunoensayo combinado con química general) (Bruce, Benjamin et al. 2007); (Petersen, Finley et al. 2007).

Inicialmente su estandarización fue mínima y los resultados variaban según los métodos empleados (Berg and Sacks 2008). En los años 1990 
fueron desarrollados varios programas de estandarización de la HbA1c, más notable en Suecia, Japón y los Estados Unidos. El sistema que más se adopta es el del National Glycohemoglobin Standardization Program (NGSP), cuyos resultados son comparables con aquellos reportados en los estudios DCCT y UKPDS. Este método es muy utilizado en el mundo, y redujo las variaciones de HbA1c entre laboratorios. (Little and Sacks 2009)

Con el propósito de mejorar este último acápite, la International Federation for Clinical Chemistry (IFCC), (Little and Sacks 2009) desarrolló un método de medición de HbA1c que utiliza un hexapéptido $\mathrm{N}$-terminal enclavado en la cadena beta de la hemoglobina por la enzima endoproteinasa Glu-C. Los hexapéptidos glucosilados y no glucosilados son separados unos de otros por high performance liquid chromatography (HPLC) y cuantificadas por métodos de espectrometría o electroforesis. Este sistema produce valores absolutos de HbA1c que son 1,5 a 2,0 \% menores que el sistema NGSP (Hoelzel, Weykamp et al. 2004) dados por la gran especificidad de este método. Sin embargo, este es técnicamente complejo, consume más tiempo y es de mayor costo, por lo que no se usa como rutina en la práctica médica. (Little and Sacks 2009)

El hecho que el método IFFC sea más específico que el NGSP explica que haya cierta diferencia entre los resultados.

\subsubsection{Interpretación de los resultados}

La HbAlc es usualmente reportada como el por ciento total de hemoglobina, tomando los valores del NGSP, que son los más usados. Para evitar confusiones con estos valores, y en conformidad con el Sistema Internacional de Unidades, los resultados IFCC son reportados en $\mathrm{mmol} / \mathrm{mol} .20,23$ Por ejemplo, un resultado de HbA1c de $7 \%$ (en unidades NGSP) es equivalente a $53 \mathrm{mmol} / \mathrm{mol}$ (en unidades IFCC), y a un promedio glucémico de $9,5 \mathrm{mmol} / \mathrm{L}(150 \mathrm{mg} / \mathrm{dl})$. Asimismo, uno de $6 \%$ es equivalente a $42 \mathrm{mmol} / \mathrm{mol}$, y a un promedio glucémico de $6,7 \mathrm{mmol} / \mathrm{L}(120 \mathrm{mg} / \mathrm{dl})$. Un documento de consenso sobre la estandarización de la $\mathrm{HbA} 1 \mathrm{c}, 24$ recomienda que sus valores pueden ser reportados en $\mathrm{mmol} / \mathrm{mol}$ (IFCC) o en $\%$ (NGSP).En personas no diabéticas el valor normal de la HbA1c es $<6 \%$. En los diabéticos, cifras menores de $7 \%$ muestran un buen control metabólico, pudiéndose aceptar niveles mayores en los ancianos. Los niveles de hemoglobina glucosilada no son similares, pero sí equivalentes con los de glucemia en plasma venoso (tabla 75). Además, representan en mejor medida el grado de control metabólico que una muestra aislada de glucemia, ya sea en 
ayunas o posprandial, por lo que las variaciones en el tratamiento de la DM frecuentemente se basan en sus resultados. Las personas diabéticas con buen control glucémico muestran niveles de HbA1c dentro de los rangos de la normalidad (Rohlfing, Little et al. 2000); (Rohlfing, Wiedmeyer et al. 2002); (Grant, Soriano et al. 2004); (Nathan, Singer et al. 1984) Disponible en: http://www.healthyinfo.com/clinical/endo/dm/hgalc.test.shtml)

\begin{tabular}{|l|c|c|}
\hline \multirow{2}{*}{$\begin{array}{l}\text { HbA 1c } \\
(\%)\end{array}$} & \multicolumn{2}{l|}{ Glucosa en sangre } \\
\cline { 3 - 3 } & $\mathrm{mmol} / \mathrm{L}$ & $\mathrm{mg} / \mathrm{dL}$ \\
\hline 4 & 3,3 & 60 \\
\hline 5 & 5,0 & 90 \\
\hline 6 & 6,7 & 120 \\
\hline 7 & 9,5 & 150 \\
\hline 8 & 11,5 & 180 \\
\hline 9 & 13,5 & 210 \\
\hline 10 & 15,5 & 240 \\
\hline 11 & 16,5 & 270 \\
\hline 12 & 17,7 & 300 \\
\hline 13 & 18,3 & 330 \\
\hline 14 & 20,0 & 360 \\
\hline
\end{tabular}

Fuente: Clin Chem. 2004;50:166-74.

Tabla 75: Relación aproximada entre los niveles de sangre venosa y el valor de Hbalc

\subsubsection{Factores que interfieren en la interpretación de los resultados}

Los resultados pueden diferir dependiendo de la técnica utilizada, la edad del sujeto, y las variaciones biológicas entre individuos. Dos individuos con igual promedio de glucemias pueden tener diferentes medidas de HbA1c tanto como $1 \% .30,31$ Las variaciones encontradas con respecto a grupos raciales o étnicos son relativamente pequeñas (£ $0,4 \% \mathrm{HbA} 1 \mathrm{c})$ y no son clínicamente significantes. Su incremento con la edad es alrededor de 0,03\% por año en individuos no diabéticos, y algunos autores concluyen que este incremento es mínimo y no se necesitan cambios en cuanto a las metas entre los diferentes grupos de edades. (Little and Sacks 2009) ; (Rohlfing, Little et al. 2000). Disponible en: http://www.clinchem.org/cgi/content/full/48/7/ 1116); 
(Hemoglobin A1c Test. MedicineNet.com [citado 8 Jul 2009]. Disponible en: http://www.medicinenet.com/hemoglobin_alc_test/article.htm)

Niveles de HbA1c no esperados pueden encontrarse en personas que recibieron recientemente una transfusión de sangre o glóbulos, o con un conteo subnormal de hematíes, como en los individuos con anemias crónicas (déficit de hierro, déficit de glucosa-6-fosfato deshidrogenasa, drepanocitosis, paludismo, pérdida de sangre crónica, o alguna otra condición que cause muerte prematura de las células rojas). Asimismo, niveles de HbA1c más altos de lo esperado se relacionan con un mayor tiempo de vida del hematíe (sujetos esplenectomizados, con deficiencia de vitamina B12 o de ácido fólico).(2009).

Un empeoramiento en los niveles de Hbalc, marcador de un mal control metabólico, en los pacientes con DM predice un deterioro de la función eréctil y se asocia a una mayor gravedad de la DE (Romeo, Seftel et al. 2000, Rhoden, Ribeiro et al. 2005).

Se objetivó en nuestra serie estableciéndose diferencias significativas el mejor nivel de Hba1c mediante el método NGSP era en los pacientes tratados con metformina, seguidos de los pacientes en tratamiento combinado con insulina, resultado consistente cuando se determinaba la Hba1c por el método IFCC.

Un resultado consistente con un comportamiento que se observaba también con la glucemia es que dentro del subgrupo de pacientes con DM y DE a tratamiento con ADOS se observaba mayor éxito de tratamiento con niveles de Hba1c más altos medidos por ambos métodos: NGSP e IFCC lo que sugiere la influencia de las hipoglucemias en una respuesta negativa al tratamiento de la DE, aunque este hecho no se observó en los pacientes con tratamiento combinado donde no existían diferencias en la respuesta al tratamiento en función del nivel de Hba1c por ninguno de los dos métodos y donde cabía también la posibilidad de existencia de Hipoglucemias aunque este hecho se podría explicar en que los pacientes al estar en tratamiento con insulina estuvieran sometidos a mayor autocontrol que en el caso del grupo anterior evitando así las hipoglucemias.

Nuestro estudio determina que un mejor control de la diabetes, monitorizado mediante la medición de Hba1c mediante el método NGSP en diabéticos tratados con metformina, se relaciona con una mejor respuesta al tratamiento de la disfunción eréctil. La hemoglobina glicosilada medida mediante el método IFCC arroja resultados similares. 
Sin embargo, según los estudios el efecto beneficioso asociado a buen control metabólico de la DE se observa que parece perderse en los pacientes de más edad (Lu, Jiann et al. 2009).

\subsection{PSA}

En nuestro estudio no hubo diferencias entre pacientes con Diabetes Mellitus con Disfunción eréctil, pacientes con DE sin Diabetes Mellitus pero con diagnósticos secundarios y pacientes con DE sin Diabetes Mellitus ni diagnósticos secundarios en comparación con el grupo general.

El PSA fue inferior en el subgrupo de pacientes Diabéticos con fracaso al tratamiento y la diferencia respecto al grupo de éxito al tratamiento es estadísticamente significativa. Este dato es motivo de debate: el PSA como marcador de tejido prostático ¿estará descendido en varones operados de próstata? ¿Asimismo, la cirugía de próstata se relaciona con más posibilidad de fracaso al tratamiento de disfunción eréctil?

Asimismo, el PSA fue inferior en el subgrupo de pacientes sin DM y diagnósticos secundarios con respuesta parcial al tratamiento y fue superior en el subgrupo de fracaso lo que nos lleva a preguntarnos: ¿fracasan más los varones con PSA superior en los no diabéticos con diagnosticos secundarios?

Queda claro que de aquellos pacientes que respondieron de forma exitosa en los tres grupos el menor nivel de PSA con una diferencia significativa era en los pacientes con DM, que también se objetiva en los pacientes con éxito al tratamiento tratados con metformina respecto a los de respuesta parcial y fracaso.

\subsection{DIAGNÓSTICOS SECUNDARIOS}

En este estudio se demuestra que en los pacientes con DM la presencia de factores de riesgo de padecer DE condiciona menores posibilidades de obtener una respuesta satisfactoria. La cardiopatía isquémica, los trastornos digestivos, el antecedente de adenomectomía prostática y el tratamiento concomitante con benzodiacepinas conllevan al fracaso del tratamiento de la Disfunción eréctil.

\subsubsection{Cardiopatía isquémica}

La cardiopatía isquémica es más prevalente en el subgrupo de hombres con disfunción eréctil y diagnósticos secundarios que en hombres con 
disfunción eréctil y Diabetes Mellitus teniendo en cuenta la limitación del tamaño muestral entre ambos grupos. La disfunción vascular o patología vascular es la primera causa de Disfunción eréctil.

Asimismo, se observa que dentro del subgrupo de pacientes diabéticos una diferencia significativa en los que tienen una respuesta nula al tratamiento con una prevalencia del $65.9 \%$ respecto a los pacientes con buena respuesta donde no existe ningún evento.

Según los estudios los pacientes diabéticos con enfermedad coronaria subclínica presentan una elevada prevalencia de DE, de hecho s, se multiplica por 14 el riesgo de sufrir una enfermedad coronaria previamente no detectada en los pacientes diabéticos que presentan DE. Por esta y otras evidencias se ha sugerido que la DE puede ser considerada un síntoma centinela de la enfermedad cardiovascular en pacientes de riesgo como los diabéticos. (Gazzaruso, Solerte et al. 2008).

Hay que considerar que los pacientes con cardiopatía isquémica y DE candidatos a recibir tratamiento con o sin DM deben tener una enfermedad cardiaca controlada y estable. Cardiópatas en otra situación no han sido analizados en este estudio porque se siguieron las recomendaciones de uso de IPD5 de la guía clínica de la EAU (Wespes, Amar et al. 2010. Esta guía está adapatada a las recomendaciones derivadas de conferencias de consenso sobre la disfunción sexual y riesgo cardiaco (Kostis, Jackson et al. 2005) (DeBusk, Drory et al. 2000).

\subsubsection{Síntomas digestivos e urológicos.}

En nuestro estudio existe una prevalencia mayor de dispepsia en el subgrupo de hombres con disfunción eréctil sin diagnosticos secundarios ni DM que en el subgrupo con Diabetes Mellitus.

Por otra parte dentro del subgrupo de evaluación de paciente con DM existía más gastritis en el subgrupo con respuesta parcial al tratamiento por lo que se investigó en este sentido y en la totalidad utilizaban inhibidores de bomba de protones: omeprazol, lanzoprazol o esomeprazol, reflexión importante dado que la ranitidina eleva la prolactina y es un factor de riesgo de disfunción eréctil, pero en nuestra serie no existió este sesgo.

En nuestro estudio existe una prevalencia mayor de prostatismo leve o prostatodinia, en el subgrupo de hombres con disfunción eréctil sin diagnosticos secundarios ni DM que en el subgrupo con Diabetes Mellitus al igual que ocurre con los síntomas digestivos. 
Los diagnósticos secundarios entre pacientes catalogados con diagnósticos secundarios respecto aquellos que no los tenían, la gastritis fue más prevalente de forma significativa en los pacientes con DE enmarcados sin diagnósticos secundarios por lo que esto nos lleva a una reflexión ¿a qué diagnósticos secundarios nos estamos refiriendo?: bien a otros tratamientos de "síntomas no graves": dispepsia y prostatismo. ¿Supone este hallazgo que los pacientes somatizan sus problemas?, es un hallazgo a considerar en futuras líneas de investigación

\subsubsection{Psicopatología.}

Hay una prevalencia del $30.43 \%$ de diagnósticos psiquiátricos $(\mathrm{n}=392)$ en nuestro estudio, sin constar como ello en nuestros pacientes con DM con DE. Se observa que es más frecuente los trastornos psiquiátricos en el subgrupo de hombres sin Diabetes Mellitus con diagnosticos secundarios así como en tratamiento neuroléptico. También existe diferencia estadísticamente significativa de pacientes en tratamiento neuroléptico en los diabéticos con respuesta nula al tratamiento de la disfunción eréctil.

Los neurolépticos el efecto terapeútico que se pretende es el bloqueo dopaminérgico en el sistema límbico y en la región prefrontal. Los efectos indeseables están relacionados con el bloqueo beta-adrenérgico y los efectos anticolinérgicos y antidopaminérgicos, que son los responsables de los efectos extrapiramidales y sexuales. Es difícil conocer la causa exacta de afectación de la esfera sexual, ya que abarcan desde el priapismo hasta la DE, pasando por alteraciones de la líbido.

Respecto a la existencia de diagnósticos secundarios entre los pacientes con DE catalogados con diagnósticos secundarios y sin ellos los trastornos psiquiátricos fueron mas frecuentes en el subgrupo no catalogado con diagnósticos secundarios, donde el consumo de benzodiacepinas también era significativamente mayor. Las benzodiacepinas recordar que producen DE por inhibición de la vía dopaminérgica central proeréctil. Por lo tanto, de nuevo nos hacemos la pregunta ¿a qué diagnósticos secundarios nos estamos refiriendo?, bien a otros tratamientos de "síntomas no graves": ansiedad. ¿Supone este hallazgo que los pacientes somatizan sus problemas?, es un hallazgo a considerar en futuras líneas de investigación.

\subsubsection{Antecedentes quirúrgicos: abdominal, pelviano.}

En nuestro estudio son muchos más prevalentes los antecedentes de cirugía abdominal como de adenomectomía en pacientes del subgrupo 
disfunción eréctil sin diagnósticos secundarios respecto a los otros dos subgrupos y de forma significativa respecto a los pacientes con DM. Esto ocurre porque en el subgrupo de hombres con disfunción eréctil y Diabetes Mellitus, los varones consultaron primariamente más por disfunción eréctil mientras que muchos varones del otro subgrupo referían disfunción eréctil en el seguimiento, en consulta de urología general, muchos de los cuales tienen el antecedente de adenomectomia. La diferencia de prevalencia también ocurría con el antecedente de hemorreidectomía.

También existe una mayor prevalencia en el subgrupo de pacientes con DE con diagnósticos secundarios respecto a los pacientes con DM en la presencia de antecedentes quirúrgicos abdominales, pelviano, hemorreidectomía y otras cirugías.

Se observó que dentro de los pacientes con DM los que tenían más antecedentes de adenoidectomía se objetiva un mayor porcentaje de respuesta nula al tratamiento viendóse la diferencia de forma significativa.

La extirpación del adenoma benigno de próstata por abordaje anterior no debería causar DE, excepto si durante el acto quirúrgico se produce un desgarro de la cápsula entre las 5 y las 7 del horario endoscópico, donde se podría lesionar el haz neurovascular. También se puede producir hematoma, infección o fibrosis pericapsular que engloba ambos fascículos neurovasculares.

Zohar et al (Zohar, Meiraz et al. 1976) refieren que el 62\% de los pacientes no informados sobre la eyaculación retrógada presentaban alteraciones de la erección, en cambio los pacienes a los que se le había prevenido no referían DE.

Gacci et al (Gacci, Bartoletti et al. 2003) evaluaron los síntomas urinarios, la DE y la calidad de vida en pacientes con HBP antes y después de adenoidectomía. Llegarón a la conclusión de que la erección, el orgasmo y la satisfacción sexual no se ven significativamente alterados. La mayoría de los autores refieren una gran influencia psicológica en la DE desarrollada tras una adenoidectomía.

Una cirugía muy frecuente que causa DE es la Prostatectomía radical (PR) cuya etioliogía es multifactorial (McCullough 2008). Si bien la función eréctil antes de la cirugía es uno de los principales factores pronósticos para establecer su situación después de la misma (Rabbani, Stapleton et al. 2000), otros mecanismos implicados incluyen lesiones vasculares y lesiones nerviosas (Rabbani, Stapleton et al. 2000). Los estudios de Walsh et al revolucionaron el tratamiento quirúrgico del cáncer de próstata mediante la 
introducción del concepto de PR con preservación nerviosa (Walsh, Lepor et al. 1983) que mejora la calidad de vida del paciente, en particular con respecto a la recuperación de la función eréctil (Mulhall, Secin et al. 2008). Incluso cuando el cirujano cree que ha logrado realizar la preservación bilateral de los haces neurovasculares, se produce, inevitablemente, una lesión nerviosa, por ejemplo, tan sólo con tracción. Esta lesión nerviosa se conoce como neuroapraxia y puede ser causada por el estiramiento mecánico del nervio que puede ocurrir durante la retracción de la próstata, el daño térmico, la isquemia de los nervios secundaria a la interrupción del aporte sanguíneo mientras se intenta controlar la hemorragia quirúrgica y efectos inflamatorios locales asociados con el trauma quirúrgico. Incluso en la disección con preservación nerviosa más meticulosa, es inevitable que se produzca algún grado de neuroapraxia debido a la proximidad de los nervios a la glándula prostática. Por otra parte, se ha demostrado en modelos animales de rata que simplemente la exposición-disección de los nervios cavernosos pueden dar lugar a DE (Mullerad, Donohue et al. 2006).

Otra causa postquirúrgica importante de DE es la cistectomía radical, donde Walsh (Walsh, Gittes et al. 1986.) fue el primero en demostrar que mediante la modificación de la técnica quirúrgica (preservación nerviosa) se podría obtener una mayor función eréctil postoperatoria en los individuos que se habían sometido a cistoprostatectomía radical. De forma similar a lo ocurrido en la cirugía del cáncer de próstata (Matsuda, Aptel et al. 2003), una mejor detección, y protocolos de seguimiento para el cáncer de vejiga causarán la migración de su estadificación y permitirán indicaciones precoces lo que permitirá con mayor facilidad la preservación neurovascular.

Por otra parte la DE es muy prevalente no sólo en pacientes con Hiperplasia benigna de próstata en tratamiento médico, sino los tratados quirúrgicamente con resección transuretral de próstata y aunque no parece existir una relación causal clara entre la DE y este tratamiento quirúrgico existe una alta prevalencia e disfunción eyaculatoria y la probable suma de factores de riesgo comunes en el mismo grupo etario.

Tanto la DE como los problemas de vaciado vesical son posibles complicaciones relacionadas con la cirugía colorrectal. Las cifras relacionadas con esta intervención (resección anterior baja (RAB) o amputación abdominoperineal (AAP) varían sustancialmente en la literatura médica, pero puede alcanzar hasta el $15 \%$ de disfunción vesical y el $40 \%$ de DE.(Jones, Stevenson et al. 2009); (Nesbakken, Nygaard et al. 2000); (Kim, Zisman et al. 2004) Según los datos de la literatura médica, la incidencia de problemas de erección es mayor tras AAP que tras RAB (Santangelo, Romano et al. 1987) . 
La DE así como los transtornos eyaculatorios tienen su origen en la lesión nerviosa retroperitoneal y pélvica (plexo simpático y parasimpático (plexo cavernoso)). La cirugía colorrectal realizada por vía laparoscópica parece segura en comparación con la cirugía abierta (2004, Guillou, Quirke et al. 2005) (Veldkamp, Kuhry et al. 2005). Los datos existentes en la literatura sugieren cifras bajas de disfunción sexual tras cirugía laparoscópica. Tanto la RAB como la AAP son los procedimientos colorrectales con mayor riesgo de lesión nerviosa, la resección de colón o sigma más alta tiene un menor incidencia de estas complicaciones RAB (Santangelo, Romano et al. 1987).

Entre otras cirugías abdominales la reparación del aneurisma de aorta abdominal causa disfunción eréctil (DePalma, Levine et al. 1978). Estudios recientes realizados con mayor número de pacientes por Lee et al (Lee, Kor et al. 2000) han comunicado un índice de DE después de cirugía vascular abdominal del 83\% independientemente del tipo de injerto empleado (bifurcado o de tubo). La causa de DE en este grupo de pacientes parece estar relacionada con la técnica quirúrgica (lesión del plexo autonómico) según lo descrito por De Palma et al (DePalma, Levine et al. 1978). Estudios recientes realizados con mayor número de pacientes por Lee et al (Lee, Kor et al. 2000) y Miles et al (Miles, Miles et al. 1982). Con respecto a la prevención de la $\mathrm{DE}$, en varios estudios se han realizado técnicas de preservación de las estructuras nerviosas autónomas durante la disección de la aorta y arteria ilíaca. Algunos autores comunican resultados muy satisfactorios a este respecto.

Por último entre otras cirugías abdominales, la disección y extirpación de los ganglios linfáticos retroperitoneales pueden causar ausencia de eyaculación permanente debido al daño en los nervios simpáticos retroperitoneales (Drasga, Einhorn et al. 1983). Los diferentes efectos del tratamiento en la esfera sexual hacen que su evaluación sea un problema complejo sobre todo en pacientes tratados con más de una modalidad terapeútica. En la literatura científica se han comunicado las grandes diferencias que existe respecto a las frecuencias de las disfunciones sexuales y la influencia de los diferentes tratamientos en pacientes con tumores testiculares y extensión retroperitoneal que están presentes en la quinta parte de los pacientes.

\subsubsection{Hábitos tóxicos: tabaco.}

Son bien conocidos los efectos del tabaco en la función eréctil: causa trombosis, arterioesclerosis, infarto, enfermedad coronaria, muerte y aumento de la incidencia de cánceres. A largo plazo produce daño en los nervios 
periféricos y daño estructural en el tejido cavernoso (Tostes, Carneiro et al. 2008).

Hoy en día está ya claramente establecido que la nicotina produce una disminución en la biodisponibilidad del NO, aumenta la producción y liberación de endotelinas y el aumento de las especies reactivas del oxígeno, y ya sabemos que la síntesis de NO es necesaria para estimular la relajación del músculo liso del cuerpo cavernoso y aumentar el flujo arterial necesario para producir la erección. La nicotina favorece la expresión de la nicotinamida adenina dinucleótido fosfato en forma reducida, la cual genera grandes cantidades de radicales libres de oxígeno, que, a su vez, reaccionan con el NO para formar peroxinitratos que afectan negativamente a la bioactividad del NO (Sáenz-de-Tejada 1997) (Koupparis, Jeremy et al. 2004) Todo ello unido a una disfunción endotelial y daño vascular asociado con arterioesclerosis (Bacon, Mittleman et al. 2006). Otros autores, tras realizar test de tumescencia nocturna, Regiscan ${ }^{\circledR}$, eco dúplex y cavernosometría, concluyen que entre los fumadores también desempeña un papel muy importante la incompentencia del mecanismo venocorporooclusivo (Elhanbly, Abdel-Gaber et al. 2004).

Se halló significativamente una mayor prevalencia de fumadores activos en el subgrupo de pacientes con Diabetes mellitus que en el subgrupo con disfunción eréctil sin Diabetes Mellitus con diagnósticos secundarios (Este hallazgo hay que considerarlo con especial precaución, puesto que el tabaquismo es un reconocido factor de riesgo independiente de disfunción eréctil) y también fue más prevalente respecto al subgrupo sin diagnósticos secundarios pero sin verse de forma significativa.

El hábito tabáquico no se asoció con la respuesta al tratamiento en varones diabéticos, aunque sí que había mayor existencia de fumadores activos en los no respondedores respecto a los de éxito en la respuesta o respuesta parcial, pero sin ser significativa, lo que apoya los diferentes grados y complejidad en los diferentes mecanismos de la DE. Sin embargo, en los otros dos subgrupos de comparación si que se halló diferencia significativa entre los pacientes con respuesta exitosa al tratamiento con hábito tabáquico siendo superior en los pacientes con DE con diagnósticos secundarios respecto a los no catologados con diagnósticos secundarios. Este dato hablaría a favor de lo que se observa en los estudios de que los fumadores muestran un mayor grado de somatización de la ansiedad e insatisfacción de su vida sexual, así como asociación importante con el abuso de alcohol y cannabis. (Corona, Mannucci et al. 2005). 


\subsubsection{HTA}

Hay una alta prevalencia de HTA como corresponde a los datos publicados en España donde se ha demostrado que los pacientes con HTA tienen una alta prevalencia de DE (46.5\%) ( De Cuéllar, 1998)

De forma significativa se encuentra una mayor prevalencia de HTA en los pacientes que presentan un fracaso. Quedando explicada esta peor respuesta porque la HTA se asocia con vasoconstricción, disminución del flujo arterial peneano y respuestas eréctiles deficientes. Mantenida en el tiempo, la HTA produce cambios estructurales en las paredes arteriales del pene (Simonsen, Garcia-Sacristan et al. 2002) y también altera la relajación del cuerpo cavernoso (Cai and Harrison 2000)

En nuestro estudio no existen diferencias en relación a la HTA en la respuesta al tratamiento en pacientes diabéticos respecto a las diferencias opciones de tratamiento con metformina, con otros antidiabéticos orales respecto a tratamiento combinado con insulina.

La HTA en pacientes diabéticos se trata con diuréticos, ARA2 o IECAS. El tratamiento con ARA2 es más frecuente en diabéticos tratados con metformina que presentan fracaso frente a los que obtienen éxito en el tratamiento de la erección. 


\section{CONCLUSIONES}



1. La edad no se asocia a peor respuesta al tratamiento de la disfunción eréctil en varones con diabetes mellitus tratados con metformina o con otros antidiabéticos orales.

2. La glucemia basal en rangos entre $73-141 \mathrm{mg} / \mathrm{dl}$ en varones diabéticos en general, con disfunción eréctil no se relaciona con la respuesta al tratamiento de dicho trastorno sexual. En los tratados con metformina, a menor glucemia basal mejor respuesta al tratamiento de la disfunción sexual.

3. Un mejor control de la diabetes, monitorizado mediante la medición de hemoglobina glicosilada mediante el método NGSP en diabéticos tratados con metformina, se relaciona con una mejor respuesta al tratamiento de la disfunción eréctil. La hemoglobina glicosilada medida mediante el método IFCC arroja resultados similares.

4. Un mejor control de la diabetes, monitorizado mediante la medición de hemoglobina glicosilada mediante el método NGSP en diabéticos tratados con otros antidiabéticos orales diferentes a la metformina, no se relaciona con una mejor respuesta al tratamiento de la disfunción eréctil. Incluso la hemoglobina glicosilada medida mediante el método IFCC en estos pacientes, es inferior en los que tienen resultado de fracaso del tratamiento de la disfunción sexual.

5. El PSA es inferior en pacientes diabéticos con disfunción eréctil respeto a otros pacientes con disfunción eréctil sin diabetes. El PSA más bajo se asocia a más éxito en la respuesta al tratamiento de la disfunción eréctil en pacientes diabéticos tratados con metformina.

6. En los pacientes diabéticos que presentan fracaso al tratamiento de la disfunción eréctil son más frecuentes la cardiopatía isquémica, los trastornos digestivos, el antecedente de cirugía prostática y el tratamiento concomitante con benzodiazepinas respecto a los que obtiene respuesta exitosa del tratamiento de la erección.

7. La HTA en pacientes diabéticos se trata con diuréticos, ARA2 o IECAS. El tratamiento con ARA2 es más frecuente en diabéticos tratados con metformina que presentan fracaso frente a los que obtienen éxito en el tratamiento de la erección. 



\section{ANEXOS}





\section{Anexo 1 \\ Índice internacional de función eréctil o IIEF-15 \\ (International Index of Erectile Function)}

\section{INDICE INTEPNACIONAL DE FUNCION ERECTIL - IIEF-}

Iniciales del paciente

No identificación

Fecha

¿Es usted sexualmente activo (definitivo como actividad sexual con pareja o estimulsción manual)?

SI

NO

En caso afirmativo, por favor cumplimente el cuestionario refativo a su actividad sexual, fen cada pregunts, marque sólo una casilla).

\begin{tabular}{|c|c|c|c|c|c|c|}
\hline & $\begin{array}{c}\text { Sil } \\
\text { Acrivolo } \\
\text { sonis }\end{array}$ & $\begin{array}{l}\text { CXSI } \\
\text { Nurica } \\
\text { Muica }\end{array}$ & $\begin{array}{l}\text { MENDSDE } \\
\text { UMMDO DE } \\
\text { US VECES }\end{array}$ & $\begin{array}{l}\text { UMArwa } \\
\text { of } \\
\text { usveces }\end{array}$ & $\begin{array}{l}\text { MSSDE } \\
\text { USTWDDE } \\
\text { US VECES }\end{array}$ & $\begin{array}{l}\text { CASI } \\
\text { SEBHPAE O } \\
\text { SOUPRE }\end{array}$ \\
\hline 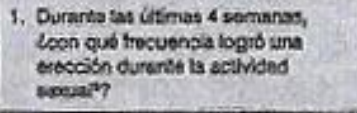 & 0 & 1 & 2 & 3 & 4 & 5 \\
\hline 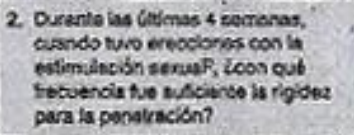 & 0 & 1 & 2 & 3 & 4 & 5 \\
\hline 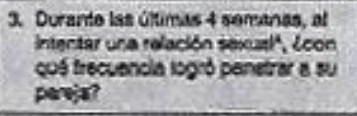 & 0 & 1 & 2 & 3 & 4 & 5 \\
\hline 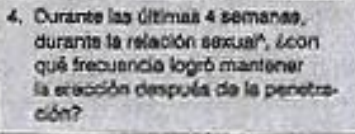 & 0 & 1 & 2 & 3 & 4 & 5 \\
\hline
\end{tabular}

\begin{tabular}{|c|c|c|c|c|c|c|}
\hline & \begin{tabular}{|c|}
$\begin{array}{c}\text { SIN ACTINDAD } \\
\text { SEXUAL }\end{array}$ \\
\end{tabular} & $\begin{array}{l}\text { ETRESHDS- } \\
\text { WETTE OACLL }\end{array}$ & MUK DAACL & DAFCIL & ALOD DIFCL & SIN OARCULTD \\
\hline 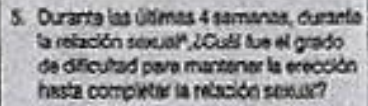 & 0 & 1 & 2 & 3 & 4 & 5 \\
\hline
\end{tabular}

\begin{tabular}{|c|c|c|c|c|c|c|}
\hline & NEGUNA & $1-2$ VECES & 3.4 KCES & S-SVECES & $7+10 y \mathrm{ECSS}$ & 11 GMAS \\
\hline 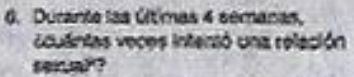 & 0 & 1 & 2 & 3 & 4 & 5 \\
\hline
\end{tabular}

\begin{tabular}{|c|c|c|c|c|c|c|}
\hline & $\begin{array}{l}\text { Sili } \\
\text { ACTivato } \\
\text { seose }\end{array}$ & $\begin{array}{l}\text { CASI } \\
\text { NoncA } 6 \\
\text { Wuase }\end{array}$ & $\begin{array}{l}\text { MENOS OE } \\
\text { UA MTNO DE } \\
\text { US VECES }\end{array}$ & $\begin{array}{l}\text { UANGTDD } \\
\text { DE } \\
\text { USVECES }\end{array}$ & $\begin{array}{l}\text { MASOE } \\
\text { LAMRRD DE } \\
\text { US VECES }\end{array}$ & $\begin{array}{l}\text { CASI } \\
\text { SEMPRE O } \\
\text { SEIPPE }\end{array}$ \\
\hline 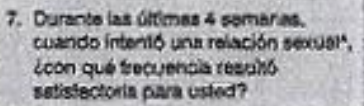 & 0 & 1 & 2 & 3 & 4 & 5 \\
\hline
\end{tabular}

A = Acto senust

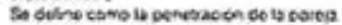

o + Actiridad strust:

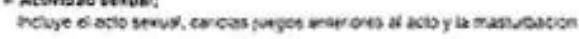

Cu Eyaculor:

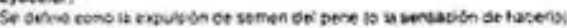
D n Eatimulacish scewal:

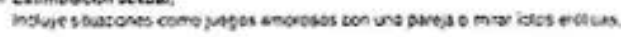




\section{INDICE INTERNACIONAL DE FUNCION ERECTIL - IIEF - (cont)}

\begin{tabular}{|c|c|c|c|c|c|c|}
\hline & $\begin{array}{l}10 \text { ADWUE } \\
\text { Q ACTO }\end{array}$ & $\begin{array}{l}\text { POOSEFUTE } \\
\text { MSOA }\end{array}$ & $\begin{array}{l}\text { soosprante } \\
\text { Mucto }\end{array}$ & $\begin{array}{c}\text { DSEFUUTE } \\
\text { LLOD }\end{array}$ & $\begin{array}{l}\text { OLSFIVTE } \\
\text { BLSTNITE }\end{array}$ & $\begin{array}{l}\text { DSFrifte } \\
\text { Musto }\end{array}$ \\
\hline 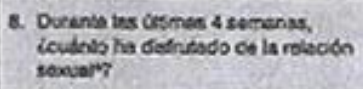 & 0 & 1 & 2 & 3 & 4 & 5 \\
\hline & $\begin{array}{l}\text { SEN } \\
\text { ACTNDAO } \\
\text { SDOLL }\end{array}$ & $\begin{array}{l}\text { CAS: } \\
\text { MacA ó } \\
\text { BuKCA }\end{array}$ & $\begin{array}{l}\text { HEVOSDE } \\
\text { LUTDO DE } \\
\text { USVECES }\end{array}$ & $\begin{array}{l}\text { CAMTEO } \\
\text { DE } \\
\text { US Veces }\end{array}$ & $\begin{array}{l}\text { MRSDE } \\
\text { LANTADDE } \\
\text { US VECES }\end{array}$ & $\begin{array}{l}\text { CLSL } \\
\text { SENPRE O } \\
\text { SIEUPAE }\end{array}$ \\
\hline 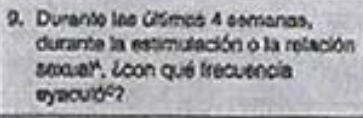 & 0 & 1 & 2 & 3 & 4 & 5 \\
\hline 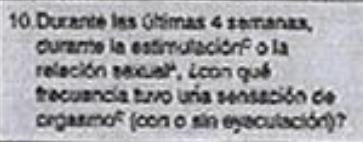 & 0 & 1 & 2 & 3 & 4 & 5 \\
\hline
\end{tabular}

Las sigulentes dos preguntas se refieren at deseo sexuat, definido como una sensación que puede ser un doseo de iener una experencia sexual foor ejemplo, masturbacibn o rolacib́n sexual), un pensamiento sobre una relación sexual o un sentimiento oe frustración par no tener una relación sexual.

\begin{tabular}{|c|c|c|c|c|c|}
\hline & 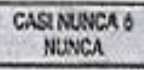 & $\begin{array}{l}\text { EN ALGUNOS } \\
\text { MOMENTOS }\end{array}$ & $\begin{array}{c}\text { GUENA PARTE DEL } \\
\text { TIENOSO }\end{array}$ & $\begin{array}{l}\text { LA MAYOR PMATE } \\
\text { DE NIEMPO }\end{array}$ & $\begin{array}{l}\text { CAST SIEMPAE } O \\
\text { SIEMPRE }\end{array}$ \\
\hline 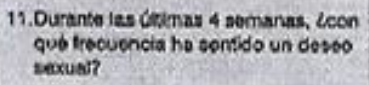 & 1 & 2 & 3 & 4 & 5 \\
\hline
\end{tabular}

\begin{tabular}{|c|c|c|c|c|c|}
\hline & Mur eNo ofoto & BAD & Mobseos & NoTo & MYY aro \\
\hline 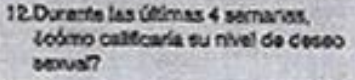 & 1 & 2 & 3 & 4 & 5 \\
\hline
\end{tabular}

\begin{tabular}{|c|c|c|c|c|c|}
\hline & $\begin{array}{c}\text { Mor } \\
\text { Asunsercio }\end{array}$ & $\begin{array}{l}\text { EASTAVIE } \\
\text { nSARSFECOO }\end{array}$ & $\begin{array}{l}\text { Me SeESFECEO } \\
\text { in Asarstectio }\end{array}$ & $\begin{array}{l}\text { ESTDWTE } \\
\text { SAnsfectio }\end{array}$ & $\begin{array}{c}\text { MUY } \\
\text { sansfecho }\end{array}$ \\
\hline 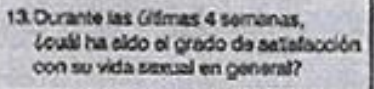 & 1 & 2 & 3 & 4 & 5 \\
\hline 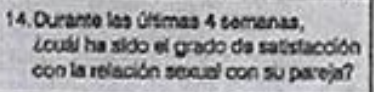 & 1 & 2 & 3 & 4 & 5 \\
\hline
\end{tabular}

\begin{tabular}{|c|c|c|c|c|c|}
\hline & MUYBNDONALO & EN3 & MODERLD & Auro & MOY AUO \\
\hline 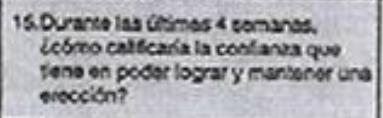 & 1 & 2 & 3 & 4 & 5 \\
\hline
\end{tabular}

A = Asto senes:

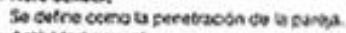

$\mathrm{a}=$ actividad saxual:

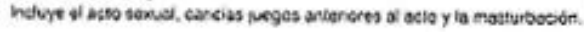

$\mathrm{C}=$ Eyocutar:

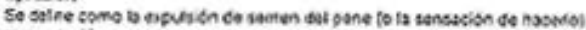

D - Estintalosiōa serval;

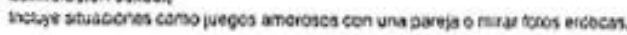




\section{Anexo 2}

\section{Abreviaturas utilizadas en el texto}

AAP Amputación abdominoperineal

ACOG American College of Obstetricians and Gynecologists

ADA American Diabetes Association

AAI Anti insulina

ADN Ácido desoxirribonucleico

ADOS Antidiabéticos orales

AG Ácidos grasos.

AGE Advanced glycation end products

arGLP-1 Agonista del receptor de GLP-1

ARA II Fármacos antagonistas de los receptors de la angiotensina II

BGYR bypass gástrico en Y de Roux

BGLA banda gástrica laparoscópica ajustable

CAD Cetoacidosis Diabética

Col Colesterol

CTLA4 Cytotoxic T- Lymphocytes Associated Antigen -4

DCCT Diabetes Control and Complications Trial

DE Disfunción eréctil

DG Diabetes Gestacional.

DM Diabetes Mellitus.

DM1 Diabetes Mellitus tipo 1

DM2 Diabetes Mellitus tipo 2

DMID Diabetes Mellitus insulinodependiente

DMNID Diabetes Mellitus no insulinodependiente

DSE Disfunción sexual eréctil

DVI Disfunción ventricular izquierda

EASD European Association for the Study of Diabetes

EAU European Association of Urology 
EC Enfermedad coronaria

ECV Enfermedad Cardiovascular

EDEM Epidemiología de la Disfunción eréctil masculina.

EDHF Factor hiperpolarizante derivada del endotelio

EDIC Epidemiology of Diabetes Interventions and Complications

EHS Escala de rigidez peneana

EMA Agencia Europea del Medicamento

e-NOS Enzimaóxido nítrico sintetasa

ET Endotelina

EURODIAB Incidence trends for childhood type 1 diabetes in Europe during 1989-2003

FDA Food and Drug Administration

FPG fasting plasma glucose

FR Factores de riesgo

GA GRUPO A varones con disfunción eréctil con diabetes mellitus.

GAa pacientes con disfunción eréctil con diabetes mellitus con resultado exitoso a su tratamiento de la DE.

$\mathrm{GAb}$ pacientes con disfunción eréctil con diabetes mellitus con resultado parcial a su tratamiento de la DE.

GAc pacientes con disfunción eréctil con diabetes mellitus con resultado de fracaso a su tratamiento de la DE.

GAm pacientes con disfunción eréctil con diabetes mellitus tratados con metformina.

GAc pacientes con disfunción eréctil con diabetes mellitus tratados con tratamiento combinado de insulina y antidiabéticos oralescundarios con resultado parcial a su tratamiento de la DE

GAo pacientes con disfunción eréctil con diabetes mellitus tratados con otros antidiabéticos orales diferentes a la metfomina (saxagliptina, sitagliptina y vildagliptina).

GAD anti glutamato decarboxilasa

GB GRUPO B varones con disfunción eréctil sin diabetes mellitus con diagnósticos secundarios. 
GBa pacientes con disfunción eréctil sin diabetes mellitus con diagnósticos secundarios con resultado exitoso a su tratamiento de la DE.

$\mathrm{GBb}$ pacientes con disfunción eréctil sin diabetes mellitus con diagnósticos secundarios con resultado parcial a su tratamiento de la DE.

GBc pacientes con disfunción eréctil sin diabetes mellitus con diagnósticos secundarios con resultado de fracaso a su tratamiento de la DE.

GBA Glucemia basal alterada.

GC GRUPO C: varones con disfunción eréctil sin diabetes mellitus sin diagnósticos secundarios.

GCa pacientes con disfunción eréctil sin diabetes mellitus sin diagnósticos secundarios con resultado exitoso a su tratamiento de la DE.

$\mathrm{GCb}$ pacientes con disfunción eréctil sin diabetes mellitus sin diagnósticos secundarios con resultado parcial a su tratamiento de la DE

GCc pacientes con disfunción eréctil sin diabetes mellitus sin diagnósticos secundarios con resultado de fracaso a su tratamiento de la DE.

GIP Péptido insulinotrópico dependiente de glucosa

GLP1 Glucagón-like peptide-1

GMPc Guanosin Monofosfato ciclíco

HAPO Hyperglycemia and Adverse Pregnancy Outcome

HbA1C Hemoglobina A1C( glicosilada)

HBP Hiperplasia benigna de próstata.

HDL Lipoproteína de alta densidad.

HLA Human leukocyte antigen

HTA Hipertensión arterial.

HNF Factor nuclear del hepatocito

IA2 Anti tirosin fosfatasa 2 
IADPSG International Association of the Diabetes and Pregnancy Study Groups

ICA Autoanticuerpos citoplasmáticos de las células de los islotes

IC50 Concentración inhibitoria máxima media de un fármaco que se requiere para una inhibición del $50 \%$ in vitro

ICC Insuficiencia cardiaca congestiva.

iDPP4 inhibidores de la dipeptidil peptidasa-4

IECAS Fármacos inhibidores de la enzima convertidora de angiotensina

IIEF-5 International Index of Erectile Function

IFFC International Federation of Clinical Chemistry

iSGLT-2 Inhibidor del cotransportador sodio-glucosa tipo 2

IGF1 Insulin-like growth factor-1

IL Interleucina

IM Infarto de Miocardio

IMC Índice de Masa corporal.

iPED5 Fármacos inhibidores de la fosfodiesterasa tipo 5

ITG Intolerancia a la glucosa

$\mathrm{Kg} \quad$ Kilogramos

MMAS Massachusetts Male Aging Study

MODY Maturity Onset Diabetes of the Young

NAPDPH Nicotinamida-Adenina-Dinucleótido-Fosfato

NDDG National Diabetes Data Group

NGSP National Glycohemoglobin Standardization Program

NHANES National Health and Nutrition Examination Survey

$\mathrm{NIH}$ National Institute of Health

NO Óxido nítrico

NOD Non obese diabetic

NPH Neutral Protamine Hagedorn

NPL Insulina lispro Protamina.

n-NOS isoforma neuronal del óxido nítrico 
NYHA New York Heart Association

LADA Latent autoinmune diabetes in adults

LDL Lipoproteina de baja densidad.

LEAD Liraglutide Effect and Action in Diabetes

OMS Organización Mundial de la Salud

OR Odds ratio

PDE-5 Enzima fosfodiesterasa tipo 5

PGE1 Prostaglandina E1

PPAR $\gamma$ receptor gamma activado por el proliferador de peroxisomas

PR Prostatectomía radical

PSA Antígeno prostático específico

PTOG Prueba de tolerancia oral a la glucosa

RAB Resección anterior baja

RAGE Receptor advanced glycation end products

RNA Ácido ribonucleico

RI Insulin resistence

ROS Especies reactivas de oxígeno

SED Sociedad española de Diabetes

SIRS Spanish Insulin Resistance Study

SOG Sobrecarga oral de glucosa

TG Triglicéridos

TTOG Sobrecarga oral de glucosa

TZD Tiazolidinedionas

UI Unidades internacionales

UKPDS The UK Prospective Diabetes Study

Vaccum Dispositivo de vacío

VEGF Factor de crecimiento de endotelio vascular

WHO World Health Organization 



\section{Anexo 3}

\section{Leyenda de figuras}

Figura 1. Prevalencia de DM2 en España (1992 - 2011), (Valdes,

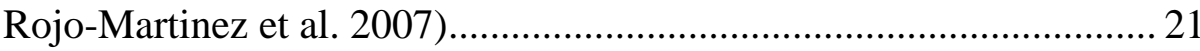

Figura 2. Criterios para el diagnóstico de Diabetes Mellitus ......................... 46

Figura 3. Tratamiento intensivo en DM 1, (Villaizán, Cortés et al. 2009)

Figura 4. Algoritmo 2010 de la Sociedad Española de Diabetes sobre el tratamiento farmacológico de la hiperglucemia en la diabetes tipo 2 58

Figura 5. Algoritmo de la Asociación Americana de Clínicos Endocrinólogos sobre el tratamiento farmacológico de la hiperglucemia en la diabetes tipo 2 .............................................. 60

Figura 6. Estrategia de insulinización ......................................................... 71

Figura 7. Cirugía bariátrica y diabetes mellitus tipo 2 en pacientes

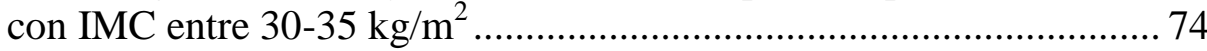

Figura 8. Fisiopatología de la disfunción eréctil diabética ........................... 77

Figura 9. Algoritmo para el tratamiento de la DE, (Jardin, Wagner

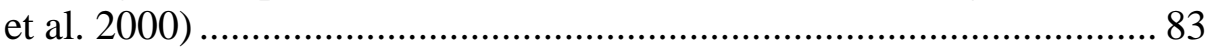

Figura 10. Distribución de la edad en la muestra general ............................ 119

Figura 11. Distribución de la edad ............................................................ 120

Figura 13. Distribución de la edad en GA ................................................. 121

Figura 14. Distribución de la edad ............................................................. 122

Figura 15. Media de la edad en los grupos .............................................. 123

Figura 16. Distribución de la edad en la muestra general GB ..................... 123

Figura 17. Distribución de la edad .......................................................... 124

Figura 18. Media de la edad en los grupos ................................................ 125

Figura 19. Distribución de la edad en la muestra general ........................... 125

Figura 20. Distribución de la edad .......................................................... 126

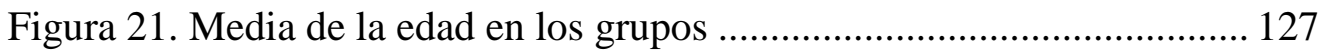


Figura 22. Distribución de la edad .......................................................... 128

Figura 23. Media de la edad en los grupos ............................................... 128

Figura 24. Distribución de la edad en la muestra general ........................... 129

Figura 25. Media de la edad en los subgrupos .......................................... 130

Figura 26. Distribución de la edad en la muestra general ............................ 131

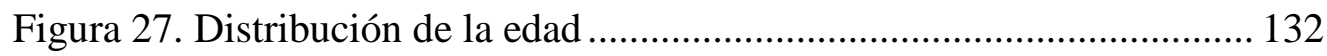

Figura 28. Media de la edad en los subgrupos ......................................... 132

Figura 29. Distribución del tiempo en la muestra general ............................ 133

Figura 30. Distribución del tiempo (meses) ............................................... 134

Figura 31. Media del tiempo en los grupos.............................................. 135

Figura 32. Distribución del tiempo en la muestra general .......................... 135

Figura 33. Distribución del tiempo (meses) ............................................... 136

Figura 34. Media del tiempo en los subgrupos ............................................ 137

Figura 35. Distribución del tiempo en la muestra general .......................... 137

Figura 36. Distribución del tiempo (meses) .............................................. 138

Figura 37. Media del tiempo en los subgrupos .......................................... 139

Figura 38. Distribución del tiempo en la muestra general .......................... 139

Figura 39. Distribución del tiempo (meses) ............................................... 140

Figura 40. Media del tiempo en los subgrupos ......................................... 141

Figura 41. Distribución del tiempo en la muestra general .......................... 141

Figura 42. Distribución del tiempo (meses) .............................................. 142

Figura 43. Media del tiempo en los subgrupos ........................................ 143

Figura 44. Distribución del tiempo en la muestra general ........................... 143

Figura 45. Media del tiempo en los subgrupos .......................................... 144

Figura 46. Distribución del tiempo en la muestra general .......................... 145

Figura 47. Distribución del tiempo en la muestra general ........................... 146

Figura 48. Distribución del tiempo (meses) ............................................. 147

Figura 49. Media del tiempo en los grupos.............................................. 147 
Figura 50. Distribución de la glucosa en la muestra general ....................... 148

Figura 51. Distribución de la glucemia........................................................ 149

Figura 52. Media de la glucemia en los subgrupos.................................... 149

Figura 53. Distribución de la glucosa en la muestra general ........................ 150

Figura 54. Distribución de la Glucosa ........................................................ 151

Figura 55. Media de la Glucosa en los subgrupos ..................................... 151

Figura 56. Distribución de la glucosa en la muestra general ....................... 152

Figura 57. Distribución de la glucosa ........................................................ 153

Figura 58. Media de la glucosa en los subgrupos ...................................... 153

Figura 59. Distribución de la glucosa en la muestra general ....................... 154

Figura 60. Distribución de la glucosa ................................................... 155

Figura 61. Media de la la glucosa en los subgrupos .................................. 155

Figura 62. Distribución de la glucosa en la muestra general ....................... 156

Figura 63. Distribución de la glucosa ...................................................... 157

Figura 64. Media de la glucosa en los grupos ........................................... 157

Figura 65. Distribución de la glucosa en la muestra general ........................ 158

Figura 66. Media de la glucosa en los grupos ........................................... 159

Figura 67. Distribución de la Glucosa en la muestra general ...................... 160

Figura 68. Distribución de glucosa ............................................................ 161

Figura 69. Media de la glucosa en los grupos ........................................... 161

Figura 70. Distribución de la hemoglobina en la muestra general............... 162

Tabla 30. La hemoglobina media en GA, GB, GC .................................... 163

Figura 71. Distribución de la hemoglobina................................................... 163

Figura 72. Media de la hemoglobina en los subgrupos................................ 164

Figura 73. Distribución de la hemoglobina en la muestra general............... 164

Figura 74. Distribución de la hemoglobina.................................................. 165

Figura 75. Media de la hemoglobina en los grupos ..................................... 166

Figura 76. Distribución de la hemoglobina en la muestra general................ 166 


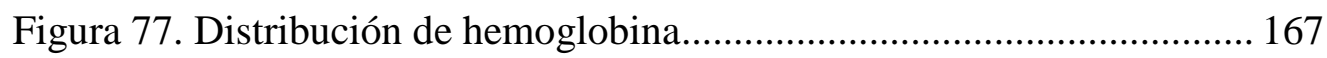

Figura 78. Media de la hemoglobina en los grupos ................................... 168

Figura 79. Distribución de la hemoglobina en la muestra general................ 168

Figura 80. Distribución de la hemoglobina................................................ 169

Figura 81. Media de la hemoglobina en los grupos .................................. 170

Figura 82. Distribución de la hemoglobina en la muestra general............... 170

Figura 83. Distribución de la hemoglobina.............................................. 171

Figura 84. Media de la hemoglobina en los grupos .................................. 172

Figura 85. Distribución de la hemoglobina en la muestra general............... 172

Tabla 35. La hemoglobina media en GAma, GAmb y GAmc..................... 173

Figura 86. Media de la hemoglobina en los grupos .................................. 173

Figura 87. Distribución de la hemoglobina en la muestra general............... 174

Figura 88. Distribución de la hemoglobina.................................................. 175

Figura 89. Media de la hemoglobina en los grupos ................................... 176

Figura 90. Distribución de la hemoglobina glicosilada NGSP en la

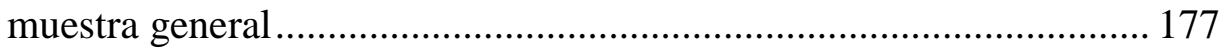

Figura 91. Distribución de la hemoglobina glicosilada NGSP ................... 178

Figura 92. Media de la hemoglobina glicosilada NGSP en los

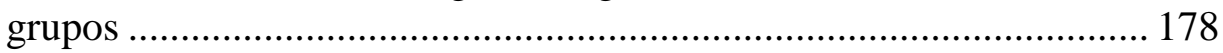

Figura 93. Distribución de la hemoglobina glicosilada NGSP en la

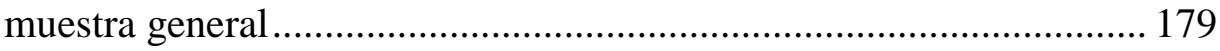

Figura 94. Distribución de la hemoglobina glicosilada NGSP ................... 180

Figura 95. Media de la hemoglobina glicosilada NGSP en los

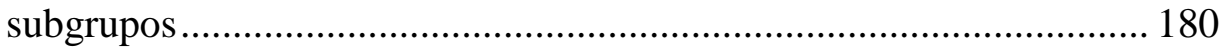

Figura 96. Distribución de la hemoglobina glicosilada NGSP en la

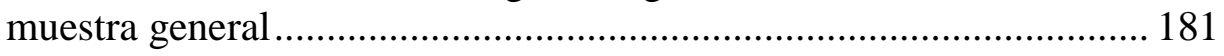

Figura 97. Distribución de hemoglobina glicosilada NGSP ....................... 182

Figura 98. Media de la hemoglobina glicosilada NGSP en los

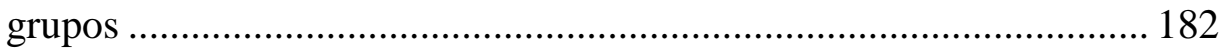


Figura 99. Distribución de la hemoglobina glicosilada NGSP en la

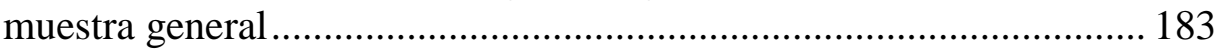

Figura 100. Distribución de hemoglobina glicosilada NGSP ..................... 184

Figura 101. Media de la hemoglobina glicosilada NGSP en los

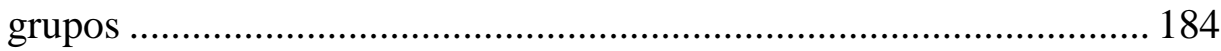

Figura 102. Distribución de la hemoglobina glicosilada NGSP en la

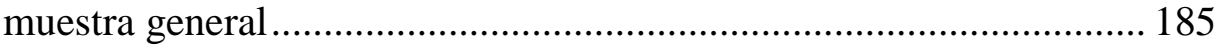

Figura 103. Distribución de la hemoglobina glicosilada NGSP .................. 186

Figura 104. Media de la hemoglobina glicosilada NGSP en los

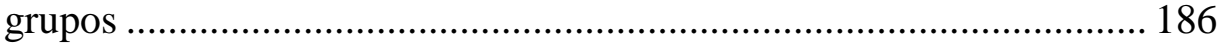

Figura 105. Distribución de la hemoglobina glicosilada NGSP en la

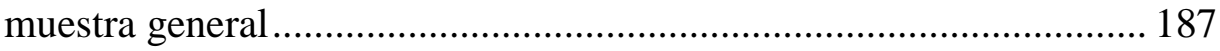

Figura 106. Media de la hemoglobina glicosilada NGSP en los

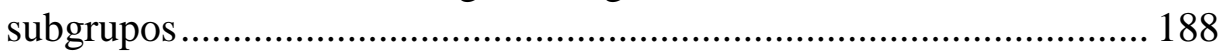

Figura 107. Distribución de la hemoglobina glicosilada NGSP en la

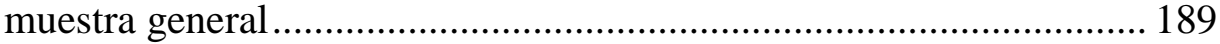

Figura 108. Distribución de la hemoglobina glicosilada NGSP .................. 190

Figura 109. Media de la hemoglobina glicosilada NGSP en los grupos

Figura 110. Distribución de la hemoglobina glicosilada IFCC en la

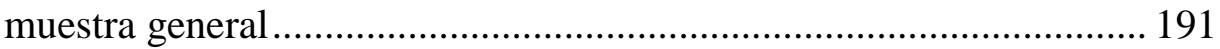

Figura 111. Distribución de la hemoglobina glicosilada IFCC

Figura 112. Media de la hemoglobina glicosilada IFCC en los grupos

Figura 113. Distribución de la hemoglobina glicosilada IFCC en la muestra general

Figura 114. Distribución de la hemoglobina glicosilada IFCC 194

Figura 115. Media de la hemoglobina glicosilada IFCC en los grupos

Figura 116. Distribución de la hemoglobina glicosilada IFCC en la muestra general.... 195

Figura 117. Distribución de la hemoglobina glicosilada IFCC 196 
Figura 118. Media de la hemoglobina glicosilada IFCC en los grupos. 196

Figura 119. Distribución de la hemoglobina glicosilada IFCC en la muestra general

Figura 120. Distribución de la hemoglobina glicosilada IFCC 198

Figura 121. Media de la hemoglobina glicosilada IFCC en los grupo. 198

Figura 122. Distribución de la hemoglobina glicosilada IFCC en la muestra general..

Figura 123. Distribución de la hemoglobina glicosilada IFCC 200

Figura 124. Media de la hemoglobina glicosilada IFCC en los grupos 200

Figura 125. Media de la hemoglobina glicosilada IFCC en los grupos 201

Figura 126. Distribución de la hemoglobina glicosilada IFCC en la muestra general. 202

Figura 127. Distribución de la hemoglobina glicosilada IFCC 203

Figura 128. Media de la hemoglobina glicosilada IFCC en los subgrupos. 204

Figura 129. Distribución del PSA en la muestra general ............................. 205

Figura 130. Distribución del PSA ............................................................... 206

Figura 131. Media del PSA en los grupos ............................................... 206

Figura 132. Distribución del PSA en la muestra general ............................ 207

Figura 133. Distribución del PSA .............................................................. 208

Figura 134. Media del PSA en los grupos ............................................... 208

Figura 135. Distribución de la PSA en la muestra general ......................... 209

Figura 136. Distribución del PSA ............................................................. 210

Figura 137. Media del PSA en los grupos ............................................... 210

Figura 138. PSA en grupos de éxito GAa, GBa y GCa ............................. 211

Figura 139. Distribución del PSA ............................................................ 212

Figura 140. Media del PSA en los grupos .............................................. 212 
Figura 141. Distribución del PSA .......................................................... 213

Figura 142. Media del PSA en subgrupos................................................ 214

Figura 143. Media del PSA en los grupos ............................................... 215

Figura 144. Distribución del PSA en la muestra general en GAc................. 216

Figura 145. Distribución del PSA ........................................................... 217

Figura 146. Media del PSA en los grupos .............................................. 217

Figura 147. Hba1c ideal. Hba1c elevada ................................................. 239 



\section{Anexo 4 \\ Leyenda de tablas}

Tabla 1. Estudios de prevalencia de DM2 en España .................................... 20

Tabla 2: Clasificación de la diabetes mellitus (ADA, 1997) ......................... 37

Tabla 3. Fármacos antidiabéticos y diabetes Mellitus tipo 2 …..................... 59

Tabla 4. Principales factores de riesgo de ECV y DE .................................. 85

Tabla 5. Datos clínicos para estratificar a los pacientes en

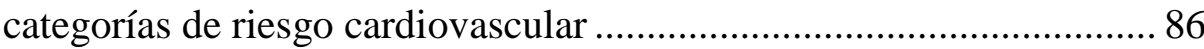

Tabla 6. Principales acontecimiento adversos de los i PED5 ....................... 93

Tabla 7. Dosis y combinaciones de las combinaciones empleadas

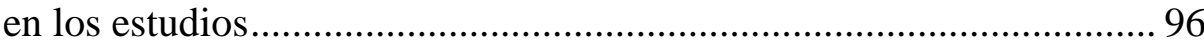

Tabla 8. Edad en GA, GB, GC ................................................................... 120

Tabla 8. Edad en GAa. GAb y GAc.......................................................... 122

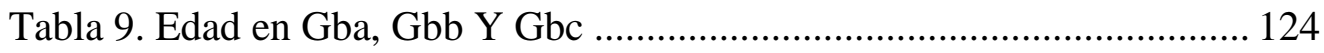

Tabla 10. Edad en GAa, GBa y GCa ….................................................. 126

Tabla 11. Edad en GAm, GAo y GAc ................................................... 127

Tabla 12. Edad en GAMa, GAMb, GAMc .............................................. 129

Tabla 13. Edad en GAOa, GAOb y GAOc .............................................. 130

Tabla 14. Edad en GACa, GACb y GACc................................................ 131

Tabla 15. Tiempo de control evolutivo en GA GB y GC ........................... 134

Tabla 16. Tiempo en GAa. GAb y GAc .................................................. 136

Tabla 17. Tiempo en GBa. GBb y GBc …............................................. 138

Tabla 18. Tiempo de control evolutivo en GAa, GBa y GCa ...................... 140

Tabla 19. Tiempo en GAm, GAo y GAc ................................................... 142

Tabla 20. Tiempo de control evolutivo en GAma, GAmb, GAmc ............... 144

Tabla 21. Tiempo en GAoa, GAob y GAoc ............................................. 145

Tabla 22. Tiempo en GAca, GAcb y GAcc .............................................. 146

Tabla 23. Glucosa media en GA, GB, GC .............................................. 148 
Tabla 24. Glucosa en GAa. GAb y GAc................................................... 150

Tabla 25. Glucosa media en Gba, Gbb, Gbc............................................. 152

Tabla 26. La glucosa media en GAa, GBa y GCa ..................................... 154

Tabla 27. Glucosa media en GAm, GAo y GAc....................................... 156

Tabla 27. La glucosa media en GAma, GAmb, GAmc .............................. 158

Tabla 28. Glucosa media en GAoa, GAob y GAoc .................................... 159

Tabla 29. Glucosa media en GAca, GAcb y GAcc..................................... 160

Tabla 30. La hemoglobina media en GA, GB, GC ................................... 163

Tabla 31. La hemoglobina media en Gaa. Gab y Gac ............................... 165

Tabla 32. La hemoglobina media en GBa, GBb y GBc............................. 167

Tabla 33. La hemoglobina media en GAa, GBa y GCa............................. 169

Tabla 34. La hemoglobina media en GAm, GAo, Gac.............................. 171

Tabla 35. La hemoglobina media en GAma, GAmb y GAmc...................... 173

Tabla 36. La hemoglobina en GAoa, GAob y GAoc.................................. 174

Tabla 37. La hemoglobina media en GAca, GAcb y GAcc......................... 175

Tabla 38. La hemoglobina glicosilada NGSP media en GA,GB y

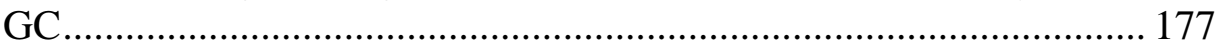

Tabla 39. Hemoglobina glicosilada media NGSP en GAa, GAb y

GAc

Tabla 40. La hemoglobina glicosilada media NGSP en GBa, GBb y

$\mathrm{GBc}$

Tabla 41. La hemoglobina glicosilada media NGSP en GAa, GBa y

$\mathrm{GCa}$

Tabla 42. La hemoglobina glicosilada media NGSP en GAm, GAo

y GAc

Tabla 43. La hemoglobina glicosilada media NGSP en GAma, GAmb y GAmc.

Tabla 44. La hemoglobina glicosilada media NGSP en GAoa, GAob y GAoc 188

Tabla 45. La hemoglobina glicosilada NGSP en GAca, GAcb y

GAcc 
Tabla 46. La hemoglobina glicosilada media IFFC en GA, GB y

$\mathrm{GC}$

Tabla 47. La hemoglobina glicosilada media IFCC en GAa, GAb y

GAc

Tabla 48. La hemoglobina glicosilada media IFCC en GBa, GBb y

$\mathrm{GBc}$

Tabla 49. La hemoglobina glicosilada media IFCC en GAa, GBa y

$\mathrm{GCa}$

Tabla 50. La hemoglobina glicosilada media IFCC en GAm, GAo y

GAc

Tabla 51. La hemoglobina glicosilada media IFCC en GAma, GAmb y GAmc.

Tabla 52. La hemoglobina glicosilada media IFCC en GAoa, GAob

y GAoc

Tabla 53. La hemoglobina glicosilada media IFCC en GAca, GAcb

y GAcc

Tabla 54. Media del PSA en GA,GB y GC …............................................. 205

Tabla 55. El PSA medio en GAa, GAb y GAc …...................................... 207

Tabla 56. PSA en GBa, GBb y GBc ........................................................ 209

Tabla 57. PSA medio en GAa, GBa y GCa ............................................... 211

Tabla 58. PSA medio en GAm, GAo y GAc .............................................. 213

Tabla 59. PSA medio en GAma, GAmb, GAmc ......................................... 214

Tabla 60. PSA medio en GAoa, GAob y GAoc........................................... 215

Tabla 61. PSA medio en GAca, GAcb y GAcc ......................................... 216

Tabla 62. Distribución de diagnósticos secundarios y condiciones en el grupo de pacientes con disfunción eréctil .................................. 218

Tabla 63. Comparación entre diagnósticos secundarios y condiciones entre GA y GB

Tabla 64. Comparación entre diagnósticos secundarios y condiciones entre GA y GC

Tabla 65. Distribución de diagnósticos secundarios y condiciones en el grupo de pacientes con disfunción eréctil y diabetes 
mellitus según el resultado de tratamiento (éxito, parcial y fracaso)

Tabla 66. Comparación entre diagnósticos secundarios y condiciones entre GAa y GAb.

Tabla 67. Comparación entre diagnósticos secundarios y condiciones entre GAa y GAc

Tabla 68. Comparación distribución entre diagnósticos secundarios y condiciones entre GAb y GAc.

Tabla 69. Distribución de diagnósticos secundarios y condiciones en el grupo de pacientes con disfunción eréctil y diabetes mellitus, el grupo con diagnósticos secundarios y el grupo sin diagnósticos secundarios según el resultado de tratamiento éxito

Tabla 70. Comparación entre diagnósticos secundarios y condiciones entre GAa y GBa

Tabla 71. Comparación entre diagnósticos secundarios y condiciones entre GAa y GAc 228

Tabla 72. Comparación distribución entre diagnósticos secundarios y condiciones entre GBa y $\mathrm{GCa}$

Tabla 73. Distribución de los tratamientos indicados para la HTA 230

Tabla 74. Efectos adversos de medicamentos de uso común en la función sexual masculina 234

Tabla 75: Relación aproximada entre los niveles de sangre venosa y el valor de Hbalc 


\section{BIBLIOGRAFÍA}

1. Bárbara, R.G.D., Historia Natural De La Diabetes Mellitus. Tratado SED De Diabetes Mellitus. Bases Moleculares Clínicas Y Tratamiento.Sociedad Española De Diabetes. Rovira. Feliu. Oyarzabal. Cap.7. Pág.1. 2007, Madrid: Editoral Panamericana.

2. Rodríguez-Miñón, J., La Diabetes. Tres Mil Quinientos Años De Historia. 1992, Madrid: Editorial Novonordisk.

3. Pombo, J.H., Historia Natural De La Diabetes Mellitus. Tratado SED De Diabetes Mellitus. Bases Moleculares Clínicas Y Tratamiento. Sociedad Española De Diabetes: Gomis.Rovira. Feliu. Oyarzabal. Cap 1. Pág 1. 2007, Madrid: Editorial Panamericana.

4. Consultation, W., World Health Organization: Definition, Diagnosis And Classification Of Diabetes Mellitus And Its Complications. 1999.

5. Arno, A.G., M.C. Santaliestra, And J.C. Pérez, Epidemiología De La Diabetes .Tratado SED De Diabetes Mellitus. Bases Moleculares Clínicas Y Tratamiento. Sociedad Española De Diabetes. Rovira. Feliu. Oyarzabal. Cap 2. Pág 13. 2007, Madrid: Editorial Panamericana.

6. Goday, A. And M.S. Rios, Epidemiología De La Diabetes Mellitus En España. Revisión Crítica Y Nuevas Perpectivas. Med Clínica (Barcelona), 1994. 102: P. 306-315.

7. Group, W.S., Diabetes Mellitus. . World Health Organ Tech Rep Ser, 1985. 727: P. 1-113.

8. Report Of The Expert Committee On The Diagnosis And Classification Of Diabetes Mellitus. Diabetes Care., 1997. 20(7): P. 1183-97.

9. Peinado, L.P. And J. Matute, La Morbilidad Diabética Conocida En La Población Rural En España. Rev Clin Esp, 1965. 159: P. 357-370.

10. Sanchez, L.P., Et Al., Prevalencia De Morbilidad Diabética Conocida En La Población Rural Española En 1978. Rev Clin Esp, 1980. 159: P. 243-249.

11. Calle-Pascual, A., Et Al., Estimation Of The Prevalence Of Diabetes Mellitus Diagnosed, And Incidence Of Type 1 (Insulin-Dependent) Diabetes Mellitus In The Avila Health Care Region Of Spain. Diabetes Res Clin Pract, 1993. 19(1): P. 75-81. 
12. Costa, B., Et Al., Grupo Para El Estudio De La Diabetes En Tarragona. Consumo De Medicación En La Diabetes Mellitus (I). Estimación Del Perfil Terapéutico Y La Prevalencia En Las Comarcas De Tarragona (548.900 Habitantes). Med Clin ( Barcelona), 1992. 99: P. 294-299.

13. Valdes, S., G. Rojo-Martinez, And F. Soriguer, [Evolution Of Prevalence Of Type 2 Diabetes In Adult Spanish Population]. Med Clin (Barc), 2007. 129(9): P. 352-5.

14. Goday, A., [Epidemiology Of Diabetes And Its Non-Coronary Complications]. Rev Esp Cardiol, 2002. 55(6): P. 657-70.

15. Soriguer, F., Et Al., Prevalence Of Diabetes Mellitus And Impaired Glucose Regulation In Spain: The Di@Bet.Es Study. Diabetologia, 2012. 55(1): P. 88-93.

16. Alberti, K. And P. Zimmet, Definition, Diagnosis And Classification Of Diabetes Mellitus And Its Complications. Part 1: Diagnosis And Classification Of Diabetes Mellitus Provisional Report Of A WHO Consultation. Diabet Med, 1998. 15(7): P. 539-53.

17. Botas, P., Et Al., Comparison Of The Diagnostic Criteria For Diabetes Mellitus, WHO-1985, ADA-1997 And WHO-1999 In The Adult Population Of Asturias (Spain). Diabet Med, 2003. 20(11): P. 904-8.

18. Paños, B.R., Et Al., Prevalencia De Diabetes Mellitus Y Su Asociación A Otros Factores De Riesgo Cardiovascular En La Provincia De Albacete. . Aten Primaria, 2000. 25: P. 166- 71.

19. Soriguer-Escofet, F., Et Al., Prevalence Of Latent Autoimmune Diabetes Of Adults (LADA) In Southern Spain. Diabetes Res Clin Pract, 2002. 56(3): P. 213-20.

20. Prevention, C.F.D.C.A. Crude And Age-Adjusted Incidence Of Diagnosed Diabetes Per 1,000 Population Aged 18-79 Years, United States, 1980-2012. 2013; Available From: Http://Www.Cdc.Gov/Diabetes/Statistics/Incidence/Fig2.Htm\%5D.

21. Alberti, K., Problems Related To Definitions And Epidemiology Of Type 2 (Non-Insulin-Dependent) Diabetes Mellitus: Studies Throughout The World. Diabetologia, 1993. 36(10): P. 978-84. 
22. Zimmet, P., D. Mccarty, And M.D. Courten, The Global Epidemiology Of Non-Insulin-Dependent Diabetes Mellitus And The Metabolic Syndrome. J Diabetes Complications, 1997. 11(2): P. 60-8.

23. Bennet, P., Et Al., Epidemiology And Natural History Of Type 2 Diabetes: Non-Obese And Obese. . International Texbook of Diabetes Mellitus. 1992: Chichester: Jonhn Wiley.

24. Trevisan, R., M. Vedovato, And A. Tiengo, The Epidemiology Of Diabetes Mellitus. Nephrol Dial Transplant, 1998. 13 Suppl 8: P. 2-5.

25. Vazquez, J., S. Gaztambide, And E. Soto-Pedre, [10-Year Prospective Study On The Incidence And Risk Factors For Type 2 Diabetes Mellitus]. Med Clin (Barc), 2000. 115(14): P. 534-9.

26. Valdes, S., Et Al., Population-Based Incidence Of Type 2 Diabetes In Northern Spain: The Asturias Study. Diabetes Care, 2007. 30(9): P. 2258-63.

27. Soriguer, F., Et Al., Incidence Of Type 2 Diabetes In Southern Spain (Pizarra Study). Eur J Clin Invest, 2008. 38(2): P. 126-33.

28. Al, A.G.E., Los Estudios De Incidencia De Diabetes Mellitus Tipo 1 En España. Análisis Comparativo Y Consenso De Metodología Estandarizada. . Av Diabetol, 1996. 12: P. 24-28.

29. Green, A., E. Gale, And C. Patterson, The EURODIAB Subarea A Study Group. Wide Variation In The Incidence Of Childhood Onset Insulin-Dependent Diabetes Mellitus In Europe. The Eurodiab ACE Study. The Lancet, 1992. 339: P. 905-909.

30. Group, E.A.S., Variation And Trends In Incidence Of Chidhood Diabetes In Europe. 2000. 355: P. 873-876.

31. Serrano-Ríos, M., Etiopatogenia De La Diabetes Mellitus Tipo 1. La Diabetes Mellitus En La Práctica Clínica. Cap 5. Pág 31-32. Vol. Cap 5. 2009, Madrid: Editorial Panamericana. 31-32.

32. Serrano-Ríos, M., Etiopatogenia De La Diabetes Mellitus Tipo 1. La Diabetes Mellitus En La Práctica Clínica. Cap 5. Pág 32. Vol. Cap 5. 2009, Madrid: Editorial Panamericana. 32.

33. Serrano-Rìos, M., A. Goday, And T.M. Larrad, Migrant Populations And The Incidence Of Type 1 Diabetes Mellitus: An Overview Of The Literature With A Focus On The Spanish-Heritage Countries In Latin America. Diabetes Metab Res Rev., 1999. 15(2): P. 113-32. 
34. Serrano-Ríos, M., Etiopatogenia De La Diabetes Mellitus Tipo 1. La Diabetes Mellitus En La Práctica Clínica. Cap 5. Pág 32-33. Vol. Cap 5. 2009, Madrid: Editorial Panamericana. 32-33.

35. Castano, L. And G. Eisenbarth, Type-I Diabetes: A Chronic Autoimmune Disease Of Human, Mouse, And Rat. Annu Rev Immunol, 1990. 8: P. 647-79.

36. Eisenbarth, G., Update In Type 1 Diabetes. J Clin Endocrinol Metab, 2007. 92(7): P. 2403-7.

37. Jahromi, M. And G. Eisenbarth, Cellular And Molecular Pathogenesis Of Type 1A Diabetes. Cell Mol Life Sci, 2007. 64(7-8): P. 865-72.

38. Serrano-Ríos, M., Etiopatogenia De La Diabetes Mellitus Tipo 1. La Diabetes Mellitus En La Práctica Clínica. Cap 5. Pág 33. Vol. Cap 5. 2009, Madrid: Editorial Panamericana. 33.

39. Pugliese, A., Genetics Of Type 1 Diabetes. Endocrinol Metab Clin North Am, 2004. 33(1): P. 1-16, Vii.

40. Bell, G., S. Horita, And J. Karam, A Polymorphic Locus Near The Human Insulin Gene Is Associated With Insulin-Dependent Diabetes Mellitus. Diabetes, 1984. 33(2): P. 176-83.

41. Kavvoura, F. And J. Ioannidis, CTLA-4 Gene Polymorphisms And Susceptibility To Type 1 Diabetes Mellitus: A Huge Review And Meta-Analysis. Am J Epidemiol, 2005. 162(1): P. 3-16.

42. Rothe, H., Et Al., Active Stage Of Autoimmune Diabetes Is Associated With The Expression Of A Novel Cytokine, IGIF, Which Is Located Near Idd2. J Clin Invest, 1997. 99(3): P. 469-74.

43. Morahan, G., Et Al., Linkage Disequilibrium Of A Type 1 Diabetes Susceptibility Locus With A Regulatory IL12B Allele. Nat Genet, 2001. 27(2): P. 218-21.

44. Redondo, M., Et Al., Genetic Determination Of Islet Cell Autoimmunity In Monozygotic Twin, Dizygotic Twin, And Non-Twin Siblings Of Patients With Type 1 Diabetes: Prospective Twin Study. BMJ, 1999. 318(7185): P. 698-702.

45. Solesz, G., Et Al., The Hungarian Child-Hood Diabetes Epidemiology Group: Rising Incidente Of Type 1 Diabetes In Hurgarian Children. Diabetic Med, 1994. 7: P. 111-114. 
46. Onkamo, P., Et Al., Worldwide Increase In Incidence Of Type I Diabetes--The Analysis Of The Data On Published Incidence Trends. Diabetologia, 1999. 42(12): P. 1395-403.

47. Bottazzo, G., Et Al., In Situ Characterization Of Autoimmune Phenomena And Expression Of HLA Molecules In The Pancreas In Diabetic Insulitis. N Engl J Med, 1985. 313(6): P. 353-60.

48. Sussman, M., L. Strauss, And H. Hodes, Fatal Coxsackie Group B Virus Infection In The Newborn; Report Of A Case With Necropsy Findings And Brief Review Of The Literature. AMA J Dis Child, 1959. 97(4): P. 483-92.

49. Foulis, A., Et Al., A Search For Evidence Of Viral Infection In Pancreases Of Newly Diagnosed Patients With IDDM. Diabetologia, 1997. 40(1): P. 53-61.

50. Hyoty, H., Et Al., A Prospective Study Of The Role Of Coxsackie B And Other Enterovirus Infections In The Pathogenesis Of IDDM. Childhood Diabetes In Finland (Dime) Study Group. Diabetes, 1995. 44(6): P. 652-7.

51. Atkinson, M., Et Al., Cellular Immunity To A Determinant Common To Glutamate Decarboxylase And Coxsackie Virus In InsulinDependent Diabetes. J Clin Invest, 1994. 94(5): P. 2125-9.

52. Tuvemo, T., Et Al., The Swedish Childhood Diabetes Study III: Igm Against Coxsackie B Viruses In Newly Diagnosed Type 1 (InsulinDependent) Diabetic Children--No Evidence Of Increased Antibody Frequency. Diabetologia, 1989. 32(10): P. 745-7.

53. Lack Of Regional Variation In IDDM Risk In Japan. Japan IDDM Epidemiology Study Group. Diabetes Care, 1993. 16(5): P. 796-800.

54. Hiltunen, M., Et Al., Serological Evaluation Of The Role Of Cytomegalovirus In The Pathogenesis Of IDDM: A Prospective Study. The Childhood Diabetes In Finland Study Group. Diabetologia, 1995. 38(6): P. 705-10.

55. Honeyman, M., Et Al., Association Between Rotavirus Infection And Pancreatic Islet Autoimmunity In Children At Risk Of Developing Type 1 Diabetes. Diabetes, 2000. 49(8): P. 1319-24.

56. Borch-Johnsen, K., Et Al., Relation Between Breast-Feeding And Incidence Rates Of Insulin-Dependent Diabetes Mellitus. The Lancet, 1984. 324(8411): P. 1083-1086. 
57. Gerstein, H., Cow's Milk Exposure And Type I Diabetes Mellitus. A Critical Overview Of The Clinical Literature. Diabetes Care, 1994. 17(1): P. 13-9.

58. Dahlquist, G., E. Savilahti, And M. Landin-Olsson, An Increased Level Of Antibodies To Beta-Lactoglobulin Is A Risk Determinant For Early-Onset Type 1 (Insulin-Dependent) Diabetes Mellitus Independent Of Islet Cell Antibodies And Early Introduction Of Cow's Milk. Diabetologia, 1992. 35(10): P. 980-4.

59. Martikainen, A., Et Al., Disease-Associated Antibodies In Offspring Of Mothers With IDDM. Diabetes, 1996. 45(12): P. 1706-10.

60. Ziegler, A., Et Al., Early Infant Feeding And Risk Of Developing Type 1 Diabetes-Associated Autoantibodies. JAMA, 2003. 290(13): P. 1721-8.

61. Norris, J., Et Al., Timing Of Initial Cereal Exposure In Infancy And Risk Of Islet Autoimmunity. JAMA, 2003. 290(13): P. 1713-20.

62. Savilahti, E., Et A1., Jejuna Of Patients With Insulin-Dependent Diabetes Mellitus (IDDM) Show Signs Of Immune Activation. Clin Exp Immunol, 1999. 116(1): P. 70-7.

63. Stene, L., Et Al., Use Of Cod Liver Oil During Pregnancy Associated With Lower Risk Of Type I Diabetes In The Offspring. Diabetologia, 2000. 43(9): P. 1093-8.

64. Vitamin D Supplement In Early Childhood And Risk For Type I (Insulin-Dependent) Diabetes Mellitus. The EURODIAB Substudy 2 Study Group. Diabetologia, 1999. 42(1): P. 51-4.

65. Mathieu, C., Et Al., Prevention Of Autoimmune Diabetes In NOD Mice By 1,25 Dihydroxyvitamin D3. Diabetologia, 1994. 37(6): P. 552-8.

66. Mcfarlane, A. And F. Scott, Enviromental Agents And Type 1 Diabetes. Chapter 17. 2003, UK: Blackwell Science.

67. Hypponen, E., Et Al., Obesity, Increased Linear Growth, And Risk Of Type 1 Diabetes In Children. Diabetes Care, 2000. 23(12): P. 175560.

68. Virtanen, S. And M. Knip, Nutritional Risk Predictors Of Beta Cell Autoimmunity And Type 1 Diabetes At A Young Age. Am J Clin Nutr, 2003. 78(6): P. 1053-67. 
69. Dahlquist, G., C. Patterson, And G. Soltesz, Perinatal Risk Factors For Childhood Type 1 Diabetes In Europe. The EURODIAB Substudy 2 Study Group. Diabetes Care, 1999. 22(10): P. 1698-702.

70. Bach, J. And L. Chatenoud, Tolerance To Islet Autoantigens In Type 1 Diabetes. Annu Rev Immunol, 2001. 19: P. 131-61.

71. Gepts, W., Pathologic Anatomy Of The Pancreas In Juvenile Diabetes Mellitus. Diabetes, 1965. 14(10): P. 619-33.

72. Narendran, P., E. Estella, And S. Fourlanos, Immunology Of Type 1 Diabetes. QJM, 2005. 98(8): P. 547-56.

73. Rabinovitch, A., An Update On Cytokines In The Pathogenesis Of Insulin-Dependent Diabetes Mellitus. Diabetes Metab Rev, 1998. 14(2): P. 129-51.

74. Mandrup-Poulsen, T., The Role Of Interleukin-1 In The Pathogenesis Of IDDM. Diabetologia, 1996. 39(9): P. 1005-29.

75. Rabinovitch, A. And W. Suarez-Pinzoz, Cytokines And Their Roles In Pancreatic Islet Beta-Cell Destruction And Insulin-Dependent Diabetes Mellitus. Biochem Pharmacol, 1998. 55(8): P. 1139-49.

76. Falorni, A. And A. Brozzetti, Diabetes-Related Antibodies In Adult Diabetic Patients. Best Pract Res Clin Endocrinol Metab, 2005. 19(1): P. 119-33.

77. Vandewalle, C., Et Al., High Diagnostic Sensitivity Of Glutamate Decarboxylase Autoantibodies In Insulin-Dependent Diabetes Mellitus With Clinical Onset Between Age 20 And 40 Years. The Belgian Diabetes Registry. J Clin Endocrinol Metab, 1995. 80(3): P. 846-51.

78. Landin-Olsson, M., Et Al., Predictive Value Of Islet Cell And Insulin Autoantibodies For Type 1 (Insulin-Dependent) Diabetes Mellitus In A Population-Based Study Of Newly-Diagnosed Diabetic And Matched Control Children. Diabetologia, 1992. 35(11): P. 1068-73.

79. Bonifacio, E., Et Al., Quantification Of Islet-Cell Antibodies And Prediction Of Insulin-Dependent Diabetes. Lancet, 1990. 335(8682): P. 147-9.

80. Schiffrin, A., Et Al., Evidence For Different Clinical Subtypes Of Type 1 Diabetes Mellitus: A Prospective Study. Diabetes Res Clin Pract, 1994. 23(2): P. 95-102. 
81. Vardi, P., Et Al., Concentration Of Insulin Autoantibodies At Onset Of Type I Diabetes. Inverse Log-Linear Correlation With Age. Diabetes Care, 1988. 11(9): P. 736-9.

82. Pugliese, A., Et A1., Two Subsets Of HLA-DQA1 Alleles Mark Phenotypic Variation In Levels Of Insulin Autoantibodies In First Degree Relatives At Risk For Insulin-Dependent Diabetes. J Clin Invest, 1994. 93(6): P. 2447-52.

83. Sanjeevi, C., Et Al., HLA And Glutamic Acid Decarboxylase In Human Insulin-Dependent Diabetes Mellitus. Diabet Med, 1996. 13(3): P. 209-17.

84. Richter, W., Et Al., Sequence Homology Of The Diabetes-Associated Autoantigen Glutamate Decarboxylase With Coxsackie B4-2C Protein And Heat Shock Protein 60 Mediates No Molecular Mimicry Of Autoantibodies. J Exp Med, 1994. 180(2): P. 721-6.

85. Gorus, F., Et Al., IA-2-Autoantibodies Complement GAD65Autoantibodies In New-Onset IDDM Patients And Help Predict Impending Diabetes In Their Siblings. The Belgian Diabetes Registry. Diabetologia, 1997. 40(1): P. 95-9.

86. Antonelli, A., Et Al., Autoimmunity To CD38 And GAD In Type I And Type II Diabetes: CD38 And HLA Genotypes And Clinical Phenotypes. Diabetologia, 2002. 45(9): P. 1298-306.

87. Rossetti, L., A. Giaccari, And R. Defronzo, Glucose Toxicity. Diabetes Care, 1990. 13(6): P. 610-30.

88. Unger, R., Lipotoxicity In The Pathogenesis Of Obesity-Dependent NIDDM. Genetic And Clinical Implications. Diabetes, 1995. 44(8): P. 863-70.

89. American Diabettes Association: Clinical Practice Recommendations 2006. Diabetes Care, 2006. 29: P. S1-S2.

90. Defronzo, R., Lilly Lecture 1987. The Triumvirate: Beta-Cell, Muscle, Liver. A Collusion Responsible For NIDDM. Diabetes, 1988. 37(6): P. 667-87.

91. Festa, A., Et Al., Differences In Insulin Resistance In Nondiabetic Subjects With Isolated Impaired Glucose Tolerance Or Isolated Impaired Fasting Glucose. Diabetes, 2004. 53(6): P. 1549-55. 
92. Ferrannini, E., Et Al., Predominant Role Of Reduced Beta-Cell Sensitivity To Glucose Over Insulin Resistance In Impaired Glucose Tolerance. Diabetologia, 2003. 46(9): P. 1211-9.

93. Mari, A., Et Al., Assessing Insulin Secretion By Modeling In Multiple-Meal Tests: Role Of Potentiation. Diabetes, 2002. 51 Suppl 1: P. S221-6.

94. Ferrannini, E., Et Al., Mode Of Onset Of Type 2 Diabetes From Normal Or Impaired Glucose Tolerance. Diabetes, 2004. 53(1): P. 160-5.

95. Goldfine, A., Et Al., Insulin Resistance Is A Poor Predictor Of Type 2 Diabetes In Individuals With No Family History Of Disease. Proc Natl Acad Sci U S A, 2003. 100(5): P. 2724-9.

96. Pratipanawatr, W., Et Al., Skeletal Muscle Insulin Resistance In Normoglycemic Subjects With A Strong Family History Of Type 2 Diabetes Is Associated With Decreased Insulin-Stimulated Insulin Receptor Substrate-1 Tyrosine Phosphorylation. Diabetes, 2001. 50(11): P. 2572-8.

97. Rabinowitz, D. And K. Zierler, Forearm Metabolism In Obesity And Its Response To Intra-Arterial Insulin. Characterization Of Insulin Resistance And Evidence For Adaptive Hyperinsulinism. J Clin Invest, 1962. 41: P. 2173-81.

98. Randle, P., Et Al., The Glucose Fatty-Acid Cycle. Its Role In Insulin Sensitivity And The Metabolic Disturbances Of Diabetes Mellitus. Lancet, 1963. 1(7285): P. 785-9.

99. Belfort, R., Et Al., Dose-Response Effect Of Elevated Plasma Free Fatty Acid On Insulin Signaling. Diabetes, 2005. 54(6): P. 1640-8.

100. Rossetti, L., Et Al., Effect Of Chronic Hyperglycemia On In Vivo Insulin Secretion In Partially Pancreatectomized Rats. J Clin Invest, 1987. 80(4): P. 1037-44.

101. Ukropcova, B., Et Al., Dynamic Changes In Fat Oxidation In Human Primary Myocytes Mirror Metabolic Characteristics Of The Donor. J Clin Invest, 2005. 115(7): P. 1934-41.

102. Morino, K., Et Al., Reduced Mitochondrial Density And Increased IRS-1 Serine Phosphorylation In Muscle Of Insulin-Resistant Offspring Of Type 2 Diabetic Parents. J Clin Invest, 2005. 115(12): P. 3587-93. 
103. Lowell, B. And G. Shulman, Mitochondrial Dysfunction And Type 2 Diabetes. Science, 2005. 307(5708): P. 384-7.

104. Ferrannini, E., Et Al., Insulin Resistance And Hypersecretion In Obesity. European Group For The Study Of Insulin Resistance (EGIR). J Clin Invest, 1997. 100(5): P. 1166-73.

105. Nogueiras, R. And M. Tschop, Biomedicine. Separation Of Conjoined Hormones Yields Appetite Rivals. Science, 2005. 310(5750): P. 985-6.

106. Knauf, C., Et Al., Brain Glucagon-Like Peptide-1 Increases Insulin Secretion And Muscle Insulin Resistance To Favor Hepatic Glycogen Storage. J Clin Invest, 2005. 115(12): P. 3554-63.

107. Weiss, R., Et Al., The "Obese Insulin-Sensitive" Adolescent: Importance Of Adiponectin And Lipid Partitioning. J Clin Endocrinol Metab, 2005. 90(6): P. 3731-7.

108. Grant, S., Et Al., Variant Of Transcription Factor 7-Like 2 (TCF7L2) Gene Confers Risk Of Type 2 Diabetes. Nat Genet, 2006. 38(3): P. 320-3.

109. Massó, F.T. And M.F. Gomez, Conceptos, Clasificación Y Diagnóstico De La Diabetes Mellitus. La Diabetes Mellitus En La Práctica Clínica. Cap 1. Pág 2-3. 2009, Madrid: Edit Panamericana.

110. Massó, F.T. And M.F. Gomez, Conceptos, Clasificación Y Diagnóstico De La Diabetes Mellitus. La Diabetes Mellitus En La Práctica Clínica. Cap 1. Pág 3. 2009, Madrid: Edit Panamericana.

111. Conget, I., [Diagnosis, Classification And Cathogenesis Of Diabetes Mellitus]. Rev Esp Cardiol, 2002. 55(5): P. 528-35.

112. Massó, F.T. And M.F. Gomez, Conceptos, Clasificación Y Diagnóstico De La Diabetes Mellitus. La Diabetes Mellitus En La Práctica Clínica. Cap 1. Pág 3-4. 2009, Madrid: Edit Panamericana.

113. Massó, F.T. And M.F. Gomez, Conceptos, Clasificación Y Diagnóstico De La Diabetes Mellitus. La Diabetes Mellitus En La Práctica Clínica. Cap 1. Pág 4. 2009, Madrid: Edit Panamericana.

114. Tébar Massó, F.J. And M. Ferrer Gomez, Conceptos, Clasificación Y Diagnóstico De La Diabetes Mellitus. La Diabetes Mellitus En La Práctica Clínica. Cap 1. Pág 4-5. 2009, Madrid: Edit Panamericana. 
115. Tébar Massó, F.J. And M. Ferrer Gomez, Conceptos, Clasificación Y Diagnóstico De La Diabetes Mellitus. La Diabetes Mellitus En La Práctica Clínica. Cap 1. Pág 5. 2009, Madrid: Edit Panamericana.

116. Lima, E.C. And W.R. Engel, Fisiopatología Y Clínica General De La Diabetes Mellitus. La Diabetes Mellitus En La Práctica Clínica. Cap 7. Pag 55. 2009, Madrid: Edit Panamericana.

117. Barker, J., Clinical Review: Type 1 Diabetes-Associated Autoimmunity: Natural History, Genetic Associations, And Screening. J Clin Endocrinol Metab, 2006. 91(4): P. 1210-7.

118. Lima, E.C. And W.R. Engel, Fisiopatología Y Clínica General De La Diabetes Mellitus. La Diabetes Mellitus En La Práctica Clínica. Cap 7. Pag 55-56. 2009, Madrid: Edit Panamericana.

119. Ceska, R., Clinical Implications Of The Metabolic Syndrome. Diab Vasc Dis Res, 2007. 4 Suppl 3: P. S2-4.

120. American Diabetes, A., Diagnosis And Classification Of Diabetes Mellitus. Diabetes Care, 2014. 37 Suppl 1: P. S81-90.

121. Massó, F.T. And M.F. Gomez, Conceptos, Clasificación Y Diagnóstico De La Diabetes Mellitus. La Diabetes Mellitus En La Práctica Clínica. Cap 1. Pág 6. 2009, Madrid: Edit Panamericana.

122. Cowie, C., Et Al., Prevalence Of Diabetes And High Risk For Diabetes Using AlC Criteria In The U.S. Population In 1988-2006. Diabetes Care, 2010. 33(3): P. 562-8.

123. Romualdo, L.G.D.G., Et Al., [The Value Of Hemoglobin Alc For Diagnosis Of Diabetes Mellitus And Other Changes In Carbohydrate Metabolism In Women With Recent Gestational Diabetes Mellitus]. Endocrinol Nutr, 2012. 59(6): P. 362-6.

124. Nowicka, P., Et Al., Utility Of Hemoglobin A(1c) For Diagnosing Prediabetes And Diabetes In Obese Children And Adolescents. Diabetes Care, 2011. 34(6): P. 1306-11.

125. Selvin, E., Et Al., Racial Differences In Glycemic Markers: A CrossSectional Analysis of Community-Based Data. Ann Intern Med, 2011. 154(5): P. 303-9.

126. Picon, M., Et Al., Hemoglobin Alc Versus Oral Glucose Tolerance Test In Postpartum Diabetes Screening. Diabetes Care, 2012. 35(8): P. 1648-53. 
127. Crowther, C., Et Al., Effect Of Treatment Of Gestational Diabetes Mellitus On Pregnancy Outcomes. N Engl J Med, 2005. 352(24): P. 2477-86.

128. Landon, M., Et Al., A Multicenter, Randomized Trial Of Treatment For Mild Gestational Diabetes. N Engl J Med, 2009. 361(14): P. 1339-48.

129. Horvath, K., Et Al., Effects Of Treatment In Women With Gestational Diabetes Mellitus: Systematic Review And Meta-Analysis. BMJ, 2010. 340: P. C1395.

130. Massó, F.T. And M.F. Gomez, Conceptos, Clasificación Y Diagnóstico De La Diabetes Mellitus. La Diabetes Mellitus En La Práctica Clínica. Cap 1. Pág 7. 2009, Madrid: Edit Panamericana.

131. Massó, F.T. And M.F. Gomez, Conceptos, Clasificación Y Diagnóstico De La Diabetes Mellitus. La Diabetes Mellitus En La Práctica Clínica. Cap 1. Pág 8. 2009, Madrid: Edit Panamericana.

132. Association, A.D., Nutrition Recommendations And Principles For People With Diabetes Mellitus. Diabetes Care, 2000. 23 Suppl 1: P. S43-6.

133. Helmrich, S., Et Al., Physical Activity And Reduced Occurrence Of Non-Insulin-Dependent Diabetes Mellitus. N Engl J Med, 1991. 325(3): P. 147-52.

134. Hu, F., Et Al., Diet, Lifestyle, And The Risk Of Type 2 Diabetes Mellitus In Women. N Engl J Med, 2001. 345(11): P. 790-7.

135. Pan, X., Et Al., Effects Of Diet And Exercise In Preventing NIDDM In People With Impaired Glucose Tolerance. The Da Qing IGT And Diabetes Study. Diabetes Care, 1997. 20(4): P. 537-44.

136. Tuomilehto, J., Et Al., Prevention Of Type 2 Diabetes Mellitus By Changes In Lifestyle Among Subjects With Impaired Glucose Tolerance. N Engl J Med, 2001. 344(18): P. 1343-50.

137. Zinman, B., Et Al., Diabetes Mellitus And Exercise (Technical Review). . Diabetes Care, 2000. 23 Suppl 1: P. S50-4.

138. Miller, W., D. Koceja, And E. Hamilton, A Meta-Analysis Of The Past 25 Years Of Weight Loss Research Using Diet, Exercise Or Diet Plus Exercise Intervention. Int J Obes Relat Metab Disord, 1997. 21(10): P. 941-7. 
139. The Effect Of Intensive Treatment Of Diabetes On The Development And Progression Of Long-Term Complications In Insulin-Dependent Diabetes Mellitus. The Diabetes Control And Complications Trial Research Group. N Engl J Med, 1993. 329(14): P. 977-86.

140. Nathan, D., Et Al., Intensive Diabetes Treatment And Cardiovascular Disease In Patients With Type 1 Diabetes. N Engl J Med, 2005. 353(25): P. 2643-53.

141. Villaizán, E.M., Et Al., Pautas De Insulización En Diabetes Mellitus. 2009, Boletín Farmacoterapéutico De Castilla-La Mancha.

142. Rosenstock, J., Et Al., Basal Insulin Glargine (HOE 901) Versus NPH Insulin In Patients With Type 1 Diabetes On Multiple Daily Insulin Regimens. U.S. Insulin Glargine (HOE 901) Type 1 Diabetes Investigator Group. Diabetes Care, 2000. 23(8): P. 1137-42.

143. Hershon, K., Et Al., Once-Daily Insulin Glargine Compared With Twice-Daily NPH Insulin In Patients With Type 1 Diabetes. Endocr Pract, 2004. 10(1): P. 10-7.

144. Hamann, A., Et Al., A Randomized Clinical Trial Comparing Breakfast, Dinner, Or Bedtime Administration Of Insulin Glargine In Patients With Type 1 Diabetes. Diabetes Care, 2003. 26(6): P. 173844.

145. Hermansen, K., Et Al., Insulin Analogues (Insulin Detemir And Insulin Aspart) Versus Traditional Human Insulins (NPH Insulin And Regular Human Insulin) In Basal-Bolus Therapy For Patients With Type 1 Diabetes. Diabetologia, 2004. 47(4): P. 622-9.

146. Brunelle, B., Et Al., Meta-Analysis Of The Effect Of Insulin Lispro On Severe Hypoglycemia In Patients With Type 1 Diabetes. Diabetes Care, 1998. 21(10): P. 1726-31.

147. Pickup, J. And A. Sutton, Severe Hypoglycaemia And Glycaemic Control In Type 1 Diabetes: Meta-Analysis Of Multiple Daily Insulin Injections Compared With Continuous Subcutaneous Insulin Infusion. Diabet Med, 2008. 25(7): P. 765-74.

148. Association, A.D., Et Al., Nutrition Recommendations And Interventions For Diabetes: A Position Statement Of The American Diabetes Association. Diabetes Care, 2008. 31 Suppl 1: P. S61-78.

149. Look, A.R.G., Et Al., Reduction In Weight And Cardiovascular Disease Risk Factors In Individuals With Type 2 Diabetes: One-Year 
Results Of The Look AHEAD Trial. Diabetes Care, 2007. 30(6): P. 1374-83.

150. Hundal, R., Et Al., Mechanism By Which Metformin Reduces Glucose Production In Type 2 Diabetes. Diabetes, 2000. 49(12): P. 2063-9.

151. Effect Of Intensive Blood-Glucose Control With Metformin On Complications In Overweight Patients With Type 2 Diabetes (UKPDS 34). UK Prospective Diabetes Study (UKPDS) Group. Lancet, 1998. 352(9131): P. 854-65.

152. American Diabetes, A., Standards Of Medical Care In Diabetes-2014. Diabetes Care, 2014. 37 Suppl 1: P. S14-80.

153. Defronzo, R. And A. Goodman, Efficacy Of Metformin In Patients With Non-Insulin-Dependent Diabetes Mellitus. The Multicenter Metformin Study Group. N Engl J Med, 1995. 333(9): P. 541-9.

154. Menéndez, E., J. Lafita, And S.A.E. Al., Recomendaciones Para El Tratamiento Farmacológico De La Hiperglucemia En La Diabetes Tipo 2. Av Diabetol. , 2010. 26: P. 331-8.

155. Krentz, A., R. Ferner, And C. Bailey, Comparative Tolerability Profiles Of Oral Antidiabetic Agents. Drug Saf, 1994. 11(4): P. 22341.

156. Bailey, C. And R. Turner, Metformin. N Engl J Med, 1996. 334(9): P. 574-9.

157. Lamanna, C., Et Al., Effect Of Metformin On Cardiovascular Events And Mortality: A Meta-Analysis Of Randomized Clinical Trials. Diabetes Obes Metab, 2011. 13(3): P. 221-8.

158. Nye, H. And W. Herrington, Metformin: The Safest Hypoglycaemic Agent In Chronic Kidney Disease? Nephron Clin Pract, 2011. 118(4): P. C380-3.

159. Excellence., N.I.F.H.A.C., Type 2 Diabetes. The Management Of Type 2 Diabetes (Update). Clinical Guideline 66. 2008, London.

160. Salpeter, S., Et Al., Risk Of Fatal And Nonfatal Lactic Acidosis With Metformin Use In Type 2 Diabetes Mellitus. Cochrane Database Syst Rev, 2010(4): P. CD002967.

161. Garber, A., Et Al., AACE Comprehensive Diabetes Management Algorithm 2013. Endocr Pract, 2013. 19(2): P. 327-36. 
162. Ismail-Beigi, F., Et Al., Individualizing Glycemic Targets In Type 2 Diabetes Mellitus: Implications Of Recent Clinical Trials. Ann Intern Med, 2011. 154(8): P. 554-9.

163. Mullan, R., Et Al., The Diabetes Mellitus Medication Choice Decision Aid: A Randomized Trial. Arch Intern Med, 2009. 169(17): P. 1560-8.

164. Bloomgarden, Z., Exploring Treatment Strategies For Type 2 Diabetes. Diabetes Care, 2007. 30(10): P. 2737-45.

165. Lingvay, I., Et Al., Insulin-Based Versus Triple Oral Therapy For Newly Diagnosed Type 2 Diabetes: Which Is Better? Diabetes Care, 2009. 32(10): P. 1789-95.

166. Ryan, E., S. Imes, And C. Wallace, Short-Term Intensive Insulin Therapy In Newly Diagnosed Type 2 Diabetes. Diabetes Care, 2004. 27(5): P. 1028-32.

167. Garber, A., Et Al., Simultaneous Glyburide/Metformin Therapy Is Superior To Component Monotherapy As An Initial Pharmacological Treatment For Type 2 Diabetes. Diabetes Obes Metab, 2002. 4(3): P. 201-8.

168. Orozco-Beltran, D., Et Al., Control Of Diabetes And Cardiovascular Risk Factors In Patients With Type 2 Diabetes In Primary Care. The Gap Between Guidelines And Reality In Spain. Int J Clin Pract, 2007. 61(6): P. 909-15.

169. Bennett, W., Et Al., Comparative Effectiveness And Safety Of Medications For Type 2 Diabetes: An Update Including New Drugs And 2-Drug Combinations. Ann Intern Med, 2011. 154(9): P. 602-13.

170. Gross, J., Et Al., Effect Of Antihyperglycemic Agents Added To Metformin And A Sulfonylurea On Glycemic Control And Weight Gain In Type 2 Diabetes: A Network Meta-Analysis. Ann Intern Med, 2011. 154(10): P. 672-9.

171. Karagiannis, T., Et Al., Dipeptidyl Peptidase-4 Inhibitors For Treatment Of Type 2 Diabetes Mellitus In The Clinical Setting: Systematic Review And Meta-Analysis. BMJ, 2012. 344: P. E1369.

172. Cryer, P., Severe Iatrogenic Hypoglycemia In Type 2 Diabetes Mellitus. Nat Clin Pract Endocrinol Metab, 2007. 3(1): P. 4-5. 
173. Loke, Y., C. Kwok, And S. Singh, Comparative Cardiovascular Effects Of Thiazolidinediones: Systematic Review And Meta-Analysis Of Observational Studies. BMJ, 2011. 342: P. D1309.

174. Kahn, S., Et Al., Glycemic Durability Of Rosiglitazone, Metformin, Or Glyburide Monotherapy. N Engl J Med, 2006. 355(23): P. 242743.

175. Hermann, L., Et Al., Therapeutic Comparison Of Metformin And Sulfonylurea, Alone And In Various Combinations. A Double-Blind Controlled Study. Diabetes Care, 1994. 17(10): P. 1100-9.

176. Fisman, E., Et Al., Oral Antidiabetic Treatment In Patients With Coronary Disease: Time-Related Increased Mortality On Combined Glyburide/Metformin Therapy Over A 7.7-Year Follow-Up. Clin Cardiol, 2001. 24(2): P. 151-8.

177. Johnson, J., Et Al., Decreased Mortality Associated With The Use Of Metformin Compared With Sulfonylurea Monotherapy In Type 2 Diabetes. Diabetes Care, 2002. 25(12): P. 2244-8.

178. Kahler, K., Et Al., Impact Of Oral Antihyperglycemic Therapy On All-Cause Mortality Among Patients With Diabetes In The Veterans Health Administration. Diabetes Care, 2007. 30(7): P. 1689-93.

179. Mannucci, E., Et Al., All-Cause Mortality In Diabetic Patients Treated With Combinations Of Sulfonylureas And Biguanides. Diabetes Metab Res Rev, 2004. 20(1): P. 44-7.

180. Olsson, J., Et Al., Increased Mortality In Type II Diabetic Patients Using Sulphonylurea And Metformin In Combination: A PopulationBased Observational Study. Diabetologia, 2000. 43(5): P. 558-60.

181. Gangji, A., Et Al., A Systematic Review And Meta-Analysis Of Hypoglycemia And Cardiovascular Events: A Comparison Of Glyburide With Other Secretagogues And With Insulin. Diabetes Care, 2007. 30(2): P. 389-94.

182. Holstein, A., A. Plaschke, And E. Egberts, Lower Incidence Of Severe Hypoglycaemia In Patients With Type 2 Diabetes Treated With Glimepiride Versus Glibenclamide. Diabetes Metab Res Rev, 2001. 17(6): P. 467-73.

183. Belcher, G., Et Al., Safety And Tolerability Of Pioglitazone, Metformin, And Gliclazide In The Treatment Of Type 2 Diabetes. Diabetes Res Clin Pract, 2005. 70(1): P. 53-62. 
184. Moses, R., Et Al., Effect Of Repaglinide Addition To Metformin Monotherapy On Glycemic Control In Patients With Type 2 Diabetes. Diabetes Care, 1999. 22(1): P. 119-24.

185. Ahren, B., Clinical Results Of Treating Type 2 Diabetic Patients With Sitagliptin, Vildagliptin Or Saxagliptin--Diabetes Control And Potential Adverse Events. Best Pract Res Clin Endocrinol Metab, 2009. 23(4): P. 487-98.

186. Bosi, E., Et Al., Effects Of Vildagliptin On Glucose Control Over 24 Weeks In Patients With Type 2 Diabetes Inadequately Controlled With Metformin. Diabetes Care, 2007. 30(4): P. 890-5.

187. Ferrannini, E., Et Al., Fifty-Two-Week Efficacy And Safety Of Vildagliptin Vs. Glimepiride In Patients With Type 2 Diabetes Mellitus Inadequately Controlled On Metformin Monotherapy. Diabetes Obes Metab, 2009. 11(2): P. 157-66.

188. Nauck, M., Et Al., Efficacy And Safety Of The Dipeptidyl Peptidase-4 Inhibitor, Sitagliptin, Compared With The Sulfonylurea, Glipizide, In Patients With Type 2 Diabetes Inadequately Controlled On Metformin Alone: A Randomized, Double-Blind, Non-Inferiority Trial. Diabetes Obes Metab, 2007. 9(2): P. 194-205.

189. Ferreira, J.A., Et Al., Efficacy And Safety Of Sitagliptin In Patients With Type 2 Diabetes And ESRD Receiving Dialysis: A 54-Week Randomized Trial. Am J Kidney Dis, 2013. 61(4): P. 579-87.

190. Nakamura, Y., Et Al., Anti-Inflammatory Effects Of Linagliptin In Hemodialysis Patients With Diabetes. Hemodial Int, 2014. 18(2): P. 433-42.

191. Gómez, R., J. Díez-Espino, And F.F.E. Al, Tratamiento De La Diabetes Tipo 2 En El Paciente Anciano. Med Clin (Barc). , 2013. 140(3): P. 134.E1-E12.

192. Elashoff, M., Et Al., Pancreatitis, Pancreatic, And Thyroid Cancer With Glucagon-Like Peptide-1-Based Therapies. Gastroenterology, 2011. 141(1): P. 150-6.

193. Li, L., Et Al., Incretin Treatment And Risk Of Pancreatitis In Patients With Type 2 Diabetes Mellitus: Systematic Review And Meta-Analysis Of Randomised And Non-Randomised Studies. BMJ, 2014. 348: P. G2366. 
194. Defronzo, R., Et Al., Effects Of Exenatide (Exendin-4) On Glycemic Control And Weight Over 30 Weeks In Metformin-Treated Patients With Type 2 Diabetes. Diabetes Care, 2005. 28(5): P. 1092-100.

195. Monami, M., N. Marchionni, And E. Mannucci, Glucagon-Like Peptide-1 Receptor Agonists In Type 2 Diabetes: A Meta-Analysis Of Randomized Clinical Trials. Eur J Endocrinol, 2009. 160(6): P. 90917.

196. Gaal, L.V., S. Gutkin, And M. Nauck, Exploiting The Antidiabetic Properties Of Incretins To Treat Type 2 Diabetes Mellitus: GlucagonLike Peptide 1 Receptor Agonists Or Insulin For Patients With Inadequate Glycemic Control? Eur J Endocrinol, 2008. 158(6): P. 773-84.

197. Klonoff, D., Et Al., Exenatide Effects On Diabetes, Obesity, Cardiovascular Risk Factors And Hepatic Biomarkers In Patients With Type 2 Diabetes Treated For At Least 3 Years. Curr Med Res Opin, 2008. 24(1): P. 275-86.

198. Zinman, B., Et Al., The Effect Of Adding Exenatide To A Thiazolidinedione In Suboptimally Controlled Type 2 Diabetes: A Randomized Trial. Ann Intern Med, 2007. 146(7): P. 477-85.

199. Montanya, E. And G. Sesti, A Review Of Efficacy And Safety Data Regarding The Use Of Liraglutide, A Once-Daily Human GlucagonLike Peptide 1 Analogue, In The Treatment Of Type 2 Diabetes Mellitus. Clin Ther, 2009. 31(11): P. 2472-88.

200. Yki-Jarvinen, H., Thiazolidinediones. N Engl J Med, 2004. 351(11): P. 1106-18.

201. Dormandy, J., Et Al., Secondary Prevention Of Macrovascular Events In Patients With Type 2 Diabetes In The Proactive Study (Prospective Pioglitazone Clinical Trial In Macrovascular Events): A Randomised Controlled Trial. Lancet, 2005. 366(9493): P. 1279-89.

202. Lewis, J., Et Al., Risk Of Bladder Cancer Among Diabetic Patients Treated With Pioglitazone: Interim Report Of A Longitudinal Cohort Study. Diabetes Care, 2011. 34(4): P. 916-22.

203. Yki-Jarvinen, H., Et Al., Comparison Of Bedtime Insulin Regimens In Patients With Type 2 Diabetes Mellitus. A Randomized, Controlled Trial. Ann Intern Med, 1999. 130(5): P. 389-96. 
204. Riddle, M., Et Al., The Treat-To-Target Trial: Randomized Addition Of Glargine Or Human NPH Insulin To Oral Therapy Of Type 2 Diabetic Patients. Diabetes Care, 2003. 26(11): P. 3080-6.

205. Swinnen, S., Et Al., A 24-Week, Randomized, Treat-To-Target Trial Comparing Initiation Of Insulin Glargine Once-Daily With Insulin Detemir Twice-Daily In Patients With Type 2 Diabetes Inadequately Controlled On Oral Glucose-Lowering Drugs. Diabetes Care, 2010. 33(6): P. 1176-8.

206. Chiasson, J., L. Naditch, And G. Miglitol Canadian University Investigator, The Synergistic Effect Of Miglitol Plus Metformin Combination Therapy In The Treatment Of Type 2 Diabetes. Diabetes Care, 2001. 24(6): P. 989-94.

207. Inzucchi, S., Et Al., Management Of Hyperglycemia In Type 2 Diabetes: A Patient-Centered Approach: Position Statement Of The American Diabetes Association (ADA) And The European Association For The Study Of Diabetes (EASD). Diabetes Care, 2012. 35(6): P. 1364-79.

208. Kendall, D., Et Al., Effects Of Exenatide (Exendin-4) On Glycemic Control Over 30 Weeks In Patients With Type 2 Diabetes Treated With Metformin And A Sulfonylurea. Diabetes Care, 2005. 28(5): P. 1083-91.

209. Zinman, B., Et Al., Efficacy And Safety Of The Human GlucagonLike Peptide-1 Analog Liraglutide In Combination With Metformin And Thiazolidinedione In Patients With Type 2 Diabetes (LEAD-4 Met+TZD). Diabetes Care, 2009. 32(7): P. 1224-30.

210. Roberts, V., Et Al., Triple Therapy With Glimepiride In Patients With Type 2 Diabetes Mellitus Inadequately Controlled By Metformin And A Thiazolidinedione: Results Of A 30-Week, Randomized, DoubleBlind, Placebo-Controlled, Parallel-Group Study. Clin Ther, 2005. 27(10): P. 1535-47.

211. Bell, D., Et Al., Triple Oral Fixed-Dose Diabetes Polypill Versus Insulin Plus Metformin Efficacy Demonstration Study In The Treatment Of Advanced Type 2 Diabetes (Tried Study-II). Diabetes Obes Metab, 2011. 13(9): P. 800-5.

212. Rosenstock, J., Et Al., Triple Therapy In Type 2 Diabetes: Insulin Glargine Or Rosiglitazone Added To Combination Therapy Of 
Sulfonylurea Plus Metformin In Insulin-Naive Patients. Diabetes Care, 2006. 29(3): P. 554-9.

213. Kiayias, J., Et Al., Rosiglitazone In Combination With Glimepiride Plus Metformin In Type 2 Diabetic Patients. Diabetes Care, 2002. 25(7): P. 1251-2.

214. Dailey, G., Et Al., Glycemic Control With Glyburide/Metformin Tablets In Combination With Rosiglitazone In Patients With Type 2 Diabetes: A Randomized, Double-Blind Trial. Am J Med, 2004. 116(4): P. 223-9.

215. Roy, R., Et Al., Real World Effectiveness Of Rosiglitazone Added To Maximal (Tolerated) Doses Of Metformin And A Sulfonylurea Agent: A Systematic Evaluation Of Triple Oral Therapy In A Minority Population. Diabetes Care, 2004. 27(7): P. 1741-2.

216. Charpentier, G., S. Halimi, And F.P.-S. Investigators, Earlier Triple Therapy With Pioglitazone In Patients With Type 2 Diabetes. Diabetes Obes Metab, 2009. 11(9): P. 844-54.

217. AJ Scheen, A.J., Et Al., Long-Term Glycaemic Control With Metformin-Sulphonylurea-Pioglitazone Triple Therapy In Proactive (Proactive 17). Diabet Med, 2009. 26(10): P. 1033-9.

218. Papa, G., Et Al., Safety Of Type 2 Diabetes Treatment With Repaglinide Compared With Glibenclamide In Elderly People: A Randomized, Open-Label, Two-Period, Cross-Over Trial. Diabetes Care, 2006. 29(8): P. 1918-20.

219. Hermansen, K., Et Al., Efficacy And Safety Of The Dipeptidyl Peptidase-4 Inhibitor, Sitagliptin, In Patients With Type 2 Diabetes Mellitus Inadequately Controlled On Glimepiride Alone Or On Glimepiride And Metformin. Diabetes Obes Metab, 2007. 9(5): P. 733-45.

220. Tran, M., M. Navar, And M. Davidson, Comparison Of The Glycemic Effects Of Rosiglitazone And Pioglitazone In Triple Oral Therapy In Type 2 Diabetes. Diabetes Care, 2006. 29(6): P. 1395-6.

221. Russell-Jones, D., Et Al., Liraglutide Vs Insulin Glargine And Placebo In Combination With Metformin And Sulfonylurea Therapy In Type 2 Diabetes Mellitus (LEAD-5 Met+SU): A Randomised Controlled Trial. Diabetologia, 2009. 52(10): P. 2046-55. 
222. Holman, R., Et Al., Three-Year Efficacy Of Complex Insulin Regimens In Type 2 Diabetes. N Engl J Med, 2009. 361(18): P. 173647.

223. Mori, Y., Et Al., Effects Of Add-On Treatment With Sitagliptin On Narrowing The Range Of Glucose Fluctuations In Japanese Type 2 Diabetes Patients Receiving Insulin Therapy. Diabetes Technol Ther, 2013. 15(3): P. 237-40.

224. Yki-Jarvinen, H., Et Al., Less Nocturnal Hypoglycemia And Better Post-Dinner Glucose Control With Bedtime Insulin Glargine Compared With Bedtime NPH Insulin During Insulin Combination Therapy In Type 2 Diabetes. HOE 901/3002 Study Group. Diabetes Care, 2000. 23(8): P. 1130-6.

225. Hermansen, K., Et Al., A 26-Week, Randomized, Parallel, Treat-ToTarget Trial Comparing Insulin Detemir With NPH Insulin As AddOn Therapy To Oral Glucose-Lowering Drugs In Insulin-Naive People With Type 2 Diabetes. Diabetes Care, 2006. 29(6): P. 1269-74.

226. Rosenstock, J., Et Al., Reduced Hypoglycemia Risk With Insulin Glargine: A Meta-Analysis Comparing Insulin Glargine With Human NPH Insulin In Type 2 Diabetes. Diabetes Care, 2005. 28(4): P. 9505.

227. Fritsche, A., Et Al., Glimepiride Combined With Morning Insulin Glargine, Bedtime Neutral Protamine Hagedorn Insulin, Or Bedtime Insulin Glargine In Patients With Type 2 Diabetes. A Randomized, Controlled Trial. Ann Intern Med, 2003. 138(12): P. 952-9.

228. Hirsch, I., Insulin Analogues. N Engl J Med, 2005. 352(2): P. 174-83.

229. Nathan, D., Et Al., Medical Management Of Hyperglycemia In Type 2 Diabetes: A Consensus Algorithm For The Initiation And Adjustment Of Therapy: A Consensus Statement Of The American Diabetes Association And The European Association For The Study Of Diabetes. Diabetes Care, 2009. 32(1): P. 193-203.

230. Inzucchi, S., Et Al., Management Of Hyperglycemia In Type 2 Diabetes, 2015: A Patient-Centered Approach: Update To A Position Statement Of The American Diabetes Association And The European Association For The Study Of Diabetes. Diabetes Care, 2015. 38(1): P. 140-9. 
231. Rodbard, H., Et Al., Treatment Intensification With Stepwise Addition Of Prandial Insulin Aspart Boluses Compared With Full Basal-Bolus Therapy (Fullstep Study): A Randomised, Treat-To-Target Clinical Trial. Lancet Diabetes Endocrinol, 2014. 2(1): P. 30-7.

232. Ohkubo, Y., Et Al., Intensive Insulin Therapy Prevents The Progression Of Diabetic Microvascular Complications In Japanese Patients With Non-Insulin-Dependent Diabetes Mellitus: A Randomized Prospective 6-Year Study. Diabetes Res Clin Pract, 1995. 28(2): P. 103-17.

233. Ampudia-Blasco, F. And J. Rosenstock, Estrategias De Insulinización En La Diabetes Mellitus Tipo 2. . Av Diabetol. , 2008. 24: P. 7-20.

234. Sjostrom, L., Et Al., Lifestyle, Diabetes, And Cardiovascular Risk Factors 10 Years After Bariatric Surgery. N Engl J Med, 2004. 351(26): P. 2683-93.

235. Sjostrom, L., Et Al., Effects Of Bariatric Surgery On Mortality In Swedish Obese Subjects. N Engl J Med, 2007. 357(8): P. 741-52.

236. Buchwald, H., Et Al., Bariatric Surgery: A Systematic Review And Meta-Analysis. JAMA, 2004. 292(14): P. 1724-37.

237. Schauer, P., Et Al., Effect Of Laparoscopic Roux-En Y Gastric Bypass On Type 2 Diabetes Mellitus. Ann Surg, 2003. 238(4): P. 467-84; Discussion 84-5.

238. Kaplan, L. And N. Ahmad, The Cutting Edge In Diabetes Treatment-Is Weight-Loss Surgery An Effective Therapeutic Strategy? Nat Clin Pract Endocrinol Metab, 2008. 4(8): P. 438-9.

239. Dixon, J., Et Al., Adjustable Gastric Banding And Conventional Therapy For Type 2 Diabetes: A Randomized Controlled Trial. JAMA, 2008. 299(3): P. 316-23.

240. Vidal, J., Et Al., Type 2 Diabetes Mellitus And The Metabolic Syndrome Following Sleeve Gastrectomy In Severely Obese Subjects. Obes Surg, 2008. 18(9): P. 1077-82.

241. Penn, L., Et Al., Importance Of Weight Loss Maintenance And Risk Prediction In The Prevention Of Type 2 Diabetes: Analysis Of European Diabetes Prevention Study RCT. Plos One, 2013. 8(2): P. E57143. 
242. Cohen, R., Et Al., Effects Of Gastric Bypass Surgery In Patients With Type 2 Diabetes And Only Mild Obesity. Diabetes Care, 2012. 35(7): P. 1420-8.

243. NIH Conference. Gastrointestinal Surgery For Severe Obesity. Consensus Development Conference Panel. Ann Intern Med, 1991. 115(12): P. 956-61.

244. Buchwald, H., Et Al., Trends In Mortality In Bariatric Surgery: A Systematic Review And Meta-Analysis. Surgery, 2007. 142(4): P. 62132; Discussion 632-5.

245. Hoerger, T., Et Al., Cost-Effectiveness Of Bariatric Surgery For Severely Obese Adults With Diabetes. Diabetes Care, 2010. 33(9): P. 1933-9.

246. Makary, M., Et Al., Medication Utilization And Annual Health Care Costs In Patients With Type 2 Diabetes Mellitus Before And After Bariatric Surgery. Arch Surg, 2010. 145(8): P. 726-31.

247. Keating, C., Et Al., Cost-Efficacy Of Surgically Induced Weight Loss For The Management Of Type 2 Diabetes: A Randomized Controlled Trial. Diabetes Care, 2009. 32(4): P. 580-4.

248. Maciejewski, M., Et Al., Survival Among High-Risk Patients After Bariatric Surgery. JAMA, 2011. 305(23): P. 2419-26.

249. Himpens, J., Et Al., Long-Term Outcomes Of Laparoscopic Adjustable Gastric Banding. Arch Surg, 2011. 146(7): P. 802-7.

250. Feldman, H., Et Al., Impotence And Its Medical And Psychosocial Correlates: Results Of The Massachusetts Male Aging Study. J Urol, 1994. 151(1): P. 54-61.

251. Bancroft, J. And P. Gutierrez, Erectile Dysfunction In Men With And Without Diabetes Mellitus: A Comparative Study. Diabet Med, 1996. 13(1): P. 84-9.

252. Klein, R., Et Al., Prevalence Of Self-Reported Erectile Dysfunction In People With Long-Term IDDM. Diabetes Care, 1996. 19(2): P. 13541.

253. Fedele, D., Et Al., Erectile Dysfunction In Type 1 And Type 2 Diabetics In Italy. On Behalf Of Gruppo Italiano Studio Deficit Erettile Nei Diabetici. Int J Epidemiol, 2000. 29(3): P. 524-31. 
254. Giuliano, F., Et Al., Prevalence Of Erectile Dysfunction Among 7689 Patients With Diabetes Or Hypertension, Or Both. Urology, 2004. 64(6): P. 1196-201.

255. Sasaki, H., Et Al., Prevalence And Risk Factors For Erectile Dysfunction In Japanese Diabetics. Diabetes Res Clin Pract, 2005. 70(1): P. 81-9.

256. Malavige, L. And J. Levy, Erectile Dysfunction In Diabetes Mellitus. J Sex Med, 2009. 6(5): P. 1232-47.

257. Wild, S., Et Al., Global Prevalence Of Diabetes: Estimates For The Year 2000 And Projections For 2030. Diabetes Care, 2004. 27(5): P. 1047-53.

258. Romeo, J., Et Al., Sexual Function In Men With Diabetes Type 2: Association With Glycemic Control. J Urol, 2000. 163(3): P. 788-91.

259. Deutsch, S. And L. Sherman, Previously Unrecognized Diabetes Mellitus In Sexually Impotent Men. JAMA, 1980. 244(21): P. 2430-2.

260. Lewis, R., Epidemiology Of Erectile Dysfunction. Urol Clin North Am, 2001. 28(2): P. 209-16, Vii.

261. Bortolotti, A., Et Al., The Epidemiology Of Erectile Dysfunction And Its Risk Factors. Int J Androl, 1997. 20(6): P. 323-34.

262. Enzlin, P., Et Al., Prevalence And Predictors Of Sexual Dysfunction In Patients With Type 1 Diabetes. Diabetes Care, 2003. 26(2): P. 40914.

263. Giugliano, F., Et Al., Determinants Of Erectile Dysfunction In Type 2 Diabetes. Int J Impot Res, 2010. 22(3): P. 204-9.

264. Rhoden, E., Et Al., Glycosylated Haemoglobin Levels And The Severity Of Erectile Function In Diabetic Men. BJU Int, 2005. 95(4): P. 615-7.

265. Jones, O., Et Al., Preservation Of Sexual And Bladder Function After Laparoscopic Rectal Surgery. Colorectal Dis, 2009. 11(5): P. 489-95.

266. Giugliano, F., Et Al., Adherence To Mediterranean Diet And Erectile Dysfunction In Men With Type 2 Diabetes. J Sex Med, 2010. 7(5): P. 1911-7.

267. Gazzaruso, C., Et Al., Erectile Dysfunction As A Predictor Of Cardiovascular Events And Death In Diabetic Patients With Angiographically Proven Asymptomatic Coronary Artery Disease: A 
Potential Protective Role For Statins And 5-Phosphodiesterase Inhibitors. J Am Coll Cardiol, 2008. 51(21): P. 2040-4.

268. Dunsmuir, W. And S. Holmes, The Aetiology And Management Of Erectile, Ejaculatory, And Fertility Problems In Men With Diabetes Mellitus. Diabet Med, 1996. 13(8): P. 700-8.

269. Saenz De Tejada, I., Et Al., Impaired Neurogenic And EndotheliumMediated Relaxation Of Penile Smooth Muscle From Diabetic Men With Impotence. N Engl J Med, 1989. 320(16): P. 1025-30.

270. Azadzoi, K. And I.S.D. Tejada, Diabetes Mellitus Impairs Neurogenic And Endothelium-Dependent Relaxation Of Rabbit Corpus Cavernosum Smooth Muscle. J Urol, 1992. 148(5): P. 158791.

271. Angulo, J., Et Al., Diabetes Exacerbates The Functional Deficiency Of NO/Cgmp Pathway Associated With Erectile Dysfunction In Human Corpus Cavernosum And Penile Arteries. J Sex Med, 2010. 7(2 Pt 1): P. 758-68.

272. Angulo, J., Et Al., Diabetes Impairs Endothelium-Dependent Relaxation Of Human Penile Vascular Tissues Mediated By NO And EDHF. Biochem Biophys Res Commun, 2003. 312(4): P. 1202-8.

273. Angelis, L.D., Et Al., Erectile And Endothelial Dysfunction In Type II Diabetes: A Possible Link. Diabetologia, 2001. 44(9): P. 1155-60.

274. Pegge, N., Et Al., The Role Of Endothelial Dysfunction In The Pathophysiology of Erectile Dysfunction In Diabetes And In Determining Response To Treatment. Diabet Med, 2006. 23(8): P. 873-8.

275. Vernet, D., Et Al., Reduction Of Penile Nitric Oxide Synthase In Diabetic BB/Wordp (Type I) And BBZ/Wordp (Type II) Rats With Erectile Dysfunction. Endocrinology, 1995. 136(12): P. 5709-17.

276. Podlasek, C., Et Al., Characterization And Localization Of Nitric Oxide Synthase Isoforms In The BB/WOR Diabetic Rat. J Urol, 2001. 166(2): P. 746-55.

277. Akingba, A. And A. Burnett, Endothelial Nitric Oxide Synthase Protein Expression, Localization, And Activity In The Penis Of The Alloxan-Induced Diabetic Rat. Mol Urol, 2001. 5(4): P. 189-97. 
278. Bivalacqua, T., Et Al., Gene Transfer Of Endothelial Nitric Oxide Synthase Partially Restores Nitric Oxide Synthesis And Erectile Function In Streptozotocin Diabetic Rats. J Urol, 2003. 169(5): P. 1911-7.

279. Angulo, J., Et Al., Impairment Of Nitric Oxide-Mediated Relaxations In Anaesthetized Autoperfused Streptozotocin-Induced Diabetic Rats. Naunyn Schmiedebergs Arch Pharmacol, 1998. 358(5): P. 529-37.

280. Bivalacqua, T., Et Al., Increased Expression Of Arginase II In Human Diabetic Corpus Cavernosum: In Diabetic-Associated Erectile Dysfunction. Biochem Biophys Res Commun, 2001. 283(4): P. 923-7.

281. Gryglewski, R., R. Palmer, And S. Moncada, Superoxide Anion Is Involved In The Breakdown Of Endothelium-Derived Vascular Relaxing Factor. Nature, 1986. 320(6061): P. 454-6.

282. Keegan, A., M. Cotter, And N. Cameron, Effects Of Diabetes And Treatment With The Antioxidant Alpha-Lipoic Acid On Endothelial And Neurogenic Responses Of Corpus Cavernosum In Rats. Diabetologia, 1999. 42(3): P. 343-50.

283. Keegan, A., M. Cotter, And N. Cameron, Corpus Cavernosum Dysfunction In Diabetic Rats: Effects Of Combined Alpha-Lipoic Acid And Gamma-Linolenic Acid Treatment. Diabetes Metab Res Rev, 2001. 17(5): P. 380-6.

284. Gocmen, C., Et Al., Effects Of Vitamin E And Sodium Selenate On Neurogenic And Endothelial Relaxation Of Corpus Cavernosum In The Diabetic Mouse. Eur J Pharmacol, 2000. 398(1): P. 93-8.

285. Young, L.D., Et Al., Effect Of PDE5 Inhibition Combined With Free Oxygen Radical Scavenger Therapy On Erectile Function In A Diabetic Animal Model. Int J Impot Res, 2003. 15(5): P. 347-54.

286. Angulo, J., Et Al., The Novel Antioxidant, AC3056 (2,6-Di-T-Butyl-4((Dimethyl-4-Methoxyphenylsilyl)Methyloxy)Phenol), Reverses Erectile Dysfunction In Diabetic Rats And Improves NO-Mediated Responses In Penile Tissue From Diabetic Men. J Sex Med, 2009. 6(2): P. 373-87.

287. Cartledge, J., I. Eardley, And J. Morrison, Impairment Of Corpus Cavernosal Smooth Muscle Relaxation By Glycosylated Human Haemoglobin. BJU Int, 2000. 85(6): P. 735-41. 
288. Seftel, A., Et Al., Advanced Glycation End Products In Human Penis: Elevation In Diabetic Tissue, Site Of Deposition, And Possible Effect Through Inos Or Enos. Urology, 1997. 50(6): P. 1016-26.

289. Wautier, M., Et Al., Activation Of NADPH Oxidase By AGE Links Oxidant Stress To Altered Gene Expression Via RAGE. Am J Physiol Endocrinol Metab, 2001. 280(5): P. E685-94.

290. Shukla, N., Et Al., The Administration Of Folic Acid Improves Erectile Function And Reduces Intracavernosal Oxidative Stress In The Diabetic Rabbit. BJU Int, 2009. 103(1): P. 98-103.

291. Morano, S., Et Al., Antioxidant Treatment Associated With Sildenafil Reduces Monocyte Activation And Markers Of Endothelial Damage In Patients With Diabetic Erectile Dysfunction: A Double-Blind, Placebo-Controlled Study. Eur Urol, 2007. 52(6): P. 1768-74.

292. Wingard, C., D. Fulton, And S. Husain, Altered Penile Vascular Reactivity And Erection In The Zucker Obese-Diabetic Rat. J Sex Med, 2007. 4(2): P. 348-62; Discussion 362-3.

293. Chang, S., Et Al., Increased Contractility Of Diabetic Rabbit Corpora Smooth Muscle In Response To Endothelin Is Mediated Via RhoKinase Beta. Int J Impot Res, 2003. 15(1): P. 53-62.

294. Sullivan, M., Et Al., Alterations In Endothelin B Receptor Sites In Cavernosal Tissue Of Diabetic Rabbits: Potential Relevance To The Pathogenesis Of Erectile Dysfunction. J Urol, 1997. 158(5): P. 196672.

295. Jesmin, S., Et Al., Effects Of Dual Endothelin Receptor Antagonist On Antiapoptotic Marker Bcl-2 Expression In Streptozotocin-Induced Diabetic Rats. Exp Biol Med (Maywood), 2006. 231(6): P. 1034-9.

296. Inoguchi, T., Et Al., Preferential Elevation Of Protein Kinase C Isoform Beta II And Diacylglycerol Levels In The Aorta And Heart Of Diabetic Rats: Differential Reversibility To Glycemic Control By Islet Cell Transplantation. Proc Natl Acad Sci U S A, 1992. 89(22): P. 11059-63.

297. Koya, D. And G. King, Protein Kinase C Activation And The Development Of Diabetic Complications. Diabetes, 1998. 47(6): P. 859-66. 
298. Ganz, M. And A. Seftel, Glucose-Induced Changes In Protein Kinase $C$ And Nitric Oxide Are Prevented By Vitamin E. Am J Physiol Endocrinol Metab, 2000. 278(1): P. E146-52.

299. Bivalacqua, T., Et Al., Rhoa/Rho-Kinase Suppresses Endothelial Nitric Oxide Synthase In The Penis: A Mechanism For DiabetesAssociated Erectile Dysfunction. Proc Natl Acad Sci U S A, 2004. 101(24): P. 9121-6.

300. Li, W., Et Al., Chronic Treatment With An Oral Rho-Kinase Inhibitor Restores Erectile Function By Suppressing Corporal Apoptosis In Diabetic Rats. J Sex Med, 2011. 8(2): P. 400-10.

301. Virag, R., P. Bouilly, And D. Frydman, Is Impotence An Arterial Disorder? A Study Of Arterial Risk Factors In 440 Impotent Men. Lancet, 1985. 1(8422): P. 181-4.

302. Mersdorf, A., Et Al., Ultrastructural Changes In Impotent Penile Tissue: A Comparison Of 65 Patients. J Urol, 1991. 145(4): P. 74958.

303. Costa, C., Et Al., Increased Endothelial Apoptotic Cell Density In Human Diabetic Erectile Tissue--Comparison With Clinical Data. J Sex Med, 2009. 6(3): P. 826-35.

304. Simopoulos, D., Et Al., Corporeal Structural And Vascular Micro Architecture With X-Ray Micro Computerized Tomography In Normal And Diabetic Rabbits: Histopathological Correlation. J Urol, 2001. 165(5): P. 1776-82.

305. Ahn, G., Et Al., The Effect Of PDE5 Inhibition On The Erectile Function In Streptozotocin-Induced Diabetic Rats. Int J Impot Res, 2005. 17(2): P. 134-41.

306. Young, L.D., Et Al., Endothelial Rehabilitation: The Impact Of Chronic PDE5 Inhibitors On Erectile Function And Protein Alterations In Cavernous Tissue Of Diabetic Rats. Eur Urol, 2008. 54(1): P. 213-20.

307. Kovanecz, I., Et Al., Early Onset Of Fibrosis Within The Arterial Media In A Rat Model Of Type 2 Diabetes Mellitus With Erectile Dysfunction. BJU Int, 2009. 103(10): P. 1396-404.

308. Hecht, M., Et A1., Neuropathy Is A Major Contributing Factor To Diabetic Erectile Dysfunction. Neurol Res, 2001. 23(6): P. 651-4. 
309. Mcvary, K., Et Al., Intrinsic And Extrinsic Apoptotic Pathways Are Employed In Neuropathic And Diabetic Models Of Erectile Dysfunction. J Sex Med 2006. 3: P. 45.

310. Cellek, S., Et Al., Selective Nitrergic Neurodegeneration In Diabetes Mellitus - A Nitric Oxide-Dependent Phenomenon. Br J Pharmacol, 1999. 128(8): P. 1804-12.

311. Kapoor, D., Et Al., Clinical And Biochemical Assessment Of Hypogonadism In Men With Type 2 Diabetes: Correlations With Bioavailable Testosterone And Visceral Adiposity. Diabetes Care, 2007. 30(4): P. 911-7.

312. El-Sakka, A., H. Sayed, And K. Tayeb, Androgen Pattern In Patients With Type 2 Diabetes-Associated Erectile Dysfunction: Impact Of Metabolic Control. Urology, 2009. 74(3): P. 552-9.

313. Tomar, R., Et Al., Contrasting Testosterone Concentrations In Type 1 And Type 2 Diabetes. Diabetes Care, 2006. 29(5): P. 1120-2.

314. Chandel, A., Et Al., Testosterone Concentration In Young Patients With Diabetes. Diabetes Care, 2008. 31(10): P. 2013-7.

315. Kapoor, D., Et Al., Erectile Dysfunction Is Associated With Low Bioactive Testosterone Levels And Visceral Adiposity In Men With Type 2 Diabetes. Int J Androl, 2007. 30(6): P. 500-7.

316. Zhang, X., Et Al., Testosterone Restores Diabetes-Induced Erectile Dysfunction And Sildenafil Responsiveness In Two Distinct Animal Models Of Chemical Diabetes. J Sex Med, 2006. 3(2): P. 253-64; Discussion 264-5, Author Reply 265-6.

317. Jardin, A., G. Wagner, And S.K.E. Al, Recommendations Of The 1st International Consultation On Erectile Dysfunction. Erectile Dysfunction: 1st International Consultation On Erectile Dysfunction. Ed. 2000, Oxford: Health Publication Ltd.

318. Wespes, E. And C. Schulman, Venous Impotence: Pathophysiology, Diagnosis And Treatment. J Urol, 1993. 149(5 Pt 2): P. 1238-45.

319. Rao, D. And C. Donatucci, Vasculogenic Impotence. Arterial And Venous Surgery. Urol Clin North Am, 2001. 28(2): P. 309-19.

320. Rosen, R., D. Hatzichristou, And G. Broderick, Clinical Evaluation And Symptom Scales: Sexual Dysfunction Assesment In Men. Sexual 
Medicine Sexual Dysfunctions In Men And Women. Ed. 2004, París, France: Health Publications.

321. $2^{\text {nd }}$ Internacional Consultation On Sexual Medicine Dysfunction. Sexual Medicine: Sexual Dysfunction In Men And Women. 2004 Ed. 2004, Paris: Health Publications.

322. Hatzichristou, D., Et Al., Clinical Evaluation And Management Strategy For Sexual Dysfunction In Men And Women. J Sex Med, 2004. 1(1): P. 49-57.

323. Moyad, M., Et Al., Prevention And Treatment Of Erectile Dysfunction Using Lifestyle Changes And Dietary Supplements: What Works And What Is Worthless, Part II. Urol Clin North Am, 2004. 31(2): P. 259-73.

324. Moyad, M., Et Al., Prevention And Treatment Of Erectile Dysfunction Using Lifestyle Changes And Dietary Supplements: What Works And What Is Worthless, Part I. Urol Clin North Am, 2004. 31(2): P. 249-57.

325. Esposito, K., Et Al., Effect Of Lifestyle Changes On Erectile Dysfunction In Obese Men: A Randomized Controlled Trial. JAMA, 2004. 291(24): P. 2978-84.

326. Guay, A., Optimizing Response To Phosphodiesterase Therapy: Impact Of Risk-Factor Management. J Androl, 2003. 24(6 Suppl): P. S59-62.

327. Goldstein, I., The Mutually Reinforcing Triad Of Depressive Symptoms, Cardiovascular Disease, And Erectile Dysfunction. Am J Cardiol, 2000. 86(2A): P. 41F-45F.

328. Martín, A., E. Vivas, And N. Cruz, Escalones De Tratamiento: Modificación De Causas Reversibles, Contol De Factores De Riesgo $Y$ Estilos De Vida. . Tratado De Andrología Y Medicina Sexual., 2011: P. Cap 69: P. 579-586.

329. Montorsi, F., Et Al., Erectile Dysfunction Prevalence, Time Of Onset And Association With Risk Factors In 300 Consecutive Patients With Acute Chest Pain And Angiographically Documented Coronary Artery Disease. Eur Urol, 2003. 44(3): P. 360-4; Discussion 364-5.

330. Thompson, I., Et Al., Erectile Dysfunction And Subsequent Cardiovascular Disease. JAMA, 2005. 294(23): P. 2996-3002. 
331. Lee, J., Et Al., Erectile Dysfunction As A Coronary Artery Disease Risk Equivalent. J Nucl Cardiol, 2008. 15(6): P. 800-3.

332. Kostis, J., Et Al., Sexual Dysfunction And Cardiac Risk (The Second Princeton Consensus Conference). Am J Cardiol, 2005. 96(2): P. 31321.

333. Banks, E., Et Al., Erectile Dysfunction Severity As A Risk Marker For Cardiovascular Disease Hospitalisation And All-Cause Mortality: A Prospective Cohort Study. Plos Med, 2013. 10(1): P. E1001372.

334. Corona, G., Et Al., Low Levels Of Androgens In Men With Erectile Dysfunction And Obesity. J Sex Med, 2008. 5(10): P. 2454-63.

335. Hannan, J., Et Al., Beneficial Impact Of Exercise And Obesity Interventions On Erectile Function And Its Risk Factors. J Sex Med, 2009. 6 Suppl 3: P. 254-61.

336. Esposito, K., Et Al., Effects Of Intensive Lifestyle Changes On Erectile Dysfunction In Men. J Sex Med, 2009. 6(1): P. 243-50.

337. Esposito, K., Et Al., Dietary Factors, Mediterranean Diet And Erectile Dysfunction. J Sex Med, 2010. 7(7): P. 2338-45.

338. Derby, C., Et Al., Modifiable Risk Factors And Erectile Dysfunction: Can Lifestyle Changes Modify Risk? Urology, 2000. 56(2): P. 302-6.

339. Cheng, J., Et Al., Physical Activity And Erectile Dysfunction: MetaAnalysis Of Population-Based Studies. Int J Impot Res, 2007. 19(3): P. 245-52.

340. Martin-Morales, A., Et Al., Prevalence And Independent Risk Factors For Erectile Dysfunction In Spain: Results Of The Epidemiologia De La Disfuncion Erectil Masculina Study. J Urol, 2001. 166(2): P. 56974; Discussion 574-5.

341. Chew, K., Et Al., Is The Relationship Between Cigarette Smoking And Male Erectile Dysfunction Independent Of Cardiovascular Disease? Findings From A Population-Based Cross-Sectional Study. J Sex Med, 2009. 6(1): P. 222-31.

342. Cheng, J., Et Al., Alcohol Consumption And Erectile Dysfunction: Meta-Analysis Of Population-Based Studies. Int J Impot Res, 2007. 19(4): P. 343-52.

343. Chew, K., Alcohol Consumption And Male Erectile Dysfunction: An Unfounded Reputation For Risk? J Sex Med, 2009. 6(8): P. 2340. 
344. Lue, T., Erectile Dysfunction. N Engl J Med, 2000. 342(24): P. 180213.

345. Wespes, E., Et Al., Guidelines On Erectile Dysfunction. Eur Urol, 2002. 41(1): P. 1-5.

346. Blazquez, J., J. Delgado, And A. Gómez, Tratamiento Farmacológico Oral De La Disfunción Eréctil. . Clínicas Urológicas De La Complutense., 2004. 10: P. P. 515-38.

347. Corbin, J., S. Francis, And D. Webb, Phosphodiesterase Type 5 As A Pharmacologic Target In Erectile Dysfunction. Urology, 2002. 60(2 Suppl 2): P. 4-11.

348. Moncada, I., Et Al., Efficacy Of Sildenafil Citrate At 12 Hours After Dosing: Re-Exploring The Therapeutic Window. Eur Urol, 2004. 46(3): P. 357-60; Discussion 360-1.

349. Langtry, H. And A. Markham, Sildenafil: A Review Of Its Use In Erectile Dysfunction. Drugs, 1999. 57(6): P. 967-89.

350. Stuckey, B., Et Al., Sildenafil Citrate For Treatment Of Erectile Dysfunction In Men With Type 1 Diabetes: Results Of A Randomized Controlled Trial. Diabetes Care, 2003. 26(2): P. 279-84.

351. Carson, C., Et Al., The Efficacy Of Sildenafil Citrate (Viagra) In Clinical Populations: An Update. Urology, 2002. 60(2 Suppl 2): P. 12-27.

352. Sairam, K., Et Al., Sildenafil Influences Lower Urinary Tract Symptoms. BJU Int, 2002. 90(9): P. 836-9.

353. Padma-Nathan, H., Et Al., A 4-Year Update On The Safety Of Sildenafil Citrate (Viagra). Urology, 2002. 60(2 Suppl 2): P. 67-90.

354. Porst, H., Et Al., Efficacy Of Tadalafil For The Treatment Of Erectile Dysfunction At 24 And 36 Hours After Dosing: A Randomized Controlled Trial. Urology, 2003. 62(1): P. 121-5; Discussion 125-6.

355. Hellstrom, W., Et Al., Tadalafil Has No Detrimental Effect On Human Spermatogenesis Or Reproductive Hormones. J Urol., 2003. 170(3): P. 887-91.

356. Brock, G., Et Al., Efficacy And Safety Of Tadalafil For The Treatment Of Erectile Dysfunction: Results Of Integrated Analyses. J Urol, 2002. 168(4 Pt 1): P. 1332-6. 
357. Saenz-De-Tejada, I., Et Al., Effects Of Tadalafil On Erectile Dysfunction In Men With Diabetes. Diabetes Care, 2002. 25(12): P. 2159-64.

358. Fiter, L. And N. García, Tratamientos Orales De La Disfunción Erectil., In En Tratado De Andrología Y Medicina Sexual. 2012, Editorial Médica Panamericana S.A.: Madrid. P. Cap 70.

359. Porst, H., Et Al., Evaluation Of The Efficacy And Safety Of Once-ADay Dosing Of Tadalafil 5mg And 10mg In The Treatment Of Erectile Dysfunction: Results of A Multicenter, Randomized, Double-Blind, Placebo-Controlled Trial. Eur Urol, 2006. 50(2): P. 351-9.

360. Bischoff, E. And K. Schneider, A Conscious-Rabbit Model To Study Vardenafil Hydrochloride And Other Agents That Influence Penile Erection. Int J Impot Res, 2001. 13(4): P. 230-5.

361. Keating, G. And L. Scott, Vardenafil: A Review Of Its Use In Erectile Dysfunction. Drugs, 2003. 63(23): P. 2673-703.

362. Montorsi, F., Et Al., Earliest Time To Onset Of Action Leading To Successful Intercourse With Vardenafil Determined In An At-Home Setting: A Randomized, Double-Blind, Placebo-Controlled Trial. J Sex Med, 2004. 1(2): P. 168-78.

363. Porst, H., Et Al., The Efficacy And Tolerability Of Vardenafil, A New, Oral, Selective Phosphodiesterase Type 5 Inhibitor, In Patients With Erectile Dysfunction: The First At-Home Clinical Trial. Int J Impot Res, 2001. 13(4): P. 192-9.

364. Potempa, A., Et Al., Efficacy Of Vardenafil In Men With Erectile Dysfunction: A Flexible-Dose Community Practice Study. Eur Urol, 2004. 46(1): P. 73-9.

365. Goldstein, I., Et Al., Vardenafil, A New Phosphodiesterase Type 5 Inhibitor, In The Treatment Of Erectile Dysfunction In Men With Diabetes: A Multicenter Double-Blind Placebo-Controlled FixedDose Study. Diabetes Care, 2003. 26(3): P. 777-83.

366. Donatucci, C., Et Al., Vardenafil Improves Erectile Function In Men With Erectile Dysfunction Irrespective Of Disease Severity And Disease Classification. J Sex Med, 2004. 1(3): P. 301-9.

367. Morales, A., Et Al., Vardenafil For The Treatment Of Erectile Dysfunction: An Overview Of The Clinical Evidence. Clin Interv Aging, 2009. 4: P. 463-72. 
368. Paick, J., Et Al., Efficacy And Safety Of Mirodenafil, A New Oral Phosphodiesterase Type 5 Inhibitor, For Treatment Of Erectile Dysfunction. J Sex Med, 2008. 5(11): P. 2672-80.

369. Limin, M., N. Johnsen, And W. Hellstrom, Avanafil, A New RapidOnset Phosphodiesterase 5 Inhibitor For The Treatment Of Erectile Dysfunction. Expert Opin Investig Drugs, 2010. 19(11): P. 1427-37.

370. Goldstein, I., Et Al., A Randomized, Double-Blind, PlaceboControlled Evaluation Of The Safety And Efficacy Of Avanafil In Subjects With Erectile Dysfunction. J Sex Med, 2012. 9(4): P. 112233.

371. Paick, J., Et Al., The Efficacy And Safety Of Udenafil [Zydena] For The Treatment Of Erectile Dysfunction In Hypertensive Men Taking Concomitant Antihypertensive Agents. J Sex Med, 2009. 6(11): P. 3166-76.

372. Kim, B., Et Al., Influence Of Alcohol On The Hemodynamic Effects And Pharmacokinetic Properties Of Mirodenafil: A Single-Dose, Randomized-Sequence, Open-Label, Crossover Study In Healthy Male Volunteers In Korea. Clin Ther, 2009. 31(6): P. 1234-43.

373. Glina, S., Et Al., Efficacy And Tolerability Of Lodenafil Carbonate For Oral Therapy Of Erectile Dysfunction: A Phase III Clinical Trial. J Sex Med, 2010. 7(5): P. 1928-36.

374. Hatzimouratidis, K. And D. Hatzichristou, Looking To The Future For Erectile Dysfunction Therapies. Drugs, 2008. 68(2): P. 231-50.

375. Gur, S., S. Sikka, And W. Hellstrom, Novel Phosphodiesterase-5 (PDE5) Inhibitors In The Alleviation Of Erectile Dysfunction Due To Diabetes And Ageing-Induced Oxidative Stress. Expert Opin Investig Drugs, 2008. 17(6): P. 855-64.

376. Hatzimouratidis, K., Et Al., Guidelines On Male Sexual Dysfunction: Erectile Dysfunction And Premature Ejaculation. European Association Of Urology Guidelines, 2010: P. P. 846-899.

377. Virag, R., Intracavernous Injection Of Papaverine For Erectile Failure. Lancet, 1982. 2(8304): P. 938.

378. Brindley, G., Cavernosal Alpha-Blockade: A New Technique For Investigating And Treating Erectile Impotence. Br J Psychiatry, 1983. 143: P. 332-7. 
379. Porst, H. And G. Adaikan, Self-Injection, Trans-Urethral And Topical Therapy In Erectile Dysfunction., In Standard Practice In Sexual Medicine., H. Porst And J. Buvat, Editors. 2006, John Wiley And Sons Ltd: Oxford: Blackwell Publishing Ltd.

380. Leungwattanakij, S., V.J. Flynn, And W. Hellstrom, Intracavernosal Injection And Intraurethral Therapy For Erectile Dysfunction. Urol Clin North Am, 2001. 28(2): P. 343-54.

381. Shabsigh, R., Et Al., Intracavernous Alprostadil Alfadex (EDEX/VIRIDAL) Is Effective And Safe In Patients With Erectile Dysfunction After Failing Sildenafil (Viagra). Urology, 2000. 55(4): P. 477-80.

382. Vardi, Y., E. Sprecher, And I. Gruenwald, Logistic Regression And Survival Analysis of 450 Impotent Patients Treated With Injection Therapy: Long-Term Dropout Parameters. J Urol, 2000. 163(2): P. 467-70.

383. Linet, O. And F. Ogrinc, Efficacy And Safety Of Intracavernosal Alprostadil In Men With Erectile Dysfunction. The Alprostadil Study Group. N Engl J Med, 1996. 334(14): P. 873-7.

384. Porst, H., The Rationale For Prostaglandin E1 In Erectile Failure: A Survey Of Worldwide Experience. J Urol, 1996. 155(3): P. 802-15.

385. Heaton, J., Et Al., Intracavernosal Alprostadil Is Effective For The Treatment Of Erectile Dysfunction In Diabetic Men. Int J Impot Res, 2001. 13(6): P. 317-21.

386. Lakin, M., Et Al., Intracavernous Injection Therapy: Analysis Of Results And Complications. J Urol, 1990. 143(6): P. 1138-41.

387. Kattan, S., Double-Blind Randomized Crossover Study Comparing Intracorporeal Prostaglandin E1 With Combination Of Prostaglandin E1 And Lidocaine In The Treatment Of Organic Impotence. Urology, 1995. 45(6): P. 1032-6.

388. Moriel, E. And J. Rajfer, Sodium Bicarbonate Alleviates Penile Pain Induced By Intracavernous Injections For Erectile Dysfunction. J Urol, 1993. 149(5 Pt 2): P. 1299-300.

389. Flynn, R. And G. Williams, Long-Term Follow-Up Of Patients With Erectile Dysfunction Commenced On Self Injection With Intracavernosal Papaverine With Or Without Phentolamine. $\mathrm{Br} \mathrm{J}$ Urol, 1996. 78(4): P. 628-31. 
390. Sundaram, C., Et Al., Long-Term Follow-Up Of Patients Receiving Injection Therapy For Erectile Dysfunction. Urology, 1997. 49(6): P. 932-5.

391. Gupta, R., Et Al., Predictors Of Success And Risk Factors For Attrition In The Use Of Intracavernous Injection. J Urol, 1997. 157(5): P. 1681-6.

392. Raina, R., Et Al., Long-Term Intracavernous Therapy Responders Can Potentially Switch To Sildenafil Citrate After Radical Prostatectomy. Urology, 2004. 63(3): P. 532-7; Discussion 538.

393. Hatzichristou, D., Et Al., Sildenafil Versus Intracavernous Injection Therapy: Efficacy And Preference In Patients On Intracavernous Injection For More Than 1 Year. J Urol, 2000. 164(4): P. 1197-200.

394. Buvat, J., A. Lemaire, And J. Ratajczyk, Acceptance, Efficacy And Preference Of Sildenafil In Patients On Long Term AutoIntracavernosal Therapy: A Study With Follow-Up At One Year. Int J Impot Res, 2002. 14(6): P. 483-6.

395. Montorsi, F., Et Al., Treatment Satisfaction In Patients With Erectile Dysfunction Switching From Prostaglandin E(1) Intracavernosal Injection Therapy To Oral Sildenafil Citrate. Int J Impot Res, 2003. 15(6): P. 444-9.

396. Zorgniotti, A. And R. Lefleur, Auto-Injection Of The Corpus Cavernosum With A Vasoactive Drug Combination For Vasculogenic Impotence. J Urol, 1985. 133(1): P. 39-41.

397. Cookson, M.S. And P.W. Nadig, Long-Term Results With Vacuum Constriction Device. J Urol, 1993. 149(2): P. 290-4.

398. Vozmediano, R., Tratamiento Intracavernoso Y Dispositivos De Vacío., In En Tratado De Andrología Y Medicina Sexual., N.C. Navarro, Editor. 2012, Editorial Médica Panamericana S.A.: Madrid. P. Cap 71.

399. Mcmahon, C., R. Samali, And H. Johnson, Treatment of Intracorporeal Injection Nonresponse With Sildenafil Alone Or In Combination With Triple Agent Intracorporeal Injection Therapy. J Urol, 1999. 162(6): P. 1992-7; Discussion 1997-8.

400. Bechara, A., Et Al., Comparative Study Of Papaverine Plus Phentolamine Versus Prostaglandin E1 In Erectile Dysfunction. J Urol, 1997. 157(6): P. 2132-4. 
401. Mcmahon, C., A Comparison Of The Response To The Intracavernosal Injection of A Combination Of Papaverine And Phentolamine, Prostaglandin E1, And A Combination Of All Three Agents In The Management Of Impotence. . Int J Impot Res, 1991. 3: P. P. 113-21.

402. Bennett, A., A. Carpenter, And J. Barada, An Improved Vasoactive Drug Combination For A Pharmacological Erection Program. J Urol, 1991. 146(6): P. 1564-5.

403. Levine, S., Et Al., Side Effects Of Self-Administration Of Intracavernous Papaverine And Phentolamine For The Treatment Of Impotence. J Urol, 1989. 141(1): P. 54-7.

404. Guay, A., Et Al., Clinical Experience With Intraurethral Alprostadil (MUSE) In The Treatment Of Men With Erectile Dysfunction. A Retrospective Study. Medicated Urethral System For Erection. Eur Urol, 2000. 38(6): P. 671-6.

405. Fulgham, P., Et Al., Disappointing Initial Results With Transurethral Alprostadil For Erectile Dysfunction In A Urology Practice Setting. J Urol, 1998. 160(6 Pt 1): P. 2041-6.

406. Mulhall, J., Et A1., Analysis Of The Consistency Of Intraurethral Prostaglandin E(1) (MUSE) During At-Home Use. Urology, 2001. 58(2): P. 262-6.

407. Lewis, R., K. Weldon, And K. Nemo, Combined Use Of Transuretrhral Alprostadil And An Adjustable Penile Constriction Band In Men With Erectrile Dysfunction: Results From A Multicenter Trial. Int J Impot Res., 1998. 10(365): P. S49.

408. Shabsigh, R., Et Al., Intracavernous Alprostadil Alfadex Is More Efficacious, Better Tolerated, And Preferred Over Intraurethral Alprostadil Plus Optional Actis: A Comparative, Randomized, Crossover, Multicenter Study. Urology, 2000. 55(1): P. 109-13.

409. Wespes, E., Et Al., The Place Of Surgery For Vascular Impotence In The Third Millennium. J Urol, 2003. 170(4 Pt 1): P. 1284-6.

410. Brison, D., A. Seftel, And H. Sadeghi-Nejad, The Resurgence Of The Vacuum Erection Device (VED) For Treatment Of Erectile Dysfunction. J Sex Med, 2013. 10(4): P. 1124-35. 
411. Núñez, C., E. Ríos, And L. Martínez-Piñeiro, Tratamiento De La Disfunción Eréctil Con Dispositivos De Vacío. Arch Esp Urol., 2000. 53(9): P. P. 819-25.

412. Raina, R., Et Al., Sildenafil Citrate And Vacuum Constriction Device Combination Enhances Sexual Satisfaction In Erectile Dysfunction After Radical Prostatectomy. Urology, 2005. 65(2): P. 360-4.

413. Kohler, T., Et Al., A Pilot Study On The Early Use Of The Vacuum Erection Device After Radical Retropubic Prostatectomy. BJU Int, 2007. 100(4): P. 858-62.

414. Michal, V., Et Al., [Direct Arterial Anastomosis On Corpora Cavernosa Penis In The Therapy Of Erective Impotence]. Rozhl Chir, 1973. 52(9): P. 587-90.

415. Michal, V., R. Kramer, And L. Hejhal, Revascularization Procedures Of The Cavernous Bodies., In Vasculogenic Impotence: Proceedings Of The First International Conference On Corpus Cavernosum Revacularization., A. Zorgniotti And G. Ross, Editors. 1980, Charles C Thomas.: Springfiel, Illinois. P. P. 239-55.

416. Hauri, D., Therapiemöglichkeiten Bei Der Vaskulär Bedingten Erektilen Importenz. Akt Urol., 1984. 15: P. P. 350.

417. Jarow, J. And A. Defranzo, Long-Term Results Of Arterial Bypass Surgery For Impotence Secondary To Segmental Vascular Disease. J Urol, 1996. 156(3): P. 982-5.

418. Goldstein, I., Et Al., Penile Revascularization. J Sex Med, 2008. 5(9): P. 2018-21.

419. Montague, D., Et Al., Chapter 1: The Management Of Erectile Dysfunction: An AUA Update. J Urol, 2005. 174(1): P. 230-9.

420. Munarriz, R., Et Al., Microvascular Arterial Bypass Surgery: LongTerm Outcomes Using Validated Instruments. J Urol, 2009. 182(2): P. 643-8.

421. Furlow, W., J. Fisher, And L. Knoll, Current Status Of Penile Revascularization With Deep Dorsal Vein Arterialization: Experience With 95 Patients. . Int J. Impot Res, 1990. 2(2): P. P. 348-349.

422. Lewis, R. And R. Munarriz, Vascular Surgy For Erectile Dysfuncion., In Campbell-Walsh Urology., A.J. Wein, Et Al., Editors. 2007, WB Saunders Elsevier: Philadelphia. 
423. Schultheiss, D., Long-Term Results Following Dorsal Penile Vein Ligation In 126 Patients With Veno-Occlusive Dysfunciton. Int J Impot Res, 1997. 9(4): P. P. 205-9.

424. Allona, A., Prótesis De Pene. Erección, Eyaculación Y Sus Transtornos. 1997, Madrid: Fomento Salud.

425. Delgado, J. And J. Blázquez, Prótesis De Pene. Indicaciones Y Técnicas Quirúrgicas., In En Tratado De Andrología Y Medicina Sexual., N.C. Navarro, Editor. 2012, Editorial Médica Panamericana S.A.: Madrid. P. Cap 73.

426. Montorsi, F., Et Al., Penile Implants In The Era Of Oral Drug Treatment For Erectile Dysfunction. BJU Int, 2004. 94(5): P. 745-51.

427. Holloway, F. And R. Farah, Intermediate Term Assessment Of The Reliability, Function And Patient Satisfaction With The AMS700 Ultrex Penile Prosthesis. J Urol, 1997. 157(5): P. 1687-91.

428. Tefilli, M., Et Al., Assessment Of Psychosexual Adjustment After Insertion Of Inflatable Penile Prosthesis. Urology, 1998. 52(6): P. 1106-12.

429. Wilson, S., M. Cleves, And J. Delk, Comparison Of Mechanical Reliability Of Original And Enhanced Mentor Alpha I Penile Prosthesis. J Urol, 1999. 162(3 Pt 1): P. 715-8.

430. Natali, A., R. Olianas, And M. Fisch, Penile Implantation In Europe: Successes And Complications With 253 Implants In Italy And Germany. J Sex Med, 2008. 5(6): P. 1503-12.

431. Montorsi, F., Et Al., AMS Three-Piece Inflatable Implants For Erectile Dysfunction: A Long-Term Multi-Institutional Study In 200 Consecutive Patients. Eur Urol, 2000. 37(1): P. 50-5.

432. Goldstein, I., Et Al., Safety And Efficacy Outcome Of Mentor Alpha-1 Inflatable Penile Prosthesis Implantation For Impotence Treatment. J Urol, 1997. 157(3): P. 833-9.

433. Beutler, L.E., Et Al., Inflatable And Noninflatable Penile Prostheses: Comparative Follow-Up Evaluation. Urology, 1986. 27(2): P. 136-43.

434. Mulhall, J., Et Al., Serial Assessment Of Efficacy And Satisfaction Profiles Following Penile Prosthesis Surgery. J Urol, 2003. 169(4): P. 1429-33. 
435. Montorsi, F., Et Al., AMS 700 CX Inflatable Penile Implants For Peyronie's Disease: Functional Results, Morbidity And PatientPartner Satisfaction. Int J Impot Res, 1996. 8(2): P. 81-5; Discussion 85-6.

436. Szostak, M., J. Delpizzo, And G. Sklar, The Plug And Patch: A New Technique For Repair Of Corporal Perforation During Placement Of Penile Prostheses. J Urol, 2000. 163(4): P. 1203-5.

437. Jarow, J., Risk Factors For Penile Prosthetic Infection. J Urol, 1996. 156(2 Pt 1): P. 402-4.

438. Minervini, A., D. Ralph, And J. Pryor, Outcome Of Penile Prosthesis Implantation For Treating Erectile Dysfunction: Experience With 504 Procedures. BJU Int, 2006. 97(1): P. 129-33.

439. Carson, C., Diagnosis, Treatment And Prevention Of Penile Prosthesis Infection. Int J Impot Res, 2003. 15 Suppl 5: P. S139-46.

440. Carson, C., Efficacy Of Antibiotic Impregnation Of Inflatable Penile Prostheses In Decreasing Infection In Original Implants. J Urol, 2004. 171(4): P. 1611-4.

441. Wolter, C. And W. Hellstrom, The Hydrophilic-Coated Inflatable Penile Prosthesis: 1-Year Experience. J Sex Med, 2004. 1(2): P. 2214.

442. Mulcahy, J., Long-Term Experience With Salvage Of Infected Penile Implants. J Urol, 2000. 163(2): P. 481-2.

443. Henry, G., Et Al., Revision Washout Decreases Penile Prosthesis Infection In Revision Surgery: A Multicenter Study. J Urol, 2005. 173(1): P. 89-92.

444. Wilson, S., Et Al., Quantifying Risk Of Penile Prosthesis Infection With Elevated Glycosylated Hemoglobin. J Urol, 1998. 159(5): P. 1537-9; Discussion 1539-40.

445. Wilson, S., Et Al., Long-Term Survival Of Inflatable Penile Prostheses: Single Surgical Group Experience With 2,384 First-Time Implants Spanning Two Decades. J Sex Med, 2007. 4(4 Pt 1): P. 1074-9.

446. Dhar, N., K. Angermeier, And D. Montague, Long-Term Mechanical Reliability Of AMS 700CX/CXM Inflatable Penile Prosthesis. J Urol, 2006. 176(6 Pt 1): P. 2599-601; Discussion 2601. 
447. Foundation., A.U.A. National Urology Research Agenda: 2010. Available From: Http:/l Www. Urologyhealth.Org/Research/Nationalurologyresearchagenda.Cfm. .

448. Angulo, J., Et Al., Enhancement Of Both EDHF And NO/Cgmp Pathways Is Necessary To Reverse Erectile Dysfunction In Diabetic Rats. J Sex Med, 2005. 2(3): P. 341-6.

449. Videla, S., Et Al., Calcium Dobesilate For The Treatment Of Erectile Dysfunction In Men With Diabetes Mellitus. Basic Clin Pharmacol Toxicol, 2008. 103(4): P. 360-6.

450. Christ, G., Et Al., Intracorporal Injection Of Hslo Cdna Restores Erectile Capacity In STZ-Diabetic F-344 Rats In Vivo. Am J Physiol Heart Circ Physiol, 2004. 287(4): P. H1544-53.

451. Melman, A., Et Al., Hmaxi-K Gene Transfer In Males With Erectile Dysfunction: Results Of The First Human Trial. Hum Gene Ther, 2006. 17(12): P. 1165-76.

452. Garcia, M., Et Al., Treatment Of Erectile Dysfunction In The Obese Type 2 Diabetic ZDF Rat With Adipose Tissue-Derived Stem Cells. J Sex Med, 2010. 7(1 Pt 1): P. 89-98.

453. Burchardt, M., Et Al., Expression Of Messenger Ribonucleic Acid Splice Variants For Vascular Endothelial Growth Factor In The Penis Of Adult Rats And Humans. Biol Reprod, 1999. 60(2): P. 398404.

454. Lasker, G., E. Pankey, And P. Kadowitz, Modulation Of Soluble Guanylate Cyclase For The Treatment Of Erectile Dysfunction. Physiology (Bethesda), 2013. 28(4): P. 262-9.

455. Vardi, Y., Et Al., Does Low Intensity Extracorporeal Shock Wave Therapy Have A Physiological Effect On Erectile Function? ShortTerm Results Of A Randomized, Double-Blind, Sham Controlled Study. J Urol, 2012. 187(5): P. 1769-75.

456. NIH Consensus Conference. Impotence. NIH Consensus Development Panel On Impotence. Jama, 1993. 270(1): P. 83-90.

457. Mcculloch, D.K., Et Al., The Prevalence Of Diabetic Impotence. Diabetologia, 1980. 18(4): P. 279-83. 
458. Bortolotti, A., Et Al., Cigarette Smoking: A Risk Factor For Erectile Dysfunction In Diabetics. Eur Urol, 2001. 40(4): P. 392-6; Discussion 397.

459. Roth, A., Et Al., Prevalence And Risk Factors For Erectile Dysfunction In Men With Diabetes, Hypertension, Or Both Diseases: A Community Survey Among 1,412 Israeli Men. Clin Cardiol, 2003. 26(1): P. 25-30.

460. Klein, R., Et Al., Prevalence Of Self-Reported Erectile Dysfunction In People With Long-Term IDDM. Diabetes Care, 1996. 19(2): P. 13541.

461. Lundberg, P., Et Al., Guidelines For Neurology. . European, 2001. 3(8): P. 2-24.

462. Kleinman, K., Et Al., A New Surrogate Variable For Erectile Dysfunction Status In The Massachusetts Male Aging Study. J Clin Epidemiol, 2000. 53(1): P. 71-8.

463. Khan, M., R. Morgan, And D. Mikhailidis, Prevalence Of Undiagnosed Diabetes Mellitus In Male Erectile Dysfunction. BJU Int, 2001. 88(9): P. 987.

464. Bloomgarden, Z., American Diabetes Association Annual Meeting, 1997. Endothelial Dysfunction, Neuropathy And The Diabetic Foot, Diabetic Mastopathy, And Erectile Dysfunction. Diabetes Care, 1998. 21(1): P. 183-9.

465. Laumann, E., A. Paik, And R. Rosen, Sexual Dysfunction In The United States: Prevalence And Predictors. Jama, 1999. 281(6): P. 537-44.

466. Burnett, A., Nitric Oxide In The Penis: Physiology And Pathology. J Urol, 1997. 157(1): P. 320-4.

467. Guay, A., Et Al., American Association Of Clinical Endocrinologists Medical Guidelines For Clinical Practice For The Evaluation And Treatment Of Male Sexual Dysfunction: A Couple's Problem--2003 Update. Endocr Pract, 2003. 9(1): P. 77-95.

468. Costabile, R., Optimizing Treatment For Diabetes Mellitus Induced Erectile Dysfunction. J Urol, 2003. 170(2 Pt 2): P. S35-8; Discussion S39. 
469. Johannes, C., Et Al., Incidence Of Erectile Dysfunction In Men 40 To 69 Years Old: Longitudinal Results From The Massachusetts Male Aging Study. J Urol, 2000. 163(2): P. 460-3.

470. Bonetti, P., L. Lerman, And A. Lerman, Endothelial Dysfunction: A Marker Of Atherosclerotic Risk. Arterioscler Thromb Vasc Biol, 2003. 23(2): P. 168-75.

471. Larsen, M., M. Horder, And E. Mogensen, Effect Of Long-Term Monitoring Of Glycosylated Hemoglobin Levels In Insulin-Dependent Diabetes Mellitus. N Engl J Med, 1990. 323(15): P. 1021-5.

472. Rohlfing, C., Et Al., Use Of Ghb (Hbalc) In Screening For Undiagnosed Diabetes In The U.S. Population. Diabetes Care, 2000. 23(2): P. 187-91.

473. Standards Of Medical Care In Diabetes--2007. Diabetes Care, 2007. 30 Suppl 1: P. S4-S41.

474. Peterson, K., Et Al., What Is Hemoglobin Alc? An Analysis Of Glycated Hemoglobins By Electrospray Ionization Mass Spectrometry. Clin Chem, 1998. 44(9): P. 1951-8.

475. Kilpatrick, E., Glycated Haemoglobin In The Year 2000. J Clin Pathol, 2000. 53(5): P. 335-9.

476. Bruce, W., Et Al., Advances In Hemoglobin Alc Point Of Care Technology. J Diabetes Sci Technol., 2007(3): P. 319-21.

477. Petersen, J., Et Al., Effect Of Point-Of-Care On Maintenance Of Glycemic Control As Measured By A1C. Diabetes Care, 2007. 30(3): P. 713-5.

478. Berg, A. And D. Sacks, Haemoglobin Alc Analysis In The Management Of Patients With Diabetes: From Chaos To Harmony. J Clin Pathol, 2008. 61(9): P. 983-7.

479. Little, R. And D. Sacks, Hbalc: How Do We Measure It And What Does It Mean? Curr Opin Endocrinol Diabetes Obes, 2009. 16(2): P. 113-8.

480. Hoelzel, W., Et Al., IFCC Reference System For Measurement Of Hemoglobin Alc In Human Blood And The National Standardization Schemes In The United States, Japan, And Sweden: A MethodComparison Study. Clin Chem, 2004. 50(1): P. 166-74. 
481. Rohlfing, C., Et Al., Defining The Relationship Between Plasma Glucose And Hba(1c): Analysis Of Glucose Profiles And Hba(1c) In The Diabetes Control And Complications Trial. Diabetes Care, 2002. 25(2): P. 275-8.

482. Grant, T., Et Al., Community-Based Screening For Cardiovascular Disease And Diabetes Using Hbalc. Am J Prev Med, 2004. 26(4): P. 271-5.

483. Nathan, D., Et Al., The Clinical Information Value Of The Glycosylated Hemoglobin Assay. N Engl J Med, 1984. 310(6): P. 3416.

484. Executive Summary: Standards Of Medical Care In Diabetes--2009. Diabetes Care, 2009. 32 Suppl 1: P. S6-12.

485. Kostis, J.B., Et Al., Sexual Dysfunction And Cardiac Risk (The Second Princeton Consensus Conference). Am J Cardiol, 2005. 96(2): P. 313-21.

486. Debusk, R., Et Al., Management Of Sexual Dysfunction In Patients With Cardiovascular Disease: Recommendations Of The Princeton Consensus Panel. Am J Cardiol, 2000. 86(2): P. 175-81.

487. Zohar, J., Et Al., Factors Influencing Sexual Activity After Prostatectomy: A Prospective Study. J Urol, 1976. 116(3): P. 332-4.

488. Gacci, M., Et Al., Urinary Symptoms, Quality Of Life And Sexual Function In Patients With Benign Prostatic Hypertrophy Before And After Prostatectomy: A Prospective Study. BJU Int, 2003. 91(3): P. 196-200.

489. Mccullough, A., Rehabilitation Of Erectile Function Following Radical Prostatectomy. Asian J Androl, 2008. 10(1): P. 61-74.

490. Rabbani, F., Et Al., Factors Predicting Recovery Of Erections After Radical Prostatectomy. J Urol, 2000. 164(6): P. 1929-34.

491. Walsh, P.C., H. Lepor, And J.C. Eggleston, Radical Prostatectomy With Preservation Of Sexual Function: Anatomical And Pathological Considerations. Prostate, 1983. 4(5): P. 473-85.

492. Mulhall, J., F. Secin, And B. Guillonneau, Artery Sparing Radical Prostatectomy--Myth Or Reality? J Urol, 2008. 179(3): P. 827-31. 
493. Mullerad, M., Et Al., Functional Sequelae Of Cavernous Nerve Injury In The Rat: Is There Model Dependency. J Sex Med, 2006. 3(1): P. 77-83.

494. Walsh, P., R. Gittes, And A. Pelmutter, Radical Retropubic Prostatectomy. . Campbell's Urology 1986.: P. 2754-75.

495. Matsuda, T., Et Al., Determinants Of Quality Of Life Of Bladder Cancer Survivors Five Years After Treatment In France. Int J Urol, 2003. 10(8): P. 423-9.

496. Nesbakken, A., Et Al., Bladder And Sexual Dysfunction After Mesorectal Excision For Rectal Cancer. Br J Surg, 2000. 87(2): P. 206-10.

497. Kim, H., Et Al., Prognostic Significance Of Venous Thrombus In Renal Cell Carcinoma. Are Renal Vein And Inferior Vena Cava Involvement Different? J Urol, 2004. 171(2 Pt 1): P. 588-91.

498. Santangelo, M., G. Romano, And C. Sassaroli, Sexual Function After Resection For Rectal Cancer. Am J Surg, 1987. 154(5): P. 502-4.

499. Guillou, P., Et Al., Short-Term Endpoints Of Conventional Versus Laparoscopic-Assisted Surgery In Patients With Colorectal Cancer (MRC CLASICC Trial): Multicentre, Randomised Controlled Trial. Lancet, 2005. 365(9472): P. 1718-26.

500. Laparoscopically Assisted Colectomy Is As Safe And Effective As Open Colectomy In People With Colon Cancer Abstracted From: Nelson H, Sargent D, Wieand HS, Et Al; For The Clinical Outcomes Of Surgical Therapy Study Group. A Comparison Of Laparoscopically Assisted And Open Colectomy For Colon Cancer. $N$ Engl J Med 2004; 350: 2050-2059. Cancer Treat Rev, 2004. 30(8): P. 707-9.

501. Veldkamp, R., Et Al., Laparoscopic Surgery Versus Open Surgery For Colon Cancer: Short-Term Outcomes Of A Randomised Trial. Lancet Oncol, 2005. 6(7): P. 477-84.

502. Depalma, R., S. Levine, And S. Feldman, Preservation Of Erectile Function After Aortoiliac Reconstruction. Arch Surg, 1978. 113(8): P. 958-62.

503. Lee, E., Et Al., Incidence Of Erectile Dysfunction After Open Abdominal Aortic Aneurysm Repair. Ann Vasc Surg, 2000. 14(1): P. 13-9. 
504. Miles, J.J., D. Miles, And G.J. Johnson, Aortoiliac Operations And Sexual Dysfunction. Arch Surg, 1982. 117(9): P. 1177-81.

505. Drasga, R., Et Al., Fertility After Chemotherapy For Testicular Cancer. J Clin Oncol, 1983. 1(3): P. 179-83.

506. Tostes, R., Et Al., Cigarette Smoking And Erectile Dysfunction: Focus On NO Bioavailability And ROS Generation. J Sex Med, 2008. 5(6): P. 1284-95.

507. Sáenz-De-Tejada, I., Erección, Eyaculación Y Sus Transtornos., In Fisiología De La Erección Peneana., A. A, Editor. 1997, Fomento Salud: Madrid. P. 13-31.

508. Koupparis, A., Et Al., Smoking And Erectile Dysfunction: The Role Of NADPH Oxidase. BJU Int, 2004. 94(3): P. 257-8.

509. Bacon, C., Et Al., A Prospective Study Of Risk Factors For Erectile Dysfunction. J Urol, 2006. 176(1): P. 217-21.

510. Elhanbly, S., Et Al., Erectile Dysfunction In Smokers: A Penile Dynamic And Vascular Study. J Androl, 2004. 25(6): P. 991-5.

511. Corona, G., Et Al., Psychobiological Correlates Of Smoking In Patients With Erectile Dysfunction. Int J Impot Res, 2005. 17(6): P. 527-34.

512. Simonsen, U., A. Garcia-Sacristan, And D. Prieto, Penile Arteries And Erection. J Vasc Res, 2002. 39(4): P. 283-303. 